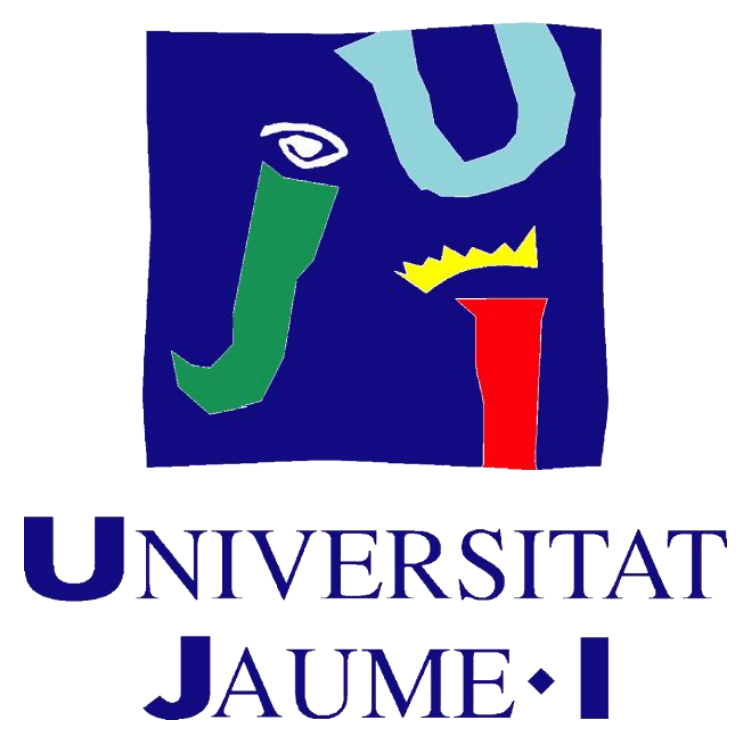

TESIS DOCTORAL

\title{
Sorteando barreras hacia la inclusión. Una historia de vida.
}

\author{
Doctoranda: Ana Doménech Vidal
}

Directora: Odet Moliner García

Departamento de Educación

Facultad de Ciencias Humanas y Sociales

Universitat Jaume I

Programa de Doctorado en Educación Secundaria RD1393/2007 (código: 14034)

Castelló de la Plana

Abril, 2017 

A MI PADRE,

POR SU CUIDADO, HONRADEZ Y ENSEÑANZAS. 



\section{AGRADECIMIENTOS}

ESTA TESIS DOCTORAL ESTÁ CARGADA DE CARIÑO, DE AMOR, DE COMPAÑERÍSMO, DE LEJANÍA, DE ADMIRACIÓN Y DE HORNADEZ. UNA TESIS HUMANA, SOCIAL Y MUY VIVA IMPOSIBLE DE CONSEGUIR SIN UN EQUIPO DE PERSONAS QUE LA RESPALDE. POR ELLO, QUIERO DEDICAR AQUÍ UN TIEMPO Y PALABRAS PARA AGRADECER EL APOYO A TODAS LAS PERSONAS QUE LA HAN HECHO POSIBLE.

EMPEZARÉ POR MI FAMILIA ACADÉMICA, A ODET, MI DIRECTORA Y 'MADRE ACADÉMICA', LA PERSONA QUE ME DIO EL EMPUJÓN, LA QUE CONFIÓ EN MÍ Y EN MIS IDEAS, LA QUE ME INTRODUJO EN EL MARAVILLOSO MUNDO DE LA INVESTIGACIÓN, GRACIAS. NO MENOS IMPORTANTES HAN SIDO MIS COMPAÑEROS Y COMPAÑERAS, GRANDES CONOCEDORES DEL MUNDO DE LA INVESTIGACIÓN Y ACOMPAÑANTES COMPRENSIVOS COMO POCOS: TODOS LOS MIEMBROS DEL MEICRI, Y CUANDO DIGO TODOS, SON TODOS: GRACIAS POR FORMAR PARTE DE ESTO Y PERMITIRME APRENDER JUNTO A VOSOTROS. A MIS COMPAÑEROS 'TASQUETEROS' (GIL, LIDÓN, ALBERTO Y DIEGO) POR DAR ÁNIMOS EN CADA CAFÉ Y POR LOS MOMENTOS MEMORABLES DE RISAS; A LOS COMPAÑEROS Y COMPAÑERAS QUE HE IDO CONOCIENDO EN LAS DISTINTAS UNIVERSIDADES, GRACIAS POR INTERCAMBIAR CONSEJOS, LECTURAS Y CONOCIMIENTO, Y COMO NO A MI 'HERMANA' ACADÉMICA ARECIA, COMPAÑERA DE TRABAJO, PASILLO Y VIDA QUE ME HA ACOMPAÑADO INCLUSO A DESHORAS CUANDO EL AGOBIO ME LLEGABA A LA GARGANTA.

SEGUIRÉ CON UNA GRAN FAMILIA, LA FAMILIA DE SERGI. GRACIAS, GRACIAS Y MIL GRACIAS MÁS POR CONFIAR EN MÍ, POR APOYARME Y ACOMPAÑARME EN ESTE CAMINO, Y SOBRETODO GRACIAS POR DARME LA OPORTUNIDAD DE CONOCEROS UN POQUITO MÁS. A ÁNGELS, POR MOSTRARME LO QUE SIGNIFICA LA RESISTENCIA Y LA LUCHA POR LOS HIJOS, QUE EL AMOR ROMPE BARRERAS Y QUE EN LOS PEORES MOMENTOS SE PUEDE SACAR UNA GRAN SONRISA, A JAVIER POR MOSTRARME LA VALENTÍA Y EL SINVIVIR POR LA FAMILIA, A GERARD POR ENSEÑARME QUE LA MADUREZ Y LA SENSATEZ NO SIEMPRE ESTÁ EN LOS ADULTOS, A XAVI POR MOSTRAR QUE LA DIVERSIÓN Y LA INTELIGENCIA PUEDEN IR DE LA MANO, AL ALBUElo MANUEl (TAMBIÉN A LA ABUELA PAQUitA) POR MOSTRAR SIEMPRE LA CARA AMABLE Y TIERNA DE LA VIDA, Y COMO NO A SERGI, POR ENSEÑARME A VER EL MUNDO DESDE OTRA PERPECTIVA, POR ENSEÑARME EL VERDADERO SIGNIFICADO DE LA VOLUNTAD, LA CONSTANCIA, LA HONRADEZ Y LA EXCEPCIONALIDAD. GRACIAS POR DEJARME CONOCERTE, GRACIAS POR CAMBIAR MI FORMA DE VER EL MUNDO.

SEGUIRÉ CON OTRO TIPO DE FAMILIA, EL RESTO DE PARTICIPANTES: GRACIAS A FRANCISCO POR MOSTRARME EL SENTIDO DE LA QUÍMICA EN LA DOCENCIA, A AZU POR ENSEÑARME QUE EL TRABAJO Y LA CONSTANCIA ABREN PUERTAS Y DERRUMBAN MUROS, A MAMEN, POR ENSEÑARME QUE EL AMOR POR LA EDUCACIÓN NO ESTÁ EN LOS LIBROS, A MARISA POR DARME UNA VISIÓN DE LA DIVERSIDAD FUNCIONAL TAN HUMANA, A LARA POR ENSEÑARME QUE EL ARTE NO NECESITA PALABRAS, A PACO POR ENSEÑARME PEDAGOGÍA DE LA BUENA, DE LA REAL, Y COMO NO A LOS COMPAÑEROS Y COMPAÑERAS DE SERGI (RODRIGO, JORDI, EVA, VERO Y OSCAR), POR MOSTRAR Y DEMOSTRAR QUE LAS LIMITACIONES ESTAN EN LOS OJOS DE QUIEN LAS QUIERE VER. ME HABÉIS DADO UNA GRAN LECCIÓN DE VIDA, GRACIAS.

Y POR ÚLTIMO DEDICARÉ UNAS PALABRAS A MI PEQUEÑA GRAN FAMILIA. A MI PADRE, GRACIAS POR LA LUZ QUE SIEMPRE ME HAS DADO Y POR ENSEÑARME QUE UNO VALE TANTO COMO CREE EN SÍ MISMO (GRACIAS POR SEGUIR HACIÉNDOLO DESDE MUY ARRIBA), A MI MADRE, POR ENSEÑARME LO QUE ES LUCHAR Y LEVANTAR CABEZA CON LA SONRISA PUESTA A PESAR DE LAS ADVERSIDADES, A MI HERMANA DEL ALMA, POR ENSEÑARME QUE LA CONSTANCIA Y EL CARIÑO LO PUEDEN TODO, GRACIAS POR EL AMOR INCONDICIONAL, GRACIAS POR LA COMPRENSIÓN, GRACIAS POR ESTAR SIEMPRE A MI LADO. AL RESTO DE MI FAMILIA (PRIM@S, TI@S Y SOBRIN@S) GRACIAS POR LOS ÁNIMOS, POR INTERESAROS Y POR PREGUNTAR MIL VECES CÓMO VA LA COSA. A MI FAMILIA SEVILLANA, POR ABRIRME LAS PUERTAS DESDE EL PRINCIPIO Y SABER ESTAR AHÍ. A MIS AMIG@S, LOS DE AQUÍ Y LOS DE ALLÍ, PORQUE AUNQUE NO ENTIENDAN MUY BIEN QUÉ HAGO CON MI VIDA HAN SABIDO QUITARME LOS NUBARRONES DE LA CABEZA EN MOMENTOS COMPLICADOS Y HACERME REÍR A CARCAJADAS. Y COMO NO A MIS CHICOS, A MIS AMORES, A ALBERT POR SABER RELAJARME CON UNA MIRADA Y POR SER CAPAZ DE QUITARME EL CANSANCIO ACUMULADO CON SOLO UNA SONRISA, Y EN ESPECIAL A MI COMPAÑERO, MI PAREJA EN ESTO DE LA VIDA. RICARDO, GRACIAS POR LA COMPRENSIÓN, POR EL APOYO, POR LA PACIENCIA, POR EL INTERÉS, POR DEDICARTE A TODO LO QUE YO HE TENIDO QUE DEJAR DE LADO, POR SER UN PADRE, AMIGO Y MARIDO EXCELENTE. GRACIAS DE TODO CORAZÓN. 



\section{$\underline{\text { ÍNDICE DE CONTENIDOS }}$}

Presentación de la investigación

\section{BLOQUe TEÓRICO (I)}

CAPítULO 1. LA DIVERSIDAD EN EL MUNDO: UN MUNDO DE DiVERSIDADES

1.1. La diversidad, un concepto tan amplio como necesario

1.2. Pero... ¿Diversidad funcional o discapacidad?

1.2.1. Modelos de discapacidad (y su evolución)

1.3. El modelo social (de la diversidad): otra forma de mirar

1.3.1. Tomar partida en el asunto

1.4. Diversidades en la forma de ser: un sinfín de posibilidades

1.4.1. Conceptos principales

1.4.1.1. Mitos y tópicos sociales sobre el TEA

1.4.2. Algunas singularidades y peculiaridades

1.4.2.1. La diagnosis ¿es el quid de la cuestión?

\section{CAPÍtULO 2. LA RESPUESTA SOCIAL Y EDUCATIVA A LA DIVERSIDAD FUNCIONAL}

2.1. De la exclusión a la indiferencia

2.2. Respuestas negativas: Barreras y limitaciones a la inclusión educativa y social 55

2.2.1. Barreras sociales 56

2.2.2. Barreras institucionales o educativas $\quad 57$

2.2.2.1. Barreras desde la administración $\quad 58$

2.2.2.2. Barreras desde la escuela $\quad 59$

$\begin{array}{ll}\text { 2.2.2.3. Barreras desde los docentes } & 60\end{array}$

2.3. Respuestas formales: las políticas de la diversidad 62

2.3.1. Políticas sociales $\quad 62$

2.3.2. Políticas educativas 64

2.3.2.1. Posibilidades de escolarización de las personas con diversidad funcional 66

2.3.2.2. Medidas de atención educativa a las personas con diversidad funcional en 67 centros ordinarios

2.4. Respuestas emergentes: algunas estrategias de superación 70

2.4.1. Estrategias sociales: relaciones sociales y ocio 70

2.4.2. Estrategias educativas o formativas $\quad 72$

2.4.2.1. Estrategias formativas desde el centro 72

2.4.2.2. Estrategias formativas dentro y fuera del centro 74

2.4.2.3. Estrategias formativas fuera del centro: la educación no formal 76 


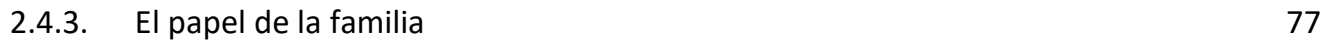

2.5. La inclusión como proyecto vital $\quad 79$

2.5.1. La calidad de vida: clave para la inclusión $\quad 79$

2.5.2. El proceso hacia la inclusión $\quad 80$

CAPÍtUlO 3. LA INVESTIGACIÓN BIOGRÁFICO-NARRATIVA: MÉtOdO Y ESTRATEGIA DE 87 INVESTIGACIÓN

3.1. La investigación cualitativa $\quad 90$

$\begin{array}{ll}\text { 3.2. El método biográfico narrativo } & 97\end{array}$

3.2.1. Origen y delimitación terminológica. $\quad 97$

3.2.2. Narrativas, biografías, historias, relatos... ¿Es lo mismo dicho de otra manera? 98

3.2.3. El cómo del método biográfico. 101

3.2.3.1. Modalidades, técnicas e instrumentos de recogida de datos 102

3.2.3.2. Modelos de construcción de historias de vida. 102

3.2.3.3. Producto final: ¿relato o historia de vida? 103

3.2.4. Consideraciones éticas del método 106

$\begin{array}{ll}\text { 3.2.4.1. La coinvestigación } & 108\end{array}$

3.2.4.2. Proceso de negociación constante 108

$\begin{array}{ll}\text { 3.2.4.3. Consentimiento informado } & 110\end{array}$

3.2.4.4. La confidencialidad y anonimato 110

3.3. El método biográfico narrativo: la investigación inclusiva 111

3.3.1. El papel (y compromiso) de la investigadora 112

3.4. Antedecentes de nuestra investigación 112

\section{BLOQUE INVESTIGADOR (II)}

Capítulo 4. Diseño de la inVestigación 115

4.1. Formulación del problema de investigación 118

4.2. Preguntas de la investigación $\quad 120$

4.3. Objetivos de la investigación 122

4.4. Método de investigación $\quad 124$

4.4.1. Muestreo: Selección de los participantes $\quad 124$

$\begin{array}{ll}\text { 4.4.1.1. Proceso de selección de la muestra } & 128\end{array}$

4.4.2. Técnicas e instrumentos. Proceso de recogida de información 133

4.4.2.1. Entrevistas 133

a) Tipos de entrevistas 135

a.1. Entrevista en profundidad 135

a.2. Entrevista temática 136

a.3. Entrevista grupal 138 
b) Proceso de construcción y realización de las entrevistas

b.1. Elaboración de las entrevistas

b.2. Realización de las entrevistas 146

b.3. Proceso de transcripción y devolución

146

4.4.2.2. Línea de vida crítico

148

4.4.2.3. Documentos

a) Documentos escritos

151

b) Documentos visuales 152

b.1. Documentos visuales: Fotografías

b.2. Otros documentos visuales: Pinturas y esculturas

4.4.2.4. Técnicas proyectivas

a) Técnica gráfica

4.4.2.5. Diario de investigación

5.2.1. Proyecto de tesis

5.2.2. Terminología

5.2.3. Investigación inclusiva y coinvestigación

5.2.4. Consentimiento informado

5.2.5. Diario de investigación

5.2.6. Participantes e instrumentos de recogida de información

5.3.1. Sucesión del proceso cíclico

5.3.1.1. Ciclo 1 de recogida de datos

5.3.1.2. Ciclo 2 de recogida de datos

5.3.1.3. Ciclo 3 de recogida de datos

5.3.1.4. Ciclo 4 de recogida de datos

5.3.1.5. Ciclo 5 de recogida de datos 183

5.3.2. Tratamiento y organización de los datos 185

5.3.3. Tipología de los datos obtenidos 187

5.4. Fase 3: Proceso de análisis de datos 190

5.4.1. Análisis deductivo: categorías y códigos previos 192

5.4.2. Análisis estructural y narrativo de los datos 203

5.4.2.1. Análisis estructural 203

$\begin{array}{ll}\text { 5.4.2.2. Análisis narrativo } & 205\end{array}$ 


\section{CAPÍtUlo 6. Resultados de LA INVESTIGACIÓN}

6.1. Resultados Fase I 212

6.1.1. Categorías y códigos $\quad 212$

6.1.1.1. Libro de categorías y códigos 213

6.1.1.2. Mapa temático- relacional de categorías y códigos 233

6.1.2. Línea de vida 235

6.1.3. Diagrama de personas en la vida de Sergi 237

6.2. Resultados Fase II: la historia de vida de Sergi 242

6.2.1. Proceso de elaboración de la historia de vida 242

6.2.2. La historia de vida de Sergi 245

6.3. La vida de Sergi a día de hoy 315

CAPÍtUlo 7. DisCUSIÓn DE RESULtAdOS Y CONCLUSIONES 319

7.1. Una vida de diversidad: principales elementos 325

7.1.1. ¿Cuáles son los principales hechos y acontecimientos que describen y explican la 325 trayectoria de vida de Sergi?

7.1.2. ¿Qué personas han acompañado a Sergi a lo largo de su vida desde contextos como el familiar, social y educativo?

7.1.3. ¿Cuáles son los elementos, personas y hechos clave de la historia de vida de Sergi?

7.2. Barreras, limitaciones y estrategias de superación hacia una inclusión social y educativa

7.2.1. ¿Cuáles son las principales barreras y limitaciones educativas y sociales con las que Sergi se han encontrado a lo largo de su vida?

7.2.1.1. Barreras y limitaciones sociales

7.2.1.2. Barreras y limitaciones educativas

a) Barreras administrativas

b) Barreras institucionales

b.1. Barreras institucionales de promoción

b.2.Barreras institucionales de organización de recursos

b.3. Barreras institucionales de relación familia-escuela

c) Barreras profesionales

c.1. Barreras actitudinales del docente

c.2. Barreras formativas del docente

7.2.2. ¿Cuáles han sido los principales apoyos, ayudas y estrategias de superación que ha tenido Sergi (familiares, educativas y sociales? 
7.2.2.1. Apoyos y ayudas sociales

a) Natación

b) Arte

7.2.2.2. Apoyos y ayudas educativas

a) Apoyos y ayudas administrativas $\quad 339$

b) Apoyos y ayudas institucionales 340

c) Apoyos y ayudas de docentes y otros profesionales 340

d) Apoyos y ayudas de los iguales (compañeros/as) 342

7.2.2.3. Apoyos y ayudas para la comprensión e interacción con el entorno 343

7.2.2.4. Apoyo y ayudas familiares 344

7.2.3. ¿Qué decisiones o determinaciones se han tomado desde el ámbito familiar para 346 superar estas barreras?

7.3. Perspectiva de futuro desde la diversidad

7.3.1. ¿Cuáles son expectativas de futuro de Sergi y las personas de su entorno en 347 cuanto a su desarrollo académico, profesional y social?

7.3.2. ¿Qué herramientas o estrategias se prevén necesarias desde el ámbito familiar y 350 educativo para garantizar la calidad de vida de Sergi?

7.4. A modo de conclusión...

7.5. Limitaciones del estudio

7.6. Propuestas post-investigación y futuras líneas de investigación 





\section{ÍNDICE DE ANEXOS}

ANEXo I: Preparación de las entrevistas

ANEXO II: Entrevistas transcritas

ANEXO III: Diario de investigación

ANEXo IV: Cronología de recogida de información

ANEXO V: Consentimiento informado coinvestigadora

ANEXO VI: Consentimiento informado adultos

ANEXO VII: Consentimiento informado menores de edad

ANEXO VIII: Consentimiento informado Sergi

ANEXO IX: Instrumentos de recogida de información transcritos para el análisis 


\section{ÍNDICE DE TABLAS}

TABLA 1. Modelos de discapacidad según diferentes autores (elaboración propia)

TABLA 2. Síntesis de los modelos de la discapacidad (elaboración propia)

TABLA 3. Principales factores de la exclusión social (Tezanos, 2001: 172)

TABLA 4. Perspectivas de investigación (Sandín, 2010: 34)

TABLA 5. Clasificación de los métodos de investigación (elaboración propia)

TABLA 6. Modalidades, tipologías y clasificaciones del método biográfico narrativo (elaboración propia)

TABLA 7. Preguntas de investigación, objetivos generales y objetivos específicos

TABLA 8. Implicación de los participantes de la investigación

TABLA 9. Secuencia de construcción de las entrevistas

TABLA 10. Recogida de datos: tipos de entrevistas, participantes y códigos

TABLA 11. Recogida de datos: Técnica de Documentos Escritos (TDE)

TABLA 12. Paradigmas de investigación y uso de datos visuales

TABLA 13. Recogida de datos: Técnica de la foto

TABLA 14. Recogida de datos: Técnica de pinturas y esculturas (TPE)

TABLA 15. Recogida de datos: Técnicas, participantes, contexto, fecha y código

TABLA 16. Leyenda de transcripción de instrumentos

TABLA 17. Recogida de datos: instrumentos, participantes, códigos y duración sesiones

TABLA 18. Tipología de datos recogidos

TABLA 19. Sistema de categorías y códigos previos

TABLA 20. Libro de categorías y códigos

TABLA 21. Estructura de la historia de vida de Sergi

TABLA 22. Preguntas de investigación, objetivos generales y objetivos específicos (II) 


\section{$\underline{\text { ÍNDICE DE FIGURAS }}$}

FIGURA 1. Esquema de los paradigmas de investigación cualitativa

Figura 2. Tipos de muestreo I

FIGURA 3. Tipos de muestreo II

Figura 4. Tipos de muestreo III

FIGURA 5. Muestra inicial

Figura 6. Proceso de selección de la muestra

FIGURA 7. Muestra por contextos

FIGURA 8. Partes de las entrevistas

FIGURA 9. Revisión de entrevista en profundidad y generación de nuevos temas

Figura 10. Proceso de elaboración y realización de entrevistas

FIGURA 11. Documento de transcripción y elementos en los que se divide

FiguRA 12. Ciclo genérico de recogida de datos

Figura 13. Ciclos de recogida de datos.

FIGURA 14. Ciclo 1 de recogida de datos

FIGURA 15. Ciclo 2 de recogida de datos

FIGURA 16. Ciclo 3 de recogida de datos

Figura 17. Ciclo 4 de recogida de datos

Figura 18. Ciclo 5 de recogida de datos

Figura 19. Clasificaciones sobre tipos de datos recogidos

Figura 20. Continuo de codificación según Boyatzis (1998)

FIGURA 21. Estructura previa de categorización

FIGURA 22. Fases de los resultados de la investigación

FiguRA 23. Mapa de categorías, códigos y relaciones

FIGURA 24. Ejemplo de texto de la historia de vida 


\section{ÍNDICE DE GRÁFICOS}

GráfIco 1. Cronograma de la investigación

Gráfico 2. Línea de vida de Sergi

GráfIco 3. Diagrama de personas en la trayectoria de vida de Sergi 


\section{ÍNDICE DE IMÁGENES}

IMAGEN 1. Fines de semana en el pueblo (fotografía no1, TF M)

IMAGEN 2. Calendario de Sergi (documento 28, TDE M)

IMAGEN 3. En Legoland (Fotografía no2, TF S)

IMAGeN 4. Las palabras de Sergi (dibujo 2, TG S)

IMAGEN 5. Libreta pictogramas (documento 46, TDE M)

IMAGEN 6. Paneles de comunicación (documento 50, TDE M)

IMAGEN 7. Feliz Navidad. (Fotografía no1, TF CE4)

IMAGEN 8. Historia social (Documento 42, TDE M)

IMAGEN 9. Sergi y Buzz LightYear (fotografía no1, TF S)

IMAGEN 10. La momia (Escultura 1, TPE PEA)

IMAGEN 11. Exclusión de Sergi (fotografía no4, TF M)

IMAGEN 12. Manos de los compañeros de Sergi (fotografía cedida por la madre (M))

IMAGEN 13. Sergi en el aula de PT (fotografía no1, TF PT IES)

IMAGEN 14. La clase. (Fotografía no1, TF C IES)

IMAGEN 15. Consiguiendo lo inimaginable (fotografía no3, TF M)

IMAGEN 16. Notícia en la revista local (Documento 68, TDE M)

IMAGen 17. Notícia en El Periodico (Documento 69, TDE M)

IMAGEN 18. El trabajo de cuidador de zoo (dibujo 4, TG S)

IMAGEN 19. El futuro de Sergi (fotografía no2, TF M) 





\section{PRESENTACIÓN DE LA INVESTIGACIÓN}

A lo largo de este informe, podrán encontrar una investigación llevada a cabo en los últimos 5 años y titulada "Sorteando barreras hacia la inclusión: Un historia de vida".

El origen de este trabajo reside en la realización de un TFM en el año 2011 titulado "La educación inclusiva desde la perspectivas de las familias" en el que se analizaba la visión de las familias de hijos con y sin diversidad funcional sobre la educación del momento y la medida en la que ésta podía considerarse inclusiva para todo el alumnado. En este estudio, después de analizar los resultados de una encuesta en la que participaron 121 familias, se contó con la participación de 4 madres (dos de ellas con hijos con diversidad funcional) para profundizar en la percepción que poseían sobre el papel que juegan los docentes, los recursos, la implicación familiar,... en la construcción de un modelo educativo inclusivo.

Una de aquellas mujeres era Àngels, madre de Sergi y de otros dos niños. Àngels había sido durante años mi vecina (y maestra de inglés). Una relación cordial y amable unía nuestras vidas y nuestras familias, pero fue a partir de este estudio previo cuando estrechamos lazos y decidimos embarcarnos en la aventura de seguir investigando.

En aquel momento, Sergi era un niño que había sido diagnosticado años atrás con un trastorno de Trastorno Generalizado del Desarrollo (TGD) y Trastorno Específico del Lenguaje (TEL). Desde entonces, la familia había recurrido a muchos profesionales intentando encontrar la clave para ayudar a su hijo. Una decepción tras otra llevó a los padres a volcarse en la educación de su hijo y tomar las riendas para trabajar, junto a otros familiares y profesionales, por una educación y sociedad inclusiva para Sergi. En aquel entonces (el año 2011) Sergi estaba escolarizado en $5^{\circ}$ de Educación Primaria en un centro ordinario, donde gracias al trabajo y apoyo de su familia y profesionales de la educación había logrado superar muchas barreras y dificultades. Sergi crecía, aprendía, se desarrollaba y participaba como uno más junto a sus compañer@s. Estábamos sin duda alguna ante un claro ejemplo de éxito educativo inclusivo.

En un momento en el que la inclusión parecía tan difícil, pensamos en la necesidad de historias como esta, historias de éxito y logros inclusivos reales para indagar en los factores que favorecen la inclusión y descubrir aquello que la posibilita y facilita. Esta familia, nos abrió la posibilidad de realizar una investigación sobre la historia de vida de su hijo y analizar las barreras y las ayudas que han permitido la situación actual: un adolescente con diversidad funcional escolarizado en un centro de educación ordinaria y participante activo en su entorno social.

Tiendo en cuenta estos antecedentes, y antes de adentrarnos en cuestiones más técnicas sobre informe, consideramos necesario dar a conocer dónde ocurre esta historia: el contexto de la investigación.

Sergi y su familia se afincaron en un pequeño pueblo costero del mediterráneo, de unos 30.000 habitantes aproximadamente, sobre el año 2002. La familia del padre es de allí, y la de la madre reside a unos $30 \mathrm{~km}$ hacia el interior. Es un contexto amable, una localidad donde todo el mundo se conoce, tranquila y alejada de los bullicios de las grandes ciudades. Un lugar en el que no faltan 
escuelas, centros juveniles, asociaciones, centros deportivos,... eso sí, para cosas que escapan de la cotidianeidad es necesario desplazarse a lugares más grandes con más y mejores servicios.

Teniendo en cuenta dónde se sitúa esta investigación, expondremos a continuación algunas consideraciones que pensamos que el lector debe conocer antes de iniciar la lectura del informe.

La primera de ellas tiene que ver con el foco de investigación. El título de esta tesis doctoral "Sorteando barreras hacia la inclusión. Una historia de vida" ya invita de por sí a pensar que en nuestro trabajo las barreras, las limitaciones, las imposiciones y las injusticias tendrán cierto protagonismo. No obstante, este protagonismo no es otorgado en aras de realzar las barreras y ponerlas en "primer plano', sino con la pretensión de focalizar en las estrategias y apoyos con los que ha contado nuestro protagonista para superarlas, y mediante su historia de vida empoderarle a él, a su familia y a otras personas en situaciones semejantes. Como se podrá comprobar en los sucesivos capítulos, hemos querido acercarnos a esta compleja realidad desde una visión positiva de la misma. Está claro que necesitamos conocer lo que ha ocurrido en su camino, lo que no ha funcionado o dificultado su inclusión, pero nuestro foco está en las ayudas y apoyos que le han permitido continuar, crecer, participar y realizarse como persona. Por ello, podrá comprobar que, por ejemplo, el autismo como tal es un tema abordado superficialmente mientras focalizamos nuestra atención en otros elementos de su trayectoria vital.

Otra de las consideraciones tiene que ver con uno de los grandes dilemas terminológicos del momento: ¿diversidad funcional o discapacidad? Consideramos que estamos en un momento de 'impasse' en el que está muy asumido y arraigado el concepto de discapacidad ${ }^{1}$ pero apoyamos y reiteramos la necesidad de avanzar hacia términos como el de 'diversidad funcional'2. A lo largo de este trabajo podrá palparse y conocer el dilema en el que nos hemos encontramos con respecto a esto y cómo hemos ido resolviéndolo. No obstante, en esta presentación queremos apuntar cuando utilizamos el concepto 'discapacidad' es: o bien por consenso con las personas responsables de esta investigación, o bien porque se parafrasea o cita a otros autores que utilizan esta terminología.

La tercera y última de estas consideraciones es la elección del método de investigación. El marco de esta investigación y la finalidad de la misma propiciaban optar por un método de indagación con una mirada humana y cercana de la realidad a estudiar. Se optó por el método biográfico-narrativo, y concretamente las historias de vida, por las posibilidades tanto prácticas como éticas que permitían en su uso. Pero es tal la variedad de ese uso y las posibilidades del método biográfico narrativo, que se decidió reservar un espacio (capítulo 3) en el marco teórico de este trabajo para esclarecer en qué punto nos encontramos y porqué acabamos optando por unos caminos y no otros.

\footnotetext{
${ }^{1}$ La Convención Internacional de Personas con Discapacidad de las Naciones Unidas (ONU) dispuso que el término adecuado para referirse a este grupo de población es Personas con Discapacidad (PCD) o Personas en Situación de Discapacidad.

2 Vinculado al movimiento de vida independiente que emergió en los años 70 en EEUU y se materializó mediante el Foro de Vida Independiente (FVI)
} 
Para finalizar esta presentación expondremos la estructura del informe. A lo largo de este trabajo encontraran dos bloques principales: el teórico (compuesto por 3 capítulos) y el investigador (compuesto por 4 capítulos).

En el capítulo 1 hacemos una primera aproximación al campo de estudio. Partimos de una concepción muy amplia de diversidad (la diversidad en el mundo) y poco a poco vamos centrando nuestra atención en la diversidad funcional para acabar aterrizando en los diferentes modelos que se han sucedido a lo largo de la historia y posicionarnos respecto a ellos. En este mismo espacio, empezaremos a dibujar aquellos elementos del autismo que nos permitirán acercarnos y conocer un poco más a Sergi y su forma de ser y vivir.

En el siguiente capítulo (capítulo 2) centramos nuestra atención en la respuesta educativa y social que se ha dado desde los diversos estamentos sociales a las personas con diversidad funcional. Este capítulo aborda las diversas respuestas posibles: respuestas negativas (en forma barreras y limitaciones a la inclusión), respuestas formales (la visión o respuesta política ante la diversidad), respuestas reales (las estrategias de superación que utilizan las personas al con diversidad funcional en su día a día) y la inclusión como el proyecto social y educativo necesario. A lo largo de todos los apartados de este capítulo, hacemos una revisión de la literatura a nivel nacional e internacional sobre lo que se ha dicho, hecho e indagado en este sentido. Consideramos este capítulo como una de las partes fundamentales de nuestra investigación desde la que emerge la necesidad de seguir indagando y profundizando en este campo, mostrando historias de éxito que visibilicen procesos y empoderen personas.

En el tercer capítulo (y último de este bloque teórico) nos centramos en dibujar a nivel teórico el tipo de investigación que queremos abordar. En la literatura, encontramos muchas referencias al método biográfico narrativo, pero la gran mayoría resultan poco detalladas en cuanto al proceso investigador. Ante esta situación, decidimos abordar en este capítulo un repaso teórico sobre esta metodología y encontrar el lugar desde el que proyectar esta investigación. Se trata de un capítulo que aborda desde la investigación cualitativa y su sentido y origen, hasta las consideraciones éticas de este método.

El capítulo 4 es el primero de los correspondientes al bloque investigador. En este espacio abordamos nuestro problema de investigación y en base a ello vamos dibujando las preguntas y objetivos de investigación que guiarán nuestro camino. A continuación encontraremos el método, los tipos de instrumentos y el muestreo de una manera detallada. Queremos que el lector conozca cómo hemos elaborado los diversos instrumentos, en qué nos hemos basado, porqué hemos decidido una muestra y no otra y porqué hemos optado por estas estrategias y no otras.

En el quinto capítulo expondremos el proceso seguido en las diferentes fases de la investigación. Se trata de un contenido que originalmente estaba insertado en el capítulo 4, pero con el tiempo fue adquiriendo entidad propia y se precisaba de un espacio más extenso para recabar todo lo acontecido. En este capítulo se recogen las idas y venidas "del campo a la mesa y de la mesa al campo" mediante las cuales se ha ido sucediendo la negociación, la recogida cíclica de información y el análisis de datos. En este capítulo, los gráficos y figuras conforman una parte importante del capítulo, pues gracias a ellos podremos entender los ciclos y procesos seguidos. 
El siguiente capítulo (capítulo 6) recoge los resultados de esta investigación organizados en dos fases o momentos diferentes. La primera fase de resultados es aquella que emerge en primer lugar del análisis y en la que se recogen las categorías, la línea de vida y el diagrama de personas de la vida de Sergi. A partir de estos primeros resultados se ha podido organizar la información y elaborar un segundo tipo de resultado: la historia de vida de nuestro protagonista.

En el séptimo y último capítulo se aborda la discusión de los resultados y las conclusiones generales de esta investigación. Al final de este mismo capítulo encontraremos las limitaciones detectadas en este estudio así como las propuestas de futuro sobre las que consideramos necesario seguir trabajando.

Tras este capítulo se expone el listado de las Referencias Bibliográficas utilizadas a lo largo de este trabajo. Cabe tener en cuenta que en el USB entregado junto al informe podrán encontrar de todos los documentos anexos en formato pdf y organizados debidamente para una sencilla identificación y rápido acceso. 




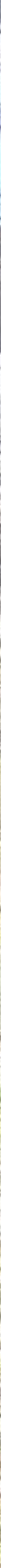



Primer capítulo, capítulo en el que usted, lector, empezará a conocer quién soy, qué intereses tengo como investigadora, cuáles son los términos generales de esta investigación y cómo me posiciono respecto a ellos. De hecho, este capítulo puede considerarse una primera impresión, un primer encuentro, por lo que me esmeraré en mis palabras, seré fiel a mis principios e ideología a la vez que intentaré trasmitir el estado de la cuestión de mi trabajo de manera rigurosa y actualizada.

En este primer capítulo encontrará un marco bastante general, pues esa es mi pretensión. Y es que no es para menos, voy a abordar un campo tan amplio como la diversidad, la diversidad social de hoy en día. A lo largo de este capítulo, procuraré ir centrando y focalizando el tema en el campo de la diversidad funcional (tradicionalmente conocida como discapacidad) y en los diversos modelos de la misma para acabar posicionándome en el modelo de la diversidad como una perspectiva necesaria en nuestro contexto.

A lo largo de este capítulo podrá encontrar los siguientes apartados que estructuran el contenido:

1.1. La diversidad, un concepto tan amplio como necesario

1.2. Pero... ¿Diversidad funcional o discapacidad?

1.2.1. Modelos de discapacidad (y su evolución)

1.3. El modelo social (de la diversidad): otra forma de mirar

1.3.1. Tomar partida en el asunto

1.4. Diversidades en la forma de ser: un sinfín de posibilidades

1.4.1. Principales conceptos

1.4.1.1. Mitos y tópicos sociales sobre el TEA

1.4.1.2. La diagnosis es el quid de la cuestión

1.4.2. Carencias y presencias del autismo 


\subsection{La diversidad, un concepto tan amplio como necesario}

Diversidad, esa palabra que todos utilizamos y que expresa una idea global y compartida, pero ¿a qué nos referimos con 'diversidad'? ¿de qué estamos hablando realmente? ¿De lo extraordinario? ¿De lo diferente?, pero de lo diferente ¿a qué? ¿a nosotros? ¿a lo nuestro? Lo cierto es que este término se utiliza en muchos ámbitos de las ciencias sociales: diversidad sexual, diversidad de género, diversidad étnica, diversidad social, diversidad funcional,... y aparentemente significa un conjunto de cosas diferentes entre sí catalogadas y asociadas a un ámbito concreto. El significado de la palabra "diversidad" es en sí mismo un tanto disperso, pues es un término que adquiere más sentido como principio ideológico que como un concepto susceptible de ser operativo. Lo que sí es cierto, es que desde hace unos años la palabra 'diversidad' se ha ido introduciendo de manera sigilosa pero con fuerza en nuestra cultura pedagógica actual (Fernández Batanero, 2009).

Si consultamos el Diccionario de la Lengua Española (RAE, 2014) encontraremos este término definido en base a elementos como "variedad, desemejanza, diferencia, abundancia y gran cantidad de varias cosas distintas". Sin embargo, en nuestro campo de estudio lo concebimos como algo más vinculado al valor de la variedad y la diferencia. La "diversidad" en sí misma no es concepto neutral ni socialmente aséptico (Jiménez-Rodrigo y Guzmán-Ordaz, 2016), sino todo lo contrario. Se trata de un término cargado de ideología, de posicionamiento político y social que representa un ideario concreto.

Somos conscientes, y tenemos en cuenta, que las relaciones y grupos sociales son diversos, variados, y como afirma Vlachou (1999) estamos en un mundo lleno de diferencias donde la normalidad no existe. Nuestra sociedad, aunque se pretenda, no puede seguir patrones de normalidad, no puede tener unos estándares a los que sus miembros deben ajustarse sino todo lo contrario. La normalidad, o mejor dicho, la norma en nuestra sociedad es la heterogeneidad, y es justamente esta idea la que nos otorga como sociedad la oportunidad de respetar y reconocer lo diverso o, lo que es lo mismo, la posibilidad de generar igualdad en la diversidad.

Existen múltiples formas y ámbitos en los que la diversidad se materializa y manifiesta. Según Cela, Gual y Màrquez (1997, citado en Fernández Batanero, 2009) esta diversidad se organizan en tres grandes dimensiones:

a. Aspectos sociales: procedencia geográfica y cultura, nivel socioeconómico, rol social (tipologías familiares, percepción social del trabajo de las familias)

b. Aspectos personales y físicos: diferencias que tienen que ver con cuestiones relacionadas con la herencia, o derivadas de determinadas jerarquizaciones que los modelos culturales imponen (color de la piel, género femenino/masculino, patrones de belleza...)

c. Aspectos psicológicos ligados a los procesos de enseñanza-aprendizaje: conocimientos previos, estilos y hábitos de aprendizaje, capacidades, motivación, intereses,...

Como vemos, estas dimensiones no son más que elementos propios de la diferencia entre los seres humanos. De alguna manera, es la diferencia entre las personas la que nos hace diversos, variados, dispares y múltiples dentro del conjunto de la sociedad. Realmente hay tantos tipos de diversidades como personas 
y características en cada una de ellas, alejándonos de lo que Skliar (2002) denomina como "diferencialismo" y asumiendo que pertenecemos a una sociedad compleja y enmarañada. Según este autor, en nuestra sociedad suelen darse procesos de diferencialismo en los que existe 'un dedo señalador' que determina y muestra quienes son los diferentes $\mathrm{y}$, por lo tanto, los nombra y constituye identificándolos por 'ser diferentes'.

El hecho de señalar, de identificar, de delimitar, tiene una vinculación directa con las relaciones de poder que permiten describir a otros sujetos que están, habitualmente, ubicados en el polo opuesto dominado (Terrén, 2001). Estaríamos ante un proceso de construcción simbólica del 'otro' por lo tanto de un 'nosotros' en relación al cual ese otro es entendido como diferente o diverso (Almeida et al., 2010). Estaríamos, por tanto, definiendo y atribuyendo características a través de un procedimiento de reproducción dicotómica de fronteras de inclusión y exclusión en relación a lo concebido como normalidad (Jiménez-Rodrigo y Guzmán-Ordáz, 2016).

Sin embargo, en esta investigación, nos basamos en un enfoque de diversidad totalmente alejada de esta concepción diferenciadora y creemos en aquella que acepta, reconoce y considera al otro por lo que es y no por lo que le distingue del resto. Asumimos diferentes formas de funcionar, de actuar, de querer, de procedencia, de estilo de vida,... pues todos procedemos de algún lugar concreto, de una familia con estilo propio, queremos de una manera determinada $y$ funcionamos y actuamos de una manera singular. Pero lo cierto es que no solo basta con un enfoque amplio de la diversidad, sino que además necesitamos de una concienciación y reconocimiento social de que "todos los seres humanos somos iguales en esencia y diferentes en existencia” (Essomba, 2009, p.45).

Como bien indica López Melero (1997) cabe tener en cuenta las siguientes matizaciones conceptuales: la diversidad hace referencia a la cualidad de la persona por la que cada cual es y como reconocimiento de la dignidad humana, mientras que la diferencia se refiere a la valoración de la diversidad donde hay manifestaciones o bien de rechazo o de comprensión, considerando la diversidad como un valor. Así mismo, la desigualdad es la jerarquización de las personas por criterios de poder social, político o económico, justamente lo contrario a la igualdad. Añadimos a esta idea las aportaciones de Eraso, Muñoz y Salcedo (2016) quienes entienden la diversidad como riqueza, posibilidad, complemento, dinámica, disenso y novedad. Pues desde este enfoque, obtenemos una concepción de diversidad como una oportunidad de complemento, y no como un desacuerdo en la sociedad.

Teniendo en cuenta esta última aportación, preferimos apartarnos de clasificaciones y tipologías de 'lo diverso', pues creemos que es una manera de volver a entrar de nuevo en un juego de 'diferenciación' e identificación con la que no comulgamos. Creemos en la diversidad en su concepto amplio, en que esta forma parte de nosotros y, por lo tanto, no necesita catalogación alguna. La diversidad podrá ser más o menos acentuada, pero es tan normal como la vida misma y hay que vivir con ella, sin categorizarla ni encorsetarla en tipologías o categorías que la jerarquizan (Fernández Batanero, 2009). No obstante, somos conscientes que las ciencias sociales inciden sobre múltiples aspectos de la vida humana y que, por lo tanto, necesitamos de nombres que nos ayuden a distinguir a qué nos referimos y a qué no cuando utilizamos el término 'diversidad'. Resulta inevitable hablar de ciertas diversidades para focalizar en aquello que nos interesa, pues a pesar de nuestra visión social de la diversidad, somos conscientes de la utilidad y necesidad 
de términos como diversidad sexual, diversidad cultural, diversidad funcional,... pues todos y cada uno de estos términos nos ayudan a delimitar un campo de estudio concreto.

En nuestro caso vamos a focalizar la atención en aquella diversidad que hace referencia a las diversas formas de funcionar, a las distintas capacidades y aptitudes en los seres humanos, vamos a centrar nuestra atención en la diversidad funcional.

\subsection{Pero... ¿Diversidad funcional o discapacidad?}

Desde los primeros planteamientos de esta investigación, se ha ido generando en numerosas ocasiones un debate interno y dilema ético y profesional sobre si referirnos a las personas con capacidad y aptitudes concretas mediante el término 'discapacidad' o el de 'diversidad funcional'. Esta dicotomía viene dada por diversas razones. La primera de ella es la de pretender respetar y considerar aquello que el propio colectivo afectado reclama y es ser denominadas personas con diversidad funcional (y no con discapacidad). Sin embargo, somos conscientes de que esta postura es la propia de un sector afectado y que sigue existiendo una masa que se sigue autodenominando como 'personas con discapacidad'. Entonces la pregunta es ¿Quiénes somos nosotros para decidir? ¿qué término acuñar en esta investigación si nosotros simplemente queremos respetar su voz $\mathrm{y}$ autodeterminación (sea cual sea)? Ante esta gran duda planteada se nos generaba otra consideración, y es que pretendemos que nuestra investigación, nuestros instrumentos y nuestras pretensiones en la pesquisa, logren los objetivos que nos planteamos.

Nuestro principal problema con respecto a esto viene dado por la creencia, y en parte certeza, de que la sociedad en general (y por lo tanto algunos de nuestros participantes) siguen reconociendo a este colectivo como 'personas con discapacidad'. Entonces la pregunta es isabrán las personas a las que entrevistamos a qué nos referimos cuando utilizamos el término "diversidad funcional"? ¿Entenderán que nos referimos a todas aquellas personas con formas de ser y actuar diversas? ¿crearemos un sesgo a nuestra propia investigación al no utilizar términos conocidos por la totalidad de los participantes?

Estos interrogantes nos llevaron a considerar la necesidad de profundizar en estos términos y las implicaciones de su uso a través de los diferentes modelos de discapacidad y su evolución a lo largo de los años.

\subsubsection{Los modelos de la discapacidad (y su evolución)}

A lo largo de la historia las personas diferentes y/o con capacidades diversas, han sido social y educativamente 'señaladas' y discriminadas. Dichas discriminaciones y las desigualdades que propician, se han convertido en una de las lacras de nuestra sociedad, una de las grandes losas que pesa sobre nuestra conciencia como conjunto social. Hoy en día en las sociedades modernas la discapacidad sigue siendo objeto de discriminación e implica aislamiento y restricción social (Barton, 1998), y es que históricamente ha sido notorio y deleznable el trato que las personas con ciertas diferencias han recibido por parte de ese resto considerado "normal". 
Desde la Edad Media, las personas con capacidades diversas (comunicativas, sociales, intelectuales,...) se consideraban una manifestación demonológica y maligna que debía ser apartada y escondida de la sociedad, incluso en los senos familiares se consideraban una deshorna y una vergüenza que había que disimular. Con el paso del tiempo, esta idea evolucionó levemente y poco a poco empezó a pensarse que socialmente debían tener una respuesta, una atención, eso sí, diferenciada esa mayoría 'normal'. Se generaron sistemas paralelos para personas con capacidades diferentes o no heteronormativas, como la educación especial o una atención pseudoterapéutica especializada. De alguna manera, el pensamiento humano empezó a considerar la posibilidad de normalizar la vida de estas personas, posibilitando en cierta manera que los denominados 'deficientes mentales' pudieran tener una existencia tan próxima a lo normal como fuera posible (Bank-Mikkelsen, 1975, citado en Castejón y Navas, 2013). Eso sí, hay que tener en cuenta que esa normalidad de la que se hablaba en aquellos tiempos, sobre los años 60, 70 y 80, estaba a años luz de lo que hoy en día podemos considerar una vida 'normal' o con ciertas garantías de calidad de vida.

Sobre los años sesenta, en los países nórdicos, empezó a generarse el denominado movimiento integrador. Este era un modelo social (no únicamente educativo) que analizaba y criticaba la atención y segregación de las personas con algún tipo de hándicap, y promulgaba nuevos presupuestos sobre la justicia, los derechos de las personas y los valores sociales (Gallego, 2015). Este movimiento fue extendiéndose por toda Europa y se estructuró en base tres principios fundamentales: el principio de normalización, el principio de sectorización y el principio de integración. A continuación vamos a detenernos brevemente en cada uno de ellos:

1. Principio de normalización: este principio busca facilitar a las personas con dificultades una vida lo más normal posible. Dentro de este mismo postulado existen diversas perspectivas: Mientras autores como BankMikkelsen promulgan que la normalización es el objetivo que hay que perseguir y la integración el medio para lograrlo, otros como Wolfensberger consideran que la integración social es el fin de la normalización (Sanz del Río, 1996) Sea como fuere, estamos ante una corriente social dirigida a resituar a los deficientes en el seno de la sociedad y a establecer relaciones de igualdad en cualquier ambiente (Gallego, 2015).

2. Principio de sectorización: este principio deriva del principio de normalización y hace referencia a los servicios y a su accesibilidad. Sectorizar, significa acercar los servicios a la persona o personas que lo demandan (Viloria, 2016). Esta es una manera de contribuir a la normalización aplicando dicho principio a la realidad geográfica donde residen las personas con discapacidades para prestar los servicios necesarios en su ambiente físico, familiar y social (Muntaner, Fortaleza y Rosselló, 1996)

3. Principio de integración: este último principio se considera el resultado e impacto que la normalización ha tenido en las relaciones entre los individuos, pues no se trata de entrar en el espacio del 'otro' sino de un espacio compartido. La integración social, en su sentido más amplio, hace referencia a un cambio de valores que lleva a apreciar positivamente la composición heterogénea y diversa de los miembros que componen la sociedad y a fomentar una sociedad democrática que no solo ofrezca las 
mismas oportunidades a todos sus miembros sino que además se beneficie de ello (Gallego, 2015).

De esta manera, según en la medida en que se respeten estos principios y se apliquen a nuestra realidad social, se estarán ofreciendo unas posibilidades académicas, laborales y sociales $u$ otras. Al fin y al cabo, la forma de mirar la diversidad y el enfoque que se proyecte sobre 'lo diferente' generará diversas perspectivas o 'modelos' desde los cuales daremos lugar unas respuestas sociales u otras. Existen múltiples maneras de responder a la diversidad en general, y a la diversidad funcional (o discapacidad) en particular. De hecho, nuestra sociedad ha ido cambiando y evolucionando la respuesta ante esta diversidad, pues hemos pasado de considerar la discapacidad como una patología de la persona que necesita "arreglos", a considerarla como una función de la interacción entre la capacidad personal y el contexto en el que la persona se desenvuelve (Wehmeyer, 2000). Llegado este punto, y antes de entrar a definir y cuestionar diferentes modelos de la discapacidad, veamos qué se entiende actualmente por 'discapacidad' desde los diferentes organismos internacionales.

Son múltiples los organismos internacionales que han elaborado a lo largo de la historia sistemas de clasificación de aquello que entienden por 'discapacidad'. Por motivos de espacio, eludiremos los sistemas precedentes al actual y nos centraremos únicamente en aquellos modelos vigentes. Nos referiremos pues a las definiciones que aportan organismos tales como la Organización Mundial de la Salud (OMS) y Naciones Unidas.

La Clasificación Internacional del Funcionamiento, la Discapacidad y la Salud (CIF) de la Organización Mundial de la Salud (2001) sostiene que "el concepto de la discapacidad engloba las deficiencias, limitaciones en la actividad, o restricciones en la participación" que resultan de la interacción entre la persona con una condición de salud y los factores ambientales. Paralelamente, la Organización de las Naciones Unidas (2006) en su Convención sobre los Derechos de las Personas con Discapacidad, afirma que la discapacidad es un concepto en evolución y que: "resulta de la interacción entre las personas con deficiencias y las barreras debidas a la actitud y al entorno que evitan su participación plena y efectiva en la sociedad en igualdad de condiciones a los demás".

Estamos, por lo tanto, ante conceptos de la 'discapacidad' muy vinculados a las deficiencias o barreras que experimenta la persona en su interacción con la sociedad y a las 'restricciones' que padece en cuanto a su participación e intervención social por ello. Al margen de que esta sea la 'concepción internacional reconocida', son múltiples los textos y manifiestos elaborados por las personas afectadas que solicitan, e incluso exigen, una adaptación terminológica que logre una definición social de la discapacidad basada en el respeto y el reconocimiento de la voz de las personas afectadas. De esta manera, exigen nuevos modelos o perspectivas de la discapacidad desvinculados totalmente de aquellos más tradicionales.

Sin embargo, antes de profundizar en estas nuevas concepciones sobre mundo de la discapacidad, haremos un breve repaso sobre algunos de los modelos propuestos por diversos autores en los últimos años: 


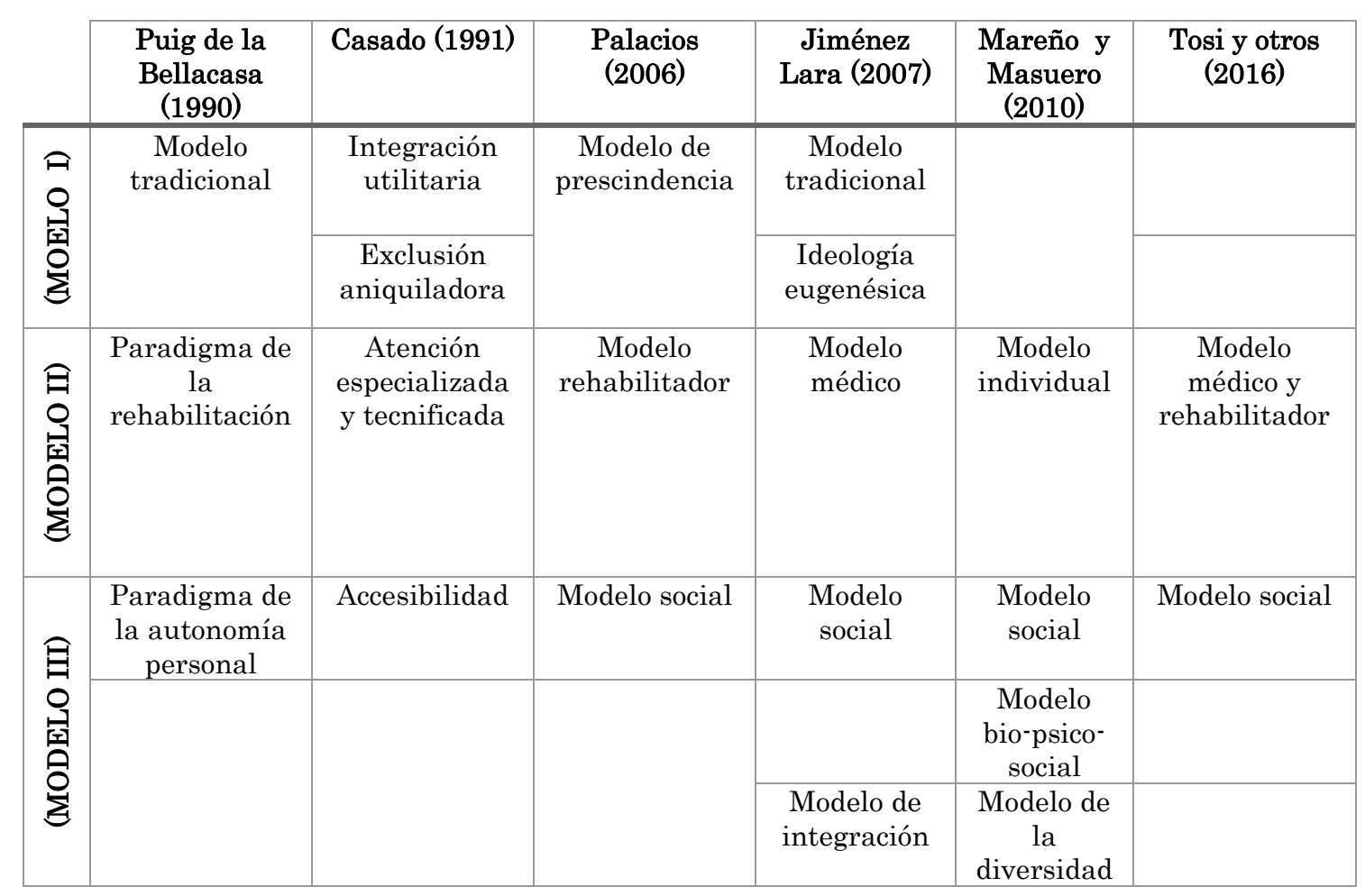

Tabla 1. Modelos de discapacidad según diferentes autores (elaboración propia)

De esta manera, en la revisión de la literatura encontramos tres tipos de modelos de discapacidad diferenciados. Son modelos que se encuentran vinculados no solo a un momento histórico concreto, sino también a un enfoque profesional concreto, y que además conllevan ciertas atribuciones de la discapacidad y determinadas respuestas (sociales y/o educativas) hacia ella.

\begin{tabular}{|c|c|c|}
\hline & CAUSAS DE LA DISCAPACIDAD & RESPUESTA A LA DISCAPACIDAD \\
\hline 曷 & $\begin{array}{l}\text { Castigo divino, demoníaco, motivo } \\
\text { religioso, causas ajenas al hombre,... }\end{array}$ & $\begin{array}{l}\text { Marginación, explotación, ocultamiento, } \\
\text { abandono, infanticidio, rechazo, } \\
\text { segregación, esterilización,... pudiendo } \\
\text { darse cierta atención }\end{array}$ \\
\hline 星 & $\begin{array}{l}\text { El individuo, su funcionamiento, } \\
\text { enfermedad o accidente de la } \\
\text { persona,... mono-causalidad biológica }\end{array}$ & $\begin{array}{c}\text { Intervención de especialistas y } \\
\text { profesionales (intervención médica } \\
\text { individual), medidas terapéuticas, } \\
\text { rehabilitadoras y compensatorias. Se } \\
\text { busca la adaptación del individuo al } \\
\text { medio }\end{array}$ \\
\hline 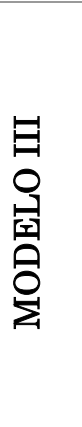 & $\begin{array}{l}\text { El problema reside en la sociedad, } \\
\text { reconocimiento de causas en el } \\
\text { individuo (su condición de salud) y en } \\
\text { el entorno (factores ambientales) } \\
\text { Concepción "bio-psico-social" de la } \\
\text { discapacidad }\end{array}$ & $\begin{array}{l}\text { Reclamación de derechos civiles de todos } \\
\text { los individuos y autodeterminación. } \\
\text { Intervención a nivel individual } \\
\text { (rehabilitación) y a nivel social: acciones } \\
\text { sociales, organización social, } \\
\text { modificaciones y adaptaciones } \\
\text { ambientales. } \\
\text { Introducción del concepto de "diversidad } \\
\text { funcional" }\end{array}$ \\
\hline
\end{tabular}

Tabla 2. Síntesis de los modelos de la discapacidad (elaboración propia) 
Como vemos en la tabla 2, en un primer momento (Modelo I) las causas de la discapacidad eran atribuidas a motivos religiosos, demoníacos y ajenos al hombre. Las personas pertenecientes a este colectivo no resultaban productivas para la sociedad y, por lo tanto, no se consideraban aptas para estar en ella. Esta atribución, condicionaba que la respuesta ante la diferencia fuera la marginación, el abandono e incluso el rechazo de su propia familia. En el mejor de los casos, se les daba una atención mínima de supervivencia, pero nada más. Obviamente, estamos ante un modelo totalmente exclusor de la discapacidad o modelo de prescindencia.

Con el paso del tiempo, esta idea de la discapacidad vinculada a lo místico y lo divino fue desapareciendo y poco a poco las atribuciones sobre las causas de la discapacidad fueron desviándose hacia la persona que las padecía (modelo II). Desde este modelo más médico- rehabilitador la discapacidad se considera el resultado de un problema de la persona y su funcionamiento ante el cual la respuesta no puede ser otra que un tratamiento individual y especializado. De esta manera, se pretendía "curar" la situación y/o enfermedad y conseguir que la persona se adaptara mejor al medio, siendo los profesionales del campo quienes mejor conocían el tratamiento que requería cada persona.

Finalmente, en las últimas décadas, estas concepciones han ido cambiando de nuevo y las causas de la discapacidad se han empezado a atribuir a la relación entre las características personales del individuo y la sociedad de la que forma parte. Desde esta concepción de la discapacidad (modelo III), se requiere en ciertos casos de intervenciones a nivel individual, pero el mayor peso de la responsabilidad recae sobre la sociedad, la cual debe generar los cambios, modificaciones y reestructuraciones que se consideren oportunas para lograr un pleno desarrollo de todas las personas. Estamos ante un modelo social de la discapacidad que se sustenta sobre cuestiones de derechos humanos como la dignidad, la igualdad de oportunidades y la participación en todos los ámbitos de la sociedad.

\subsection{El modelo social (de la diversidad): otra forma de mirar}

El modelo social de discapacidad surge como rechazo a los modelos explicativos anteriores: el de prescindencia y el médico-rehabilitador. Desde esta formar de mirar la discapacidad se critica que la sociedad no está preparada para responder y atender a todos los miembros que forman parte de ella ya que, al menos de momento, solo responde a las necesidades de un grupo mayoritario. Este modelo social de la discapacidad, aunque ha sido uno de los últimos en emerger no es reciente, sino que sus los primeros planteamientos cuentan con más de dos décadas de antigüedad. Veamos, en primer lugar, algunas definiciones sobre este modelo.

Tanto a nivel nacional como internacional, el modelo social de la discapacidad ha sido descrito por múltiples autores. En una primera aproximación expondremos la reflexión de Vega Fuente (2004):

El modelo social considera la discapacidad como un fenómeno principalmente 'social', desde el punto de vista de la integración de las personas con discapacidad en la sociedad. La discapacidad no es un atributo de la persona, sino un complicado conjunto de condiciones, muchas de las cuales son creadas por el ambiente social. Por lo tanto, el manejo del problema requiere la actuación social y es responsabilidad 
colectiva de la sociedad hacer las modificaciones ambientales necesarias para la participación plena de las personas con discapacidad en todas las áreas de la vida social. De aquí que, en realidad, la discapacidad se configura como un tema de índole político. (Vega Fuente, 2004: 102)

Asimismo, a nivel internacional se ratifica esta visión exigiendo además un carácter 'no opresor' desde la sociedad. Barton (2009) considera que el modelo social de la discapacidad es fundamentalmente la lucha por la igualdad y por un mundo no opresivo ni discriminatorio. Para este autor, la base de este movimiento radica en el hecho de ir más allá de la propia cuestión de la discapacidad y centrarse más bien en el establecimiento y mantenimiento de un mundo social en el que todas las personas experimenten la realidad de los valores inclusivos y de las relaciones.

Por lo tanto, estamos ante un modelo, que además de demandar a la sociedad responsabilidades sobre la no discriminación, se establece como un modelo al servicio de las personas con discapacidad ofreciéndoles (Barton, 2009):

- Un marco y una lengua para que los discapacitados puedan describir sus experiencias. La discriminación, la exclusión y la desigualdad pueden ser mencionadas y cuestionadas.

- Un medio para poder explicar y entender la cuestión de la discapacidad en términos de condiciones y relaciones socioeconómicas más amplias.

- Una base para el apoyo y el compromiso colectivo entre los discapacitados.

- Un medio a través del cual se puede ofrecer una alternativa y proyectar una imagen positiva de la discapacidad en el mundo de los no discapacitados (función educativa).

Muy vinculado al nacimiento y brote de este movimiento se encuentran aportaciones como las de Oliver (1998). Oliver, como persona con discapacidad y profesional del campo, siempre se ha manifestado muy comprometido con el movimiento social de la discapacidad y, de hecho, sus aportaciones, son una escucha activa de las personas afectadas. En su trabajo, recupera el siguiente fragmento de Bourne:

No eran los negros quienes debían ser analizados, sino la sociedad blanca; no se trataba de educar a blancos y negros para la integración, sino de combatir el racismo institucional; el campo de estudio no eran las relaciones raciales, sino el racismo. (Bourne, 1980, p.339, citado en Oliver, 1998)

Este autor, utiliza este fragmento y lo traslada al terreno de la discapacidad, alegando que no son los discapacitados quienes deben ser analizados, sino la sociedad capacitada. Para Oliver (1998), al igual que para Bourne (1980), no se trata de educar a capacitados y discapacitados para la integración, sino dejar de focalizar en las relaciones de discapacidad y combatir directamente cuestiones como el minusvalidismo, qué sentido tiene y porqué surge. Estamos en una sociedad que focaliza más en las limitaciones de las personas que en las potencialidades, y debemos empezar a considerar que la solución pasa por la acción social. La responsabilidad última es de la sociedad y, por lo tanto, debe ser ésta la que realice las modificaciones pertinentes para facilitar la plena participación de todas las personas y en todas las áreas de la vida (Jiménez Lara, 2007) 
Tal y como ya hemos expuesto en este capítulo, este modelo social de la discapacidad critica y cuestiona firmemente la identificación y catalogación de las personas en base a sus características personales físicas, sensoriales o intelectuales. Barton (1998) interpreta esta situación como la actuación poder de un grupo sobre otro, al que define e identifica de manera diferenciada. En torno a esta última idea, ciertos autores van incluso más allá y identifican la situación de las personas con discapacidad como un elemento de "opresión social" (Finkkelstein, 1980; Barret, 1981; Brittan y Maynarde, 1984, citados en Oliver, 2008). En relación a esta línea Oliver (2008) plantea en su trabajo que la participación social es reclamada por las personas con discapacidad, y que según sus voces, no son las limitaciones personales las que evitan su participación, sino que son las restricciones sociales que la misma sociedad les impone.

Asimismo, para autores como Abberley (2008), es conveniente que a la hora de formular una teoría social de la discapacidad, se haga a través de este concepto de opresión, ya que solo a través de él las personas con discapacidad pueden transformar la situación en la que se encuentran. Para este autor, hablar de opresión social de las personas con discapacidad implica al mismo tiempo afirmar una serie de puntos adicionales como: que el grupo de personas con discapacidad se encuentra en una posición inferior a la de otras personas en la sociedad por el hecho de tener discapacidad, que las desventajas que éstos padecen están relacionadas con una ideología que justifica y perpetua esta situación, que éstas desventajas así como la ideología que las sostiene no son ni naturales ni inevitables y que conlleva la identificación de algún beneficiario de esta situación.

Estamos ante un modelo de la discapacidad que vela por el respeto a la dignidad humana de todas las personas afectadas, la igualdad de oportunidades y la libertad personal, de manera que se propicia la inclusión social basada en principios de no discriminación, accesibilidad universal, normalización del entorno y una vida independiente (Illán, 2013). Se trata de un modelo que apuntala la filosofía de vida independiente con esos principios fundamentales que describen la discapacidad como una forma específica de opresión social (Hasler, Barnes y Zarb, 2003).

Justamente esta última idea, la de vida independiente (o movimiento de vida independiente), surgió en los Estados Unidos en los años 70 a través de un grupo de estudiantes universitarios con discapacidad de Berkeley (California). Este grupo de estudiantes se negaron a permitir que sus vidas fueran controladas por instituciones gubernamentales paternalistas, asociaciones benévolas o familiares con buenas intenciones. Exigían el derecho (sencillo y digno) de asumir la responsabilidad de su propia vida generando, ideas que se fueron extendiendo a otros países a los largo de los 80 y 90 (Rodríguez-Picavea, 2013). Este movimiento representaba la exigencia de las personas con discapacidad de sentirse parte de la sociedad a la que pertenecen, de sentirse libres de tomar decisiones y de poseer igualdad de oportunidades en cualquier ámbito de su vida. Sin barreras, sin limitaciones impuestas, sin excusas para derivarlos a caminos o sistemas paralelos al resto de la sociedad.

Este nuevo paradigma de vida independiente es, de alguna manera, la consecuencia de las acciones desarrolladas por las personas que con su lucha hicieron valer sus derechos (Illán y Molina, 2013). Es un camino abierto a las personas con discapacidad que quieran salir de la trampa que supone el sistema 
tradicional de "rehabilitación", recuperar su libertad y convertirse en protagonistas de sus propios destinos individuales (García, 2003).

Recientemente, Tosi et al. (2016), basándose en trabajos de otros autores como Centeno, Lobato y Romanach (2008) y Aspaym (2007) elaboraron los principios sobre los que se sustenta el derecho a la vida independiente reclamada desde este movimiento:

- Autodeterminación: garantizar que puedan tomar el control y decisiones sobre su desarrollo.

- No discriminación: erradicar todo tipo de barreras para que puedan ejercer de forma efectiva sus derechos.

- Des-institucionalización: proporcionar a las personas los apoyos que necesitan pero sin institucionalizar, pues esta es una forma de evidenciar que la sociedad no está generando una respuesta adecuada a todas las personas que forman parte de ella.

- Des-medicalización: la discapacidad no es un asunto médico, es un asunto social, y la visión médico-rehabilitadora contribuye a disminuir la capacidad de las personas a ejercer sus derechos.

- Control por parte del consumidor: los servicios fundamentales (educación, transporte o vivienda) deben adaptarse a las personas y no al revés.

- Apoyo entre iguales: facilitar herramientas sociales contra la discriminación y las desventajas sociales a través del intercambio de experiencias.

- Emancipación: implementar los mecanismos necesarios para que todas las personas puedan ejercer la autodeterminación como un derecho.

Pero para que estos principios se cumplan la sociedad en general, y cada persona en particular, deberíamos revisar nuestras acciones y posiciones (personales, sociales y políticas) contribuyendo así a un giro en la conciencia social sobre la diversidad funcional. Es una cuestión de derechos: derecho a la educación inclusiva, al acceso al trabajo y actividades de ocio, a los procesos e instituciones políticas, el derecho a las relaciones personales y sexuales, a la paternidad y la maternidad, y a participar en la vida de la comunidad (García, 2008).

Este movimiento de vida independiente, es una corriente que, aunque en Estados Unidos se desarrolló entre finales de los 60 y principios de los 70 , en nuestro país se materializó en 2001 mediante la aparición del Foro de Vida Independiente (FDV). Desde entonces, y mediante las estructuras de esta plataforma, las reivindicaciones se centran en el empoderamiento de las personas con diversidad funcional, la desmedicalización y la desinstitucionalización, el apoyo entre iguales, el poder tomar decisiones y la libertad de elegir la forma de vida (Rodríguez-Picavea, 2013).

A partir de este modelo social, según Rodríguez-Picavea (2913), surgieron otros como el modelo o enfoque de capacidades de Nussbaum (2007) según el cual la dignidad no puede definirse sin tener en cuenta las capacidades humanas. Según esta autora existe una lista de 10 capacidades básicas que dan forma y contenido a la idea abstracta de dignidad. Respecto a ellas, existe la idea de un umbral para cada capacidad por debajo del cual se considera que los ciudadanos no pueden 
funcionar de un modo auténticamente humano (Nussbaum, 2007) Ante ello, una sociedad justa tiene la obligación de proveer los recursos necesarios para que las personas puedan desarrollar sus capacidades básicas hasta el mínimo requerido, lo que les permitirá elegir libremente sus propios planes de vida (Cuenca, 2012)

Aproximadamente a la par que este modelo anterior, en 2006, a raíz de los avances legislativos, sociales y políticos para las personas con diversidad funcional, aparece el denominado modelo de la diversidad. Según Rodríguez- Picavea (2013), este nuevo modelo es una evolución del modelo social y de sus principios de vida independiente, dejando de lado términos como capacidad y normalidad, para centrarse exclusivamente en la dignidad y la diversidad.

En resumen, este modelo partirá de la búsqueda de la plena dignidad, tanto la extrínseca como la intrínseca, de todas las mujeres y hombres, incluidas aquellas que tienen una diversidad funcional. Para ello utilizará dos herramientas que ya están bastante desarrolladas en la sociedad occidental moderna: los Derechos Humanos y la Bioética. Estos dos pivotes deberán ser suficientes, de momento, para iniciar una revolución en dos vías: por un lado la plena consecución de la dignidad de las mujeres y hombres con diversidad funcional y por otro, la apertura de la conciencia de que esa dignidad resulta necesaria para toda la humanidad, si quiere aceptar plenamente la diversidad inherente a su propia existencia y al desarrollo de las sociedades modernas. (Palacios y Romañach, 2006: 190)

Este nuevo modelo de diversidad, evoluciona a partir del modelo social pero propone sobre éste los siguientes cambios (FVID, 2016):

- Erradicar la capacidad como indicador para el colectivo y sustituirlo por la dignidad: mismo valor para las vidas y mismos derechos.

- Reivindicar el valor de la diversidad humana y la participación en esta diversidad de nuestro colectivo.

- Propugnar un cambio de terminología: sustituir "personas con discapacidad" por "hombres y mujeres discriminados por su diversidad funcional" o, más breve "personas con diversidad funcional"

Como podemos observar, una de las modificaciones más notorias sobre este cambio es el uso del término 'diversidad funcional' en sustitución de otros más discriminatorios y ofensivos. Recordemos que según la clasificación internacional del Funcionamiento, la Discapacidad y la Salud (OMS, 2001), el concepto de discapacidad se vincula a limitaciones y restricciones a una vida considerada 'normal'. Pero ¿quiénes somos el resto de personas para identificar la vida de alguien como normal o no? ¿qué juicios de valor estamos utilizando para ello? ¿lo que nos gustaría que fuera y no es? ¿lo saludable? Debido a cuestionamientos de este tipo, el mismo Foro de Vida Independiente (FVI) rechazó nomenclaturas de este tipo por considerarse negativas con las personas y propuso el término de 'diversidad funcional'. Como algunos autores indican, se considera necesario avanzar en nomenclaturas más respetuosas y en activismo político orientado al reconocimientos de capacidades de decisión y participación en la vida colectiva mediante la lucha por el reconocimiento de los derechos legales y de ciudadanía y una participación actica en el discurrir general de la vida social (Rodríguez y Ferreira, 2010). 
Mediante el concepto de 'diversidad funcional' el FVI reclama el respeto a la dignidad integral de la persona humana de manera que la diversidad funcional se convierta en una herramienta de reflexión sociológica. No es suficiente con asumir presupuestos morales y consensuar sensibilidades sino que se trata de tomar medias prácticas y hacerlo desde una reconfiguración de nuestros esquemas de pensamiento (Rodríguez y Ferreira, 2010).

El último y reciente avance respecto a este modelo tuvo lugar en 2010 a través de la aparición de un nuevo concepto, el término divertad. Esta idea es el resultado de años de activismo del FVI contribuyendo y luchando, a nivel social y político, por mejorar la dignidad y derechos de las personas con cualquier tipo de diversidad. Esta nueva palabra, gestada en el epicentro del FVI, es una palabra inventada que pretende sintetizar varias ideas: libertad y dignidad en la diversidad. Se trata de un ideal en que personas con cualquier tipo de diversidad (de raza, cultura, religión, género, orientación sexual, funcional, edad,...) tengan plena dignidad y plena libertad, sin discriminación ni opresión por su diferencia y con las mismas oportunidades que el resto de las personas (Romañach, 2009). Este concepto, creado desde el mismo Foro de Vida Independiente impregnó el ideario de esta comunidad pasando a denominarse desde 2010 Foro de Vida Independiente y Divertad.

Estamos pues ante una mirada distinta de lo diverso y toca empezar a denominar las situaciones y experiencias como lo que son y no atribuirlas a cuestiones de menor capacidad de las personas, falta de ella o sus limitaciones. En nuestro campo de estudio trabajamos con personas que poseen sensibilidades, intereses, pretensiones y sueños. No debemos ni tenemos derecho a decidir por ellas, y ni mucho menos a encorsetar su estilo de vida en un modelo con el que no se sientan identificadas. Bajo el lema "nada sobre nosotros sin nosotros" demandan que no solo escuchemos y visibilicemos su voz, sino que gritemos juntos.

\subsubsection{Tomar partida en el asunto}

Llegado este punto y antes de seguir adentrándonos en otras cuestiones relacionadas con nuestro tema de estudio, debemos retomar el dilema ético y profesional planteado anteriormente. En este apartado no escatimaré en exponer mis sensaciones como investigadora y, por qué no, como persona. No puedo negar que el debate interno sobre si utilizar una terminología u otra (discapacidad o diversidad funcional) no solo afecta cuando estoy sentada trabajando en esta investigación, sino que aparece en otros ámbitos personales e íntimos de mi ser.

Entiendo que la investigación es eso justamente, que aquello que te despierta interés, aquello en lo que nos lanzamos a investigar durante unos años trascienda más allá de nuestro 'yo profesional' y llegue a cada esquinita de nuestro cuerpo. Reconozco que el dilema de cómo referirme a las personas diversas, a las personas con capacidades diferentes, ha estado presente en mí desde el inicio hasta el final de esta investigación.

Desde un primer momento parecía tener muy claro lo que iba a hacer. Las diversas lecturas sobre diversidad funcional y los discursos del colectivo en los diferentes medios me hacían pensar en la necesidad de utilizar el término de 'diversidad funcional'. El uso del término 'discapacidad' se restringiría a la referencias de otros autores que sí lo han utilizado de manera explícita. Pero cuando la investigación arrancó y empezaron las primeras reuniones de negociación con los participantes, este debate interno emergió de nuevo. Como se 
podrá comprobar más adelante, en las primeras tomas de contacto con la familia se negociaron aspectos como las preguntas de investigación, los objetivos, los instrumentos,... En este momento surgieron de nuevo las dudas ¿utilizamos en todo momento el término 'diversidad funcional'? Sabemos que a algunas personas les sonará el término, a otras se lo podremos explicar, pero ¿y aquellas personas mayores o niños que participan en la investigación? ¿Sabremos trasladarles correctamente a qué nos referimos con este término?

En todo momento hemos sido conscientes que la utilización de un término $\mathrm{u}$ otro es una cuestión ética, social y política, pero ¿es necesario que nuestros participantes conozcan nuestra posición al respecto para participar en la investigación? De repente aparecieron miedos, muchos miedos. Emergió la incertidumbre de pensar que se podría sesgar la investigación por cuestiones de este tipo ¿cómo asegurar que todos los participantes entienden y comparten nuestra postura? Ante esta situación, decidimos contar con la aportación de la familia del protagonista de nuestra historia de vida. Nos encontrábamos en un punto en el que había que arrancar la investigación y que, de partida, no sabíamos qué terminología utilizar. Los planteamientos, nuestro posicionamiento en un modelo de la diversidad estaba clarísimo, pero llegó el momento de materializarlo y no sabíamos cómo hacerlo.

A lo largo de las conversaciones con la familia se plantearon los distintos modelos de la discapacidad, las implicaciones de uno y otro, e incluso las concepciones que existen de cada uno de ellos. Discutimos abiertamente sobre en qué contextos se utilizan unos u otros términos, y cómo el uso reiterado de un determinado modelo acaba afianzando los conceptos y, por lo tanto, consolidando el constructo social. Tras las diversas discusiones, asumimos que familia e investigadora comulgábamos con un modelo de la diversidad (la evolución del modelo social de discapacidad) y manifestamos nuestro acuerdo en utilizar términos respetuosos con sus postulados. No obstante, éramos conscientes que este no es un término socialmente conocido. Justamente ellos, la familia del protagonista de nuestra historia, es quien mejor conoce a los participantes de esta investigación y las posibilidades y dificultades que puede generar utilizar un término u otro y cuestionaban firmemente que todos los participantes lo pudieran entender.

Finalmente, la familia de Sergi y la investigadora principal asumimos el término 'diversidad funcional' como el único que respeta, dignifica y visibiliza los derechos de las personas con características diferentes. No obstante, en aquello que acontece a los participantes (como negociaciones e instrumentos) se decidió seguir utilizando el término 'discapacidad' intentando reducir tanto como fuera posible el uso de este concepto. Esto mismo se repitiría al citar a otros autores, bien en parafraseo o bien en cita literal, utilizando la terminología elegida por cada autor.

Por supuesto, esta decisión fue costosa y dura para la investigadora, pues es como proclamarse a los cuatro vientos a favor de una ideología pero no ser totalmente fiel a ella. Esta determinación fue necesaria y debidamente deliberada con las personas implicadas a pesar del desasosiego que nos generaba. Es de suponer que estas ideas volvieron a brotar en forma de remordimiento y desazón en otros momentos de la investigación pero, de nuevo, al repasar todos estos argumentos, nos ratificábamos en nuestra decisión. 


\subsection{Diversidades en la forma de ser: un sinfín de posibilidades}

Como ya se ha ido introduciendo en este capítulo, esta investigación centra su atención en la diversidad social actual, concretamente en la diversidad funcional. Y esto lo hace desde un modelo de la diversidad que no solo busca visibilizar, sino dignificar y acompañar en la exigencia de los derechos humanos de las personas con diversidad funcional. De esta manera, el elemento principal de esta investigación es la construcción de la historia de vida de un joven con diversidad funcional.

Nuestro protagonista, Sergi, es un adolescente de 14 años con intereses muy diversos, con capacidades bien definidas y con una humanidad abrumadora. Y es que Sergi, desde bien pequeño y hasta día de hoy, siempre ha sido reconocido entre los suyos por su personalidad, por su peculiaridad y por su carisma. Es una persona completa, educada $\mathrm{y}$, como dicen quienes le conocen, con un futuro brillante.

Sergi, al igual que otros niños con diversidad funcional, ha experimentado en sus carnes aquellas concepciones de la discapacidad vinculadas a la desigualdad, a las barreras y a las etiquetas. En capítulos próximos, podremos observar cómo lamentablemente sigue persistiendo en las escuelas y calles un modelo médicorehabilitador de la discapacidad desde el que se 'atiende' a las personas con diversidad funcional con 'tratamientos especializados' en categoría de 'clientes'. Asimismo, podremos ver cómo desde otros contextos como el familiar, el modelo de la diversidad es un modelo mucho más desarrollado y desde ahí se generan estrategias y herramientas para superar adversidades.

El autismo, concretamente un diagnóstico entre TEL y TGD, persigue a Sergi por donde quiera que vaya como si de una carta de presentación se tratara. Una carta en la que a veces pasan desapercibidos sus intereses, sus motivaciones, sus sueños,... que son relegados a un segundo plano. Probablemente, el peso del autismo y del trastorno del lenguaje no deja a ciertas personas ver más allá y encorsetan a Sergi por aquello que unos especialistas han dicho que no tiene o no es capaz de hacer, en lugar de hacerlo por sus virtudes y potencialidades. Desde nuestro posicionamiento criticamos y nos oponemos firmemente a los etiquetajes y diferenciación de las personas, pues las personas son diversas en su esencia, sea del modo que sea, y acusar, identificar y colgar ese peso sobre los hombros de otro es un medio de castigo y discriminación encubierto en el siglo XXI.

No obstante, entendemos que los estudios de la psicología evolutiva y de la educación, y la neurociencia, tienen un sentido no solo científico sino también educativo y social. Su finalidad es entender el funcionamiento del cerebro y la mente humana para poder mejorar la calidad de vida de todas las personas. Entendemos por lo tanto, que aunque nuestra postura se aleje de la concepción diferenciadora de la diversidad, sí debemos ser conocedores de qué es el autismo, a qué áreas afecta y cuáles son las herramientas por excelencia que ayudan a superar las dificultades. En este punto, declaramos ser plenamente conscientes de que cada persona es diversa por el mero hecho de ser persona y que los patrones son eso, patrones obtenidos a base de estudios sobre la población. Nunca podemos, ni debemos, esperar que las personas se ajusten a ellos. 
Veamos a continuación una breve descripción de qué es el autismo y algunos rasgos definitorios básicos que nos ayudarán a comprender ciertos elementos de la historia de vida de Sergi.

\subsubsection{Conceptos principales}

Cuando hablamos y leemos sobre autismo, son muchos los trabajos que mencionan otros términos como TEA, TGD, TGD- NE,... pero ¿qué significan cada uno de estos acrónimos? ¿a qué se refieren? ¿Significan lo mismo que el autismo? Generalmente, si no pertenecemos al campo de la psicología educativa y/o neurociencia, puede que tengamos cierta confusión sobre estos términos. Por ello, y con la pretensión de clarificar ciertos conocimientos al respecto, revisaremos algunos de ellos:

Autismo: es una alteración que se da en el neurodesarrollo de competencias sociales, comunicativas y lingüísticas y de las habilidades para la simbolización y la flexibilidad (FESPAU, 2012). El autismo, considerado un continuo en lugar de una entidad o categoría, es comprendida por una desviación en el desarrollo psicológico o un trastorno en el desarrollo (Benites, 2010).

Trastorno del espectro Autista (TEA): es el continuo de posibilidades (espectro) en el que las presentaciones de la alteración son muy heterogéneas. Este concepto implica que individuos con un mismo diagnóstico puedan variar enormemente en sus características externas (dependiendo del nivel de afectación en los componentes de desarrollo social, comunicativo lingüístico, de la flexibilidad y la simbolización, de la presencia y grado de discapacidad cognitiva, etc.). De hecho, el actual DSM-V (2013), Manual Diagnóstico y estadístico de los Trastornos Mentales de la American Psychiatric Association, sustituyó la denominación de Trastorno Generalizado del Desarrollo (TGD) por este nuevo término: Trastorno del Espectro Autista (TEA), entendiendo el TEA como una perturbación grave y generalizada del ámbito socio-comunicativo y de intereses fijos y conductas repetitivas.

En este mismo manual, la categoría general "trastornos del espectro autista" (TEA) se divide en cuatro subtipos: trastorno autista, síndrome de Asperger, trastorno desintegrativo infantil y TGD no especificado, dejando fuera del sistema de clasificación el síndrome de Rett (contemplado en este grupo en ediciones anteriores) (APA, 2013). Las personas con TEA son definidas por Wing (1988, citado en Pié 2014) como aquellas que presentan trastorno de reciprocidad social, trastorno de comunicación verbal y no verbal, ausencia de capacidad simbólica, conducta imaginativa y patrones repetitivos de actividad e intereses.

Otra de las definiciones sobre el autismo la encontramos en trabajos como el de Albores, Hernández, Díaz y Cortés (2008), quienes lo definen en términos generales como un trastorno neuropsicológico de curso continuo asociado, frecuentemente, a retraso mental. Según esos mismos autores se trata de un transtorno con un inicio anterior a los tres años de edad, que se manifiesta con una alteración cualitativa de la interacción social y de la comunicación así como con unos patrones comportamentales restringidos, repetitivos y estereotipados con distintos niveles de gravedad.

Cabe añadir aquí que el concepto TEA, no existe como término clasificatorio en la Clasificación Internacional de los Síndromes y de los 
Trastornos Psíquicos y del Comporamiento de la OMS (CIE-10), pues esta organización sigue utilizando el término Trastorno Generalizado del Desarrollo en sus diferentes versiones y lo considera un sinónimo de autismo (Pié, 2014).

Trastorno Generalizado del Desarrollo (TGD): Es la categoría utilizada por el DSM-IV (hasta 2013) para referirse al conjunto de trastornos del desarrollo caracterizados por alteraciones graves y generalizadas de varias áreas de desarrollo: habilidades para la interacción social, habilidades para la comunicación y presencia de comportamientos, intereses y actividades estereotipados, considerándose como subtipos trastorno autista, trastorno de Rett, trastorno desintegrativo infantil, trastorno de Asperger y trastorno generalizado del desarrollo no especificado (APA, 2002). Actualmente es un término descatalogado en el DSM-V.

Trastorno Generalizado del Desarrollo No Especificado (TGD-NE): es una alteración social recíproca o de las habilidades de comunicación verbal o no verbal, o cuando hay comportamientos, intereses y actividades estereotipadas pero no se cumplen los criterios de un trastorno generalizado del desarrollo específico, esquizofrenia, trastorno esquizotípico de la personalidad o trastorno de la personalidad por evitación. Esta categoría incluye el 'autismo atípico', es decir, casos que no se cumplen los criterios de trastorno autista por una edad de inicio posterior, una sintomatología atípica o una sintomatología subliminal o, por todos estos hechos a la vez (APA, 2002). El TGD-NE es un subtipo de TEA categorizado por el DSM-V (APA, 2013).

Esta categoría, a pesar de considerarse una etiqueta residual como testimonio vacío de la esfera diagnóstica (López y Rivas, 2014), y en contra de lo que se pueda esperar, es una de las más frecuentes en la práctica clínica diagnóstica, pues el desconocimiento de los límites sobre este tipo de trastornos provoca que se ubiquen en esta categoría un gran número de personas que no cumplen con los criterios establecidos en otros trastornos (Artigas, 2001).

En este punto, cabe añadir, que en múltiples ocasiones, el autismo o TEA se confunde, relaciona o asocia a Trastornos Específicos de Lenguaje (TEL). En el caso del protagonista de nuestra historia, se da esta relación entre TEA y TEL, pues desde los primeros diagnósticos y hasta día de hoy, los profesionales que lo han evaluado y diagnosticado no se han posicionado firmemente y admiten una gran ambigüedad en este sentido. El Trastorno Específico del Lenguaje (TEL) es definida como la "anormal adquisición, comprensión o expresión del lenguaje hablado o escrito. El problema puede implicar a todos, uno o algunos de los componentes fonológico, morfológico, semántico, sintáctico, o pragmático del sistema lingüístico. Los individuos con trastornos del lenguaje tienen frecuentemente problemas de procesamiento del lenguaje o de abstracción de la información significativa para almacenamiento y recuperación por la memoria a corto o a largo plazo" (ASHA, 1980, citado en Báez y Cabeza, 2006).

Son diversos los autores que constatan en sus trabajos que tanto el TEL como el TEA comparten una base etiológica común (Tellechea, 2013) que condiciona que a pesar de encontrarse definidos de manera bien distinta, comparten ciertas características de alteraciones del lenguaje y del comportamiento social (Rescorla, 2003 y Geschwind, 2009) 


\subsubsection{Mitos y tópicos sociales sobre el TEA}

Una vez hemos definido los conceptos generales del Trastorno del Espectro autista y lo hemos esclarecido con respecto a otros términos, procederemos a identificar y desmitificar aquellos tópicos y mitos que socialmente se oyen (y a veces se creen) sobre el autismo. Existen, por lo tanto, ciertas ideas erróneas sobre el autismo muy extendidas (Ministerio de Salud y Política social, 2009) como:

1.- "Son así porque sus padres no les quieres o les han maleducado". El autismo es una alteración neurológica crónica que nada tiene que ver con la crianza.

2.- "Todos los niños con TEA tienen retraso mental". Generalmente existen alteraciones cognitivas asociadas al TEA, sin embargo, puede darse el caso de que niños con TEA no presenten ninguna afectación a nivel cognitivo o incluso que tengan capacidades superiores a la media. Así mismo, otros manifiestan habilidades extraordinarias en ámbitos como la música, las matemáticas, la pintura,,..

3.- "No son capaces de comunicarse, no miran a los ojos, no sonríen ni responden a las muestras de afecto". Los niños y niñas con TEA son sensibles a las muestras de cariño y expresan sus sentimientos, emociones y afectos aunque a veces lo hagan de un modo distinto al de los niños de su edad.

4.- "El origen del problema está relacionado con la administración de vacunas, intolerancias alimentarias (gluten, caseína) o intoxicación por metales pesados (mercurio, plomo)". Estas teóricas carecen de aval científico y han sido rebatidas en diversas ocasiones. En este sentido, la Asociación Americana de Pediatría rechazó la relación causal entre vacunas y el autismo.

\subsubsection{Algunas singularidades y peculiaridades}

En la literatura encontramos múltiples y extensas clasificaciones sobre aquello que posee, carece (y por tanto necesita) una persona diagnosticada con autismo. Como venimos alegando en este capítulo, consideramos que no es nuestra función elaborar una comparación de las diferentes tipologías y necesidades de las personas con autismo. Sin embargo, pensamos que Sergi, nuestro protagonista, sí manifiesta algunas características y peculiaridades en su personalidad y forma de actuar que consideramos destacables.

En la literatura, se constatan un sinfín de singularidades y peculiaridades estudiadas en relación al autismo como rasgos definitorios del TEA. Aunque aquí no van a encontrar una revisión de ellas, sí consideramos necesario poner en sobre aviso al lector sobre aquellas que destacan en Sergi, pues resultaran de gran apoyo en capítulos posteriores:

Autismo y comunicación: La comunicación y el lenguaje son los ámbitos en los que la particularidad del niño con autismo se manifiesta de forma más significativa. Puede que exista una ausencia total o bien un parloteo un tanto inteligible, lenguaje ecolálico y /o repetición de frases que han escuchado decir a su interlocutor o que proceden de películas y medios de comunicación, generando grandes dificultades para acceder a la simbolización (Pié, 2014). Será esta simbolización la que determine las posibilidades en las relaciones sociales y el acceso al aprendizaje. 
Estas dificultades de comunicación y lenguaje suelen manifestarse independientemente de la capacidad intelectual de la persona con TEA. De hecho, a pesar de poder tener un lenguaje más o menos desarrollado pueden presentar enormes dificultades para expresar muchas de sus necesidades, emociones, sentimientos, dificultades, frustraciones,... o simplemente relacionarse de forma normal con las personas de su entorno social próximo (Simarro, 2013). En este sentido, los sistemas de comunicación aumentativo y alternativo conforman un elemento fundamental para la superación de dificultades comunicativas.

En Sergi, algunas de estas dificultades se manifiestan en diversos momentos de su vida, sobretodo en cuanto a las relaciones sociales y amistades, pues la comunicación y las relaciones sociales poseen una relación directa obvia. Así mismo, podremos destacar el papel que ejercen los distintos sistemas de comunicación y cómo han contribuido a una mejora de la calidad de vida de nuestro protagonista.

Autismo y relaciones sociales: la comunicación social es la base sobre la que se erigen las relaciones sociales con los demás y, generalmente, las personas con TEA suelen presentar dificultades y complicaciones en esta área. De hecho, en el proceso de socialización en las personas con TEA se evidencian trastornos cualitativos de la relación social, alteraciones de las capacidades de referencia conjunta (acción, atención y preocupación conjunta), trastornos de las capacidades intersubjetivas y mentalistas, trastornos en las competencias de anticipación y esquematismo mental y comportamental.

En este sentido, la familia en primer lugar y el entorno educativo en segundo, son los contextos de mayor incidencia y, por lo tanto, quienes deben apuntar hacia cambios estructurales para conseguir el mayor desarrollo posible de las capacidades personales, sociales e intelectuales de todos los alumnos, sin discriminación alguna (Gutiérrez, 2006), incluyendo a los alumnos con TEA. Más adelante, podremos ver cómo Sergi ha ido forjando sus propias relaciones y vínculos sociales, y el papel que tanto la familia como el centro educativo han ejercido para ello.

Autismo y creatividad. La creatividad, la originalidad y la inventiva son características generalmente asociadas a las personas con autismo. El mismo Riviére (1999) indica que las capacidades de representación y visoespaciales de las personas con autismo pueden ser iguales o incluso superiores al resto. Este autor, describe como sus creaciones no tienen la intención de emocionar a los demás, sino de extraer sus propias emociones y exteriorizar sus sentimientos. De hecho, en los dibujos realizados por alumnos autistas destacan algunas características como (Flores Díaz, 2007): Riqueza de detalles, dibujo lineal, dibujo muy expresivo, rapidez en la ejecución, gran capacidad de representación en perspectiva, gran imaginación y creatividad, dibujos dinámicos o cinéticos.

De hecho, tanto es así, que la expresión de una persona con autismo por medio del dibujo y otros elementos visuales se convierte en una herramienta que les permite expresar qué piensan, qué siente, qué desean, los miedos, cómo perciben las relaciones y/o el concepto de la familia o la amistad (Flores Díaz, 2013). Como veremos más adelante, la creatividad y el arte ocupan un lugar privilegiado en la vida de nuestro protagonista. 
Autismo y deporte: Tras la revisión de la literatura podemos afirmar que, aunque son escasos los trabajos sobre autismo y deporte, son múltiples los beneficios que la actividad física aporta tanto a nivel físico como intelectual y social. Tanto es así, que autores como García-Gómez, Risco, Rubio, Guerrero, y García-Peña (2014) afirman que la participación en actividades deportivas y de ocio son una variable esencial para cualquier programa que pretenda mejorar la calidad de vida de las personas.

De hecho, aunque los estudios sobre deporte y autismo no han conseguido aportar evidencias definitivas sobre la relación entre ambos, sí es cierto que se pueden observar algunos beneficios como: crear oportunidades de integración social, disminución de conductas estereotipadas, mejorar el rendimiento motor y las habilidades físicas en general, favorecer la autodeterminación y la calidad de vida, mejorar habilidades cognitivas y rendimiento académico, reducir el estrés y mejorar las competencias sociales (Sowa \& Meulenbroek, 2012). A lo largo de la historia de vida de Sergi podremos observar la trascendencia del deporte así como los múltiples beneficios que le aporta.

Estas son tan solo algunas de las peculiaridades más destacadas en Sergi $\mathrm{y}$, como podemos observar, mientras algunas han sido tradicionalmente estudiadas junto al autismo, otras no lo han sido tanto. Por lo tanto, podemos añadir que las personas son lo que són por sí mismas, por la esencia que las caracteriza, sin tener en cuenta patrones, clasificaciones o cuadros diagnósticos elaborados previamente. Pero entonces, ¿por qué el diagnóstico se considera tan importante? ¿por qué parece que sea el inicio del trabajo con personas con diversidad funcional?

\subsubsection{La diagnosis ¿es el quid de la cuestión?}

Al margen de si nuestras concepciones sobre la diversidad y el autismo encajan o no en los enfoques de la psicología y la neurociencia, debemos tener en cuenta que la detección precoz y la premura en el diagnóstico se están convirtiendo en una de las prioridades de la investigación sobre el Trastorno del Espectro Autista (TEA). La razón de ello es que en diversas investigaciones se constata que el diagnóstico y tratamiento precoz pueden mejorar sustancialmente el desarrollo de este trastorno debido a la neuroplasticidad propia de los primeros años de vida (Klin, Klaiman \& Jones, 2015). De esta manera, se entiende que logrando una detección temprana de los niños y niñas con autismo se generará una mayor posibilidad de una intervención temprana y, por lo tanto, un efecto positivo en el desarrollo de las habilidades adaptativas de los niños que posibiliten una educación en centros ordinarios (Karanth \& Chandhok, 2013).

Se estima que la tardanza en la evaluación inicial del TEA tiene relación con aquellos facultativos que son partidarios de una postura expectante hasta que los síntomas son obvios e innegables (Klin et al, 2015). Wiggins, Baio y Rice (2006) observaron en su trabajo que niños que fueron objeto de una evaluación inicial por un posible TEA a una edad media de 4 años no se les acabó diagnosticando dicho trastorno como mínimo hasta los 5 años de promedio. Asimismo, en estudios realizados en los Estados Unidos, se constató que, a pesar de la tardanza en el diagnóstico, el 30\% de los padres de niños con TEA sospechó problemas de desarrollo antes del primer aniversario del niño/a, y el 50\% sobre los 18 meses. (Chawarska et al., 2007; Wetherby, Brosnan-Maddox, Peace \& Newton, 2008). 
Como vemos, aunque los síntomas del autismo y otros trastornos asociados pueden estar presentes desde el primer año de vida, en realidad este diagnóstico suele concretarse sobre les 4 o 5 años. Cuando empiezan las primeras sospechas muchos clínicos se resisten a dar este diagnóstico a pesar de que existan síntomas, por motivos como: miedo a angustiar a la familia, resistencia a etiquetar al niño, evitar equivocarse en el diagnóstico y, sobretodo, por la quedar a la espera de que los síntomas remitan (Pié, 2014).

En este punto, consideramos necesario resaltar ciertos efectos contradictorios que generan el diagnóstico y etiquetaje de las personas con diversidad funcional. Por un lado, destacamos el efecto negativo que provoca el propio diagnóstico. Las etiquetas asociadas a pesonas concretas son una imagen, pero una imagen proyectada hacia el futuro, que condiciona las redes sociales de la persona y que, por lo tanto, dirige su desarrollo (Calderón, 2016), derivando en actitudes y expectativas que interfieren en su calidad de vida. Por otro, encontramos el efecto tranquilizador que el diagnóstico provoca en las familias. Parece ser que cuando las familias encuentran un diagnóstico que explique qué le pasa a su hijo o hija, cuando lo identifican con un tipo de trastorno o circunstancia concreta, se tranquilizan, y es el momento de ponerse 'manos a la obra' y buscar vías de trabajo para ayudarle.

Por lo tanto, si sabemos que el diagnóstico conlleva efectos negativos en las personas con diversidad funcional, pero ayuda a sus familias a saber qué hacer y cómo actuar ante las dificultades de sus hijos, ¿debemos considerar el diagnóstico como el quid de la cuestión? ¿es realmente necesario para ayudar a los niños y niñas con diversidad funcional? ¿o es una necesidad creada desde una versión positivista de la diversidad funcional?

Ante estas cuestiones que escapan a nuestro alcance, únicamente vamos a añadir que, desde nuestro punto de vista, tenemos en cuenta que la clasificación y etiquetaje de diversidad (y personas) conlleva efectos negativos tanto a nivel personal como social, además de no respetar aquellos derechos exigidos por las personas afectadas como la dignidad, la libertad, la autodeterminación y del derecho a participar. Pues este etiquetaje además de suponer una clara diferenciación de aquellos que se sitúan en una posición de poder (médicos, psicólogos, psicopedagogos,...), implica el tratamiento de la diversidad desde un modelo médico-rehabilitador, basado en la figura del 'experto especialista'. 




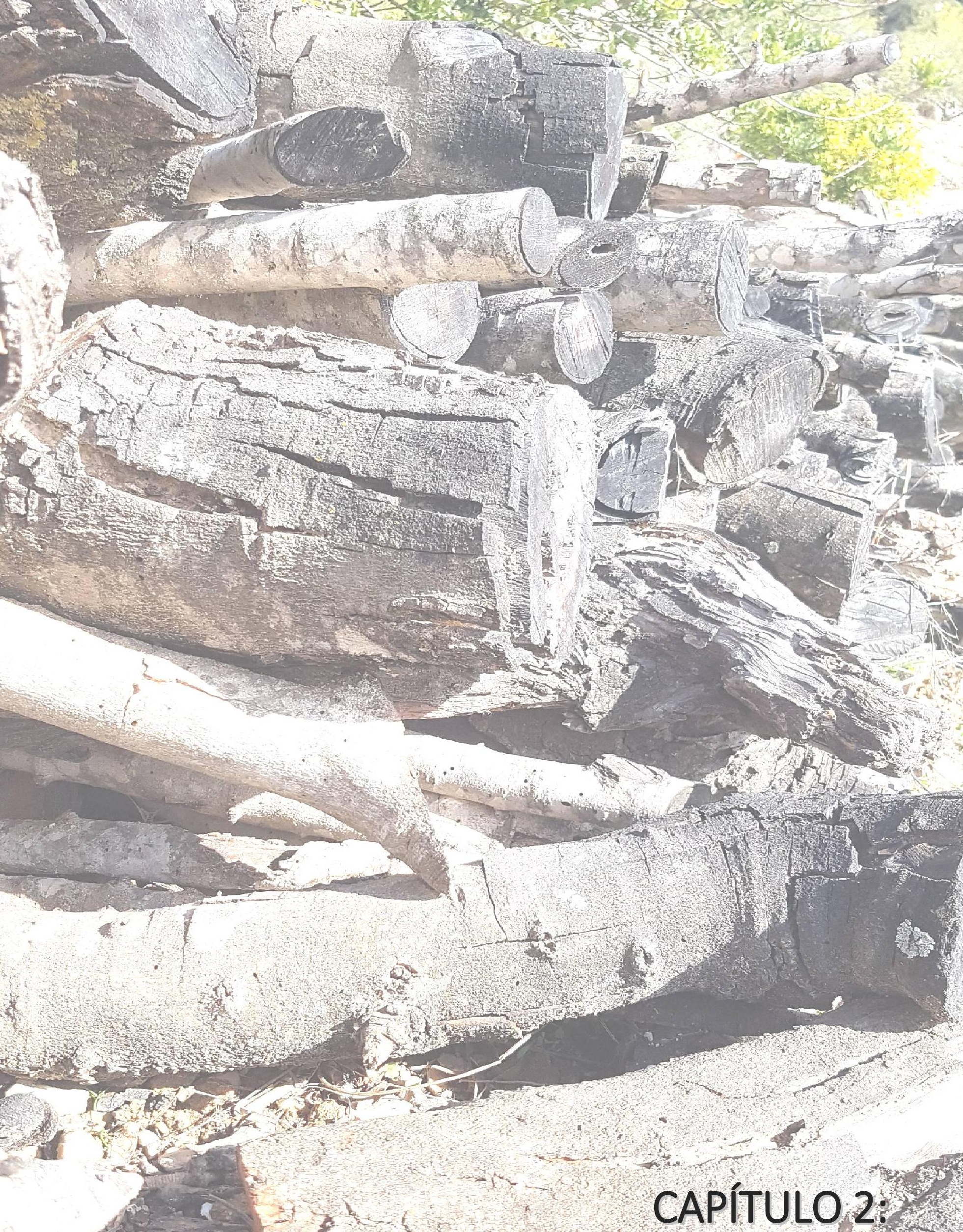

La respuesta social y educativa a la diversidad funcional 


Continuando con el cometido del primer capítulo complementamos nuestro marco teórico con el capítulo 2. Deseamos continuar resituándonos en nuestro campo de estudio y empezar a desgranar los principales cimientos sobre los que se sustenta esta investigación

En esta ocasión empezaremos a fluctuar sobre elementos más concretos y arraigados a nuestros planteamientos iniciales, pues necesitamos revisar qué se ha estudiado y escrito sobre la respuesta educativa y social con la que se encuentran las personas con diversidad funcional, y cómo estas se concretan en barreras y/o apoyos con las que se encuentran en su trayectoria.

La estructura que seguiremos en este capítulo es la siguiente:

2.1. De la Exclusión a la indiferencia

2.2. Respuestas negativas: Barreras y limitaciones a la inclusión educativa y social

2.2.1. Barreras sociales

2.2.2. Barreras institucionales o educativas

2.2.2.1. Barreras desde la administración

2.2.2.2. Barreras desde la escuela

2.2.2.3. Barreras desde los docentes

2.3. Respuestas formales: las políticas de la diversidad

2.3.1. Políticas sociales

2.3.2. Políticas educativas

2.3.2.1. Posibilidades de escolarización de las personas con diversidad funcional

2.3.2.2. Medidas de atención educativa a las personas con diversidad funcional en centros ordinarios

2.4. Respuestas emergentes: algunas estrategias de superación

2.4.1. Estrategias sociales: relacoines sociales y ocio

2.4.2. Estrategias educativas o formales

2.4.2.1. Estrategias educativas desde el centro

2.4.2.2. Estrategias educativas dentro y fuera del centro

2.4.2.3. Estrategias educativas fuera del centro: la educación no formal

2.4.3. El papel de la familia

2.5. La inclusión como proyecto vital

2.5.1. La calidad de vida: clave para la inclusión

2.5.2. El proceso hacia la inclusión 


\subsection{De la exclusión a la indiferencia}

Tal y como ya veníamos introduciendo en el capítulo primero, todo aquello que tiene que ver con lo diferente o lo disonante a la gran mayoría, se ha visto envuelto tradicionalmente en estigmas sociales vinculados a la 'desigualdad' y a la 'no normalidad'. Ya venimos adelantando en páginas anteriores que la diversidad y la variedad no es algo que se pueda atribuir a un grupo de personas, pues se trata de algo inherente a la existencia del ser humano. Somos diferentes, somos dispares, desiguales y discrepantes, y eso es lo verdaderamente rico. Lo diverso no hace aprender, nos hace más enriquecer, nos hace crecer.

Sin embargo, parece que esta realidad no es percibida por igual en el conjunto de la sociedad. Parece que esos modelos de la discapacidad o diversidad de los que hablábamos en el capítulo 1 no están tan superados como nos gustaría creer. De hecho, de la mano de esos modelos, aparecen concepciones tales como que ciertos grupos no poseen la capacidad suficiente o no les corresponde según qué espacios o estamentos de nuestra sociedad. Una triste y lamentable concepción proveniente de modelos médicos y rehabilitadores de la diversidad que generan discriminación, prejuicios y estigmatizaciones sociales que derivan de manera irrevocable, y en ocasiones irreversible, en procesos de exclusión social.

La exclusión en sí misma no tiene porqué estar arraigada necesariamente a un contexto social marginado, puede darse en el ámbito familiar, laboral, educativo, político,... y venir motivado por diversas cuestiones: étnicas, de género, económicas, de capacidad, de procedencia,... De hecho, a pesar de las atribuciones sociales al respecto, hablar de exclusión social no requiere necesariamente hablar de pobreza económica, pues son conceptos que se organizan de manera bien distinta. Mientras el concepto de pobreza se construye desde la metáfora espacial de 'arriba y abajo' según indicadores económicos, la exclusión social:

L... I se construye sobre la metáfora de "dentro y fuera"; los excluidos
son los que no cuentan, son insignificantes y sobran... La exclusión
añade a la pobreza la impotencia, la fragilidad de los dinamismos
vitales, los contextos inhabilitantes. Mientras los pobres iban en la
última fila del autobús, los excluidos no llegaron a subir a él, son
poblaciones sobrantes. (García, 2003: 3)

En este trabajo, partiremos de una concepción de la exclusión desde una vertiente estructural, multidimensional y procesual del concepto (Laparra y otros, 2007). Según Castells (1997), para que exista un sector excluido debe haber otro incluido. Para este autor, la exclusión se relaciona con procesos sociales que conducen a determinados individuos y grupos a permanezcer al margen de ciertas organizaciones y comunidades en las que se articula la sociedad, implicando una pérdida del sentido de pertenencia, y la negación de derechos y oportunidades económicos, sociales, políticos, culturales y/o educativos.

El propio concepto de exclusión social en sí mismo presenta una gran complejidad y entramado de variables que intervienen. Sin embargo, con la pretensión de esclarecer los elementos que lo conforman, tomamos en cuenta la aportación de Tezanos (1999), quién presenta en su trabajo una aproximación a los principales factores que influyen en el concepto de exclusión social: 


\begin{tabular}{|c|l|}
\hline Variables & \multicolumn{1}{|c|}{ Factores de exclusión } \\
\hline Laborales & $\begin{array}{l}\text { Paro, subempleo, temporalidad (agricultura, servicios, etc.), } \\
\text { precariedad laboral, carencia de Seguridad Social, carencia de } \\
\text { experiencias laborales previas. }\end{array}$ \\
\hline Económicas & $\begin{array}{l}\text { Ingresos insuficientes, ingresos irregulares (economía sumergida), } \\
\text { carencia de ingresos, endeudamiento, infravivienda, hacinamiento, sin } \\
\text { vivienda. }\end{array}$ \\
\hline Culturales & $\begin{array}{l}\text { Pertenencia a minorías étnicas, extranjería, barreras idiomáticas y } \\
\text { culturales, pertenencia a grupo de "rechazo" (cultural y político), } \\
\text { analfabetismo o baja instrucción, elementos de estigma. }\end{array}$ \\
\hline Versonales & $\begin{array}{l}\text { Variables "críticas" de edad y sexo (jóvenes y mujeres), minusvalías, } \\
\text { hándicaps personales, alcoholismo, drogadicción, etc., antecedentes } \\
\text { penales, enfermedades, violencia, malos tratos, etc., débil estructura de } \\
\text { motivaciones y actitudes negativas, pesimismo, fatalismo, exilio } \\
\text { político, refugiados. }\end{array}$ \\
\hline Sociales & $\begin{array}{l}\text { Carencia de vínculos familiares fuertes, familias monoparentales, } \\
\text { carencia de otras redes sociales de apoyo, entorno residencial decaído, } \\
\text { aislamiento. }\end{array}$ \\
\hline
\end{tabular}

Tabla 3. Principales factores de la exclusión social (Tezanos, 2001: 172)

A estos grandes ejes sobre los que se articula la exclusión social propuesta por Tezanos (1999), otros autores como Subirats (2005) añaden otros como la ciudadanía, el formativo, el sociosanitario, el de vivienda, el relacional, el político y el espacial.

Desde nuestro punto de vista, la exclusión no se trata de un estado en el que se está o no se está, sino más bien de un proceso. Bajo esta perspectiva, entendemos la exclusión no tanto como una dicotomía de 'dentro o fuera' propuesta anteriormente por García (2003), sino más bien desde una postura más cercana a Procacci (1999), quien critica el concepto de exclusión social por hacer hincapié en la individualización de las situaciones y no contemplar las desigualdades estructurales. Según Gimeno Sacristán (2001) "La desigualdad implica distancia entre unos y otros, la exclusión supone un alejamiento irrecuperable, la degradación del excluido que pasa a la categoría de negado" (p. 160). Desde este punto de vista, la desigualdad social sería más bien el factor condicionante de la estructura social que origina tanto los procesos como las situaciones de exclusión que experimentan determinados grupos sociales o miembros de determinados colectivos (Díaz Velázquez, 2010).

Como bien indica Castel (2014) los problemas de la exclusión ya no se encuentran única y exclusivamente en los márgenes de la sociedad, sino que también atañen a personas o grupos que no han podido integrarse en ella o que aún teniendo capacidad para llevar una vida digna, se convierten en condenados a llevar una vida precaria, con la incertidumbre de qué va a ser de ellos el día de mañana y con la sensación de no controlar su propio destino.

Existen diversas clasificaciones sobre los grupos de personas que han sido tradicionalmente excluidos, entre los que podemos encontrar la aportación de Parrilla y Susinos (2004):

- Los grupos humanos pertenecientes a clases sociales desfavorecidas dentro de cada sociedad, con limitado acceso a la cultura, la información y con una economía precaria. 
- Los grupos humanos pertenecientes a culturas no hegemónicas: minorías étnicas, inmigrantes, y en general colectivos cuyas culturas de referencia se ignoran en la cultura social o escolar dominante.

- Los grupos de mujeres y niñas y los colectivos con dificultades para acceder en igualdad de oportunidades a la vida social, escolar o laboral por razón de su género.

- Los grupos humanos de personas con diversas (dis)capacidades y necesidades educativas, con dificultades especiales para acceder a los aprendizajes escolares y sociales y progresar en la escuela

Sea como fuere, a partir de esta clasificación y enfocándonos a nuestro objeto de estudio, concebimos el grupo de personas con capacidades y necesidades diversas como uno de los grupos tradicionalmente excluidos. Este colectivo, a pesar de poseer condiciones compartidas con otros grupos sociales parece que sea, como hemos visto en el capítulo 1, uno de los grupos más atacados con procesos continuos de desigualdad en múltiples ámbitos de su día a día.

La pregunta es ¿por qué si somos conscientes de la discriminación que sufren las personas con diversidad funcional no hacemos nada? ¿por qué tras un aparente estado o país pro-inclusión se esconden políticas sociales y educativas cada vez más severas con este colectivo? ¿por qué no cumplimos con aquellos pactos y tratados que ratificamos? ¿por qué en nuestro día a día nos desinteresamos sobre las discriminaciones sociales y educativas que ocurren a nuestro alrededor? ¿estamos siendo cínicos? ¿alardeamos de ser inclusivos y no discriminatorios pero en realidad no lo somos?

Lamentablemente no tenemos una respuesta concreta a estas preguntas, pero deducimos que detrás esa impasividad y despreocupación solo puede haber una perspectiva egocéntrica del mundo. Una forma de entender la realidad en la que 'si no me afecta a mí o a los míos no me importa': la indiferencia.

Hemos decidido incorporar el concepto de indiferencia colectiva a este capítulo por la relación directa que posee con la discriminación vivida por personas de cualquier colectivo en una situación de desigualdad social. Como apunta Slee (2012), la indiferencia colectiva es la manera en la que las personas 'miramos para otro lado'. Es una forma de indiferencia que compartimos con otros, de manera colectiva, y aunque puede llegar a ser inconsciente, explica porqué no se cuestiona la exclusión y por qué alcanzar la inclusión total es tan difícil.

El imaginario social actual (Taylor, 2004) ha cambiado, pues la globalización, el capitalismo, la competitividad y el individualismo entre otros, fomentan la desvinculación de las personas respecto los valores humanos; y fomentan procesos cuya finalidad última radica en conseguir entrar en los mejores colegios, en las mejores universidades, obtener los mejores puestos laborares y lograr los mayores éxitos profesionales. Una dinámica que, por supuesto, deja al margen términos como la solidaridad, el respeto, la humanidad y los derechos como un valor, no como un regalo o caridad.

Debemos alejarnos, por lo tanto, de esa sociedad indiferente basada en ciudades llenas de personas ligeramente comprometidas (Sennet, 2009). Una sociedad en la que el neoliberalismo y la cultura y prácticas individualistas 
retroalimentan la indiferencia y generan vías cada vez más sutiles de segregación y diferenciación social. Pues sin duda alguna, esta indiferencia contribuye y alimenta la creación de nuevas barreras y limitaciones sociales, políticas y educativas a esas personas o colectivos a los que ni siquiera mira.

Y es que según la mirada que proyectemos, según el cristal a través del que contemplemos nuestro alrededor, generaremos un tipo de actuaciones u otras, un tipo de respuestas hacia la diversidad, u otras. En este sentido, este capítulo intenta hacer un recorrido por los diferentes tipos de respuestas que reciben las personas de este colectivo: respuestas negativas (barreras y limitaciones), respuestas políticas o normativas (aquello contemplado en la normativa), las respuestas de a pie o reales (aquellas que se generan desde la individualidad de cada caso y que no están recogidas en las anteriores) y la respuesta que consideramos necesaria y hacia la que pretendemos caminar (la inclusión como un proyecto vital, real y extendido a todos los campos).

\title{
2.2. Respuestas negativas: Barreras y limitaciones a la inclusión educativa y social
}

\begin{abstract}
"Las barreras no están en las niñas y en los niños, ni en sus posibles limitaciones (o necesidades). Las barreras están del otro lado, es decir, del lado de los gobiernos, de las leyes, de las autoridades educativas, de las comunidades, de las familias y, de manera más destacada, del lado de algunas escuelas, que tradicionalmente han constituido sistemas cerrados, refractarios a influencias nuevas" (García 2008: s/p)
\end{abstract}

En el campo de la diversidad las barreras, limitaciones y obstáculos a la inclusión educativa y social han sido estudiados desde múltiples y diversas perspectivas. La exploración de barreras institucionales, estructurales, ideológicas y materiales en la sociedad constituyen uno de los ejes de análisis crítico en los estudios sobre diversidad funcional (Swain, French, Barnes \& Thomas, 2004). De alguna manera, parece que si identificamos debidamente esas barreras y establecemos caminos alternativos, lograremos acercarnos un poco más a la una inclusión real en nuestra sociedad.

Las barreras, al igual que las estrategias y apoyos para superarlas, se pueden encontrar en todos los aspectos y estructuras del sistema social y educativo. Dentro de los centros educativos, en las comunidades o en las políticas locales y nacionales; y dentro de cada uno de estos se pueden encontrar en los valores, creencias y actitudes compartidas, así como en aspectos concretos y precisos: planes de acción, de organización o de funcionamiento (Echeita y Simón, 2007).

Tal y como ya venimos adelantando, estamos ante una investigación que focaliza su interés en los contextos social, educativo y familiar de un joven con diversidad funcional, y suponemos, por lo tanto, que las principales barreras con de su trayectoria poseerán o bien una perspectiva más social (contexto familiar, relacional y de ocio) o una perspectiva más institucional (educativa, formativa, organizativa,...) 


\subsubsection{Barreras sociales}

Las barreras sociales son limitaciones o dificultades que desde el contexto social (y/o político) se configuran, consciente o inconscientemente, y corresponden a aquellos factores que estando presentes o ausentes limitan el funcionamiento y generan 'discapacidad' (Mella, Díaz, Muñoz, Orrego y Rivera, 2014). Concretamente las 'barreras sociales' se conciben como los obstáculos o restricciones que la propia sociedad impone a la plena participación social de algunos de sus integrantes (Zarb, 1997). Son impedimentos que 'discapacitan', excluyen o segregan a individuos y grupos enteros de la vida social (Calvo y Susinos, 2006) mediante factores relacionados con la accesibilidad en el entorno físico, la tecnología, las actitudes de la población frente a la diversidad funcional y los sistemas, servicios y políticas (WHO, 2002).

Autores como Sherman y Sherman (2013) estudiaron recientemente sobre este campo y detectaron determinadas áreas o ámbitos que podían considerarse barreras sociales a la inclusión. En este estudio se detectaron: (a) incapacidad económica para participar en actividades de la sociedad y ampliar las relaciones sociales (Myers, Ager, Kerr \& Myles, 1998; Abbott \& McConkey, 2006); (b) vacío de aceptación en la sociedad o actitudes discriminatorias (Reynolds, 2002; Verdonschot, De Witte, Reichrath, Buntinx, \& Curfs, 2009) y (c) problemas de transporte generalizados (Davies, Stock, Holloway \& Wehmeyer, 2010; Minton \& Dodder, 2003; Reynolds, 2002; Samuel, Lacey, Giertz, Hobden, \& LeRoy, 2013; Verdonschot et al., 2009).

Cuando hablamos de barreras a las personas con diversidad funcional, se tiende a pensar en barreras físicas, en impedimentos más bien visibles y concretos. Sin embargo, existen otras barreras más difíciles de detectar, las barreras que no se ven. Las barreras sociales pueden presentar múltiples formas, entre las que resaltaremos dos como principales: las barreras derivadas de actitudes de las vivencias de las personas, y las barreras del propio entorno de contenido físico (Etxeberria, 2011); o lo que es lo mismo las barreras actitudinales y las físicas.

Otros autores desmenuzan un poco más estas barreras sociales que afectan a las personas con diversidad funcional y señalan cuatro tipos diferentes de barreras sociales o ambientales (Mella et al, 2014):

a. Barreras arquitectónicas: son aquellos obstáculos físicos que limitan el acceso o movilización por un espacio determinado.

b. Barreras actitudinales: corresponden al conjunto de actitudes poco favorables a la inclusión y altamente relacionadas con prejuicios, discriminaciones y bajas expectativas sobre las personas con diversidad funcional.

c. Barreras comunicativas: aquellos obstáculos que impiden o dificultan a la persona el correcto entendimiento con los demás, ya que no se poseen los medios de comunicación adaptados a las necesidades de las personas.

d. Barreras pedagógicas: aquellos obstáculos referentes al acceso al currículum (serán desarrolladas más profundamente en el siguiente apartado de este capítulo) 
Como podemos observar, las barreras expuestas en este apartado se pueden organizar a su vez en barreras visibles y tangibles (arquitectónicas, comunicativas y pedagógicas) y barreras invisibles (actitudinales). Estas últimas, las que no se ven a simple vista, son consideradas por autores como Gitlow (2001) como aquellas barreras más difíciles de cambiar o modificar.

Además, estas barreras actitudinales son un tipo de barrera que se arraiga al seno de la sociedad. Mella et. al (2014) detectaron en su trabajo ciertos elementos de los que se componían este tipo de barreras y sobre los que había que focalizar. Para estos autores, la falta de información sobre diversidad (y sus múltiples formas) y la necesidad latente y urgente de apoyos como la sensibilización y la concientización social son condiciones que hay que resolver para que las actitudes hacia la diversidad puedan modificarse. De esta manera, al incidir sobre el sistema de actitudes y creencias se promueve la inclusión social de todas las personas y se reconoce el concepto de "persona" por encima de cualquier calificativo o etiqueta (Martiza, 2005).

\subsubsection{Barreras institucionales o educativas}

Sin duda alguna, las políticas y acciones sociales para la eliminación de barreras deben revertir y ser acompañadas a su vez, por principios y actuaciones educativas en la misma línea. Se trata de trabajar conjuntamente para que en nuestros centros educativos se eliminen las barreras que limitan la presencia, aprendizaje y participación de cualquier alumno o alumna en la vida y cultura escolar, con particular atención en aquellos más vulnerables (Ainscow, Booth \& Dyson, 2006). O lo que es lo mismo, trabajar por la inclusión educativa como finalidad en sí misma y única opción válida para nuestra sociedad.

Por barreras institucionales o educativas, entendemos aquellas barreras que los alumnos de características diversas encuentran en su paso por las distintas instituciones educativas y formativas. Ainscow (2008a) y la UNESCO (2007) utilizan la expresión 'barreras al aprendizaje exitoso' para referirse a una descripción de obstáculos que en algún momento los alumnos pueden encontrar a lo largo de su escolaridad. Se trata de situaciones en la que una persona no puede acceder al currículo, cuando no se le da la oportunidad de participar en el aula, cuando sus capacidades no son debidamente valoradas o cuando los iguales rechazan su interacción o amistad (Messiou, 2006). Nos referimos a aquellas personas y voces identificadas en la literatura como 'voces escondidas' o silenciadas (Moriña y Perera, 2015)

En los últimos años, diversos trabajos en nuestro contexto y fuera de él, han focalizado su atención en el análisis de las barreras educativas (Booth, Ainscow, Black-Hawkins, Vaugan \& Shaw, 2002; López Melero, 2008; Fernández de la Iglesia, Fuia y Zabaza, 2013). En la revisión bibliográfica, se han podido observar incluso investigaciones educativas en función del nivel o etapa educativa: infantil (Buysse, Wesley, \& Keyes, 1998; Pineda, 2014), primaria (Biklen, 2000; Holt, 2003; Norwich \& Kelly, 2004; Law, Petrenchik, King, \& Hurley, 2007; Rojas, Gómez y García Vázquez, 2013; Sharma, Loreman, \& Simi, 2017), secundaria (Kam Pum, 2008; Martínez, 2011; Hernández de la Torre y Medina, 2014; Calvo y Manteca, 2016) o universidad (Hopkins, 2011; Aquino, García e Izquierdo, 2012; Moriña, 2014; Moriña, Cortés y Melero, 2014; Agarwal, Moya, Yasui, \& Seymour, 2015; Gebretsadik, 2015). 
En nuestro contexto encontramos en esta misma línea trabajos como los elaborados por Fernández de la Iglesia et al. (2013) y López Melero (2008). Estos autores plantean a través de sus investigaciones diversas tipologías de barreras a la inclusión educativa pero usando terminologías distintas. Por un lado López Melero (2008) identifica barreras políticas (leyes y normativas), barreras culturales y barreras didácticas, mientras que Fernández de la Iglesia et al. (2013) distinguen entre barreras relacionadas con la administración, barreras que tienen que ver con el centro y barreras propias del aula.

Con la pretensión de encontrar un punto intermedio entre las aportaciones de los diversos autores que nos permita revisar qué se ha dicho sobre las barreras educativas a la inclusión, distinguiremos entre: barreras generadas desde la administración educativa, barreras generadas desde las escuelas y barreras generadas por los docentes.

\subsubsection{Barreras desde la administración educativa}

Las barreras administrativas suelen ser limitaciones a la inclusión ocasionadas por el propio sistema educativo y sus opciones de acceso y promoción. Son barreras que provocan distinciones entre el alumnado y generan ciertas necesidades educativas o problemas (Boggino y Boggino, 2014) que arrastran o condicionan el resto de su escolarización, y muy probablemente, su vida adulta.

En el contexto internacional, Powell (2016) destaca en su estudio que las principales barreras a la inclusión residen en determinadas prácticas como políticas partidistas, estructuras burocratizadas y programas educativos escasamente financiados.

En nuestro contexto, Fernández de la Iglesia et al. (2014) en su estudio expuso que según los docentes, las barreras administrativas se pueden clasificar en:

- La transitoriedad de las políticas y leyes: preocupación laboral y gasto de energía en la labor educativa por seguir las leyes.

- La fisura entre la formación y las necesidades reales de los centros: formación inicial deficiente, carente política formativa del profesorado, escaso reconocimiento de las acciones formativas de los docentes, y carencia de tiempo y estructuras para la formación continua.

- Difícil comunicación entre la administración y los centros: medidas propuestas desde la administración que no corresponden a las necesidades de los centros, las medidas propuestas no se adecuan ni a los tiempos y ni a las posibilidades reales de los centros, excesiva burocracia cuando se solicita orientación o ayuda a la administración, y diálogo complicado y farragoso entre la administración y los centros.

\subsubsection{Barreras desde las escuelas}

Las barreras desde la escuela son aquellas mediante las cuales el propio centro educativo genera en los estudiantes situaciones de diferenciación, desigualdad e incluso exclusión educativa. Son las políticas, actitudes y prácticas concretas del contexto y los agentes socio-educativos los que, precisamente, 
dificultan y obstaculizan las posibilidades de aprendizaje y participación del alumnado (Booth \& Ainscow, 2011).

Según la UNESCO (2004, citado en Estévez, 2015) las barreras institucionales y de centro que afectarían de forma general a todos los niños y niñas que por cualquier causa sufran dificultades para desarrollarse y participar en las aulas son:

- Barreras derivadas de las acciones docentes, directores e inspectores escolares (en función de cómo perciban la diversidad lo proyectarán al resto de la comunidad escolar)

- Los sistemas legales y de regulación institucional que determinan el tratamiento a la diversidad.

- Los elementos del curriculum según su rigidez y capacidad de atención a la diversidad.

- Los enfoques pedagógicos y los materiales para el aprendizaje según si son facilitadores de un aprendizaje significativo y si responden a la diversidad de su centro.

Desde hace casi un par de décadas, autores como Buysse et al (1998) ya expusieron en su trabajo que las barreras relacionadas con la inclusión en un entorno educativo tenían que ver con:

1. La calidad de los programas ofertados: esta barrera tiene que ver con el gran número de estudiantes por aula, el tipo de relación entre docente y discente, la escasa formación docente en términos de discapacidad y los problemas de planificación docente.

2. Fuentes comunitarias: esta barrera tiene que ver con las opciones limitadas para una estancia de calidad de estudiantes con discapacidad dentro del centro, así como las dificultades de transporte.

3. Coordinación e integración entre servicios: limitaciones en cuanto a la participación de los miembros de la familia en la planificación y coordinación de servicios ofertados como su evaluación, la identificación de necesidades y la disponibilidad de servicios especiales.

4. Actitudes y creencias: la falta de información y conocimiento de docentes, padres, especialistas y administradores en relación con las políticas prácticas inclusivas.

A pesar de que las contribuciones de Buysse, Wesley y Keyes (1998) puedan considerarse desfasadas por ser de hace bastantes años, lo más sorprendente e inquietante es que son aportaciones que podrían ser perfectamente válidas para la escuela de hoy en día: dificultades en la planificación, problemas en los servicios, dificultades en la coordinación entre diferentes agentes educativos y actitudes y creencias negativas respecto a la diversidad. Con esta observación no pretendemos elaborar apuntes desalentadores sobre la situación en nuestras escuelas, sino visibilizar que los problemas de hoy en día no son nuevos, las 
dificultades y las barreras siempre han estado ahí y nuestro cometido debe ser seguir trabajando en la línea de su erradicación.

En la investigación realizada por Fernández de la Iglesia et. al (2013), los autores apuntaban a determinadas barreras en el centro educativo como uno de los obstáculos a la inclusión educativa. En este trabajo, los mismos docentes detectaban dos ejes o líneas obstaculizadoras de la inclusión. Estas son: la relación entre docentes (relaciones complicadas entre el propio profesorado que dificultan e imposibilitan el trabajo en equipo) y la organización del centro (incompatibilidad de horarios y las dificultades para compartir espacios y tiempos). Sin duda, estas son grandes barreras de centro que no acompañan para nada la implementación de la educación inclusiva. Sin embargo, la literatura nos deriva a un tercer tipo de barrera institucional: los recursos para la atención a la diversidad.

Cuando pensamos en un alumno/a con diversidad que acude a un centro ordinario tendemos a deducir que se tratará de un alumno/a incluido en la dinámica del centro y que no solo pertenece sino que además participa en el mismo. Sin embargo, hoy en día, una de los temas de organización de centros es la carencia y gestión (cuando los hay) de los recursos educativos. En trabajos como el realizado por EDAD (2008) se revela que más de un 30\% del alumnado diverso escolarizado en centros ordinarios no recibe ningún tipo de apoyo personalizado (Toboso, Ferreira, Díaz, Fernández-Cid, Villa, y Gómez de Esteban, 2012) Es más, investigaciones recientes en nuestro contexto destacan una carencia generalizada en nuestros centros en cuanto a estructuras organizativas, recursos humanos especializados y recursos materiales precisos para dar una respuesta inclusiva (Domingo y Palomares, 2013). De hecho, uno de los planes eficaces para alentar la participación de los alumnos es el modo en que se emplean los recursos disponibles, en especial los recursos humanos (Ainscow, 2012)

\subsubsection{Barreras desde los docentes}

Las barreras a la inclusión generadas desde los docentes son aquellos elementos que generan una respuesta a la diversidad más propia de un enfoque educativo segregacionista o asimilacionista que de un enfoque inclusivo. En estudios recientes se observa cómo entre los elementos clave para una inclusión educativa efectiva tiene mucho que ver el docente, sus actitudes, su formación, su capacidad de trabajo en equipo y los apoyos que éste otorga al alumnado (Glazzard, 2011).

Siguiendo con el trabajo de Fernández de la Iglesia et al. (2013) desarrollado en nuestro contexto, en lo que concierte al aula existen tres tipos de barreras relacionados con el docente y con la percepción que estos poseen sobre su alumnado:

a) Las actitudes ante la diversidad: basadas en elementos como la concepción de la diversidad, la toma de conciencia sobre la diversidad física, psicológica o contextual, la reflexión sobre la realidad del aula, el aprendizaje autónomo frente al académico, y la escucha y respuesta a las necesidades del alumnado bajo el prisma de la inclusión.

b) La metodología de aula: el libro de texto como limitador de las posibilidades metodológicas y de la atención a la diversidad e individualidad de cada alumno (Fernández Enguita, 2001) y la dificultad para cambiar las prácticas docentes. 
c) Falta de motivación y disciplina: tanto por parte del estudiantado como en cuanto a su formación para afrontarlo.

Sin duda alguna, la cuestión de la actitud docente es uno de los puntos fuertes en cuanto a las barreras educativas, pues suponen uno de los mayores obstáculos que limitan la aplicabilidad de las leyes y sus principios ante las temáticas de discapacidad, reproduciendo dinámicas excluyentes que poco favorecen la inclusión en su totalidad (IESALC, 2006). La actitud es una posición u orientación del pensamiento que se traduce en una forma determinada de pensar, actuar o reaccionar (Beltrán, 2008, citado en Granada, Pomés y Sanhuerza, 2013); de esta manera, en función de las actitudes y preconcepciones docentes sobre la diversidad, éste podrá actuar como un instrumento para la inclusión educativa o, por el contrario, como una de las barreras más infranqueables para el alumnado con diversidad funcional.

En este sentido, Horne y Timmons (2009) plantean la necesidad de una actitud positiva hacia la inclusión educativa. Sin embargo, estos autores conciben que para que esto resulte viable es necesario acompañarlo de un mayor apoyo administrativo, tiempo de planificación y capacitaciones sobre estrategias pedagógicas específicas según discapacidades, pues de no ser así la percepción positiva que los docentes pueden poseer sobre la diversidad podría verse deteriorada.

Otro de las grandes barreras de los docentes a la inclusión tiene que ver con las carencias formativas de éstos. En sus respectivos trabajos Holt (2003) y Kam Pun (2003) ya hacían referencia a la falta de preparación de los docentes como factores que, junto a número de estudiantes y los recursos disponibles, inciden directamente sobre los procesos de inclusión. De hecho, para poder enseñar de manera efectiva a todos los niños y niñas en el sistema ordinario es necesario que los docentes posean capacidad y conocimiento para ello (Peterson, 2006; Padilla, 2011).

En relación a estas barreras formativas de los docentes, un estudio reciente de nuestro contexto (Pegalajar y Colmenero, 2017) revela que alrededor de un $25 \%$ de los docentes participantes en su investigación consideran insuficientes los conocimientos sobre educación inclusiva recibidos a lo largo de su proceso de formación inicial, considerando necesaria una adecuada formación inicial sobre educación inclusiva $(90.2 \%)$. Estos autores destacan que estos mismos docentes conciben las actividades de formación continua y permanente como una mejora de la práctica de aula $(89,9 \%)$, así como también la adquisición y perfeccionamiento de conocimientos sobre educación inclusiva $(89,1 \%)$. Por lo tanto, la formación del docente es un elemento clave para nuestras escuelas pero que está aún sin resolver, pues principalmente esta formación inicial del profesorado es la que es capaz de preparar a los docentes para aceptar la diferencia como un reto positivo (Palorames, 2004).

\subsection{Respuestas formales: las políticas de la diversidad}

Como vemos, son diversas y variadas las barreras detectadas a través de los estudios e investigaciones en el campo de la diversidad. Las barreras se encuentran en todos los niveles del ámbito educativo (desde infantil hasta la 
universidad) y en todos los rangos, desde las propuestas a nivel macro de la administración educativa, a las acciones y actitudes del docente a nivel micro en su aula. Sin duda alguna, este es un campo digno de estudio, de reflexión y de acción, pues necesitamos conocer qué está pasando en nuestros centros educativos para proponer cambios y promover otro tipo de respuestas a la diversidad.

Llegado este punto, consideramos necesario conocer un poco más sobre este tema. En el apartado anterior hemos revisado las barreras a la inclusión que se desarrollan desde diferentes focos de atención, pero ¿qué dice la legislación actual? ¿qué cosas se están haciendo desde la política y la administración educativa para promover la inclusión educativa y social? ¿Cuáles son las posibilidades educativas, al menos 'sobre el papel', de las personas con diversidad funcional? Desde esa perspectiva formal, ¿tienen razón de ser las barreras anteriormente identificadas?

Con la pretensión de localizar la respuesta a estas preguntas, necesitamos revisar con qué se encuentra una persona con diversidad funcional cuando decide formar parte de su contexto educativo de referencia y de su entorno social.

\subsubsection{Políticas sociales}

En primer lugar, centraremos nuestra atención en lo que se refiere a políticas y legislación de inclusión social. El desarrollo de ese modelo social de diversidad expuesto en el capítulo 1, es una cuestión de responsabilidad social compartida, en el que no se trata de dejar entrar al que esta fuera, sino de que todos los que conformamos la comunidad nos aseguremos de que estamos todos reconocidos y con oportunidades equitativas de participación social (Del Río, 2016).

En nuestro contexto las primeras bases de inclusión social se iniciaron con la aprobación de la Carta Manga en 1978 (el artículo 9 exigía a los poderes públicos garantizar el máximo bienestar de vida a todos los ciudadanos) y con la Constitución Española de 1978 (en el artículo 49, se preconiza una política de previsión e integración de las personas con discapacidad). Desde entonces, la elaboración y aplicación de políticas sociales más o menos inclusivas ha experimentado un largo y lento recorrido. Los avances en materia de inclusión han ido proliferando muy poco a poco, partiendo en primer lugar de medidas de reconocimiento y visibilización para después llegar a políticas, más o menos, inclusivas.

De la Fuente y Hernández (2013) realizaron una profunda revisión de la legislación española en cuanto a la inclusión de personas con diversidad funcional, de la cual podemos abstraer algunas notas generales:

- El primer texto legal español que introdujo el concepto de 'eliminación de barreras' fue la Ley 13/1982 de 7 de Abril, de Integración Social de los Minusválidos.

- Desde finales de los años 80 y durante los años 90 cada una de las Comunidades Autónomas ejerció su competencia aprobando sus propias leyes de eliminación de barreras arquitectónicas, urbanísticas, del transporte y la comunicación, centradas especialmente en atender las necesidades de las personas con limitaciones en sus capacidades funcionales motoras, obviando las necesidades de la ciudadanía con dificultades sensoriales, mentales o intelectuales. Todas estas medidas no poseían un 
régimen sancionador, por lo que las infracciones al respecto quedaban totalmente impunes.

- El I Plan Nacional de Accesibilidad, aprobado el 5 de julio del 2003 y vigente durante el período 2004-2012, es el primer documento en el que el concepto 'eliminación de barreras' se sustituye por el concepto 'diseño para todos' realizándose una revisión terminológica de modo que se eliminan términos negativos adoptándose una terminología mucho más positiva e inclusiva. Los conceptos 'Igualdad de Oportunidades' y 'Diseño para Todos' son las dos grandes ideas que movilizan la lucha por la accesibilidad en los últimos años, y aparecen conjuntamente como lema de este Plan.

- Siguiendo esta premisa, se aprobó la Ley 51/2003, de 2 de diciembre, de Igualdad de Oportunidades, no Discriminación y Accesibilidad Universal de las Personas con Discapacidad (LIONDAU). Esta Ley tiene por objeto establecer medidas para garantizar y hacer efectivo el derecho a la igualdad de oportunidades de las personas con discapacidad. A pesar de la obligación legal de desarrollar la LIONDAU en el periodo de dos años para su aprobación no es hasta 2007 cuando se producen los nuevos desarrollos legislativos a través de los Reales Decretos y con ello la primera ley que contenía régimen sancionador en cuanto a la legislación en materia de diversidad del momento.

- La última de las disposiciones legales es la Ley 39/2006, de 14 de diciembre, de Promoción de la Autonomía Personal y Atención a las personas en situación de dependencia. Mediante esta ley se pretende como motivo primero "atender las necesidades de aquellas personas que, por encontrarse en situación de especial vulnerabilidad, requieren apoyos para desarrollar las actividades esenciales de la vida diaria, alcanzar una mayor autonomía personal y poder ejercer plenamente sus derechos de ciudadanía”.

Esta última ley, la más inclusiva hasta el momento, se focaliza en la promoción de la autonomía de las personas con diversidad funcional de nuestro país pero, sin embargo, presenta ciertos elementos altamente criticados. De todas las críticas revisadas sobre esta ley, destacamos tres elementos reseñables: El primero de los elementos criticados es el uso del término dependencia, pues en las disposiciones de esta ley se vincula la dependencia a la persona que presenta las dificultades, no al entorno; constituyéndose, por lo tanto, sobre un modelo médicorehabilitador de la discapacidad (De Asis, 2007). El segundo de ellos tiene que ver con la aplicación de servicios, pues estos se conciben desde carácter asistencial, en vez de promocionar la autonomía personal, ofreciendo, además, dichos servicios de forma restrictiva, dejando fuera a muchas personas que viven en situación de dependencia (Rodríguez-Picavea, 2013). El tercero de estos elementos criticados sobre esta ley son los masivos recortes presupuestarios y políticas de máxima austeridad como estrategia para abordar la crisis que atraviesa nuestro país. Una opción política que tuvo y tiene consecuencias inmediatas sobre la igualdad de oportunidades y sobre la justicia social y educativa (Susinos y Parrilla, 2013).

De esta manera, en la actualidad, parece que la aplicación y funcionamiento de esta ley de Promoción de la Autonomía Personal dista bastante de lo previsto inicialmente en sus planteamientos. De Asis y Barranco (2010) detectan un carácter reducido de las prestaciones, complejidad del proceso para el reconocimiento del derecho existente según la comunidad en la que se encuentre la 
persona en situación de dependencia, escasa participación de estas personas en la configuración de la prestación y la más que cuestionable estructuración de los recursos económicos en los que se sustenta el derecho.

Como vemos, a pesar de poseer una legislación cuya finalidad es la promoción de la autonomía de las personas con diversidad funcional, éstas se encuentran actualmente un tanto desamparadas por la política social. Sus posibilidades de autonomía y calidad de vida se encuentran actualmente muy ligadas a los recursos y apoyo del entorno inmediato, y de las asociaciones y organizaciones de personas con diversidad funcional a las que tengan acceso. Estos factores del entorno que garantizan la promoción de las personas con diversidad funcional serán abordados más adelante en este capítulo. Procederemos ahora a revisar la respuesta política que se da a la inclusión desde una mirada educativa.

\subsubsection{Políticas educativas}

Al igual que en el apartado anterior, la respuesta política de inclusión educativa en España está siendo un proceso gradual pero pausado. Desde el inicio de la regulación con la primera ley educativa de 1970 con la Ley General de Educación, que permitía la escolarización de personas con discapacidad en entornos ordinarios, hasta la actual Ley Orgánica 8/2013 de 9 de diciembre para la mejora de la calidad educativa (LOMCE), catalogada como una de las leyes más antidemocráticas de la historia (Subirats, 2014), muchas idas y venidas han acontecido en materia de inclusión en España.

A modo de repaso, Toboso et al. (2012) destacaron algunas medidas legales más significativas en materia de inclusión de las personas con diversidad funcional:

- Siguiendo a la Ley General de Educación de 1970 en la que se permitía la escolarización de las personas con diversidad funcional en entornos ordinarios, otras medidas se sucedieron como la creación del Instituto Nacional de Educación Especial (INEE) y otros espacios como el Real Patronato de Educación y atención a los Deficientes.

- A partir de la Constitución Española de 1978, emergieron nuevas políticas más vinculadas a una vertiente integradora de la educación, en la que empezaron a consolidarse ciertos principios que garantizaran la integración de las personas con diversidad funcional. Es el caso de la Ley 13/1982, de 7 de abril, de Integración Social de los Minusválidos (LISMI) o el Real Decreto 334/1985, de 6 de marzo, de ordenación de la educación especial.

- Mediante la Orden de 20 de marzo de 1985 sobre planificación de la educación especial y experimentación de la integración en el curso 1985/86, se considera que la integración del alumnado con discapacidad en las aulas ordinarias comenzó a ser un hecho.

- Unos años después entró en vigor la Ley Orgánica 1/1990, de 3 de octubre, de Ordenación General del Sistema Educativo (LOGSE), en la que se establecía como norma que siempre que fuera posible debía realizarse la escolarización ordinaria del alumnado con necesidades educativas especiales, previa evaluación psicopedagógica y dictamen de los equipos de orientación (Fernández Santamaría, 2011). Este fue el momento en el que se utilizó por primera vez en la ley el término 'necesidades educativas especiales' 
- La Declaración de Salamanca sobre Necesidades Educativas Especiales, de 1994, y la Conferencia Mundial sobre Necesidades Educativas Especiales: Acceso y Calidad (UNESCO, 1994), marcaron el inicio de la época inclusiva en España, en la que se planteó la inclusión educativa de todo el alumnado, con independencia de sus diferencias individuales, incluidos aquellos con discapacidades graves, pero aceptando, sin embargo, la posibilidad de que algunos casos no pudieran ser matriculados en centros ordinarios por razones consideradas de peso.

- Uno de los últimos pasos en materia de inclusión del alumnado con diversidad funcional fue la Ley Orgánica 2/2006, de 3 de mayo, de Educación (LOE). Esta ley promocionaba la autonomía de los centros para adaptar la normativa a las características de su entorno y de la población que atendían, y la flexibilidad del sistema en todos sus aspectos (pedagógicos, organizativos, etc.), facilitando la generalización de la educación inclusiva (Casanova, 2011).

Tras estos pequeños antecedentes sobre respuestas políticas educativas cada vez más inclusivas, en diciembre de 2013 se aprobó la LOMCE, Ley Orgánica 8/2013 de 9 de diciembre para la mejora de la calidad educativa. Esta ha sido sin duda una de las leyes educativas más polémicas hasta día de hoy, pues posee un contenido altamente criticado por todos los sectores de la comunidad educativa.

Si revisamos la ley, encontramos en su preámbulo (punto V):

[...] De acuerdo con la Estrategia Europea sobre Discapacidad 20102020, aprobada en 2010 por la Comisión Europea, esta mejora en los niveles de educación debe dirigirse también a las personas con discapacidad, a quienes se les habrá de garantizar una educación y una formación inclusivas y de calidad en el marco de la iniciativa "Juventud en movimiento", planteada por la propia Estrategia Europea para un crecimiento inteligente. A tal fin, se tomará como marco orientador y de referencia necesaria la Convención Internacional sobre los Derechos de las Personas con Discapacidad, adoptada por las Naciones Unidas en diciembre de 2006, vigente y plenamente aplicable en España desde mayo de 2008.

Sin embargo, estos planteamientos iniciales desde un enfoque inclusivo se diluyen cuando nos adentramos en el contenido de la ley. Para mostrar con mayor detalle cuáles son las respuestas políticas actuales con las que se encuentra un alumno/a con diversidad funcional a su llegada a la escuela, repasaremos dos aspectos clave: la escolarización y las medidas de atención a la diversidad vigentes en la ley actual.

\subsubsection{Posibilidades de escolarización actual de las personas con diversidad funcional}

La escolarización en la legislación educativa actual (LOMCE, 2013) emerge desde un planteamiento teóricamente inclusivo, pero que se convierte a un enfoque integrador en la práctica. En esta ley se asimilan el modelo inclusivo con el integrador como si fueran el mismo aunque se traten de términos totalmente diferentes. En este sentido, Abrisketa (2014) elabora en su trabajo un repaso por las principales características de esta ley y expone ciertas condiciones poco inclusivas de la misma como: 
- El alumnado queda sometido a los dictámenes de escolarización que de oficio se hacen al comenzar cada etapa educativa y que se pueden repetir en cualquier momento de la escolarización a demanda del centro escolar.

- Los dictámenes, vinculantes para la Administración, pueden derivar al alumno a un centro de educación especial aún sin el acuerdo de la familia.

- La realización de pruebas de evaluación al final de cada etapa y la elección, una vez concluida la ESO, entre el Bachillerato y la Formación Profesional Básica contribuyen a que el alumnado que presenta necesidades educativas especiales se encuentre en una situación más vulnerable que el resto (art. 30 de la LOMCE).

A nivel normativo, las diferentes modalidades de escolarización para el alumnado con diversidad funcional no han cambiado en relación a la legislación anterior. De más a menos inclusivas estas posibilidades de escolarización son:

a) Escolarización en un centro y aula ordinaria

b) Escolarización en aula específica dentro de centro ordinario

c) Escolarización combinada entre centro de educación especial y centro de educación ordinario

d) Escolarización en centro de educación especial (general o especializado en algún tipo de trastorno concreto)

La segunda de estas posibilidades, las unidades de educación especial en centro ordinario, son presentadas como una medida que pretende propiciar la inclusión de los alumnos con necesidades educativas especiales en el grupo de referencia ordinario, a la vez que garantizar un trabajo especializado desde el aula de necesidades específicas (Tomás y Grau, 2016). En la actualidad, existen diferentes tipos de aulas específicas en centros ordinarios: aula de Pedagogía Terapéutica, el aula de Audición y Lenguaje o el aula específica para alumnado con necesidades educativas especiales.

Necesitamos acercarnos un poco más al contexto de esta investigación (provincia de Castellón) y por ello nos interesa conocer con qué posibilidades de escolarización cuenta un alumno/a diagnosticado con Trastorno del Espectro Autista (TEA) y Trastorno Específico del Lenguaje (TEL) en la Comunidad Valenciana.

En la Comunidad Valenciana, una de las medidas de atención en aula específica por excelencia son las denominadas aulas CyL (aulas de Comunicación y Lenguaje) (Resolución de 27 de julio de 2016 por la que se dictan instrucciones para la organización y el funcionamiento de las unidades específicas de comunicación y lenguaje ubicadas en centros públicos). Estas son unidades específicas de educación especial ubicadas en centros ordinarios que pretenden dar una respuesta educativa adecuada a determinadas necesidades del alumnado con Trastorno Mixto del Lenguaje Receptivo-Expresivo (TML) o con TGD (Bellver, Díez, López y Navarro, 2009; Peirats, 2012; Mascarell y Grau, 2013). La escolarización combinada entre el aula CyL y el aula de referencia pretende compaginar un espacio, tiempo y actividades altamente estructurados en el aula CyL con la integración en el aula ordinaria el resto de la jornada (Blaco, Martínez y Santamaría, 2006). 
Este tipo de escolarización combinada posee sus defensores y sus detractores. Mientras autores como Tomás y Grau (2016) exponen que es una forma de brindar al alumnado mayores posibilidades de interacción con contextos normalizados que los que se puedan encontrar en un centro de educación especial, otros como Molina (2015) critican su efectividad. Esta autora, considera que se debe apostar más bien por una vertiente más inclusiva de la modalidad de escolarización en la que se evita la separación del alumnado de su grupo de referencia y se le proporcionan los recursos que el alumnado necesite en el aula ordinaria. Según Molina (2015) cuando, por diversas cuestiones, los alumnos reciben los apoyos especializados separados del aula de referencia se generan, al menos, tres consecuencias: (a) se reducen los niveles de aprendizaje y expectativas (Fisher, Roach \& Frey, 2002), (b) el resto del alumnado tiene dificultades para percibirles como compañeros de pleno derecho y tienden a percibirlos como "compañeros a tiempo parcial" (McGregor \& Vogelsberg, 1998) afectando también a la socialización entre el alumnado, y (c) el profesorado tiende a interpretar que la educación de este alumnado es responsabilidad y competencia de los especialistas, quienes tienen el conocimiento adecuado del que ellos carecen (Armstrong, Armstrong, Lynch \& Severin, 2005).

Teniendo ya presentes cuáles son las modalidades de escolarización posibles para las personas con diversidad funcional, vamos a proceder a indagar en cuáles son las medidas de atención a la diversidad con las que se encuentran una vez se accede a un centro de educación ordinario.

\subsubsection{Medidas de atención educativa a las personas con diversidad funcional en centros ordinarios}

Derivadas de la legislación educativa actual y su concepción de la diversidad, emergen las medidas o actuaciones de la diversidad en el contexto escolar. Según Araque y Barrio (2010), la atención a la diversidad consiste en la aplicación de un modelo de educación que es capaz de ofrecer a cada alumno la ayuda pedagógica que necesita. En base de las medidas de atención a la diversidad y los recursos existentes se podrá desarrollar una educación única, igualitaria y de calidad que desestime cualquier tipo de exclusión educativa y que potencie la participación y el aprendizaje equitativo.

Las medidas de atención a la diversidad no son precisamente un elemento tratado explícitamente en la LOMCE (2013), pues la mención que se hace de acuerdo con la atención a la diversidad es el planteamiento de medidas de flexibilización en la enseñanza y en la evaluación de la lengua extranjera, pero sin explicar cuáles son esas medidas ni de qué forma se van a organizar en los centros docentes (Ruiz, 2013). En el caso concreto de la Comunidad Valenciana, sigue estando vigente la orden de 2001 (ORDEN de 16 de julio de 2001 por la que se regula la atención educativa al alumnado con necesidades educativas especiales escolarizado en centros de Educación Infantil ( $2^{\circ}$ ciclo $)$ y Educación Primaria).

Para revisar qué medidas de atención a la diversidad están a disposición del alumnado con diversidad en un centro ordinario, tomaremos en consideración las aportaciones de Fernández Batanero (2015) quien establece la siguiente tipología de medidas:

- Medidas de atención a la diversidad ordinarias: estrategias didácticas, metodológicas y organizativas cuyo objetivo es adecuar el currículum a las 
características particulares de los alumnos para ofrecer una respuesta a sus necesidades educativas lo más individualizada posible sin modificar los elementos básicos del ciclo o etapa. Estas medidas van dirigidas a todo el alumnado y deben ser prioritarias frente a las medidas específicas. Entre las medidas de atención a la diversidad ordinarias podemos diferenciar:

- Planificación educativa desde la diferencia para ofrecer una respuesta amplia y diversa

- Refuerzo educativo (ya sea como prevención de dificultades de aprendizaje o como respuesta a las dificultades manifestadas)

- Agrupamientos diversos y flexibles:

- Aulas multinivel

- Desdoblamiento de grupos

- Agrupamientos diversos (gran grupo, grupo-clase, pequeños grupos, parejas, trabajo individual)

- Alternativas metodológicas:

- Centros de interés

- Tutoría entre iguales

- Trabajo por proyectos

- Unidades didácticas globalizadas

- Apoyo educativo docente:

- Co-docencia

- Apoyo colaborativo (grupos de apoyo entre docentes)

- Comunidades de aprendizaje

- Actividades diversificadas

- Espacios multifuncionales

- Horarios flexibles

- Materiales diversos y adecuados

- Medidas de atención a la diversidad específicas: medidas a las que se recurre cuando las ordinarias no son suficientes y cuya pretensión es que el alumnado alcance el máximo desarrollo posible. Entre estas medidas se pueden diferenciar entre:

- Aulas específicas en centros ordinarios

- Personal especializado en la atención del alumnado con necesidades educativas especiales:

- Maestros/as especialistas en Pedagogía Terapéutica (PT) 
- Maestros/as especialista en Audición y Lenguaje (AL)

- Monitores/as de educación especial

- Intérpretes de lengua de signos

- Educadores/as sociales

- Equipos de Orientación Educativa Especializados

- Adaptaciones curriculares

- Adaptaciones curriculares significativas

- Adaptaciones curriculares no significativas

Sean cuales sean las circunstancias del alumnado, una de las recomendaciones más reiteradas por los expertos es no sacar al alumnado con dificultades de su aula de referencia. Como ya hemos apuntado anteriormente a través del trabajo de Molina (2015), sacar a un niño o niña del aula para compensar ciertas dificultades no solo puede no resulta efectivo, sino que además se generan otros problemas añadidos no compensados.

Si tomamos como referencia el caso de nuestro protagonista, un niño diagnosticado con TEA y TEL, debemos evitar caer en el error común de pensar que por las conductas disruptivas asociadas al autismo, la ubicación ideal sería el aula de educación especial. En este sentido Casanova y Rodríguez (2014) exponen en su trabajo que es justamente la tolerancia a la conducta disruptiva del aula de educación especial la que aparentemente la convierte en la medida más adecuada. Sin embargo, se ha observado que los niños con autismo gritan menos, se levantan menos y trabajan más en el aula ordinaria.

Es una realidad que en contextos ordinarios el desarrollo de habilidades sociales y de generalización del aprendizaje resulta más eficaz que en entornos especiales (Riviére, 2001). Es más, investigaciones de los últimos años evidencian que los niños y niñas con autismo en entornos inclusivos: establecen relaciones que les brindan oportunidades de adquirir habilidades sociales y comunicativas, están constantemente expuestos a modelos que proporcionan vías para aprender, generalizan con más facilidad sus adquisiciones educativas y aumentan las probabilidades de ajuste social a largo plazo (Moreno-Pérez, 2013; Villegas, Simón y Echeita, 2014).

\subsection{Respuestas emergentes: Algunas estrategias de superación}

Llegado este punto, y tras revisar las respuestas formales a la diversidad, consideramos necesario hablar de otro tipo de estrategias y ayudas: son las respuestas que emergen de cada caso concreto y basadas en las peculiaridades de cada persona. No es que sean respuestas o estrategias al margen de la legalidad, sino que son respuestas que se generan y gestionan en el propio terreno. Son estrategias basadas en necesidades concretas detectadas en cada campo de actuación y consideradas indispensables para el éxito educativo de las personas con diversidad funcional. 
Estas las podemos identificar como ayudas o apoyos desarrollados mediante personas (docentes, familiares, amigos y/o asociaciones y organizaciones) del contexto inmedianto de la persona con diversidad funcional. Al fin y al cabo, son ayudas que, vengan de donde vengan, actúan como herramientas para superar las barreras y limitaciones a la inclusión y que permiten una autonomía y participación que otra manera no sería posible.

Por lo tanto, en este apartado presentaremos diversos tipos de estrategias de superación: Las provenientes del contexto social (relaciones sociales y ocio), las que provinenen del contexto educativo o formal (no contempladas en el apartado anterior) y las que proporciona la familia (considerado un tipo de apoyo con carácter propio y trasversal a los otros dos)

\subsubsection{Estrategias sociales: relaciones sociales y ocio}

Las estrategias y ayudas sociales son aquellas facilidades que se encuentran en el contexto social inmediato de las personas con diversidad funcional y que posibilitan que se sientan parte del mismo y participen activamente en él. Somos conscientes que el tipo de estrategias pueden ser muy variadas y distintas en función del contexto, edad y características de cada persona. Sin embargo, tras revisar la literatura, optamos por incorporar las 'relaciones sociales' y el 'ocio' como estrategias de superació de barreras.

Las relaciones sociales de las personas están unidas a los contextos o ámbitos a los que pertenecen y participan, y suponen un valor de suma importancia por su conciencia personal y social en la mutua influencia de las normas y su cumplimento con las actitudes y valores (Parra y Rojas, 2015). Estas relaciones o amistades consideradas apoyos para las personas con diversidad funcional, son denominados como apoyos naturales (Echeita y Simón, 2007; Pallisera, Fullana, Martín, Vilá, 2013; Riera, 2003). Estos apoyos son personas que de una forma natural establecen relaciones de amistad y compañerismo con las personas con diversidad funcional, y a través de su empatía y dedicación actúan como facilitadores de su inclusión social y contribuyen a su calidad de vida.

Así mismo, una manera natural de construir estos apoyos fuera del círculo familiar y educativo es a través del ocio. El ocio en sí mismo es un espacio privilegiado para la autonomía y la autodeterminación, y para adquirir capacidades y hacer aquello que deseamos. Dicho ocio resulta revolucionario para muchas personas con diversidad funcional que ven limitadas sus actividades, restringida su participación e incluso negada su capacidad y libertad para desear. Asimismo, es uno de los ámbitos indispensables para la interacción y la inclusión comunitaria y social (Fantova, 2007).

El ocio, también para las personas con diversidad funcional, es una experiencia humana integral (vivencia, satisfacción, libertad y creatividad) y un derecho humano fundamental. La verdadera inclusión en el ocio no se produce por un ordenamiento de experiencias, integración social u organización de actividades; la verdadera inclusión tiene que ver una dinámica social que implica cambios en el entorno y en los participantes, y en la que las interacciones entre personas con y sin discapacidad estén basadas en un verdadero interés del uno por el otro, con objetivos comunes y en términos de igualdad, sentido de pertenencia, relaciones duraderas, oportunidades de compromiso social, y en un clima de comunicación sin juicios ni prejuicios (Compton, 2003). 
El ocio de las personas con diversidad funcional y su acceso, está actualmente determinado por las condiciones de accesibilidad de la oferta de ocio comunitaria, por el tipo de oferta especializada desde las asociaciones de discapacidad, y por el propio estilo de ocio de la persona con diversidad funcional (Madariaga, 2009). Esta concepción del ocio dista de aquello que define Parrilla (2001) del ocio como un derecho humano, que se dirige a todas las personas, basado en un modelo sociológico, que apuesta por la inclusión total y global de toda persona, que implica una reforma estructural, que toma como referencia la comunidad y el entorno social, que plantea una oferta común para todas las personas, que se articula desde una organización inclusiva, que requiere formación profesional y que supone apostar y comprometerse por un ocio inclusivo.

Desde estas visión humanista, el ocio se considera un elemento altamente vinculado a la calidad de vida de las personas, pues posee múltiples beneficios a nivel personal, aumenta la autoestima, produce sensación de identidad y participación, percepción de control y competencia, permite desarrollar la creatividad, proporciona experiencias de éxito, mejora la salud física y mental, favorece el desarrollo personal y es fuente de significado. A nivel social, el ocio fomenta la cohesión, fortalece valores comunitarios, facilita las relaciones interpersonales, ayuda a mejorar y desarrollar habilidades sociales y a establecer nuevas relaciones (Lázaro, 2008). En la misma línea, Jobling, Moni y Nolan (2000) apuntan a beneficios directos sobre la persona como un mayor sentido de pertenencia, la valoración del cometido, incremento de la autoeficiencia, conocimiento más profundo de los recursos comunitarios, una red de amistades más amplia y compacta y una técnica más depurada o especializada en la actividad.

De esta manera, cuando este ocio es abordado como un conjunto de actividades con un fin en sí mismas, no como actividades utilitarias o terapéutica, pueden detectarse seis dimensiones (Cuenca, 2000; Madariaga, 2000; Gorbeña, 1999 y Lázaro, 1999):

a) Dimensión lúdica: hace referencia a las actividades relativas en el juego en la cual el ocio cobra un carácter de diversión y de descanso que proporciona una mayor estabilidad, tanto psíquica como física. El juego en el tiempo libre es algo intrínseco, no un medio para alcanzar un fin. Ha de ser espontáneo, gratificante y realizado de forma voluntaria tras una elección entre varias alternativas.

b) Dimensión deportiva: relacionada con la práctica de los deportes y contribuye al desarrollo integral de la persona, incrementa las capacidades de tipo motor, fomenta las relaciones sociales, y promueve los hábitos de salud e higiene corporal.

c) Dimensión festiva: posee un carácter comunitario en el que el individualismo se convierte en una actitud antagónica al propio concepto de fiesta. La dimensión festiva del ocio posibilita unos niveles de disfrute elevados que no solo se dan cuando se participa en el acto festivo sino que, tanto la experiencia de preparar una fiesta como posteriormente el recuerdo de ella, proporcionan sensaciones placenteras.

d) Dimensión creativa: relacionada con las artes en general, como la música, la pintura, la literatura,... Posee un carácter formativo, 
cultural y de desarrollo personal mediante el aprendizaje y la formación. Tiene una finalidad en sí misma y debe de ser elegida libremente, diferenciándose de otro tipo de ocio por su naturaleza reflexiva.

e) Dimensión ecológica: encuentro con la naturaleza desde una perspectiva de gozo y disfrute. Lo que prevalece por encima de todo es divertirse, relajarse y recrearse en los entornos naturales que proporciona la naturaleza.

f) Dimensión solidaria: aquellas actividades realizadas de forma desinteresada, basadas en la entrega en beneficio de otros.

De todas estas dimensiones del ocio aquí expuestas, la dimensión creativa y la deportiva, son las que presentan estructuras y organizaciones constituidas desde más hace tiempo y con elementos muy estables. Gran variedad de clubes, federaciones, organizaciones y asociaciones se dedican a planificar actividades y eventos de todo tipo, ya sea de modo general, o de manera específica para las personas con diversidad funcional.

\subsubsection{Estrategias educativas o formativas}

La idea de apoyos y ayudas, en este caso desde la perspectiva educativa, debe tener según Fantova (2000) una triple ambición: la primera será siempre responder a las necesidades de las personas y mejorar su calidad de vida; la segunda será que los apoyos podrán contribuir a los aprendizajes y la tercera, que generarán cambios en las situaciones en las que están inmersas las personas. Desde esta perspectiva, entendemos los apoyos y las ayudas educativas como palancas de cambio que hacen referencia a acciones que se pueden realizar para modificar el comportamiento de una organización y de las personas que la integran (Senge, 1989, citado en Fernández de la Iglesia et al., 2013).

Las estrategias formativas a las que nos referimos, no tienen porque ser necesariamente las que tienen lugar en espacios educativos formales, sino que pueden darse también en entornos no reglados. Por lo tanto, en este apartado discriminaremos entre estrategias formativas dentro del centro, estrategias que pueden darse tanto dentro como fuera de la escuela, y estrategias formativas fuera del centro.

\subsubsection{Estrategias formativas desde el centro}

Cualquier actividad o acción que realiza una institución o centro educativo para atender a la diversidad de su alumnado es un 'apoyo necesario' (Booth \& Ainscow, 2011) sin el cual no será posible un modelo de educación inclusiva. Según Andújar y Rosoli (2014), los apoyos y ayudas facilitados desde un centro educativo inclusivo deben definirse desde una mirada amplia de toda la escuela, implicando un cambio de la cultura y de la práctica educativa, y no solo en función de los niños y las niñas que presentan mayores necesidades en sus aprendizajes.

En este sentido, y habiendo desarrollado en apartado anterior las medidas de atención a la diversidad desde el punto de vista formal, procederemos a identificar ahora algunos apoyos y estrategias para la inclusión educativa más informales, y no por ello menos efectivos. En este apartado distinguiremos entre los iguales como apoyo, y la flexibilidad educativa. 


\section{a) Los iguales como apoyo}

Los apoyos naturales de las personas con diversidad funcional por excelencia son la familia, los amigos y los hermanos, cuya tendencia suele ser ir desapareciendo o delegando funciones en la medida que la persona va adoptando una vida más independiente y autónoma (Huerte y Pallero, 2016). El papel de la familia como apoyo lo desarrollaremos en el punto siguiente, por lo que ahora centraremos nuestra atención en los iguales de las personas con diversidad funcional como apoyos y ayudas a la inclusión.

En un estudio reciente, las madres de niños con TEA manifestaban que la relación de sus hijos/as con sus compañeros y compañeras es una de las razones y motivaciones para mantener el proceso de inclusión educativa (Villegas et al., 2014). Es más, las experiencias compartidas entre personas con diversidad funcional y sus iguales favorece el entendimiento de la complejidad de las desventajas sociales y facilita obtener herramientas sociales necesarias para combatir la discriminación (Aspaym, 2007).

De hecho, cuando las interacciones entre alumnado con y sin diversidad funcional se estructuran con una finalidad académica se produce el aprendizaje entre iguales, condición íntimamente ligada a la educación inclusiva (Durán, 2009). Múltiples autores, manifiestan la importancia de la ayuda entre iguales (Johnson, Johnson \& Holubec, 1999; Slavin, 2002; Carter, Asmus \& Moss, 2014) como elemento indispensable para una educación inclusiva. Mediante el aprendizaje entre iguales, los beneficios del aprendizaje en términos de logros académicos (Bowman-Perrott et al., 2013; Okilwa \& Shelby, 2010; Topping, 2001) se complementan con los de tipo social, de comunicación y afectivo (Miller, Topping, \& Thurston, 2010; Xu, Gelfer, Sileo, Filler, \& Perkins, 2008).

\section{b) Flexibilidad educativa}

La inclusión educativa aboga por aulas y centros que fomenten el aprendizaje de todo el estudiantado, independientemente de las condiciones sociales, culturales o personales, y lo hace bajo un mismo paraguas y desde un diseño flexible y abierto para todos y todas. En esta línea, adquiere relevancia la 'flexibilidad educativa', la capacidad de plantear elementos del currículum abiertos que se adapten a las circunstancias personales de cada persona.

Esta idea, nos lleva a pensar en el Diseño Universal del Aprendizaje (DUA) como un diseño que desde el centro educativo permite desarrollar estrategias de aprendizaje adaptadas a las circunstancias y diversidad del aula. Citamos aquí el DUA con la pretensión de rescatar sus principios básicos por la relación que poseen con un modelo educativo inclusivo y la capacidad de generar realidades respetuosas con los distintos ritmos individuales del alumnado.

Los principios del DUA propuestos por el Centro de Tecnología Especial Aplicada (CAST, 2011) son:

- Proporcionar múltiples formas de representación de la información y los contenidos: las redes de reconocimiento de cada alumno funcionan de forma distinta, manifestándose en una amplia variedad de formas de percibir, procesar y comprender la información. 
- Proporcionar múltiples formas de acción y expresión del aprendizaje: los alumnos presentan habilidades organizativas y estratégicas diferentes en base al funcionamiento de sus redes estratégicas, lo que conlleva que cada uno sea más capaz de expresar lo que sabe de una forma que de otra.

- Proporcionar múltiples formas de implicación: atender las diferencias en el modo en que los estudiantes se motivan y se comprometen con el propio aprendizaje.

Mientras un currículum inflexible, diseñado de manera rígida y con un única 'talla para todos' (CAST, 2011) genera barreras al aprendizaje: un currículum abierto además de repercutir en objetivos, contenidos, materiales, actividades y evaluación adaptados, deriva en horarios, espacios, comunicación, apoyos personalizados y formas de interacción adaptadas a la realidad del aula.

\subsubsection{Estrategias formativas dentro y fuera del centro}

Otras tipo estrategias de apoyo a destacar son aquellos apoyos no contemplados en los apartados anteriores y que, tras la revisión de la literatura detectamos como necesarios para la inclusión de alumnado con TEA en un entorno ordinario, tanto dentro como fuera de la escuela: son los apoyos y recursos visuales.

La alta capacidad de abstracción de información de los recursos visuales convierte a este tipo de apoyos en un medio valioso tanto para el aprendizaje como para el desarrollo de la autonomía personal de las personas con TEA. Aunque cada persona es diferente, recurrir a estos medios mejora no solo el ámbito socioeducativo y la calidad de vida, sino que contribuye a un mejor conocimiento para aquellas personas que desconocen este tipo de trastorno (Barrios, 2013; Regis, 2014).

Existen diversos elementos y tipos de apoyo visual para la inclusión de personas con TEA en contextos ordinarios, entre los que Regis y Castejón (2015) proponen:

a) Pictograma: representa todo tipo de conceptos, acciones (individuales o grupales) u objetos en forma de dibujos a través un lenguaje visual que se ve reflejado a través de imágenes simples.

b) El cartel: Ilustración que actúa como imagen expositiva en la que transmite un mensaje que debe de ser recibido por el receptor, positivo o negativo. Una de sus funciones es llamar la atención y promover la búsqueda de información sobre él, su relación con otros aspectos de la vida o sus vidas, conformando un círculo vicioso en el cual el objeto y sujeto están relacionados entre sí, buscándose el uno al otro.

c) Historieta gráfica: cómic. La historieta gráfica o cómic son un conjunto de imágenes fijas secuenciadas en la que se narra algo significativo. El uso que se le da a este tipo de apoyo con el alumnado con TEA tanto con el uso de un cómic previamente elaborado como con la elaboración de este por parte del alumnado.

d) La fotografía: al igual que la pintura es una forma de plasmar aquello que la persona quiere. La fotografía funciona reproduciendo una 
realidad, a veces simbólica, que va más allá de ésta, provocando una capacidad de evocación en la que funciona simultáneamente como imagen icónica y como metafórica. Su uso puede ser, entre otros, el de registrar como se ve uno mismo, expresar sentimientos y/o capacitar alguna acción.

e) La imagen secuenciada: stop motion: Es una técnica artística y audiovisual mediante la que se representa una realidad armonizando técnicas tanto de la fotografía como la del vídeo. Este tipo de elementos proyecta la creación de narrativas reales o ficticias creadas imagen a imagen utilizando el sonido y el montaje como factores para el desarrollo creativo. En personas con TEA promueve una serie de factores para el desarrollo personal y social como: fomento de la independencia en la toma de decisiones, trabajo en grupo e individual, desarrollo y aplicación elementos artísticos de la herramienta audiovisual, adquisición de habilidades sociales y comunicativas de participación con los iguales, contribuye a la creatividad y soluciones extrapolables a la vida de uno mismo.

f) La imagen secuenciada: el cinemagraph: son imágenes fijas en las que se puede apreciar un elemento en "vivo" aportando una sensación de movimiento. Es una técnica alternativa a la anterior que se puede realizar desde todo tipo de dispositivos de grabación audiovisual y que resulta muy atractiva y atrayente para todo tipo de alumnado.

g) El vídeo: este tipo de apoyo es concebido como una herramienta de comunicación para la expresión del lenguaje visual, auditivo, moralista... que permite determinar qué es lo que queremos difundir, enseñar o aprender a través de este (Regis, 2015). El trabajo con este tipo de apoyo permite integrar elementos de la vida de uno mismo, y posee infinitas posibilidades didácticas, entre ellas la artística.

h) Las historias sociales: Son explicaciones de forma oral en las que se nutre de apoyos visuales para una mejor explicación de aquello que se quiere argumentar utilizando, por ejemplo, dibujos para una narración instantánea de lo que se quiere explicar. Son dibujos o imágenes que se hacen de forma inmediata, en el mismo momento que se está realizando la explicación o acción a llevar a cabo. Múltiples estudios apoyan el uso de este tipo de apoyos visuales en alumnado con TEA por la gran variedad beneficios en el área de comportamiento (Scattone, Tingstrom \& Wilczynski, 2006; Agosta, Graetz, Mastropieri \& Scruggs, 2004; Plavnick \& Ferreri, 2011; Cihak, Kildare, Smith, McMahon \& Quinn-Brown, 2012) y de habilidades sociales (Sansosti, Powell-Smith \& Kincaid, 2004).

Este tipo de apoyos, independientemente del contexto de aplicación, son de un elevado valor para las personas con TEA, pues la funcionalidad, adaptabilidad y versatilidad de los apoyos visuales los convierte en elementos no solo necesarios sino ineludibles cuando el área del lenguaje se encuentra afecta.

\subsubsection{Estrategias formativas fuera del centro: la educación no formal}

De la misma manera que en los casos anteriores, la educación no formal (fuera del centro) se convierte en una estrategia de apoyo y ayuda tanto para 
cualquier persona como para las personas con diversidad funcional. La educación no formal en sí misma es un espacio educativo que surge como opción para llenar algunos vacíos o necesidades formativas de los sistemas formales, y cuya autonomía curricular le permite ser dinamizadora y llevar a cabo una diversidad de procesos de formación adaptados a realidades específicas (Chacón-Ortiz, 2015).

Según Olcott (2013), la educación no formal es una modalidad de formación institucionalizada, intencionada y organizada por un proveedor de educación cuya principal característica es que representa una alternativa o complemento a la educación formal de las personas dentro del proceso de aprendizaje a lo largo de la vida. Su estructura no implica necesariamente una trayectoria continua y suele conducir a certificaciones que no son reconocidas por las autoridades nacionales o subnacionales competentes.

Existen diversos enfoques centrales dentro de la educación no formal, entre los que podemos encontrar (Maroto, 2016):

- Educación de adultos: Incluye la alfabetización, capacitación para el trabajo (artes, oficios), como el extensionismo agrícola o pecuario, con acreditación pero sin certificación. Muchas de estas prácticas de educación no formal pueden acercarse a modelos escolarizados sobre todo desde una perspectiva ideológica asistencia y entonces tienden a parecerse más a las escuelas.

- Desarrollo Comunitario: enfocada al cambio social, acciones de salud, desarrollo y producción, donde el hecho educativo es complementario.

- Centro cultural. Casas de la cultura, centros culturales, casas populares, museos, centros de cultura ambienta, unidades deportivas.

- Asociacionimo: sindicatos, partidos políticos, clubes o asociaciones religiosas, deportivas, sociales, culturales y los grupos de ayuda mutua.

Estos enfoques de educación no formal aquí expuestos acaban siendo en mayor o menor medida una prolongación del sistema de educación formal. Las estrategias o herramientas en las que derivan y se concretan son múltiples, pues en nuestro entorno podemos detectar entre otros: escuelas taller, escuelas musicales, de danza, escuelas de arte, de formación en lenguas, académicas de apoyo al estudio, de refuerzo educativo, clubes de deporte, de juegos, culinarios, agrícolas, de vecinos,... un sinfín de posibilidades. Lo que sí es cierto es que, independientemente del ámbito y estructura que adopte cualquier institución o asociación de educación no formal, se convierte en una herramienta o estrategia para la inclusión y desarrollo personal de cualquier persona, y más concretamente de las personas con diversidad funcional.

Una de las últimas consideraciones que aportaremos a este apartado es la función que la familia ejerce como pieza de engranaje que articula todas las estrategias emergentes aquí expuestas. La familia en sí misma y el papel que desempeñe determinará y condicionará el éxito de cualquiera de los apoyos y estrategias para la inclusión aquí expuestas, pues como veremos a continuación, su actuación resulta fundamental para inclusión social y educativa de las personas con diversidad funcional. 


\subsubsection{El papel de la familia}

La familia es el grupo de representación y socialización de referencia en todos los seres humanos, y sin duda, es el principal y más permanente apoyo para el individuo. De su actuación van a depender muchas de las expectativas, posibilidades y bienestar de la persona (Baña Castro, 2015). La familia es para cualquier persona su primer núcleo de convivencia y de actuación, donde irá modelando su construcción como ser social a partir de las relaciones que allí establezca (Brazelton \& Greenspan, 2005). De hecho, junto a los hermanos y compañeros de estudio y trabajo, son considerados los apoyos naturales por excelencia de las personas con diversidad funcional (Riera, 2003).

Sin embargo, en cuanto al TEA, debido al modelo médico-rehabilitador imperante durante tantos años, la familia no fue considerada importante hasta hace relativamente poco cuando, desde el modelo social empezó a considerar el papel educativo, estimulador, normalizador e inclusivo de la familia (Baña Castro, 2015). En el caso concreto de personas con TEA, se convierte en necesaria la comunicación, coordinación e intervención con la familia para propiciar el desarrollo personal, académico y social.

Cuando el autismo, así como cualquier otro tipo de diversidad funcional, llega al seno de una familia, se suceden evidentes procesos de impacto, adaptación y reorganización. Al igual que cada persona es un mundo, cada familia también lo es, por lo que la manera en la que se reacciona y actúa será también diversa (Heward, 2000). Trabajos recientes recogen que las familias con hijos/as con autismo desempeñan un mayor número de tareas y papeles que otras familias que no tienen estas características (Baña Castro, 2015). Para Panaigua (1999) estas tareas se resumen en las siguientes implicaciones:

1. Preocupación por el presente y el futuro del hijo o hija

2. Decisión sobre tratamientos médicos, elección de profesionales y opciones educativas

3. Aumento de dedicación: cuidados físicos, tiempo de interacción, más situaciones de juego y estudio compartido, programas de estimulación temprana, actividades de ocio y refuerzo de la escolarización

4. Gastos extraordinarios (de tipo médico, ortopédico, educativo, rehabilitador)

5. Futuro lleno de interrogantes e incertidumbre ante la venida independiente del hijo/a con Trastorno del Espectro del Autismo.

Ante esta situación, la familia de una persona con TEA adquiere un papel que trasciende más allá de las paredes de su casa, llegando a cualquier rincón de la sociedad e incluso dentro de las aulas en los centros educativos. De alguna manera, la familia se convierte en el agente principal para el desarrollo personal y un factor relevante para la autonomía personal (Huete y Pallero, 2016).

No hay duda alguna, de que estas implicaciones familiares, junto con las barreras identificadas anteriormente en este capítulo, convierten la tarea familiar en un duro y tenebroso camino. Las opciones son diversas: aceptar la situación actual y acogerse a lo que ofrece la administración y estamentos públicos, o negarse 
a consentir, crecerse y luchar por los derechos de sus hijos e hijas. Esta última opción es la difícil, es la que quita el sueño por las noches y la que revuelve las tripas, pero es también la que contribuye a que las personas con diversidad funcional encuentren un entorno social y educativo lo más inclusivo posible.

De esta última forma de enfrentarse a la realidad que vive una persona con diversidad funcional emerge lo que se conoce como 'teoría de la resistencia'. La teoría de resistencia es un concepto que se ha utilizado tanto para referirse al empoderamiento y gestión contrahegemónica de los centros educativos (Giroux, 1993) como para a referirse a la resistencia y lucha de las personas con diversidad funcional y sus familias (Susinos y Parrilla, 2013). La teoría de la resistencia emerge en contraposición a la 'teoría de la reproducción', teoría que niega el espacio para la creación, la mediación y la resistencia, y que focaliza enteramente en el poder y en las formas sobre cómo la cultura dominante asegura la sumisión y derrota de los grupos y clases subordinadas (Baltar, 2003).

La denominada 'Teoría de la Resistencia' nace de estudios etnográficos y de índole cultural en los que se otorga una gran importancia a las nociones de conflicto, lucha y resistencia. Es una teoría que hace referencia al carácter activo y progresista de los grupos oprimidos que poseen habilidades para construir colectivamente no solo teorías sino también sus propias prácticas transformadoras (Giroux, 1992). De esta manera, cuando se generan actos o prácticas que involucran una reacción, consciente o inconsciente, contra las relaciones de dominación construidas por el propio sistema, se propicia una contralógica de rechazo al discurso dominante basado en la resistencia (Baltar, 2003).

En cuanto a la diversidad funcional y la inclusión social, política y educativa, esta teoría de la resistencia se convierte en una herramienta que nos permite reconocer y explicar la capacidad individual de resistir y reaccionar a las condiciones socialmente impuestas y a los discursos hegemónicos (Parrilla y Susinos, 2008). Se trata de procesos mediante los cuales las personas con discapacidad resisten a esos discursos dominantes del estigma, a la exclusión política y social y al poder de los expertos en su propia vida, ofreciendo una forma de entendimiento de las complejas relaciones y negociaciones entre las ideas divergentes que en la actualidad no terminan de encontrar cabida en el modelo social de la discapacidad (Gabel y Peters, 2004).

De esta manera, la resistencia es el primer paso hacia la liberación de los lazos esclavizadores que niegan y excluyen a las personas y grupos oprimidos, pues constituyen fórmulas que de una manera u otra se oponen a la interiorización y acoptación continuada (Calderón y Habegger, 2012). El desarrollo de la teoría de la resistencia en el campo educativo y social, tiene que ver con la relación existente entre las personas con diversidad funcional y el propio sistema, pero sin olvidar bajo ningún concepto un tercer factor: las familias (Ortiz, 2010).

En esta teoría de la resistencia, las familias se convierten en la clave para no acomodarse y luchar ante los discursos y narrativas predominantes que promulgan una actitud de asimilación y resignación. En la mayoría de los casos son actos de protesta y denuncias, porque destapan un conflicto latente y silenciado (Caledón y Habegger, 2012), son respuestas que tienen mucho que ver con la indignación no solo moral, sino también política, social y educativa, y que además se convierte en un mecanismo para crear nuevos caminos de emancipación y transformación social. 
Esta resistencia y lucha de las personas con diversidad funcional y sus familias, es la que a través del discurso contrahememónico, y desde un posicionamiento local reclaman y exigen un cambio global hacia sistemas $\mathrm{y}$ estructuras sociales más inclusivas. De tal forma que, mientras esto no sea una realidad, utilizan y utilizaran sus propias armas, herramientas y mecanismos para aproximarse a esta condición inclusiva tanto como sea posible.

\subsection{La inclusión como proyecto vital}

Tal y como venimos apuntando, tanto las personas con diversidad funcional como sus familias y entorno anhelan, persiguen y luchan por un modelo educativo y social inclusivo. Un proyecto de sociedad en el que todas las personas sean reconocidas por lo que son, y no por lo que les diferencia de otros. Una manera de mirarnos los unos a los otros desde el respecto, desde el reconocimiento y la pertenencia a una única estructura social: una sociedad inclusiva.

En el capítulo 1, hacíamos referencia a diversos formas o modelos de entender y mirar hacia la diversidad (modelo de prescindencia, modelo médico-rehabilitador y modelos social) que, a su vez, se corresponden con diversos modelos sociales y educativos concretos: segregacionista, integrador e inclusivo. De esta manera, en función del modelo discapacidad desde el que nos posicionemos, facilitaremos y generaremos espacios, entornos y situaciones más o menos inclusivas.

La inclusión no es simplemente un resultado de la evolución en el tiempo de la educación especial. Podemos decir que el término 'inclusión'es más bien un término que requiere de un cambio de paradigma debido al movimiento social internacional contra la exclusión estructural, cultural y educativa que experimenta el alumnado señalado como 'diferente' (Carrington, 1999, 2017; Slee, 2005).

\subsubsection{La calidad de vida: clave para la inclusión}

Todos estos esfuerzos, todo el trabajo pedagógico y social, todas las reivindicaciones y toda la lucha por la inclusión toman sentido cuando revierten sobre la misma sociedad y nos otorgan a todos y todas espacios de participación, reconocimiento y autodeterminación. Lo diverso es lo normal, lo diverso es lo real, y desde esa diversidad debemos pensarnos, reflexionar y actuar. Actuaciones y planteamientos, que sean del tipo que sean, deben contar con la participación y aportaciones de las personas implicadas.

Concretamente en esta línea, en el campo de la diversidad funcional, emergió un lema reivindicatorio de esta postura "nada sobre nosotros sin nosotros", utilizado por los estadounidenses que arrancaron el movimiento de vida independiente en los años 70 y vigente hoy en día (desarrollado en el capítulo 1). Tras este emblema, el colectivo de personas con diversidad funcional no solo reclama sus derechos políticos, sociales y educativos, sino que además exigen formar parte de esas reflexiones, planteamientos y decisiones que pretenden contribuir a su autonomía, independencia, autodeterminación y calidad de vida.

La inclusión de las personas con diversidad funcional tanto en su contexto educativo como en el social, genera una mejora de su calidad de vida, de la percepción que esta posee sobre sus condiciones vitales $\mathrm{y}$, por lo tanto, de su 
desarrollo personal. El concepto o término de calidad de vida en sí misma se entiende como 'un estado de bienestar personal' (Verdugo, Gómez, Arias y Schalock, 2009) que se articula en base a diversas dimensiones: bienestar físico, bienestar emocional, bienestar material, relaciones interpersonales, inclusión social, desarrollo personal, autodeterminación y derechos (Schalock y Verdugo, 2007).

El modelo de calidad de vida (CDV) es (a) multidimensional y tiene los mismos componentes para todas las personas; (b) está influenciado por factores personales y ambientales; (c) se mejora con la autodeterminación, los recursos, el propósito de vida y un sentido de pertenencia; y (d) su aplicación debe basarse en la evidencia. Este modelo de apoyo a las personas con diversidad funcional se basa y fundamenta en la visión de estas personas y focaliza su atención en lo esencialmente humano (no en la alteración y trastorno), cediendo las decisiones sobre qué quiere conseguir en la vida a la persona protagonista y concediendo una amplia trascendencia a la autodeterminación, la inclusión y las relaciones personales, entre otros (Schalock, Gardner \& Bradkley, 2007). Se trata de un modelo con una gran capacidad para promover transformaciones en las vidas de las personas y su entorno (Shalock y Verdugo, 2007).

Es precisamente ese modelo de CDV el que nos abre el paraguas y nos hace entender la necesidad de entornos, ambientes y sociedades realmente inclusivas, pues desde enfoques inclusivos, no solo educativos sino también sociales, podremos ir aticulando las palancas de cambio que permitan la autodeterminación, control y satisfacción de cada uno de nosotros con su experiencia vital.

De hecho, aunque apostamos por un cambio global, amplio e incluso radical que implique toda la sociedad, focalizaremos nuestra atención ahora en el ámbito educativo. Decidimos adentrarnos ahora en este contexto por considerar la etapa educativa como un elemento de gran trascendencia para el desarrollo humano de cualquier persona y, por otra, una de las claves para la inclusión social.

\subsubsection{En proceso hacia la inclusión}

Al hablar del modelo de inclusivo, Fernández Batanero (2015) apunta que no se trata de un nuevo enfoque, sino un punto y aparte de modelos anteriores que se presenta como una idea trasversal presente en todos los ámbitos de la sociedad (social, laboral, familiar,...) . Se trata de una ampliación del punto de mira hacia lo social como el elemento generador de contextos, valores y principios inclusivos que la escuela vertebra y recrea (Parrilla, 2002), donde la igualdad se convierte en el punto de arranque desde la cual articular la construcción de comunidades para todos que permitan y valoren la diferencia y adopten el principio de equidad como bandera (Ainscow, Dyson, Goldrick \& West, 2013).

Pero para que esto sea posible debemos parar y preguntarnos ¿qué estamos haciendo? ¿qué hemos conseguido como sociedad en este sentido? ¿cuál ha sido nuestro recorrido? ¿en qué punto nos encontramos en materia de inclusión en nuestra sociedad? y por lo tanto, ¿qué dirección debemos tomar ahora?

(¿De dónde venimos?)

$\mathrm{Al}$ hablar de educación inclusiva estamos hablando de un concepto sobre el que se lleva teorizando desde hace décadas. De hecho, múltiples autores (Moriña, 
2008; Parrilla, 2001; Kiuppis, 2014; Aziz Ghoneim, 2014; Amar, Tello, Bianchi, y Asprella, 2015; Skliar, 2015; Limbach-Reich, 2015; Esteban-Guitart y Llopart, 2016; Escudero, 2016; Wagner, 2017) sitúan los principios del movimiento de educación inclusiva en 1990 cuando se celebró la conferencia de la Unesco en Jomtien (Tailandia) y en la que por primera vez se hizo pública la idea de "Educación para todos". Fue en ese momento cuando emergió por primera vez el concepto de inclusión educativa, y tan solo cuatro años después en la "Conferencia Mundial sobre Necesidades Educativas Especiales. Acceso y Calidad", en Salamanca, (UNESCO, 1994), se definió y asentó la inclusión educativa como principio y política educativa. Este fue el primer foro global en el que se pedía explícitamente la inclusión de todos los niños y niñas con diversidad funcional en el sistema educativo ordinario y en cuya conferencia participaron 88 países y 25 organizaciones vinculadas a la educación. En este contexto, todos estos países y organizaciones admitieron y se comprometieron a trabajar por y para el desarrollo y promoción de políticas educativas con orientación inclusiva. Esta conferencia supuso el reconocimiento explícito de la noción de inclusión en el ámbito internacional, planteando la educación inclusiva como un derecho de todos y todas.

Otra fecha clave en la consolidación de la filosofía de inclusión fue el año 1996, nombrado Año Internacional contra la Exclusión, en el que se propuso la desconexión total de los términos inclusión y exclusión. En el año 2000, la inclusión educativa da el salto definitivo a la agenda política global en la conferencia de Dakar de 2000 a través del Programa de Educación para Todos (EPT) de la UNESCO. Más tarde, en 2006, en la Convención de los Derechos de las Personas con Discapacidad adoptada por la Asamblea General de Naciones Unidas, se consagra el derecho a la educación inclusiva en las leyes internacionales, especificando en el punto 1 del artículo 24 que los Estados partes reconocen el derecho de las personas con discapacidad a la educación, siendo éstos quiénes asegurarán un sistema de educación inclusivo a todos los niveles.

A los pocos años, se realizó a nivel mundial la Conferencia Internacional realizada en Salamanca en 2009 con motivo del 15 aniversario de la Declaración de Salamanca de 1994. Dicha conferencia titulada "Volviendo a Salamanca: Conferencia Global sobre Educación Inclusiva. Afrontando el Reto: Derechos, Retórica y situación Actual" acometía la movilización de la agenda global sobre educación inclusiva, afianzó el compromiso global de Educación para Todos garantizando y promoviendo vías de intercambio y difusión de prácticas, experiencias, políticas y estrategias de promoción de la educación inclusiva a nivel internacional.

Uno de los últimos acontecimientos internacionales en materia de inclusión fue The Inclusive Education Summit (TIES) realizado en 2015 en la Universidad de Victoria, en Melbourne. En esta conferencia, el tema clave fue "Ofreciendo sentido a la práctica diaria" basada en la discusión sobre la mejor manera de fortalecer las prácticas de educación inclusiva en beneficios de todos los estudiantes. Esta discusión, generada desde diversas posturas de los participantes, focalizaba su atención en un nuevo enfoque pedagógico: el enfoque pedagógico inclusivo o la pedagogía inclusiva. Según Black-Hawkins (2017), la principal idea de este nuevo enfoque es 'mover' el pensamiento pedagógico docente...

... lejos de un enfoque tradicional o individualizado de la diversidad del alumnado que realiza una planificación o provisión para la mayoría de 
los estudiantes y otra diferenciada o adicional para aquellos con necesidades particulares.

... y hacia un enfoque pedagógico que parte del aprendizaje de todos y todas.

Este último evento, ha sido uno de los detonantes de nuevos enfoques pedagógicos, nuevas perspectivas que se desmarcan de ese concepto de inclusión procedente de la crítica al modelo integrador y generan una nueva concepción educativa de la diversidad. Este término y sus implicaciones serán abordados más adelante en este capítulo, pues constituyen uno de los caminos futuros de la inclusión en nuestro contexto.

\section{(¿Dónde estamos?)}

Tras este breve recorrido sobre los principales acontecimientos internacionales en cuanto a la inclusión educativa, procedemos a definir qué entendemos por educación inclusiva en base a nuestros referentes teóricos. En la literatura, podemos encontrar diversas posturas desde las que se define el concepto de inclusión sin un aparente consenso. De hecho, esto mismo indica Parrilla (2001) en su trabajo:

Distintos autores y distintos grupos de presión, educativos, sociales, etc., entienden la inclusión destacando alguna de sus dimensiones. Habiendo además quien lucha dentro del mismo movimiento incluso defendiendo unas y otras concepciones (Parrilla, 2001)

Además estas posturas diversas, el término 'inclusión' es un concepto que ha experimentado una rápida y profunda evolución en los últimos años. Cuando nos referimos a la inclusión estamos hablando de un proceso llamado "never-ended", que nunca termina, un camino que debe diseñarse, recorrerse y apoyarse continuamente (Verdugo y Parrilla, 2009; Parrilla, 2010). La inclusión en sí misma busca fomentar la participación de todos los estudiantes y reducir la exclusión cultural y educativa de algunos de ellos (Muthukrishna, 2002). Se trata de un proceso desde el que se cuestionan las formas de responder a la diversidad, cómo se convive con la diferencia y cómo se aprende de ella (Ainscow, 2008b).

Una de las aportaciones internacionales de referencia en este campo ha sido la de autores como Ainscow, Booth y Dyson (2006), quienes entienden la educación inclusiva en base a tres variables relevantes: la presencia, el aprendizaje y la participación:

- La presencia se refiere a dónde están ubicados los alumnos, ya que aunque esto no sea definitorio, los lugares son importantes para estos autores. Se considera difícil que el alumno aprenda a reconocer y valorar la diversidad humana en la distancia, en centros y aulas segregados de aquellos espacios donde se educan los alumnos sin discapacidad.

- Por aprendizaje se entiende que el centro se preocupa de adoptar las medidas necesarias para que los alumnos con necesidades de apoyo educativo asociadas a condiciones de discapacidad puedan obtener el mejor 
rendimiento escolar posible en todas las áreas del currículo y en cada etapa educativa.

- Por participación se entiende el deber de reconocer y apreciar la identidad de cada alumno y la preocupación por su bienestar personal y social, además de por la ausencia de maltrato, exclusión o aislamiento social.

Entendemos la educación inclusiva como un concepto y práctica poliédrica, con múltiples facetas y planos, cada uno de los cuales tiene algo de la esencia de su significado pero que, por otra, no lo agota en su totalidad (Echeita, 2013). La inclusión requiere de la construcción de espacios inclusivos para la flexibilización del currículum, el cambio de estructuras educativas, la visibilización y erradicación de la cultura del individualismo reestructurando el sistema de actitudes frente a la diferencia, la generación de espacios de convivencia de la comunidad educativa y la consideración de la diversidad más allá de la metodología, valorándola como una opción política, social, cultural y ética (Dos Santos, 2003)

Por educación inclusiva nos referimos, por tanto, a un proceso educativo en el que se potencia la participación de todos los estudiantes, además de celebrar y aceptar las diferencias como enriquecimiento para todos y todas. Desde este posicionamiento se demanda un currículum común, implicando la reestructuración educativa que trasciende más allá de las cuatro paredes de la escuela, fomentando una sociedad más inclusiva y justa (Moriña, 2004).

El movimiento de inclusión promueve que todos los niños, niñas y jóvenes reciban una educación de calidad y con equidad (Casanova y Rodríguez, 2014) focalizando la atención en la trasformación de los sistemas educativos para atender a la diversidad mediante la eliminación de barreras al aprendizaje y la participación (Blanco, 2005). Se trata de una ideología en la que cualquier persona puede participar en el proceso de enseñanza - aprendizaje y en la que la cultura y organización de los ambientes de aprendizaje complementan y contribuyen a una ciudadanía democrática (Whitburn y Plows, 2017).

Consideramos necesario, por lo tanto, elaborar una apuesta educativa fuerte, enmarcada en el seno de la sociedad y desde la que no haya lugar a ambigüedades o matizaciones sobre este tema. Necesitamos de un planteamiento que implique a las personas con diversidad a la hora de elaborar una respuesta para todos y todas. Necesitamos pues, de un planteamiento alejado de la pedagogía conformista y tranquilizadora, que se convierta en un elemento crítico, concienciador y liberador. Necesitamos la investigación y profundización sobre la teoría, la política, la práctica, el currículum y la cultura para aprender "las posibilidades de recuperar esta pedagogía" (Harwood \& Allan, 2014).

\section{(¿Hacia dónde vamos?)}

Tal y como Black- Hawkins (2017) expone en su último trabajo, existe una confusión terminológica en cuanto a conceptos como educación inclusiva, prácticas inclusivas y pedagogía inclusiva. Aunque son términos con una relación directa sobre la vertiente inclusiva de la educación no deben considerarse 'intercambiables'.

Ya hemos adelantado en este capítulo que la educación inclusiva proviene de la atención a las necesidades educativas especiales en aquellos identificados 
como 'discapacitados' y que con el tiempo, empezó a concebirse más bien como un proceso de inclusión dirigido a todas las personas en situación de vulnerabilidad como también puede ser por razones de pobreza, género, sexualidad y conflicto (UNESCO, 2015). En cambio, la práctica inclusiva se refiere a diversas acciones y actividades que los profesionales de la educación llevan a cabo en las escuelas o fuera de ellas para dar sentido a lo que ellos entienden como educación inclusiva (Florian, 2009). Finalmente, la pedagogía inclusiva es el enfoque de enseñanzaaprendizaje que focaliza en extender aquello al alcance de todos para que todos puedan participar en el aula, en oposición a crear para todos y diferenciar lo de algunos (Black- Hawkins, 2017).

Desde esta perspectiva el reto consiste en un 'esfuerzo pedagógico complejo' (Florian y Black-Hawkins, 2011), en el que superar esas prácticas adicionales diseñadas para unos y generar enfoques para todos, pues no tiene sentido considerar que una pedagogía efectiva para esa mayoría no lo puede ser para todos. 


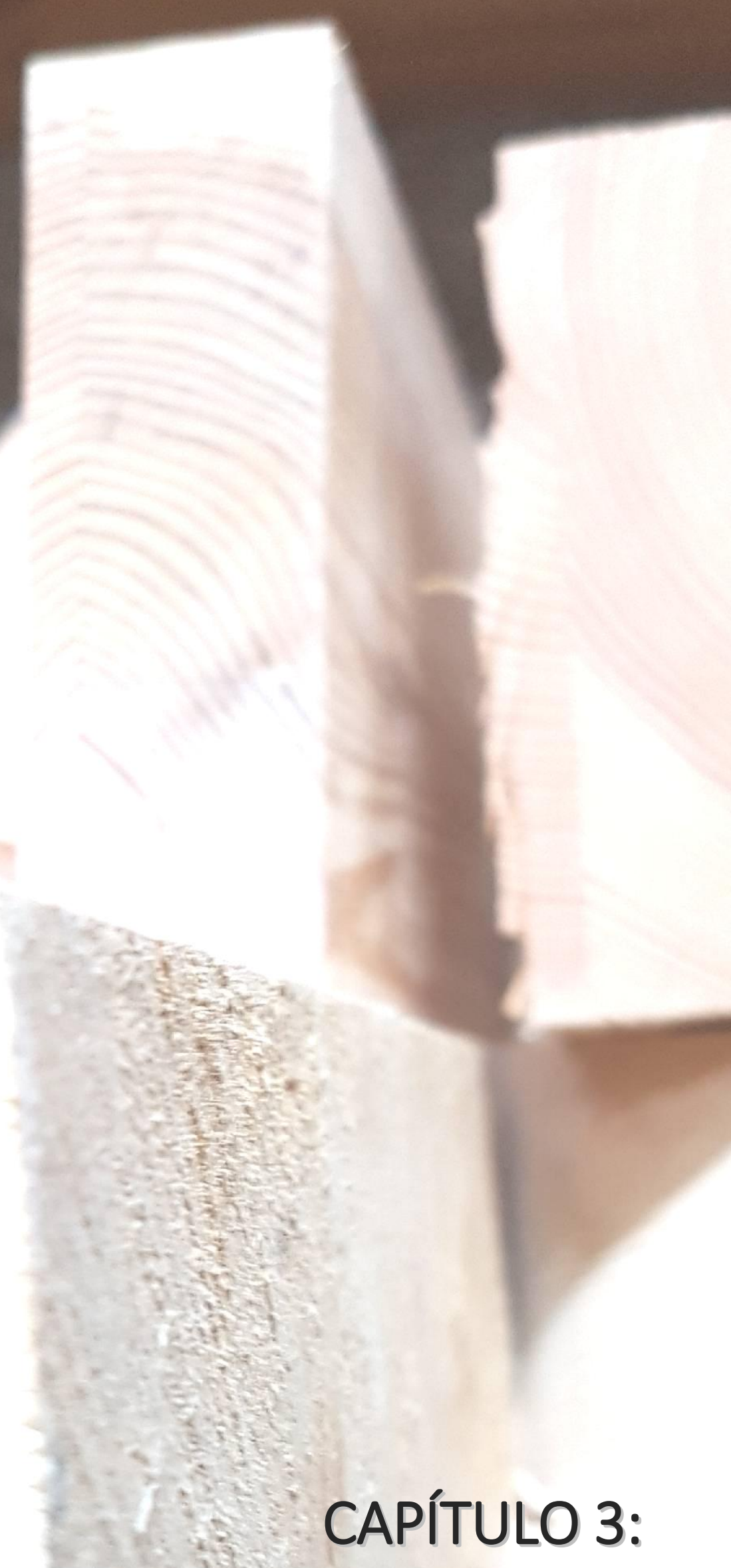

\section{La investigación biográfico-narrativa: método y estrategia de investigación}



En esta contextualización teórica empezamos a acercarnos a nuestra investigación desde una visión más técnica, pues estamos ante un capítulo teórico sobre investigación.

Mientras iba forjando y dibujando los cimientos de esta investigación me cercioraba de las carencias formativas que tenía como investigadora. Hay muchas formas de decir lo mismo y formas muy similares de decir cosas diferentes. Reiteré en ese momento la necesidad de un capítulo sobre la estrategia de investigación utilizada y que me permitiera a mí, y en consecuencia al lector, determinar claramente la perspectiva y planteamientos desde los que enfocamos esta investigación.

Éste ha sido un capítulo duro, difícil, de mucha lectura y relectura, de búsqueda de sentido y de una gran ansiedad por encontrar el lugar donde me sintiera cómoda y segura a la vez. Considero este capítulo como un momento investigador indispensable, sin el cual el segundo bloque de la tesis no se hubiera entendido correctamente.

3.1 La investigación cualitativa

3.1. El método biográfico narrativo

3.1.1. Origen y delimitación terminológica.

3.1.2. Narrativas, biografías, historias, relatos... ¿Es lo mismo dicho de otra manera?

3.1.3. El cómo del método biográfico.

3.2.3.1. Modalidades, técnicas e instrumentos de recogida de datos

3.2.3.2. Modelos de construcción de historias de vida.

3.2.3.3. Producto final: ¿relato o historia de vida?

3.1.4. Consideraciones éticas del método

3.2.4.1. La coinvestigación

3.2.4.2. Proceso de negociación constante

3.2.4.3. Consentimiento informado

3.2.4.4. La confidencialidad y anonimato

3.3. El método biográfico narrativo: la investigación inclusiva

3.3.1. El papel (y compromiso) de la investigadora 
La investigación es sin duda una forma de entender la vida, una forma de problematizar la realidad que nos rodea para estudiarla y analizarla desde múltiples miradas y perspectivas. Así mismo, la investigación posee la venerable capacidad de ofrecer al investigador un abanico inmenso de posibilidades para la indagación. Grandes investigadores y teóricos a través de su experiencia y su profundo y exhaustivo trabajo, nos brindan diferentes perspectivas entre las que podemos trastear y escoger la más adecuada para nuestro tema de estudio. Se tratan de diferentes formas de mirar al mundo, de aproximarnos a una realidad concreta y de utilizar unas herramientas determinadas.

El diseño de una investigación es el que determina la metodología que debe utilizarse, así como la manera de enfocar los problemas y de buscar respuestas a los mismos (Taylor y Bogdan, 1992). La peculiaridad del campo, los acontecimientos inesperados, las situaciones particulares y otros elementos colaterales van a inferir en nuestra investigación. Ignorarlo u obviarlo sería una precipitación al vacío, el fracaso anunciado de un diseño metodológico. Por ello, el diseño de una investigación en el campo educativo es, y debe ser, flexible, emergente y cambiante, pues será el mismo campo el que nos irá redirigiendo y reconstruyendo el diseño previamente establecido por el investigador

\subsection{La investigación cualitativa}

La investigación cualitativa es mucho más que una alternativa a las investigaciones cuantitativas imperantes en el mundo académico. De hecho, su razón de ser reside en las necesidades metodológicas e interpretativas con las que, en su día, se encontraron los estudiosos de las ciencias sociales. Este tipo de investigación parte del supuesto básico de que el mundo social está construido de significados y símbolos (Jiménez-Domínguez, 2000), otorgándole a la intersubjetividad una papel protagonista para poder entender la compleja realidad del mundo social. Se recurre al texto como material empírico (en lugar del número), se parte de la construcción de realidades sociales y se focaliza en la perspectiva de los participantes, de las prácticas y del conocimiento cotidiano que hacen referencia al problema de estudio (Flick, 2015). Como bien indica Sandoval (2002), en investigación cualitativa se asume que el conocimiento es una creación compartida a partir de la interacción entre el investigador y el investigado, donde los valores median e influyen, por lo que es necesario "sumergirse en la realidad" estudiada para poder comprenderla tanto en su lógica interna como en su especificidad.

Denzin y Lincoln (2005) definen la investigación cualitativa como:

Conjunto de prácticas materiales interpretativas que hacen visible el mundo. Estas prácticas transforman el mundo. Lo convierten en una serie de representaciones, incluidas notas de campo, entrevistas, conversaciones, fotografias, grabaciones y memorandos personales. En este nivel, la investigación cualitativa implica un enfoque interpretativo, naturalista del mundo. ESo significa que los investigadores cualitativos estudian las cosas en su entorno natural intentando dar sentido a los fenómenos o interpretarlos desde el punto de vista de los significados que les dan las personas. (Denzin y Lincoln, 2005: 3)

Lo que suscita el inicio de una investigación (sea del tipo que sea), lo que mueve a un investigador a plantearse la posibilidad de arrancar un trabajo de este 
tipo, no es otra cosa que la voluntad o la intención de ir a la caza o búsqueda de respuestas que ayuden a resolver o explicar un determinado problema de investigación. En otras palabras, la intención o interés que yace en las entrañas de una investigación es la que determinará en qué paradigma o enfoque se sitúa el/la investigador/a y, por lo tanto, qué método debe utilizar. Dicho de otro modo, el paradigma es el sistema básico de creencias o visión del mundo que guía al investigador tanto a elegir el método como las formas fundamentales (Guba \& Lincoln, 2002).

En este sentido, Habermas (1986) distingue entre 3 tipos diferentes de intereses de investigación. En primer lugar encontramos el interés técnico, el cual daría origen al paradigma neo-positivista y se expresaría en las ciencias empíricoanalíticas de naturaleza esencialmente cuantitativa; en segundo lugar hablaríamos del interés práctico, dando origen a las ciencias histórico hermenéuticas de naturaleza cualitativa. Y por último, destacaríamos el interés emancipatorio, el cual daría lugar a ciencias socio-críticas que metodológicamente utilizan herramientas y procedimientos cualitativos que suelen complementar sus resultados con elementos cuantitativos. En la tesis aquí expuesta, nos situaremos en una vertiente investigadora a caballo entre el interés práctico y el emancipatorio. Nuestra investigación es de naturaleza cualitativa y busca explicar desde una racionalidad interpretativa la realidad de un contexto y una situación particular. No obstante, esta interpretación de la realidad es elaborada situando a las personas en el centro de la investigación, otorgándoles un papel protagonista en la toma de decisiones y determinaciones de la propia investigación.

Esta postulación de paradigma en función de los intereses investigadores, encaja perfectamente con el planteamiento de una gran variedad de autores que identifican la existencia 3 tipos de paradigmas en investigación educativa (Buendía, Colás y Hernández, 1997; Colás y Buendía, 1992; De Miguel, 1988; Del Rincón, Arnal, Latorre y Sans, 1995; Denzin \& Lincoln, 1998; Husen, 1988; Latorre, Del Rincón y Arnal, 1996; Sandín, 2010; Vallés, 1997):

- Perspectiva empírico- analítica, de base positivista-racionalista (paradigma positivista y postpositivista)

- Perspectiva humanístico-interpretativa, de base naturalistafenomenológica (paradigma interpretativo)

- Perspectiva crítica, basada en la tradición filosófica de la teoría crítica (paradigma sociocrítico).

Cada una de estas perspectivas se basa en unos fundamentos teóricos concretos, posee una finalidad de investigación distinta a las otras perspectivas, requiere un tipo de metodología concreta, etc. Ante esto, Sandín (2010) nos ofrece una síntesis de las características que otros autores (Latorre et al., 1996) plantean a estas 3 perspectivas de investigación: 


\begin{tabular}{|c|c|c|c|}
\hline \multirow[t]{2}{*}{ Dimensión } & \multicolumn{3}{|c|}{ Paradigma } \\
\hline & Positivista & Interpretativo & Sociocrítico \\
\hline Fundamentos & $\begin{array}{l}\text { Positivismo lógico. } \\
\text { Empirismo }\end{array}$ & $\begin{array}{c}\text { Fenomenología. Teoría } \\
\text { interpretativa. }\end{array}$ & Teoría crítica. \\
\hline $\begin{array}{l}\text { Naturaleza de la } \\
\text { realidad }\end{array}$ & $\begin{array}{l}\text { Objetiva, estática, única, } \\
\text { dada, fragmentable, } \\
\text { convergente. }\end{array}$ & $\begin{array}{l}\text { Dinámica, múltiple, } \\
\text { holística, construida, } \\
\text { divergente. }\end{array}$ & $\begin{array}{l}\text { Compartida, histórica, } \\
\text { construida, dinámica, } \\
\text { divergente. }\end{array}$ \\
\hline $\begin{array}{l}\text { Finalidad de la } \\
\text { investigación }\end{array}$ & $\begin{array}{l}\text { Explicar, predecir, } \\
\text { controlar los fenómenos, } \\
\text { verificar teorías. Leyes } \\
\text { para regular los } \\
\text { fenómenos. }\end{array}$ & $\begin{array}{l}\text { Comprender e interpretar la } \\
\text { realidad, los significados de } \\
\text { las personas, percepciones, } \\
\text { intenciones, acciones. }\end{array}$ & $\begin{array}{l}\text { Identificar potencial de } \\
\text { cambio, emancipar } \\
\text { sujetos. Analizar la } \\
\text { realidad. }\end{array}$ \\
\hline Relación sujeto/objeto & $\begin{array}{l}\text { Independencia. } \\
\text { Neutralidad. No se } \\
\text { afecta. Investigador } \\
\text { externo. Sujeto como } \\
\text { "objeto" de investigación. }\end{array}$ & $\begin{array}{l}\text { Dependencia. Se afectan. } \\
\text { Implicación investigador. } \\
\text { Interrelación. }\end{array}$ & $\begin{array}{l}\text { Relación influida por el } \\
\text { compromiso. El } \\
\text { investigador es un sujeto } \\
\text { más. }\end{array}$ \\
\hline Valores & $\begin{array}{c}\text { Neutros. Investigador } \\
\text { libre de valores. Método } \\
\text { es la garantía de } \\
\text { objetividad }\end{array}$ & $\begin{array}{l}\text { Explícitos. Influyen en la } \\
\text { investigación. }\end{array}$ & $\begin{array}{c}\text { Compartidos. Ideología } \\
\text { compartida. }\end{array}$ \\
\hline Teoría/práctica & $\begin{array}{c}\text { Disociadas, construyen } \\
\text { entidades distintas. La } \\
\text { teoría, norma para la } \\
\text { práctica }\end{array}$ & $\begin{array}{c}\text { Relacionadas. } \\
\text { Retroalimentación mutua. }\end{array}$ & $\begin{array}{c}\text { Indisociables. Relación } \\
\text { dialéctica. La práctica es } \\
\text { teoría en acción. }\end{array}$ \\
\hline Criterios de calidad & $\begin{array}{l}\text { Validez, fiabilidad, } \\
\text { objetividad. }\end{array}$ & $\begin{array}{l}\text { Credibilidad, confirmación, } \\
\text { transferibilidad. }\end{array}$ & $\begin{array}{l}\text { Intersubjetividad, } \\
\text { validez consensuada. }\end{array}$ \\
\hline $\begin{array}{l}\text { Técnicas: } \\
\text { instrumentos y } \\
\text { estrategias }\end{array}$ & $\begin{array}{l}\text { Cuantitativos, medición } \\
\text { de tests, cuestionario, } \\
\text { observación sistemática. } \\
\text { Experimentación. }\end{array}$ & $\begin{array}{l}\text { Cualitativos, descriptivos. } \\
\text { Investigador principal } \\
\text { instrumento. Perspectiva } \\
\text { participantes. }\end{array}$ & $\begin{array}{l}\text { Estudio de casos. } \\
\text { Técnicas dialécticas. }\end{array}$ \\
\hline Análisis de datos & $\begin{array}{l}\text { Cuantitativo: estadística } \\
\text { descriptiva e inferencial. }\end{array}$ & $\begin{array}{l}\text { Cualitativo: inducción } \\
\text { analítica, triangulación. }\end{array}$ & $\begin{array}{l}\text { Intersubjetivo. } \\
\text { Dialéctico. }\end{array}$ \\
\hline
\end{tabular}

Tabla 4. Perspectivas de investigación (Sandín, 2010:34)

Cuando nos planteamos una investigación en general, y en educación en particular, puede que ésta no se adapte a la perfección a una de las tres perspectivas planteadas, sino que posee elementos comunes a diversas perspectivas a la vez. La investigación aquí expuesta no es una excepción de ello, ya que responde a elementos mayoritariamente de un paradigma interpretativo, pero sin embargo, posee elementos comunes al sociocrítico. Esto, lejos de suponer un problema para el investigador, pone de manifiesto que las investigaciones están al servicio de las realidades que estudian y de los intereses que las subyacen. De hecho, eston nos lleva a considerar los paradigmas de investigación como complementarios entre sí, no como elementos excluyentes.

El investigador debe ubicar el paradigma donde se encuentra y desde ahí, desde ese punto, mirar al mundo (Denzin \& Lincoln, 2005). En nuestro caso, situamos nuestra investigación en un punto intermedio entre el paradigma interpretativo y el sociocrítico. Se trata de una investigación que no busca verificar ni hallar teorías, sino comprender la realidad estudiada y explicarla a través de un diálogo compartido con las personas, construyendo de manera conjunta el conocimiento científico.

Somos conscientes de la relación sujeto y objeto, y que se trata de una interrelación que ayuda a construir la realidad para comprenderla e interpretarla. 
Queremos indagar en las diversas perspectivas que poseen los participantes y respetarlas, no unificarlas, ni estandarizarlas, sino visibilizarlas y que ésta visibilización contribuya y retroalimente la realidad social y educativa que nos acontece.

Una vez situado en un marco de investigación interpretativo y sociocrítico de la realidad, profundizamos en cada uno de estos paradigmas para profundizar en las corrientes y escuelas que las componen desde las cuales resituar y enfocar nuestra investigación.

En primer lugar, tomamos como referencia el paradigma interpretativo, compuesta por tres corrientes fundamentales (Crotty, 1998):

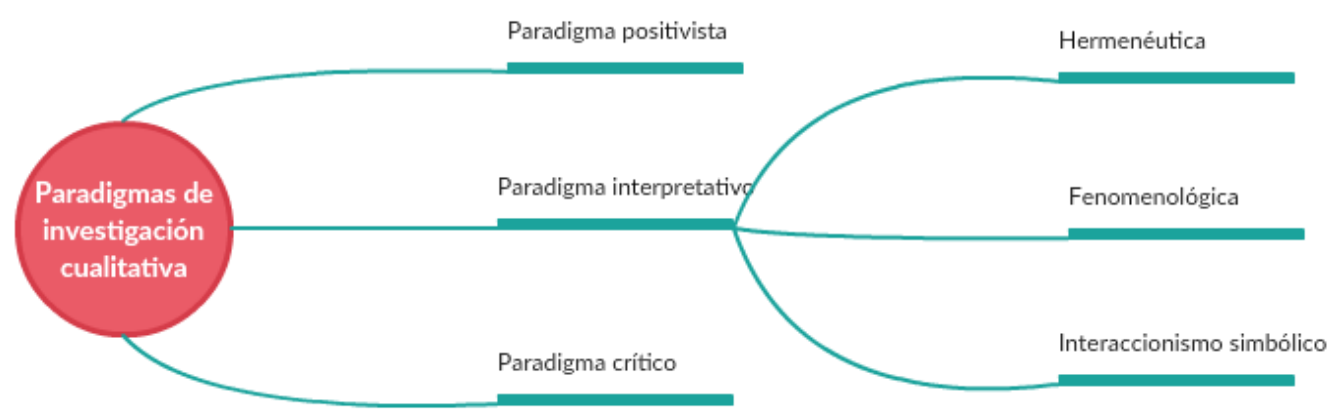

Figura 1. Esquema de los paradigmas de investigación cualitativa (elaboración propia)

Estas tres corrientes o enfoques corresponderían a su vez a las distintas formas de plantear o diseñar una investigación de tipo interpretativo. Hablaremos de una investigación proyectada desde una corriente hermenéutica cuando a través de ella busquemos fundamentar y legitimar aproximaciones interpretativas mediante métodos de investigación que se centren en la comprensión y el significado en contextos específicos. Así mismo, consideraremos que estamos ante una investigación de tipo fenomenológica cuando se establezca como base del conocimiento la experiencia subjetiva inmediata de los hechos tal y como son percibidos vinculándolo al término de 'intencionalidad' y 'conciencia'. Por último, consideraremos que una investigación pertenece a la corriente del interaccionismo simbólico, cuando ponemos de manifiesto que la experiencia humana está mediatizada por la interpretación que las personas realizan en interacción con el mundo social (Forner y Latorre, 1996). En el caso de ésta última, estamos hablando de una visión más pragmática de la investigación en contraposición con las dos corrientes anteriores, en la que el investigador debe situarse dentro del proceso de definición del actor para comprender su acción, mirando el mundo desde el ángulo de las personas que se estudian (Sandín, 2010).

Debemos ser capaces de tomar el rol de otros. Esta toma de rol es una 'interacción'. Es una interacción 'simbólica' porque es posible solo por los "símbolos significativos", esto es el lenguaje y otras herramientas simbólicas, que los seres humanos compartimos y a través de los cuales nos comunicamos. Solo a través del diálogo podemos ser consciente de las percepciones, sentimientos y 
actitudes de los demás e interpretar sus significados. De ahí el término interaccionismo simbólico. (Crotty, 1998: 75)

Es desde este interaccionismo simbólico desde donde nuestra investigación pretende acercarse al campo de estudio, y desde el que busca no solo conocer o recolectar hechos, sino situarse desde el punto de vista de cada uno de los y las participantes para interpretar la realidad y así analizar las diferentes situaciones y experiencias vividas por las personas. El interaccionismo simbólico, presenta además tres factores relevantes que deben considerarse en cuanto a la metodología de trabajo (Álvarez-Gayou, 2003). El primero de ellos es asumir que el único medio de conocer a los seres humanos y para detectar sus interacciones es mediante la investigación naturalista, es decir, estar en el lugar donde se presentan las interacciones. El segundo elemento consiste en la exploración inicial a cualquier realidad que se quiera estudiar, de esta manera se obtendrá un punto de partida desde el que indagar en el problema de estudio. El último y tercer elemento es la inspección, que señala más bien a un desarrollo teórico y de entramado de relaciones y conceptos que buscan dar respuestas a las preguntas y cuestiones que se generan acerca del material empírico recogido. Cada uno de estos elementos han sido tenidos en cuenta a la hora de plantear el diseño de esta investigación, pues como se verá más adelante (capítulos 4 y 5), la entrada en el campo, la exploración y reconocimiento del mismo y el análisis del material han sido elaborado en base a estos factores.

Tal y como ya hemos adelantado, esta investigación se nutre también de fundamentos propios del paradigma sociocrítico. Desde este planteamiento no solo se produce el conocimiento co-construido, sino que, además, la personas que investiga interviene de una manera más activa para genera una transformación en la realidad social (Guzmán-Valenzuela, 2014). Se trata de un enfoque que no pretende describir el mundo, sino cambiarlo comprendiendo las relaciones entre valor, interés y acción (Zabert, 2013).Según Popkewitz (1998, citado en Zabert, 2013) algunos de los principio de este paradigma son (a) conocer y comprender la realidad como praxis; (b) unir teoría y práctica, integrando conocimiento, acción y valores; (c) orientar el conocimiento hacia la emancipación y liberación del ser humano; y (d) proponer la integración de todos los participantes, incluyendo el investigador, en procesos de autorreflexión y de toma de decisiones consensuadas, las cuales se asumen de manera corresponsable.

Este paradigma, es el más reciente de los tres por lo que las nuevas corrientes que emergen del mismo poseen un carácter novedoso, con connotaciones vinculadas a la visión activa de las personas dentro de la sociedad y considerando la participación como elemento base. Se trata de un enfoque investigador de carácter más militante, de compromiso social y reflexión compartida que contribuye al cambio y a la transformación (y mejora) de la realidad actual.

Según González (2002), en el enfoque sociocrítico podemos distinguir tres formas básicas de investigación: la investigación-acción, la investigación colaborativa y la participativa. En nuestra investigación, a pesar de poseer pinceladas de cualquiera de estos enfoques de investigación, consideramos que estamos más cerca de un tipo de investigación colaborativa, en la que la esencia se encuentra en el principio de investigar en, con y para el otro (Jiménez y Vilà, 1999). A pesar de que la investigación colaborativa es una vertiente muy aplicada en educación (equipos de investigación colaborativa entre investigadores y docentes en activo), en nuestro caso es trasladado a un ámbito más personal. Establecemos 
relación colaborativa con la familia, concretamente con la madre de nuestro protagonista, y desde ahí construimos todo el proyecto de investigación. El trabajo colaborativo permitió no solo planificar el proceso en función de la realidad, sino también ajustar y solventar conflictos que se fueron produciendo a lo largo del mismo (Lozano y Alcaraz, 2010).

Cabe tener en cuenta aquí, que todas las corrientes o enfoques de investigación derivan de la necesidad de abordar ciertos métodos de investigación frente a otros, dando lugar a una amplísima variedad metodológica dentro de un mismo paradigma de investigación. La riqueza de la investigación cualitativa en cuanto a métodos y estrategias de investigación denotan la complejidad y alcance de este enfoque en el abordaje de la investigación socioeducativa y requiere que se ensayen clasificaciones o categorías que aporten un orden conceptual en el ámbito de investigación y permitan la comunicación en la comunidad investigadora (Sandín, 2003). Sin embargo, cuando se revisan los diversos manuales y textos especializados se observa una gran pluralidad de términos en la clasificación de tipologías, convirtiendo la elección del método o estrategia de investigación en una maraña conceptual desconcertante y de gran complejidad para todo investigador o investigadora.

Son muchos los autores que han planteado clasificaciones o categorías de los diferentes métodos de investigación buscando orientar los planteamientos de futuras investigaciones (Jacob, 1988; Patton, 1990; Cajide, 1992; Atkinson, Delamont \& Hammersley, 1988; Strauss \& Corbin, 1990; Tesch, 1990; Bartolomé, 1992; Denzin \& Lincoln, 1994; Morse, 1994; Rodríguez Gómez, Gil Flores y García Jiménez, 1996; Buendía et al., 1997; Mertens, 1998; Crotty, 1998), sin embargo las divergencias entre todas ellas convierten este proceso en un momento clave, enrevesado y complejo. Tras múltiples lecturas, y teniendo en cuenta la revisión sobre este tema que ya expuso Sandín (2003) en su trabajo, presentamos una tablaresumen de algunas de las posibles clasificaciones que ofrecen diversos autores sobre los métodos de investigación: 


\begin{tabular}{|c|c|c|c|c|c|c|c|}
\hline Jacob (1988) & $\begin{array}{c}\text { Strauss y Corbin } \\
(1990)\end{array}$ & Bartolomé (1992) & $\begin{array}{c}\text { Buendía et. al } \\
\text { (1997) }\end{array}$ & Crotty (1998) & $\begin{array}{c}\text { Denzin y Lincoln } \\
(2005)\end{array}$ & Tójar (2006) & $\begin{array}{c}\text { Hernández et al. } \\
(2006)\end{array}$ \\
\hline $\begin{array}{l}\text { Etología } \\
\text { humana }\end{array}$ & $\begin{array}{c}\text { Teoría } \\
\text { fundamentada }\end{array}$ & Etnometodología & $\begin{array}{l}\text { Fenomenología } \\
\text { hermenéutica }\end{array}$ & Biografía & Estudio de casos & \multirow{3}{*}{ 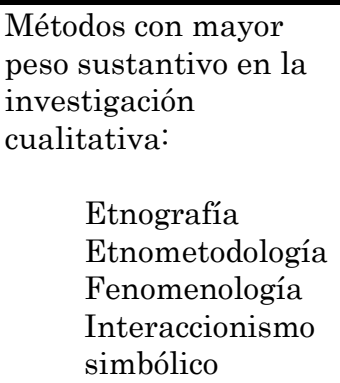 } & $\begin{array}{c}\text { Diseños } \\
\text { etnográficos }\end{array}$ \\
\hline $\begin{array}{l}\text { Psicología } \\
\text { holística }\end{array}$ & Etnografía & Fenomenografía & Etnografía & Fenomenología & $\begin{array}{l}\text { Etnografía, } \\
\text { observación } \\
\text { participante, } \\
\text { etnografía } \\
\text { performativa }\end{array}$ & & $\begin{array}{c}\text { Diseños } \\
\text { fenomenológicos }\end{array}$ \\
\hline $\begin{array}{l}\text { Antropología } \\
\text { cognitiva }\end{array}$ & Fenomenología & Fenomenología & $\begin{array}{l}\text { Interaccionismo } \\
\text { simbólico }\end{array}$ & $\begin{array}{c}\text { Teoría } \\
\text { fundamentada }\end{array}$ & $\begin{array}{l}\text { Fenomenología, } \\
\text { etnometodología }\end{array}$ & & $\begin{array}{l}\text { Diseños de } \\
\text { investigación- } \\
\text { acción }\end{array}$ \\
\hline $\begin{array}{l}\text { Etnografía de } \\
\text { la comunicación }\end{array}$ & \multirow[t]{5}{*}{$\begin{array}{c}\text { Análisis } \\
\text { conversacional }\end{array}$} & $\begin{array}{l}\text { Interaccionismo } \\
\text { simbólico }\end{array}$ & \multirow[t]{5}{*}{ Etnometodología } & Etnografía & $\begin{array}{l}\text { Historias de } \\
\text { vida, } \\
\text { testimonios }\end{array}$ & $\begin{array}{l}\text { Investigación } \\
\text { acción } \\
\text { Estudio de caso } \\
\text { Teoría } \\
\text { fundamentada }\end{array}$ & $\begin{array}{c}\text { Diseños } \\
\text { narrativos }\end{array}$ \\
\hline \multirow[t]{4}{*}{$\begin{array}{l}\text { Interaccionismo } \\
\text { simbólico }\end{array}$} & & Etnografía & & \multirow[t]{4}{*}{$\begin{array}{l}\text { Estudio de } \\
\text { casos }\end{array}$} & $\begin{array}{l}\text { Métodos } \\
\text { históricos }\end{array}$ & \multirow{4}{*}{$\begin{array}{l}\text { Métodos menos } \\
\text { característicos pero } \\
\text { relevantes en la } \\
\text { investigación } \\
\text { cualitativa: } \\
\\
\text { Hermenéutica } \\
\text { Psicología } \\
\text { ecológica } \\
\text { Psicología } \\
\text { humanista } \\
\text { Investigación } \\
\text { histórica } \\
\text { Investigación } \\
\text { heurística } \\
\text { Fenomenografía }\end{array}$} & \multirow[t]{4}{*}{$\begin{array}{l}\text { Diseños de teoría } \\
\text { fundamentada }\end{array}$} \\
\hline & & $\begin{array}{l}\text { Estudio de } \\
\quad \text { casos }\end{array}$ & & & $\begin{array}{l}\text { Investigación- } \\
\text { acción, } \\
\text { investigación } \\
\text { aplicada }\end{array}$ & & \\
\hline & & $\begin{array}{l}\text { Investigación } \\
\text { evaluativa }\end{array}$ & & & $\begin{array}{l}\text { Investigación } \\
\text { clínica }\end{array}$ & & \\
\hline & & $\begin{array}{l}\text { Investigación- } \\
\text { acción }\end{array}$ & & & & & \\
\hline
\end{tabular}

Tabla 5. Clasificación de métodos de investigación (elaboración propia) 
Ésta es tan solo una leve pincelada de la variedad terminológica y conceptual que podemos encontrar en la literatura. Como vemos, no resulta fácil definir con claridad qué tipo de método vamos a utilizar en nuestra investigación, por qué, y cómo discriminarlo del resto. Es más, las distintas estrategias de investigación no son precisas en su límite respecto a otras, pues puede darse el caso de utilizar los mismos instrumentos de recogida de datos y/o estrategias de análisis en métodos de indagación distintos.

En nuestro caso, pretendemos llevar a cabo un estudio basado en el método biográfico narrativo y acabar generando como resultado una 'historia de vida', 'relato' o 'biografía' (según el autor que se tome por referencia). Veamos a continuación qué se entiende por método biográfico narrativo, qué elementos lo conforman y las distintas variantes del mismo.

\subsection{El método biográfico narrativo}

A pesar de que el método biográfico narrativo se originó en los años 20, sigue siendo un método sobre el que existe una nube terminológica bastante confusa. Las múltiples y diversas interpretaciones en cuanto al enfoque en la investigación y los términos que lo definen, hacen de él un método sobre el que todo investigador debe plantearse (1) si conviene o no para el tipo de investigación a realizar y (2) cómo se lleva a cabo. En la misma literatura, según los autores que tomemos como referencia, podemos encontrar diferentes términos para referirse a lo mismo, o incluso conceptos que son entendidos de distinta manera según el autor/a que lo utiliza.

Con la finalidad de aportar nuestro humilde granito de arena a este campo y como base conceptual sobre la que se sustenta esta investigación, haremos un breve repaso sobre el origen de este método, cómo se define según diferentes autores y cómo se puede llevar a la práctica.

\subsubsection{Origen y delimitación terminológica}

En el campo de la investigación, concretamente en la investigación a través de relatos y narraciones, se utilizan términos como narrativa, biografías, investigación biográfica, método biográfico narrativo,... Como vemos, términos aparentemente similares y sobre los que consideramos necesario profundizar y recabar matizaciones.

Según Bertaux, (2005), se considera que existe relato de vida desde el momento que una persona cuenta a otra (investigador o no) un episodio cualquiera de su vida, pues el verbo "narrar" significa que la producción discursiva del sujeto ha adoptado forma de 'narrativa'. Sin embargo, narrativa o método biográfico narrativo puede significar muchas cosas según el punto de vista que tomemos como referencia.

En este sentido, Bolívar, Domingo y Fernández (2001) realizan una aportación con la que pretenden esclarecer algunos de estos conceptos. En su trabajo, estos autores establecen una clara diferencia entre narrativa, investigación narrativa y uso de la narrativa. Para Bolívar et a. (2001) la narrativa es entendida como el relato oral o escrito en sí mismo, la investigación narrativa se entiende como el modo de recordar, elicitar, construir y reconstruir el pasado, y el uso de la narrativa como el dispositivo usado para promover cambios en la práctica a través 
de relatos previamente elaborados. Sin embargo, estos mismos autores exponen un doble sentido de la investigación narrativa, pues a la vez que es el modo de recordar y reconstruir el pasado es también un modo específico de análisis y descripción de datos en forma de relato. Todos estos y otros muchos términos y elementos, acaban englobándose en una categoría más amplia y general, un extenso conjunto de modos de obtener y analizar relatos de vida, estamos ante el denominado método biográfico narrativo.

El método biográfico narrativo es desde donde se plantea y desarrolla esta investigación. Estamos ante nuestro marco de trabajo, nuestro referente desde el que ir adentrándonos poco a poco en un proceso indagador que acabe dando forma al resultado final esperado: la historia de vida de Sergi. Desde el primer momento en el que nos planteamos utilizar el método biográfico narrativo, fuimos conscientes de la confusión terminológica que siempre ha fluctuado sobre este método y de las dificultades de delimitación conceptual con las que nos íbamos a encontrar. No obstante, optamos por hacer una profunda revisión de la literatura que nos ayudara a entender el método en todas sus versiones y poder establecer de esta manera nuestro plan o modus operandis.

Si nos remontamos a los orígenes de este método para poder entenderlo desde su aparición, debemos remontarnos al año 1920. Según autores como Pujadas (1992), éste método emergió mediante el tercer y último volumen de The Polish Peasant de Thomas y Znaniecki. Fue entonces cuando, por primera vez, empezó a utilizarse un término muy vinculado a este método: el término life history. En aquel entonces, por life history se entendía tanto la narrativa vital de la persona como la versión final elaborada a partir de la narrativa inicial, es decir, el producto resultante. Fue más tarde cuando a este término se le añadieron otros que buscaban concretar y puntualizar el primero. De esta manera apareció el concepto life story para referirse ahora a aquellas narraciones biográficas que se publicaban sin retocar, conservando incluso las peculiaridades lingüísticas de la persona.

A partir de esta época etnógrafos, periodistas, antropólogos y sociólogos fueron adoptando (y adaptando) este método a sus estudios como una estrategia de indagación, consiguiendo así aportar a sus trabajos un carácter biográfico mediante el que se buscaban las respuestas en las vivencias personales de otros. Se puede presuponer, que al ser un método de estudio abordado desde diferentes campos y escuelas, la variación conceptual y teórica que se ha generado es bastante amplia y confusa. Esto, lejos de facilitar el trabajo del investigador, acaba provocando una especie de pánico inicial por no entender qué matices o diferencias existen entre unos términos y otros. Todo parece referirse a lo mismo de maneras distintas, pero si indagamos un poco más en la literatura descubrimos que la definición de cada uno de ellos está clara, pero será distinta según el autor que tomemos como referencia.

\subsubsection{Narrativas, biografías, historias, relatos... ¿Es lo mismo dicho de otra manera?}

El método biográfico narrativo, además de poseer un amplio abanico de posibilidades en cuanto a técnicas y estrategias metodológicas se refiere, puede dar lugar a investigaciones bien distintas según la corriente o escuela sobre la que sustenten los principios del estudio. Consideramos que no es objeto de este trabajo repasar las diferentes corrientes acontecidas desde la aparición de los primeros 
estudios biográficos en 1920 y en los distintos puntos de la geografía mundial. Consideramos más interesante para el lector presentar una buena delimitación terminológica entre lo que es y no es una historia de vida y otros términos relativos a este.

Cabe introducir en primer lugar, que sean cuales sean las pretensiones del investigador éste puede trabajar desde el método biográfico narrativo como un método en sí mismo o, por el contrario, como una técnica o combinación de técnicas al servicio de otro tipo de métodos de indagación. La versatilidad y flexibilidad de este método y sus estrategias metodológicas, consiguen una perfecta articulación entre las fuentes orales y las documentales personales que otros métodos no pueden ofrecer. En definitiva, se trata de un método muy atractivo para el investigador cualitativo, pues posee, en primer lugar, la virtud de captar los mecanismos que subyacen a los procesos que utilizan los individuos para dar sentido y significación a sus propias vidas, y en segundo lugar, permite un análisis descriptivo, interpretativo, sistemático y crítico de los documentos de 'vida' (Sanz, 2005).

Uno de los conceptos que se interpreta de forma más genérica en este campo es el término narrativa. Por narrativa entendemos una forma particular de reconstrucción de la experiencia en la que, mediante un proceso reflexivo, se pasa del plano de la acción al del lenguaje, dotando de significado, a lo sucedido o vivido (Bolívar et al. 2001). De esta manera, narrativa y lenguaje se requieren el uno al otro para dar lugar a los distintos tipos relatos narrativos en los que la temporalidad acaba convirtiéndose en un elemento fundamental. De esta manera, la narrativa dará lugar a un tipo de relato u otro según el procedimiento reflexivo seguido durante el proceso de construcción del mismo.

Los tipos de relatos narrativos más extendidos y comunes entre los lectores son la autobiografía y la biografía. En su trabajo, Bolívar et al. (2001) concibe la autobiografía como la narración escrita (u oral) que uno mismo hace de su propia vida en la que autor, narrador y personaje coinciden, mientras que una biografía está elaborada por una persona distinta a la biografiada, de manera que narrador y personaje no coinciden. En esta misma línea, Denzin (1989) ya apuntaba en su trabajo la diferencia entre life-story (relato de vida, narración autobiográfica o autobiografía) entendida como narraciones realizadas por el propio protagonista, contadas con sus propias palabras, pudiendo ser más o menos amplias en cuanto a su extensión, etapas o aspectos concretos de su vida, y life- history (historias de vida, biografías) que son más bien reconstrucciones narradas de la vida de alguna persona realizadas por un investigador o biógrafo y en las que se suele contar con el recuerdo además de otras técnicas (documentos, entrevista a otras personas,...) para su elaboración.

Esta distinción se corrobora en trabajos posteriores como los de Goodson (1996, citado en Bolívar et al., 2001) y De Garay (2001, citado en Álvarez-Gayou, 2006), quienes distinguen también entre life-story o relatos de vida (relato inicial que una persona hace de su vida y en el que la subjetividad del investigador puede estar presente en la edición del texto) y life-history o historia de vida (relato triangulado, siendo un punto del trípode el propio life-story o relato de vida, complementado con los testimonios de otras personas, fuentes documentales, transcripciones o archivos relacionados y en el que el investigador se vuelve más presente en las interacciones que hace al conjuntar los datos de diversas fuentes). 
Sin embargo, Pennef (1990) concibe estos términos de manera distinta. Este autor entiende la historia de vida como una entrevista libre en la que un locutor evoca el pasado sin una dirección precisa y sin elaboración previa y una autobiografía como aquellos relatos trabajados y construidos según un esquema preestablecido en base a una secuencia lógica y cronológica, en definitiva, relatos que resultan del trabajo investigador propiamente dicho.

En nuestro contexto, Pujadas (1992), basándose en los dos conceptos originales del método elaboró una nueva propuesta. Propuso que al llevar estos términos a nuestro contexto se hiciera utilizando el término relato de vida para aludir al término life story (récit de vie en francés) e historia de vida para referirse a life history (historie de vie en francés). Este mismo autor, aporta matices a estos dos conceptos originales planteados por los autores anglosajones. Por un lado, entiende que historia de vida hace referencia a un relato autobiográfico obtenido por el investigador mediante entrevistas sucesivas, a través de las que pretende mostrar el testimonio subjetivo de una persona en la que se recojan tanto los acontecimientos como las valoraciones que dicha persona hace de su propia vivencia. Asimismo, este autor se refiere a la autobiografía para hacer referencia a las narrativas realizadas por la propia iniciativa de una persona, a partir de unas motivaciones personales y cuyo sistema de elaboración es totalmente desconocido. No obstante, se propone un tercer tipo de estructura narrativa, la biografía, entendida como un relato objetivo construido por el investigador a partir de las evidencias e información disponible (exista o no una narración previa de la persona).

Como podemos observar, aunque los términos sean los mismos o muy similares, el sentido que se le otorga a uno y otro cambia en función del autor o autores que tomemos como referencia. En nuestro caso, y con el ánimo de tomar un punto de partida, nos situamos en lo que originalmente Denzin (1989) planteó como historia de vida o life-story, pues estamos ante un trabajo en el que el investigador ejerce un rol activo y reflexivo, en el que busca construir y reconstruir la vida de una persona a partir de los datos aportados por múltiples técnicas y fuentes orales y documentales.

Una vez llegado a este punto, y habiendo establecido la historia de vida (biografía para algunos autores) como eje central de nuestra investigación, nos planteamos el tipo de relato que queremos construir. Para ello tomamos en consideración los diferentes tipos de relatos o biografías propuestos por Pujadas (1992):

- Relato biográfico de caso único: el grado de información y la significatividad de la misma dependerá de la posición de cercanía que el investigador tenga con el/la protagonista de la historia de vida registrada, generalmente utilizado como estrategia de arranque de una investigación más amplia.

- Relatos biográfico paralelos: procedimiento para realizar estudios en unidades sociales amplias. En este tipo de trabajos, conviene acumular una muestra amplia de relatos biográficos para realizar comparaciones, categorizaciones, establecer hipótesis teóricas,... en definitiva, establecer generalizaciones sobre un ámbito de estudio concreto. 
- Relatos biográficos cruzados: es la aplicación del método desde una perspectiva multicéntrica pero referida a un solo objeto. El procedimiento consiste en hacer converger los relatos de experiencias personales hacia un punto central de interés, hacia un tema común, del que todas las personas han sido a la vez protagonistas y observadores externos. En cuanto a este tipo de relato, Pujadas (1992) menciona la aportación de June Nash (1974) a través de una estructura de relato polifónico. En este ejemplo, se recoge mediante el método biográfico el punto de vista de dos generaciones y de ambos sexos, dando lugar a una narración central basada en la singularidad y relevancia de uno de ellos y, a la cual, el resto de participantes enriquecen el relato original mediante sus aportaciones. Como bien indica el autor, estaríamos ante una melodía creada por el personaje central y a la que se le añade la armonía, el contrapunto y la fuga mediante la aportación del resto de participantes.

En el caso de esta tesis doctoral, aplicamos el método biográfico narrativo con la finalidad de construir la historia de vida de Sergi mediante los relatos biográficos de tipo cruzado. A través de la voz de diferentes familiares, compañeros y compañeras y docentes de Sergi se construye su historia de vida. En este tipo de trabajo, la polifonía de voces se convierte en un elemento clave, pues a través de ella nos aproximamos al centro de interés de esta investigación (la trayectoria vital de Sergi) desde diferentes perspectivas y enfoques para lograr una construcción lo más cercana a la realidad posible.

\subsubsection{El cómo del método biográfico}

Para poder plantear y diseñar la investigación aquí expuesta fue necesario, en primer lugar, indagar en el cómo del método: cómo se materializa en acciones, cómo se realiza la recogida de datos, cómo se construye una historia de vida a partir de este método,... Para ello, recurrimos a la literatura y detectamos que existen diferentes tipos de estudios narrativos en función de sobre qué versan las historias de vida. En su propuesta, Creswell (2005) diferencia entre: (a) la historia de vida completa de una persona o grupos, (b) una época de dicha historia de vida o (c) uno o varios episodios. En este último tipo de estudio narrativo, el investigador utiliza dichos episodios para analizar cuestiones como la historia, los acontecimientos, el ambiente, los hechos, las interacciones, la secuencia de eventos, los resultados,... y posteriormente reconstruir la cadena de sucesos y describir e identificar las categorías y temas emergentes de los datos narrativos (Salgado, 2007). Paralelamente a esta clasificación, Mertens (2005) establece que, según a qué elementos van enfocados, los estudios narrativos pueden clasificarse en: (a) estudios narrativos de tópicos (cuando se centran en una temática, suceso o fenómeno), (b) estudios narrativos biográficos (cuando versan sobre una persona, grupo o comunidad y en el estudio no se incluye la narración de los participantes "en vivo" porque fallecieron, porque no tienen el recuerdo debido a la avanzada edad o enfermedad o porque son inaccesibles) y (c) estudios narrativos autobiográficos (son aquellos que versan sobre una persona, grupo o comunidad pero sí que incluye los testimonios orales "en vivo" de los participantes).

En nuestro caso, y tomando como referencia estas clasificaciones, podemos decir que el tipo de estudio narrativo que realizamos en esta tesis doctoral versa sobre la vida completa de una persona (Creswell, 2005) a través de los testimonios 
orales "en vivo" de los participantes (estudio narrativo autobiográfico propuesto por Mertens, (2005)). Sin embargo, hemos detectado en la literatura especializada en el método biográfico narrativo que existen múltiples enfoques para la realización de estos estudios. El resultado de la investigación será bien distinto según el modelo de construcción de historia de vida, la modalidad de recogida de datos y los instrumentos y técnicas utilizado para ello.

\subsubsection{Modalidades, técnicas e instrumentos de recogida de datos}

Antes de plantearnos construir una historia de vida (relato o biografía) y el procedimiento que vamos a seguir para ello, debemos preguntarnos cómo vamos a obtener la información necesaria para después elaborar esa historia final. La primera cuestión que debemos tratar en cuanto a esto es la modalidad de recogida de datos, pues ésta puede ser directa o indirecta (Vieytes, 2004). La recogida de datos indirecta estaría ligada a la utilización de documentos e información recopilada por otros investigadores (archivos orales, visuales o escritos), mientras que la recopilación directa supondría el empleo de fuentes vivas que ofrecen su testimonio en primera persona.

Esta recogida de datos, se concreta en el campo en la utilización de unos u otros instrumentos de recogida de datos. Al igual que sucede con los términos y conceptos teóricos de este método, son muy diversas y variadas las clasificaciones en cuanto a técnicas e instrumentos que podemos encontrar en la literatura. Por un lado, Smith (1994) nos plantea como posibles técnicas: diarios, memorias, perfiles, esbozos, retratos, representaciones gráficas, biografías, autobiografías y prosopografías (descripción de un personaje) o biografías de grupos. En la misma línea, Clandinin y Connely (1994) proponen instrumentos como: historia oral, anal y crónica, historias/relatos de familias, fotografías, memorias y recuerdos personales, entrevistas, diarios, escritos autobiográficos, cartas, conversaciones, notas de campo e historias de campo. Por su parte, Bolívar et al. (2001) proponen instrumentos de recogida de información como la entrevista, los incidentes críticos, el biograma, la trayectoria de vida, los diarios autobiográficos y la carpeta de aprendizaje.

Con respecto a la recogida de datos, encontraremos en el siguiente capítulo una exposición detallada de qué instrumentos y de qué manera los hemos adaptado para utilizarnos en nuestra investigación. No obstante, creemos necesario adelantar que dicha recogida de datos ha sido realizada principalmente mediante una modalidad directa a través de la voz de los distintos participantes, cuyos datos y se han complementando mediante fotografías, documentos y otras técnicas proyectivas.

\subsubsection{Modelos de construcción de historias de vida}

Tras realizar la recogida de los datos pertinentes, cabe distinguir el cómo se quiere construir la historia de vida en sí, pues según el enfoque llevado a cabo en el momento de la (re)construcción, el resultado será bien distinto. Como ya hemos visto anteriormente, una historia de vida o biografía se realiza con la intención de contar o narrar la historia de una persona o grupo más allá de los acontecimientos sucedidos. En nuestro estudio en concreto, los giros en la historia, lo que hay detrás de ellos, los 'porqués' de lo sucedido, las causas y las consecuencias de unos y otros hechos de la trayectoria vital toman especial relevancia en la construcción de la historia. 
En este sentido, autores como McKernan (1999), plantean modalidades de historia de vida según el proceso de construcción de la misma: completas, temáticas y editadas. Para este autor, las historias de vida completas son aquellas que abarcan toda la trayectoria vital o carrera profesional del individuo, mientras que las temáticas se ciñen más a la investigación a fondo sobre un tema, un asunto o periodo particular de la vida de una persona. Un tercer tipo de de historias de vida son las editadas, que pueden ser completas o temáticas, pero su característica distintiva es que combina la narración de la historia junto con comentarios, explicaciones y narraciones de otras personas que no son el protagonista de la biografía

Paralelamente, Connick y Gordard (1998) plantean la existencia de diversas formas temporales de causalidad a partir de los cuales se acaban derivando diferentes modelos de construcción de historia de vida. Según estos autores cabe distinguir entre:

- Modelo arqueológico: se busca un punto de inicio, un origen a partir del que desarrollar la biografía de la persona.

- Modelo procesual o de trayectorias: se centra en estudiar el proceso en sí mismo y en cómo se van desencadenando los acontecimientos en la vida de una persona, buscando determinar los elementos causales que intervienen en cada secuencia biográfica.

- Modelo estructural: Observa las temporalidades externas sobre las que estructurar la biografía, entendiendo por esas temporalidades elementos coyunturales, históricos o contextuales que pueden marcar la propia historia de vida.

En nuestra investigación, utilizaremos una modalidad de historia de vida editada (combinando las narraciones con otros comentarios y explicaciones), desde un modelo procesual de construcción de historia de vida (que explica cómo se van sucediendo los acontecimientos), pues esta es la forma más adecuada de resolver a nuestro objetivo y preguntas de investigación plantados en el siguiente capítulo.

No obstante, consideramos que independientemente del modelo de construcción de historia de vida escogido por el biógrafo o investigador, la historia de vida nunca debe llevarse a cabo desde una lógica individualista y alejada del protagonista y su realidad, sino que tal y como se aborda en otros puntos de este capítulo, la construcción debe ser compartida y horizontal, garantizando así la veracidad la narración y respetando los postulados básicos de este método.

\subsubsection{Producto final: ¿relato o historia de vida?}

Tal y como ya hemos adelantado, existe una gran variación terminológica en cuanto al producto o resultado que se puede obtener a través del método biográfico narrativo: biografía, relato de vida, historia de vida, autobiografía,... No vamos a abordar de nuevo la diferencia que existe entre uno y otro según los diferentes autores, sino simplemente nos posicionaremos respecto a cómo vamos a denominar nuestro producto y resultado final. 
Como venimos observando a lo largo de este capítulo, la variedad terminológica en cuanto a este método es muy extensa y esto, además de generar ciertos miedos al investigador, requiere de una buena delimitación conceptual para poder después generar un buen diseño de investigación. En nuestro caso, ya hemos afirmado que nos posicionábamos en la concepción clásica de historia de vida aportada por Denzin (1989), y que además, según lo expuesto por McKernan (1999), tendrá un carácter editado en el que se combina la narración de la persona protagonista con otras narraciones y explicaciones de otros participantes (concepto de polifonía de voces planteado por Pujadas, 1992). Por lo tanto, el término utilizado para referirnos al resultado y producto generado a partir del método biográfico narrativo será el de historia de vida.

Finalmente, con la pretensión de resituar al lector expondremos en la siguiente tabla las diferentes modalidades, tipologías y clasificaciones desarrolladas en cuanto al método biográfico narrativo. 


\begin{tabular}{|c|c|c|c|c|c|c|c|c|}
\hline \multirow{2}{*}{\multicolumn{2}{|c|}{$\begin{array}{l}\text { Tipos de estudios narrativos } \\
\begin{array}{c}\text { Creswell Mertens (2005) } \\
\text { (2005) }\end{array}\end{array}$}} & \multirow{2}{*}{$\begin{array}{c}\begin{array}{c}\text { Modalidad de } \\
\text { recopilación } \\
\text { de datos }\end{array} \\
\text { Vieytes (2004) }\end{array}$} & \multicolumn{3}{|c|}{$\begin{array}{l}\text { Tipos de instrumentos de recogida de información del } \\
\text { método }\end{array}$} & \multirow{2}{*}{$\begin{array}{c}\text { Modalidades de } \\
\text { enfoque en la } \\
\text { construcción de } \\
\text { la narración } \\
\text { Connick y } \\
\text { Gordard (1998) }\end{array}$} & \multicolumn{2}{|c|}{$\begin{array}{l}\text { Tipos de productos o resultados } \\
\text { del método }\end{array}$} \\
\hline & & & Smith (1994) & $\begin{array}{c}\text { Clandinin y } \\
\text { Connely (1994) }\end{array}$ & $\begin{array}{l}\text { Bolívar et. al } \\
\text { (2001) }\end{array}$ & & $\begin{array}{l}\text { Denzin (1998), De } \\
\text { Garay (2001) } \\
\text { Goodson (1996) y } \\
\text { Bolívar et al. } \\
\text { (2001) } \\
\end{array}$ & $\begin{array}{c}\text { McKernan } \\
\text { (1999) }\end{array}$ \\
\hline $\begin{array}{l}\text { Vida } \\
\text { completa }\end{array}$ & De tópicos & Indirecta & Diarios & $\begin{array}{l}\text { Historia oral, } \\
\text { anal y crónica }\end{array}$ & Entrevista & Arqueológico & Relatos de vida & $\begin{array}{l}\text { Historias } \\
\text { de vida } \\
\text { completas }\end{array}$ \\
\hline $\begin{array}{l}\text { Una época } \\
\text { de la vida }\end{array}$ & Biográficos & Directa & Memorias & $\begin{array}{l}\text { Historias/relatos } \\
\text { de familias }\end{array}$ & $\begin{array}{l}\text { Incidentes } \\
\text { críticos }\end{array}$ & Procesual & Historias de vida & $\begin{array}{l}\text { Historias } \\
\text { de vida } \\
\text { temáticas }\end{array}$ \\
\hline \multirow[t]{9}{*}{$\begin{array}{c}\text { Uno o } \\
\text { varios } \\
\text { episodios }\end{array}$} & Autobiográficos & & Perfiles & Fotografías & Biograma & Estructural & & $\begin{array}{l}\text { Historias } \\
\text { de vida } \\
\text { editadas }\end{array}$ \\
\hline & & & Esbozos & $\begin{array}{c}\text { Memorias y } \\
\text { recuerdos } \\
\text { personales }\end{array}$ & $\begin{array}{l}\text { Trayectoria de } \\
\text { vida }\end{array}$ & & & \\
\hline & & & Retratos & Entrevistas & $\begin{array}{c}\text { Diarios } \\
\text { autobiográficos }\end{array}$ & & & \\
\hline & & & $\begin{array}{l}\text { Representacion } \\
\text { es gráficas }\end{array}$ & Diarios & $\begin{array}{l}\text { Carpeta de } \\
\text { aprendizaje }\end{array}$ & & & \\
\hline & & & Biografías & $\begin{array}{c}\text { Escritos } \\
\text { autobiográficos }\end{array}$ & & & & \\
\hline & & & Autobiografías & Cartas & & & & \\
\hline & & & $\begin{array}{l}\text { Prosopografías } \\
\text { (descripción de } \\
\text { un personaje) }\end{array}$ & Conversaciones & & & & \\
\hline & & & $\begin{array}{l}\text { Biografías de } \\
\text { grupos }\end{array}$ & Notas de campo & & & & \\
\hline & & & & $\begin{array}{l}\text { Historias de } \\
\text { campo }\end{array}$ & & & & \\
\hline
\end{tabular}

Tabla 6. Modalidades, tipologías y clasificaciones del método biográfico narrativo (elaboración propia) 
Estos son nuestros referentes teóricos y metodológicos para el diseño de nuestra investigación y desde los cuales construiremos la historia de vida de Sergi. No obstante, antes de adentrarnos en este diseño consideramos necesario hacer un paréntesis y exponer brevemente las consideraciones éticas propias de este estudio.

\subsubsection{Consideraciones éticas del método}

Un investigador en el ámbito de las ciencias sociales debe ser consciente de que está indagando principalmente sobre la condición humana y su naturaleza. Esto significa, que se construye el conocimiento mientras se tiene en cuenta la complejidad, la ambigüedad, la flexibilidad, la singularidad, la pluralidad, lo contingente, lo histórico, lo contradictorio y lo afectivo, entre otros, de la subjetividad del ser humano y su carácter social (González, 2002). Estamos, por tanto, ante un campo de estudio en el que ciertas valoraciones o estimaciones éticas son condiciones sine qua non de la calidad del propio proceso de investigación.

La ética y la calidad en la investigación cualitativa poseen una gran vinculación que, según Flick (2014), puede entenderse desde tres puntos de vista diferentes. El primero de ellos es considerar que la calidad es una condición previa para una investigación éticamente sólida, pues solo si se trata de un estudio de calidad valdrá la pena que las personas participantes se impliquen en ella y revelen su intimidad, de hecho, el caso contrario no sería ético. Un segundo punto de vista sobre la relación entre calidad y ética yace en concebir que los problemas éticos como la protección de datos, respeto a la intimidad,...son un rasgo distintivo de calidad de la investigación. De esta forma, una reflexión ética sobre el proceso de investigación desarrollado garantiza de alguna manera una investigación cualitativa de calidad y respetuosa con el marco social que le acontece. Por último, un tercer punto de vista sería la consideración sobre cómo ciertos estándares de calidad afectan a los planteamientos éticos. Es decir, el investigador debe hacer balance en el caso de que exista conflicto entre los planteamientos metodológicos y las preocupaciones éticas, pues investigaciones sobre ciertas sensibilidades de nuestra sociedad pueden resultar hirientes para los participantes de la misma (p.e. personas con enfermedades terminales, trayectorias personales duras que resulten dolorosas de recordar,...).

La ética en sí misma, es un elemento intrínseco a las investigaciones cualitativas, pues más allá de la simple moralidad, se considera un criterio de calidad en sí mismo. Por esta razón, en el presente apartado focalizaremos nuestra atención en aquellos elementos éticos sobre los que se ha reflexionado en este estudio y a través de los cuales se pretende no solo acercarnos a un modelo de investigación de calidad, sino también a una investigación basada en valores sociales de respeto y tolerancia hacia los participantes, el entorno y sus circunstancias.

La ética de investigación debe estar al servicio de los investigados y debe estar ser basada en el cuidado y responsabilidad, siendo horizontal y comunitaria (Denzin \& Lincoln, 2012). De hecho, la reflexión sobre la ética es relevante tanto en el campo como cuando se está preparando una propuesta de actuación, y debe desempeñar un papel fundamental sobre las consideraciones en relación a cómo planificar un estudio sobre las personas con las que se quiera trabajar y sobre el modo en que vamos a actuar en el campo (Flick, 2015). 
La ética más que dar soluciones plantea problemas y conflictos morales al investigador que deben ser resueltos para lograr una construcción del conocimiento fiable y consistente, pues su abandono o falta de atención podrían suponer verdaderos problemas tanto para el investigador como para quienes son investigados (Eisner, 1990). Los dilemas éticos del investigador surgen cuando en un mismo planteamiento, se encuentran implicados valores contrarios (De Laine, 2000) ante lo que el investigador debe responder mediante la ética de la convicción y la ética de la responsabilidad (Arias y Giraldo, 2011). Esta última es considerada mediante tres aspectos diferenciados: (1) la obligación de hacer las cosas bien, (2) la conciencia de las consecuencias y (3) la obligación de responder ante alguien (Gómez y Molina, 2006).

Ante estos planteamientos, es necesario establecer ciertas bases éticas en investigación cualitativa que garanticen el tacto y respeto tanto al contenido de la investigación como a los propios participantes y su contexto. En la literatura nacional, autores como Galeano (2004) nos plantean ciertas reflexiones como invitación para la construcción colectiva de orientaciones éticas sobre el trabajo cualitativo. Entre ellas encontramos:

- El consentimiento informado a través del cual los participantes deben ser consultados y lograr acuerdos con el investigador sobre la utilización de las técnicas de registro, así como garantizar su derecho a conocer qué información va a ser registrada, con qué propósitos, si va a ser compartida con otros investigadores y a qué público va a llegar.

- Confidencialidad y anonimato garantizado a través de la utilización de seudónimos que impidan la identificación de los informantes o personas a los que se refiere.

- Retorno social de la información obtenida dando a conocer a los participantes el curso y utilización de la información que aportaron a la investigación.

- Analizar, prever y minimizar los efectos del registro sobre los informantes y sobre el investigador y estar preparado a modificar las estrategias de registro cuando las condiciones de desarrollo de la investigación lo demanden.

Es necesario que estas orientaciones y consideraciones éticas se estimen elementos morales de toda investigación social y que se garanticen a lo largo del proceso de investigación. En nuestro caso, al tratarse del método biográficonarrativo, no solo han sido tenidas en cuenta, sino que además se ha convertido en los pilares éticos de nuestra investigación, pues el "juego de subjetividades" creado entre la investigadora principal y cada uno de los participantes así lo ha requerido.

A modo de síntesis, veamos a continuación los diferentes elementos clave de la ética de esta investigación plateados con la finalidad de resolver los dilemas y conflictos morales surgidos. 


\subsubsection{La coinvestigación}

Cabe destacar aquí, que en nuestra investigación, entendemos la investigación como un proceso que va más allá de incorporar la visión de las personas participantes. Se trata de un enfoque que legitima las aportaciones de éstos, asumiendo que deben los propios participantes quienes controlen y manejen la investigación y no a la inversa. Esta visión no solo inclusiva sino emancipadora de la investigación, nos lleva a plantearnos si la madre del protagonista de la historia no ejerce más bien una función de co-investigadora que de participante activa (o muy activa). Mediante el término 'co-investigadora', rescatamos un concepto utilizado por algunos autores en investigación social (Parrilla, 2009; Pallisera y Puyalto, 2014; Valenzuela, 2008; Hartley \& Benington, 2000; Benington \& Hartley, 2004; March, Steingold, Justice \& Mitchell, 1997) y que pretende reflejar el trabajo profundo, dialectico y reflexivo que se crea entre la participante y la investigadora principal.

En nuestra investigación, el trabajo con la co-investigadora (y madre del protagonista) es algo más que un diálogo fluido y continuo. Se trata de un trabajo reflexivo y constructivo en el que se ponen sobre la mesa y se debate todo lo relacionado en el proceso de investigación: objetivos, diseño, muestreo, elaboración de los instrumentos, recogida de datos, análisis, elaboración de los resultados,... Todo se comparte y revisa de manera conjunta y horizontal. En cierta manera, la decisión de incorporar esta figura de co-investigadora no fue previa a los planteamientos, sino que al dar comienzo a la revisión de los objetivos se consideró necesario compartirlos con los padres (y representantes legales de Sergi). Estábamos ante la historia de vida de un menor, con matices y acontecimientos delicados y muy personales, y pensamos que era menester compartirlos con ellos. En esta sesión detectamos rápidamente el feedback reflexivo que recibíamos de ellos, y observamos que de manera casi automática sentían la investigación como algo propio, algo de lo que formaban parte. Por ello, propusimos la figura de 'coinvestigador' la cual por consenso (debido a la dedicación y tiempo disponible) fue otorgada a la madre de Sergi: Àngels.

\subsubsection{Proceso de negociación constante}

Otro de los elementos éticos de esta investigación es el proceso de negociación constante mantenido con todos los participantes. La negociación en una investigación de tipo cualitativa es una cuestión de búsqueda de equilibrio, pues deben valorarse las ganancias obtenidas y las concesiones otorgadas, así como las consideraciones éticas y estratégicas para que sean las más convenientes de acuerdo con los propósitos de la investigación y las circunstancias que la rodean (Hammersley \& Atkinson, 1983, citado en Tójar, 2006). De hecho, el propio término de 'negociación' nos lleva a pensar en acuerdos, en consensos durante el proceso de investigación (antes, durante y después del trabajo de campo). En el proceso de negociación deberán establecerse las condiciones y principios morales en los que se desarrolla la producción de datos, su análisis, discusión y difusión, siendo esto aceptado y respetado por todas las personas participantes en la investigación (Badilla, 2006).

En este sentido, Pujadas (1992), establece la necesidad de lo que él denomina una perspectiva contractual del proceso de negociación en la que deben quedar claramente especificados todos los extremos como: 
1. Las finalidades de la investigación y el uso que se hará de la información

2. La forma de registro de la información y al acceso de terceras personas a ella

3. El anonimato del sujeto y el camuflaje de situaciones, nombres de lugar y de personas que aparezcan en el relato (punto medio entre los derechos del sujeto y la veracidad del documento)

4. Perspectivas de publicación del material, especificando la participación de cada uno en los derechos de autoría

5. Formas de compensación al sujeto por el trabajo que se le requiere.

Así mismo, teniendo en cuenta estas orientaciones y para lograr un trabajo horizontal con los participantes de la investigación, es necesario que esta negociación sea totalmente participativa, explícita y flexible (Fernández y Santos, 1992), pues solo de esta manera se puede conseguir que los participantes de la misma se sientan reconocidos, reflejados y cómodos a lo largo de todo el proceso de investigación. Es más, es necesario que la opinión, voluntades y deseos de los participantes guíen de alguna manera la toma de decisiones y cambios de rumbo del propio proceso indagador. Solo de esta manera estaremos desarrollando una investigación vinculada al campo de estudio y altamente respetuosa y fiel con los participantes de la misma.

En nuestra investigación, y siguiendo las indicaciones de los autores anteriormente citados, el proceso de negociación se llevó a cabo a lo largo del trascurso de la investigación, desde el inicio hasta el final. No solo con la madre y co-investigadora de este estudio sino con todos y cada uno de los participantes de la misma. De esta manera, se atajaron con cada uno de ellos los temas y cuestiones correspondientes según las necesidades y voluntades personales, las del campo y las de la propia investigación. Tal y como se podrá observar más adelante (capítulo 5), el proceso de negociación inicial se asume como un momento clave y complejo de la investigación, pues es cuando se establece el diseño de la investigación y todos los elementos relativos a éste con la co-investigadora.

Así mismo, y vinculado al proceso de negociación, se establecía con cada participante el procedimiento a seguir para la devolución de la información. Toda información contemplada en esta investigación ha pasado por diferentes etapas: (a) recogida de información a través de grabadora, (b) transcripción de los datos de manera literal por parte de la investigadora principal, (c) devolución al propietario de la información para su revisión, modificación y/o aprobación, (d) registro de las modificaciones por parte de la investigadora principal y (e) codificación y clasificación del instrumentos en el corpus total de documentos de análisis.

El proceso de devolución de la información no puede ser entendido como un acto unidireccional, sino más bien como un proceso comunicativo y reflexivo. Según González y Padilla-Carmona (2014) el participante no solo tiene derecho a conocer qué se informa de él, sino que también debe tener la opción de modificar aquello con lo que no está de acuerdo, cuya perspectiva será muy enriquecedora para el producto final a elaborar por el investigador/a principal. 


\subsubsection{Consentimiento informado}

El consentimiento informado es un documento de carácter informativo considerado uno de los estándares éticos de la investigación cualitativa y uno de los elementos más importantes del proceso de indagación. Este término se acuñó por primera vez con la intención de prevenir prácticas experimentales en el campo biomédico que violaran los derechos individuales (Beauchamp et al., 1982, citado en Eisner, 1990). Hoy en día se ha convertido en un documento habitual en las investigaciones cualitativas llegando a ser totalmente necesario y, casi, obligatorio en todos los estudios del ámbito de las ciencias sociales (Flick, 2015), y más concretamente en el campo educativo.

El consentimiento informado se considera una herramienta para informar y aclarar términos, objetivos y expectativas de una investigación a la persona que lo acepta con su firma. Se trata de un elemento cuya finalidad es asegurar que "los individuos participen en la investigación propuesta solo cuando ésta sea compatible con sus valores, intereses y preferencias; y que lo hacen por propia voluntad con el conocimiento suficiente para decidir con responsabilidad sobre sí mismos" (González, 2002: 101).Cualquier persona firmante de este consentimiento, debe percibir y sentir que es totalmente libre de interrumpir el proceso y abandonarlo sin sentir incomodidad o desasosiego por ello.

Según González (2002) este consentimiento debe incluir, al menos, información relativa a la finalidad, riesgos, beneficios y alternativas del estudio, asegurando la comprensión de la persona firmante y otorgándole a ella la toma de decisión libre y no forzada sobre si participar o no en la investigación. Esta obligación ética del investigador se convierte en indispensable en el caso de entrevistar a personas menores y/o muy mayores (Flick, 2006), pues son personas con una sensibilidad menor para exigir cierta información y, posiblemente, poco consecuentes con el uso o mal uso que se puede hacer de ella.

De hecho, el consentimiento informado tiene sentido tanto en cuanto desde el planteamiento de una investigación se considere que las personas poseen valor en sí mismas, y que por encima de los intereses del estudio está el preservar el derecho de cualquier participante.

\subsubsection{La confidencialidad y el anonimato}

En cuanto a la investigación cualitativa se refiere, y más concretamente al método biográfico-narrativo, la garantía de confidencialidad y anonimato es una obligación a la vez que un reto para el investigador. Uno de los problemas o dificultades con la que se topan este tipo de investigaciones es que la cercanía de las interrelaciones personales que exige la metodología puede producir problemas especiales y complicados de confidencialidad y anonimato (Guba \& Lincoln, 1989 en Guba \& Lincoln, 2002).

Ante todo, no podemos olvidar que estamos frente a historias que ocurren en lugares concretos, bajo circunstancias determinadas y en contextos muy definidos. Se tratan de elementos y características necesarios para la investigación (pues forman parte del objeto de estudio) pero sobre los que, a su vez, hay que preservar el derecho de anonimato, pero ¿hasta qué punto debemos disfrazar la información o utilizar pseudónimos que garanticen el anonimato? ¿No estaremos ofreciendo una información sesgada? 
Sea como fuere, una de las cuestiones que se debe respetar en investigación cualitativa es el principio ético de beneficiencia (Kvale, 2011) en la que se garantiza que el riesgo de daño sobre el sujeto es el menor posible. Es necesario garantizar a todos los participantes que no se informará bajo ningún concepto de sus datos privados (Kvale, 2011), sino que además éstos serán modificados para evitar la identificación de los participantes a través de ciertos elementos. Para ello, Parker (2005) propone abiertamente un diálogo con las personas participantes e implicadas en la investigación debatiendo con ellos sobre si quieren ser nombrados o no, y qué tipo y cantidad de información sobre ellos mismos desean que se difunda. Estas y otras consideraciones fueron tomadas en cuenta en la fase de negociación de esta investigación y recogidas en la elaboración del consentimiento informado (Capítulo 5).

\subsection{El método biográfico narrativo: la investigación inclusiva}

Tal y como se puede observar en el diseño y desarrollo de esta investigación (capítulos 4 y 5), la presencia y relevancia metodológica de uno de los participantes de la investigación (madre del protagonista de la historia) adquiere un papel principal sobre el resto. La razón de ello se debe no solo a la representación legal de ésta sobre el protagonista, sino también a la trascendencia de sus aportaciones en el planteamiento y toma de decisiones en todo el proceso investigador. Estamos por lo tanto ante un rol concreto que supera lo que se ha entendido clásicamente como 'participante de una investigación'.

Sobre esta cuestión, encontramos en la literatura diferentes roles o papeles que pueden adquirir los participantes de una investigación según su nivel de implicación. Tójar (2006) en su trabajo distingue entre: anfitrión (pertenece al campo y facilita el acceso a él), portero (más o menos colaborador pero indispensable para acceder al campo), colaborador (presta algún tipo de servicio en sintonía con los propósitos de la investigación), informador (colabora ofreciendo algún tipo de información para la investigación) y colaborador activo (proporcionan información relevante para la investigación y desde un papel más cercano que el anterior), pudiendo darse el caso de que los participantes pasen de un papel a otro o incluso ocupen varios al mismo tiempo.

En el caso concreto de nuestra investigación, podríamos decir que mientras la gran mayoría de los participantes desarrollan un rol de informadores y/o colaboradores activos, la madre del protagonista de la historia se situaría incluso en un nivel superior al de 'anfitriona', pues no solo pertenece al campo y facilita el acceso a éste, sino que su papel sobrepasa dichas cuestiones de acceso para formar parte de conversaciones y debates con la investigadora principal sobre posicionamientos teóricos, decisiones muestrales e incluso metodológicas.

Tal y como indica Moriña (2016) en su trabajo, otorgar la voz a los participantes es una seña de identidad de los métodos narrativos, de manera que algunos investigadores e investigadoras reclaman que los Otros lleguen a ser coautores de las aventuras narrativas y se construya la investigación a través de un proceso dialógico entre quien investiga y los participantes de la investigación.

Estaríamos frente a lo que muchos autores denominan como inclusión en la investigación o investigación inclusiva (Walmsley, 2001, 2004, 2008; Walmsley \& 
Johnson, 2003; Johnson, 2009; Manson \& Danby, 2011; Parrilla, 2009; Susinos y Parrilla, 2008, 2013; Pallisera y Puyalto, 2014; Atkinson, 2005; Brookes, Archibald, McInnes, Cross, Daniel \& Johnson, 2012; Deguara, Jelassi, Micallef \& Callus, 2012; Garbutt, Tattersall, Dunn \& Boycott-Garnett, 2009). La investigación inclusiva ha sido principalmente utilizada en estudios sobre diversidad funcional, y más concretamente en aquellos casos donde los participantes o foco de las investigaciones son las personas con diversidad funcional. En términos generales, desde este enfoque (Walmsley, 2001, 2004, 2008; Walmsley \& Johnson, 2003) se defiende que las personas con experiencias personales relevantes en relación al tema investigado deben ser incluidas en el estudio, y debe facilitarse su participación en todas las fases del mismo, desde el planteamiento de los objetivos de investigación a su difusión. De esta manera, la investigación inclusiva acaba generando una transformación en la propia concepción de la investigación, en sus objetivos, procedimientos y las relaciones entre las personas que participan en ella (Parrilla, 2009)

Así mismo, una de las autoras referentes en investigación inclusiva (Walmsley, 2004b), especifica a su vez la diferencia entre investigación sobre inclusión e investigación inclusiva. Para esta autora, la investigación inclusiva va más allá de poner la mirada en los procesos de inclusión sino que además, los participantes están altamente implicados en el estudio reconociéndolos como fuente activa de conocimiento social. En la misma línea, Parrilla (2009) recoge en su trabajo la apreciación de Chappell (2000), quien precisa que dicha implicación (o inclusión) en la investigación puede tomar a su vez dos tradiciones metodológicas diferentes: la tradición participativa y la tradición emancipadora.

En este caso, apostamos por esa investigación emancipadora, que auque no pretendar ser desafiante, sí cuestiona algunos supuestos de paradigmas más tradicionales en busca de la emacipación de las personas que participan en la investigación, un tipo de investigación en el que los conocimientosy aptitudes de los investigadores e investigadoras se ponen al servicio de quienes participan, y no a la inversa (Moriña, 2016).

\subsubsection{El papel (compromiso) de la investigadora}

En investigaciones de este tipo, la voz del investigador y el papel que éste ejerce en el campo estudiado resulta fundamental. En nuestro caso, consideramos necesario hablar incluso de compromiso del investigador con la causa estudiada. Estamos ante una investigación muy personal, íntima y arraigada a lo más profundo del ser, ante la que el investigador solo puede adoptar, como indica Lincoln (1991), un papel de 'participante apasionado'.

En nuestra investigación, pretendemos alejarnos de un modelo de investigador monológico y directivo para acercarnos a un modelo mucho más dialógico y activo. Un modelo que no solo conoce y reconoce las voces de los y las participantes, sino que interactúa con ellas, se sienta junto a ellas, dialoga y construye con ellas. Se trata de un tipo de investigación en la que el compromiso personal y ético con la investigación se convierte en notorio para todas las partes.

Tal y como indican Guba y Lincoln (2002) en este tipo de investigaciones el rol del investigador es un rol activamente comprometido en la reconstrucción de las 'múltiples voces' (la suya y la de otros participantes). Se trata de un proceso en el 
que se pretende no solo una elaboración fiel de la realidad, sino que además los participantes se sientan cómodos con la investigación y, a la vez, parte de ella.

A pesar de que la ciencia tradicional aparta el sentir del investigador del proceso indagativo, el simple hecho de utilizar el método biográfico-narrativo como método de investigación recompone y reorganiza las posiciones de poder dentro de la propia ciencia. Estamos ante un método en el que la investigadora se preocupa por acercarse a las personas, por sentarse a su lado, por pensar con ellas, por dialogar con y sin grabaciones, y por entender, como no, todas las posiciones y opciones personales ante la investigación. La vertiente más personal e íntima de los participantes, y del propio investigador/a, se remueven con cada negociación, con cada entrevista y con cada revisión de los datos. Ponerse en el lugar del otro, saber respetar los espacios y demostrar el interés real de por qué nos hemos puesto en contacto, son elementos necesarios para adquirir, por ambas partes, el compromiso ético y moral necesario en esta investigación.

Sin embargo, no solo la empatía debe estar presente sino también el respeto. Respeto por lo que haces, respeto por lo que eliges, respeto por lo que me cuentas y respeto y especial cuidado con la información delicada y sensible que me transmites. No podemos olvidar que cuando utilizamos el método biográficonarrativo las personas nos cuentan su vida, nos cuentan sus intimidades, se 'desnudan' ante nosotros y nos los dan sin más, sin esperar nada a cambio.

Como investigadora, este último razonamiento me ha retumbado cientos de veces en la cabeza. Cualquier persona con la que establecemos el contacto se entrega a nosotros, nos da lo que es, lo que siente y lo que desea para un futuro. Si nos paramos a pensar en lo que obtiene a cambio nos daremos cuenta de que es una postura totalmente altruista, totalmente entregada a la causa objeto de estudio pero por la que no se obtiene nada a cambio, y sin embargo lo hacen, pero ¿por qué lo hacen? ¿haría yo lo mismo en su lugar? ¿estaría contando abiertamente la historia de vida de mi hijo, de mi hermano o de mi alumno? ¿Sería capaz?

Todas estas preguntas no me llevan a otra conclusión que una verdadera y sincera admiración. Admiración a la familia por volcarse en la investigación, admiración por la dedicación y entrega de todos los participantes y admiración por la valentía y paciencia y admiración de ayudarme a reconstruir. Por estas y otras tantas razones puedo y debo afirmar en este punto que la investigación me ha 'calado' y me ha transformado. Como se verá en los capítulos posteriores se trata de una investigación rigurosa y científica pero que no abandona la parte humana de la misma, y es que no se puede permitir ese abandono. Estamos hablando de personas, de sentimientos, de emociones, de desilusiones,... que sin duda alguna me han reconfortado, me han hecho llorar, me han hecho reír y sobre todo me han hecho crecer como persona y como investigadora.

\subsection{Antecedentes de la investigación}

Antes de adentrarnos en el bloque investigador de este trabajo, consideramos necesario revisar previamente aquellas investigaciones que anteceden a nuestro estudio. Esta revisión no solo servirá para reconocer aquello que se ha investigado hasta el momento, sino también para ubicar nuestro trabajo en ese corpus de trabajos previos y valorar la aportación que éste hace al campo de estudio. Teniendo en cuenta que estamos ante una investigación biográfico- 
narrativa sobre un joven con diversidad funcional, iniciamos nuestra búsqueda con la pretensión de revisar investigaciones similares basadas en este método y realizadas en este mismo campo de estudio.

Una de las primeras impresiones que obtenemos al realizar de esta revisión, es que existe una amplia trayectoria en el ámbito nacional e internacional de investigar en educación mediante historias de vida poniendo el foco de atención sobre los docentes. En los últimos años, en nuestro contexto, encontramos trabajos como la historia de vida en profundidad sobre la experiencia pedagógica del profesor Jaime Alfonso Escalante Gutiérrez (Pari, 2011), el trabajo de Delgado (2015) sobre los relatos biográficos del profesorado sénior de la universidad y el trabajo realizado por Leite (2011) que lleva por título "Historias de vida de maestros y maestras. La interminable construcción de las identidades: vida personal, trabajo y desarrollo profesional”, entre otros. Así mismo, basado en el método biográfico-narrativo destacan investigaciones sobre la identidad profesional del docente y el rol que éste desempeña en cuanto a la consecución de una educación inclusiva (García y Doñate, 2008; Echavarría y Hernández, 2013; Cortés, Leite y Rivas, 2014; Rivas, 2014; Moriña, Molina, Melero y Carballo, 2015; Leite, Cortés y Rivas, 2016; Sotos, López y Sánchez, 2016; Molina, Perera, Melero, Cotán y Moriña, 2016). Así mismo, en el ámbito internacional, podemos destacar diversos trabajos que focalizan su objeto de estudio en la narrativa sobre docentes y su papel en educación (Kirk \& Wall, 2009; Hamilton, 2010; Savvidou, 2011; Anspal, Eisenshmidt \& Löfström, 2012; Leandro, Costa y Aquino, 2012; Heyd-Metzuyanim, 2013; Blume, 2015; Ostovar-Namaghi, Norouzi, \& Hosseini, 2015; Pascueletto, 2015; da Rosa \& Baraldi, 2015; Bullough, 2016).

No obstante, si en esta revisión cerramos un poco más el foco y lo enfocamos hacia las historias de vida de personas con diversidad funcional, los estudios encontrados son bastante más escasos. Es cierto que las asociaciones o fundaciones internacionales, como las Associations for Community Living canadienses, el Marsha Forest Centre, el Global Applied Disability Research and Informationi Network (GLANDNET) o el International Disability Alliance (IDA), recogen testimonios vitales de personas con diversidad funcional y sus familias, narrando los procesos de inclusión en diferentes ámbitos. Pero son pocas las investigaciones desarrolladas de forma rigurosa, bien mediante estudios de casos o mediante historias de vida. Entre ellas encontramos algunos trabajos como: Bunch, 1991; Bunch \& Finnegan, 1996; Schaefer, 1997; Priestley, 2001; Salem, 2006; Snow, 2011; DeMarassé, 2006.

De los trabajos previos revisados, destacamos los siguientes estudios realizados en nuestro contexto:

- Uno de los trabajos a tener en cuenta es la historia de vida de Anxela, realizada por Nuñez (2008). Esta es la historia de una joven con parálisis cerebral que tras el largo camino de la escolarización finalizó sus estudios de derecho y empezó a trabajar como asesora jurídica de una asociación destinada al apoyo de personas con discapacidad. Entre los resultados de esta investigación destacan elementos como las resistencias a su escolarización, el menosprecio de algunas personas, la lucha de la familia, la implicación de algunos profesionales, el rechazo de otros y la búsqueda del sentido de pertenencia a su grupo de referencia. 
- De la Rosa (2008, 2010, 2013) a través de la historia de vida de Ángel nos muestra una historia de vida de un joven, de unos 30 años, con discapacidad motora. El foco de esta investigación es la trayectoria vital de este joven, haciendo especial hincapié en la perspectiva comunicativa a lo largo de su vida.

- Otro ejemplo de investigación mediante historias de vida y diversidad funcional es el trabajo de Moriña $(2014,2015)$ (Moriña, Cortés y Melero, 2014; López y Moriña, 2015; Moriña, Cortés y Molina, 2015; Moriña y Perera, 2015; Moriña, 2017). A través de este estudio se pretende indagar en las barreras y ayudas que los estudiantes con discapacidad perciben en su acceso, trayectoria y resultados académicos en el ámbito universitario. Desde este trabajo se visibilizan tanto las barreras encontradas como los apoyos recibidos, su procedencia y el beneficio generado. Los resultados de esta investigación apuntan a tres grandes apartados: barreras y ayudas institucionales, barreras arquitectónicas e infraestructuras en la universidad y la prospectiva sobre la visión que los alumnos poseen sobre cómo sería su universidad ideal.

- En esta misma línea, añadimos el trabajo de Cotán (2015) cuya principal finalidad es analizar las barreras, ayudas y propuestas de mejora que los estudiantes con discapacidad identifican en su trayectoria de formación en la universidad. Este trabajo se compone de una micro-historia y dos historias de vida. Algunos de los resultados a destacar sobre este trabajo tienen que ver con las barreras y ayudas institucionales, las arquitectónicas, las actitudinales y las formativas.

- Finalmente, añadiremos aquí un apartado sobre los trabajos que aunque no focalicen directamente sobre la diversidad funcional, son trabajos basados en biografías de personas con circunstancias concretas (socioculturales, y/o económicas) que determinan sus trayectorias personales y académicas. En este sentido podemos destacar la historia de vida de Elena, una joven estudiante, de clase obrera, mediante la cual se pretende indagar en los procesos de fracaso escolar en contextos ordinarios (Calderón, 2015a, 2016) Así como trabajos sobre procesos escolares de fracaso y reforma de menores realizados por Calderón (2014b, 2015b) y Herrera (2015).

Como hemos podido comprobar en la revisión de las investigaciones previas, son escasos los trabajos que en nuestro contexto utilizan el método biográficonarrativo para indagar en las trayectorias vitales de personas con diversidad funcional. Sin embargo, entre aquellos que utilizan esta perspectiva de investigación, encontramos algunos que focalizan en ámbitos o aspectos de vida concretos de las personas con discapacidad, como el contexto universitario o el ámbito comunicativo. De esta manera, se reduce un tanto más el número de trabajos que indagan desde una visión amplia de la vida de la persona y abarcando diversos ámbitos y contextos del protagonista, puesta óptica es necesaria para establecer relaciones entre los diferentes elementos y desglosar y analizar la trayectoria vital en profundidad. 



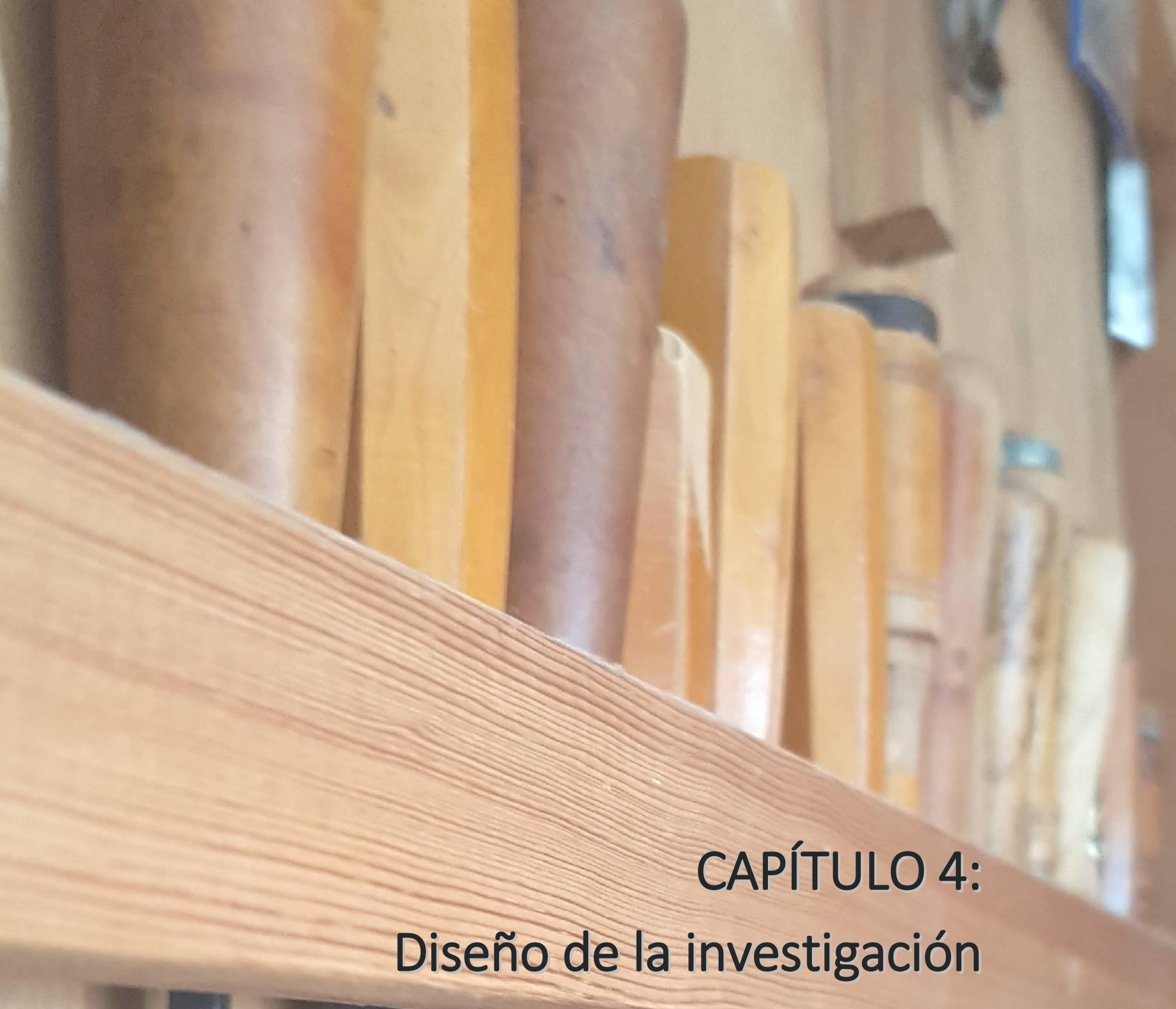



Por fin llegamos al diseño de la investigación, al capítulo donde quiero demostrar que mi trabajo es consistente y científico, donde deseo presentar mis inquietudes personales e investigadoras (pues no he encontrado forma alguna de dividirlas). En este capítulo quiero que el lector aprecie y sienta mis dilemas en la investigación y que conozca y reconozca mis decisiones como necesarias para avanzar en la misma.

Como se podrá observar, a lo largo de este capítulo he tenido la necesidad de justificar profundamente mis decisiones y atrevimientos. He necesitado exponer el recorrido vivido en cada uno de los apartados, desde la selección de la muestra a los tipos de instrumentos y construcción de los mismos. Sinceramente, deseo que no resulte farragoso y excesivo para el lector, aún teniendo la sensación de que lo es, pero debo admitir que de no hacerlo así sentía el diseño fraccionado, sin hilo conductor.

En este capítulo, vamos a encontrar definidos los principales aspectos relativos al diseño metodológico que han permitido llevar a cabo esta investigación.

4.1. Formulación del problema de investigación

4.2. Preguntas de la investigación

4.3. Objetivos de la investigación

4.4. Método de investigación:

4.4.1. Muestreo: Selección de los participantes

4.4.1.1. Proceso de selección de la muestra

4.4.2. Técnicas e instrumentos. Proceso de recogida de información

\subsubsection{Entrevistas}

a) Tipos de entrevistas

a.1. Entrevista en profundidad

a.2. Entrevista temática

a.3. Entrevista grupal

b) Proceso de construcción y realización de las entrevistas

b.1. Elaboración de las entrevistas

b.2. Realización de las entrevistas

b.3. Proceso de transcripción y devolución

4.4.2.2. Línea de vida crítico

4.4.2.3. Documentos

a) Documentos escritos

a.1. Técnica de documentos escritos

b) Documentos visuales

b.1. Documentos visuales: Fotografías

b.2. Otros documentos visuales: Pinturas y esculturas

4.4.2.4. Técnicas proyectivas

a) Técnica gráfica

4.4.2.5. Diario de investigación 


\subsection{Formulación del problema de investigación}

Cualquier investigación parte de un tema concreto, de la problematización de una parte de la realidad que requiere ser explorada y cuyo proceso de investigación no puede considerarse de forma independiente al método de indagación (Flick, 2007). De hecho, una investigación emerge (aparente e inicialmente) del interés por descubrir una parcela de la realidad que nos envuelve, un problema de estudio que evoca a una necesidad de investigación.

El planteamiento problemático de una investigación busca comunicar a sus lectores sobre el objeto de estudio, sobre el problema concreto que se quiere abordar y sobre las finalidades y los ejes orientadores de la investigación (Cisterna, 2005). Por ello, esta problematización de la realidad suele ser una de las primeras discusiones intrínsecas con las que se encuentra un investigador.

En esta investigación en concreto, debemos remontarnos a uno de los modelos educativos que buscan implantarse en las escuelas desde hace décadas, hablamos del modelo educativo inclusivo. Tal y como ya se ha desarrollado en el capítulo 2, desde el modelo de educación inclusiva se entiende que la escolarización y la plena participación tanto educativa como social son derechos fundamentales innegables a cualquier ser humano. Se trata de un fundamento ideológico imperante en la Declaración Universal de los Derechos Humanos a partir de la cual los poderes públicos tienen la obligación de garantizar una enseñanza no segregadora, que se prolongue después de la integración en la sociedad, a todos los alumnos, sean cuales sean sus condiciones físicas, sociales o culturales (Moriña, 2004).

Diversos autores (Moriña, 2004, 2008; Parrilla, 2001, 2002, Sarto y Venegas, 2009; Stubbs, 2008; UNESCO, 2009) sitúan el origen del concepto de la educación inclusiva en la Conferencia Mundial de Jomtien (Thailanda) en 1990. Desde ese momento y hasta la actualidad los tratados, informes, declaraciones y pactos internacionales han ido proliferando hasta calar en las políticas estatales de los países firmantes. Tal y como se ha expuesto en el capítulo 1, la evolución de la educación inclusiva en España ha tenido sus propias idas y venidas. De hecho, en los últimos años, parece que el asentamiento del modelo educativo inclusivo en España está retornando a niveles del pasado, pues leyes recientes (LOMCE, 2013) hacen un planteamiento y un tratamiento de la diversidad que muchos autores catalogan de recesivo históricamente hablando (Subirats, 2014; Gimeno Sacristán, 2014; García Luque, 2016; Reyes y Méndez, 2016; Romero Sánchez, García Luque y Cambil Hernández, (2016)

Sea como fuere, y posicionamientos políticos aparte, lo cierto es que en España sigue habiendo una sensación de que los planteamientos teóricos citados en las numerosas declaraciones e informes, no llegan a calar del todo en el ámbito educativo. Se percibe que hay un interés, un acercamiento, pero la situación actual dista de un modelo educativo inclusivo. En este sentido, Casanova y Rodríguez (2014) afirma que este "estancamiento" hacia el modelo poco tiene que ver con cuestiones económicas (pudiendo ser este el motivo), pues esta autora insiste en que para poder hacerlo real se debe empezar por una actitud favorable hacia la inclusión, la aceptación abierta de todo tipo de alumnado en el centro, la utilización variada de los recursos didácticos disponibles, la diversificación de métodos por parte del profesorado, la implementación del trabajo en grupo y colaborativo entre compañeros y compañeras, la adaptación del currículum a determinadas 
características del alumnado, la promoción de las familias en su compromiso con las actividades del centro, y un largo etcétera.

En este marco, la investigación aquí presentada, además de tener en cuenta el modelo educativo inclusivo como un referente teórico no se puede obviar la relación directa e indiscutible que mantiene con el modelo de la diversidad planteado en el capítulo 1. De hecho, este modelo incorporado en la Convención sobre los Derecho de las Personas con Discapacidad, es asumido por la educación inclusiva, cambiando el eje de la atención al contexto social que rodea a la persona y de qué manera este contribuye a su exclusión de la plena participación (Parra, 2010). Podríamos decir que la educación inclusiva es una representación en el campo educativo del modelo de diversidad.

De esta manera, desde el modelo de diversidad se considera que la incapacidad es producida por la sociedad, no por la persona que presenta una discapacidad, de forma que es la sociedad la que no está preparada para responder $\mathrm{y}$ atender a todos los miembros que forman parte de ella y que, de momento, solo responde a las necesidades del grupo mayoritario. Como vemos, estamos hablando de que la discapacidad es un fenómeno principalmente 'social' (Vega Fuente, 2004) que surge del fracaso del entorno estructurado a la hora de ajustarse a las necesidades y las aspiraciones de los ciudadanos con carencias, más que que de la incapacidad de los individuos discapacitados por adaptarse a las exigencias de la sociedad (Hahn, 1986).

La investigación que aquí nos ocupa se enfoca a partir de una mirada social de esa diversidad en la que se busca la plena participación de todas las personas en los distintos ámbitos de su vida. Por ello, estaremos hablando no solo de una educación que debería ser inclusiva para todos y todas, sino también de una sociedad inclusiva sin discriminación, exclusión o clasificación en base a las características de los individuos. En este punto es donde se posiciona el estudio aquí presentado cuya finalidad es explicar y analizar la trayectoria vital de un adolescente con diversidad funcional en los distintos ámbitos de su vida: educativo, familiar y social. El protagonista de la historia es un adolescente con autismo llamado Sergi, que además de presentar una gran capacidad y voluntad en los diferentes contextos de su vida, ha contado con una familia y un entorno luchador que ha creído en él. En cierta manera podríamos decir que gracias a sí mismo y a su entorno ha conseguido un éxito educativo y social negado por ciertos profesionales de la educación desde un principio. En este sentido, la búsqueda de cómo se ha construido su historia, las barreras con las que se ha encontrado y los apoyos con los que ha contado para poder superarlas, entre otros, serán elementos que nos darán pistas sobre cómo se articula la vida de una persona con diversidad funcional en un entorno (social y educativo) que se declara, y debería ser, inclusivo.

Cabe resaltar en este punto, que el resultado último de esta investigación pretende ser una historia de vida de construcción polifónica (relatos biográficos cruzados en términos utilizados por Pujadas, 1992), construida a partir de las voces de las personas allegadas y cercanas a nuestro protagonista. Con esta construcción compartida y cruzada, pretendemos obtener una visión de conjunto en la que entender cómo se ha desarrollado la trayectoria vital de Sergi a partir de él mismo y su contexto.

Sin embargo, debemos retomar aquí que la forma de construir esta historia de vida no está pensada ni pautada de antemano, sino que emerge a partir de los 
requerimientos y las necesidades de la propia investigación. El proceso de recogida de información se inició a través de varias entrevistas cronológicas en profundidad con la madre del protagonista, de la cual emergieron una serie de personas (futuros participanes) y temas clave identificados como fundamentales en esta historia. En base a estos participantes y temas a indagar, se organizaron nuevas sesiones de recogida de datos para seguir indagando en otros temas y (si se consideraba conveniente) otros participantes. Tras varios ciclos de este tipo, el círculo se cerró con una entrevista en profundidad al padre de Sergi.

Cabe destacar aquí, que a lo largo de todo el proceso de investigación la madre del protagonista de la historia posee tanto la condición de participante como la de coinvestigadora. Como veremos más adelante, esta postura se adoptó en una de las primeras negociaciones de la tesis, pues se trata de un trabajo tan personal, íntimo y delicado que no podemos permitirnos hacerlo sin ella. Somos conscientes de que la investigación no es de la doctoranda, no es de la comunidad científica, es de Sergi (su familia y su entorno) y de no ser por cuestiones legales (Sergi es menor) él debería ser el coinvestigador. Sin embargo, como se especifica más adelante, se decide por consenso que la madre de Sergi sea la coinvestigadora de este trabajo.

A lo anteriormente mencionado cabría anotar que una novedad técnica que pretende aportar esta tesis es que los datos no son únicamente de tipo verbal o escritos, sino que en la recogida de información también se contemplan materiales, fotografías y videos que ayudan a complementar información ya obtenida, y de este modo complementar información así como ofrecer nuevos datos que de otro modo no sería posible. Esta es una forma de triangular tanto la fuente de información (múltiples informantes) como el tipo de información en la recogida de datos. Toda la información recogida es organizada y sistematizada para su posterior análisis y dar la posibilidad de construir la historia de vida de nuestro protagonista.

Todo el proceso de investigación es llevado a cabo con la mucha sensibilidad, teniendo en cuenta que los datos son delicados y personales y que requieren de un tratamiento, cuanto menos, especial. Pero ¿qué conseguimos con esta investigación? ¿Para qué realizamos este estudio? Esta historia de vida no solo nos ayudará a visibilizar situaciones que son vividas día tras día por las personas con discapacidad, sino también a encontrar los mecanismos y estrategias que ayudan a superar toda una serie de barreras impuestas por la sociedad y el entorno, y de las cuales puede que no seamos ni siquiera conscientes. Nos ayudará a avanzar hacia ese modelo de sociedad inclusiva (y de escuela inclusiva) que apoyamos a través de tratados y declaraciones internacionales y que parece que nunca acaban de aterrizar en nuestras calles y aulas.

\subsection{Preguntas de investigación}

Para acercarnos al problema de investigación propuesto, es necesario que nos formulemos una serie de preguntas para que nos ayuden a orientar nuestra indagación en el campo. Estas preguntas deben ser lo suficientemente claras para no llevarnos a confusión o aspectos muy abstractos a lo largo del proceso de investigación, pero sin restringir la mirada del investigador a la incorporación de nuevos datos o resultados no contemplados previamente. Tras la problematización de la realidad estudiada, debemos plantearnos qué tipo de preguntas queremos resolver a través de nuestra investigación. Cabe considerar aquí que según el tipo 
de pregunta formulada, se condiciona el foco y la dirección que la investigación va a tomar, dependiendo de esta manera el qué y el cómo se va a estudiar el problema (Lewis-Beck, Bryman \& Liao, 2004).

Según Blaikie (2000), existen tres tipos de preguntas de investigación: el "qué" (requiere de una respuesta descriptiva, pretenden descubrir y describir las características y regularidades de un fenómeno), el "por qué" (indaga en las razones o las causas de la existencia de ciertas características y regularidades, pretenden entender y establecer las relaciones entre elementos y/o actividades o procesos sociales), y el "cómo" (focaliza la preocupación en provocar cambio, resultados prácticos e intervenir).

Teniendo en cuenta este referente, procedemos a presentar aquí las preguntas de investigación que nos planteamos en relación a nuestro problema:

a. ¿Cuáles son los principales hechos y acontecimientos que describen y explican la trayectoria de vida de Sergi?

b. ¿Qué personas han acompañado a Sergi a lo largo de su vida desde contextos como el familiar, social y educativo?

c. ¿Cuáles son los elementos, personas y hechos clave de la historia de vida de Sergi?

d. ¿Cuáles son las principales barreras y limitaciones educativas y sociales con las que Sergi se han encontrado a lo largo de su vida?

e. ¿Cuáles han sido los principales apoyos, ayudas y estrategias de superación que ha tenido Sergi (familiares, educativas y sociales)?

f. ¿Qué decisiones o determinaciones se han tomado desde el ámbito familiar para superar estas barreras?

g. ¿Cuáles son expectativas de futuro de Sergi y las personas de su entorno en cuanto a su desarrollo académico, profesional y social?

h. ¿Qué herramientas o estrategias se prevén necesarias desde el ámbito familiar y educativo para garantizar la calidad de vida de Sergi?

Como podemos observar, nos encontramos frente a una investigación formulada principalmente a través de preguntas basadas en el qué, es decir, preguntas que buscan la descripción y la explicación de los elementos o peculiaridades de nuestro problema de investigación. Aunque, sin embargo, no podemos obviar el proceso de emancipación y transformación al que estamos contribuyendo a partir de nuestro trabajo.

De esta manera, la finalidad de esta investigación no es otra que:

\section{Explicar y analizar la trayectoria vital de un adolescente con diversidad funcional desde los ámbitos educativo, familiar y social}




\subsection{Objetivos de la investigación}

Tras la formulación de nuestras preguntas de investigación y finalidad de investigación, es conveniente que concretemos nuestro trabajo en diversos tipos de objetivos. En primer lugar deberemos definir los objetivos generales de nuestra investigación, que no son otra cosa que la inversión de las preguntas en términos de finalidades, y a continuación concretarlos en objetivos específicos, que desglosan y operacionalizan los primeros (Cisterna, 2005).

Veamos pues, cuales son los objetivos generales y específicos relativos a nuestras preguntas de investigación: 


\section{Preguntas de investigación}

a. ¿Cuáles son los principales hechos acontecimientos que describen y explican la trayectoria de vida de Sergi?

b. ¿Qué personas han acompañado a Sergi a lo largo de su vida desde contextos como el familiar, social y educativo?

c. ¿Cuáles son los elementos, personas hechos clave de la historia de vida de Sergi?

d. ¿Cuáles son las principales barreras y limitaciones educativas y sociales con las que Sergi se han encontrado a lo largo de su vida?

¿Cuáles han sido los principales apoyos, ayudas y estrategias de superación que ha tenido Sergi (familiares, educativas y sociales)?

f. ¿Qué decisiones o determinaciones se han tomado desde el ámbito familiar para superar estas barreras?

g. ¿Cuáles son expectativas de futuro de Sergi y las personas de su entorno en cuanto a su desarrollo académico, profesional y social?

Determinar cuáles son las expectativas y los posibles itinerarios o recorridos educativos y profesionales de Sergi a medio y largo plazo.

h. ¿Qué estrategias se consideran necesarias para garantizar la calidad de vida en el

futuro de Sergi?

\section{Objetivos específicos}

1. Describir y explicar los principales acontecimientos, hechos y personas de la trayectoria vital de Sergi, así como los elementos clave de su historia en cuanto a los ámbitos educativo, familiar y social.

2. Profundizar y analizar cuáles han sido las barreras y limitaciones con las que se ha encontrado Sergi así como las estrategias de superación con las que ha contado para superarlas.
1.1. Conocer las vivencias y experiencias de Sergi en relación a sus contextos familiar, educativo y social como visibilización de aquello con lo que convive una persona con diversidad funcional.

1.2. Exponer y evidenciar las personas han acompañado a Sergi en su trayectoria vital desde los diferentes contextos y cuál ha sido su papel.

1.3. Determinar los elementos se clave en la trayectoria vita de nuestro protagonista.

2.1. Describir cuales han sido las barreras y limitaciones sociales y educativas con las que Sergi se ha encontrado lo largo de su vida.

2.2. Identificar el tipo y procedencia de apoyos, ayudas y estrategias de superación de barreras con las que Sergi ha contado y que han contribuido su éxito personal, académico y social

3.1. Conocer cuáles son las expectativas de futuro (social, educativo y laboral) de Sergi y así como de su entorno inmediato.

3.2. Explorar los procesos de formación (formal y no formal) de los que dispone Sergi para garantizar su calidad de vida y un pleno desarrollo personal y profesional a medio y largo plazo.

Tabla7. Preguntas de investigación, objetivos generales y objetivos específicos 


\subsection{Método de investigación}

El método de investigación, el cómo de las investigaciones, el cuerpo y el alma del proceso de indagación. El método de investigación debe ser algo plenamente meditado y reflexionado, debe estar acorde con la perspectiva de investigación, ofrecer materiales, instrumentos y participantes que posibiliten responder las preguntas de investigación y alcanzar, por lo tanto, los objetivos propuestos. De alguna manera, se trata de un elemento que, de ser consistente, de ser adecuado, dará resultados muy fructíferos y de calidad, pero de no serlo generará grandes problemas al investigador.

Sin duda alguna, uno de los elementos inherente al método de investigación y su calidad es el concepto de triangulación. El concepto de triangulación es considerado como la utilización de múltiples métodos, materiales empíricos, perspectivas y observadores para agregar rigor, amplitud y profundidad a cualquier investigación (Denzin \& Lincoln, 1998).

A partir de las aportaciones de Denzin (1970, citado en Janesick, 1998), se proponen 4 tipos de triangulación en investigación cualitativa: (a)triangulación de datos, es la utilización de diversas fuentes de datos en un estudio; (b) triangulación de investigadores, es la utilización de diferentes investigadores o evaluadores; (c) triangulación de teorías, se refiere a utilizar múltiples perspectivas para interpretar un mismo grupo de datos, y triangulación metodológica, como la utilización de diferentes métodos para estudiar un mismo problema.

Desde los primeros planteamientos de nuestra investigación la triangulación estuvo presente en nuestras mentes. Desde los diseños iniciales ya se pensaba y recapacitaba una y otra vez sobre cómo obtener datos de diversas fuentes de información, cómo garantizar más de una mirada investigadora sobre el mismo estudio, cómo enganchar diversas perspectivas o enfoques teóricos de investigación y, por último, cómo utilizar diversos métodos para resolver nuestras preguntas de investigación. Como solución, elaboramos una propuesta de investigación que fue revisada y negociada una y mil veces con la intención de mejorarla y afinarla. El resultado lo pueden comprobar a continuación. .

\subsubsection{Muestreo: selección de los participantes}

En una investigación de tipo cualitativo como la nuestra la selección de los participantes es un momento clave, pues en según el tipo de muestreo que se haga se condiciona un determinado enfoque de comprensión del campo y de los casos seleccionados (Tójar, 2006; Flick, 2004). Por ello, la decisión del tipo de muestreo más adecuado a nuestro objeto de estudio es un planteamiento inicial que no debemos ni podemos obviar.

En este caso, para presentar la estrategia de muestreo seguida en nuestra investigación, seguiremos la clasificación establecida por Teddlie y Yu (2007). Estos autores indican que existen 4 diferentes tipos de muestreo: muestreo probabilístico, muestreo intencional, muestreo por conveniencia y muestreo mixto, siendo los dos primero los más frecuentes en la mayoría de las investigaciones. 


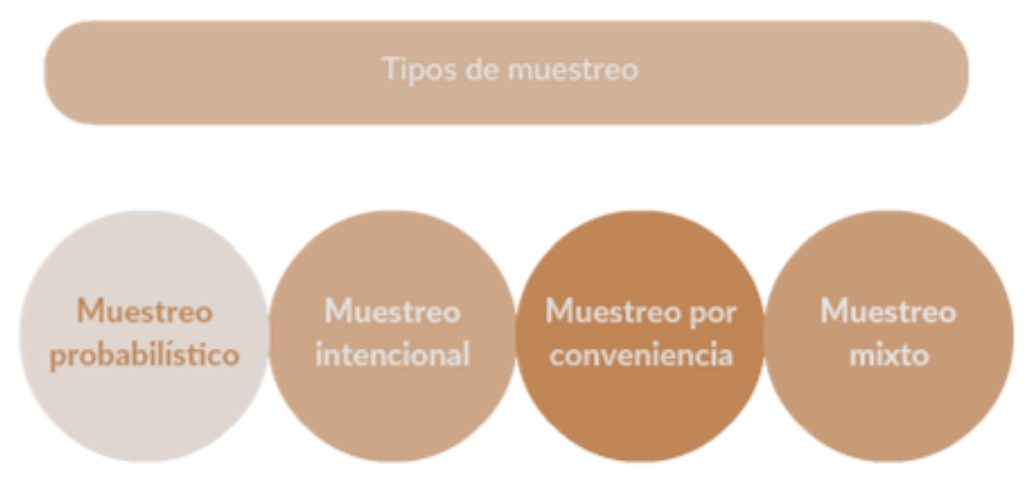

Figura 2. Tipos de muestreo I (elaboración propia)

Por lo general, la utilización de un muestreo probabilístico, no entraña grandes problemas a la hora de la generalización de los resultados, pues toda la población de estudio posee las mismas probabilidades de ser seleccionado como muestra y permite efectuar inferencias sobre el resto de la población (Alaminos y Castejón, 2006). En este caso, esa generalización de los resultados se expresa mediante parámetros como la validez externa y la interna (posibilidad de generalizar los resultados obtenidos a otras poblaciones y hacer inferencias correctas sobre los participantes examinados respectivamente). Ahora bien, esto no es suele ser aplicable en los muestreos de tipo intencional como el de la investigación que aquí nos acontece. En estos casos, la generabilidad de los resultados cualitativos se sustenta en términos como la transferibilidad y la reflexividad (Marshall, 1996; Teddlie \& Yu, 2007; Mayan, 2009; Martínez-Salgado, 2012). La transferibilidad es la que permite generalizar los resultados de un determinado contexto a otro cuyo significado sea similar al del contexto estudiado, lo cual solo puede darse a partir de una descripción rica y profunda de cada fenómeno en su contexto, sin tener como fundamento el número de casos estudiados (Martínez-Salgado, 2012). En cuanto a la reflexividad, este concepto nos remite a los numerosos matices de las relaciones intersubjetivas que se dan entre los participantes (Kvale, 2007; Pyett, 2003; Mantzoukas, 2004). Ésta última es la razón por la que se da tanta importancia al registro, análisis y relato del papel que ejerce el propio investigador o investigadora, pues se reconoce la subjetividad humana como un hecho que no puede dejarse de lado en las investigaciones y del que dar cuenta (Schütz, 1995).

De esta manera, mientras en el muestreo estadístico dependeríamos de una muestra aleatoria y representativa que nos permita hacer generalizaciones posteriores, en el caso del muestreo intencional su potencial reside en la selección de casos ricos en información para estudiar nuestro objeto de estudio en profundidad. Teniendo en cuenta esto, entendemos que el muestreo intencional es el más idóneo para el tipo de investigación aquí presentada, pues aunque de forma más o menos fortuita, se seleccionó un caso complejo, rico en matices y detalles, donde interfieren elementos y personas que acaban consiguiendo el éxito educativo y social de un niño con TEA y TEL.

Habiendo encauzado esta investigación en un muestreo de tipo intencional, cabe tener en cuenta que existen diversos subconjuntos diferentes de este tipo de 
muestreo (Teddlie \& Yu, 2007). En primer lugar encontramos el muestreo para la representatividad o comparación entre casos, utilizado cuando el investigador pretende (a) seleccionar una muestra intencional que representa un grupo de casos tan parecidos como sea posible o (b) establecer comparaciones entre diferentes tipos de casos. En segundo lugar encontramos el muestreo especial o de caso único, el cual se utiliza cuando el caso individual en sí mismo, o el grupo específico de casos, es el centro de la investigación (más que el propio tema). En tercer lugar cabe destacar el muestreo secuencial, este tipo de muestreo utiliza la selección gradual de la muestra cuando (a) el objetivo de la investigación es la generación de teoría (o definir temas en general) o (b) cuando la muestra evoluciona en sí misma a medida que los datos son recogidos. Por último, encontramos el muestreo mixto de técnicas intencionales, que se refiere al uso de múltiples técnicas cualitativas de muestreo en el mismo estudio.

En esta investigación estamos ante una historia que se construye gracias a la participación de múltiples y variadas personas que ofrecen su voz, su vivencia y su experiencia para poder construir una única historia. La forma de acceder a la muestra es generalmente a través de la madre y coinvestigadora, quien indica por conocimiento de la historia, qué personas pueden ofrecer una información más rica, más completa y más cercana a lo que ha vivido y experimentado Sergi en los diversos espacios y contextos. Así mismo, en las mismas entrevistas con los participantes puede darse el caso de que emerjan nuevos datos y que se destaquen a ciertas personas desconocidas hasta el momento. En ese caso, se consulta de nuevo a la madre y coinvestigadora y ésta, de la misma manera, informa de la idoneidad de incorporar o no a los nuevos informantes. Podemos señalar entonces, que estamos claramente ante un tipo de muestreo secuencial, pues los participantes se van seleccionando gradualmente a medida que se recogen los datos.

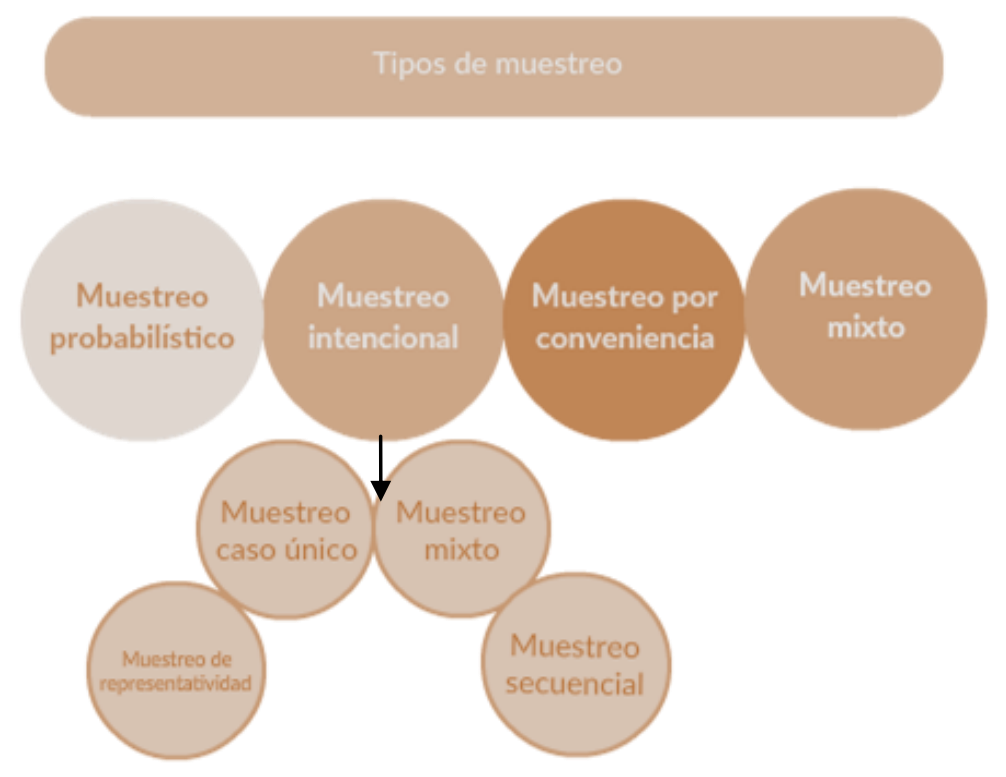

Figura3. Tipos de muestreo II (elaboración propia) 
De la misma manera que en nivel anterior, existen diversas técnicas de muestreo intencional secuencial y todas ellas poseen la similitud de llevar a cabo una selección gradual de la muestra. Podemos diferenciar entre (Teddlie \& Yu, 2007):

- Muestreo teórico: en el cual el investigador/a examina instancias particulares del fenómeno de interés. Cuando el investigador necesita entender un concepto o teoría, puede muestrear casos que le ayuden a tal comprensión, eligiendo a las unidades o informantes porque poseen uno o varios atributos que contribuyen a desarrollar la teoría (Miles \& Huberman, 1994; Creswell, 1998, 2005). En palabras de Amezcua y Gálvez (2002) se seleccionan nuevos casos en función de su potencial para ayudar a refinar o expandir los conceptos y teorías ya desarrollados.

- Muestreo de casos confirmatorios o contradictorios: La muestra se compone de patrones que van emergiendo de la información recogida. Este tipo de muestreo suele aplicarse cuando ya se ha aplicado un muestreo previo y el estudio o la investigación ya está avanzando, cuando ya se ha explorado un fenómeno social y se han observado pautas regulares de comportamiento, mostrando específicamente casos que sirvan para confirmar y casos para contradecir las conclusiones preliminares (Alaminos y Castejón, 2006).

- Muestreo de oportunidad (o emergente): se van siguiendo las pistas que surgen durante el trabajo de campo con una flexibilidad que permite aprovechar lo inesperado. Se tratan de casos que de manera fortuita se presentan ante el investigador, justo cuando éste los necesita, pueden ser individuos que por motivos ajenos a la investigación se reúnen y proporcionan una oportunidad extraordinaria para el trabajo de campo. (Miles \& Huberman, 1994; Creswell, 1998, 2005)

- Muestreo de "bola de nieve": Este tipo de muestreo se suele emplear generalmente en poblaciones especiales o de difícil acceso, de esta manera se identifican los casos de interés a partir de alguien que conozca a alguien que puede resultar un buen candidato para participar. Este tipo de muestras es en definitiva, un sistema de aproximación para localizar informantes, a partir de las tramas de interrelaciones internas de todo grupo (Alaminos y Castejón, 2006) 


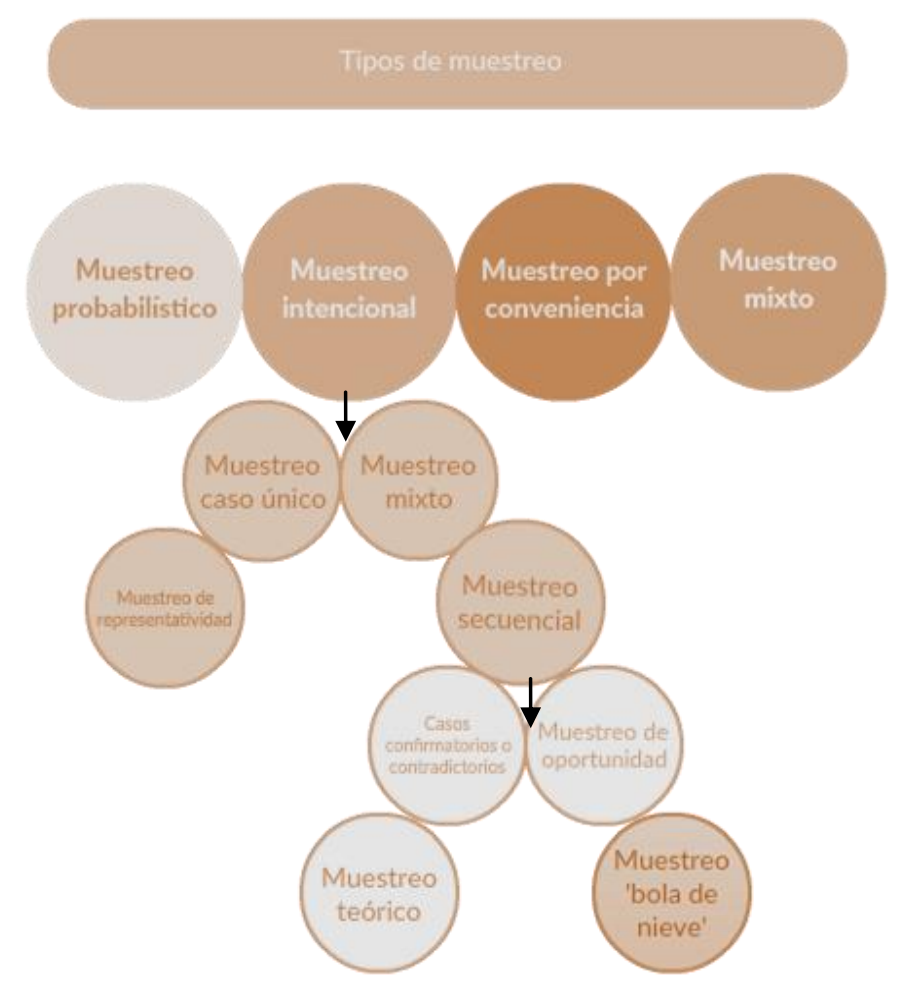

Figura 4. Tipos de muestreo III (elaboración propia)

En este último nivel de muestreo identificamos el muestreo de "bola de nieve" como el idóneo para este estudio. Nos encontramos ante un grupo o conjunto de personas, todas interrelacionadas entre sí, y vinculados por la presencia e implicación en la vida de Sergi. De esta manera, todos los participantes son siempre seleccionados a partir de lo que dice o indica otro, buscando siempre la máxima idoneidad y riqueza en los datos que estos puedan aportar a la investigación.

\subsubsection{Proceso de selección de la muestra}

El proceso de selección de la muestra de esta investigación arrancó con una negociación inicial con la madre y coinvestigadora. Es ella quien mejor conoce la historia en todas sus perspectivas y contextos y quien mejor puede discriminar aquellos participantes que poseen una mayor vinculación y relevancia en la historia de vida de Sergi. A partir de esta negociación inicial se elaboraró un listado de personas que debían formar parte de la muestra de este estudio, a la vez que se asignó a cada participante una sigla o diminutivo para referirse a él en todos los documentos de este trabajo. En esta primera negociación se incorporaron los siguientes participantes: 


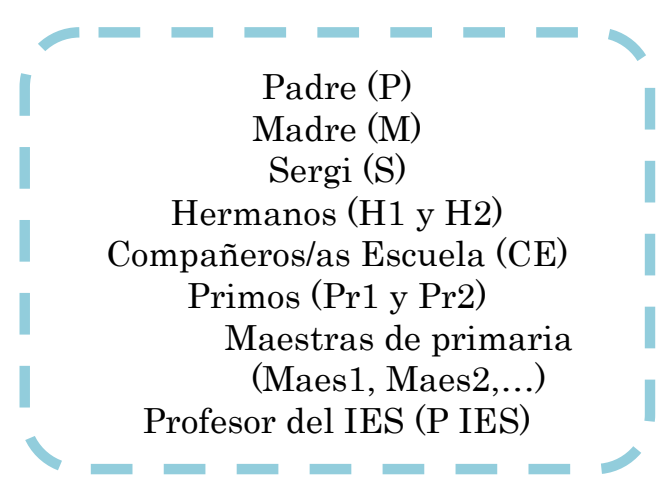

Figura 5. Muestra inicial.

Tras esta negociación inicial se iniciaron las primeras sesiones de recogida de datos con los participantes de la investigación. A medida que estas sesiones fueron avanzando, los mismos datos iban sugiriendo nuevos contextos y nuevos personajes de la historia que no se habían contemplado desde un principio. Así mismo, se comprobó que en esa negociación inicial se habían seleccionado participantes que se solapaban entre sí. Es decir, se había planteado entrevistar a diferentes personas que iban a poder aportar más o menos el mismo tipo de dato y/o desde la misma perspectiva. Ante esta situación se optó por establecer ciertos criterios que facilitaran la selección de participantes. En primer lugar se estableció el criterio de cercanía, es decir, elegir a la persona que conoce con mayor detalle y desde una posición más cercana las vivencias de Sergi. Este criterio busca asegurar que la información aportada por el/la participante seleccionado/a será lo más rica, variada y profunda posible. El otro criterio es el de pertenencia a diversos contextos $o$ ámbitos, es decir, que la persona seleccionada esté presente en más de un contexto o ámbito de la vida de Sergi (ocio, escolar o familiar). Mediante este criterio se pretende conseguir que la visión aportada por los participantes sea lo más poliédrica posible y que permita, al mismo tiempo, establecer relaciones o hacer inferencias entre elementos o personas pertenecientes a diferentes contextos o ámbitos de la vida de Sergi. 
De esta manera, la muestra inicial se fue modificando a lo largo del proceso de recogida de información de la siguiente forma:

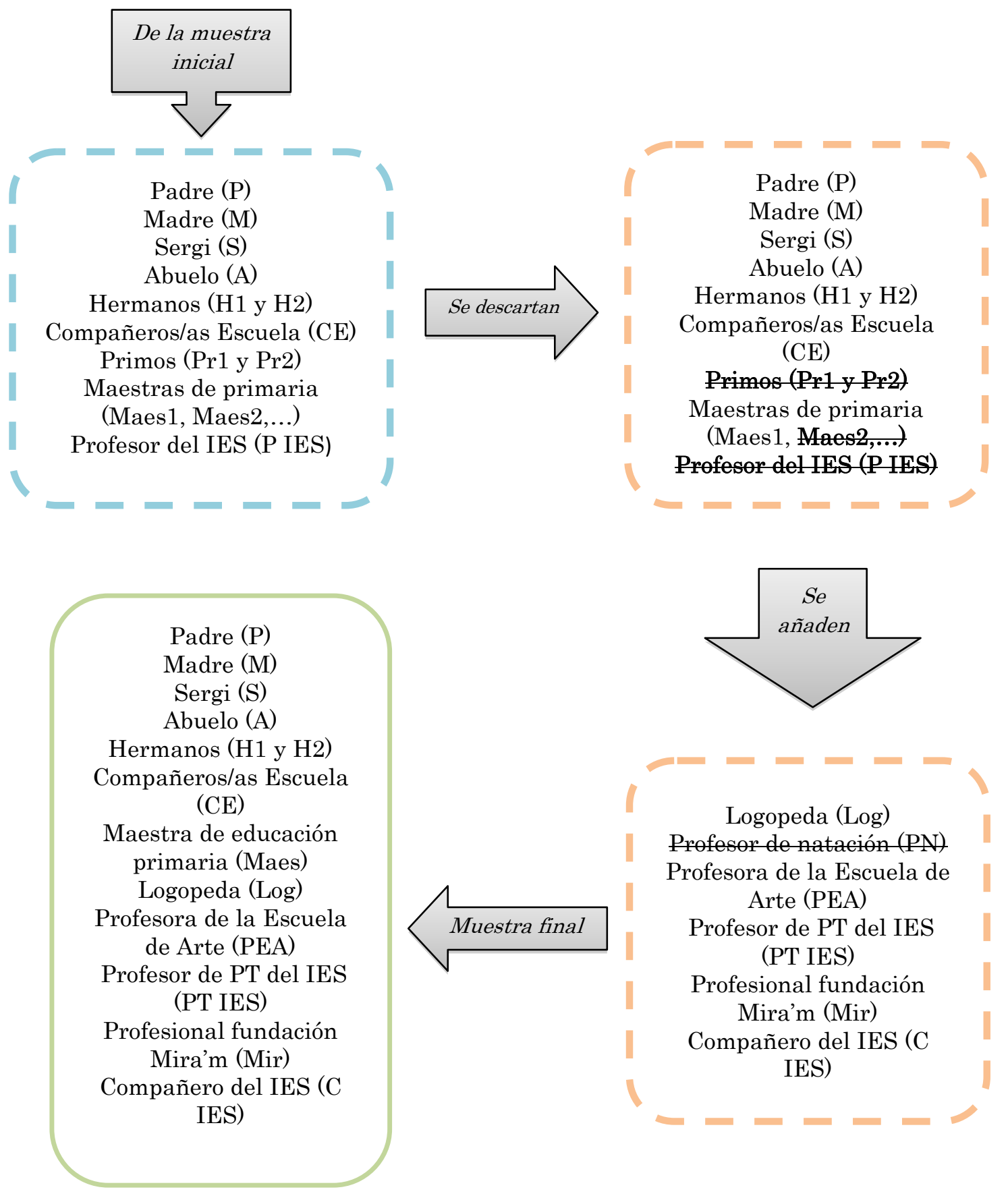

Figura 6. Proceso de selección de la muestra

Como podemos comprobar en el gráfico anterior, de la muestra inicial establecida en las primeras negociaciones con la madre y coinvestigadora, se decidió eliminar a los Primos (Pr1 y Pr2), pues los datos aportados por éstos era previsible que se solaparan con los aportados por los hermanos (H1 y H2). Además, los hermanos se encuentran presentes no solo en el contexto familiar, sino también en el de ocio y en el educativo, cumpliéndose de esta manera los dos criterios establecidos para la selección de participantes en el caso de solapamiento (criterio de cercanía y criterio de pertenencia a diversos contextos). 
De la misma manera, en un principio se estableció la posibilidad de entrevistar a diversas maestras de primaria para obtener datos desde la perspectiva docente de la escuela. Iniciado el proceso de recogida de datos se consideró que la información aportada por las diversas maestras se vería solapada en las entrevistas, pues el tipo de datos y la perspectiva desde la que provienen esas voces es la misma. Por esta razón, y ateniéndonos al criterio de cercanía, la madre y coinvestigadora hizo una selección de aquella maestra (Maes) con mayor implicación y dedicación hacia Sergi a lo largo de su escolarización. Por lo tanto, se estableció que solo contaríamos con una única maestra de la etapa de la educación primaria entre la muestra.

Así mismo, de esta muestra inicial fue eliminado el profesor del IES (P IES) e incorporado el profesor de Pedagogía Terapéutica (PT IES). En un principio, la idea de incorporar al profesor (P TIES) como muestra estaba vinculada a la posibilidad de obtener datos desde una perspectiva docente en el ámbito de la educación secundaria y su planteamiento académico futuro. No obstante, se reconsideró esta elección ya que el profesor de Pedagogía Terapéutica (PT IES) es quien trabaja de manera más cercana al protagonista de la historia (criterio de cercanía), conoce de primera mano su trabajo dentro y fuera del aula, elabora los materiales de Sergi y supervisa todas las pruebas o trabajos en los que Sergi participa. De esta manera, podríamos además obtener la visión de cómo los diferentes docentes que pasan por el aula de Sergi interactúan con él, cómo se implican en su labor docente y qué tipo de estrategias de participación utilizan para incluir a Sergi en la dinámica de aula.

A medida que avanzaba el proceso de recogida de información, los datos aportados por diversos participantes hacían referencia a otros contextos o ámbitos no considerados hasta el momento, e incluso señalaban y destacaban a ciertas personas en particular como significativas en cada uno de ellos. Ante esta situación, se renegoció con la madre y coinvestigadora la posibilidad e idoneidad de incorporar estos nuevos contextos con sus respectivas voces destacadas. De esta manera fueron añadidos a la muestra final participantes como su logopeda particular (Log), el profesor de natación (PN), la profesora de la Escuela de Arte (PEA), una de las profesionales de la Fundación Mira'm de Valencia (Mir) y un compañero de clase del instituto de Sergi (C IES). Todas y cada una de estas incorporaciones no respondían solamente a motivos de citación de otros participantes, sino que debía ser una reiteración constante por varios participantes y ser considerado, además, relevante en su ámbito o contexto con respecto a la vida de Sergi.

De esta manera, la muestra de esta investigación estaría compuesta por 17 participantes con distintos niveles de participación e implicación. No obstante, debemos apuntar aquí, que por motivos externos a la investigación, la familia de Sergi decidió prescindir de las aportaciones del profesor de natación (PN), motivo por el cual este participante fue eliminado de la lista y se redujo la muestra a 16 participantes. Veamos como se organiza la muestra final de la investigación según los contextos social, educativo y familiar: 


\section{$\underline{\text { Contexto ocio }}$}

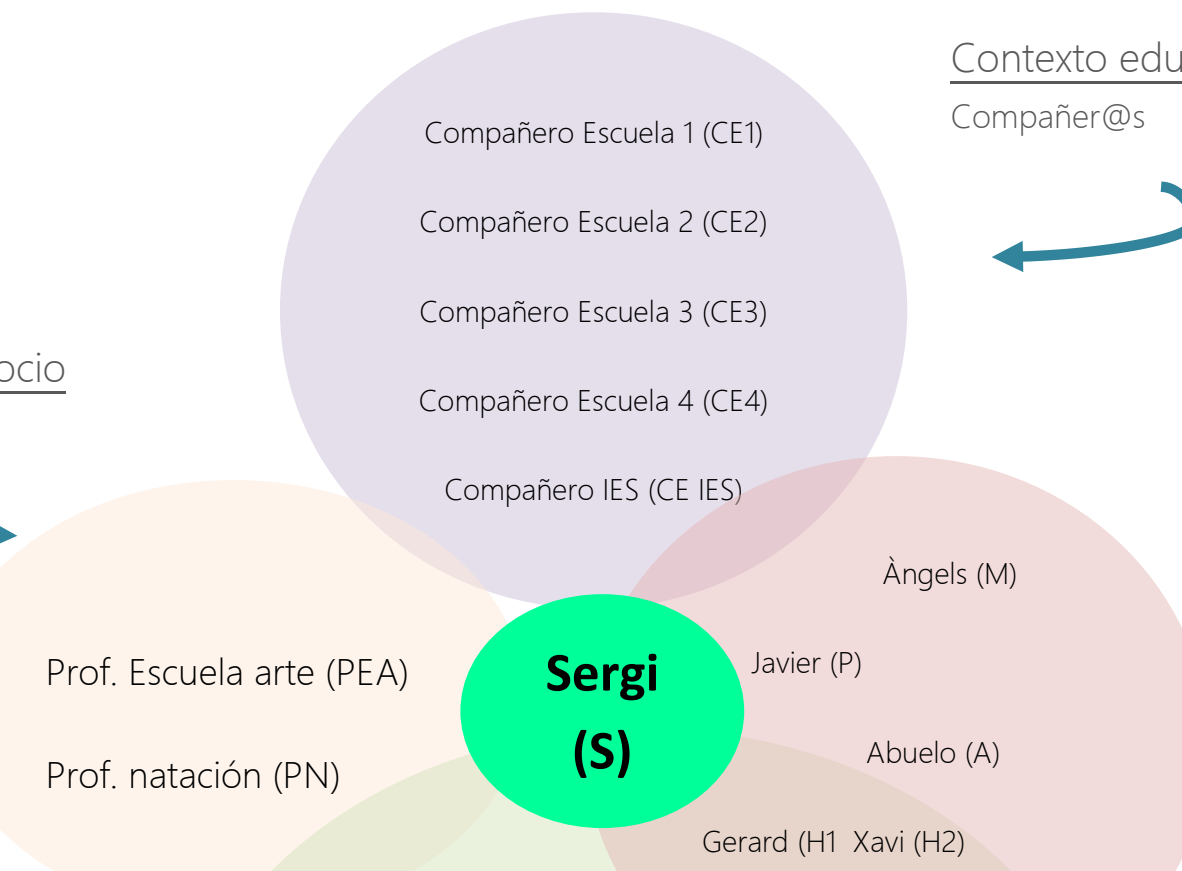

Educador (Edu)

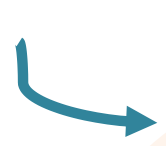

Gerard $(\mathrm{H} 1$ Xavi $(\mathrm{H} 2)$

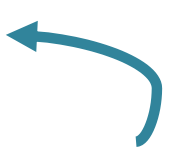

Educador (Edu)

$\underline{\text { Contexto familiar }}$

Fundació Mira'm (Mir)

$$
\text { Logopeda (Log) }
$$

Maestra

Profesor Pedagogía

Primaria (Maes)

Terapéutica (PT IES)

Contexto educativo

Profesionales

Figura 7. Muestra por contextos

Tal y como hemos expuesto previamente en el capítulo 3, según Tójar (2006) existen diversos tipos de implicación de los participantes en una investigación en función del tipo de colaboración que prestan. Veamos a continuación cómo se traslada esto a nuestra muestra: 


\begin{tabular}{|c|c|c|c|}
\hline $\begin{array}{c}\text { Ámbito de } \\
\text { Pertenencia }\end{array}$ & \multicolumn{2}{|c|}{ Participantes } & Tipo de implicación \\
\hline $\begin{array}{c}\text { Protagonista } \\
\text { de la } \\
\text { historia }\end{array}$ & \multicolumn{2}{|l|}{ Sergi (S) } & Colaborador activo \\
\hline \multirow{5}{*}{$\begin{array}{l}\text { Ámbito } \\
\text { familiar }\end{array}$} & \multicolumn{2}{|l|}{ Madre (M) } & Anfitrión (coinvestigadora) \\
\hline & \multicolumn{2}{|l|}{ Padre $(\mathrm{P})$} & Colaborador activo \\
\hline & \multicolumn{2}{|l|}{ Abuelo (A) } & Colaborador activo \\
\hline & Hermanos (H1 y H2) & Hermano 1 & Colaborador activo \\
\hline & & Hermano 2 & Colaborador activo \\
\hline \multirow{8}{*}{$\begin{array}{l}\text { Ámbito } \\
\text { escolar }\end{array}$} & Compañeros/as & Compañer@1 & Colaborador activo \\
\hline & \multirow{3}{*}{ Escuela (CE) } & Compañer@2 & Colaborador activo \\
\hline & & Compañer@3 & Informador \\
\hline & & Compañer@ 4 & Informador \\
\hline & \multicolumn{2}{|c|}{ Maestra de educación primaria (Maes) } & Informador \\
\hline & \multicolumn{2}{|l|}{ Logopeda (Log) } & Informador \\
\hline & \multicolumn{2}{|c|}{ Compañero del IES (C IES) } & Informador \\
\hline & \multicolumn{2}{|c|}{ Profesor de PT del IES (PT IES) } & Informador \\
\hline \multirow{2}{*}{$\begin{array}{l}\text { Ámbito de } \\
\text { ocio }\end{array}$} & \multicolumn{2}{|c|}{ Profesora de la Escuela de Arte (PEA) } & Informador \\
\hline & \multicolumn{2}{|c|}{ Profesional fundación Mira'm (Mir) } & Informador \\
\hline
\end{tabular}

Tabla 8. Implicación de los participantes de la investigación

\subsubsection{Técnicas e instrumentos. Proceso de recogida de información}

En la investigación biográfico narrativa, cabe tener en cuenta la existencia de un amplio espectro de instrumentos o estrategias de recogida de datos posible que pueden ayudarnos a construir el texto biográfico en sí mismo. Clandinin y Connelly (1994) proponen en su trabajo que para abordar un estudio de tipo biográfico-narrativo podemos utilizar a instrumentos tales como: historias orales, crónicas, historias o relatos de familia, fotografías, memorias y otros artefactos personales, entrevistas, diarios, escritos autobiográficos, cartas, conversaciones y notas de campo y otras historias de campo.

En esta investigación, tendiendo en cuenta este amplio abanico de posibilidades del método, han sido múltiples y diversas las técnicas de recogida de datos utilizadas en el trabajo de campo. Debido a las diferentes características de cada una de ellas, podemos decir que, durante el mismo proceso de recogida, unas técnicas nos iban dando las claves y pistas necesarias para el planteamiento y utilización de otras. Así mismo, no todas las técnicas de recogida de datos han sido utilizadas con todos los participantes de la investigación, sino que esto ha variado en función de cada participante, su vinculación e implicación con la vida de Sergi y sus características personales.

En primer lugar se procederá a exponer y describir de manera detallada los diversos instrumentos o técnicas utilizadas en esta recolección de datos para más tarde pormenorizar el proceso seguido en esta recolección.

\subsubsection{Entrevistas}

La entrevista es una de las técnicas o instrumentos de recogida de datos más utilizados en las investigaciones de tipo cualitativo, pues la variabilidad y flexibilidad que ofrecen junto con la gran cantidad de información que permiten recoger, hacen de ellas un elemento esencial para el investigador. De hecho, Bolívar 
et al. (2001) ya indicaban en su trabajo que las entrevistas, en sus diversas variantes y formatos, son la base metodológica de una investigación biográfica. Las entrevistas no son una conversación sin más (Atkinson, 1998), sino que por muy espontáneas y familiares que resulten hay un objetivo de investigación que las sustenta y les da sentido. No podemos obviar, por lo tanto, la intencionalidad subyacente ni alterar el flujo de información a través de opiniones particulares y personales.

La entrevista como técnica de recolección de datos busca entender asuntos del mundo de las personas entrevistadas a través de su propia perspectiva y expresados con sus propias palabras. Se trata de una técnica mediante la que se pretende obtener información sobre aspectos subjetivos de la persona (creencias, opiniones, valores y actitudes) en relación al tema de estudio (Bisquerra, 2004). En esta técnica de recolección de datos, entrevistador y entrevistado establecen una interacción cara a cara, un intercambio y diálogo que acaba permitiendo la construcción de conocimiento (Kvale, 2011). Tal y como Kvale (2011) indica, el propósito de las entrevistas es obtener descripciones del mundo de vida del entrevistado/a respecto a la interpretación de los significados de los fenómenos descritos. Se trata de una herramienta flexible y adaptable a situaciones individuales, donde se pueden observar tanto comportamientos verbales como no verbales y en las que existe un alto índice de respuesta (McMillan y Schumacher, 2005).

Según Rubin y Rubin (1995) es preferible que el diseño de las entrevistas sea flexible, iterativo y continuo a imponer al principio un plan a llevar a cabo. Por diseño flexible se entiende la adaptabilidad en función de los entrevistados, por iterativo el cambio del plan de muestreo y enfoque de entrevista individual varias veces y en varias etapas, y en último lugar, por continuo se entiende la posibilidad de rediseñar y adaptar este diseño a lo largo de todo el proceso de investigación. Solo de esta manera obtendremos entrevistas que además de responder las preguntas de nuestra investigación respetan las características de los participantes, los tiempos y las necesidades del campo de estudio.

La forma más habitual de clasificar los tipos de entrevistas se basa en su grado de estructuración, del cual resulta un continuo delimitado por sus extremos: las entrevistas altamente estructuradas y las no estructuradas o espontáneas (Albert, 2006). Para este trabajo, se ha elegido un tipo de entrevista que no se posiciona en ninguno de estos extremos, estamos hablando de las entrevistas llamadas semiestructuradas (Kvale, 2011). De esta forma, nos encontramos ante un instrumento que aunque parte de un esquema de interacción preestablecido, no aplica literalmente un protocolo fuertemente estructurado (Bolívar et al., 2001) y otorga cierto grado de flexibilidad y libertad en relación a aspectos como la dirección de la conversación y las respuestas del entrevistado. La entrevista semiestructurada puede definirse como una conversación donde, mediante una planificación previa, se establecen los ámbitos sobre los que versarán las cuestiones y se organiza mediante una serie de preguntas que buscan descubrir acontecimientos y dimensiones subjetivas de las personas tales como las creencias, pensamientos, valores,... (Buendía, Colás y Hernández, 1998).

Según Kvale (2011) previamente a la realización de las entrevistas es necesario establecer una organización temática, es decir, plantearse cuestiones como el por qué (propósito), el qué (conocimiento previo sobre la materia a estudiar) y el cómo (conocer técnicas de entrevista y aplicar la más adecuada) (Kvale, 2011). Todas estas cuestiones fueron planteadas en relación a la investigación aquí 
expuesta y de ello emergieron: los objetivos que se pretenden alcanzar cada una de las entrevistas (detallados en cada una de ellas), la materia sobre la que indagar que emergía de entrevistas realizadas a otros participantes (este proceso de generación de temas se explicará más adelante) y se eligieron diferentes tipos de entrevistas en función de las necesidades de la propia investigación (detallados a continuación).

\section{a) Tipos de entrevista}

En función de los objetivos de nuestra investigación y la muestra a la que deseamos acceder, planteamos diferentes tipos de entrevistas:

\section{a.1. Entrevista en Profundidad (EP)}

La entrevista en profundidad es, según Tójar (2006), la más comúnmente empleada en investigación cualitativa. Como tal este tipo de entrevistas, tiene un carácter abierto, flexible, dinámico y persistente que posibilita una amplia riqueza informativa, pues se trata de un proceso comunicativo fluido entre entrevistador y entrevistado, que garantiza la incorporación de nuevos temas o cuestiones al cuerpo de datos de una forma altamente natural. Las entrevistas en profundidad se entienden como reiterados encuentros cara a cara entre el investigador y los informantes, encuentros dirigidos hacia la comprensión de las perspectivas que tienen los informantes respecto de sus vidas, experiencias o situaciones (Taylor \& Bogdan, 2009).

Para Alonso (1994), existen 4 campos básicos de utilización de este tipo de entrevistas: (a) reconstrucción de acciones pasadas, (b) estudio de las representaciones sociales personalizadas, (c) estudio de la interacción entre constituciones psicológicas personales y conductas sociales específicas prospección de los campos semánticos, vocabulario y discursos arquetípicos de grupos y (d) colectivos sobre los que posteriormente se pasará un cuestionario.

En nuestro caso, la entrevista en profundidad pretende ahondar en el primero de estos campos, la reconstrucción de acciones pasadas, pero contemplando también expectativas y perspectivas futuras desde un enfoque biográfico. Por ello, esta entrevista en profundidad utilizada en esta investigación posee además un carácter biográfico, en el que la persona entrevistada explora su pasado para rememorar episodios vividos $\mathrm{y}$, a través de la intervención del entrevistador, profundizar en diversos aspectos de su vida (Bolívar et al., 2001). Se trata de un instrumento que ayuda al investigador/a a reconstruir la historia de vida de una persona y sus diversas dimensiones desde la perspectiva del mismo entrevistado.

En esta investigación, se realiza una entrevista en profundidad (EP) a la madre del protagonista y coinvestigadora con la pretensión de obtener una visión cronológica lo más completa posible sobre la trayectoria vital de Sergi. Es la madre (M) la persona elegida para la realización de esta entrevista puesto que, en las negociaciones iniciales, se manifestó que ella es quién conoce con mayor profundidad los matices y detalles de la historia y quien más ha establecido un contacto directo con los diferentes "personajes" que aparecen en la historia. A través de este instrumento se pretende rememorar las distintas etapas por las que ha ido transcurriendo Sergi e ir reconstruyendo acontecimientos, problemas, ayudas y personas relevantes que se han ido sucediendo a lo largo de su trayectoria. Por ello, esta entrevista en profundidad (EP) con carácter biográfico se 
encuentra organizada en base las distintas etapas o episodios (nacimiento, infancia, educación primaria, transición a la educación secundaria y previsiones de futuro) hasta llegar a la actualidad, pretendiendo al mismo tiempo repasar aquello acontecido en cada uno de los diferentes ámbitos o contextos que pretende estudiar esta investigación (social, familiar y educativo). Debido a la extensión de esta entrevista, se requirieron diversos encuentros para poder completar todas las etapas de la historia de vida de Sergi.

Veamos en la siguiente ilustración cómo se organizó dicha entrevista:

Objeto de la entrevista:

\section{Entrevista en profundidad}

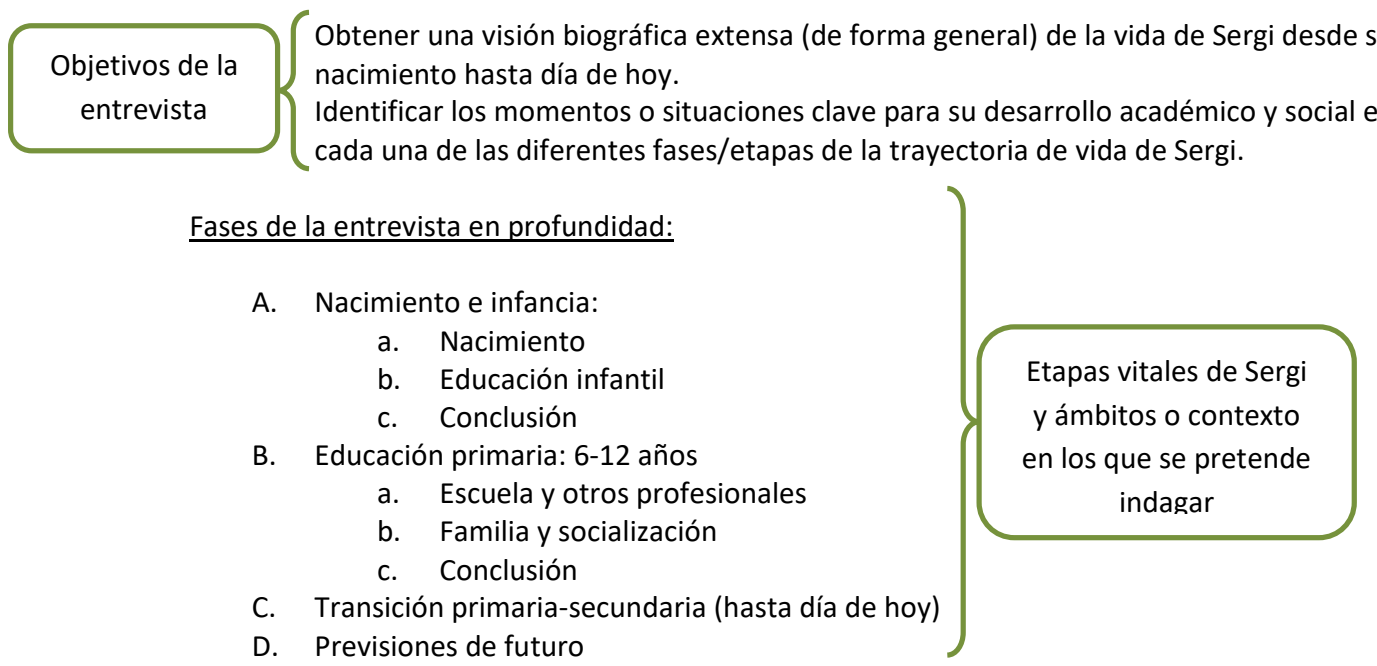

A.-Nacimiento e infancia

NACIMIENTO:

An1. Desde el momento en el que os enterasteis de que estabas embarazada, ¿Cómo recibisteis la noticia? ¿Cómo fue la preparación en casa para su llegada (hermano, organización,...)?

Guion de preguntas de la entrevista de cada etapa y ámbito de investigación

An2. Hablemos ahora del momento del parto ¿Cómo fue? Cuéntame cómo sucedió ¿Hubo algún tipo de complicación?

An3. Ahora centrémonos en la llegada a casa, ¿cómo fue el proceso de adaptación al hogar? ¿Cómo dirías que lo acogieron: hermanos, familia y amigos de la familia?

An4. En aquel momento, ¿en qué situación se encontraba la familia? ¿Trabajabais los dos? ¿El hermano iba al colegio? ¿Cómo os organizasteis?

Figura 8. Partes de las entrevistas

\section{a.2. Entrevista Temática (ET)}

Tras la realización de la Entrevista en Profundidad (EP), se procedió a transcribir y revisar los datos recogidos. Como indica Bolívar et al. (2001), el texto transcrito debe ser sometido a un primer análisis para la búsqueda de puntos oscuros o "en blanco" que no puedan ser conexionados o elementos que faltan para 
poder comprender la trayectoria. La idea de encontrar estos puntos oscuros y/o establecer las primeras hipótesis interpretativas de la trayectoria de vida del protagonista, dio lugar a futuras entrevistas que buscaban complementar y contrastar los datos obtenidos mediante este primer instrumento.

Siguiendo estas indicaciones, una vez transcritos los datos de la Entrevista en Profundidad a la Madre (EPM), se procedió a la revisión de su contenido, detectando "cuestiones emergentes", dudas o nuevos temas que debían ser abordados en las futuras entrevistas. De esta manera, se hallaron "cuestiones" relativas tanto a la persona entrevistada (madre de Sergi) como a otros participantes de esta investigación. De esta manera se generaron nuevas entrevistas que denominaremos temáticas (que focalizan en temas o contenidos concretos) a realizar con la misma persona entrevistada en un segundo encuentro o con nuevos participantes.

Generalmente, el término entrevista focalizada suele estar más extendido que el de entrevistas temáticas, pues éste último es utilizado por un nombre más reducido de autores (Stefanini, Scherer, Scherer, Cavalin \& Guazzelli, 2015; Naciones Unidas, 2004; Bermúdez y Rodríguez, 2009; De la Cruz, 2012; Moura, Araújo, Flores, Muniz, y Braga, 2002; Fisk, Kendall \& Merton, 1998; Vallejo y Finol de Franco, 2010). De hecho, existe una cierta confusión en la literatura entre lo que se entiende por entrevistas temáticas y entrevistas focalizadas. Tras la pertinente revisión de la literatura observamos que mientras las 'entrevistas temáticas' buscan obtener respuestas a fondo sobre cada tema abordado y son consideradas un método de recogida de información especialmente adecuado cuando no existe una teoría exacta sobre el tema a tratar, (Huamán, 2005), las 'entrevistas focalizadas' se basan en otras pretensiones. Autores como Merton y Kendall (1956, citado en Canales, 2006), exponen que las entrevistas focalizadas indagan sobre personas que han sido expuestas a eventos o situaciones bien delimitadas en el espacio y tiempo. Algunos ejemplos de estas situaciones son el visionado de una película, vivir una experiencia concreta, escuchar un programa de radio, leer un determinado libro o artículo,... Se suele utilizar generalmente en estudios que buscan indagar en cambios de actitud, para estudiar situaciones que serán objeto de trabajo social, animación cultural o de tipo educativo; igualmente para abordar problemas poco conocidos por el investigador y que se prevé que serán estudiadas más adelante (Ander-Egg, 1982, citado en Pérez, 2005).

En nuestro estudio, tras obtener la visión cronológica y extendida de la trayectoria de Sergi mediante la Entrevista en Profundidad (EP), nos enfrentamos a ciertos temas que es necesario abordar de nuevo con diferentes participantes. De esta manera, se van obteniendo nuevas Entrevistas Temática (ET) con cada uno de los participantes sobre temas concretos, y de estas entrevistas vuelven a surgir nuevos temas a abordar en futuros encuentros. Se trata de una especie de "cadena" en la construcción de las entrevistas temáticas, donde siempre lo dicho o aportado por un participante nos lleva a nuevas cuestiones o nuevos participantes de la investigación.

Cabe tener en cuenta aquí que este tipo de entrevistas posee una estructura mucho más definida que la entrevista en profundidad, pues parte de un guión temático previamente establecido. En este caso el guión determina de antemano la información relevante que necesitamos obtener, permitiendo 
entrelazar temas e ir construyendo un conocimiento holístico y comprensivo de la realidad (Bisquerra, 2004)

A continuación podemos observar un ejemplo de cómo a partir de la revisión de datos de la transcripción de la Entrevista en Profundidad (EP) realizada a la madre del protagonista, se obtienen ciertas dudas emergentes o temas que, tras el pertinente proceso de organización y distribución, acaba por concretarse en bloques temáticos de una nueva Entrevista Temática: 


\section{Entrevista en Profundidad (EP) revisada}

natación. Al principio lloraba un poco sabes, pero yo siempre.... Ya le empezaba a ir con los pictogramas y "nadar" y la "mamá contenta" y el "papá contento", yy le hacía caritas y él entonces sí se quedaba. Ahora cuando ibas a buscarlo tenía una alegria (R), se tiraba encima en plan "ya está, ahora ya hay alguien que me entiende" (R). Pero yo creo que a él pobre el hecho de no saberse explicar $y$ todo eso, lo frustraba, le causaba angustia, frustración.... y a los sitios donde iba a veces me decian, "algún ratito él se va allí a un rinconcito y yo lo dejo estar" y yo siempre les decía "sí, sí, déjalo estar porque él necesita su espacio". Es que tiene que ser frustrante esta, querer comunicar y no poder. Si le pasa todavía ahora. Él en una explicación muy general pues... pilla algo per sino desconecta porque no se entera.

$E: Y$ en esta época, las relaciones sociales fueron un tipo de ayuda para vosotros y para él...

M: Nosotros en aquella época intentábamos también hacer la vida juntos. No teníamos a Xavi todavía... pero intentábamos ir los 4, adaptarnos. Fue cuando de Valencia nos dijeron "tenéis que salir de casa, tenéis que ir a los sitios y Sergi tiene que saber qué hay en un restaurante, que se tiene que esperar para que le traigan la comida, si queréis ir a un parque temático tiene que saber que tiene que esperar un turno y tal "entonces eso empezamos a llevarlo poco a poco asi. "'Ahora iremos aquí, ahora iremos allá" haciamos nuestras historietas sociales. También saliamos mucho con unos amigos de Benicarló y con ellos f́bamos mucho a esquiar. Cuando empezó a esquiar Sergi tenía 5 años. Y Y le buscábamos un monitor que tuviera mucha paciencia y antes de salir del hotel yo le hacía todos los dibujitos, que tenía que hacer la cuña en forma de casita, porque él quería bajar recto (R). Pero no nos limitó para nada. Yo creo que siempre

\section{Comentario [A1]: EF PN(comunicación) \\ Comentario [RM2]: EFP y EFA (dificil comienzo en la atación}

Comentario [RM3]: EFs (necesidad de soledad)

Comentario [A4]: EFMir (trabajo de la cotidianeidad)

Comentario [A5]: EFM (historias sociales y función)

Comentario [RM7]: EFs (inicio y gusto por el esqui)

$\prod$

Preguntas emergentes o dudas (a quién y qué se debe preguntar)

\section{Entrevista Temática (ET) emergente a partir de la revisión de EP}

Tras la entrevista en profundidad a la madre de Sergi (M), se realizó la transcripción y revisión del contenido para poder generar una primera aproximación de la trayectoria vital de protagonista. Dicha revisión, generaba nuevas preguntas, dudas o "huecos de información" que se necesitaban rellenar para poder entender la globalidad de la historia. En base a esto se formularon nuevas preguntas y se aglutinaron en diversas o núcleos de preguntas.

\section{Objetivos de la entrevista:}

Aclarar conceptos o términos utilizados en la entrevista en profundidad. Rellenar huecos informativos sobre lugares, personas,... importantes en la historia de vida de Sergi.

Profundizar en elementos clave o trascendentales de la historia para una mayor comprensión de los mismos.

\section{Categorías de la entrevista:}

E. Diagnóstico

F. Materiales y ayudas

G. El día a día de Sergi

H. Personas en la vida de Serg

I. Con el centro

Las amistades (+ despedida de Sergi)

K. Ocio

L. Sergi y su personalidad

M. Último año

N. Otros

o. Cierre
Temas o bloques de una nueva entrevista a partir de otras anteriores

Figura 9. Revisión de entrevista en profundidad y generación de nuevos temas 


\section{a.3. Entrevista Grupal (EG)}

Una de las modalidades de entrevista utilizadas en el presente trabajo es la entrevista grupal. Según Ruiz Olabuénaga (1996), el término 'grupo' debemos entenderlo como sinónimo de un colectivo de personas que participan en poseen los mismos intereses, los mismos valores, la misma situación social o la misma experiencia, y son analizadas tras haber sido puestas de algún modo u otro en contacto entre sí. La entrevista grupal supone la realización de una única entrevista a varias personas a la vez (Flick, 2015) para que estas expresen sus opiniones, revelen sus actitudes o manifiesten sus conductas (Ruiz Olabuénaga, 1996). Ésta no debe confundirse con la técnica de grupos de discusión (o focus group), pues ambas tienen objetivos diferentes: El grupo de discusión es una entrevista en la que un conjunto de personas que comparten alguna característica, se reúnen para expresar y confrontar sus opiniones bajo la coordinación de un moderador, buscando la creación de un discurso grupal a través de la interacción social. En cambio, en una entrevista grupal los componentes del mismo no constituyen un discurso grupal, sino que más bien la conversación se compone de intervenciones individuales pese al contexto grupal (Llopis, 2004).

En este sentido, una entrevista grupal vendría a ser una escucha al grupo en la que se habla como entrevistado singular y aislado predominando el punto de vista personal (Canales y Peinado, 1995). Estamos ante un instrumento de recogida de datos que lejos de buscar la interacción grupal, pretende indagar en asuntos, temas, hechos o significados que nada o poco tienen que ver con la interacción social creada dentro del grupo. Es decir, el grupo en sí se convierte en un medio para conocer (y por lo tanto analizar) algo de fuera del grupo (Ruiz Olabuénaga, 1996).

En lo que se refiere a nuestra investigación, se recurrió a la entrevista grupal por ser un instrumento de recogida de datos que nos permitía realizar la misma entrevista a varias personas a la vez. Dicha técnica fue empleada en momentos puntuales de la investigación y con determinados participantes. Estamos hablando de aquellos casos en los que (a) resultaba complicado identificar qué persona del grupo tenía una visión más completa y profunda de la vida de Sergi (recordemos aquí los criterios de selección de la muestra como el de cercanía y el de pertenencia a varios contextos) y se acordó seleccionar al grupo en conjunto, y (b) se consideraba que al realizar la entrevista de manera grupal los participantes se sentirían más cómodos y relajados y, entre unos y otros, complementarían sus aportaciones. La entrevista grupal (EG) solo fue empleada con los hermanos de Sergi (H1 y H2) y con los compañeros/as de escuela de Sergi (CE).

\section{b) Proceso de construcción y realización de las entrevistas}

Para la realización de las diferentes entrevistas, se han realizado sistemáticamente una serie de pasos que coinciden con los planteados por Atkinson (1998) y Sanmartín (2003). Estos autores establecen que toda entrevista debe pasar por los pasos de planificación o preentrevista, el encuentro o desarrollo de la entrevista y la transcripción e interpretación. A continuación se expone cómo se han realizado estos pasos en nuestra investigación: 


\section{b.1. Elaboración de las entrevistas}

Para la elaboración y preparación de las entrevistas de esta investigación, se optó por una estrategia emergente, es decir, que fueran los propios datos los que fueran indicando la necesidad de generar nuevas preguntas, incorporar nuevos participantes y nuevos temas. Pero para ello, era necesario arrancar con una entrevista que nos ofreciera una visión general de la situación, una panorámica de donde partir a la búsqueda de nuevos datos y nuevos participantes, la entrevista con profundidad a la madre del protagonista (EPM). La principal finalidad de este encuentro era la obtención de una cronología general en la que se contemplaran los tres ámbitos de la vida de Sergi estudiados (ocio, familia y educación).

A partir de todo lo aportado por la madre en esta entrevista (EPM), emergieron de su lectura una serie de temas nuevos, de "cuestiones emergentes", dudas o vacíos de información que era necesario retomar en encuentros posteriores. En este sentido, podían darse dos circunstancias, (a) que fueran "cuestiones" que había que retomar de nuevo con la madre para encontrar una aclaración al respecto, o (b) que fueran cuestiones referidas a otras personas $u$ otros contextos, por lo que había que abrir la posibilidad de encontrarse con un nuevo informante de la investigación (y de una nueva entrevista).

Con la finalidad de controlar este proceso, se elaboraron unos mapas temáticos (anexo I) donde se aprecia cómo a partir de esta primera entrevista en profundidad (EPM) emergen las nuevas "cuestiones" que se realizarían a otros participantes, y cómo de estos nuevos encuentros se revertía a nuevas entrevistas.

Estamos ante una sucesión de entrevistas en cadena, siempre basadas en las aportaciones de los y las participantes. Este proceso de creación de entrevistas finalizó cuando no se hallaron nuevas cuestiones ni se requerían nuevos participantes para complementar la información (saturación), y el ciclo de recogida de datos se cerró sobre sí mismo. De hecho, el cierre de esta recogida de datos se realizó con la Entrevista Temática al Padre de Sergi (ETP), pues éste, al igual que la madre tuvo un papel clave en el inicio del proceso, el padre poseía una visión muy amplia para poder cerrar el resto de cuestiones que habían ido apareciendo.

Para poder entender el proceso al que nos referimos, se recomienda revisar con detenimiento el anexo $I$. No obstante, a continuación podemos encontrar un esquema-resumen de cómo se llevó a cabo el proceso de construcción de entrevistas aquí expuesto. 


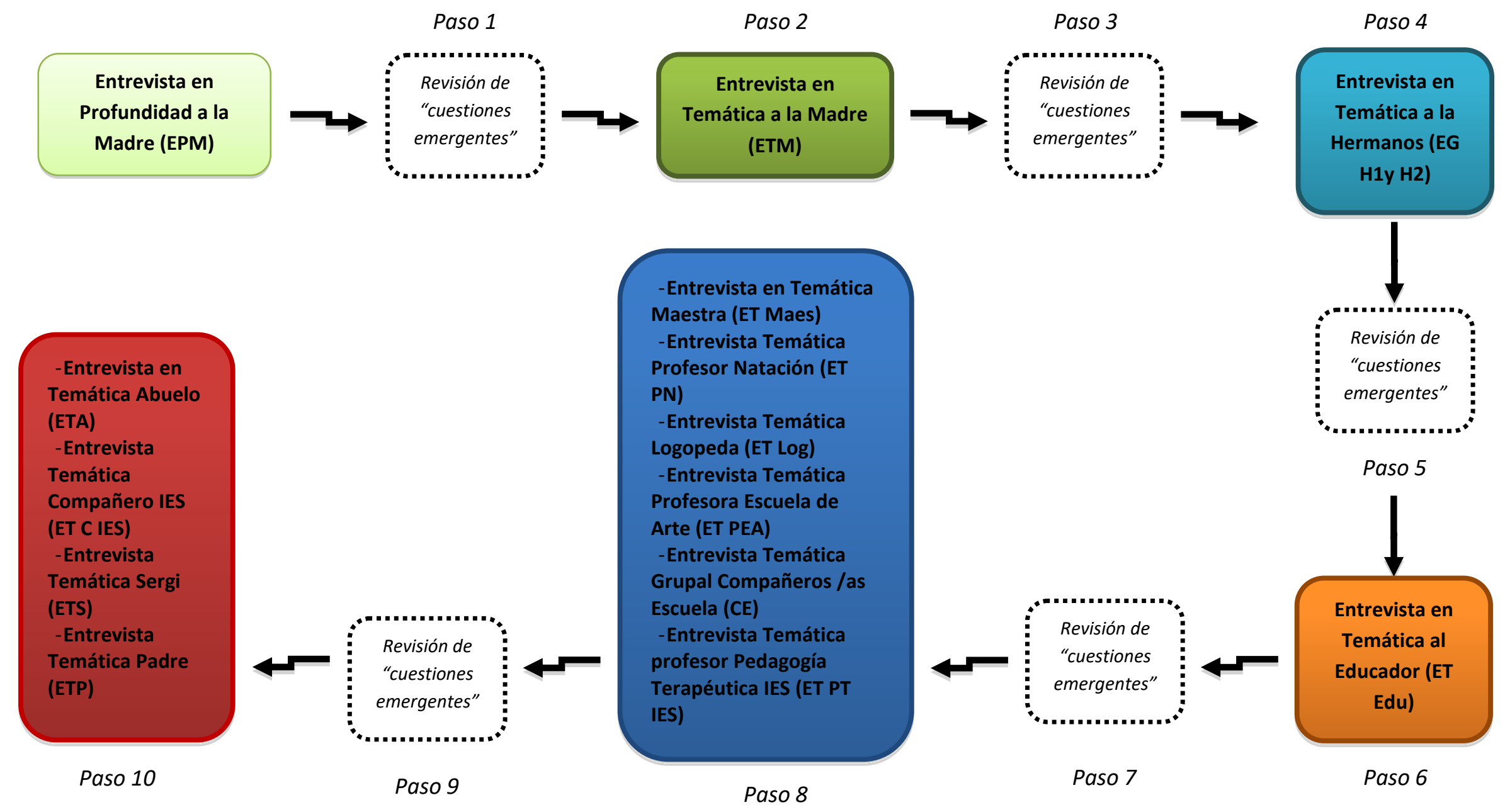

Figura 10. Proceso de elaboración y realización de entrevistas 
Veamos en la siguiente secuencia cómo se ha llevado a cabo el proceso de revisión y construcción de las entrevistas a partir del esquema anterior:

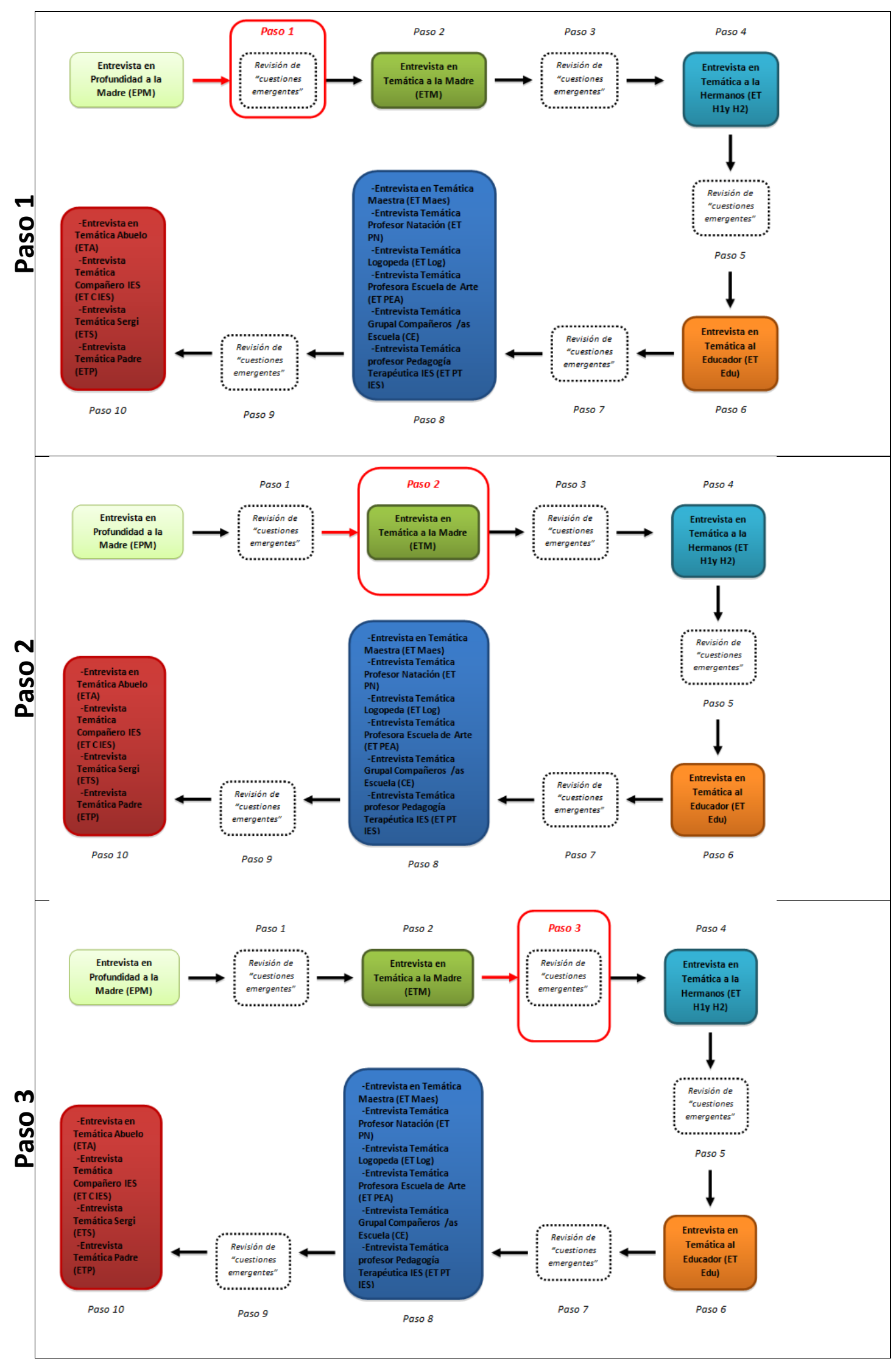




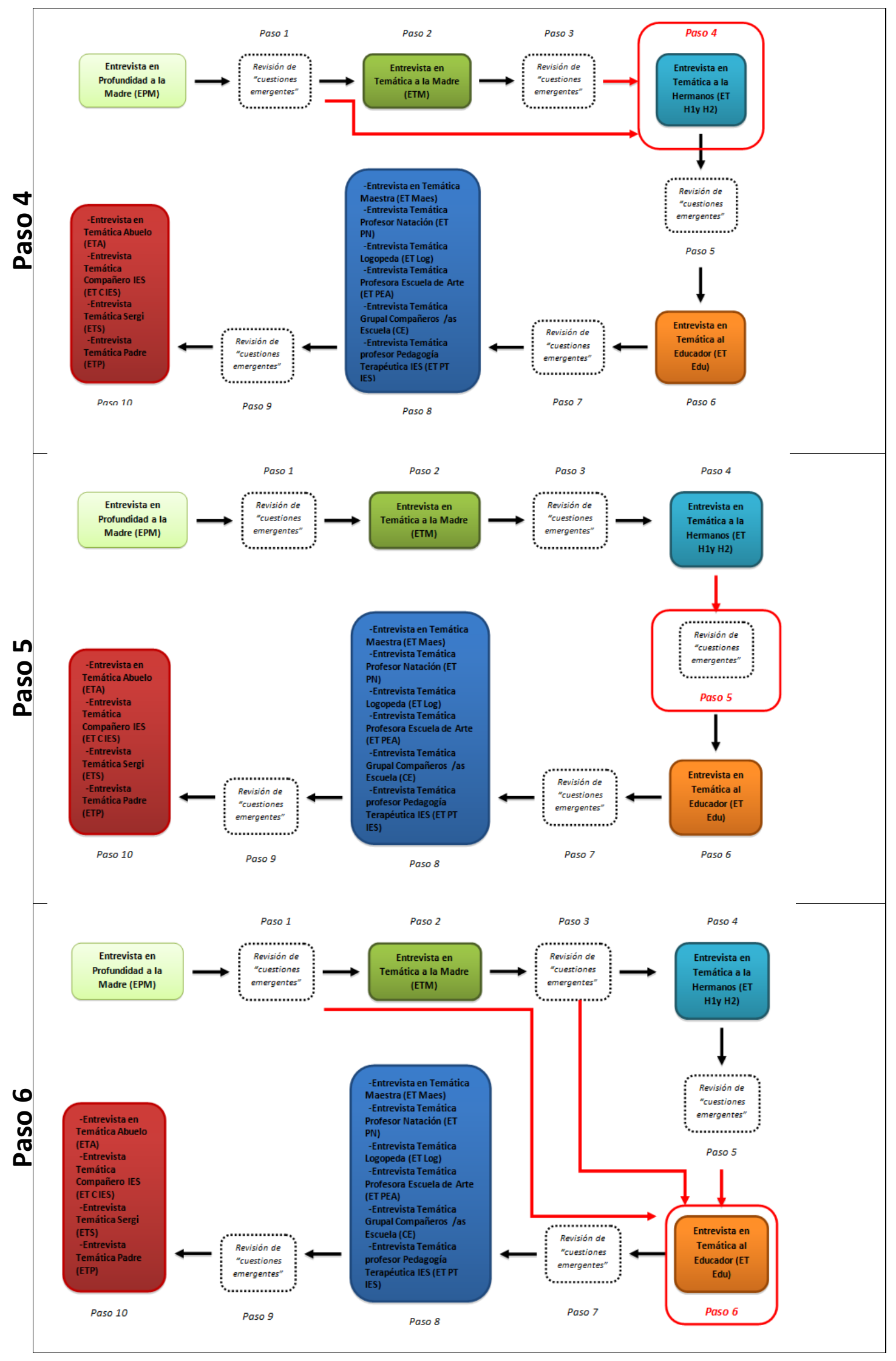




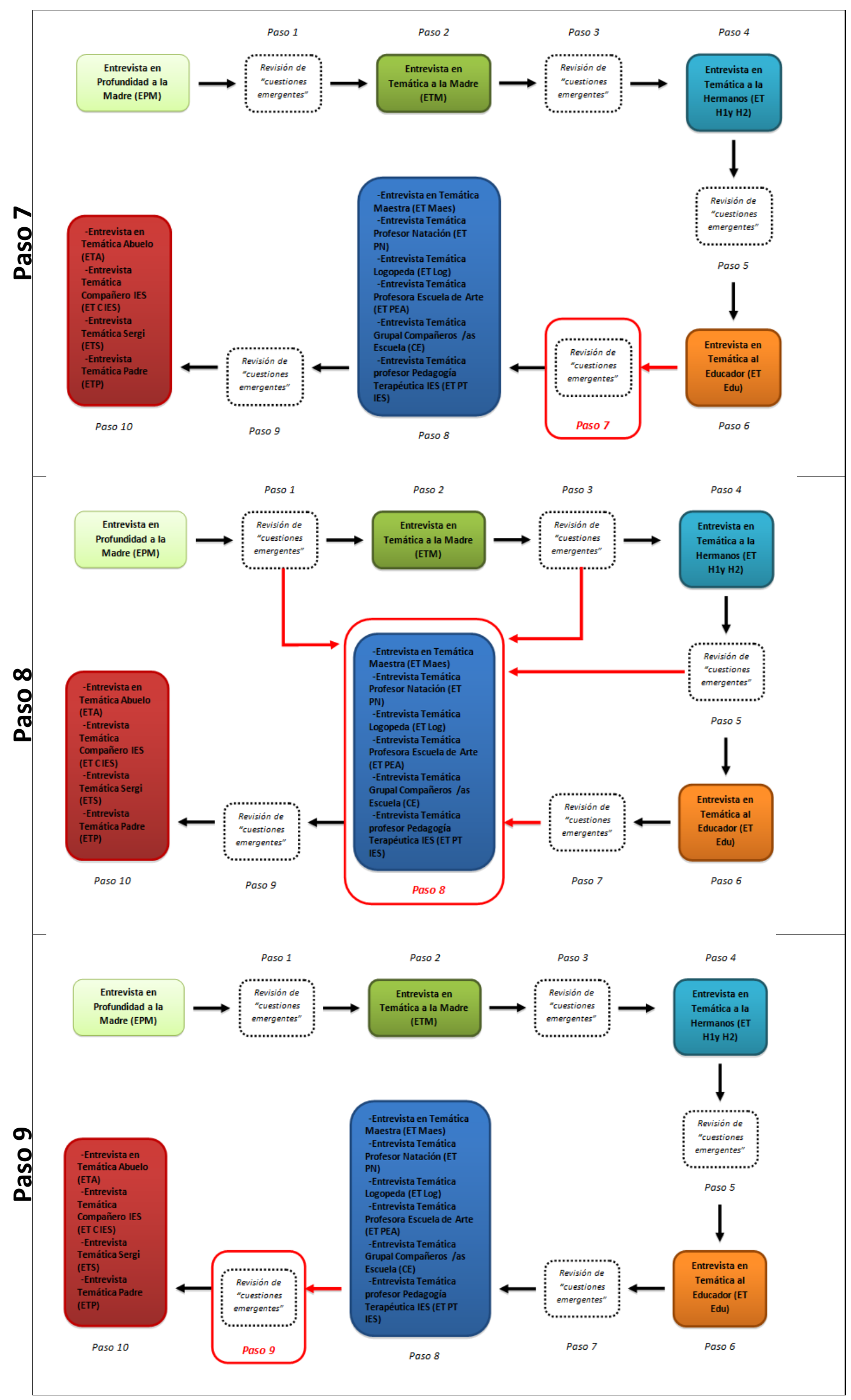




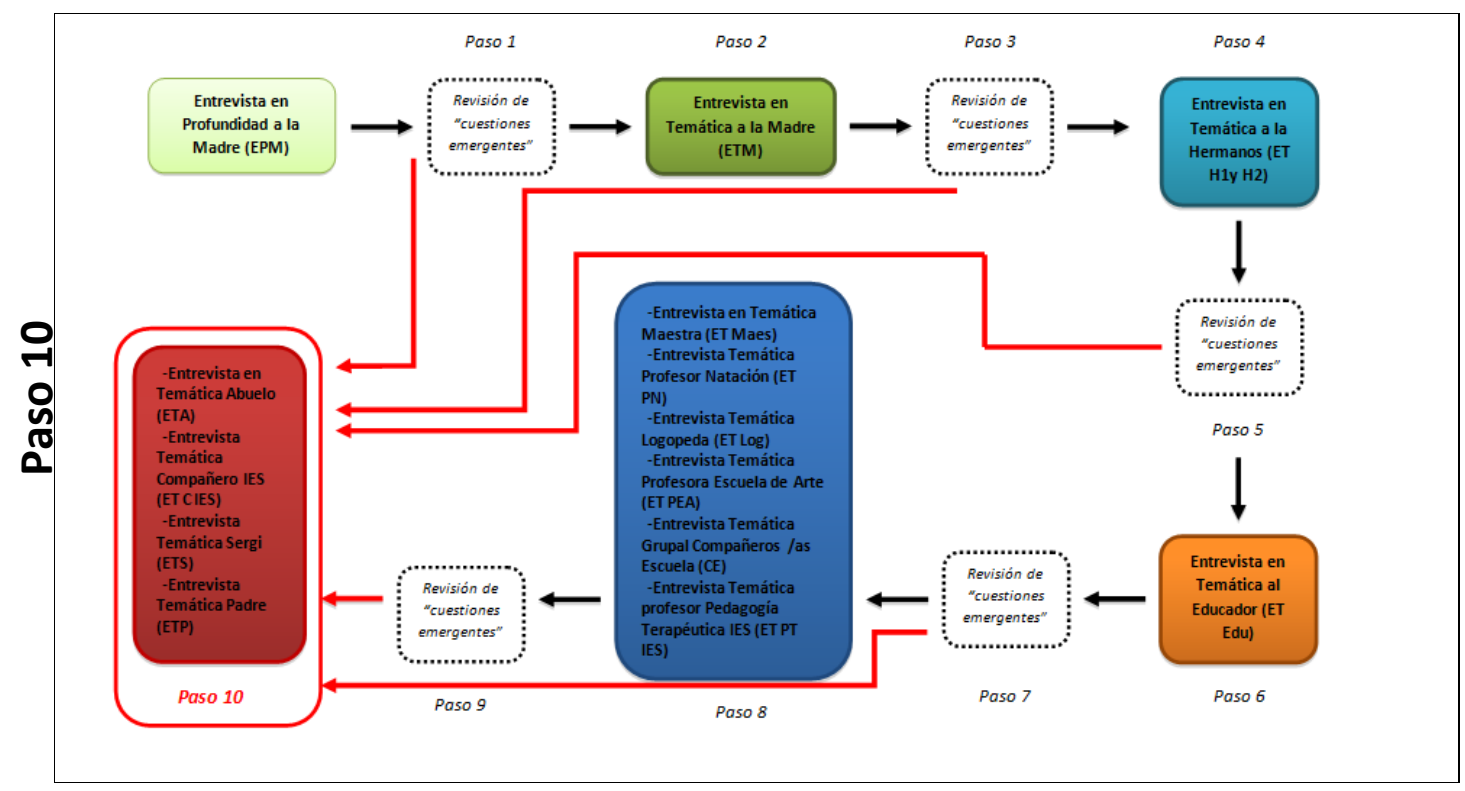

Tabla 9. Secuencia de construcción de las entrevistas 


\section{b.2. Realización de las entrevistas}

Una vez las entrevistas estaban construidas, eran revisadas con la madre y coinvestigadora de la investigación para asegurarnos de que el planteamiento, los temas a tratar y la forma, eran adecuados a cada uno de los participantes. Tras las modificaciones pertinentes, la madre facilitaba el contacto y, a partir de ese punto, era la investigadora principal quien se encargaba del resto del proceso. Al establecer el contacto con cada uno de los participantes se explicaba brevemente la intención del encuentro y se pactaba una cita para ello (hora, día y lugar que el entrevistado eligiera).

Llegado el momento de la entrevista, la sesión siempre se iniciaba con un proceso de reconocimiento, de descripción de quién es la investigadora principal, qué tipo de trabajo se está llevando a cabo, el porqué de esta investigación y sobretodo porqué se solicita su participación en esta investigación. Se trata de una introducción informativa que permite iniciar el contacto, darse a conocer, informar sobre cómo se va a desarrollar la sesión, relajar tensiones en cuanto a la entrevista, a la grabadora y a las preguntas,... En este punto, cabe añadir que todos los participantes recibían el consentimiento informado (capítulo 3 y 5) y las preguntas de la entrevista días antes del encuentro. Con ello, se pretendía asegurar que todos los participantes tuvieran el tiempo necesario para leer con calma estos documentos y se pudieran plantear preguntas en relación a la investigación, a su participación y a detectar elementos que les gustaría modificar. En resumidas cuentas, se pretendía conseguir que los participantes llegaran a la entrevista lo más relajados posible y con unas condiciones mínimas de privacidad y tranquilidad que garantizaran la calidad de la entrevista (Valles, 2014).

Tras finalizar cada entrevista, se explicaba a los participantes cómo se iba a realizar el proceso de transcripción de la sesión y se establecía un canal de devolución de la entrevista (este canal de devolución era pactado con cada uno de los y las participantes de manera individual y podía ser por correo electrónico o texto impreso). Este proceso de devolución aseguraba al mismo tiempo que cada participante tuviera oportunidad de revisar el material transcrito y que, con toda tranquilidad, pudiera modificar, añadir o eliminar cualquier información del texto que considerara oportuna.

\section{b.3. Proceso de transcripción y devolución}

Tras la realización de la sesión de entrevista, se iniciaba el proceso de transcripción y devolución de la información. El documento de transcripción de cada una de las entrevistas (anexo II) se encuentra dividida en diversos elementos o partes:

- Objetivos de la entrevista: propósitos específicos de cada una de las entrevista.

- Núcleos temáticos de la entrevista: temas o núcleo de preguntas tratados en cada una de las entrevistas.

- Descripción del instrumento de recogida: Tipo de instrumento, participante, tipo de grabación, codificación, fecha, hora y duración de la entrevista.

- Leyenda de transcripción: descripción de los diferentes matices gestuales que se pueden recoger a lo largo de la transcripción y el código 
utilizado para cada uno de ellos. Esta leyenda de matices ha sido construida a lo largo de todo el proceso de recogida de datos según las necesidades de las diferentes entrevistas.

- Breve descripción sobre el encuentro: explicación sobre cómo se establece el contacto con cada participante, cómo sucede el primer encuentro y la conversación desde que nos encontramos hasta el inicio de la entrevista y grabación.

- Transcripción de la entrevista: exposición literal de lo ocurrido a lo largo de la entrevista. En esta transcripción se exponen tanto los elementos verbales como los nos verbales (vocalización, expresiones faciales o gestos corporales) expresados por los participantes. La finalidad de esto es ser lograr una reproducción lo más fiel posible de lo ocurrido y evitar de esta manera la pérdida de información "en el camino". transcripción:

A continuación podemos observar un ejemplo de un documento de 


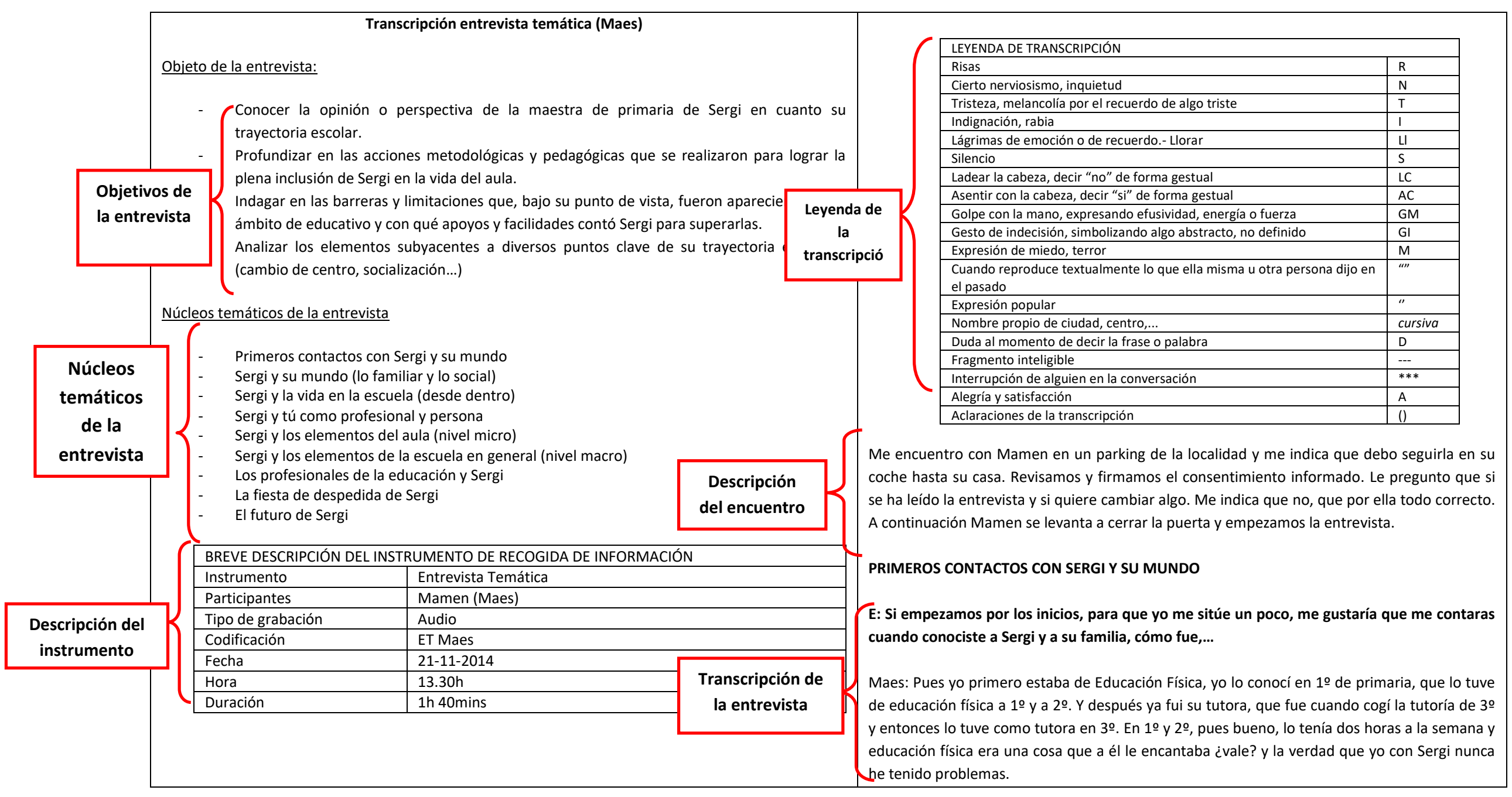

Figura 11. Documento de transcripción y elementos en los que se divide 
Una vez el documento de transcripción estaba finalizado, se enviaba a cada uno de los participantes para que lo revisara con calma y se tomaran el tiempo que fuera necesario. Mediante el canal de devolución que ellos mismos habían elegido, se les expuso cómo se había realizado esta transcripción y qué partes encontrarían en ella. Se les solicitaba que la leyeran con tranquilidad y que efectuaran, sobre el mismo documento, los cambios que consideren oportunos. La pretensión de este proceso de devolución era que cada participante estuviera de acuerdo $100 \%$ con la información que aportaba a la investigación y asegurarnos al máximo que los datos eran fieles a lo que cada participante quería y deseaba transmitir. Tras esta revisión (y en su caso modificación), el documento era archivado para su posterior análisis.

De esta manera, en esta investigación se realizaron un total de 21 sesiones para recoger 1 Entrevista en Profundidad (EP), 12 Entrevistas Temáticas y 2 Entrevistas Grupales:

\begin{tabular}{|c|c|c|c|}
\hline Tipo de entrevista & Participante & № de sesiones & Códigos \\
\hline $\begin{array}{l}\text { Entrevista en Profundidad } \\
\text { (EP) }\end{array}$ & Madre (M) & 3 & EPM \\
\hline \multirow[t]{12}{*}{ Entrevista Temática (ET) } & Madre (M) & 3 & ET M \\
\hline & Educador (Edu) & 1 & ET Edu \\
\hline & Logopeda (Log) & 2 & ET Log \\
\hline & Maestra Primaria (Maes) & 1 & ET Maes \\
\hline & Profesor de Natación (PN) ${ }^{3}$ & 1 & ET PN \\
\hline & Profesora Escuela de Arte (PEA) & 1 & ET PEA \\
\hline & $\begin{array}{c}\text { Profesor Pedagogía Terapéutica IES (PT } \\
\text { IES) }\end{array}$ & 1 & ET PT IES \\
\hline & Profesional Mira'm (Mir) & 1 & ET Mir \\
\hline & Compañero IES (C IES) & 1 & ET C IES \\
\hline & Abuelo (A) & 1 & ET A \\
\hline & Padre (P) & 1 & ET P \\
\hline & Sergi (S) & 1 & ETS \\
\hline \multirow[t]{2}{*}{ Entrevista Grupal (EG) } & Hermanos (H1 y H2) & 2 & EG H1 y H2 \\
\hline & $\begin{array}{c}\text { Compañeros Escuela (CE1, CE2, CE3 y } \\
\text { CE4) }\end{array}$ & 1 & $\begin{array}{c}\text { EG CE1, CE2, } \\
\text { CE3 y CE4 }\end{array}$ \\
\hline
\end{tabular}

Tabla 10. Recogida de datos: tipos de entrevistas, participantes y códigos

\subsubsection{Línea de vida crítico}

Para la elaboración de este instrumento, se ha tenido en cuenta la técnica denominada como graphic life map, life-line o time-line, enmarcada dentro de los métodos visuales de investigación (Moriña, 2016). Se trata de un tipo de técnica que busca representar gráfica y cronológicamente los distintos acontecimientos vividos por una persona e identificar aquellos más importantes o significativos para su trayectoria.

3 La entrevista temática al profesor de natación (ET PN) fue eliminada a petición de la familia de Sergi. 
Desde un primer momento, se consideró la línea de vida como un instrumento relevante para nuestra investigación, pues los datos aportados a través de éste complementan todo aquello aportado por los participantes en las entrevistas y otros instrumentos y nos ayudan a clarificar y ubicar en la historia de vida de Sergi los distintos elementos clave. La línea de vida, al fin y al cabo, se entiende como un cronograma personalizado sobre los hitos e incidentes que jalonan la vida de una persona y la interpretación de los mismos (Parrilla, 2009).

La representación de dicha línea de vida, puede adoptar múltiples formas. Algunas son lineales sin incluir ninguna valoración, otras incluyen gradación valorando positiva y negativamente los acontecimientos (Moriña, 2016), los hay que incluyen elementos icónicos, otros se ciñen más a elementos textuales,... En nuestro caso, optamos por un instrumento de dos ejes (cronología y valoración en positivo o negativo), dejando total libertad a la representación gráfica y visual que quisieran incorporar los participantes. La única premisa que se incorporaba es que en este instrumento se debían representar los elementos y momentos clave (o críticos) en la historia de vida de Sergi. Estamos hablando de lo que algunos autores denominan como incidentes críticos.

Según Denzin (1989), los incidentes críticos o epifanías son "momentos o experiencias que dejan macas en la vida (...), que tienen un carácter personal, que son frecuentemente momentos de crisis y que alteran las estructuras de significados fundamentales en una vida”. El interés que estos incidentes críticos poseen en esta investigación coinciden con los planteados por Bolívar et al. (2001), pues según este autor los incidentes críticos o puntos de inflexión permiten (a) delimitar fases críticas haciéndose mención de los momentos de cambio que causaron un fuerte impacto, (b) determinar la aparición de personas que han desempeñado un impacto importante en la biografía personal y sobre el que conviene indagar y (c) condicionan y explican los cambios operados en la trayectoria vital.

La idea original era que la madre (M) y el padre (P) de Sergi realizaran esta técnica conjuntamente y que entre los dos representaras la trayectoria de su hijo junto con los incidentes críticos correspondientes. En la práctica real, por consenso y practicidad, los padres de Sergi decidienron que esta técnica fue aplicada solo con la madre (M). En la misma sesión en la que elaboró la línea de vida de Sergi, se le pidió que relatara de 'viva voz' todo aquello representado en el gráfico. Durante esta narración, la investigadora fue tomando notas que se utilizaron en forma de preguntas sobre los diferentes elementos. Los datos orales recogidos mediante esta técnica fueron grabados y transcritos para su posterior análisis.

\subsubsection{Documentos}

Las técnicas documentales en investigación cualitativa pueden ser utilizadas con diversas intenciones y finalidades. Una posibilidad es incorporarlas al estudio como estrategia de acercamiento al campo, como una forma de conocer y tener información previa antes de adentrarse en el contexto de investigación (Tójar, 2006). Sin embargo, en nuestro caso, la intencionalidad de estas técnicas documentales va en otra línea. A partir de ciertos elementos o documentos pretendemos obtener datos que, a su vez, complementen los aportados en entrevistas u otras estrategias de recogida de información. De esta manera, nos 
encontramos ante lo que ciertos autores denominan como 'artefactos' y/o 'documentos'.

En la literatura encontramos que, por un lado, autores como McMillan y Schumacher (2005) utilizan el término 'artefacto' para referirse a aquellas manifestaciones tangibles que describen experiencias de la gente, su conocimiento, sus acciones y sus valores. Para estos autores, los artefactos pueden clasificarse como: documentos personales (narraciones en primera persona que describe acciones, experiencias y opiniones), documentos oficiales (documentos, registros, materiales oficiales y públicos) y objetos (símbolos y formas tangibles). Para ellos, la selección y análisis de los 'artefactos' requiere cinco estrategias diferentes: (1) localización de los artefactos (buscados por el investigador u ofrecido por los participantes), (2) identificación de los artefactos, (3) análisis de los artefactos (datos descriptivos sobre el mismo), (4) crítica de los artefactos (significado de los artefactos en el contexto) e (5) interpretación del artefacto (corroborada por la observación y datos de la entrevista)

De la misma manera, otros autores utilizan el término 'documento' para referirse a estas mismas estrategias de recogida de datos. De hecho, diversos manuales de investigación social establecen un tipo de técnicas o estrategias denominadas como 'documentales' como la tercera fuente de evidencia (Erlandson, Harris, Skipper \& Allen, 1993), (la observación y la entrevista son la primera y segunda fuente de evidencia en las investigaciones).

Para referirse a estas técnicas, Ruiz Olabuénaga e Ispizua (1989) exponen:

A la observación y la entrevista podríamos añadir una tercera técnica de recogida de datos, la lectura de textos, entendiendo por tales, todos los documentos que contienen significado (una carta, un periódico, una autobiografia, una estatua, un edificio, las pinturas de una cueva prehistórica, las tumbas faraónicas,...). A todos estos 'textos', en realidad, se les puede 'entrevistar' mediante preguntas implícitas y se les puede 'observar' con la misma intensidad y emoción con la que se observa un rito nupcial, una pelea callejera, una manifestación popular. En este caso la lectura es una mezcla de entrevista/observación y puede desarrollarse como cualquiera de ellas. (Ruiz Olabuénaga e Ispizua, 1989: 69)

Son muchos los autores que han hecho referencia al análisis de 'documentos' como estrategia de investigación y que plantean clasificaciones al respecto (Apalategui, 1987; McDonald \& Tipton, 1993; González Rodríguez, 2000; Hodder, 1994; Cea D'Ancona, 1996), pero en este punto nos acogeremos a la tipología de documentos aportada en el trabajo de McDonald y Tipton (1993):

\section{A. Documentos escritos}

1. Documentos oficiales de las administraciones públicas: informes y estadísticas oficiales en general.

2. La prensa escrita (periódico y revistas)

3. Los "papeles privados" (cartas, diarios, memorias, material biográfico o autobiográfico en general).

\section{B. Documentos visuales}


1. Fotografías

2. Pinturas

3. Esculturas

4. Arquitectura.

En la investigación aquí expuesta se han considerado esta última clasificación para organizar los documentos (o artefactos) aportados a la investigación. Cabe considerar aquí que la investigadora principal interpelaba a los participantes a aportar aquello que consideraran relevante y significativo para la investigación, y eran los mismos participantes quienes, voluntariamente, lo seleccionaban y aportaban como elemento de análisis. Todos los documentos aportados a la investigación no solo fueron registrados sino que también se utilizaron como foco del diálogo y análisis entre la investigadora principal y los participantes. Veamos a continuación qué tipo de documentos se incorporaron a la investigación y cómo se trabajó con cada uno de ellos.

\section{a) Documentos escritos}

Diversos tipos de 'documentos escritos' fueron incorporados a la investigación y tratados como una estrategia más de recogida de datos. En este punto, se tuvo en cuenta la aportación de Sandoval (1996), quien sugiere que los documentos sean analizados en cinco etapas o momentos diferentes: rastreo de documentos existentes y disponibles, clasificación de los documentos, selección de aquellos que sean pertinentes, lectura profunda del contenido y realización de notas sobre tendencias, similitudes y patrones, y lectura cruzada y comparativa de documentos para la construcción de una síntesis comprensiva global.

En el caso de nuestra investigación, se llevó a cabo una variante de la sugerencia expuesta por Sandoval (1996), con la diferencia de que el rastreo de documentos lo hacían de manera voluntaria los participantes y que la lectura profunda del contenido y comparación que nos indica el autor, se realizaba dialogando con el/la participante que aportaba cada uno de los documentos. Recordemos aquí que el aportar o no estos documentos (y su análisis) es un asunto que se planteaba a todos los participantes como algo voluntario y opcional. En ningún momento se les exigió esta aportación, así como no se establecía un número mínimo o máximo de documentos a aportar.

\section{a.1. Técnica de Documentos Escritos (TDE)}

En el contacto previo a la entrevista con cada participante, se informaba de la posibilidad de aportar a la investigación materiales, documentos, objetos,... relevantes para la historia de vida de Sergi. Se hacía especial hincapié en que se trataba de una cuestión voluntaria y que, además, debía existir una relación directa y notable con los temas de la entrevista.

Esta técnica de indagación documental pretendía ser un complemento a la entrevista, un extra de aquella información que no se puede conseguir mediante preguntas y respuestas orales, sino que requiere de otras técnicas alternativas. Ésta técnica fue llevada a cabo mediante los siguientes pasos:

1. Petición a los participantes de documentos y/o materiales que se consideren relevantes para la investigación. 
2. Selección (voluntaria) de dichos documentos por parte de los participantes

3. Realización de la técnica sobre documentos escritos

a. Identificación del documento seleccionado

b. Análisis del documento mediante preguntas orales preestablecidas.

- Descripción del documento: ¿qué es? ¿qué elementos contiene? ¿Cuál es su origen?

- Relación del material con la vida de Sergi (momento y significación)

- Motivo de la elección de este material

c. Registro fotográfico y clasificación de los materiales aportados por cada participante.

La realización de esta técnica fue llevada a cabo en una interacción cara a cara (entrevistador-entrevistado) y grabada para después poder ser transcrita e incorporada al cuerpo de datos a analizar, pues Erlandson (1993) en su manual de investigación social, propone la utilización de estos datos procedentes de documentos de la misma manera que se tratan los derivados de las entrevista $u$ observaciones. De esta manera se obtuvieron y analizaron los siguientes documentos:

\begin{tabular}{|c|c|c|}
\hline Participante & Tipo de Documento Escrito (TDE) & $\mathbf{N}^{\mathbf{0}}$ de materiales \\
\hline Madre (M) & $\begin{array}{c}\text { Material de aula, Calendarios, } \\
\text { Informes, historias sociales, } \\
\text { pictogramas y paneles de } \\
\text { comunicación, juegos, exámenes, } \\
\text { dibujos, noticias, publicaciones, y } \\
\text { libro de dedicatorias }\end{array}$ & 27 \\
\hline Hermano (H1) & Redacción para un concurso escolar & 1 \\
\hline Logopeda (Log) & $\begin{array}{c}\text { Historias sociales, Actividades de } \\
\text { aprendizaje }\end{array}$ & 1 \\
\hline $\begin{array}{c}\text { Maestra de } \\
\text { Primaria (Maes) }\end{array}$ & $\begin{array}{c}\text { Libro de firmas y fotografías de la } \\
\text { clase de Sergi }\end{array}$ & 3 \\
\hline Profesor PT IES & Temas de estudio de Sergi \\
\hline PT IES) & & \\
\hline
\end{tabular}

Tabla 11. Recogida de datos: Técnica de Documento Escrito (TDE)

\section{b) Documentos visuales}

En este apartado distinguiremos entre las fotografías como documentos visuales por excelencia, y las pinturas y esculturas como otro tipo de documentos visuales de interés para nuestra investigación.

\section{b.1. Documentos visuales: fotografías}

En las últimas décadas, se ha producido una creciente utilización de métodos y datos visuales en investigación cualitativa para indagar en cómo las personas lidian con condiciones y desafíos sociales y personales 'a través de sus propios ojos' (Luttrell and Chalfen, 2010). Tradicionalmente, era común utilizar los 
métodos visuales como una evidencia de que los datos aportados a la investigación eran ciertos, pero hoy en día su uso se ha convertido más bien en una fuente, medio y recurso de la investigación cualitativa (Tójar, 2006).

En la utilización de métodos visuales, los participantes son animados a documentar visualmente sus panoramas personales para situar en sus manos el poder de la documentación fotográfica (Packard, 2008) y obtener, a través de la discusión con ellos, más datos de los que inicialmente se pueden esperar de un método exclusivamente verbal (Gauntlett, 2007; Moss, 2008).

La fotografía sirve como obra de arte o icono que conecta un acontecimiento pasado, que hemos vivido y por lo tanto una experiencia, con el presente. (Regis y Castejón, 2015). Sin duda alguna, las fotografías poseen el potencial de estimular ideas y generar nuevas cuestiones, por ello, debemos tener claro el tipo de información que estamos buscando, qué tipo de conocimiento queremos producir y cómo podemos incorporarlo a nuestra investigación (Farough, 2006; Goopy \& Lloyd, 2005; Glover-Graf, 2000; Killion, 2001; Samuels, 2004). La utilización de esta técnica y, concretamente, del material visual como dato de una investigación conlleva una declaración de intenciones, pues es una forma de buscar una mirada al mundo a través de los ojos de otro(s), ya sea a través de fotografías o grabaciones del pasado o mediante la petición de efectuarlas en el mismo proceso de recogida de datos.

Las formas o estrategias mediante las cuales se incorporan datos visuales a una investigación son diversas. En los últimos años, numerosas investigaciones vienen incorporando los datos visuales al proceso de recogida de datos mediante una creciente e imperante técnica denominada "fotovoz" (Photovoice en inglés). Esta, es una estrategia de investigación cuyos principios fundamentales se basan en un enfoque de la investigación crítico-participativa, en la que los participantes realizan fotografías de su contexto, su vida, sus situaciones y vivencias, plasmando en ellas reflexiones y puntos de vista personales que enlazan con los objetivos de una investigación concreta. Se trata de una técnica utilizada primordialmente en áreas como: la acción social, la salud y la educación. (Doval, Martínez y Raposo, 2013). En el campo educativo, ha sido una técnica utilizada para abordar temáticas como educación general, autismo, educación inclusiva, diversidad funcional, educación universitaria, coeducación,.... (Graziano, 2004; Kaplan \& Howes, 2004; Edwards, Perry, Janzen \& Menzies, 2012; Joubert, 2012; Kroeger, Embury, Cooper, Brydon-Miller, Laine \& Johnson, 2012; Latz, 2012; Leipert \& Anderson, 2012; Messiou, 2012). De hecho, se trata una herramienta bastante popular entre los investigadores, educadores y otros profesionales, particularmente entre los que trabajan con grupos marginados para la concienciación de la promoción social y la justicia (Aldridge, 2012; Allen, 2012; DeJean, 2008; Guerrero \& Tinkler, 2010; Mizen \& Ofosu-Kusi, 2010; Narayan, 2000; Radley, Hodgetts \& Cullen, 2005; Wang, Cash \& Powers, 2000; Ziller, 1990).

Sin embargo, debido a las características de nuestra investigación, y concretamente a la finalidad de la incorporación de los datos visuales, se desestimó la posibilidad de utilizar la técnica "fotovoz". Cabe tener en cuenta, que al tratarse de una investigación biográfico-narrativa, se busca indagar en el pasado, en los entresijos de aquello que ha venido aconteciendo en la vida de nuestro protagonista para poder conocerlo en profundidad y analizarlo posteriormente. Por lo tanto, las imágenes y datos visuales aportados a la investigación deben tener relación con la 
historia de vida de Sergi, o lo que es lo mismo, con su pasado. Por esta razón, y a pesar de la riqueza de una técnica como la "fotovoz" se decide buscar un enfoque distinto para el tratamiento y análisis de datos visuales que respondan a la intencionalidad de nuestro trabajo.

Recurrimos entonces a la clasificación que Sarmento (2014) nos presenta en su trabajo. Este autor expone que los usos o métodos visuales utilizados en una investigación dependen de los paradigmas teórico-metodológicos que la sustentan. De esta manera, teniendo en cuenta los 3 paradigmas expuestos en el capítulo anterior (capítulo 3), podemos hablar de 3 usos distintos de los métodos visuales:

\begin{tabular}{|c|c|}
\hline Paradigma teórico-metodológico & Uso de los datos visuales \\
\hline Positivista & $\begin{array}{c}\text { Producción de imágenes como medio de } \\
\text { investigación. }\end{array}$ \\
\hline Interpretativo & $\begin{array}{c}\text { Utilización de imágenes preexistentes como } \\
\text { fuentes primarias. }\end{array}$ \\
\hline Crítico-participativo & $\begin{array}{c}\text { Producción de imágenes como medio de } \\
\text { comunicación de los resultados de } \\
\text { investigación (esta sería la técnica "fotovoz" } \\
\text { recientemente expuesta) }\end{array}$ \\
\hline
\end{tabular}

Tabla 12. Paradigmas de investigación y uso de datos visuales

Teniendo en cuenta esta clasificación, y que nuestra investigación se sitúa a caballo entre el paradigma interpretativo-simbólico y el crítico, uno de los métodos visuales acorde es el que tiene que ver la "utilización de imágenes preexistentes como fuentes primarias". Consideramos que una imagen es un objeto comunicativo construido a partir de un punto de vista particular, que exprime una realidad social (Sarmento, 2014). En esta utilización de imágenes preexistentes a la investigación, cabe tener en cuenta que las imágenes contienen una biografía, es decir, han estado envueltas previamente en la vida de las personas (Appaurai, 1986) y por ello, hay que tener en cuenta la existencia de 3 inserciones o marcos sociales de la propia fotografía: el contexto de producción original, el contexto de la historia posterior a las fotografías y el contexto en que el investigador utiliza las fotografías en el trascurso de la investigación (Banks, 2010).

Dicho en otras palabras, todas y cada una de las imágenes poseen algo que podemos denominar como "narrativa" (la historia que esas imágenes cuentan). Las estructuras de la narrativa en las fotografías se establecen y entienden por convención, y son innatas y universales. De hecho, podemos distinguir entre dos tipos de narrativas: la interna y la externa (Banks, 2001, 2010). La narrativa interna es aquella que se responde directamente con la pregunta "¿Qué aparece en la fotografía?", podríamos decir que se trata de los elementos superficiales que nos ofrece una determinada imagen. Mientras que la narrativa externa es la historia que se construye alrededor de ella, los elementos más humanos de una imagen y que se responden mediante preguntas como "¿Quién hizo esta foto?¿Cuándo se hizo?¿Por qué se hizo?”.

Teniendo en cuenta las aportaciones de este autor (Banks, 2001, 2010), procedemos a construir nuestra propia técnica de indagación fotográfica acorde con los objetivos y pretensiones de la investigación. Cabe destacar aquí, que esta estrategia de recogida de datos, al igual que el resto, es complementaria y totalmente voluntaria para los participantes. En la realización de esta técnica, no se estableció previamente un número máximo o mínimo de fotografías que aportar, 
simplemente se indicaba a los participantes que aportaran aquello que consideran significativo para entender la historia de vida de Sergi.

\section{Técnica de foto (TF)}

De igual manera que en la técnica anterior, en el contacto previo a la entrevista se informaba a todos los participantes sobre la posibilidad de aportar a la investigación fotografías relacionadas con la historia de Sergi, su pasado, las vivencias con él,... Se remarcaba en este momento que se trataba de una cuestión voluntaria y que debían ser imágenes altamente significativas y relevantes para la investigación.

Para la realización de esta técnica fotográfica se llevaron a cabo los siguientes pasos:

1. Petición a los participantes de fotografías que se consideren relevantes para la investigación.

2. Selección (voluntaria) de dichas fotografías por parte de los participantes

3. Realización de la técnica fotográfica:

a. Identificación de la fotografía mediante un nombre o título por parte del participante

b. Análisis de las narrativas de cada fotografía (Banks, 2010) mediante las siguientes puntos:

- Narrativa interna:

- Descripción la fotografía: ¿qué se observa en ella? ¿qué elementos contiene?

- Narrativa externa:

- ¿Quién tomó la fotografía? ¿Cómo era la situación de aquel momento? ¿Cómo era la vida de Sergi en aquel momento? ¿Cómo ha cambiado hasta el día de hoy?

○ ¿Por qué has elegido esta fotografía? ¿qué significa para ti?

c. Registro y clasificación de las fotografías aportadas.

Esta técnica se realizó en interacción cara a cara con el entrevistado y se grabó la conversación mantenida para posteriormente poder transcribirla e incorporarla al análisis de datos, ya que como bien indican Emmel y Clark (2011), los datos obtenidos a través de métodos visuales deben ser tratados con el mismo rigor que cualquier otro dato obtenido por otro tipo de método. La técnica fotográfica, a diferencia de otras estrategias, va a permitir evocar el pasado de cada participante y facilitará la aportación de grandes detalles sobre una escena o situación concreta (Aldridge, 2007), pues ya lo dice el refrán "una imagen vale más que mil palabas".

De esta manera, se llevaron a cabo 11 sesiones de indagación fotográfica en las que 11 participantes aportaron un total de 33 fotografías y 1 vídeo corto: 


\begin{tabular}{|c|c|c|}
\hline Participante & $\mathrm{N}^{\circ}$ de documentos visuales & $\mathrm{N}^{0}$ de sesiones \\
\hline Hermano 1 (H1) & 4 & 1 \\
\hline Hermano 2 (H2) & 3 (+ un vídeo corto) & 1 \\
\hline Abuelo (A) & 5 & 1 \\
\hline $\begin{array}{c}\text { Compañeros Escuela } 1 \\
\text { (CE1) }\end{array}$ & 2 & 1 \\
\hline $\begin{array}{c}\text { Compañeros Escuela } 2 \\
\text { (CE2) }\end{array}$ & 2 & 1 \\
\hline $\begin{array}{c}\text { Compañeros Escuela } 3 \\
\text { (CE3) }\end{array}$ & 1 & 1 \\
\hline $\begin{array}{c}\text { Compañeros Escuela } 4 \\
\text { (CE4) }\end{array}$ & 3 & 1 \\
\hline Compañero IES (C IES) & 1 & 1 \\
\hline $\begin{array}{l}\text { Profesor Pedagogía } \\
\text { Terapéutica (PT IES) }\end{array}$ & 5 & 1 \\
\hline Madre (M) & 4 & 1 \\
\hline Sergi $(S)$ & 3 & 1 \\
\hline
\end{tabular}

Tabla 13. Recogida de datos: Técnica de la foto

\section{b.2. Otros documentos visuales: Pinturas y esculturas}

Para llevar a cabo la recogida de datos a través de pinturas y esculturas se recurrió a aquellos elementos aportados por la madre (M) y que no se habían podido clasificar como documentos escritos (sección A de este apartado). Cada uno de estos elementos (pinturas y esculturas) fueron realizados por el protagonista de la historia de vida en diferentes momentos de su vida pero siempre en el mismo contexto: la Escuela de Arte. Por este motivo, la investigadora principal y la madre del protagonista, acordaron en el proceso de negociación que la persona idónea para trabajar y dialogar a partir de estos elementos era la Profesora de la Escuela de Arte (PEA), pues fue con ella y bajo sus directrices cuando Sergi elaboró la mayoría de estos elementos.

A diferencia de otros documentos de la recogida de datos, en este caso no fue la participante (PEA) la que voluntariamente aportó los documentos por su significación, sino que fue una proposición de la investigadora en consenso con la madre de Sergi y coinvestigadora. Para ello, se acordó con la Profesora de la Escuela de Arte (PEA) una fecha, hora y lugar para poder dialogar sobre estos documentos y analizarlos conjuntamente. La estructura de la sesión de análisis de las pinturas y esculturas siguió el mismo guión que el establecido para la indagación documental (sección A de este apartado) basado en las sugerencias propuestas pos Sandoval (1996).

\section{Técnica de pinturas y esculturas (TPE)}

En el contacto previo a la entrevista con la Profesora de la Escuela de Arte (PEA), se acordó el momento y el procedimiento a seguir en esta técnica de recogida de datos. Los puntos a tratar en este encuentro fueron:

1. Identificación del documento o material seleccionado

2. Análisis del documento o material mediante preguntas orales preestablecidas. 
a. Descripción del documento: ¿qué es? ¿qué elementos contiene? ¿Cuál es su origen?

b. Relación del material con la vida de Sergi (momento y significación)

c. Motivo de la elección de este material

3. Registro fotográfico y clasificación de los materiales aportados por cada participante.

$\mathrm{Al}$ igual que el resto de técnicas de recogida de datos, esta fue llevada a cabo en una interacción cara a cara (entrevistador-entrevistado) y grabada para después poder ser transcrita e incorporada al cuerpo de datos a analizar.

A partir de esta técnica se trabajó en una sola sesión sobre 11 documentos visuales, 5 pinturas y 6 esculturas:

\begin{tabular}{|c|c|c|}
\hline Participante & Tipo de documentos visual & $\mathbf{N}^{\circ}$ de documentos \\
\hline Profesora Escuela de Arte & Pinturas & 5 \\
\cline { 2 - 3 } (PEA) & Esculturas & 6 \\
\hline
\end{tabular}

Tabla 14. Recogida de datos: Técnica de pinturas y esculturas (TPE)

\subsubsection{Técnicas proyectivas}

Las técnicas proyectivas constituyen un conjunto de técnicas de obtención de información utilizada en múltiples ámbitos, desde el campo de la investigación al laboral, criminológico o clínico. El objetivo de este tipo de técnicas es investigar el desarrollo de los procesos que ocurren en la subjetividad, y su riqueza radica en que son instrumentos mediadores con un gran valor instrumental (Baez, 2009).

Cabe tener en cuenta, que estas técnicas proyectivas tienen su origen en el concepto de 'proyección' descrito por Sigmund Freud, y han sido y son utilizadas en el campo de la intervención clínica desde un enfoque basado en el psicoanálisis. Sin embargo, en nuestra investigación nos posicionamos en un tipo de técnicas proyectivas más propias de la investigación de la sociedad y del mercado, mediante las cuales no se persigue un análisis tan profundo del subconsciente, sino más bien la obtención de un tipo de dato complementario a la entrevista o grupos de discusión más tradicionales.

En nuestra investigación, realizaremos una adaptación de las 'técnicas de elaboración' propuestas por Baez (2009). Según este autor, la técnica por elaboración por excelencia es la conocida como Rey pack, y consiste en pedir a los informantes (niños o adultos) que realicen alguna tarea a través de la expresión plástica (con papel y puntura, crayón, arcilla,...), pues este tipo de elaboraciones puede resultar más elocuente que la palabra. Al tratarse de una adaptación, hemos optado por denominar a la técnica como técnica de elaboración gráfica o técnica gráfica.

\section{a) Técnica gráfica}

Esta técnica de elaboración gráfica fue utilizada con el protagonista de la historia de vida y se compone de elementos gráficos, verbales y/o textuales. A 
través de esta técnica, se propuso a Sergi (S) que representara de manera visual ciertos aspectos o elementos clave de su vida para después complementarlos de manera oral o escrita.

La técnica gráfica, aplicada exclusivamente con Sergi (TG S) se estructuró en tres partes o etapas:

1. La madre y coinvestigadora debería dialogar con Sergi y ayudarle a identificar ciertos momentos, situaciones o vivencias relevantes en su vida pasada, así como pensar cómo cree que será su vida dentro de 15 años.

2. En un segundo momento, cuando Sergi lo considerara oportuno, debería representar gráficamente (mediante historias sociales, cómics o dibujos simples) esos elementos o momentos clave de su vida, así como el futuro que espera tener.

3. En un próximo encuentro con la investigadora, Sergi debería expresar el sentido de cada uno de estos dibujos, cuál es su significado y lo que le ha motivado a representarlo.

Gracias a esta técnica pretendemos conseguir mediante los elementos gráficos un registro o tipo de mirada distinta de la que nos proporcionan los textos orales o escritos (Esteban-Guirart, Pallisera, Fullana y Gifre, 2017), pues a través de estos elementos gráficos se permiten representaciones más concisas de los elementos clave de la experiencia de los participantes (Bagnoli, 2009; Harper, 2002; Keats, 2009; Mitchell, 2011; Pink, 2006; Prosser \& Loxley, 2008). 
A modo de conclusión del apartado de técnicas e instrumentos de recogida de datos presentamos una tabla-resumen que contiene: las técnicas de recogida de datos utilizadas en esta investigación, los participantes con los que se ha realizado cada una de ellas, el contexto al que pertenece cada uno de estos participantes (educativo, ocio o familiar), el número de sesiones utilizado para ello (en las entrevistas), el número de documentos que aportan los participantes (en las técnicas documentales) y la codificación que empleamos para su clasificación y posterior análisis.

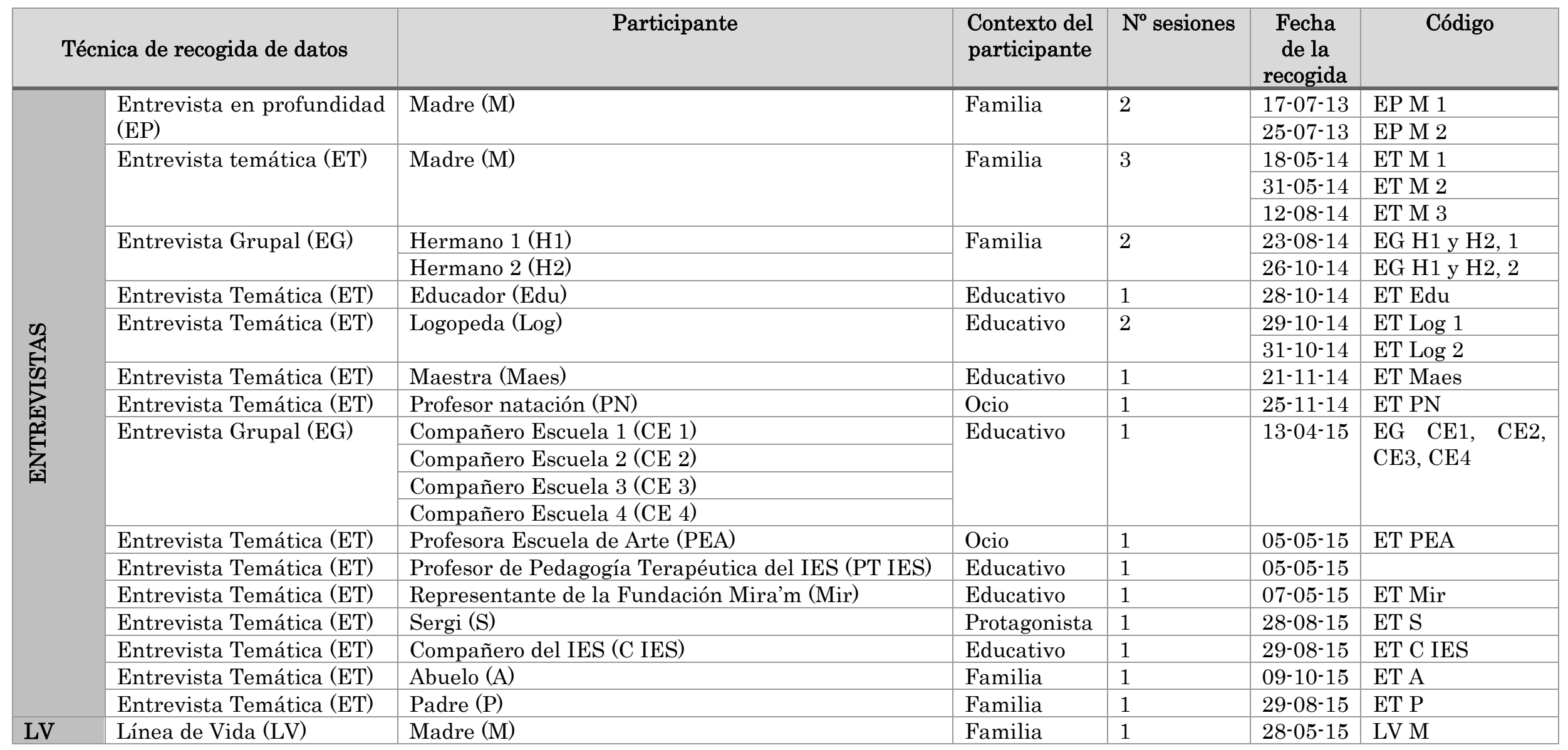




\begin{tabular}{|c|c|c|c|c|c|c|}
\hline \multicolumn{2}{|c|}{ Técnica de recogida de datos } & Participante & Contexto del & $\mathrm{N}^{\circ} \mathrm{de}$ & Fecha de la & Código \\
\hline \multirow{18}{*}{ 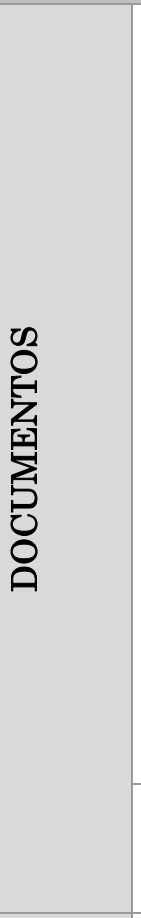 } & \multirow{16}{*}{$\begin{array}{l}\text { Técnica de Documentos } \\
\text { Escritos (TDE) }\end{array}$} & Maestra (Maes) & Educativo & 1 & $28-03-15$ & TDE Maes \\
\hline & & Hermano 1 (H1) & Familia & 1 & $31-03-15$ & TDE H1 \\
\hline & & $\begin{array}{l}\text { Profesor de Pedagogía Terapéutica del IES (PT } \\
\text { IES) }\end{array}$ & Educativo & 3 & $05-05-15$ & TDE PT IES \\
\hline & & Logopeda (Log) & Educativo & 12 & $08-05-15$ & TDE Log \\
\hline & & Madre (M) & Familia & 27 & $26-08-15$ & TDE M \\
\hline & & Hermano 1 (H1) & Familia & 4 & $31-03-15$ & TF H1 \\
\hline & & Hermano (H2) & Familia & 4 & $31-03-15$ & $\mathrm{TF} \mathrm{H} 2$ \\
\hline & & Compañero Escuela 1 (C1) & Educativo & 2 & $13-04-15$ & TF CE1 \\
\hline & & Compañero Escuela 2 (C2) & Educativo & 2 & $13-04-15$ & TF CE2 \\
\hline & & Compañero Escuela 3 (C3) & Educativo & 1 & $13-04-15$ & TF CE3 \\
\hline & & Compañero Escuela 4 (C4) & Educativo & 3 & $13-04-15$ & TF CE4 \\
\hline & & $\begin{array}{l}\text { Profesor de Pedagogía Terapéutica del IES (PT } \\
\text { IES) }\end{array}$ & Educativo & 5 & $01-08-15$ & TF PT IES \\
\hline & & Compañero del IES (C IES) & Educativo & 1 & $29-08-15$ & TF C IES \\
\hline & & Abuelo (A) & Familia & 5 & $09-10-15$ & TF A \\
\hline & & Madre (M) & Familia & 4 & $11-10-15$ & TF M \\
\hline & & Sergi (S) & Protagonista & 3 & $11-10-15$ & TF S \\
\hline & \multirow[t]{2}{*}{$\begin{array}{l}\text { Técnica de Pinturas y } \\
\text { Esculturas (TPE) }\end{array}$} & \multirow[t]{2}{*}{ Profesora Escuela de Arte (PEA) } & \multirow[t]{2}{*}{ Ocio } & $\begin{array}{l}6 \\
\text { esculturas }\end{array}$ & \multirow[t]{2}{*}{$27-08-15$} & \multirow[t]{2}{*}{ TPE PEA } \\
\hline & & & & 5 pinturas & & \\
\hline 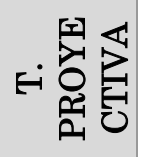 & Técnica gráfica (TG) & Sergi (S) & Protagonista & 4 & $19-09-16$ & TG S \\
\hline
\end{tabular}

Tabla 15. Recogida de datos: Técnicas, participantes, contexto, fecha y código. 


\subsubsection{Diario de investigación}

Paralelamente y de forma sistemática a lo largo de todo el proceso de recogida de información, la investigadora principal ha ido complementando un diario de investigación. Este diario es una especie de cuaderno de reflexión en el que se plasman las inquietudes, las dudas, los intereses propios y ajenos, los recursos disponibles, la naturaleza del tema a investigar (Tójar, 2006).

Si bien es cierto que el origen de los diarios se relacionaba con los viajes y expediciones que los colonizadores y grandes descubridores realizaban para conocer mundo, pronto, las Ciencias Sociales y especialmente los antropólogos y los sociólogos, detectaron en ellos una herramienta que permitía recopilar gran cantidad de información de diferentes formas de vida, culturas, vivencias... Dicha utilidad era algo más que el simple hecho de acercar el conocimiento adquirido a otras personas, en la sociología y antropología, se convirtió en una estrategia en el proceso de adquisición de conocimiento acerca de una cultura, y/o búsqueda de una explicación a un problema formulado teóricamente con anterioridad (Garcia Jorba, 2000).

Cabe tener en cuenta aquí, que los diarios se pueden entender desde muy diversas perspectivas. Mientras autores como Kemmis y Mctaggart (1988) lo entienden como parte del proceso de aprendizaje, otros (Gimero Soria, 2005) lo consideran más bien como una herramienta de reflexión en general y de las comunidades de aprendizaje en particular. Ante esto, concordamos con una tercera visión, aquella que entiende el diario como un instrumento básico de investigación y formación (Elliot, 1999; López Górriz, 1997) que además de permitir la recogida de datos significativos permite la reflexión de los mismos, su análisis y su sistematización (Jurado, 2011).

En cuanto a esta última perspectiva, López Gorriz (1997) plantea que el diario y su análisis debe ser entendido como una herramienta que permite la autohetero-observación y la auto-hetero-evaluación de todo lo que acontece. Si bien es cierto que algunos autores como López Górriz, Gabari Gambarte, Vega y Jurado (2007) consideran la escritura del diario como un proceso lento y costoso con una alta inversión de tiempo y energía, sabemos que dicho diario ayuda a profundizar en el campo de estudio y da la posibilidad de dejar constancia de la experiencia vivida. Esto permitirá poder contrastar nuestra visión con la del otro y obtener así un mayor crecimiento y aprendizaje de todo el proceso vivido, dejando huella de nuestra singularidad ante la globalidad de los acontecimientos sociales (Jurado, 2011).

Sin embargo, otros autores como García Jorba (2000), le da un giro más al concepto al emplear el término "diario de campo". Para dicho autor, el diario de campo es una representación del testimonio de cómo se investiga, de qué manera se hace, y cuáles son los modos mediante los que se afrontan los problemas y vicisitudes que se presenta a lo largo del proceso de construcción del conocimiento, siendo además un tipo particular de texto (Geertz, 1989; Prat, 1991; Sanjek, 1990). Como tal, este texto, no solo permite el análisis de aquello que acontece, sino que se considera un método eficaz para controlar a la vez las relaciones que se establecen entre quien investiga, aquellas personas y/o fenómenos que son investigados, y la investigación misma (García Jorba, 2000). 
En nuestro caso, utilizaremos el término 'diario de investigación' para referirnos a este instrumento, pues consideramos que no se trata de una cuestión terminológica sino más bien de una cuestión de fondo, una cuestión de concepto. Este diario elaborado por la investigadora principal reflejará desde los distintos acontecimientos que suceden a lo largo de toda la investigación, hasta dudas, cuestionamientos individuales, encuentros con otros participantes, decisiones o negociaciones, emociones, sensaciones que emergen en los diferentes momentos,... Todo ello tiene cabida en este diario de investigación. Se trata de reflejar en él qué y cómo vivimos y sentimos esta investigación. (Puede consultarse este diario en el anexo III)

La información de este diario no será sometida al análisis de datos propiamente dicho, pues se trata de una visión muy subjetiva y técnica de la investigadora. Sin embargo, estos datos servirán de apoyo y registro de todo el proceso investigador y como tal, nos permitirá volver en cualquier momento sobre los diferentes acontecimientos de la investigación.

Como podremos comprobar en el capítulo 5, excepto el diario de investigación, todas las técnicas de recogida de datos expuestas en este capítulo se irán sucediendo en el tiempo con los diversos participantes de la investigación. Se generarán ciclos de recogida de datos en los que aparecerán unas u otras en función del momento, participante y pretensiones de uso. 
Es increíble lo costoso que resulta plasmar en un papel un proceso tan complejo como una investigación de este tipo. Personalmente creo que es un trabajo de organización y síntesis constante que debemos hacer los investigadores y muy necesario para el lector/a pueda apreciar importantes matices del trabajo.

No pensé inicialmente en un capítulo sobre las fases de investigación, la verdad, pero la complejidad de lo vivido en el campo así lo requiere. Quiero contarlo, quiero contarlo todo, y quiero contarlo bien. Por lo tanto, necesito espacio, necesito explayarme, necesito un capítulo aparte. Esto es distinto del diseño, distinto de los resultados, es un estado "del campo a la mesa y de la mesa al campo", yendo y volviendo miles de veces, con la sensación de estar abrumada en ocasiones, y otras totalmente bloqueada.

Espero que este capítulo aporte al lector el carácter personal que he querido darle a esta investigación y se sienta un poco más cercano a lo vivido durante el largo y sabroso proceso de trabajo de campo. En este capítulo, encontraremos definidos los principales aspectos sobre cómo se ha llevado a cabo esta investigación.

5.1. Un recorrido por los datos: cronograma

5.2. Fase 1: Negociación

5.2.1. Proyecto de tesis

5.2.2. Terminología

5.2.3. Investigación inclusiva y coinvestigación

5.2.4. Consentimiento informado

5.2.5. Diario de investigación

5.2.6. Participantes e instrumentos de recogida de información

5.3. Fase 2: Proceso cíclico de recogida de datos

5.3.1. Sucesión del proceso cíclico

5.3.1.1. Ciclo 1 de recogida de datos

5.3.1.2. Ciclo 2 de recogida de datos

5.3.1.3. Ciclo 3 de recogida de datos

5.3.1.4. Ciclo 4 de recogida de datos

5.3.1.5. Ciclo 5 de recogida de datos

5.3.2. Tratamiento y organización de los datos

5.3.3. Tipología de los datos obtenidos

5.4. Fase 3: Proceso de análisis de datos

5.4.1. Análisis deductivo: categorías y códigos previos

5.4.2. Análisis estructural y narrativo de los datos

5.4.2.1. Análisis estructural

5.4.2.2. Análisis narrativo 
Tras conocer en profundidad el problema y objetivos de esta investigación, el tipo de muestreo y qué instrumentos han sido utilizados para la recogida de datos, procedemos a exponer aquí cómo se ha realizado dicha investigación. Recordemos que nos encontramos ante una investigación cuya aproximación al campo de estudio se realiza desde un enfoque interpretativo y socio-crítico que utiliza el método biográfico-narrativo para conocer y analizar la trayectoria vital de Sergi desde los ámbitos educativo, familiar y social mediante la construcción de su historia de vida.

Para lograr esto, la investigación ha ido evolucionando a través de una serie de fases hasta cumplimentar todo el proceso de investigación. Como veremos, estas fases o etapas se han ido solapando en el tiempo, lo que ha permitido idas y venidas' del campo a la mesa y de la mesa al campo para construir la historia de vida a través de la voz de todos los participantes.

\subsection{Un recorrido por los datos: cronograma}

Pero antes de adentrarnos en la descripción de todas estas fases, consideramos conveniente presentar el cronograma de esta investigación. De esta manera, el lector no solo podrá ser conocedor que aquello que ha ocurrido, sino también resituarse en el tiempo a lo largo de la lectura de este capítulo.

Para elaborar esta cronología se ha tenido en cuenta el anexo IV (Recogida de información), en que a lo largo de todo el proceso de investigación se han ido registrando los encuentros, técnicas y tareas a realizar con cada participante, cuándo tenía lugar cada uno de estos encuentros y qué documentos o materiales había que preparar para cada sesión. 
Capítulo 5: "Del campo a la mesa y de la mesa al campo": Fases de investigación

Cronograma de investigación

Conclu
siones

Resul

tados

Fase 3:

Análisis de datos

Fase 2 (b): Devolución de la información

Fase 2: Proceso cíclico de recogida

Fase 1: Negociación

Revisión bibliográfica

Diseño inicial

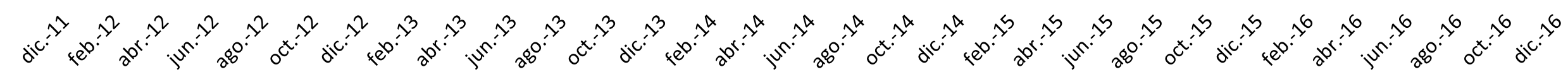

Gráfico 1. Cronograma de la investigación

167 


\subsection{Fase 1: Negociación}

Tal y como ya hemos expuesto en el capítulo 3, la negociación no debe entenderse como un proceso puntual, pues aunque en este trabajo situemos la fase del negociación al inicio de la investigación, debe tenerse en cuenta que se trata de una etapa que se prolonga durante todo el trabajo de investigación, llegando a estar presente incluso en el mismo proceso de elaboración de las conclusiones. Aun así, por cuestiones meramente expositivas del trabajo, decidimos situarla como la primera de las fases de esta investigación, pues es al inicio de la misma donde adquiere un papel más imperante y continuado.

En lo que se refiere a nuestra investigación, los acuerdos y consensos se llevaron a cabo tanto al comienzo de la investigación (varias sesiones de negociación con los padres del protagonista), así como a lo largo de todo el proceso de investigación (ciclos de negociación constante con todos los participantes). En la primera negociación inicial se abordaron los temas y elementos clave que determinarían el diseño y posterior trascurso de la investigación. Una vez ya arrancada la investigación, se iban detallando pequeños matices con cada uno de los participantes. Veamos cuáles fueron los temas abordados en esa primera negociación inicial:

\subsubsection{Proyecto de tesis}

En esta negociación inicial, se mantuvieron diversas y profundas sesiones de negociación con los padres del protagonista sobre el proyecto de tesis elaborado por la investigadora principal. Con ello se pretendía no solo establecer contacto con ellos, sino también ir poniendo sobre la mesa cuestiones tales como el tipo de investigación a realizar, los objetivos que se pretendían alcanzar, la metodología de investigación, los instrumentos de recogida que se preveía utilizar, así como una posible temporalización de todo este proceso. En esta primera negociación los padres manifiestaron ya su voluntad y deseo de participar en esta investigación y reiteradamente expusieron la necesidad de visibilizar casos particulares como el de Sergi y que éste pudiera servir como reflejo de la situación que viven personas como él.

\subsubsection{Terminología}

Lo siguiente que aconteció en estas negociaciones iniciales fue establecer y pactar la terminología a utilizar con todos los participantes de esta investigación. En este tipo de investigaciones es muy importante que los conceptos a utilizar sean compartidos por todos participantes y garantizar de alguna manera que a la hora de relacionar la información aportada por unos y otros no se den confusiones o suposiciones que darían lugar a un sesgo en la investigación. En este punto, uno de los temas importantes a tratar fue la utilización del concepto de "diversidad funcional" o el de "discapacidad" a la hora de referirnos a Sergi o a otras personas en su misma situación. En este sentido, se mantuvo una larga conversación sobre lo que suponía utilizar tanto un término como el otro y los diferentes modelos que existen detrás de cada uno de ellos.

Tanto los padres de Sergi como la investigadora principal reafirmamos en este punto nuestro posicionamiento a favor del modelo de la diversidad (FVID, 
2016), entendiendo que las personas con diversidad funcional tienen los mismos derechos que cualquier otra persona y que es la misma sociedad la que tiene que garantizar su plena inclusión y participación en todos los ámbitos. No obstante, somos conscientes de que al trasladar esto al campo de estudio, el término de "diversidad funcional" puede dar lugar a confusiones y malinterpretaciones de los propios participantes. En este sentido se acordó que, a pesar de posicionarnos en el modelo de la diversidad, considerabamos posible que los participantes de esta investigación conocieran y manejaran el término "discapacidad" y no tanto el de "diversidad funcional". Cabe tener en cuenta aquí, que en el trabajo de campo se preveía desde su inicio la participación tanto de personas mayores como de niños pequeños, siendo posible que algunos de ellos desconozcieran el segundo de los términos. Consideramos incluso, que probablemente la mayoría de los participantes, comulgaban totalmente con el modelo de diversidad pero, sin embargo, desconocían el significado o el sentido del término "diversidad funcional". Se acordó, por tanto, la utilización del concepto 'discapacidad' a lo largo de este trabajo sin obviar el posicionamiento teórico del que partíamos.

\subsubsection{Investigación inclusiva y coinvestigación}

En esta investigación, la colaboración y contribución de los participantes como miembros activos de la misma es considerada como un elemento necesario e imprescindible (capítulo 3), pues solo de esta manera podemos garantizar que respetamos sus deseos, circunstancias y voluntades en cuanto al proceso de investigación. Teniendo esto presente, el planteamiento inicial de la misma contemplaba dos niveles de implicación y colaboración de los y las participantes que fueron dialogados y consensuados con los padres del protagonista:

El primero de ellos tiene que ver con el derecho de todos los participantes a reconocer como propia aquella parte o etapa de investigación que les acontece. Esto significa que los participantes de este trabajo no solo deben de estar informados sobre el tipo de trabajo y proceso a seguir, sino que además tienen la responsabilidad de revisar el tipo de temas y cuestiones abordados en las diferentes técnicas de recogida de información, explorar y modificar las transcripciones correspondientes a su aportación, realizar propuestas temáticas y aportar documentación complementaria.

Un segundo nivel de participación en este sentido es el que denominamos como coinvestigación (expuesto en el capítulo 3). Tal y como ya se ha adelantado en capítulo anteriores, en este proceso de negociación inicial se reflexionó y conversó con los padres de Sergi sobre la necesidad de contar además con una persona inmersa en la investigación que supervisara, opinara y decidiera de la mano de la investigadora principal: un coinvestigador o coinvestigadora. La idea era que esta persona fuera participante de la investigación, a la vez que miembro activo en todas y cada una de las etapas de la investigación. Consideramos que esta es una forma de asegurar que la investigación esté altamente ligada al campo y que un "pedacito" de ese campo actúa a la vez como guía de la propia investigación. Se acordó en este punto que la persona adecuada para esta función era la madre de Sergi, pues la disponibilidad horaria, la relación con todos los posibles participantes y el pleno conocimiento de la trayectoria de Sergi hacían de ella la candidata idónea. 


\subsubsection{Consentimiento informado}

Otro del los elementos que se abordaron en esta negociación inicial fue la elaboración de un documento de consentimiento informado que garantizara el cumplimiento de ciertas cuestiones éticas relativas a la investigación (expuestas en el capítulo 3). Para ello, la investigadora principal presentó a los padres del protagonista un borrador del mismo. Este documento fue revisado y debatido entre los 3 (investigadora principal y padres de Sergi) hasta la obtención un documento final adaptado a las características de la investigación. De esta manera, se revisó y rectificó no solo en cuanto a su forma (concreción, claridad y precisión), sino también el contenido del mismo.

Finalmente, se obtuvo el documento de Consentimiento informado en el que se exponían elementos esenciales de la investigación (contexto, justificación, finalidad y funciones de la investigadora y de la coinvestigadora), el procedimiento planificado para la recogida y análisis de datos, la confidencialidad y anonimato, y la expresa voluntad de participación a través de la firma del documento. Se elaboraron en primer lugar dos modelos de consentimiento informado: uno expreso para la figura de la coinvestigadora (anexo V) y un modelo estándar y genérico de consentimiento informado para todos los participantes de la investigación (anexo VI). Cabe destacar aquí, que cualquiera de los modelos elaborados en esta investigación permitían incorporar tantas modificaciones y cambios como fuera necesario. Una de tercera versión de este consentimiento informado fue la de un modelo adaptado para menores de edad, pues en la muestra se contempla la participación de diversos menores y había que incorporar la aprobación de los padres o tutores legales correspondientes (anexo VII). La última de las adaptaciones y modificaciones se realizó con la finalidad de elaborar un modelo de consentimiento informado adaptado a Sergi y sus particularidades. Con la supervisión de la coinvestigadora, se adaptó el contenido y la forma del consentimiento para facilitar a Sergi su lectura y comprensión (anexo VIII).

\subsubsection{Diario de investigación}

En una investigación de este tipo el proceso de reflexión constante sobre lo que ocurre, sobre los acontecimientos, sobre lo que pasa en los encuentros con los participantes de la investigación y sobre las sensaciones que se producen son tan necesarios como los propios datos recogidos en a través de los instrumentos. La perspectiva que puede darnos de todo ello el diario de investigación hace de él un instrumento indispensable en este tipo de trabajos.

Por ello, en esta fase de negociación inicial, se acordó con los padres y tutores de Sergi la incorporación el diario de investigación como una herramienta complementaria a la recogida de datos. En este sentido, siendo que se trata de una investigación 'codo con codo' con la coinvestigadora, se decidió que el diario de investigación no solo sería llevado a cabo por la investigadora principal, sino que además la coinvestigadora elaboraría su propio diario de investigación. La finalidad era recolectar, al margen de las técnicas e instrumentos, todo aquello acontecido, sentido y percibido por la investigadora principal y la coinvestigadora a lo largo de la investigación. Sin embargo, por cuestiones laborales y personales la coinvestigadora y madre de Sergi a penas pudo dedicarle tiempo al diario de investigación, por lo que el proceso de investigación solo pudo registrarse en el diario de la investigadora (anexo III). Como ya se ha adelantado en el capítulo 4, 
los registros y datos de este diario son un reflejo de lo acontecido, cuya finalidad no es el análisis sino el seguimiento del proceso.

\subsubsection{Participantes e instrumentos de recogida de información}

El último elemento a considerar en esta etapa de negociación con los padres fue la elección de la muestra y de los instrumentos de recogida de datos. Para tratar este tema, se elaboró una primera lista de posibles participantes que, además de ser cercanos a Sergi, garantizaran cierta "representatividad" de todos los ámbitos de la vida de Sergi (familia, escuela y ocio), obteniendo así una visión poliédrica de su trayectoria vital. Cabe tener en cuenta aquí, que esta primera lista de la muestra se fue modificando y adaptando a medida que avanzaba la investigación, pues las características del campo y las distintas casuísticas de los participantes fueron determinando y definiendo la muestra final (véase capítulo 4).

De la misma manera, los instrumentos de recogida de información también fueron consensuados en esta primera fase de negociación. La investigadora principal presentó una lista con los distintos instrumentos de recogida de datos propios del método biográfico-narrativo, y a través del diálogo con los padres se determinaron cules eran los más adecuados tanto para esta investigación como para los participantes seleccionados. No obstante, al igual que con la muestra, la posibilidad de incorporación, eliminación o modificación en cualquiera de los instrumentos de recogida queda sujeta a las exigencias y necesidades del campo y de sus participantes.

Por último, en esta etapa de negociación se puso de manifiesto la necesidad de adaptar aquellos instrumentos a utilizar con Sergi, pues debido a su diagnóstico en Trastorno del Espectro Autista (TEA) y Trastorno Específico del Lenguaje (TEL) se requerirían ciertas adaptaciones visuales y de lenguaje. Dichas adaptaciones se realizaron entre la investigadora principal y la coinvestigadora.

\subsection{Fase 2: Proceso cíclico de recogida de datos}

Una vez finalizada la etapa de negociación inicial que permitía situar y planificar la investigación, se procedió a abrir una segunda etapa: el proceso cíclico de recogida de datos. Este proceso de ciclos sucesivos, ha sido la parte central de esta tesis doctoral en la que los mismos procesos que se iban sucediendo se generaban en función de las necesidades de la propia investigación y de las manifestadas por los participantes. Cabe tener en cuenta, que todos estos ciclos se componen de cuatro partes fundamentales: negociación, recogida de información, tratamiento de datos y planteamiento de "vacíos" de información. 


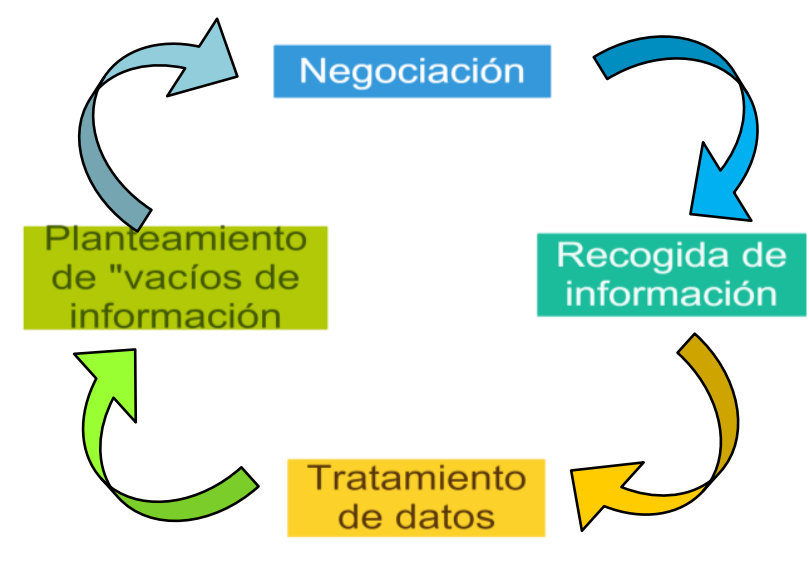

Figura 12. Ciclo genérico de recogida de datos

El primer elemento a considerar en cada uno de los ciclos es la negociación. Como ya se ha ido introduciendo en apartados anteriores, en una investigación cualitativa de este tipo, la negociación es un elemento que debe estar presente a lo largo de todo el proceso. La negociación y renegociación continua es el elemento que permite que la investigación se adapte a la perfección a las características y singularidades del campo, que se respete al participante en sus deseos y voluntades así como en sus singularidades, y que se consideren los distintos acontecimientos del campo como parte del proceso investigador. La renegociación de las condiciones y procedimiento con cada uno de los participantes asegura no solo un encuentro cómodo y relajado entre investigadora y participante, sino también garantiza una recogida de datos más fructífera.

Tras las negociaciones pertinentes, entra en juego la recogida de información. En ella se siguen los parámetros establecidos durante la negociación con cada participante y se realizan los encuentros con las técnicas de recogida de datos pactadas con cada uno de ellos. La recogida de información siempre es precedida por la negociación, asegurando así que ésta recogida esté totalmente ajustada a las características, circunstancias y posibilidades de cada uno de los participantes de la investigación.

Una vez se han obtenido los datos del campo, estos deben ser tratados por el investigador. En este punto hablamos de tratamiento de datos y no de 'análisis de datos' propiamente dicho para diferenciarlo del análisis que se realiza a posteriori. Debe tenerse en cuenta que aunque la fase de análisis de datos suela situarse siempre tras el trabajo de campo, realmente ésta fase se inicia a la vez que el propio proceso de recogida de información (Rodríguez et al., 1996), pues desde el inicio el investigador está detectando y revisando los datos recogidos para plantearse nuevas preguntas y reorganizar acciones futuras de investigación. Dicho de otra manera, se trata de una focalización y delimitación en la propia recogida de datos que podemos considerar como un preanálisis de manera implícita que descarta ciertas variables y relaciones y atiende a otras (Miles \& Hubermas, 1994). El tratamiento de datos durante la recogida se realiza con la finalidad concreta de: (a) obtener una transcripción que debe ser revisada, modificada (si es preciso) y 
ratificada en su contenido por cada participante y (b) examinar dichas transcripciones para poder identificar ciertos temas, cuestiones emergentes o dudas que dan lugar al siguiente paso del ciclo.

En este cuarto y último punto del ciclo, el planteamiento de "vacíos" de información, se detectan ciertos "huecos" en los datos aportados por los participantes sobre los que es necesario profundizar o indagar de maneras diversas. De esta manera, no solo se acaban planteando nuevas preguntas o temas sobre los que seguir investigando, sino también se detecta la necesidad de incorporar nuevos participantes a la investigación que ayuden a complementar el proceso de recogida de datos.

El proceso cíclico expuesto en este apartado, sería un ejemplo muy claro de lo que Velasco y Díaz de Rada (1997) identifican como viajes "del campo a la mesa y de la mesa al campo". En investigaciones de este tipo, existe una relación directa entre lo que ocurre durante la recogida de datos y los planteamientos que el investigador se hace constantemente acerca del proceso, facilitando de esta manera que las acciones sean encauzadas con aquello que el campo y el propio objeto de investigación requieren.

\subsubsection{Sucesión del proceso cíclico}

Desde el inicio hasta el final de esta fase de recogida de datos, se han sucedido diversos ciclos. La consecución y composición de cada uno de ellos, dependía del punto en el que se encontraba la investigación, de las circunstancias colaterales y de la disponibilidad de los participantes. Somos conscientes que estos procesos cíclicos son complejos e incluso se llegaron a solapar en el tiempo. Por ello, para que el lector posea en primer lugar una visión global de esta fase, presentaremos el mapa general de todos los ciclos para, a continuación, ir desmenuzando cada uno de ellos. 
MAPA 1 
Tras obtener esta visión global de todo el proceso, veamos a continuación aquello acontecido en cada uno de los ciclos de recogida de datos:

\subsubsection{Ciclo 1 de recogida de datos}

En las negociaciones iniciales, se estableció que era preciso "arrancar" la recogida de información con una voz clave, es decir, una persona que fuera capaz de aportar a la investigación una visión amplia y genérica de la historia de vida de Sergi. Con ello, se buscaba esbozar lo que sería una aproximación a la cronología de la vida del protagonista en la que se dibujaran las diversas etapas y acontecimientos vividos por Sergi, obteniendo así una base temática sobre la que construir posteriormente nuevos encuentros con el mismo u otros participantes. Fue en las mismas negociaciones iniciales en las que se determinó que esta 'voz clave' sería la madre y coinvestigadora de este trabajo.

Para ello, se negoció y se realizó la Entrevista en Profundidad a la Madre $(E P M)$, en la que se recogía una amplia información sobre la trayectoria de vida de Sergi en los diferentes ámbitos estudiados (ocio, familia y educación). Tras su transcripción se procedió a su devolución a la madre para la revisión de su contenido. El ciclo finalizó con la renegociación del contenido y estructura de una nueva entrevistas Entrevista Temática a la Madre (ETM), a realizar en el siguiente ciclo:

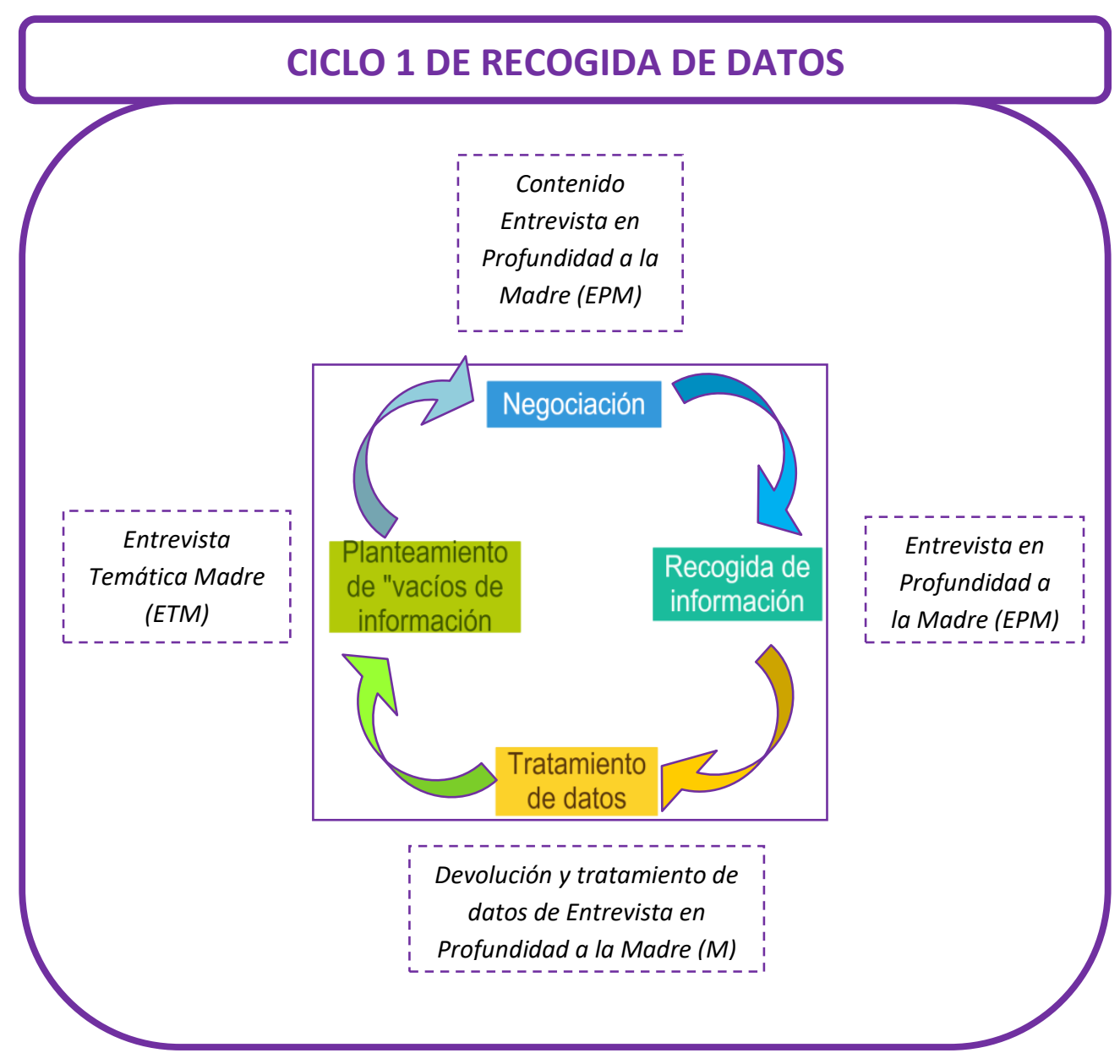

Figura 14. Ciclo 1 de recogida de datos 


\subsubsection{Ciclo 2 de recogida de datos}

El segundo ciclo de recogida de información arrancó con la negociación de la estructura y contenido de la Entrevista Grupal a los Hermanos de Sergi (EG H1yH2) con la coinvestigadora. Cuando esta fue aceptada por la madre se procedió a negociar el encuentro y procedimiento de la entrevista con los propios protagonistas, los hermanos de Sergi. Terminadas las negociaciones pertinentes se originó la recogida de la información mediante la Entrevista Temática a los hermanos (EG H1yH2) y la Entrevista Temática a la Madre (ETM), construida a partir de los datos del ciclo anterior. En este mismo ciclo, la madre aprovechó la ocasión para entregar a la investigadora principal un conjunto de documentos, informes y materiales que serán retomados más adelante en el proceso de investigación. Estos materiales y documentos serán los que se trabajaran en una futura Técnica Documentos Escritos a realizar con la Madre (TDE M).

Una vez transcritas dichas entrevistas fueron devueltas a los participantes para su revisión y ratificación. Cuando tanto la madre como los hermanos dieron su visto bueno se procedió a negociar con la coinvestigadora las próximas entrevistas (Entrevista Temática Educador -ET Edu-, la Entrevista Temática a la Logopeda ET Log-, la Entrevista Temáticas con la Maestra -ET Maes- y la Entrevista Temáticas con el profesor de natación -ET PN-)

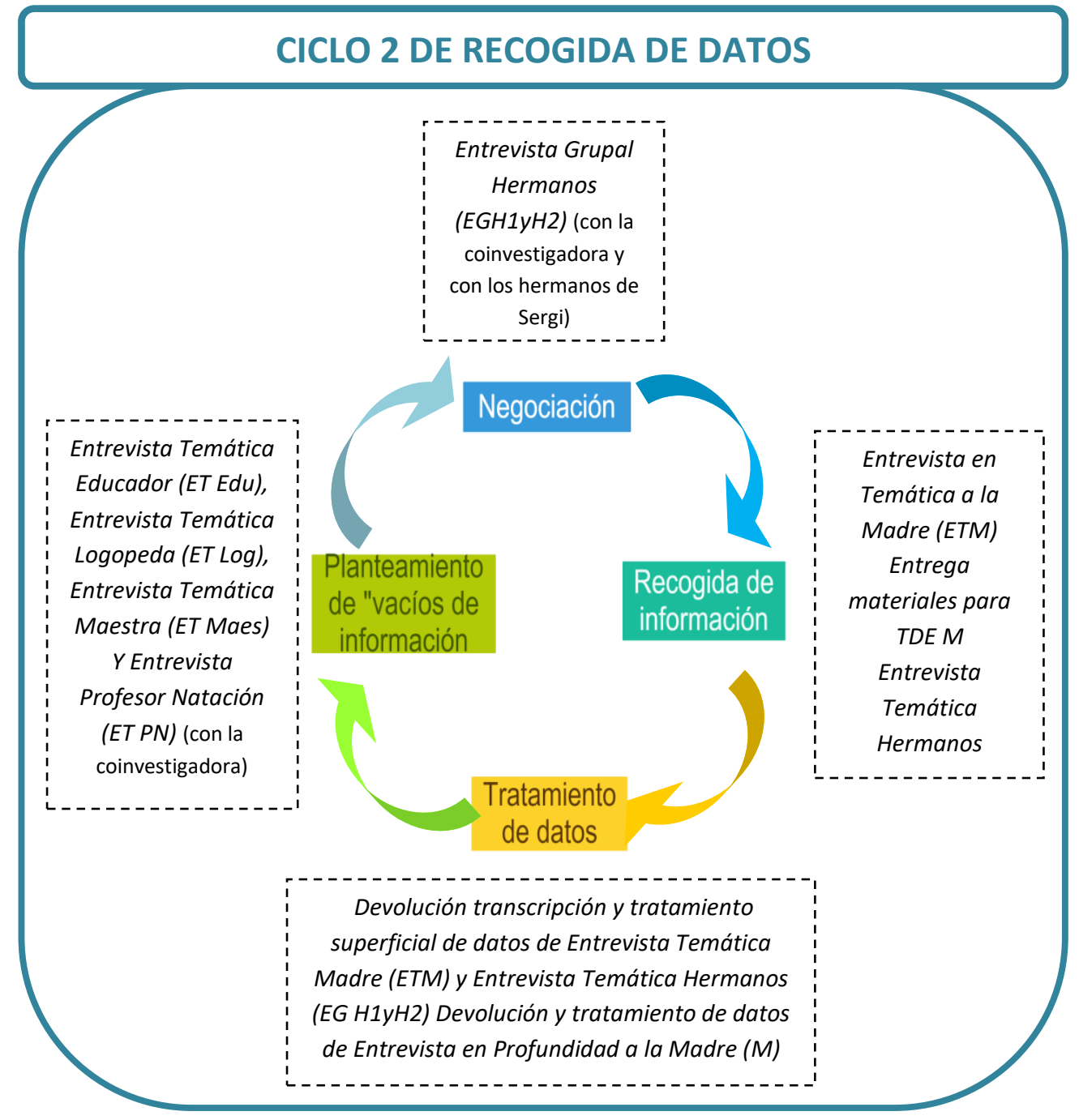

Figura 15. Ciclo 2 de recogida de datos 


\subsubsection{Ciclo 3 de recogida de datos}

Este tercer ciclo de recogida de información se inicia con la negociación con cada uno de los participantes cuyas entrevistas ya se han trabajado previamente con la coinvestigadora. Para ello, se establece contacto con todos y cada uno de ellos y se preparan los encuentros correspondientes. Una vez se pacta el contenido y procedimiento de las diferentes entrevistas se procede, en varias sesiones, a realizar la Entrevista Temática al Educador (ET Edu), la Entrevista Temática a la Logopeda (ET Log), la Entrevista Temática al Profesor de Natación (ET PN) y la Entrevista Temática a la Maestra (ET Maes). Ésta última, la maestra, además de participar en la entrevista como tal, aportó ciertos materiales que consideraba interesantes a incorporar a la investigación. Dicho materiales serán tratados más adelante en un futuro encuentro para realizar la Técnica de Documentos Escritos con la Maestra (TD Maes).

Terminada la recogida de información de todas estas entrevistas, se inició un largo proceso de transcripción, pues, como ya se ha adelantado en apartados anteriores, el ciclo no se podía cerrar sin la revisión y aceptación del contenido de la transcripción por parte de cada uno de los participantes. Cuando estas transcripciones fueron aceptadas se procedió a preparar el siguiente ciclo. En este caso se negoció con la coinvestigadora la estructura y contenido de la Entrevista Temática Grupal a los Compañeros de la Escuela (ETG CE), la Entrevista Temática a la Profesora de la Escuela de Arte de Sergi (ET PEA), la Entrevista Temática al Profesor de Pedagogía Terapéutica del Instituto (ET PT IES) y la Entrevista Temática a la Profesional del Mira'm (ET Mir). 


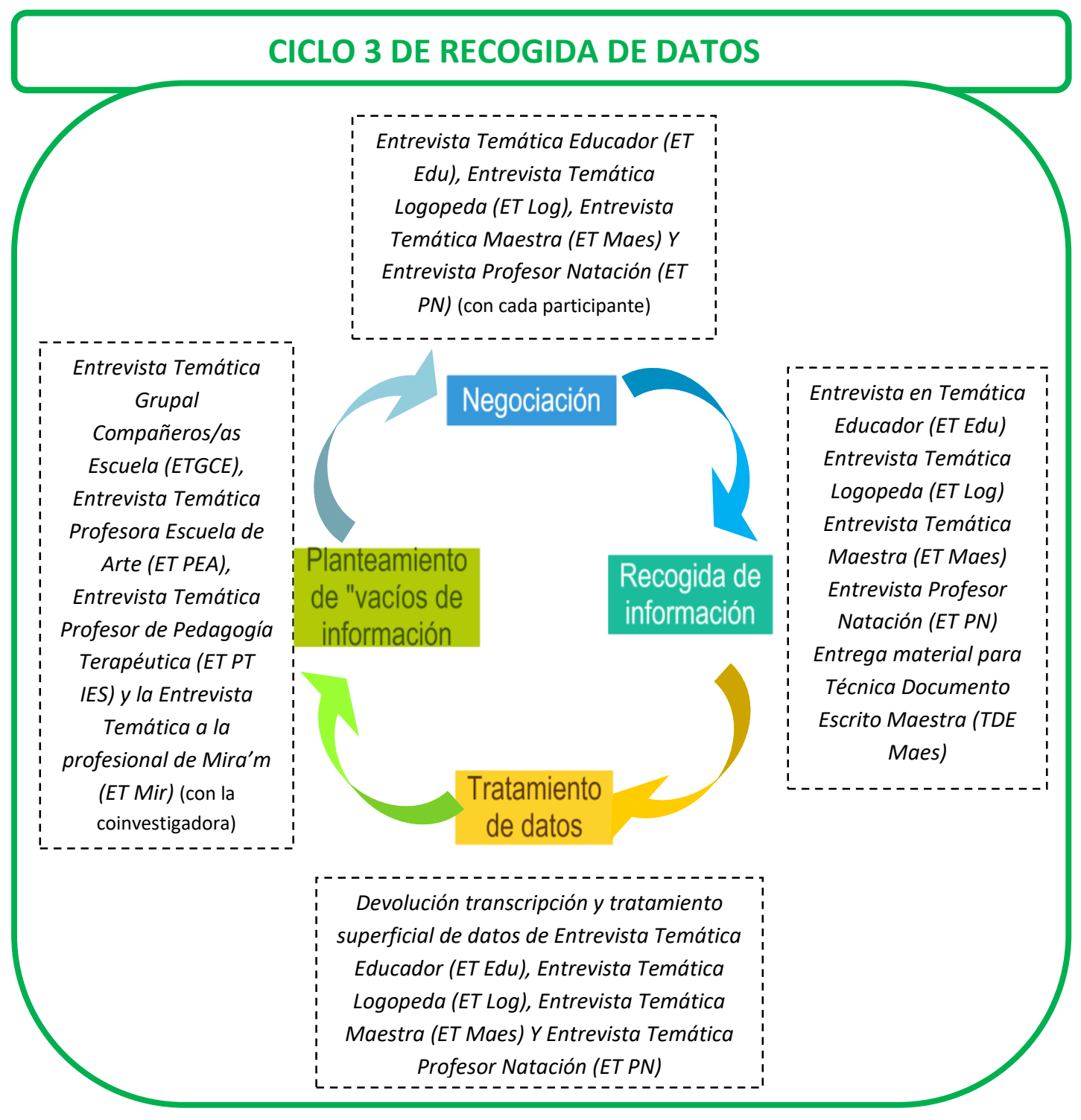

Figura 16. Ciclo 2 de recogida de datos 


\subsubsection{Ciclo 4 de recogida de datos}

El $4^{\circ}$ ciclo de esta fase de la investigación se inicia con la preparación y negociación de numerosas sesiones con diversos participantes: el grupo de compañeros y compañeras de la escuela de Sergi, su profesora de la Escuela de Arte, el profesor de Pedagogía Terapéutica del IES y con una de las profesionales de la Fundación Mira'm con la que la familia estuvo trabajando durante varios años.

Para todas y cada una de estas sesiones se negoció fecha, hora y lugar para las entrevistas, el contenido de estas entrevistas así como la posibilidad y voluntad de incorporar a los datos fotografías, materiales, documentos,... a través de la Técnica Fotográfica (TF) y la Técnica de Documentos Escritos (TDE). Se podrá observar, por tanto, que la Técnica Documental y/o la Técnica Fotográfica pueden no utilizarse con todos los participantes, pues esto deriva directamente de las negociaciones previas con cada uno de ellos. A continuación se organizaron las diferentes sesiones con los participantes. Dependiendo de la extensión de la Entrevista Temática y del número de técnicas adicionales que se realizaron el número de encuentros con cada uno de ellos osciló entre 2 o 3 sesiones.

En este cuarto ciclo, el trascurso de tiempo entre la recogida de información y la devolución a sus participantes fue más prolongado, pues la gran cantidad de información a transcribir así lo exigía. Una vez obtenidas las transcripciones éstas fueron devueltas a sus protagonistas para la revisión y, en su caso, modificación del contenido. Seguidamente se procedió a analizar de forma superficial su contenido y a preparar gracias a ello futuras entrevistas. Como última parte del ciclo, se negociaron y revisaron con la coinvestigadora los instrumentos de recogida de datos a utilizar con el compañero del IES de Sergi, con su abuelo, con el propio Sergi y con el padre de éste. 


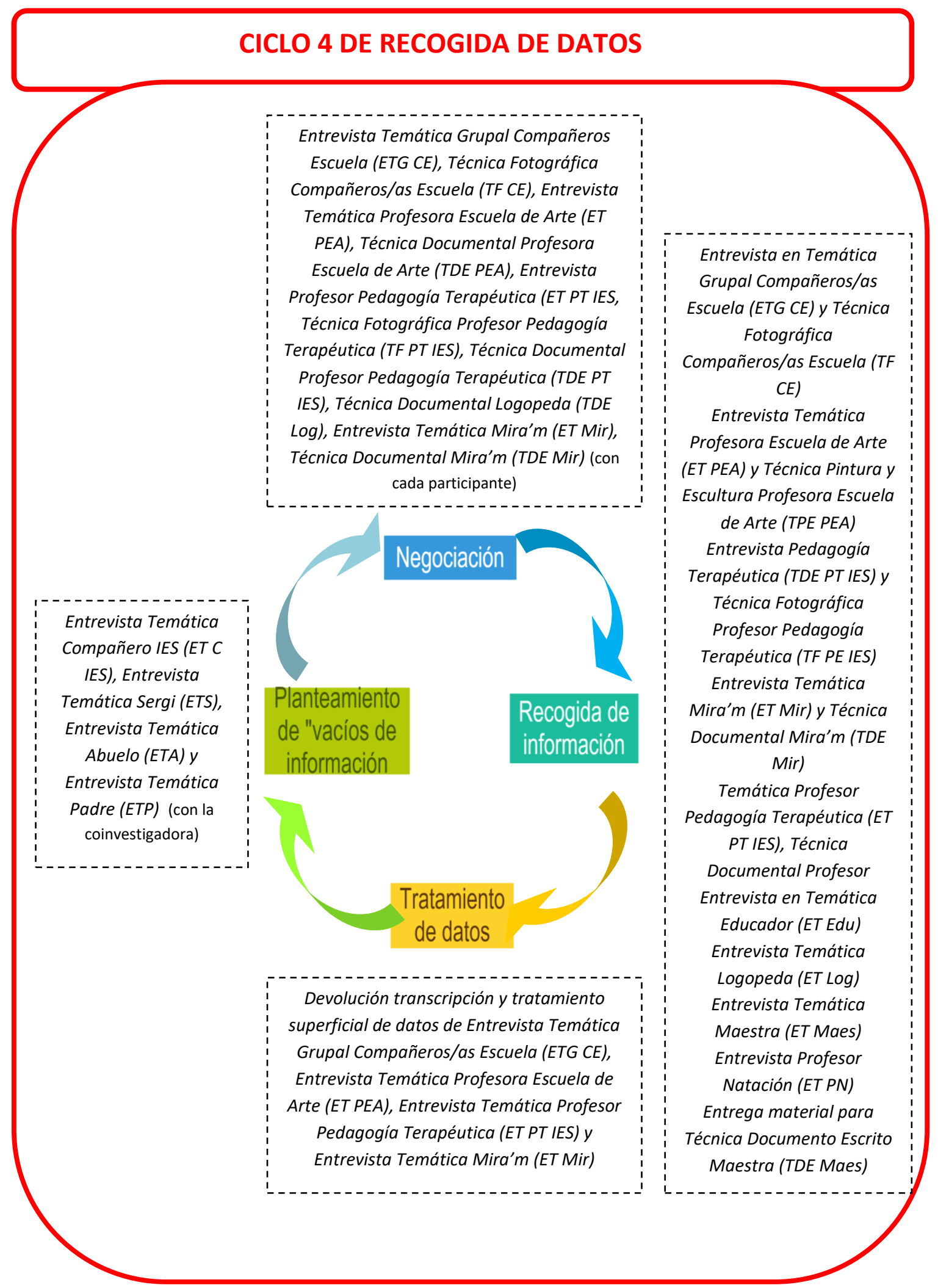

Figura 17. Ciclo 4 de recogida de datos 


\subsubsection{Ciclo 5 de recogida de datos}

En este último ciclo, se trabajó con ciertos participantes que se incorporaron más adelante a la muestra (como el caso del compañero del IES de Sergi), así como con participantes que servirían para 'cerrar' el proceso de recogida de datos (como es el caso de Sergi y de su padre). La decisión de realizar el encuentro con Sergi (S) y con su padre (P) al final del proceso de recogida de datos, fue una de las negociaciones que se establecieron al inicio del mismo. Se acordó con la coinvestigadora que, al igual que la recogida de datos a través de la madre (M) del protagonista sirvió como 'arranque' del proceso, se consideró que tanto Sergi (S) como su padre (P), podían actuar como 'cierre', pues ellos son quienes más aclaraciones y especificaciones pueden aportar a las dudas o nuevos temas emergidos a lo largo de todo el proceso. Como estrategia de 'cierre' también fueron incorporadas a este ciclo otras técnicas que ayudarían a obtener una visión global sobre la propia historia de vida como el caso de la Línea de Vida realizada con la madre de Sergi (M).

Estas sesiones de recogida de datos fueron un tanto más complicadas de organizar y llevó un cierto tiempo negociar una cita que no interfiriera con las actividades académicas y extraacadémicas tanto del compañero del IES (C IES) de Sergi como de Sergi (S). Asimismo, se procuró respetar que los últimos encuentros fueran con Sergi $(S)$ y con su padre $(P)$ como 'cierre' del proceso de recogida de información. El último paso de este ciclo fue la devolución de las transcripciones a sus correspondientes participantes para poder iniciar tras ello el análisis de datos propiamente dicho. 


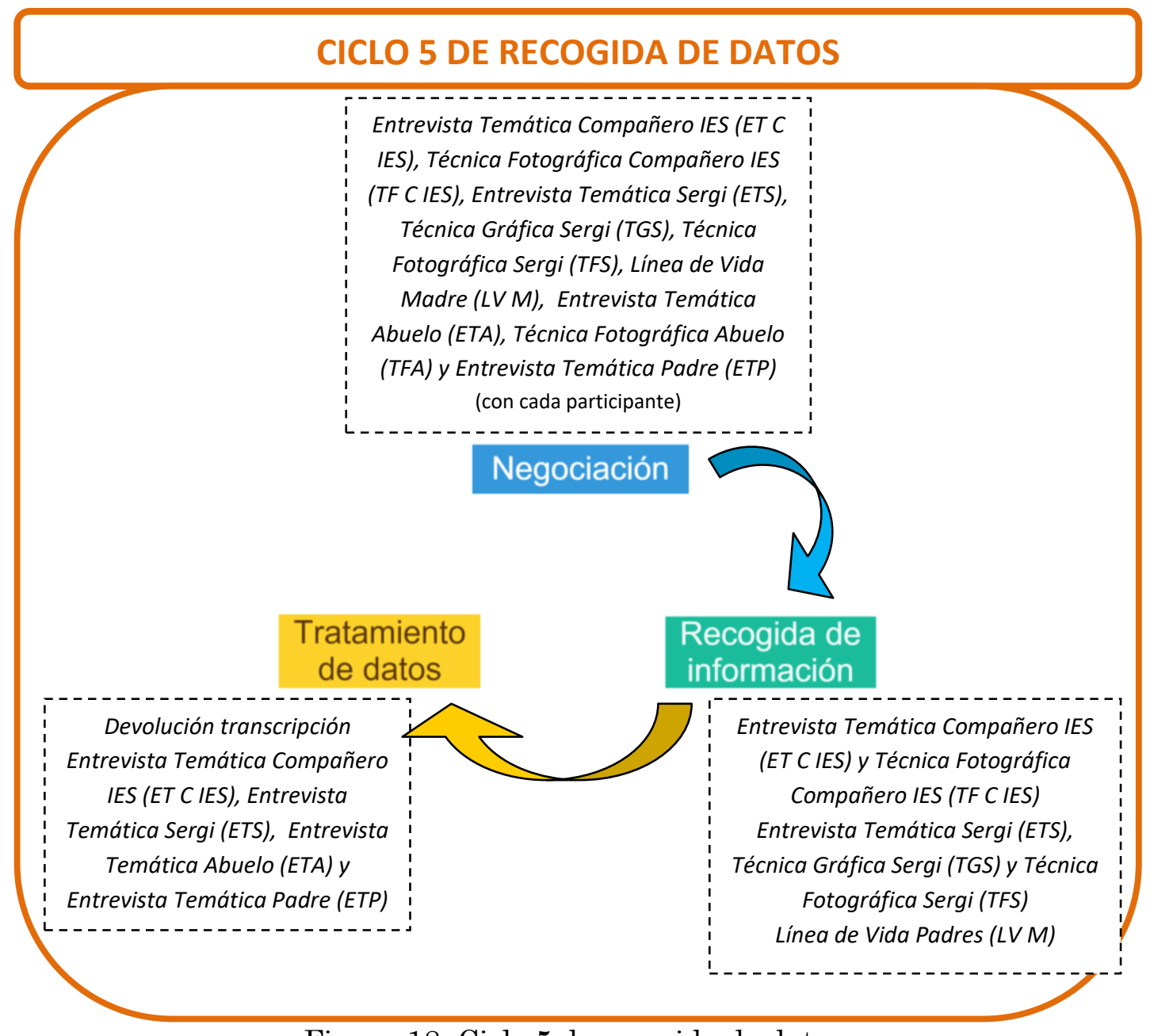

Figura 18. Ciclo 5 de recogida de datos 


\subsubsection{Tratamiento y organización de los datos}

Al finalizar la recogida de datos mediante cualquiera de las técnicas expuestas, se iniciaba una especie de proceso interno: la transcripción y clasificación de los datos. En estos momentos, la investigadora debía lograr representar a través del texto escrito aquello dicho por cada participante con sus correspondientes detalles y matices. Escribir y describir aquello acontecido en una interacción cara a cara que permitiera reproducirlo y analizarlo más adelante solo se puede conseguir a través de la literalidad de los datos. Con esta pretensión se creó un sistema de códigos de transcripción que, al intercalarlos en el texto, permitían representar los detalles y los gestos de comunicación no verbal.

Para llevar a cabo esta transcripción, se tuvieron en cuenta las aportaciones que Pujadas (1992) expone en su trabajo:

(a) Revisar y estandarizar los fallos de concordancia morfosintáctica para que el texto sea perfectamente legible.

(b) Recoger las pausas, énfasis, dudas y cualquier otro tipo de expresividad oral por medio de un código preestablecido

(c) Mantener las expresiones y giros idiosincrásicos y el léxico jergal que utilice el informante.

Siguiendo estas recomendaciones, se elaboró una leyenda de transcripción que, tomando como ejemplo otros trabajos (De la Rosa, 2008), se construyó en función de las necesidades de los documentos transcritos. Es decir, en el trascurso del proceso de transcripción se iban creando unos códigos de transcripción u otros para recoger fielmente los matices de la entrevista. Si el código ya estaba creado con anterioridad se tomaba como referencia y se anotaba entre paréntesis. Si tal código no existía, se creaba y se incorporaba a la leyenda de códigos de transcripción. Veamos a continuación la leyenda definitiva utilizada en esta investigación:

\begin{tabular}{|l|l|}
\hline LEYENDA DE TRANSCRIPCIÓN & $\mathrm{R}$ \\
\hline Risas & $\mathrm{N}$ \\
\hline Cierto nerviosismo, inquietud & $\mathrm{T}$ \\
\hline Tristeza, melancolía por el recuerdo de algo triste & $\mathrm{I}$ \\
\hline Indignación, rabia & $\mathrm{Ll}$ \\
\hline Lágrimas de emoción o de recuerdo.- Llorar & $\mathrm{S}$ \\
\hline Silencio & $\mathrm{LC}$ \\
\hline Ladear la cabeza, decir “no" de forma gestual & $\mathrm{AC}$ \\
\hline Asentir con la cabeza, decir "si" de forma gestual & $\mathrm{GM}$ \\
\hline Golpe con la mano, expresando efusividad, energía o fuerza & $\mathrm{GI}$ \\
\hline Gesto de indecisión, simbolizando algo abstracto, no definido & $\mathrm{M}$ \\
\hline Expresión de miedo, terror & “"” \\
\hline $\begin{array}{l}\text { Cuando reproduce textualmente lo que ella misma u otra persona } \\
\text { dijo en el pasado }\end{array}$ & \\
\hline Expresión popular & ' \\
\hline Nombre propio de ciudad, centro,... & cursiva \\
\hline Duda al momento de decir la frase o palabra & $\mathrm{D}$ \\
\hline Fragmento inteligible & --- \\
\hline
\end{tabular}




\begin{tabular}{|l|l|}
\hline Interrupción de alguien en la conversación & $* * *$ \\
\hline Alegría y satisfacción & A \\
\hline Aclaraciones de la transcripción & () \\
\hline
\end{tabular}

Tabla 16. Leyenda de transcripción de instrumentos

Una vez los datos estaban transcritos literalmente, se enviaban a los participantes correspondientes para verificar su contenido y modificarlo en caso de que fuera necesario. Cuando se obtenía respuesta de éstos se daba por zanjada la revisión de su contenido. (Véanse los diferentes instrumentos transcritos y preparados para el análisis en el anexo II). Cada documento o técnica se codificaba y organizaba en el cómputo total de información, sistematizando de esta manera la información para un rápido acceso e identificación. El sistema final de códigos de instrumentos quedó de la siguiente manera: 


\begin{tabular}{|c|c|c|c|}
\hline Instrumentos & Participantes & Códigos & Duración \\
\hline $\begin{array}{ll}\text { Entrevista } & \text { en } \\
\text { Profundidad (EP) } & \end{array}$ & Madre $(1,2)$ & EP M & $3 \mathrm{~h} 22 \mathrm{mins}$ \\
\hline \multirow{12}{*}{ Entrevista temática (ET) } & Madre $(1,2,3)$ & ET M & $6 \mathrm{~h} 14 \mathrm{mins}$ \\
\hline & Educador & ET Edu & $3 \mathrm{~h} 02 \mathrm{mins}$ \\
\hline & Logopeda & ET Log & 4h $33 \mathrm{mins}$ \\
\hline & Maestra primaria & ET Maes & $1 \mathrm{~h} 25 \mathrm{mins}$ \\
\hline & Profesor Natación & ET PN & $2 \mathrm{~h} 50 \mathrm{ming}$ \\
\hline & Profesora Escuela de Arte & ET PEA & $38 \mathrm{mins}$ \\
\hline & $\begin{array}{l}\text { Profesor } \begin{array}{l}\text { Pedagogía } \\
\text { Terapéutica del IES }\end{array} \\
\end{array}$ & ET PT IES & 1h $24 \mathrm{mins}$ \\
\hline & Profesional de Mira'm & ET Mir & $1 \mathrm{~h} 18 \mathrm{mins}$ \\
\hline & Compañero IES & ET C IES & 37 mins \\
\hline & Abuelo & ET A & $1 \mathrm{~h} 31 \mathrm{mins}$ \\
\hline & Sergi & ET S & $1 \mathrm{~h} 14 \mathrm{mins}$ \\
\hline & Padre & ET P & 1h $39 \mathrm{mins}$ \\
\hline \multirow{2}{*}{$\begin{array}{l}\text { Entrevista } \\
\text { grupal (EG) }\end{array}$} & Hermanos & EG H1 y H2 & $57 \mathrm{mins}$ \\
\hline & Compañeros/as escuela & ETG CE & $1 \mathrm{~h} 10 \mathrm{mins}$ \\
\hline \multirow{5}{*}{$\begin{array}{l}\text { Técnica documentos } \\
\text { escritos (TDE) }\end{array}$} & Hermano & TD H1 & $13 \mathrm{mins}$ \\
\hline & Logopeda & TD Log & 1h $15 \mathrm{mins}$ \\
\hline & Madre & TD M & $45 \mathrm{mins}$ \\
\hline & Maestra & TD Maes & $7 \mathrm{mins}$ \\
\hline & $\begin{array}{ll}\text { Profesor } & \text { Pedagogía } \\
\text { Terapéutica IES } & \end{array}$ & TD PT IES & $25 \mathrm{mins}$ \\
\hline \multirow{11}{*}{ Técnica fotográfica (TF) } & Abuelo & TF A & $17 \mathrm{mins}$ \\
\hline & Compañero IES & TF CIES & $5 \mathrm{mins}$ \\
\hline & $\begin{array}{lll}\begin{array}{l}\text { Compañero/a } \\
\text { (Vero) }\end{array} & \text { Escuela } & 1 \\
\end{array}$ & TF CE 1 (V) & 4 mins \\
\hline & Compañero/a Escuela 2 (Eva) & TF CE $2(\mathrm{E})$ & $7 \mathrm{mins}$ \\
\hline & $\begin{array}{lll}\begin{array}{l}\text { Compañero/a } \\
\text { (Jordi) }\end{array} & \text { Escuela } & 3 \\
\end{array}$ & TF CE 3 (J) & 3 mins \\
\hline & $\begin{array}{lll}\begin{array}{l}\text { Compañero/a } \\
\text { (Rodrigo) }\end{array} & \text { Escuela } & 4 \\
\end{array}$ & TF CE 4 (R) & 4 mins \\
\hline & Hermano1 & TF H1 & 15 mins \\
\hline & Hermano2 & TF H2 & 19 mins \\
\hline & Madre & $\mathrm{TF} \mathrm{M}$ & $24 \mathrm{mins}$ \\
\hline & $\begin{array}{ll}\text { Profesor } & \text { Pedagogía } \\
\text { Terapéutica IES } & \\
\end{array}$ & TF PT IES & escrito \\
\hline & Sergi & TF S & $13 \mathrm{mins}$ \\
\hline $\begin{array}{l}\text { Técnica Pinturas } \\
\text { Esculturas (TPE) }\end{array}$ & Profesora Escuela de Arte & TPE PEA & 33 mins \\
\hline Técnica Gráfica (TG) & Sergi & TG S & escrito \\
\hline
\end{tabular}

Tabla 17. Recogida de datos: Instrumentos, participantes, códigos y duración

\subsubsection{Tipología de los datos obtenidos}

El resultado de este proceso de recogida de datos fue un cuerpo de datos muy denso, variado y complejo. En palabras de Rodríguez et al. (1996), los datos son entendidos como:

Una elaboración realizada por el investigador o por cualquier otro sujeto presente en el campo de estudio, en la que se recoge información acerca de la realidad interna o externa a los sujetos y que es utilizada con 
propósitos indagativos. El dato soporta una información sobre la realidad, implica una elaboración conceptual de esa información y un modo de expresarla que hace posible su conservación y comunicación. (Rodríguez et al., 1996: 199)

Como ya se ha ido adelantando en apartados anteriores, en la investigación que nos ocupa, hemos dispuesto de una gran diversidad de instrumentos de recogida de información según las características tanto del campo como de los participantes. Como es lógico, esta variedad en las técnicas acabó generando una gran variedad de datos, de diversa naturaleza, y procedencia. Para poder iniciar la fase siguiente del proceso de investigación (el análisis de datos) se consideró necesario que los datos fueran organizados y sistematizados previamente para poder controlar y verificar el tipo y volumen de datos del que se disponía. En nuestro caso, establecimos una clasificación y sistematización de los datos en base a la fuente y naturaleza del dato.

Para la elaboración de esta clasificación se tuvo en cuenta diversas clasificaciones aportadas por autores como Pujadas (1992), McDonald y Tipton (1993) (en Valles, 1999) y McMillan y Schumacher (2005). Las propuestas de estos autores en cuanto a la clasificación de fuentes de datos y tipos de datos son las siguientes:

Pujadas (1992)

\begin{tabular}{l}
\hline Documentos personales \\
- Autobiografías \\
- Diarios personales \\
- Corresopndencia \\
- Objografias, películas, vídeos,... \\
\hline Relatos biográficos \\
- Historias de vida \\
- De relato único \\
- De relatos cruzados \\
- De relatos paralelos \\
- Relatos de vida \\
- Biogramas
\end{tabular}

MacDonald y Tipton (1993) (en Valles, 1999)

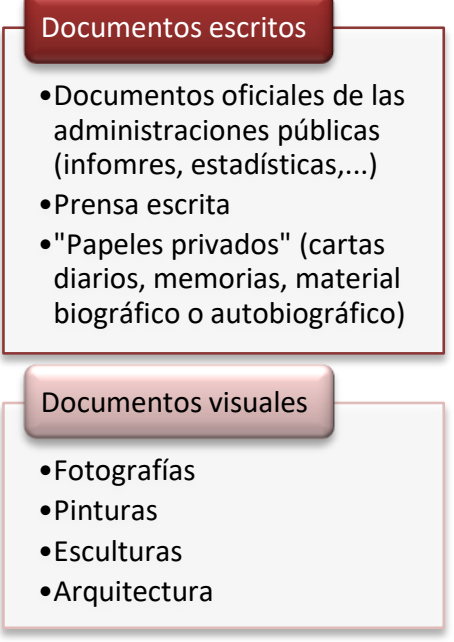

McMillan y Schumacher (2005)

\begin{tabular}{l}
\hline Documentos personales \\
- Diarios \\
- Cartas personales \\
- Anotaciones anecdóticas \\
- Documentos oficiales \\
- Papeles internos \\
- Anotaciones y expedientes \\
- Datos estadísticos \\
Objetos \\
- Símbolos \\
- Objetos
\end{tabular}

Figura 19. Clasificaciones sobre tipos de datos recogidos

Tras revisar las diferentes clasificaciones aportadas por estos autores y la tipología de los datos recogidos en nuestra investigación, se optó por elaborar una nueva clasificación de las fuentes y los datos de la investigación que tuviera en cuenta las aportaciones de estos autores pero que, a su vez, fuera coherente con la naturaleza de datos de nuestra investigación. De esta manera obtuvimos la siguiente clasificación y sistematización de los datos recogidos: 


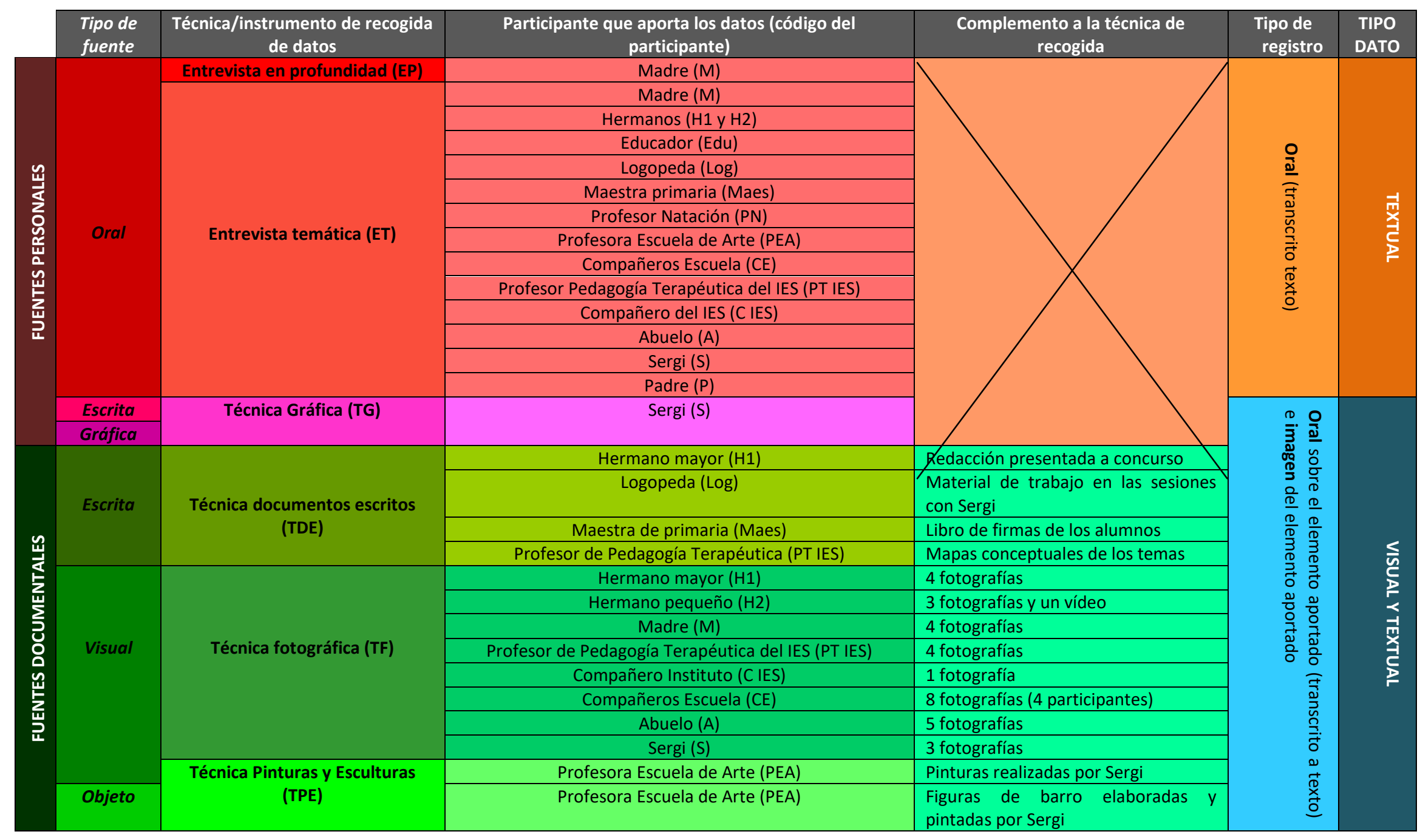

Tabla 18. Tipología de datos recogidos 
El conjunto de instrumentos transcritos y clasificados se podrán localizar en el anexo $I X$ de este trabajo. A partir de esta clasificación y con una mirada global de la cantidad y tipo de datos de los que disponíamos, procedimos a plantear la siguiente fase: el análisis de datos. Cabe resaltar aquí, que durante el mismo proceso de recogida y transcripción de datos ya se inició un boceto del análisis y se obtuvieron las primeras aproximaciones a los resultados (aunque esto no se hiciera de manera explícita), pues en este tipo de trabajos no hay una clara separación entre recogida y análisis de datos. De alguna manera, el transcriptor se convierte en intérprete durante el mismo proceso (Bolívar et al. 2001) pues como nos indica (Gibbs, 2012: 22) "el análisis puede y debe comenzar en el campo".

\subsection{Fase 3: Proceso de análisis de datos}

El análisis de los datos es uno de los momentos más ricos, profundos y delicados de la investigación pero, no obstante, también es percibido por muchos investigadores como el momento o etapa más temida. Desde el planteamiento de un estudio de este tipo, el investigador experimenta lo que Amescua y Gálvez (2002) definen como 'efectos perversos de la investigación cualitativa' debido a la gran variabilidad existente en la manera de afrontar el análisis: Imprecisión y confusión de conceptos, multiplicidad de métodos, más descripción que interpretación, riesgo de especulación, escasa visión de conjunto, ateorización,... hasta el punto que hoy día no podríamos hablar del análisis cualitativo, sino más bien de los análisis cualitativos.

Estos mismos autores (Amescua y Gálvez, 2002) definen la fase de análisis de datos como el lado oscuro de la investigación cualitativa, pues consideran que cualquiera que sea el estilo analítico adoptado, hay un momento en el que el investigador se encierra a solas con los datos y es entonces cuando comienzan verdaderamente las dificultades, pues tiene que responder a preguntas, tales como: ¿Cómo realizar técnicamente las seductoras propuestas de la teoría?, ¿Qué hacer con una información tan heterogénea?, ¿Cómo debe ser el manejo para hacer emerger ese torrente de conceptos y proposiciones que sugiere el análisis cualitativo?

Más allá de los miedos, el investigador deberá concebir la dificultad analítica como un reto y acercarse a los datos con humildad pero con decisión y, por supuesto, sin pretensiones de encontrarse con algo simple. Se trata de una etapa de la investigación compleja pero sabrosa, que devolverá al investigador y a los participantes del estudio los primeros frutos del trabajo realizado.

Revisando la literatura, encontramos diversas definiciones de lo que se entiende por análisis de datos. Sin ir más lejos, Taylor y Bodgan (2009), entienden el análisis de datos como un proceso continuo, dinámico y creativo, que además se da de forma simultánea a la recolección, codificación, interpretación y escritura narrativa de los datos. Se trata de un proceso en el que los datos son fragmentados en unidades significativas pero que siguen manteniendo conexión con el total, logrando al final una organización derivada directamente de ellos mismos (Coffey \& Atkinson, 2003).

Hemos de ser conscientes que cuando iniciamos una investigación siempre lo hacemos con una intención, con una visión concreta de la realidad predefinida por los conceptos de nuestra investigación. Podemos detectar, por lo tanto, ciertas 
ideas o constructos implícitos desde el planteamiento del problema de investigación y desde las cuales iniciamos la mirada en el campo. Estamos hablando de lo que Cisterna (2005) denomina como categorías apriorísticas. Para este autor, estas categorías son aquellas que se construyen antes del proceso de recopilación de información. Son tópicos o temas teóricos centrales claves para delimitar nuestra investigación y que se encuentran presentes desde la formulación de los propios objetivos de investigación. Paralelamente a estas, existen las denominadas categorías emergentes, que según este autor, son aquellas que surgen desde el levantamiento de referenciales significativos a partir de la propia investigación, es decir, las que nos marcan e indican los datos recogidos en el campo.

Estos dos tipos de categorización planteados por Cisterna (2005) son fruto de distintos tipos o enfoques analíticos: el análisis deductivo y análisis inductivo. Bajo nuestro parecer, estas son dos estrategias de análisis que lejos de ser contrapuestas entre sí, se complementan aportando una mayor riqueza conceptual a las investigaciones, pues a la vez que se tienen en cuenta los constructos preestablecidos en la literatura, se entiende la investigación como una forma de crecimiento teórico y epistemológico constante en el que queda mucho camino por recorrer.

Esta dicotomía analítica, puede entenderse a su vez como un continuo ininterrumpido, pues así es como lo plantea Boyatzis (1998). Para este autor la codificación de los datos vendría a ser un conjunto de posibilidades entendidas de forma gradual, cuyos extremos serían el análisis puramente deductivo y el puramente inductivo, dando la posibilidad a 3 principales estrategias de codificación: (a) codificación teórica (o deductiva), (b) codificación a partir de investigaciones o datos anteriores y (c) codificación a partir de los datos (o inductiva).

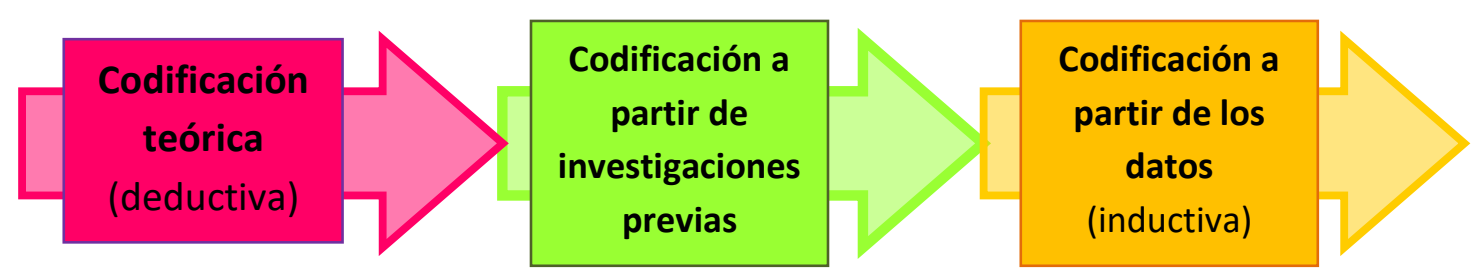

Figura 20. Continuo de codificación según Boyatzis (1998)

En nuestro caso, optamos por realizar un análisis amplio y completo que abordara el objeto de estudio tanto desde una perspectiva deductiva como inductiva. De esta manera, además de indagar teóricamente en el objeto de estudio, nos sumergimos en los datos 'en bruto' para extraer nueva información. Esta es una manera de tener en cuenta los principios teóricos de nuestra investigación a la vez que se estudia desde la singularidad y riqueza de nuestro objeto, pues solo es posible deducir o descubrir algo desconocido de un fenómeno a partir de una parte conocida del mismo (Diesing (1971) en Boyatzis, 1998).

Por lo tanto, teniendo en cuenta las aportaciones de estos autores, podemos distinguir dos momentos en nuestro análisis de datos. En primer lugar podemos diferenciar la perspectiva deductiva del análisis a partir de las categorías previas o teóricas $\mathrm{y}$, en segundo lugar, la perspectiva inductiva mediante el análisis narrativo y estructural (coherente con el método de estudio). Estos dos momentos o subfases del análisis no fueron sucesivos en el tiempo, sino simultáneos. Se inició el 
análisis de datos desde la estructura de categorías y códigos preestablecida y ésta se fue modificando y complementando mediante el análisis estructural y narrativo de los datos. Al finalizar el análisis de todos los datos pudimos, a partir del mapa de categorías y códigos resultante, elaborar y analizar la historia de vida de nuestro protagonista.

\subsubsection{Análisis deductivo: categorías y códigos previos}

Desde este enfoque analítico mixto, iniciamos el análisis desde una categorización previa o apriorística que contribuya a la comprobación y corroboración de sus constructos teóricos (análisis deductivo). A continuación, esta utilizará como base para examinar y revisar los datos minuciosamente y así modificar, ampliar y transformar dicha categorización hasta lograr un sistema de categorías y códigos coherente y consistente con los datos de la investigación (análisis inductivo).

Según Mc Millan y Schumacher (2005), la categorización previa proviene de fuentes como: (a) preguntas de investigación, (b) instrumentos de investigación, (c) la experiencia personal que resulta relevante en el campo de trabajo, y (d) las categorías encontradas en la bibliografía. Teniendo en cuenta estos precedentes y tras revisar los apartados pertinentes, procedemos a elaborar el sistema de categorías y códigos apriorísticos o previos desde el que arranca esta investigación. Para ello, buscamos elaborar una categorización razonable con las pretensiones del estudio y que a la vez resulte manejable y útil para con los datos de nuestra investigación. Más allá de la confección de un listado, tomamos en cuenta las indicaciones de Boyatzis (1998) con la pretensión de captar la riqueza cualitativa del fenómeno. Según este autor, una buena codificación debe poseer estos 5 elementos:

(a) Etiqueta (o nombre del código): debe ser conceptualmente significativa en relación al objeto de estudio, clara, concisa y cercana a los datos.

(b) Definición: tema o asunto al que concierte el código

(c) Descripción del código: cómo saber cuándo se da el código

(d) Criterio: exposición de los calificativos que describen el código y otros que lo excluyen para evitar errores a la hora de la identificación del mismo.

(e) Ejemplos de posibles textos codificados. 


\begin{tabular}{|c|c|c|c|c|c|c|}
\hline CATEGORÍA & CÓDIGO & \multicolumn{5}{|c|}{ IDENFITICACIÓN DEL CÓDIGO } \\
\hline \multirow{4}{*}{$\begin{array}{l}\text { Ámbito } \\
\text { personal }\end{array}$} & Características & Etiqueta & Definición & Descripción del código & Criterio & Ejemplo \\
\hline & personales & $\begin{array}{c}\text { Características } \\
\text { personales }\end{array}$ & $\begin{array}{c}\text { Peculiaridades y } \\
\text { singularidades } \\
\text { de Sergi }\end{array}$ & $\begin{array}{l}\text { Aspectos y/o peculiaridades } \\
\text { propios de Sergi que en su } \\
\text { conjunto lo definen como } \\
\text { persona y como ser social en } \\
\text { relación con su contexto. }\end{array}$ & $\begin{array}{l}\text { (+) Son cualidades, defectos, } \\
\text { peculiaridades,... que tienen } \\
\text { relación directa con su forma de } \\
\text { ser, sea cual sea el contexto y } \\
\text { que son propios de él y no de } \\
\text { otra persona. } \\
\text { (-) No son reacciones concretas } \\
\text { o actitudes de Sergi ante un } \\
\text { determinado estímulo }\end{array}$ & $\begin{array}{c}\text { "Sergi es una persona muy } \\
\text { con mucha voluntad para } \\
\text { trabajar" }\end{array}$ \\
\hline & Puntos fuertes & Etiqueta & Definición & Descripción del código & Criterio & Ejemplo \\
\hline & & Puntos fuertes & $\begin{array}{l}\text { Características } \\
\text { positivas de } \\
\text { Sergi }\end{array}$ & $\begin{array}{l}\text { Características propias de Sergi } \\
\text { que son consideradas por los } \\
\text { participantes de la } \\
\text { investigación como positivas, } \\
\text { favorables y/o beneficiosas } \\
\text { para Sergi y su desarrollo y } \\
\text { crecimiento personal, así como } \\
\text { para la relación de éste con el } \\
\text { entorno. }\end{array}$ & $\begin{array}{l}\text { (+) Son cualidades, habilidades, } \\
\text { destrezas, aptitudes, } \\
\text { capacidades,... para la } \\
\text { realización de ciertas tareas o } \\
\text { actividades que facilitan su } \\
\text { aprendizaje y relación con el } \\
\text { entorno. } \\
\text { (-) No son defectos, carencias, } \\
\text { dificultades,... para la realización } \\
\text { de ciertas tareas o actividades } \\
\text { que imposibilitan o dificultan su } \\
\text { aprendizaje y relación con el } \\
\text { entorno. }\end{array}$ & $\begin{array}{l}\text { “Ten en cuenta que él saca } \\
\text { mucha información de las } \\
\text { imágenes, él aprendió a } \\
\text { comunicarse así, y su } \\
\text { mundo es más visual que } \\
\text { otra cosa" } \\
\text { “Es un 'crack' nadando, } \\
\text { tiene una fuerza increíble y } \\
\text { ha rebajado los tiempos a } \\
\text { una velocidad increíble... su } \\
\text { entrenador no se lo podía } \\
\text { creer" }\end{array}$ \\
\hline
\end{tabular}




\begin{tabular}{|c|c|c|c|c|c|c|}
\hline & \multirow[t]{2}{*}{ Puntos débiles } & Etiqueta & Definición & Descripción del código & Criterio & Ejemplo \\
\hline & & Puntos débiles & $\begin{array}{c}\text { Características } \\
\text { negativas de } \\
\text { Sergi }\end{array}$ & $\begin{array}{l}\text { Características propias de Sergi } \\
\text { que son consideradas por los } \\
\text { participantes de la } \\
\text { investigación como negativas, } \\
\text { desfavorables y/o perjudiciales } \\
\text { para Sergi y su desarrollo y } \\
\text { crecimiento personal, así como } \\
\text { para la relación de éste con el } \\
\text { entorno. }\end{array}$ & $\begin{array}{l}\text { (+) Son defectos, carencias, } \\
\text { dificultades,... para la realización } \\
\text { de ciertas tareas o actividades } \\
\text { que imposibilitan o dificultan su } \\
\text { aprendizaje y relación con el } \\
\text { entorno. } \\
\text { (-) No son cualidades, } \\
\text { habilidades, destrezas, } \\
\text { aptitudes, capacidades,... para la } \\
\text { realización de ciertas tareas o } \\
\text { actividades que facilitan su } \\
\text { aprendizaje y relación con el } \\
\text { entorno. }\end{array}$ & $\begin{array}{c}\text { "Su mayor problema es la } \\
\text { comunicación, que siempre } \\
\text { está ahí... latente" } \\
\text { “Le cuesta mucho } \\
\text { entender las bromas e } \\
\text { ironías, lo intenta y a veces } \\
\text { las hace él, pero después } \\
\text { siempre lo tiene que } \\
\text { explicar para que se } \\
\text { entienda lo que quiere } \\
\text { decir o hacer" }\end{array}$ \\
\hline Ámbito & Elementos & Etiqueta & Definición & Descripción del código & Criterio & Ejemplo \\
\hline familiar & $\begin{array}{c}\text { clave } \\
\text { familiares }\end{array}$ & $\begin{array}{l}\text { Elementos } \\
\text { clave } \\
\text { familiares }\end{array}$ & $\begin{array}{c}\text { Elementos o } \\
\text { aspectos clave } \\
\text { en el ámbito } \\
\text { familiar }\end{array}$ & $\begin{array}{l}\text { Características o elementos } \\
\text { familiares que desde la } \\
\text { perspectiva actual se } \\
\text { consideran clave o elementales } \\
\text { para lograr la fructífera } \\
\text { evolución y crecimiento } \\
\text { personal, académico y social } \\
\text { que ha vivido Sergi a lo largo de } \\
\text { su trayectoria }\end{array}$ & $\begin{array}{c}\text { (+) Son condiciones, hechos, } \\
\text { personas o características } \\
\text { familiares que se pueden } \\
\text { considerar fundamentales (por } \\
\text { algún motivo o razón concreto) } \\
\text { en la trayectoria vital de Sergi. } \\
\text { (-) No son características que } \\
\text { definan en general a la familia o } \\
\text { lo vivido por esta, sino que tiene } \\
\text { que tener una significación } \\
\text { concreta en la vida de Sergi }\end{array}$ & $\begin{array}{l}\text { "La risa es algo que en } \\
\text { nuestra familia siempre ha } \\
\text { estado muy presente, y de } \\
\text { no ser así no sé que habría } \\
\text { sido de nosotros. Esto } \\
\text { había que afrontarlo con } \\
\text { valentía y con ánimo, no } \\
\text { con la cabeza agachada" } \\
\text { "Sin la madre nada de esto } \\
\text { habría sido posible, ella lo } \\
\text { ha sido todo, todo,..." }\end{array}$ \\
\hline
\end{tabular}




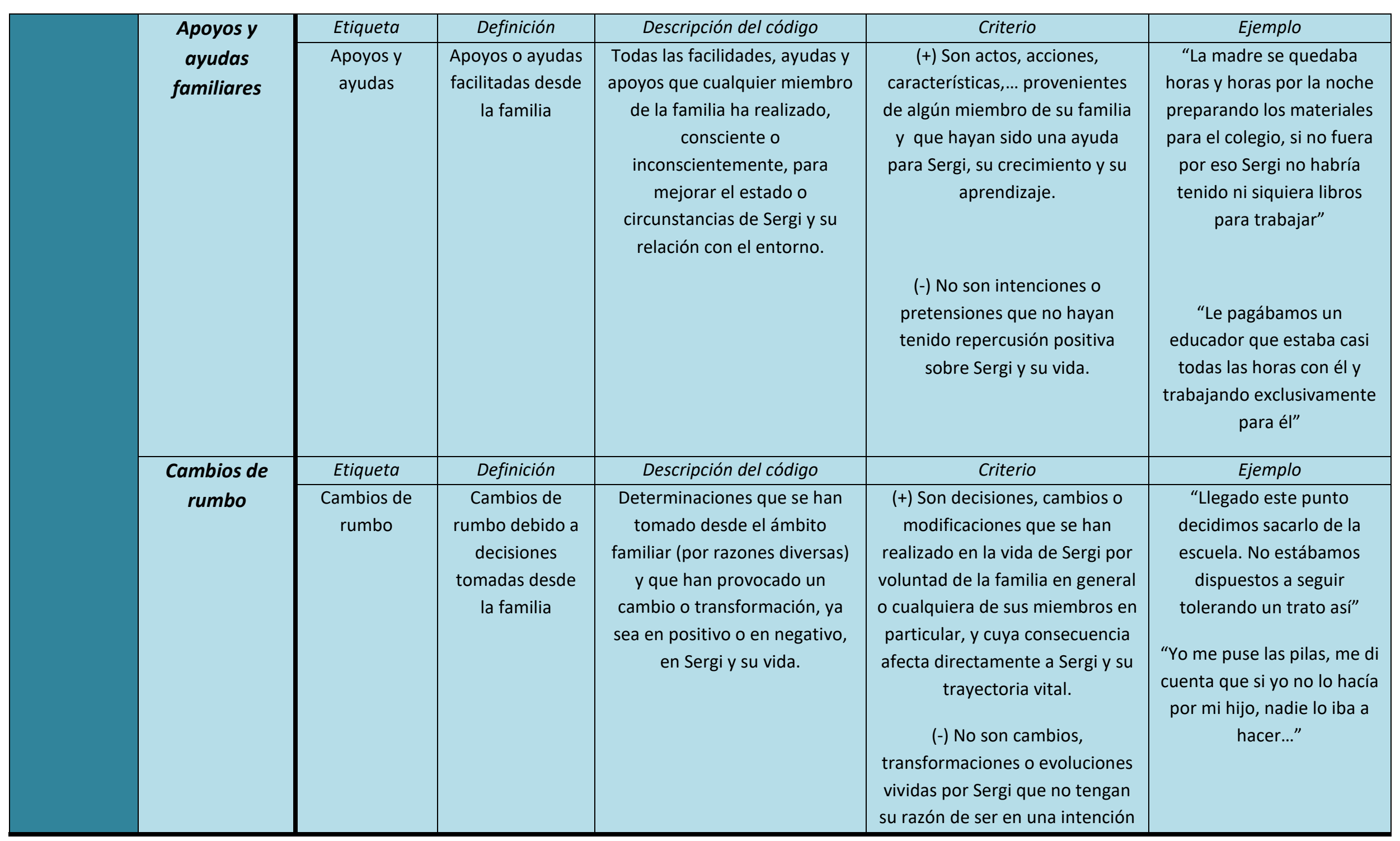




\begin{tabular}{|c|c|c|c|c|c|c|}
\hline & & & & & $\begin{array}{l}\text { provocada desde la familia o } \\
\text { cualquiera de sus miembros. }\end{array}$ & \\
\hline \multirow{4}{*}{$\begin{array}{c}\text { Ámbito } \\
\text { educativo }\end{array}$} & \multirow{2}{*}{$\begin{array}{c}\text { Elementos } \\
\text { clave } \\
\text { educativos }\end{array}$} & Etiqueta & Definición & Descripción del código & Criterio & Ejemplo \\
\hline & & $\begin{array}{c}\text { Elementos } \\
\text { clave } \\
\text { educativos }\end{array}$ & $\begin{array}{l}\text { Elementos o } \\
\text { aspectos clave } \\
\text { en el ámbito } \\
\text { educativo }\end{array}$ & $\begin{array}{l}\text { Características o elementos } \\
\text { educativos que desde la } \\
\text { perspectiva actual se } \\
\text { consideran clave o elementales } \\
\text { para el aprendizaje de Sergi y } \\
\text { su crecimiento personal. }\end{array}$ & $\begin{array}{c}\text { (+) Son condiciones, hechos, } \\
\text { personas o características } \\
\text { educativas propias de las } \\
\text { personas del ámbito educativo, } \\
\text { del centro o de la propia } \\
\text { institución en general, que se } \\
\text { pueden considerar } \\
\text { fundamentales (por algún } \\
\text { motivo o razón concreto) en la } \\
\text { trayectoria educativa de Sergi y } \\
\text { en su crecimiento personal. } \\
\text { (-) No son características que } \\
\text { definan en general a la escuela o } \\
\text { elementos propios de esta sin } \\
\text { relación con la evolución de } \\
\text { Sergi, sino que tiene que tener } \\
\text { una significación concreta en la } \\
\text { vida de Sergi }\end{array}$ & $\begin{array}{l}\text { "En la escuela ha habido } \\
\text { personas que han } \\
\text { demostrado que } \\
\text { verdaderamente creían en } \\
\text { Sergi y se ha notado, Sergi } \\
\text { se abrió mucho más al } \\
\text { estar, por ejemplo, con } \\
\text { Mamen. Ella trabajó mucho } \\
\text { la parte relacional de la } \\
\text { escuela" } \\
\text { "La clase era una piña, se } \\
\text { han comportado como } \\
\text { verdaderos amigos con él y } \\
\text { gracias a eso él ha } \\
\text { entendido el sentido de la } \\
\text { amistad. Para Sergi esos } \\
\text { son sus amigos" }\end{array}$ \\
\hline & \multirow{2}{*}{$\begin{array}{c}\text { Barreras } \\
\text { educativas }\end{array}$} & Etiqueta & Definición & Descripción del código & Criterio & Ejemplo \\
\hline & & $\begin{array}{c}\text { Barreras } \\
\text { educativas }\end{array}$ & $\begin{array}{l}\text { Obstáculos y } \\
\text { trabas de tipo } \\
\text { educativo }\end{array}$ & $\begin{array}{l}\text { Son todos aquellos obstáculos } \\
\text { al aprendizaje y desarrollo de } \\
\text { Sergi impuestos por la escuela, } \\
\text { ya sea proveniente de personas }\end{array}$ & $\begin{array}{c}\text { (+) Son obstáculos, trabas o } \\
\text { dificultades interpuestas por el } \\
\text { centro educativo (por la } \\
\text { institución o personas concretas) }\end{array}$ & $\begin{array}{c}\text { "El profesor entraba y ni } \\
\text { siquiera le saludaba, como } \\
\text { si fuera un perrito en el } \\
\text { rincón" }\end{array}$ \\
\hline
\end{tabular}




\begin{tabular}{|c|c|c|c|c|c|}
\hline & & & $\begin{array}{l}\text { concretas o de la propia } \\
\text { institución. }\end{array}$ & $\begin{array}{c}\text { y que se consideran como } \\
\text { acciones o elementos } \\
\text { discriminatorios hacia Sergi, ya } \\
\text { sean de tipo burocrático, } \\
\text { material, participativo, de } \\
\text { gestión,... } \\
\text { (-) No son aquellas limitaciones o } \\
\text { trabas educativas en general } \\
\text { propias de la institución o del } \\
\text { centro (es decir, aquellas que } \\
\text { afecten a todo el centro o todo } \\
\text { el contexto educativo reglado) }\end{array}$ & $\begin{array}{l}\text { “El material todo lo } \\
\text { preparaba yo Ana, si por } \\
\text { ellos fuera Sergi hubiera } \\
\text { estado pintando y } \\
\text { dibujando durante mucho } \\
\text { tiempo" } \\
\text { "Llegó el momento de } \\
\text { entregar las autorizaciones } \\
\text { para ir a Port Aventura y se } \\
\text { las entregaron a todo el } \\
\text { mundo menos a Sergi. No } \\
\text { querían que fuera" }\end{array}$ \\
\hline \multirow{2}{*}{$\begin{array}{c}\text { Ayudas } \\
\text { educativas }\end{array}$} & Etiqueta & Definición & Descripción del código & Criterio & Ejemplo \\
\hline & $\begin{array}{c}\text { Ayudas } \\
\text { educativas }\end{array}$ & $\begin{array}{c}\text { Ayudas } \\
\text { facilitadas desde } \\
\text { la escuela }\end{array}$ & $\begin{array}{l}\text { Todas las facilidades, ayudas y } \\
\text { apoyos que cualquier miembro } \\
\text { del centro ha realizado, } \\
\text { consciente o } \\
\text { inconscientemente, para } \\
\text { mejorar el estado o } \\
\text { circunstancias de Sergi. }\end{array}$ & $\begin{array}{l}\text { (+) Son actos, acciones, } \\
\text { características,... provenientes } \\
\text { del propio centro o de algún } \\
\text { miembro de éste y que hayan } \\
\text { sido una ayuda para Sergi, su } \\
\text { crecimiento y su aprendizaje. } \\
\text { (-) No son intenciones o } \\
\text { pretensiones que no hayan } \\
\text { tenido repercusión positiva } \\
\text { sobre Sergi y su vida. }\end{array}$ & $\begin{array}{l}\text { “Francisco le enseñó todo } \\
\text { lo que tenía que ver con la } \\
\text { organización, la agenda, el } \\
\text { día a día,... y eso le permitía } \\
\text { entender también cómo } \\
\text { funcionaba el mundo" } \\
\text { "Él ha aprendido a } \\
\text { relacionarse con sus } \\
\text { compañeros, gracias a ellos }\end{array}$ \\
\hline
\end{tabular}




\begin{tabular}{|c|c|c|c|c|c|c|}
\hline & & & & & & $\begin{array}{c}\text { tenía la necesidad de hablar } \\
\text { y no perdía nunca la } \\
\text { intención comunicativa" }\end{array}$ \\
\hline & \multirow{2}{*}{$\begin{array}{c}\text { Futuro } \\
\text { educativo }\end{array}$} & Etiqueta & Definición & Descripción del código & Criterio & Ejemplo \\
\hline & & $\begin{array}{c}\text { Futuro } \\
\text { educativo }\end{array}$ & $\begin{array}{l}\text { Expectativas } \\
\text { educativas } \\
\text { futuras }\end{array}$ & $\begin{array}{l}\text { Todas aquellas posibilidades } \\
\text { futuras (positivas o negativas) } \\
\text { que se vislumbran desde el } \\
\text { presente en torno a la } \\
\text { evolución educativa de Sergi. }\end{array}$ & $\begin{array}{l}\text { (+) Son expectativas reales o } \\
\text { posibles que se consideran en } \\
\text { cuanto a Sergi, sus capacidades, } \\
\text { posibilidades y voluntades } \\
\text { futuras (aquello que se cree que } \\
\text { va a poder o querer hacer en un } \\
\text { futuro más o menos cercano, así } \\
\text { como lo que se considera } \\
\text { imposible que consiga hacer) } \\
\text { (-) No son deseos infundados y } \\
\text { desvinculados de la realidad en } \\
\text { cuanto a Sergi y sus } \\
\text { posibilidades en el ámbito } \\
\text { académico. }\end{array}$ & $\begin{array}{l}\text { "Yo creo que él va a hacer } \\
\text { algo relacionado con } \\
\text { animales, le encantan los } \\
\text { animales y si a él le interesa } \\
\text { es capaz de hacerlo. El } \\
\text { posee ciertos centros de } \\
\text { interés" } \\
\text { "Yo sé que no va a terminar } \\
\text { la ESO, es que no puede } \\
\text { ser, pero por lo menos que } \\
\text { acabe en un programa } \\
\text { especial o algo..." }\end{array}$ \\
\hline \multirow{2}{*}{$\begin{array}{c}\text { Ámbito } \\
\text { social (ocio) }\end{array}$} & \multirow{2}{*}{$\begin{array}{c}\text { Elementos } \\
\text { clave sociales }\end{array}$} & Etiqueta & Definición & Descripción del código & Criterio & Ejemplo \\
\hline & & $\begin{array}{c}\text { Elementos } \\
\text { clave de ocio }\end{array}$ & $\begin{array}{l}\text { Elementos o } \\
\text { aspectos clave } \\
\text { en el ámbito } \\
\text { social y de ocio }\end{array}$ & $\begin{array}{l}\text { Características o elementos del } \\
\text { contexto de ocio (natación, } \\
\text { Escuela de Arte,...) que desde la } \\
\text { perspectiva actual se } \\
\text { consideran clave o elementales } \\
\text { para lograr la fructífera } \\
\text { evolución y crecimiento }\end{array}$ & $\begin{array}{l}\text { (+) Son condiciones, hechos, } \\
\text { personas o características } \\
\text { sociales o del contexto de ocio } \\
\text { que se pueden considerar } \\
\text { fundamentales (por algún } \\
\text { motivo o razón concreto) para } \\
\text { Sergi, su aficiones y su relación }\end{array}$ & $\begin{array}{l}\text { “Nos dijeron que la } \\
\text { natación era buena para } \\
\text { Sergi, y a pesar de que no } \\
\text { quería lo llevamos un día y } \\
\text { otro día, y otro día,... hasta } \\
\text { que empezó a gustarle eso } \\
\text { del agua. Ester y su }\end{array}$ \\
\hline
\end{tabular}




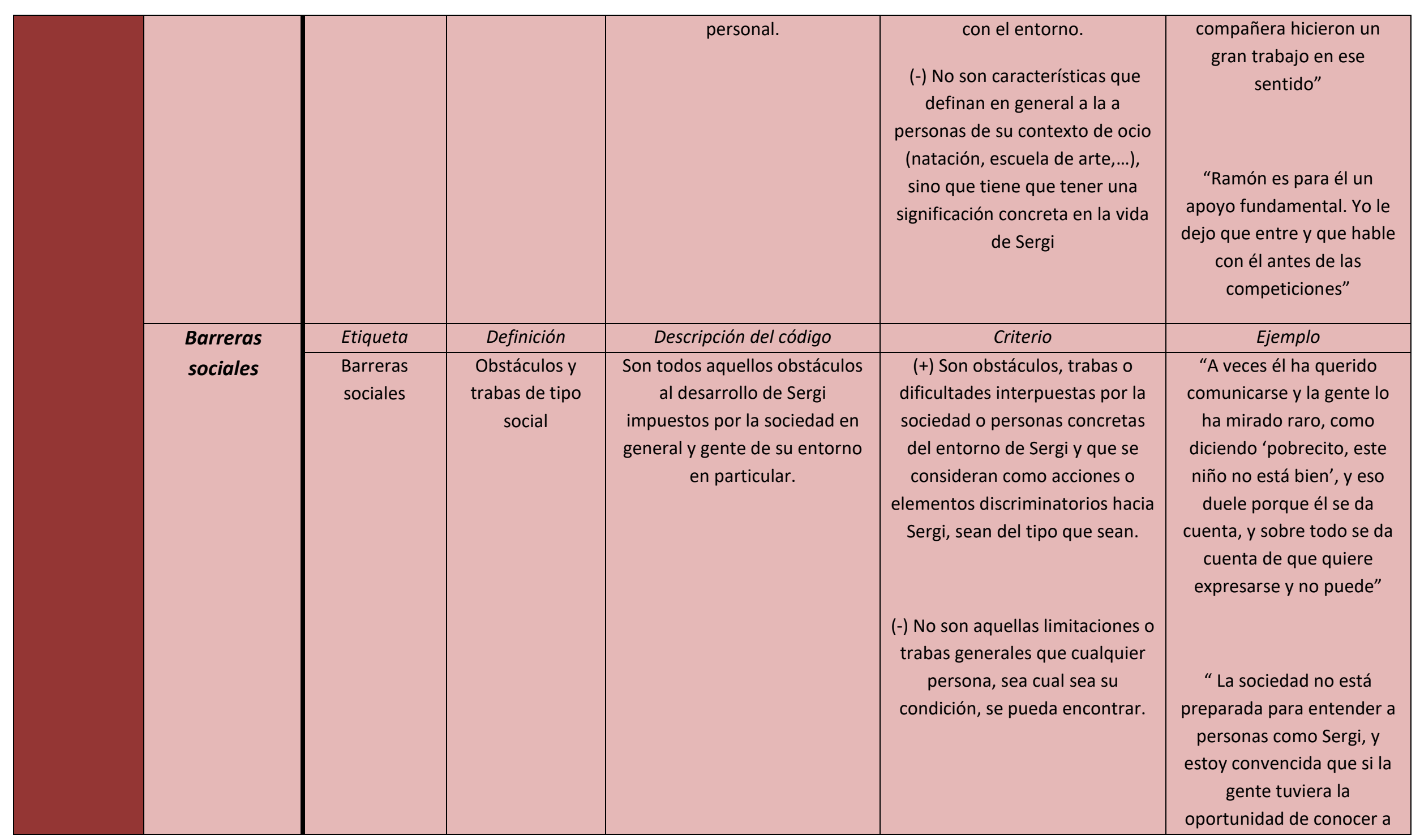




\begin{tabular}{|c|c|c|c|c|c|}
\hline & & & & & $\begin{array}{c}\text { personas como él cambiaria } \\
\text { su forma de entender el } \\
\text { autismo" }\end{array}$ \\
\hline \multirow{2}{*}{$\begin{array}{l}\text { Ayudas } \\
\text { sociales }\end{array}$} & Etiqueta & Definición & Descripción del código & Criterio & Ejemplo \\
\hline & $\begin{array}{l}\text { Ayudas } \\
\text { sociales }\end{array}$ & $\begin{array}{c}\text { Ayudas } \\
\text { facilitadas en el } \\
\text { ámbito social y } \\
\text { de ocio }\end{array}$ & $\begin{array}{l}\text { Todas las facilidades, ayudas y } \\
\text { apoyos que cualquier persona } \\
\text { del contexto social ha } \\
\text { realizado, consciente o } \\
\text { inconscientemente, para } \\
\text { mejorar el estado o } \\
\text { circunstancias de Sergi. }\end{array}$ & $\begin{array}{c}\text { (+) Son actos, acciones, } \\
\text { características,... provenientes } \\
\text { del contexto social o del ámbito } \\
\text { de ocio (natación, escuela de } \\
\text { arte,...) de Sergi y que hayan sido } \\
\text { una ayuda para él, su } \\
\text { crecimiento personal y su } \\
\text { relación con el entorno. } \\
\\
\text { (-) No son intenciones o } \\
\text { pretensiones que no hayan } \\
\text { tenido repercusión positiva } \\
\text { sobre Sergi y su vida. }\end{array}$ & $\begin{array}{l}\text { "Su entrenado se entregó. } \\
\text { Dedicó horas y horas para } \\
\text { conseguir que Sergi dejara } \\
\text { de nadar bien a ser un gran } \\
\text { nadador" } \\
\text { "Él no quería preguntarme } \\
\text { como hacer una } \\
\text { determinada figura, un } \\
\text { dibujo, hasta que entendió } \\
\text { que me necesitaba para } \\
\text { mejorar y se apoyó en mi y } \\
\text { empezó a preguntarme" }\end{array}$ \\
\hline \multirow[t]{2}{*}{ Futuro social } & Etiqueta & Definición & Descripción del código & Criterio & Ejemplo \\
\hline & $\begin{array}{c}\text { Futuro en el } \\
\text { ocio }\end{array}$ & $\begin{array}{l}\text { Expectativas de } \\
\text { ocio futuras }\end{array}$ & $\begin{array}{l}\text { Todas aquellas posibilidades } \\
\text { futuras (positivas o negativas) } \\
\text { que se vislumbran desde el } \\
\text { presente en torno al contexto } \\
\text { de ocio de Sergi. }\end{array}$ & $\begin{array}{c}\text { (+) Son expectativas reales o } \\
\text { posibles que se consideran en } \\
\text { cuanto a Sergi, sus capacidades, } \\
\text { posibilidades y voluntades } \\
\text { futuras (aquello que se cree que } \\
\text { va a poder o querer hacer en un } \\
\text { futuro más o menos cercano, así } \\
\text { como lo que se considera }\end{array}$ & $\begin{array}{c}\text { "Si él quiere puede llegar } \\
\text { muy lejos en natación, y te } \\
\text { hablo de unos juegos } \\
\text { paralímpicos" } \\
\text { "Yo creo que va a querer } \\
\text { seguir viniendo a la Escuela }\end{array}$ \\
\hline
\end{tabular}




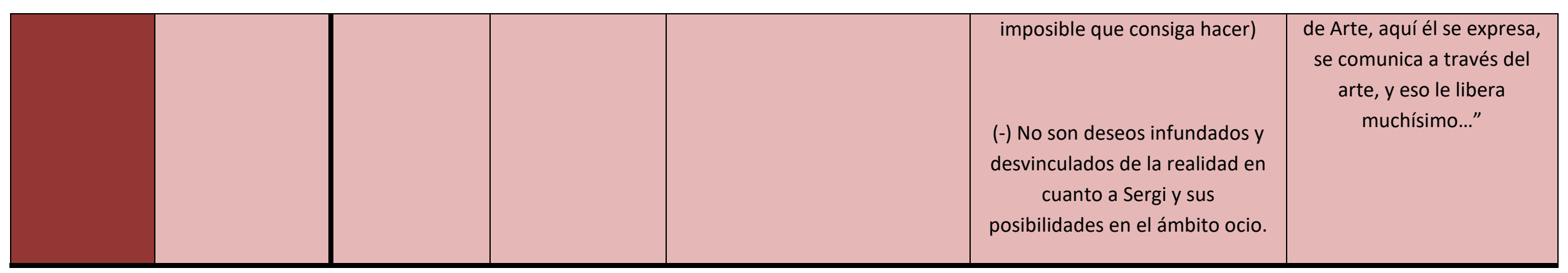

Tabla 19. Sistema de categorías y códigos previos 
De esta manera, obtenemos lo que consideramos una estructura previa de categorización (categorías y códigos) la cual presenta la siguiente forma:
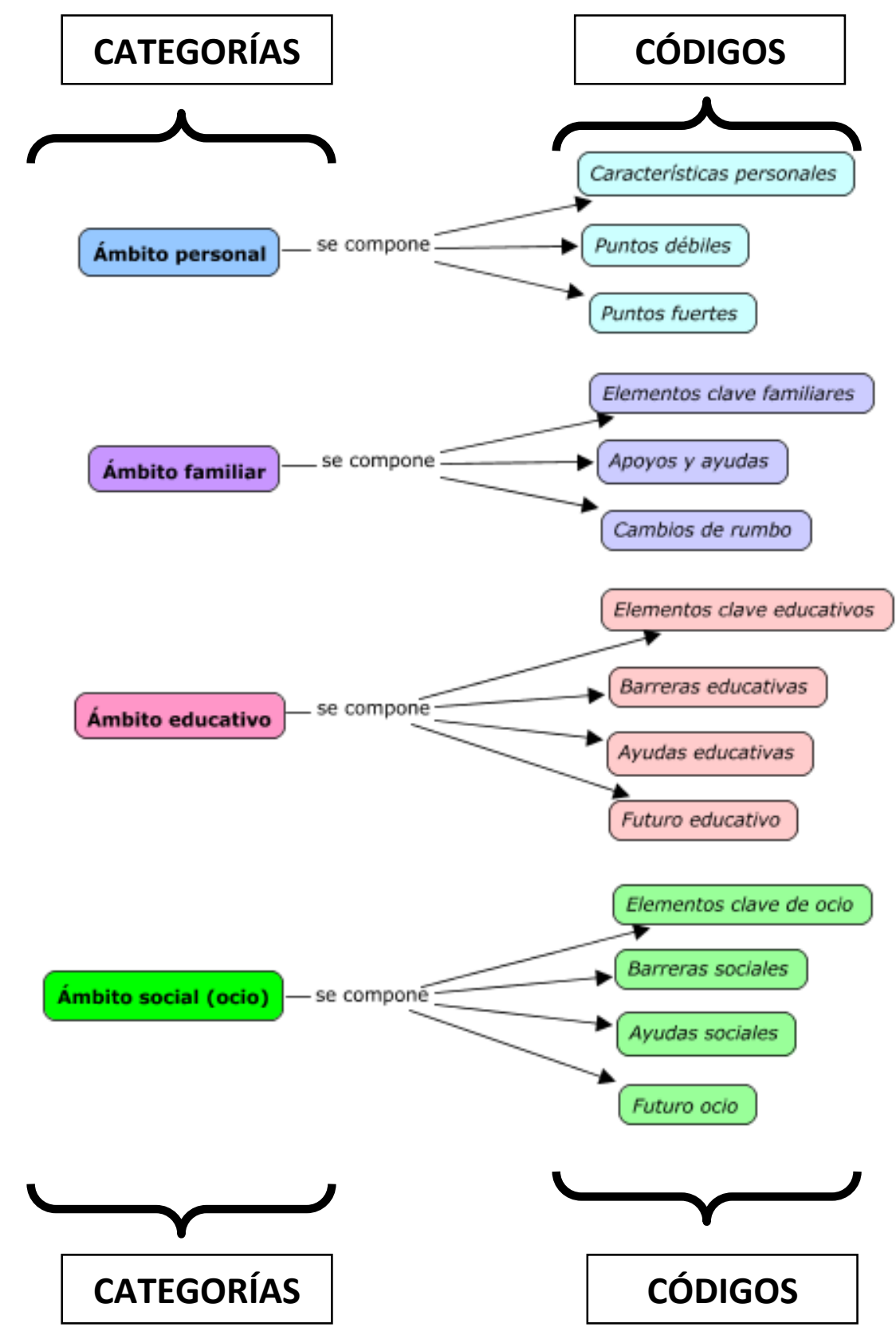

Figura 21. Estructura previa de categorización

El análisis de datos llevado a cabo en esta investigación se realizó mediante el programa asistido por ordenador MaxQDA 12. El primer paso fue introducir el sistema de categorías y códigos previo en el programa informático y partir de ahí, mediante este programa iniciar la reducción de los datos. Durante este proceso empezaron a emerger nuevas categorías y códigos que modificaban y ampliaban la categorización inicial. Este fue el arranque de una perspectiva de análisis más inductiva en la que los propios datos "pedían" nuevas categorías y códigos. En este momento empezamos a desarrollar un enfoque más inductivo del análisis de datos y arrancamos así un análisis estructural y narrativo de los mismos. 


\subsubsection{Análisis estructural y narrativo de los datos}

La perspectiva inductiva de análisis, es un proceso sistemático mediante el cual las categorías y códigos emergen de los propios datos a través de la selección, categorización, comparación, síntesis e interpretación de la información para lograr explicaciones sobre el fenómeno de interés (McMillan, y Schumacher, 2005). Mediante en este enfoque en el análisis obtuvimos una categorización definitiva, completa, amplia, fiel y coherente con la información aportada por los participantes, la cual se convirtió en la base para la construcción de la historia de vida de nuestro protagonista.

Cabe destacar en este punto, que el tratamiento y análisis de datos llevado a cabo en una investigación cualitativa no depende únicamente del tipo de datos recogidos y de las técnicas utilizadas, sino que además se encuentra delimitado por la intencionalidad de la investigación. Por lo tanto, siendo que en nuestro caso la motivación investigadora estaba altamente ligada a la historia de vida de Sergi, la visibilización de su trayectoria y estrategias y mecanismos de superación, se consideró el análisis narrativo y estructural como las herramientas analíticas más idóneas y convenientes.

\subsubsection{Análisis estructural}

En el análisis estructural de los datos se tuvo en cuenta la propuesta de Miles y Huberman (1994). Para ello, en primer lugar, necesitábamos trabajar con unidades de análisis manejables, mucho más simples y reducidas que la cantidad de datos 'en bruto' recogidos en el campo. En este proceso, seguimos las tres tareas básicas planteadas por estos autores: (1) reducción de datos en un sistema de categorías y códigos, (2) organización y transformación de los datos para su presentación y (3) extracción y verificación de conclusiones (capítulo 7 ). Debemos ser conscientes de que estas tres tareas no se suceden nunca de manera lineal y aislada, sino que el investigador irá saltando de una a otra según las necesidades del análisis a lo largo del todo el proceso. No obstante, y para facilitar la comprensión de este proceso, mostraremos estas 3 tareas de forma secuenciada entre este y otros capítulos venideros.

\section{a) Reducción de datos}

La reducción de datos hace referencia a la simplificación de los datos haciendo la información recabada más abarcable y manejable para el investigador. Esta reducción de datos se encuentra muy alejada de lo que puede concebirse como mero resumen de los datos, sino que para que tenga sentido y genere un libro o sistema de códigos coherente con la información aportada, necesita de la presencia y predominancia de la relevancia interpretativa de los datos (Tójar, 2006), es decir, focalizar la atención en aquellos datos que resulten relevantes frente a otros y que además ofrezcan al investigador un carácter interpretativo necesario para el análisis.

Esta tarea supone, de alguna manera, descartar o seleccionar para el análisis parte del material informativo recogido, teniendo en cuenta determinados criterios teóricos o prácticos (Rodríguez et al., 1996). Para llevar a cabo la reducción de los datos recogidos, estos autores proponen diversos momentos:

- Separación en unidades. Esto se puede establecer según diversos criterios (temáticos, cronológicos, sociales, contextuales, conversacionales o gramaticales). En nuestro caso apostamos por un criterio principalmente temático teniendo siempre en cuenta el contexto de referencia, pues no 
podemos obviar que estamos en un tipo de investigación que aborda 3 ámbitos de la vida de Sergi (familiar, social y educativo). Paralelamente, también tomamos en cuenta la vertiente cronológica que posee la historia de nuestro protagonista. Por lo tanto, en este proceso se realizó en función de la etapa o momento de la vida de Sergi en la que sucedió un determinado acontecimiento, el contexto de vida en el que tuvo lugar y la relación temática que posee con los diferentes temas propuestos.

- Categorización y/o codificación. Este proceso se basa en la clasificación conceptual de las unidades bajo un mismo criterio buscando hallar puntos de encuentro y afinidad entre las categorías para lograr un corpus organizado de información. Esta asignación conceptual no es exclusiva de una unidad, es decir, puede haber varias unidades que pertenecen a una misma categoría o código, pues una misma unidad puede ser analizada desde criterios diversos. Abordar este proceso bajo el término "categorización” o "codificación”, depende mucho del enfoque de investigación cualitativa abordado y los autores referentes que tengamos en cuenta. Gibbs (2012) en su trabajo ya trataba este debate terminológico, pues mientras algunos autores utilizan el término 'temas' (Smith, 1995; King, 1998) desde una vertiente más fenomenológica del análisis, otros utilizan el término 'índice' (Ritchie, Spencer \& O'Connor, 2003) al relacionar pasajes del texto con cada tema de dicho índice, y Dey (1993) se refiere a la 'categoría' como la asignación de nombres a pasajes del texto según su contenido, refiriéndose con el término 'codificación' a la asignación directa de categorías a los datos cualitativos.

En nuestro caso, optamos por el planteamiento que Gibbs (2012) expone sobre la codificación en su trabajo. Para este autor, la codificación es el modo en el que el investigador trata los datos que está analizando e identifica y registra diversos pasajes que se vinculan a un nuevo nombre, es decir, a un código. En definitiva, es una forma de indexar o categorizar el texto para establecer un marco de ideas temáticas sobre él. Según este autor, para llevar a cabo la codificación de los datos debemos partir de los que él denomina como 'códigos descriptivos' (muy cercanos a los datos) para después obtener una 'categorización' (categorías que engloban los códigos) y finalmente desde una visión más analítica abstraer de los datos 'códigos más analíticos y teóricos'. El resultado final de este proceso de codificación no es otro que un libro de códigos: un esquema conceptual que ayuda a responder las preguntas de investigación.

Como se puede deducir, esta categorización no resulta ajena a categorización previa desde una perspectiva más deductiva. Recordemos que estamos ante un tipo de análisis mixto (inductivo-deductivo) y la categorización previa es la base de partida para la categorización de tipo más inductivo. Esta reelaboración de la categorización previa mediante un proceso más inductivo es lo que Strauss (1987, citado en Rodríguez et.al, 1996) denominaba como "codificación abierta". En este proceso, a la vez que se revisan y examinan los datos, se establece la relación con las categorías ya definidas previamente y, de no ser posible, se crean otras nuevas emergentes, pues categorizar implica valorar si las unidades separadas en el paso anterior pueden ser incorporadas o no a un determinado código.

Cabe resaltar en este punto, que además de la categorización propiamente dicha, durante el análisis se utilizaron otros elementos como los memorandos. Según Gibbs (2012), basándose en las aportaciones de Glaser (1978), estos se 
consideran un modo de teorizar sobre ideas acerca de la codificación y desarrollo general del análisis y son comentadas por el investigador sobre la marcha. Se tratan de pensamientos y aclaraciones sobre las que el investigador desea dejar constancia a medida que avanza en el análisis y que debe diferenciar muy bien de los datos recogidos, pues pertenecen al investigador, y sirven como apoyo y refuerzan la codificación de los datos.

- Síntesis y agrupamiento. El proceso de síntesis y agrupamiento se da de forma implícita a la propia codificación, pues durante este proceso los códigos se reubican y reorganizan, las categorías son sintetizadas, renombradas y reagrupadas en metacategorías, siempre en base a los atributos de las categorías y de acuerdo con los vínculos y relaciones que se van descubriendo entre ellas.

Todo este proceso aquí expuesto acabó por ofrecer como resultado un sistema de categorías y códigos (libro de códigos) emergente de nuestros datos y que constituiría la base para el siguiente paso en el análisis: el análisis narrativo, dejando para el final la organización y transformación de los datos que nos permitiría, más tarde, la construcción de la historia de vida de Sergi.

\subsubsection{Análisis narrativo}

Existe un continuo de formas de abordar el análisis narrativo, todas ellas delimitadas por dos extremos o puntos más alejados. En un lado de ese extremo estaría el análisis de datos no formalizado, muy cercano a la descripción literaria y reportajes periodísticos, mientras en el otro encontraríamos el análisis formalizado, que busca acercarse a un análisis 'cuantitativo' de los datos mediante procesos numéricos de relaciones y porcentajes de categorías cuantificadas (Bolívar et al. 2001). En nuestro caso, lejos de posicionarnos en un extremo u otro, pretendimos buscar el equilibrio entre ambos respetando la parte descriptiva propia de una narración pero otorgándole un carácter analítico. Esta postura analítica, corresponde con lo que Demazière y Dubar (1997) definen como aquella postura desde la que se interpreta y reconstruye el sentido de la entrevista y se convierte en narrativa. En esta posición se busca la elaboración de categorías que ofrezcan un marco comprensivo y pongan de manifiesto las intenciones y comportamientos implícitos del autor.

A través del análisis narrativo no solo buscamos investigar sobre aquello que las personas dicen y expresan directamente, sino que ahondamos en cómo lo dicen, y qué es lo que sienten y experimentan al respecto. De hecho, en este análisis indagaremos en elementos como acontecimientos (qué sucedió), experiencias (sentimientos, reacciones, significados), explicaciones (justificaciones, excusas) y narraciones (forma retórica y lingüística de contar los acontecimientos, la secuencia temporal, los personajes, la construcción de la trama,...) (Gibbs, 2012). Para ello, tomaremos como referencia la propuesta que hace Rosenthal (1993, citado en Bolívar et al, 2001), quien en el análisis narrativo distingue entre:

- Análisis genético de la historia de vida: reconstrucción del significado biográfico de las experiencias ocurridas, según la secuencia cronológica que establece el autor de la autobiografía

- Análisis temático de los relatos de vida: estudio de los temas y aspectos narrados según el significado otorgado por el biógrafo/investigador 
En esta investigación, realizaremos el análisis narrativo teniendo en cuenta estas dos perspectivas o fórmulas del mismo, es decir, pretendemos conjugar por un lado el análisis cronológico de los acontecimientos ocurridos, a la vez que tomamos en cuenta la red temática que explica las relaciones entre los distintos tópicos (mapa de categorías y códigos elaborado previamente y expuesto en el capítulo 6). Consideramos que esta postura es la más adecuada para un tipo de investigación como la nuestra, pues una de las finalidades del propio método biográfico-narrativo es capturar la voz de las personas participantes para ofrecer una colección de temas o tópicos que ayuden a entender el objeto estudiado, todo ello respetando la vertiente cronológica propia de las narraciones y relatos. De esta manera, nos adentraremos en el proceso acuñado como "restorying" (reconstrucción de la historia) en el cual la meta del investigador no es otra que definir los elementos clave de la vida de la persona, identificar los temas principales, descubrir las secuencias destacables y contar o narrar la historia dándole sentido a su contenido (Suter, 2011)

Como último paso de este análisis, realizamos el segundo procedimiento propuesto por Miles y Humerban (1994): la organización y transformación de los datos.

\section{a) Organización y transformación de los datos: construcción de la historia de vida}

Esta es una delicada etapa en la que el investigador debe pensar y reflexionar cual es la manera más idónea para presentar los datos al lector, pues su lectura facilitará la comprensión y análisis de la investigación. Existen múltiples formas de organizar y transformar los datos, pero de acuerdo con los objetivos y método estudio de este trabajo optamos por presentar los datos mediante la narración de la historia de vida de nuestro protagonista.

Como ya planteábamos en el capítulo 3, entre los modelos de construcción de historias de vida presentes en la literatura, hemos optado por recoger la clasificación de Connick y Gordard (1998), quienes plantean estos 3 modelos:

- $\quad$ Modelo arqueológico: se busca un punto de inicio, un origen a partir del que desarrollar la biografía de la persona.

- Modelo procesual o de trayectorias: se centra en estudiar el proceso en sí mismo y en cómo se van desencadenando los acontecimientos en la vida de una persona, buscando determinar los elementos causales que intervienen en cada secuencia biográfica.

- Modelo estructural. Observa las temporalidades externas sobre las que estructurar la biografía, entendiendo por esas temporalidades elementos coyunturales, históricos o contextuales que pueden marcar la propia historia de vida.

En nuestro caso, la construcción de la historia se posicionó principalmente en un modelo procesual o de trayectorias el cual permitió exponer mediante la propia historia las relaciones entre los diferentes elementos y establecer los vínculos entre ellos para una mayor comprensión de la trayectoria vital de nuestro protagonista. En esta construcción se tuvo en cuenta la estructura de categorías y códigos obtenida en la primera parte de este análisis, pues gracias a ella toda la información recogida en el campo fue organizada y gestionada para encontrar el sentido final de la historia. Tanto el sistema de categorías y códigos como la historia resultante de este proceso serán expuestos en el capítulo 6 de este documento. Seguidamente, la última tarea propuesta 
per Miles y Huberman (1994) se expondrá en el capítulo 7 a través de la extracción y verificación de conclusiones obtenidas mediante el análisis. 


Los resultados, ese preciado apartado donde se recogen los frutos de un largo y complejo proceso de investigación y donde, por fin, la persona investigadora siente que empieza a crear y construir una aportación científica al campo de conocimiento. Un momento delicado pero precioso para el investigador en que uno "pone toda la carne en el asador' para asegurarse que el lector será capaz de apreciar con su misma intensidad los resultados obtenidos.

En este capítulo he puesto todo mi empeño en mostrar que esta investigación aporta gran cantidad de resultados a un área del conocimiento en el que, como ya se ha discutido en capítulos anteriores, debemos avanzar. Pero sobretodo, he pretendido ofrecer al lector la voces, los matices y el carácter de todos los y las participantes la manera más pura posible.

\subsection{Resultados Fase I}

6.1.1. Categorías (sistema de categorías y matriz explicativa)

6.1.1.1. Mapa temático- relacional de categorías y códigos

6.1.2. Línea de vida

6.1.3. Diagrama de personas en la vida de Sergi

6.2. Resultados Fase II: la historia de vida de Sergi

6.2.1. Proceso de elaboración de la historia de vida

6.2.2.La historia de vida de Sergi

6.3. La vida de Sergi a día de hoy 
En este capítulo, se exponen los resultados obtenidos tras analizar los datos procedentes de los diversos instrumentos de recogida de información. Tal y como se ha especificado en el capítulo anterior, se ha realizado un análisis temático y cronológico mediante el programa informático de análisis de datos Maxqda12 cuya pretensión última es la construcción de la historia de vida de Sergi.

Como veremos a continuación, los resultados de esta investigación se exponen en dos fases o momentos. En primer lugar, encontraremos aquellos resultados que nos permiten descifrar, organizar y entender los elementos principales de la trayectoria vital de Sergi (fase I). Estos resultados, desde formatos y contenidos bien distintos, nos permiten visibilizar partes o secciones desde una determinada perspectiva analítica. El trabajo sobre estos primeros resultados, nos permitirá acceder a la fase II de los resultados: la construcción de la narración de la historia de vida de Sergi.

De una manera gráfica, nuestros resultados presentan la siguiente forma:

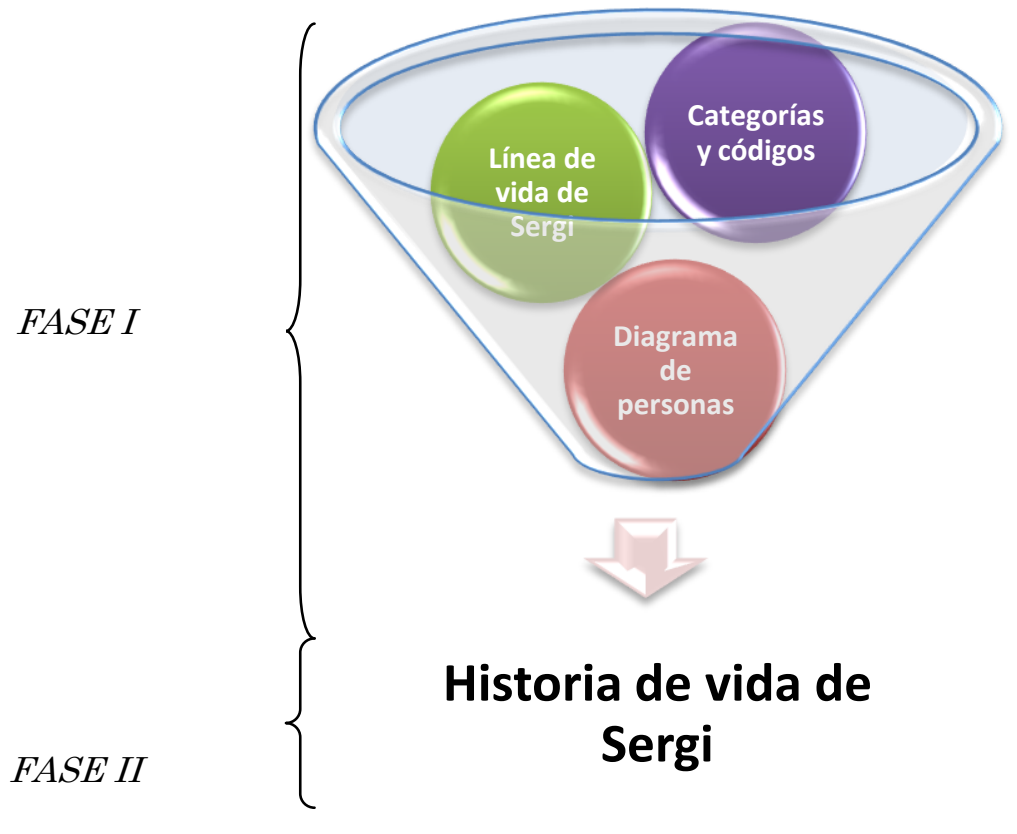

Figura 22. Fases de los resultados de la investigación

\subsection{Resultados fase I}

Los resultados contemplados es esta primera fase se componen de: libro de categorías y códigos, mapa temático-relacional de categorías, la línea de vida de Sergi y el diagrama de las personas que forman parte de la vida de Sergi.

Veamos cada uno de ellos con mayor detalle:

\subsubsection{Categorías y códigos}

Uno de los resultados obtenidos en el análisis fue el conjunto de categorías y códigos que definían los grandes temas o tópicos de la historia de vida de nuestro protagonista. Tal y como ya se ha apuntado en el capítulo anterior, a lo largo del análisis, se codificaron las categorías y códigos, se sintetizaron y agruparon en forma de grandes bloques o apartados temáticos. Este análisis no se materializó únicamente en un orden jerárquico de categorías (unas dentro de otras), sino que dio lugar a establecer también 
relaciones, correspondencias y nexos entre ellas. Estas interconexiones entre diferentes categorías y códigos no se basaron en interpretaciones subjetivas de la investigadora, sino única y exclusivamente en las aportaciones de los participantes.

\subsubsection{Libro de categorías y códigos}

Por lo tanto, el primer resultado de este proceso analítico, es el libro de categorías y códigos a partir del cual describir, reconstruir y analizar teóricamente la historia de vida de Sergi. Este libro de categorías y códigos es un reflejo latente de los planteamientos iniciales de nuestra investigación, así como de las aportaciones de todos y cada uno de los participantes. Este libro se divide en los siguientes apartados:

- Ámbitos o contextos (dónde): en los planteamientos iniciales de esta investigación, se postuló la necesidad de dividir los datos recogidos según el contexto o ámbito al cual pertenecían y analizarlos desde esta lógica (ámbito personal, familiar, social y educativo). Es importante tener en cuenta que no solo importa lo que ocurre, sino dónde ocurre (el contexto). Cada persona, en su interacción con el medio, forma parte del contexto en el que se desarrolla y contribuye a construirlo de una manera activa, de forma que persona y contexto se convierten en elementos inseparables para describir las realidades (Rivas, 2007).

Por lo tanto, en el 'libro de categorías y códigos' encontraremos un apartado denominado "contextos". En este apartado hallaremos los cuatro contextos previamente planteados junto con aquellos que emergieron a lo largo del análisis, como el 'ámbito comunicativo' (pues la comunicación y sus elementos se conciben como un ámbito transversal y con entidad propia en esta investigación).

- Momentos (cuándo): Otro de los planteamientos iniciales de esta investigación era tener en cuenta la cronología vital de Sergi. Es decir, no solo importa qué ocurre (tópicos y temas) y dónde ocurre (contexto), sino también cuándo ocurre. Por esta razón, encontraremos en el 'libro de categorías y códigos' un apartado específico de etapas. Cabe tener en cuenta, que este apartado se organiza en función de las etapas educativas de nuestro sistema escolar, pues a lo largo de la recogida de datos, ha sido la referencia utilizada por los participantes en su discurso.

- Personas (quién): cualquier narrativa, historia o relato sobre una experiencia concreta va vinculada siempre a varias personas. Por un lado está el 'narrador' de aquello contado (el participante de la investigación que cuenta desde su perspectiva algo concreto), y por otro la persona o personas a las que se hace referencias en la narrativa ('persona implicada en la acción o situación contada'). A lo largo del análisis, se ha podido observar que este 'narrador' y 'persona implicada' pueden ser la misma persona o bien personas diferentes. Por ejemplo, un participante puede contar algo que le ocurrió a él mismo en el pasado, o contar algo referente a otra u otras personas. De esta manera, en cualquier fragmento o unidad de los datos, se han encontrado diversas personas referenciadas directa o indirectamente.

Uno de los dilemas planteados durante el análisis fue tener en cuenta o no a qué personas se hacía referencia en los datos. Tras realizar diversas 
lecturas y revisar los fundamentos de esta investigación, se consideró importante reseñar el 'quién' de la narración, pero teniendo en cuenta únicamente las referencias directas a cada persona (no las indirectas). Es decir, cuando un/a participante referenciaba directa y literalmente a una persona concreta estos datos eran codificados como tal, pero no en el caso de que esto fuera una referencia indirecta o inferencia de la investigadora principal. Por esta razón, en el propio 'libro de categorías y códigos' se podrá observar un apartado de personas. En ellas se recogen aquellas personas que forman o han formado parte de la red social, educativa y/o familiar de Sergi.

- Expectativas de futuro: Otro de los elementos referenciados en las preguntas de investigación iniciales fueron las expectativas de futuro sobre Sergi. A lo largo de la recogida de datos y durante el análisis, estas expectativas se han abordado de forma paralela al resto de elementos, asumiendo por lo tanto, que las expectativas de futuro debía conformar un apartado propio con esencia e identidad pero con cierta vinculación al resto de apartados del análisis.

Como veremos a continuación, el 'libro de categorías y códigos' recoje las categorías, los códigos y subcódigos resultantes, así como el número de codificaciones de cada uno de ellos y su descripción. Podrá observarse que algunos códigos y subcódigos no presentan ninguna codificación (codificación ' 0 '), esto no significa que no posea ningún texto codificado (se habría eliminado el código), significa que la codificación se halla en un nivel inferior en la jerarquía. Es decir, que por el ejemplo el código 'red familiar' no posee codificación pero sí cada uno de los subcódigos que lo componen. 


\begin{tabular}{|c|c|c|c|}
\hline CATEGORIAS & CÓDIGOS Y SUBCÓDIGOS & $\mathrm{N}^{\circ}$ & DESCRIPCIÓN \\
\hline \multirow{25}{*}{ 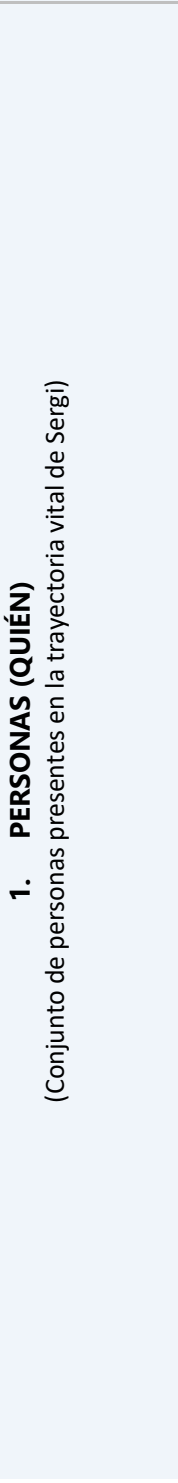 } & 1.1 Red de Ocio & 0 & Personas pertenecientes al círculo de ocio y tiempo libre de Sergi \\
\hline & 1.1.1 Entrenador 3 & 3 & $\begin{array}{l}\text { El papel del entrenador de natación (3) en la trayectoria deportiva de } \\
\text { Sergi }\end{array}$ \\
\hline & 1.1.2 Entrenador 2 & 2 & $\begin{array}{l}\text { El papel del entrenador de natación (2) en la trayectoria deportiva de } \\
\text { Sergi }\end{array}$ \\
\hline & 1.1.3 Entrenadora 1 & 1 & El papel del entrenador de natación en la trayectoria deportiva de Sergi \\
\hline & 1.1.4 Josefina & 1 & Papel de Josefina en la escuela de arte \\
\hline & 1.1.5 Cristian & 1 & El papel de su amigo Cristian en el entorno de ocio \\
\hline & 1.1.6 Lara (PEA) & 5 & $\begin{array}{l}\text { Papel de la Profesora de la Escuela de Arte (PEA), Lara, en el contexto de } \\
\text { ocio de Sergi }\end{array}$ \\
\hline & 1.2 Red educativa & 0 & \\
\hline & 1.2.1 Amigos/Compañer@s & 2 & El papel de los amigos y compañeros en la vida de Sergi \\
\hline & 1.2.1.1 CENTRO 2 & 0 & Amigos de Sergi pertenecientes al centro 2 \\
\hline & 1.2.1.1.1 Oscar (C IES) & 4 & Papel de Oscar, uno de sus compañeros del centro 2 \\
\hline & 1.2.1.2 CENTRO 1 & 0 & Amigos de Sergi pertenecientes al centro 1 \\
\hline & 1.2.1.2.1 Vero (C3) & 2 & Papel de Vero en la trayectoria vital de Sergi \\
\hline & 1.2.1.2.2 Eva (C4) & 5 & Papel de Eva en la trayectoria vital de Sergi \\
\hline & 1.2.1.2.3 Jordi (C2) & 1 & Papel de Jordi en la trayectoria vital de Sergi \\
\hline & 1.2.1.2.4 Rodrigo (C1) & 2 & Papel de Rodrigo en la trayectoria vital de Sergi \\
\hline & 1.2.2 Profesionales de la educación & 0 & $\begin{array}{l}\text { Red de profesionales que trabajaban con Sergi dentro y fuera de la } \\
\text { escuela }\end{array}$ \\
\hline & 1.2.2.1 Extracentro & 0 & $\begin{array}{l}\text { Red de profesionales externos al centro que trabajaban con Sergi en las } \\
\text { diferentes etapas educativas }\end{array}$ \\
\hline & 1.2.2.1.1 Ed. secundaria extracentro & 0 & $\begin{array}{l}\text { Red de profesionales externos al centro que trabajan con Sergi en la } \\
\text { etapa de educación secundaria }\end{array}$ \\
\hline & 1.2.2.1.1.1 Madre & 4 & $\begin{array}{l}\text { Papel de la madre en el desarrollo personal y académico de Sergi en esta } \\
\text { etapa de educación secundaria }\end{array}$ \\
\hline & 1.2.2.1.1.2 Azucena (logopeda) & 3 & $\begin{array}{l}\text { Papel de Azucena en cuanto a el desarrollo personal y académico de } \\
\text { Sergi en esta etapa de educación secundaria }\end{array}$ \\
\hline & 1.2.2.1.2 Ed. primaria extracentro & 0 & $\begin{array}{l}\text { Red de profesionales externos al centro que trabajaron con Sergi durante } \\
\text { la etapa de educación primaria }\end{array}$ \\
\hline & 1.2.2.1.2.1 Madre & 0 & $\begin{array}{l}\text { Papel de la madre en el trabajo fuera del centro durante la educación } \\
\text { primaria }\end{array}$ \\
\hline & 1.2.2.1.2.2 Luz (log y edu) & 10 & $\begin{array}{l}\text { Papel de Luz, logopeda que trabajaba con Sergi fuera del centro, a la vez } \\
\text { que dentro de éste ejercía como educadora externa }\end{array}$ \\
\hline & 1.2.2.1.2.3 Mira'm & 27 & $\begin{array}{l}\text { Papel de la fundación Mira'm como profesionales externos al centro que } \\
\text { trabajaban con Sergi y su familia }\end{array}$ \\
\hline
\end{tabular}




\begin{tabular}{|c|c|c|}
\hline 1.2.2.1.2.4 Azucena (log) & 21 & Papel de Azucena, Logopeda extraescolar de Sergi \\
\hline 1.2.2.1.2.5 Francisco (Educador) & 38 & Papel de Francisco, el educador, en la trayectoria académica de Sergi \\
\hline 1.2.2.1.3 Ed. infantil extracentro & 0 & $\begin{array}{l}\text { Red de profesionales externos al centro que trabajaron con él durante la } \\
\text { etapa de educación infantil }\end{array}$ \\
\hline 1.2.2.1.3.1 Caronila (edu) & 7 & Papel de Caronlina, el educador externa en la etapa de educación infantil \\
\hline 1.2.2.1.3.2 Madre & 11 & $\begin{array}{l}\text { Papel de la madre entre los profesionales de la educación que trabajaban } \\
\text { con Sergi en la etapa de educación infantil }\end{array}$ \\
\hline 1.2.2.2 Intracentro & 0 & $\begin{array}{l}\text { Red de profesionales pertenecientes al centro en las diferentes etapas } \\
\text { educativas }\end{array}$ \\
\hline 1.2.2.2.1 Ed. secundaria intracentro (centro 2) & 0 & $\begin{array}{l}\text { Red de profesionales pertenecientes al centro que trabajaron con Sergi } \\
\text { durante el curso académico en el IES Ciutat del Mar }\end{array}$ \\
\hline 1.2.2.2.1.1 Salva (música) & 1 & $\begin{array}{l}\text { Papel del profesor de música del centro } 2 \text { en la trayectoria educativa de } \\
\text { Sergi }\end{array}$ \\
\hline 1.2.2.2.1.2 Logopeda (centro 2) & 5 & Papel de la logopeda del centro 2 (IES Ciutat del Mar) \\
\hline 1.2.2.2.1.3 Beatriz (centro2) (tutora) & 1 & $\begin{array}{l}\text { Papel de Beatriz, profesor de castellano y tutora de Sergi en } 1 \text { 을 ESO } \\
\text { (centro 2) }\end{array}$ \\
\hline 1.2.2.2.1.4 Pedro (centro2) (PT) & 5 & Papel Pedro, profesor de Pedagogía Terapéutica del IES (centro 2) \\
\hline 1.2.2.2.1.5 Paco (centro2) (PT) & 14 & Papel de Paco, profesor de Pedagogía Terapéutica del IES (centro 2) \\
\hline 1.2.2.2.2 Ed. secundaria intracentro (centro 1) & 0 & $\begin{array}{l}\text { Red de profesionales pertenecientes al centro que trabajaron con Sergi } \\
\text { durante el curso académico que curso educación Secundaria en Virgen } \\
\text { del Carmen }\end{array}$ \\
\hline 1.2.2.2.2.1 Jaume (música) & 3 & Papel de Jaume, el profesor y maestro de música del centro 1 \\
\hline 1.2.2.2.2.2 Miriam (tutora $1^{\circ}$ ) & 3 & Papel de Miriam, la tutora de $1^{\circ}$ de la ESO en el centro 1 \\
\hline 1.2.2.2.2.3 Antonio (matemáticas $1^{\circ} \mathrm{ESO}$ ) & 2 & Papel de Antonio, profesor de matemáticas de 1 으 del centro 1 \\
\hline 1.2.2.2.2.4 Sonia (1ESO) & 3 & Papel de Sonia, profesora del centro 1 de ESO \\
\hline 1.2.2.2.2.5 Pilar (1ºESO) & 6 & Papel de Pilar, profesora del centro 1 \\
\hline 1.2.2.2.2.6 Telma PT4 (1º ESO) & 9 & $\begin{array}{l}\text { Papel de Telma (PT) en el ámbito académico de Sergi tras llegar a } \\
\text { Educación Secundaria (centro 1) }\end{array}$ \\
\hline 1.2.2.2.2.7 Pepe Logopeda ( $1^{\circ}$ ESO) & 1 & Papel de Pepe, logopeda de educación secundaria (centro 1) \\
\hline 1.2.2.2.2.8 Psicopedagogo Víctor ( $\left.1^{\circ} \mathrm{ESO}\right)$ & 9 & Papel del psicopedagogo del centro educativo 1 \\
\hline 1.2.2.2.3 Educación primaria intracentro & 0 & $\begin{array}{l}\text { Red de profesionales pertenecientes al centro que trabajaron con Sergi } \\
\text { durante la etapa de educación primaria }\end{array}$ \\
\hline 1.2.2.2.3.1 Júlia (maestra 1r ciclo) & 6 & Papel de Júlia, la maestra de $1{ }^{\circ}$ y $2^{\circ}$ curso de Sergi \\
\hline 1.2.2.2.3.2 Juanjo PT 2 (PT) $\left(3^{\circ}-6^{\circ}\right)$ & 4 & $\begin{array}{l}\text { Papel de Juanjo, un maestro de PT que trabajó con Sergi en el centro en } \\
\text { infantil y en } 4 \text { o de primaria. Esta categorización hace referencia a su } \\
\text { segunda etapa en el centro (ed. primaria) }\end{array}$ \\
\hline 1.2.2.2.3.3 Telma PT $1\left(4^{\circ}-6^{\circ}\right)$ & 11 & Papel de Telma en el desarrollo académico de Sergi \\
\hline 1.2.2.2.3.4 Mamen (Maestra $2^{\circ}$ ciclo) & 43 & Papel de Mamen, la maestra de 3 y 4 으 curso de Sergi \\
\hline 1.2.2.2.3.5 Mª Jesús (maestra $3 r$ ciclo) & 6 & Papel de Mã Jesús como maestra en la evolución académica de Sergi \\
\hline
\end{tabular}




\begin{tabular}{|c|c|c|c|}
\hline & 1.2.2.2.3.6 Pablo (ed. física) & 3 & $\begin{array}{l}\text { El papel del maestro de educación física en la evolución académica de } \\
\text { Sergi }\end{array}$ \\
\hline & 1.2.2.2.3.7 Jaume (música) & 7 & El papel del maestro de música en la evolución académica de Sergi \\
\hline & 1.2.2.2.4 Ed. infantil intracentro & 1 & $\begin{array}{l}\text { Papel de los profesionales de la educación que trabajaban con Sergi en la } \\
\text { etapa de Educación infantil }\end{array}$ \\
\hline & 1.2.2.2.4.1 Esther (maes P3) & 3 & $\begin{array}{l}\text { Papel de Esther, maestra de P3, en la trayectoria vital de Sergi y cómo } \\
\text { ésta ha influido en su desarrollo }\end{array}$ \\
\hline & 1.2.2.2.4.2 Silvia PT (P3-P4) & 4 & Papel de Silvia, la primera PT que estuvo en P3 y P4 \\
\hline & 1.2.2.2.4.3 Lourdes (Log SPE -P4) & 1 & $\begin{array}{l}\text { EI SPE (Servicio Psicopedagógico Escolar) y su papel en la evolución } \\
\text { académica de Sergi }\end{array}$ \\
\hline & 1.2.2.2.4.4 Carmen (maestra infantil P4 y P5) & 6 & $\begin{array}{l}\text { El papel en la educación de Sergi de Carmen, maestra en educación } \\
\text { infantil }\end{array}$ \\
\hline & 1.2.2.2.4.5 Juanjo 1 (Log) (P5) & 3 & $\begin{array}{l}\text { Papel de Juanjo, un maestro de PT que trabajó con Sergi en el centro en } \\
\text { infantil y en } 4 \text { o de primaria. Esta categorización hace referencia a su } \\
\text { primera etapa en el centro }\end{array}$ \\
\hline & 1.2.2.2.4.6 PT centro Paula (P5) & 1 & $\begin{array}{l}\text { Papel del maestro/a de Pedagogía Terapéutica perteneciente al centro y } \\
\text { facilitado por la administración educativa }\end{array}$ \\
\hline & 1.3 Red familiar & 0 & $\begin{array}{l}\text { Miembros de la familia más o menos directa de Sergi y su papel en su } \\
\text { trayectoria vital }\end{array}$ \\
\hline & 1.3.1 Primos paternos & 3 & Papel de los primos paternos en la trayectoria vital de Sergi \\
\hline & 1.3.2 Primos maternos & 1 & Papel de los primos maternos en la trayectoria vital de Sergi \\
\hline & 1.3.3 Padres & 7 & Acciones o momentos en que los padres toman un papel protagonista \\
\hline & 1.3.3.1 Padre & 4 & Papel del padre en la trayectoria de vida de Sergi \\
\hline & 1.3.3.2 Madre & 12 & Acciones o ámbitos en los que la madre tomaba un papel protagonista \\
\hline & 1.3.4 Hermano pequeño & 19 & Papel del hermano pequeño de Sergi en su trayectoria vital \\
\hline & 1.3.5 Hermano mayor & 17 & Papel del hermano mayor de Sergi en su trayectoria vital \\
\hline & 1.3.6 Tío materno & 2 & Papel del tío materno de Sergi en su trayectoria vital \\
\hline & 1.3.7 Abuelo materno & 12 & Papel del abuelo materno de Sergi en su trayectoria vital \\
\hline & 1.3.8 Abuela materna & 1 & Papel de la abuela materna de Sergi en su trayectoria vital \\
\hline & 1.3.9 Abuelos paternos & 2 & Papel de los abuelos paternos de Sergi en su trayectoria vital \\
\hline & 1.3.10 Tía paterna & 1 & Papel de la tía paterna en la trayectoria vital de Sergi \\
\hline & 2.1 Transversal & 128 & Elementos trasversales a cualquier etapa de su trayectoria vital \\
\hline 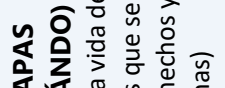 & 2.2 De los 0 a 3 años & 27 & $\begin{array}{l}\text { Etapa comprendida desde el nacimiento de Sergi hasta su incorporación } \\
\text { a la etapa de educación infantil (0-3 años) }\end{array}$ \\
\hline & 2.3 De los 3-6 años (Ed. infantil) & 83 & Etapa desde los 3 a los 6 años que se incorporó a la educación primaria \\
\hline & 2.4 De los 6-12 años (Ed. primaria) & 239 & Etapa de Sergi en Educación primaria \\
\hline 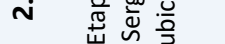 & 2.5 De los $12-13$ años (ESO centro 1) & 134 & Etapa de Sergi en Educación Secundaria antes de cambiar de centro \\
\hline & 2.6 De los 13 - 15 años (ESO centro 2) & 181 & Etapa de Sergi en la Educación Secundaria tras cambiar de centro \\
\hline
\end{tabular}


2.7 Futuro

3.1 Ámbito comunicativo - relacional

3.1.1 Apoyos y ayudas a la interacción social

3.1.1.1 Apoyo logopédico

3.1.1.2 Apoyos organizativos

3.1.1.2.1 Anticipación en los hechos

3.1.1.2.2 Organización temporal

3.1.1.2.3 Paneles de organización

3.1.1.3 Apoyos de acceso a la información

3.1.1.3.1 Historias sociales

3.1.13.1.1 Teoría de la mente

3.1.1.3.1.2 Modificación de conducta

3.1.1.3.2 Imágenes

3.1.1.4 Apoyos comunicativos

3.1.1.4.1 Pictogramas comunicativos

3.1.1.4.1.1 Función pictogramas

\subsection{2 Área relacional}

3.1.2.1 Evolución

3.1.2.1.1 Lenguaje

3.1.2.1.2 Crecimiento académico y personal
0

26

7

21

23

15

25
Aspectos relacionados con el futuro de Sergi como expectativas, deseos, voluntades,...

Aquellos elementos comunicativos no vinculados a ninguno de los otros contextos y de carácter trasversal

Conjunto de ayudas recibidas para mejorar elementos de la interacción social

Conjunto de apoyos basado en el trabajo de la expresión y comprensión oral y escrita

Conjunto de apoyos que facilitan que Sergi pueda manejarse en la organización temporal establecida socialmente

Proceso por el que el cual la madre (y otras personas cercanas) le anticipaban a Sergi aquello que iba a pasar para que estuviera preparado y fuera consciente de ello.

Sergi necesita organización temporal para poder entender cómo suceden las cosas y cómo interactuar con el entorno

Conjunto de materiales y elementos pictográficos para la organización temporal y espacial del día a día de Sergi

Conjunto de apoyos que facilitan a Sergi acceder a información ya sea de indole social o académica

Trabajo con historias sociales que ayuden a Sergi a comprender cómo debe responder socialmente ante una determinada situación

Importancia del trabajo sobre la teoría de la mente para que Sergi entendiera el funcionamiento social

Las historias sociales permiten que trabajar con Sergi al modificación de

conducta mediante la imagen y las viñetas

Las imágenes como apoyos de los que Sergi es capaz de extraer gran cantidad de información

Conjunto de elementos que sirven de apoyo para la comunicación Conjunto de pictogramas de comunicación elaborado por la madre de Sergi como método alternativo de comunicación

Función de interacción social de dichos pictogramas para Sergi

Elementos relativos a cómo Sergi se relaciona y crece con su entorno inmediato

Proceso por el que Sergi ha ido adquiriendo y mejorando ciertos elementos relativos a la interacción con otras personas

Sergi experimente evolución positiva notoria en el lenguaje, su uso y funcionalidad

Sergi experimenta un gran crecimiento académico y personal el cual le abre un gran abanico de posibilidades 
3.1.2.1.3 Apertura social

3.1.2.2 Dificultades

3.1.2.2.1 Rechazo a la cercanía

3.1.3 Área de expresión y comprensión

3.1.3.1 Comunicación con el entorno

3.1.3.1.1 Retroceso

3.1.3.1.2 Comunicación alternativa

3.1.3.1.2.1 Elementos comunicativos

3.1.3.1.2.1.1 Madre

3.1.3.1.3 Comunicación verba

3.1.3.1.3.1 Ecolalias

3.13.1.3.2 Dificultades de expresión

3.1.3.1.3.2.1 Falta de fluidez

3.1.3.1.3.2.2 Expresión sentimientos

3.1.3.1.3.23 Estructuración

3.1.3.1.3.2.4 Vocabulario

3.1.3.1.3.2.5 Uso del lenguaje

3.1.3.1.3.2.6 Efectos de las dificultades

3.1.3.1.3.2.6.1 Desconexión

3.1.3.1.3.2.6.2 Frustración

3.1.3.1.3.2.6.3 Conciencia

3.1.3.1.3.3 Dificultades de comprensión
0

8

1

7

5

18

15

14

0

9
Sergi se abre a otras personas y experiencias con el paso del tiempo y su propio crecimiento personal

Dificultades que se pueden identificar en Sergi en cuanto la relación con

su entorno

Rechazo del contacto físico, el cariño y la cercanía con las personas en un determinado momento de su vida

Elementos relativos a la comunicación, a la expresión y a la comprensión

Procedimiento por el cual Sergi se relaciona y comunica con su entorno

Retroceso en el habla y comunicación experimentado por Sergi a los 2 o

3 años de edad aproximadamente

Uso con Sergi de sistemas de comunicación alternativa

Todos aquellos recursos alternativos de comunicación elaborados por el entorno cercano de Sergi para facilitarle la comunicación y el acceso a la información

Todos aquellos recursos elaborados por la madre en cuanto a la

comunicación de Sergi

Inicio de la comunicación de Sergi mediante el sistema verbal.

Utilización de frases de películas, o frases hechas debido a las dificultades para construir oraciones completas

Dificultades de Sergi en cuanto a la comunicación y a la fluidez en una conversación

Sergi presenta dificultades a la hora de seguir una conversación cara a cara

Sergi se caracteriza por una escasa expresión de sentimientos. Los conoce pero no los expresa

Sergi presenta ciertos errores en la estructuración y expresión oral de frases

Sergi posee un vocabulario limitado que hay que ir ampliando para que su expresión vaya mejorando

Sergi presenta dificultades en el uso del lenguaje

Efectos de estas dificultades sobre el área de expresión y comprensión de

Sergi

Desconexión del contexto por no poder seguir una explicación y

conversación y, por lo tanto, aislamiento

Sentimiento de frustración y enfado por no poder comunicarse y expresarse

Sergi es consciente de sus dificultades y de los problemas que esto le

acarrea

Dificultades manifestadas por Sergi a la hora de comprender aquello que 


\begin{tabular}{|c|c|c|}
\hline & & se le quiere transmitir oralmente \\
\hline 3.1.3.1.3.3.1 Conciencia fonológica & 3 & $\begin{array}{l}\text { Sergi tiene dificultades en cuanto a la conciencia fonológica que, como } \\
\text { tal, afecta tanto al área de expresión y comprensión oral como a la de } \\
\text { lectoescritura }\end{array}$ \\
\hline 3.1.3.1.3.3.2 Lenguaje abstracto & 6 & Sergi presenta grandes dificultades en cuanto al lenguaje abstracto \\
\hline 3.1.4 Área de Lectoescritura & 0 & $\begin{array}{l}\text { Elementos propios de la lectoescritura y el proceso de adquisición de } \\
\text { esta }\end{array}$ \\
\hline 3.1.4.1 Acceso a la lectura & 3 & Proceso por el cual Sergi accede a la lectura \\
\hline 3.1.4.1.1 Motivación al aprendizaje & 3 & $\begin{array}{l}\text { Una vez Sergi accedió al mundo de la lectoescritura se le abrió el mundo } \\
\text { de la información y eso le motivó a Sergi aprendiendo }\end{array}$ \\
\hline 3.1.4.2 Bloqueo a la lectura & 2 & $\begin{array}{l}\text { Sergi presenta un bloqueo a la lectura mediante el que tiene dificultades } \\
\text { para aprender a leer }\end{array}$ \\
\hline 3.1.5 Proceso de aprendizaje & 8 & $\begin{array}{l}\text { Proceso por el cual Sergi adquiere conocimientos, destrezas y } \\
\text { herramientas para la comunicación y otros conocimientos generales }\end{array}$ \\
\hline 3.1.5.1 Sergi como guía & 3 & $\begin{array}{l}\text { Sergi expresa y marca debidamente aquello que necesita y tiene deseos } \\
\text { de aprender }\end{array}$ \\
\hline 3.1.5.2 Aprendizaje realista & 10 & $\begin{array}{l}\text { Aprendizaje a partir de situaciones reales o con ejemplos reales para que } \\
\text { Sergi aprendiera a responder }\end{array}$ \\
\hline 3.2 Contexto educativo & 0 & \\
\hline 3.2.1 TRABAJO EXTRAESCOLAR (AYUDA) & 1 & Elementos y situaciones relativas al trabajo extraescolar \\
\hline 3.2.1.1 Trabajo extraescolar (durante centro2) & 0 & $\begin{array}{l}\text { Conjunto de elementos del trabajo extraescolar estando Sergi } \\
\text { escolarizado en el centro2 }\end{array}$ \\
\hline 3.2.1.1.1 Logopeda (Azu) & 3 & $\begin{array}{l}\text { Trabajo con la logopeda de fuera del centro mientras está escolarizado } \\
\text { en el centro } 2\end{array}$ \\
\hline 3.2.1.2 Trabajo extraescolar (durante centro1) & 2 & $\begin{array}{l}\text { Todo aquel trabajo académico que Sergi realizaba al finalizar el horario } \\
\text { lectivo }\end{array}$ \\
\hline 3.2.1.2.1 Perjuicios & 2 & El trabajo extraescolar repercute negativamente en Sergi \\
\hline 3.2.1.2.2 Beneficios & 1 & $\begin{array}{l}\text { El trabajo extraescolar aporta beneficios a Sergi necesarios para su } \\
\text { desarrollo }\end{array}$ \\
\hline 3.2.1.2.3 Trabajo en equipo & 2 & $\begin{array}{l}\text { Importancia del equipo de profesionales externo que trabajan con Sergi y } \\
\text { la coordinación entre ellos para favorecer el aprendizaje y desarrollo } \\
\text { personal y académico }\end{array}$ \\
\hline 3.2.1.2.3.1 Equipo multidisciplinar & 7 & $\begin{array}{l}\text { Se considera una ayuda o facilidad para la inclusión cuando los docentes } \\
\text { colaboran con otros profesionales de la educación que estén trabajando } \\
\text { con Sergi }\end{array}$ \\
\hline 3.2.1.2.4 Mira'm & 10 & $\begin{array}{l}\text { Papel de la Fundación Mira'm en cuanto al trabajo extraescolar de Sergi } \\
\text { en casa u otros espacios extraescolares }\end{array}$ \\
\hline 3.2.1.2.4.1 Orientaciones/coordinación con la familia & 7 & $\begin{array}{l}\text { Desde la Fundación Mira'm se dan ciertas orientaciones sobre cómo } \\
\text { realizar actividades o elaborar materiales }\end{array}$ \\
\hline
\end{tabular}




\begin{tabular}{|c|c|c|}
\hline 3.2.1.2.4.2 Programa individualizado & 2 & $\begin{array}{l}\text { La función de los informes y programas individualizados de Mira'm } \\
\text { realizados para Sergi }\end{array}$ \\
\hline 3.2.1.2.4.3 Orientaciones/ coordinación con la escuela & 2 & $\begin{array}{l}\text { Mira'm y sus profesionales se coordinaban con los profesionales del } \\
\text { centro para facilitarles y orientarles en el trabajo con Sergi }\end{array}$ \\
\hline 3.2.1.2.4.4 Registros & 6 & Función de los registros sobre el aprendizaje y evolución de Sergi \\
\hline 3.2.1.2.5 Logopeda & 21 & $\begin{array}{l}\text { Papel de la logopeda en cuanto al trabajo extraescolar de Sergi en casa u } \\
\text { otros espacios extraescolares }\end{array}$ \\
\hline 3.2.1.2.5.1 Exigencia & 2 & La exigencia como un elemento propio de Azucena (logopeda) \\
\hline 3.2.1.2.6 Madre - casa & 11 & Papel de la madre en cuanto al trabajo extraescolar de Sergi en casa \\
\hline 3.2.2 CENTRO 2 & 0 & Elementos y situaciones relativas al centro 2 (IES Ciutat del Mar) \\
\hline 3.2.2.1 Elementos descriptivos del contexto (centro 2) & 0 & $\begin{array}{l}\text { Conjunto de elementos que ayudan a entender el contexto educativo y } \\
\text { los elementos correspondientes referentes al centro } 2\end{array}$ \\
\hline 3.2.2.1.1 Apoyo educativo en casa & 4 & $\begin{array}{l}\text { El apoyo educativo que desde la familia se hace con Sergi facilita su pleno } \\
\text { desarrollo e inclusión en el centro }\end{array}$ \\
\hline 3.2.2.1.2 Rechazo hacia el centro 1 & 3 & Sergi rechaza y repudia al centro 1 tras incorporarse al centro2 \\
\hline 3.2.2.1.3 Sentido de pertenencia & 3 & Sergi se siente vinculado al centro y que pertenece a él \\
\hline 3.2.2.2 Barreras educativas & 0 & $\begin{array}{l}\text { Conjunto de elementos o situaciones que se considerar una barrera a la } \\
\text { inclusión educativa de Sergi }\end{array}$ \\
\hline 3.2.2.2.1 Ignorancia compañer@s & 1 & $\begin{array}{l}\text { A pesar de la buena integración en el centro, hay ciertos alumn@s que } \\
\text { ignoran un poco a Sergi y sus intereses }\end{array}$ \\
\hline 3.2.2.2.2 Falta de concienciación educativa & 3 & $\begin{array}{l}\text { Se considera la falta de concienciación de profesionales de la educación } \\
\text { como una barrera educativa, pues desde los departamentos de } \\
\text { orientación hay que concienciarles del sentido de comunidad y de } \\
\text { atención a todo el alumnado }\end{array}$ \\
\hline 3.2.2.3 Ayudas y facilidades & 0 & $\begin{array}{l}\text { Conjunto de ayudas y facilidades generadas por el centro } 2 \text { para } \\
\text { garantizar la inclusión de Sergi en el centro }\end{array}$ \\
\hline 3.2.2.3.1 Compañeros/as & 0 & $\begin{array}{l}\text { Los nuevos compañeros y compañeras de Sergi actúan como un } \\
\text { elemento de inclusión }\end{array}$ \\
\hline 3.2.2.3.1.1 Valoración de la diversidad & 5 & $\begin{array}{l}\text { Por parte de los compañeros se observa un gran respeto a la diversidad } \\
\text { en el aula, lo cual se convierte en un facilitador para el desarrollo } \\
\text { personal y académico de Sergi }\end{array}$ \\
\hline 3.2.2.3.1.2 Integración en el grupo & 9 & $\begin{array}{l}\text { La integración en el grupo como un elemento que facilita la inclusión } \\
\text { educativa de Sergi }\end{array}$ \\
\hline 3.2.2.3.1.2.1 Vínculos de amistad & 15 & $\begin{array}{l}\text { La amistad derivada de sus compañeros y compañeras de clase se } \\
\text { considera una ayuda o facilitador de la inclusión }\end{array}$ \\
\hline 3.2.2.3.2 Administración educativa & 0 & $\begin{array}{l}\text { Facilidades y ayuda por parte de la administración educativa a Sergi y su } \\
\text { familia para lograr un pleno desarrollo de éxito }\end{array}$ \\
\hline 3.2.2.3.2.1 Supervisión del caso & 1 & $\begin{array}{l}\text { Implicación por parte de la inspección educativa en cuanto a la } \\
\text { escolarización de Sergi y la supervisión de las medidas de atención a la }\end{array}$ \\
\hline
\end{tabular}




\begin{tabular}{|c|c|c|}
\hline & & diversidad que se adoptan con él. \\
\hline 3.2.2.3.3 Centro & 0 & $\begin{array}{l}\text { Papel de centro para ayudar y facilitar el desarrollo académico y personal } \\
\text { de Sergi en el centro, así como la inclusión educativa de este }\end{array}$ \\
\hline 3.2.2.3.3.1 Plan de trabajo de centro & 3 & $\begin{array}{l}\text { Plan de trabajo establecido por el centro para trabajar con Sergi y } \\
\text { fomentar su desarrollo académico y personal }\end{array}$ \\
\hline 3.2.2.3.3.1.1 Comunicación familia-escuela & 6 & Comunicación y coordinación con la familia por parte del centro 2 \\
\hline 3.2.2.3.3.1.2 Dpto. Orientación & 0 & $\begin{array}{l}\text { El propio departamento de orientación y sus profesionales como } \\
\text { elementos facilitadores de la inclusión y el desarrollo académico de Sergi }\end{array}$ \\
\hline 3.2.2.3.3.1.2.1 Seguimiento & 2 & $\begin{array}{l}\text { El equipo multidisciplinar del centro realiza un seguimiento para } \\
\text { garantizar el pleno desarrollo académico de Sergi }\end{array}$ \\
\hline 3.2.2.3.3.1.2.2 Coordinación interdisciplinar & 5 & $\begin{array}{l}\text { Coordinación entre todos los docentes de Sergi, el departamento de } \\
\text { orientación, y la persona especialista en Educación especial de la } \\
\text { Conselleria de Educació }\end{array}$ \\
\hline 3.2.2.3.3.1.2.3 Adaptaciones curriculares & 4 & $\begin{array}{l}\text { Proceso por el cual se realizan adaptaciones curriculares a Sergi en el } \\
\text { centro } 2\end{array}$ \\
\hline 3.2.2.3.3.1.2.4 Atención individualizada (PT) & 10 & $\begin{array}{l}\text { Sergi tiene en el centro atención individualizada mediante profesores de } \\
\text { PT y apoyo }\end{array}$ \\
\hline 3.2.2.3.3.1.2.5 Sensibilización autismo & 2 & $\begin{array}{l}\text { Proceso por el cual se introdujo a Sergi y su personalidad al grupo-clase } \\
\text { al que pertenecía }\end{array}$ \\
\hline 3.2.2.3.3.1.2.6 Adaptación de materiales y recursos & 7 & $\begin{array}{l}\text { La adaptación de materiales por parte de los profesionales del dpto. de } \\
\text { orientación como un facilitador de la inclusión }\end{array}$ \\
\hline 3.2.2.3.3.1.2.7 Trabajo fuera del aula & 3 & $\begin{array}{l}\text { Trabajo de los profesionales del dpto. de orientación del centro fuera del } \\
\text { aula }\end{array}$ \\
\hline 3.2.2.3.3.1.2.8 Trabajo en el aula & 1 & $\begin{array}{l}\text { Trabajo de los profesionales del dpto. de orientación del centro dentro } \\
\text { del aula }\end{array}$ \\
\hline 3.2.2.3.4 Docentes/profesionales & 0 & $\begin{array}{l}\text { Ayudas y facilidades generadas o provenientes de los profesionales de la } \\
\text { educación en particular (docentes y otros profesionales) }\end{array}$ \\
\hline 3.2.2.3.4.1 Creencia en Sergi & 1 & $\begin{array}{l}\text { El centro apuesta por Sergi y esto facilita en gran medida su inclusión y } \\
\text { desarrollo personal }\end{array}$ \\
\hline 3.2.2.3.4.2 Ofrecer oportunidades de aprendizaje & 7 & $\begin{array}{l}\text { Ofrecer oportunidades de aprendizaje desde el ámbito educativo se } \\
\text { considera un elemento de ayuda y favorecimiento a la inclusión }\end{array}$ \\
\hline 3.2.2.3.4.3 Participación & 2 & $\begin{array}{l}\text { La participación en general como elemento de inclusión en sus distintos } \\
\text { niveles }\end{array}$ \\
\hline 3.2.2.3.4.3.1 Actividades extracurriculares & 9 & $\begin{array}{l}\text { La participación en actividades de centro y extracurriculares como } \\
\text { elemento favorecedor de la inclusión }\end{array}$ \\
\hline 3.2.2.3.4.3.2 Actividades de aula & 5 & $\begin{array}{l}\text { Fomento de la participación de Sergi y otros niños con dificultades en el } \\
\text { aula }\end{array}$ \\
\hline 3.2.2.3.4.3.2.1 Exámenes & 2 & $\begin{array}{l}\text { Participación de Sergi en los exámenes como actividades de aula con los } \\
\text { mismos contenidos que sus compañeros/as aunque de forma más simple }\end{array}$ \\
\hline
\end{tabular}


3.2.2.3.4.3.2.2 Trabajo en grupo

3.2.2.3.4.4 Implicación

3.2.3 CENTRO

3.2.3.1 Elementos descriptivos del contexto (centro 1)

3.2.3.1.1 Ganas de asisti

3.2.3.1.2 Dirección familiar

3.2.3.1.3 Materiales - madre

3.2.3.1.4 Adaptaciones curriculares

3.2.3.1.4.1 SPE

3.2.3.1.4.2 Madre

3.2.3.1.4.3 Mira'm

3.2.3.2 Ayudas y facilidades inclusivas

3.2.3.2.1 Compañer@s

3.2.3.2.1.1 Defensa de derechos

3.2.3.2.1.1.1 Apoyo incondicional

3.2.3.1.1.1.1 Fiesta de despedida amigos

3.2.3.2.1.1.1.1.1 Fiesta de despedida centro

3.2.3.2.1.2 Integración en el grupo

2.3.2.1.2.1 Vínculos de amistad

3.2.3.2.1.2.1.1 Eva (C4)

3.2.3.2.1.2.1.2 Vero (C3)

3.2.3.2.1.2.1.3 Jordi (C2)

3.2.3.2.1.2.1.4 Rodrigo (C1)

3.2.3.2.1.3 Valorar diversidad

3.2.3.2.2 Administración educativa
10

otros compañeros del aula

Implicación de los docentes con Sergi para facilitarle su desarrollo

académico y social

0

Elementos y situaciones relativas al centro 1 (Virgen del Carmen)

Conjunto de elementos que ayudan a entender el contexto educativo y

los elementos correspondientes referentes al centro 1

Sergi ha manifestado siempre deseos de asistir a la escuela diariamente

Las decisiones tomadas por la familia y el hecho de dirigir todo el proceso

educativo relacionado con Sergi se identifica como un elemento positivo

clave dentro de la historia de vida

Materiales aportados y elaborados por la madre de Sergi para su

aprendizaje y desarrollo

Las adaptaciones curriculares de Sergi y qué persona/s las llevan a cabo

Papel del SPE en las adaptaciones curriculares y su aplicación

Papel de la madre en las adaptaciones curriculares

Papel de Mira'm en las adaptaciones curriculares

Todas las facilidades, ayudas y apoyos que cualquier miembro del centro

ha realizado, consciente o inconscientemente, para mejorar el estado o circunstancias de Sergi.

Los compañeros del centro como un apoyo incondicional de Sergi

Los compañeros defienden de los derechos de Sergi ante la vulneración

por parte de los docentes o la propia institución educativa

Ante la falta de injusticia, diversos sectores del ámbito escolar

manifiestan un apoyo incondicional a Sergi y su familia

Fiesta de despedida preparada por los amigos y compañeros de Sergi ante la noticia de marcha del centro

Fiesta de despedida que se preparó desde el centro como respuesta a la

fiesta de despedida de amigos de Sergi ante su marcha

Integración en el grupo de Sergi y ser tratado como uno más

Relaciones y vínculos de amistad con sus compañeros/as de aula

Papel de Eva en la trayectoria vital de Sergi

Papel de Vero en la trayectoria vital de Serg

Papel de Jordi en la trayectoria vital de Sergi

Papel de Rodrigo en la trayectoria vital de Sergi

Los compañeros/as de Sergi saben valorar la diversidad y otorgarle un

elevado valor

$0 \quad$ Acciones o elementos facilitadores de la inclusión que tienen que ver con la administración pública y sus políticas educativas 
3.2.3.2.2.1 Flexibilidad en el horario

3.2.3.2.2.2 Profesionales públicos

3.2.3.2.3 Docentes/ profesionales

3.2.3.2.3.1 Francisco (educador)

3.2.3.2.3.1.1 Canal de comunicación con familia

3.2.3.2.3.1.2 Agente educativo

3.2.3.2.3.1.3 Agente socializador

3.2.3.2.3.2 Creencia en Sergi

3.2.3.2.3.2.1 Oportunidades de aprendizaje

3.2.3.2.3.3 Ubicación junto a compañer@s

3.2.3.2.3.4 Apertura/receptividad

3.2.3.2.3.5 Participación activa

3.2.3.2.3.5.1 Presencia continua en el aula

3.2.3.2.3.5.1.1 Integración

3.2.3.2.3.5.2 Actividades de centro

2.3.2.3.5.3 Actividades de aula

3.2.3.2.3.5.3.1 Trabajos en grupo

3.2.3.2.3.5.3.2 Exámenes

3.2.3.2.3.6 Implicación

3.2.3.2.4 Centro

3.2.3.2.4.1 Receptividad de materiales externos
Permiso y flexibilidad de horarios en cuanto a Sergi en base a sus necesidades educativas

La administración educativa otorga a Sergi la posibilidad de acceder a profesionales públicos.

Acciones o elementos facilitadores de la inclusión que tienen que ver con los docentes

El educador de Sergi como un elemento o factor de ayuda a la inclusión El educador se encuentra en constante coordinación con la familia de Sergi

2
El papr

2 El papel del educador como agente socializador y mediador entre Sergi y el grupo de referencia

8 Se considera el hecho de creer en Sergi y sus posibilidades como un elemento que favorece y posibilita la inclusión

Docentes que tratan y exigen a Sergi tanto como a los demás. Al creer en Sergi generan automáticamente oportunidades de aprendizaje de forma igualitaria respetando los diferentes niveles.

Ciertos docentes, a pesar de que el centro había estipulado que Sergi debía estar ubicado en la parte frontal del aula, decidían por su cuenta integrarlo del nuevo en el grupo durante la clase.

Se considera un elemento favorecedor de la inclusión cuando los

docentes están abiertos a nuevas ideas, nuevas metodologías, nuevos materiales,... y son receptivos con ellos

$0 \quad$ Participación de Sergi como un alumno más en el centro y el aula al que pertenece

3 Para que se pueda dar la participación activa es necesario que Sergi esté presente en el aula continuamente, como uno más

7 Momentos o etapas educativas de Sergi en las que se considera que existe una verdadera inclusión educativa Sergi participa en las actividades de centro como un miembro más

16 Sergi participa en actividades y elementos del aula como un alumno más

2 Realización de trabajos en grupo/parejas en los que Sergi participaba Proceso por el cual Sergi se preparaba los exámenes y estudiaba para participar como uno más en las aulas

21

La implicación docente como una ayuda o facilidad a la inclusión Acciones o elementos facilitadores de la inclusión que tiene que ver con el centro educativo concertado en el que estaba Sergi

5 Se plantea la apertura o receptividad de materiales externos como un elemento facilitador propiciado por el centro 


\begin{tabular}{|c|c|c|}
\hline 3.2.3.2.4.2 Coordinación familia-escuela & 5 & $\begin{array}{l}\text { Acciones de coordinación y trabajo conjunto entre la familia y la escuela } \\
\text { para beneficio de Sergi }\end{array}$ \\
\hline 3.2.3.2.4.3 Apertura a otros profesionales & 7 & $\begin{array}{l}\text { El centro accedía a que profesionales de fuera (no públicos) entraran en } \\
\text { las aulas para mejorar el trabajo con Sergi }\end{array}$ \\
\hline 3.2.3.3 Barreras educativas & 0 & $\begin{array}{l}\text { Son todos aquellos obstáculos al aprendizaje y desarrollo de Sergi } \\
\text { impuestos por la escuela, ya sea proveniente de personas concretas o de } \\
\text { la propia institución. }\end{array}$ \\
\hline 3.2.3.3.1 Falta de justicia & 2 & $\begin{array}{l}\text { Se pone de manifiesto la falta de justicia que ha habido en el caso de } \\
\text { Sergi en cuanto al contexto educativo }\end{array}$ \\
\hline 3.2.3.3.1.1 Cambio de centro & 18 & $\begin{array}{l}\text { Sergi cambia un centro concertado a uno público donde va a continuar } \\
\text { sus estudios de educación secundaria }\end{array}$ \\
\hline 3.2.3.3.1.1.1 Apoyo de la inspección & 3 & $\begin{array}{l}\text { En cuanto la inspección se enteró de que en el caso de Sergi no se están } \\
\text { atendiendo sus necesidades apoyaron a la familia }\end{array}$ \\
\hline 3.2.3.3.1.1.2 Realidad más inclusiva & 1 & $\begin{array}{l}\text { El cambio de centro provocado por las barreras e injusticias educativas } \\
\text { dan lugar a realidades más inclusivas para Sergi }\end{array}$ \\
\hline 3.2.3.3.1.1.3 Miedo & 5 & $\begin{array}{l}\text { Miedo provocado por el cambio de centro de Sergi, cómo se va a } \\
\text { adaptar, cómo lo va a interpretar,... }\end{array}$ \\
\hline 3.2.3.3.1.2 Vulneración de derechos & 6 & $\begin{array}{l}\text { Se identifican acciones o momentos en los que se considera que se } \\
\text { vulneran ciertos derechos a Sergi u otros estudiantes del centro }\end{array}$ \\
\hline 3.2.3.3.1.2.1 Toma de conciencia (docentes) & 3 & $\begin{array}{l}\text { Algunos docentes se dan cuenta y son conscientes de la injusticia vivida } \\
\text { por Sergi en el centro }\end{array}$ \\
\hline 3.2.3.3.2 Administración & 0 & $\begin{array}{l}\text { Barreras la inclusión de Sergi procedentes de la administración y sus } \\
\text { políticas }\end{array}$ \\
\hline 3.2.3.3.2.1 Posibilidades escolarización & 5 & $\begin{array}{l}\text { Existe una carencia por parte de la administración en cuanto a posibles } \\
\text { vías de escolarización del alumnado con necesidades educativas }\end{array}$ \\
\hline 3.2.3.3.2.2 Falta de opciones formativas & 1 & $\begin{array}{l}\text { Se detecta que no existen opciones formativas para el alumnado con } \\
\text { discapacidad más allá de la educación especial }\end{array}$ \\
\hline 3.2.3.3.3 Centro & 0 & Barreras a la inclusión interpuestas por el centro \\
\hline 3.2.3.3.3.1 Repetición curso & 6 & Petición del centro sobre la repetición de curso de Sergi \\
\hline 3.2.3.3.3.1.1 Resistencia familiar & 2 & $\begin{array}{l}\text { Resistencia familiar a que Sergi repitiera curso académico y se separara } \\
\text { de sus compañeros/as }\end{array}$ \\
\hline 3.2.3.3.3.2 Conflicto con la familia & 3 & $\begin{array}{l}\text { Momentos o situaciones en los que la familia y la escuela han estado en } \\
\text { conflicto }\end{array}$ \\
\hline 3.2.3.3.3.2.1 Trabas a la familia & 4 & $\begin{array}{l}\text { El centro educativo decide bloquear todos los procesos que tiene } \\
\text { abiertos con los padres de Sergi }\end{array}$ \\
\hline 3.2.3.3.3.2.2 Intervención Conselleria & 1 & $\begin{array}{l}\text { Conselleria interviene entre la familia y el centro educativo para mediar } \\
\text { entre ambos y ayudar al centro a ofrecer a la familia lo que necesita }\end{array}$ \\
\hline 3.2.3.3.3.3 Rechazo a otros profesionales & 3 & $\begin{array}{l}\text { Ciertos docentes del centro manifiestan rechazo hacia las aportaciones } \\
\text { de profesionales externos al centro }\end{array}$ \\
\hline
\end{tabular}




\begin{tabular}{|c|c|c|}
\hline 3.2.3.3.3.3.1 Defensiva & 1 & $\begin{array}{l}\text { Posición defensiva frente a otros profesionales que quieren o apuestan } \\
\text { por colaborar con el centro }\end{array}$ \\
\hline 3.2.3.3.3.3.2 Rechazo educador & 22 & $\begin{array}{l}\text { Rechazo de algunos docentes hacia Francisco, el educador de Sergi al } \\
\text { llegar a la etapa de educación secundaria }\end{array}$ \\
\hline 3.2.3.3.3.4 Aislamiento/ Exclusión de Sergi & 29 & Proceso de exclusión de Sergi dentro del mismo centro educativo \\
\hline 3.2.3.3.3.5 Corporativismo & 9 & $\begin{array}{l}\text { El corporativismo de los centros educativos concertados y privados como } \\
\text { una barrera a la inclusión educativa de todo el alumnado }\end{array}$ \\
\hline 3.2.3.3.3.5.1 Clientelismo & 4 & $\begin{array}{l}\text { Vinculado al corporativismo se observa actitudes y actos totalmente } \\
\text { centrados en la satisfacción del cliente (padres) }\end{array}$ \\
\hline 3.2.3.3.3.5.2 Presiones intracentro & 8 & $\begin{array}{l}\text { Presiones ejercidas desde dentro del centro a sus propios docentes para } \\
\text { generar respuesta y pensamiento único (derivado del corporativismo) }\end{array}$ \\
\hline 3.2.3.3.3.6 Sacarlo del aula & 11 & $\begin{array}{l}\text { Efecto negativo de sacar a Sergi del aula en él mismo y su inclusión } \\
\text { educativa }\end{array}$ \\
\hline 3.2.3.3.3.7 Falta de recursos educativos & 6 & $\begin{array}{l}\text { La falta de recursos educativos en el centro y cómo eso afectó } \\
\text { negativamente en la evolución de Sergi }\end{array}$ \\
\hline 3.2.3.3.3.7.1 Falta de materiales & 10 & Escasez de materiales y recursos para el trabajo en el aula con Sergi \\
\hline 3.2.3.3.4 Docentes/ Profesionales & 0 & $\begin{array}{l}\text { Acciones o elementos que actúan como barreras a la inclusión que tienen } \\
\text { que ver con los docentes del centro }\end{array}$ \\
\hline 3.2.3.3.4.1 No atención necesidades & 19 & $\begin{array}{l}\text { Existe una gran falta de atención a las necesidades educativas del } \\
\text { alumnado de este centro }\end{array}$ \\
\hline 3.2.3.3.4.2 No creencia en Sergi & 15 & $\begin{array}{l}\text { Los docentes en particular, muestran una actitud de no creencia en Sergi } \\
\text { y, por lo tanto, de escasa implicación para con él }\end{array}$ \\
\hline 3.2.3.3.4.3 Límites al aprendizaje & 12 & $\begin{array}{l}\text { Los propios docentes del centro limitaban el aprendizaje de Sergi a una } \\
\text { serie de ítems o elementos concretos }\end{array}$ \\
\hline 3.2.3.3.4.4 Falta de sensibilidad & 10 & $\begin{array}{l}\text { Ciertos docentes muestran hacia Sergi y otros elementos del centro una } \\
\text { gran falta de sensibilidad hacia la diversidad funcional del alumnado }\end{array}$ \\
\hline 3.2.3.3.4.5 Ignorancia a Sergi & 22 & Manifestar ignorancia por Sergi y sus necesidades \\
\hline 3.2.3.3.4.6 Falta de implicación & 35 & $\begin{array}{l}\text { Falta de implicación profesional por parte de los docentes y profesionales } \\
\text { de la educación }\end{array}$ \\
\hline 3.2.3.3.4.7 Falta de formación & 24 & $\begin{array}{l}\text { Falta de formación de docentes en cuanto al autismo, TEL y otros } \\
\text { diagnósticos, así como el trabajo individualizado con ellos }\end{array}$ \\
\hline 3.3 Contexto familiar & 0 & \\
\hline 3.3.1 Composición familiar & 0 & $\begin{array}{l}\text { Miembros de la familia de Sergi y su relevancia con respecto a su } \\
\text { trayectoria vital }\end{array}$ \\
\hline 3.3.1.1 PADRES & 7 & El papel de los padres en la vida de Sergi \\
\hline 3.3.1.1.1 Madre & 12 & $\begin{array}{l}\text { Papel relevante de la madre como parte activa del proceso de lucha por } \\
\text { Sergi }\end{array}$ \\
\hline 3.3.1.1.1.1 Perseverante & 5 & $\begin{array}{l}\text { La perseverancia de la madre que ha permitido que Sergi pueda aprender } \\
\text { y evolucionar a nivel personal y académico }\end{array}$ \\
\hline
\end{tabular}


3.3.1.1.1.2 Referente

3.3.1.1.2 Padre

3.3.1.2 Abuelo

3.3.1.2.1 Vinculación y dedicación al ocio

3.3.1.3 Hermanos

3.3.1.3.1 Visibilización historia Sergi

3.3.1.3.2 Ocio y juego

3.3.2 Proceso familiar de adaptación

3.3.2.1 1 Llegada de Serg

3.3.2.2 2 Adaptación familia

3.32 .2 .1 Indicios autistas

3.3.2.2.2 Caos familiar

3.3.2.2.3 Diagnósticos

3.3.2.2.3.1 Impreciso

3.3.2.2.3.2 Falta de profesionalidad

3.3.2.2.4 Desconcierto inicial

3.3.2.2.5 2.1. Proceso crecimiento en familia

3.3.2.2.5.1 Frustración

3.3.2.2.5.2 Sufrimiento

3.3.2.2.5.3 Actividades familiares

3.3.2.2.5.4 Superación de barreras cotidianas
Los padres de Sergi se convierten en un referente para otros padres (apoyo, ayuda, consejos,...)

Papel del padre de Sergi en su trayectoria vital

Papel del abuelo en la trayectoria vital de Serg

Vínculo y dedicación especial entre Sergi y su abuelo, así como la dedicación absoluta de éste en cuanto a elementos de ocio.

13 Tipo de relación y juegos que Sergi compartía con los hermanos en cas Calado de la historia de vida de Sergi y cómo su hermano la lleva a un concurso de redacción para la visibilización de esta

Posibilidades y oportunidades de ocio y juego compartido entre Sergi y sus hermanos tanto dentro como fuera del contexto familiar

Proceso familiar de adaptación a las nuevas circunstancias familiares debido al TEA

$3 \quad$ Situación y costumbres de la familia cuando Sergi llegó a sus vidas. Proceso de adaptación a un nuevo hijo.

Proceso por el cual Sergi se adaptó a la familia y la familia se adaptó a él

Ciertos indicios que hacen pensar que tal vez Sergi tenga algún problema de tipo comunicativo antes de que fuera diagnosticado. Previo a la aceptación.

$4 \quad$ Estado de caos general en la familia debido a la falta de información y no saber qué le ocurría a Sergi y cómo actuar y trabajar con él

Diagnósticos en lo que se intentaba a perfilar y categorizar una etiqueta en la encajara Sergi

2 Existe una gran ambigüedad diagnóstica en cuanto al tipo de trastorno que tiene Sergi

Profesionales del campo de la educación y la psicología que en proceso diagnóstico carecían de profesionalidad y que no resultaron positivos para la familia y para Sergi en particular

Proceso de confusión sobre la situación al empezar a obtener información pero no saber bien como encajarla.

La familia, con las nuevas circunstancias, necesita adaptarse para seguir adelante y lucha constantemente contra adversidades y dificultades Sentimiento de frustración de la madre en cuanto a la situación de Sergi Sensación de sufrimiento de los miembros de la familia debido a la situación de Sergi y su futuro

13 La familia realiza actividades de ocio y familiares en las que Sergi participa como un miembro más de la familia

La familia ha tenido que ir superando poco a poco las barreras con las que se encontraba Sergi en su día a día 
3.3.3 Apoyo y ayudas familiares

3.3.3.1 Resistencia familiar

3.3.3.2 Toma de riendas

3.3.3.3 Lucha por los derechos

3.3.3.4 Apoyos y ayudas hermanos

3.3.3.4.1 Modelo social

3.3.3.4.2 Estímulo de interacción

3.3.3.4.3 Protección/supervisión

3.4 Ámbito personal

3.4.1 Relación con Sergi

3.4.1.1 Conexión

3.4.1.2 Aprendizaje a partir de Sergi

.4.2 Necesidades

3.4.2.1 Más tiempo

3.4.2.2 Ser como los demás

3.4.2.3 Comprensión del mundo

3.4.2.4 Búsqueda de soledad

3.4.3 Capacidades

3.4.3.1 Rápido aprendizaje

3.4.3.2 Capacidad de superación

3.4.3.3 Capacidad de sorprender

3.4.3.4 Capacidad de trabajo
16 tros y como elemento de ayuda y apoyo incondicional

Papel y función de los diferentes miembros de la familia de Sergi en su vida

Proceso por el cual la madre decide tomar las riendas de la educación de su hijo

2 La familia se mantiene firme a la lucha por los derechos de Sergi y su cumplimento

$0 \quad$ Conjunto de apoyos y ayudas brindados exclusivamente por los hermanos derivado de la relación entre iguales

16 El hermano mayor como un modelo a seguir y a admirar por Sergi

11 La relación con los hermanos es un estímulo de interacción y crecimiento personal para Sergi

Los hermanos, especialmente el mayor, actúa como protector de Sergi en diversos contextos

0

Efectos de la relación con Sergi como persona

Cuando hay un interés y una implicación hacia Sergi, las personas hablan de 'conexión' con él

6 Sergi es una persona de la que se suele aprender mucho y desarrollas ciertas capacidades que de otra forma no sería posible

$0 \quad$ Al margen de sus características Sergi mostraba ciertas necesidades personales que requería cumplir

La influencia del tiempo en Sergi y sus efectos negativos

Deseos y manifestaciones de Sergi de ser y actuar como el resto de sus compañeros

$9 \quad$ Entre sus necesidades personales se encuentra la de conocer el mundo como estrategia para poder formar parte del mismo

Necesidad de Sergi por encontrar momentos y espacios en los que estar solo

$0 \quad$ Conjunto de capacidades propias de Sergi

5 Sergi es una persona que una vez entiende aquello que se le quiere trasmitir lo asimila rápidamente

21 Sergi es una persona que supera aquello que se espera de él y llega a éxitos sobre lo que nunca se había esperado

$21 \quad$ Capacidad de Sergi de sorprender a familiares y personas cercanas al

reaccionar de manera sorprendentemente positiva ante una determinada situación

Capacidad de Sergi para trabajar y estar un gran número de horas 


\begin{tabular}{|c|c|c|}
\hline & & trabajando \\
\hline 3.4.3.5 Adaptación al cambio & 20 & Facilidad de adaptación al cambio y a situaciones o personas novedosas \\
\hline 3.4.3.6 Capacidad de memoria & 5 & $\begin{array}{l}\text { Gran capacidad de Sergi de retener acontecimientos, momentos y } \\
\text { recuerdos del pasado }\end{array}$ \\
\hline 3.4.4 Características personales & 0 & $\begin{array}{l}\text { Aspectos y/o peculiaridades propios de Sergi que en su conjunto lo } \\
\text { definen como persona y como ser social en relación con su contexto. }\end{array}$ \\
\hline 3.4.4.1 Hipersensibilidad & 3 & Sergi es una persona muy audaz en cuanto al sentido del oído \\
\hline 3.4.4.2 Reservado & 2 & $\begin{array}{l}\text { Sergi es interpretado como una persona reservada en ciertos aspectos de } \\
\text { su vida }\end{array}$ \\
\hline 3.4.4.3 Originalidad & 6 & Sergi muestra ser una persona muy original en todo lo que hace \\
\hline 3.4.4.4 Carácter & 2 & $\begin{array}{l}\text { Sergi es una persona que tiene y demuestra su carácter en ciertas } \\
\text { ocasiones }\end{array}$ \\
\hline 3.4.4.5 Comunicativo & 1 & $\begin{array}{l}\text { Sergi es una persona que, a pesar de sus limitaciones, siempre ha } \\
\text { demostrado una intención comunicativa potente }\end{array}$ \\
\hline 3.4.4.6 Autoestima & 1 & Sergi destaca por ser una persona con una gran autoestima \\
\hline 3.4.4.7 Disciplinado & 6 & $\begin{array}{l}\text { Sergi es considerado un niño muy disciplinado al que le cuesta mucho } \\
\text { saltarse las reglas }\end{array}$ \\
\hline 3.4.4.8 Agradecido & 3 & $\begin{array}{l}\text { Sergi es una persona muy agradecido con los suyos y especialmente con } \\
\text { aquellos que le ayudan }\end{array}$ \\
\hline 3.4.4.9 Cariñoso & 17 & $\begin{array}{l}\text { Sergi es una persona que demuestra el cariño a sus seres queridos con } \\
\text { abrazos y con mimos }\end{array}$ \\
\hline 3.4.4.10 Autonomía & 13 & Sergi desarrolla autonomía personal \\
\hline 3.4.4.11 Voluntad & 9 & La voluntad como característica de Sergi que hace fácil el trabajo con él \\
\hline 3.4.4.12 Pedir ayuda & 5 & $\begin{array}{l}\text { Facilidad de Sergi para pedir ayuda ante situaciones que no puede } \\
\text { resolver solo }\end{array}$ \\
\hline 3.4.4.13 Intereses restringidos & 4 & $\begin{array}{l}\text { Sergi presenta intereses restringidos en cuanto a aquello de lo que le } \\
\text { gusta hablar, en qué participar,... }\end{array}$ \\
\hline 3.4.4.14 Felicidad & 12 & Sergi desprende felicidad y alegría en aquello que hace \\
\hline 3.4.4.15 Simpatía & 3 & Alegría, sonrisas y actitud positiva hacia distintos elementos \\
\hline 3.4.4.16 Bondad & 4 & Actitud buena hacia elementos externos \\
\hline 3.4.4.17 Pulcritud & 6 & Pulcritud en sus actos y relaciones \\
\hline 3.5 Contexto social (ocio) & 0 & \\
\hline 3.5.1 Vertiente social & 0 & Desarrollo social de Sergi en diversos entornos y contextos \\
\hline 3.5.1.1 Relaciones sociales & 0 & $\begin{array}{l}\text { Elementos relativos a las relaciones sociales de Sergi dentro del centro } \\
\text { escolar }\end{array}$ \\
\hline 3.5.1.1.1 Concepto de amistad & 5 & Concepto de amistad propio de Sergi (cómo entiende él la amistad) \\
\hline 3.5.1.1.1.1 Dificultades de abstracción & 2 & $\begin{array}{l}\text { En cuanto a la amistad, lo que significa, lo que acarrea,... Sergi presenta } \\
\text { dificultades }\end{array}$ \\
\hline
\end{tabular}


3.5.1.1.2 Resistencia a la apertura

3.5.1.1.3 Delimitadas

3.5.1.1.4 Satisfactorias

3.5.1.1.5 Escasez

3.5.1.1.6 Superficialidad

3.5.1.2 Ayudas sociales

\begin{tabular}{l} 
3.5.1.2.1 Arte \\
\hline 3.5.1.2.1.1 Escuela de Arte \\
3.5.1.2.1.1.1 Inicio escuela de arte \\
3.5.1.2.1.1.2 Creaciones artísticas \\
\hline 3.5.1.2.1.2 Actividades artísticas
\end{tabular}

3.5.1.2.1.2 Actividades artísticas

3.5.1.2.1.2.1 Figuras de arena

3.5.1.2.1.2.2 Sombras chinas

3.5.1.2.1.3 Efectos del arte

3.5.1.21.3.1 Distanciamiento social

3.5.1.2.1.3.2 Expresión

3.5.1.2.1.3.3 Relajación

3.5.1.2.1.3.4 Libertad

3.5.1.2.1.4 Habilidades artísticas

3.5.1.2.1.4.1 Tecnicidad

3.5.1.2.1.4.2 Imaginativo

3.5.1.2.1.4.3 Inteligencia espacial

3.5.1.2.1.4.4 Creatividad artística

3.5.1.2.1.4.5 Detalle artístico
Sergi es una persona que se resiste a abrirse a cualquier persona que se le acerque, pero cuando te considera de su círculo se abre totalmente y se entrega

2

4

Sergi tiene delimitadas qué personas son amigas y qué personas no Las relaciones sociales para Sergi, a pesar de las dificultades que le acarrean, le resultan satisfactorias generalmente

3 Relaciones sociales con pocas personas, aquellos que lo conocen y entienden

(as relaciones sociales carecen de profundidad, es decir, se establecen siempre en base a elementos externos

Sergi cuenta con ciertas ayudas de su contexto social para poder participar activamente en la sociedad

Parte artística de Sergi y el proceso de desarrollo de la misma

Participación de Sergi en el arte, concretamente en la Escuela de Arte

Inicios de Sergi en la escuela de arte como alumno

Recopilación de creaciones artísticas elaboradas por Sergi

Conjunto de actividades de artísticas que Sergi realiza y que le ayudan a desarrollarse

$4 \quad$ Sergi posee una gran capacidad para construir en la arena de la playa figuras de arena

Capacidad de Sergi de realizar sombras chinas y satisfacción al obtener reconocimiento

Beneficios que el arte le aporta a nivel personal, académico y profesional

a Sergi

relaciones sociales y amistades no le interesan.

El arte permite que Sergi se exprese a su manera, donde apenas hay reglas o normas de expresión

El arte consigue relajar a Sergi y que sienta el control de aquello que hace Sergi experimenta el sentimiento de libertad a través del arte

Sergi demuestra grandes habilidades artísticas

El arte requiere de tecnicismos para poder realizar creaciones

Habilidad de Sergi de ser imaginativo en sus trabajos

Capacidad artística de Sergi de utilizar la inteligencia espacial en sus trabajos

18 Sergi plantea siempre en sus trabajos una perspectiva diferente artísticamente hablando que, por lo general, es diferente a la planteada por la mayoría

10 Sergi manifiesta en sus dibujos y sus creaciones un nivel elevado de 


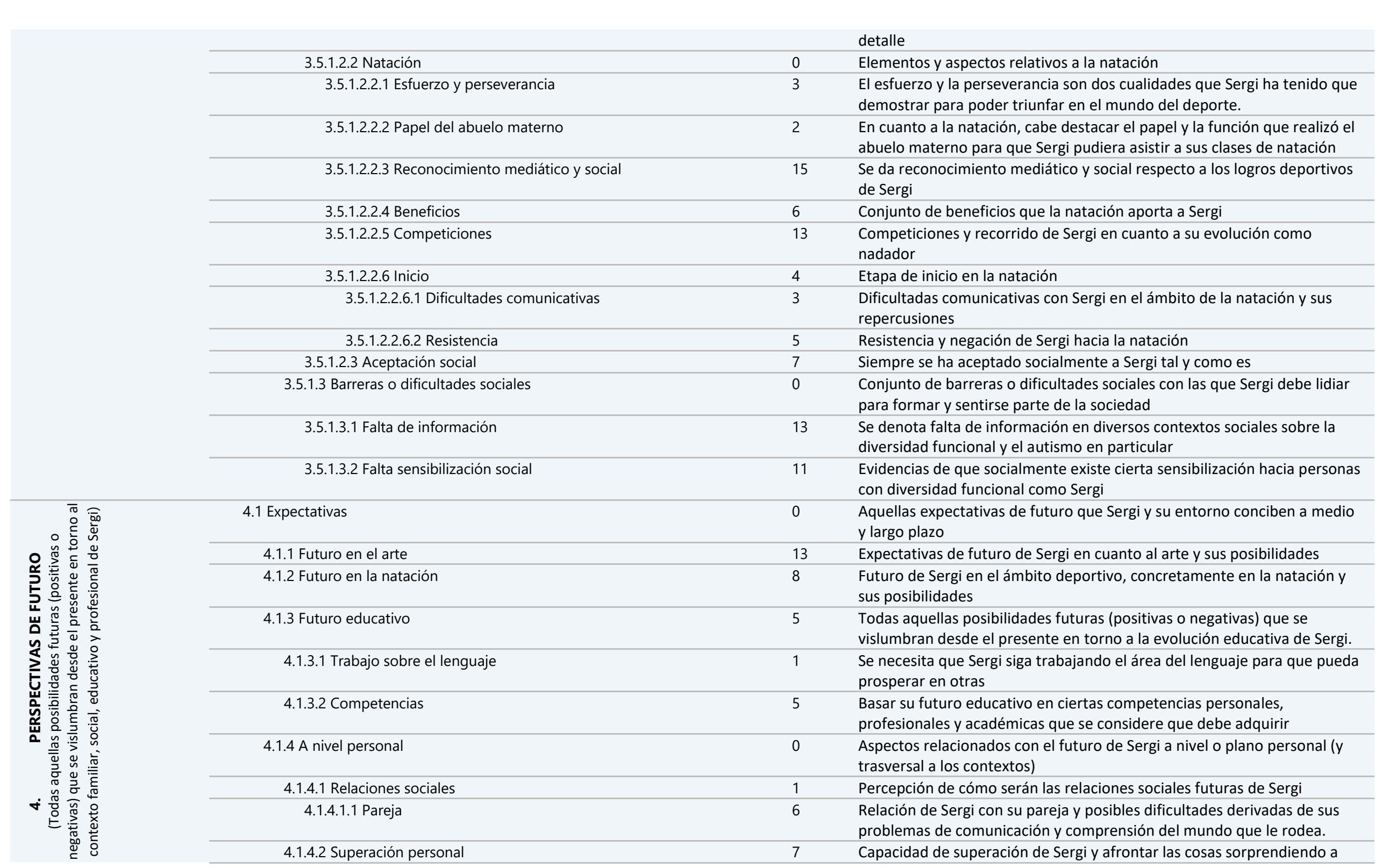




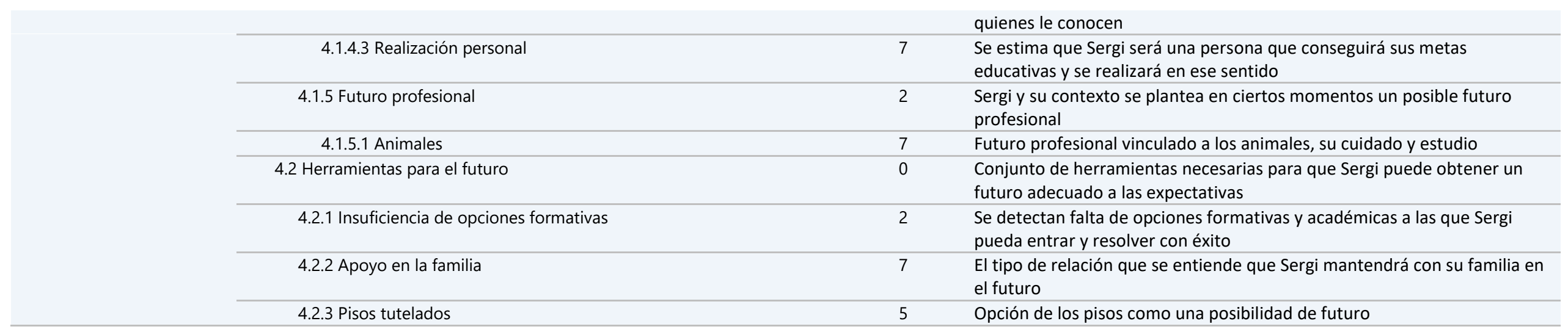

Tabla 20. Libro de categorías y códigos 
Como podemos observar, la tabla 20, se presenta una estructura aparentemente jerárquica, pues una tabla que recoja esta información no permite al investigador vislumbrar las interconexiones y red de relaciones entre los diferentes elementos. No obstante, y con la finalidad de superar esta carencia de la tabla, en el siguiente apartado se presenta un mapa temático con las diferentes categorías y códigos y las relaciones establecidas entre ellas.

\subsubsection{Mapa temático y relacional}

En este mapa temático y relacional de categorías y códigos se observan los conjuntos y subconjuntos de las categorías y códigos, además de las relaciones y nexos entre unos y otros. 

MAPA 2 

En este mapa de categorías y códigos, se reflejan los componentes del 'libro de categorías y códigos' ramificados y organizados en categorías, códigos y subcódigos. Entre los diferentes elementos del mapa, encontramos un nexo, una palabra clave o conjunción que nos ayuda a entender la relación entre los elementos. Así mismo, podemos observar unas líneas discontinuas rojas que marcan y orientan las relaciones entre las diferentes categorías y códigos. En su conjunto, todos estos elementos componen un mapa temático que organiza y relaciona los resultados del análisis. Este mapa de categorías y códigos, junto con el resto de resultados expuestos a continuación, orientaran la organización de datos y construcción de la historia de vida de Sergi.

\subsubsection{Línea de vida de Sergi}

Tras exponer el mapa temático del análisis, es necesario visibilizar ahora cómo se encadenan estos elementos el paso tiempo, en un eje cronológico. Para ello, y teniendo en cuenta toda la información recogida, se elaboró con la madre de Sergi la línea de vida de nuestro protagonista. Mediante este instrumento, se recogieron y situaron en una línea del tiempo las personas, circunstancias y acontecimientos más significativos en la trayectoria vital de Sergi. Así mismo, esto se relacionó con la progresión y evolución personal y académica de Sergi. La composición final es un gráfico en el que se recogen la evolución y desarrollo que Sergi ha experimentado (tanto en positivo como en negativo), las personas más influyentes en su desarrollo y los acontecimientos y sucesos más relevantes. Para poder interpretar con mayor facilidad esta línea de vida, es necesario tener en cuenta la siguiente leyenda:

\footnotetext{
- Personas: $\downarrow$

- Acontecimientos: $\star$

- Progreso de Sergi: $\star$
} 


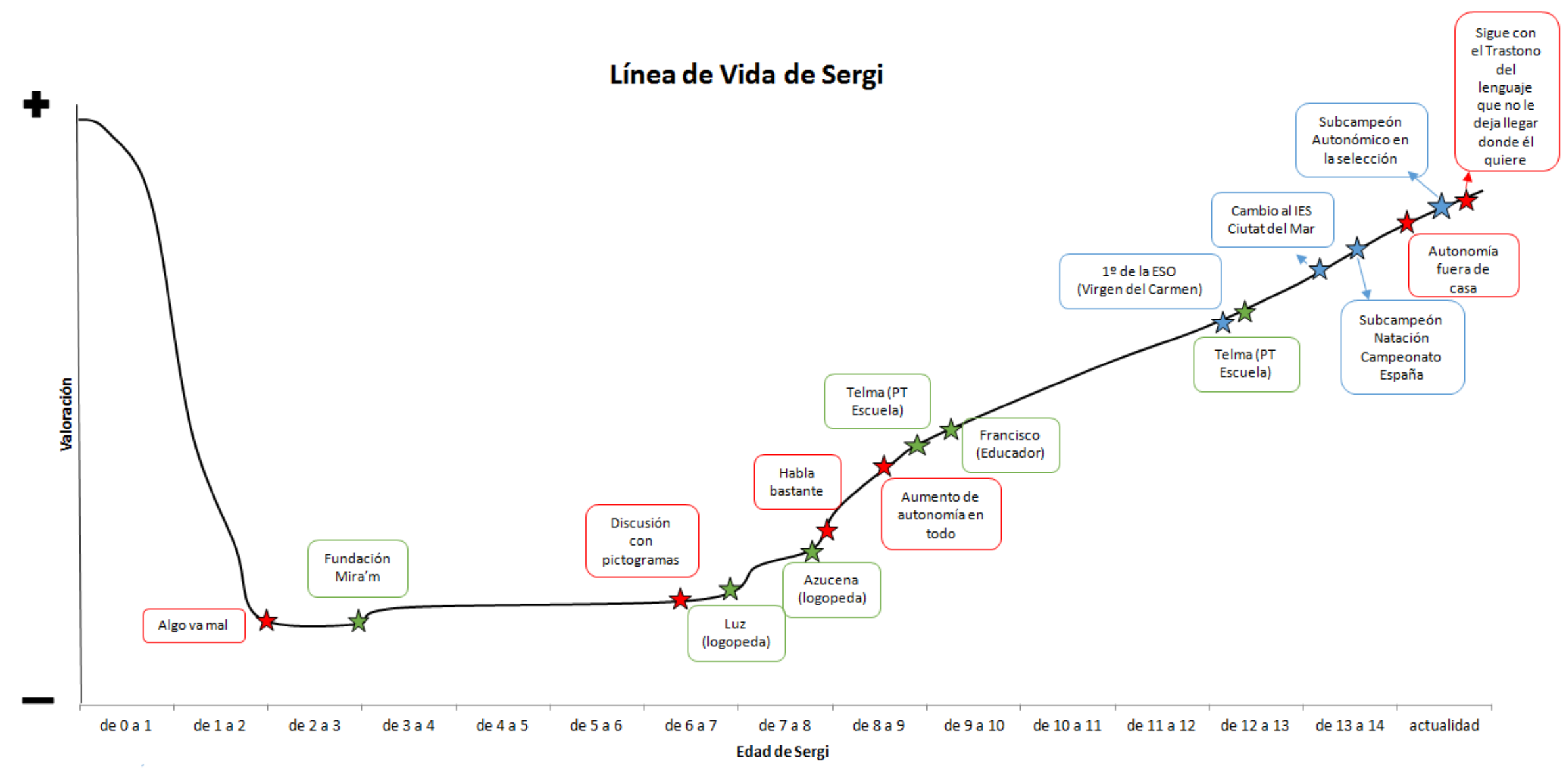

Gráfico 2. Línea de Vida de Sergi. 


\subsubsection{Diagrama de personas en la vida de Sergi}

Como hemos podido observar en los resultados expuestos anteriormente, las personas del entorno de Sergi y su influencia sobre él son elementos altamente destacados. En el mapa temático, ya se observaba un apartado muy completo sobre las personas que inciden en cada uno de los contextos de la vida de Sergi. Sin embargo, como en cualquier otra historia, las personas no son eternas, sino que algunas de ellas llegan y más tarde se van, otras permanecen al lado de Sergi durante mucho tiempo y poco a poco se difumina su presencia y, en cambio, unas pocas permanecen a su lado desde su nacimiento y hasta el día de hoy.

Para poder entender y comprender la trayectoria vital y desarrollo vital de Sergi, es importante reconocer las personas que le han acompañado en este proceso desde diferentes localizaciones. No obstante, la complejidad de las relaciones y contextos hace difícil esta tarea para el lector, pues el entramado de relaciones, llegadas y salidas resulta muy complejo. Con la finalidad de arrojar un poco de luz sobre este aspecto, se ha reconstruido y elaborado un diagrama cronológico sobre las diferentes personas que participan y acompañan a Sergi en su evolución y desarrollo personal según el ámbito de su vida al que pertenecen. 


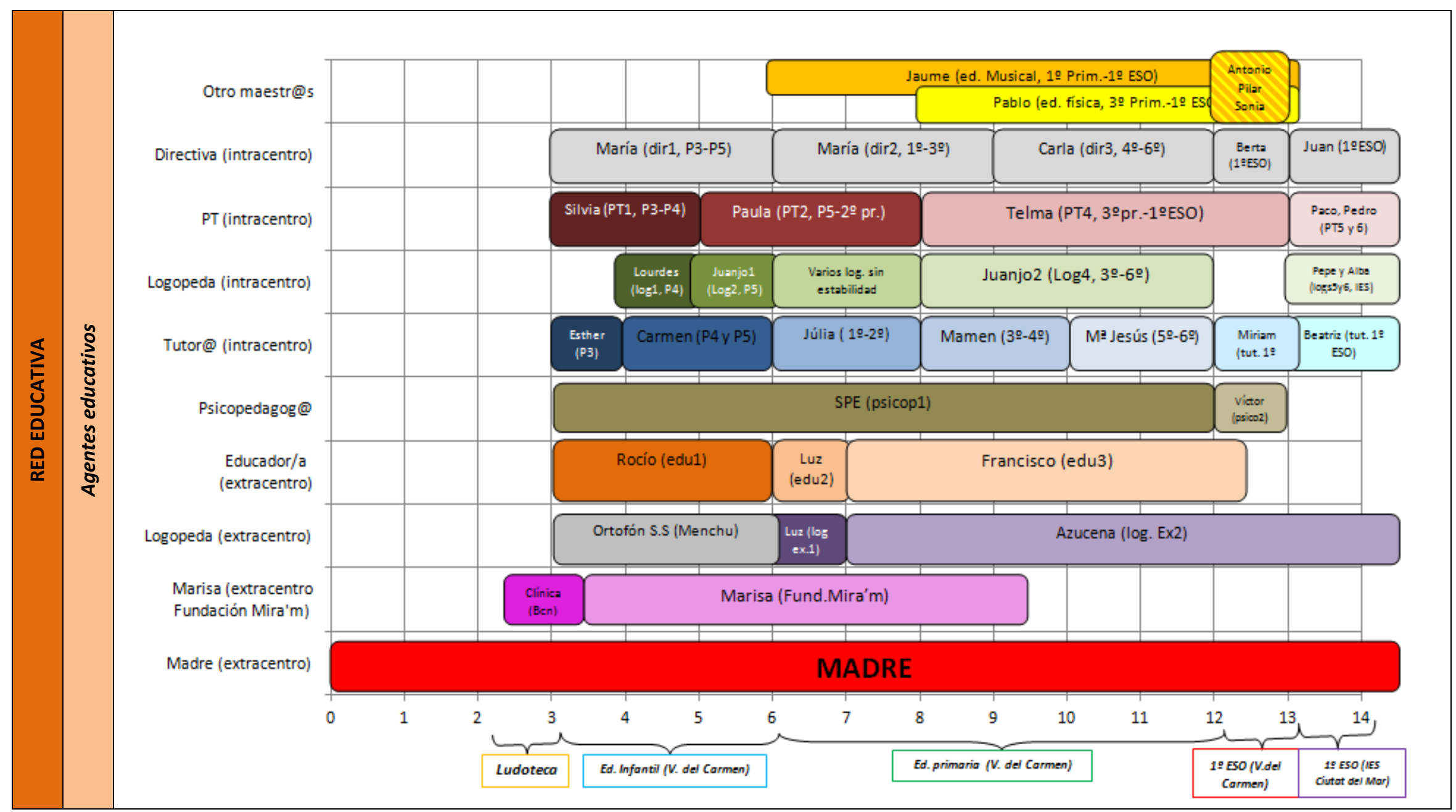




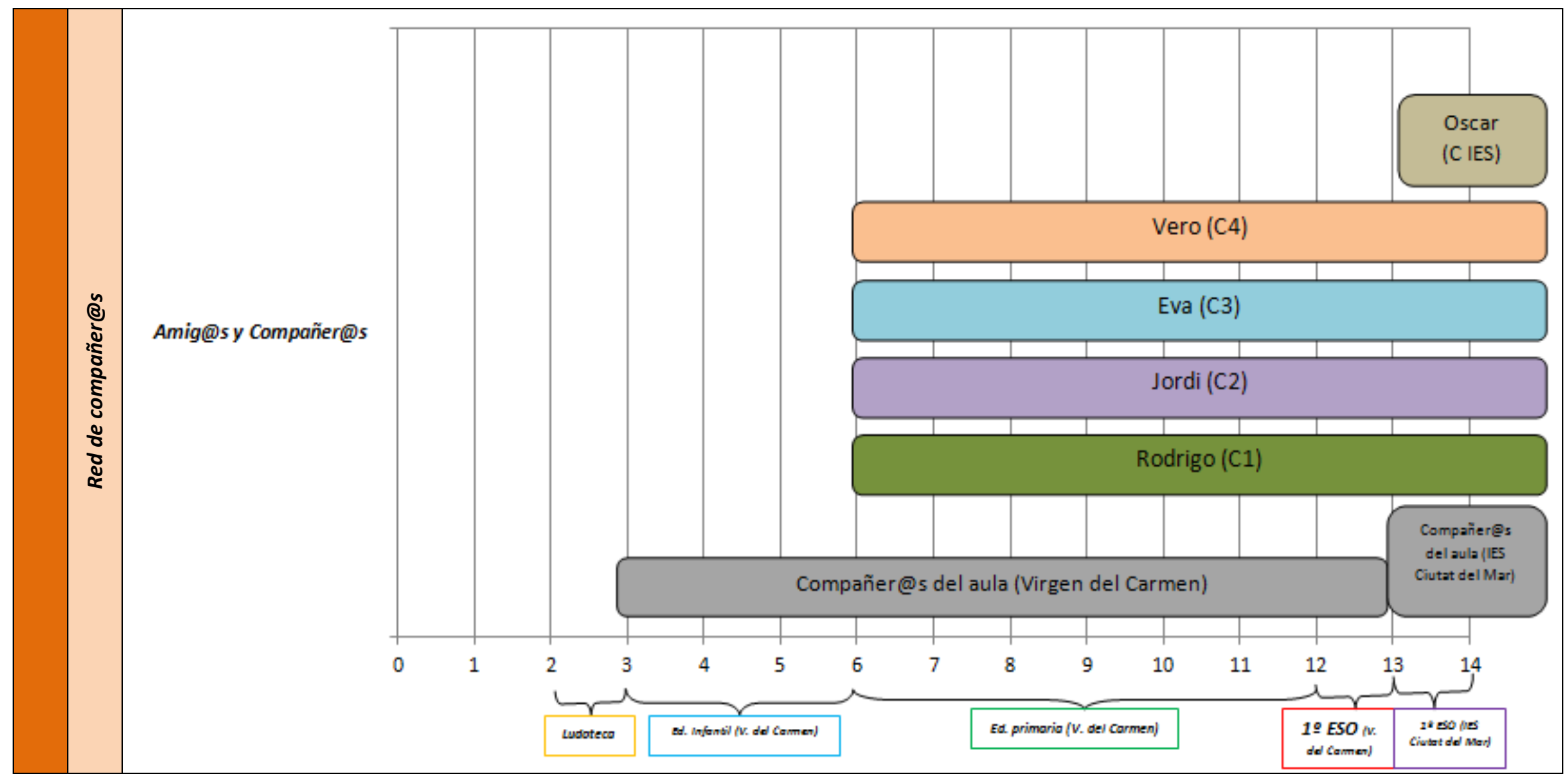




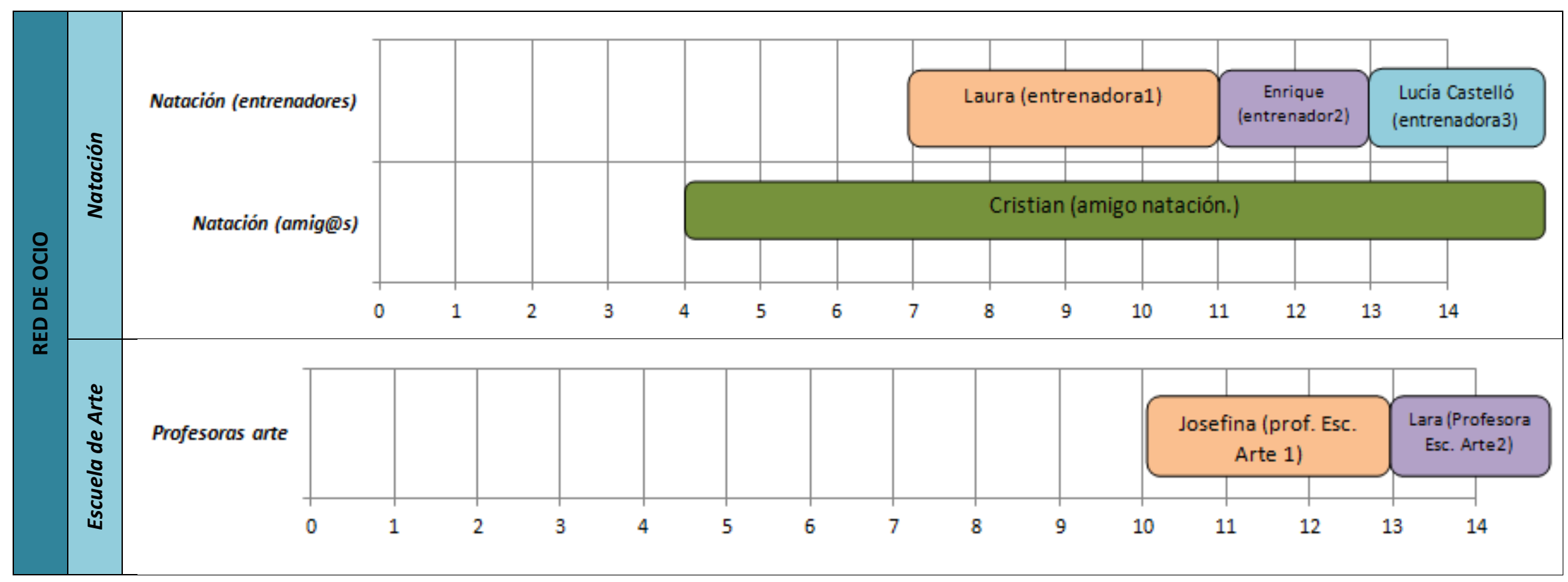




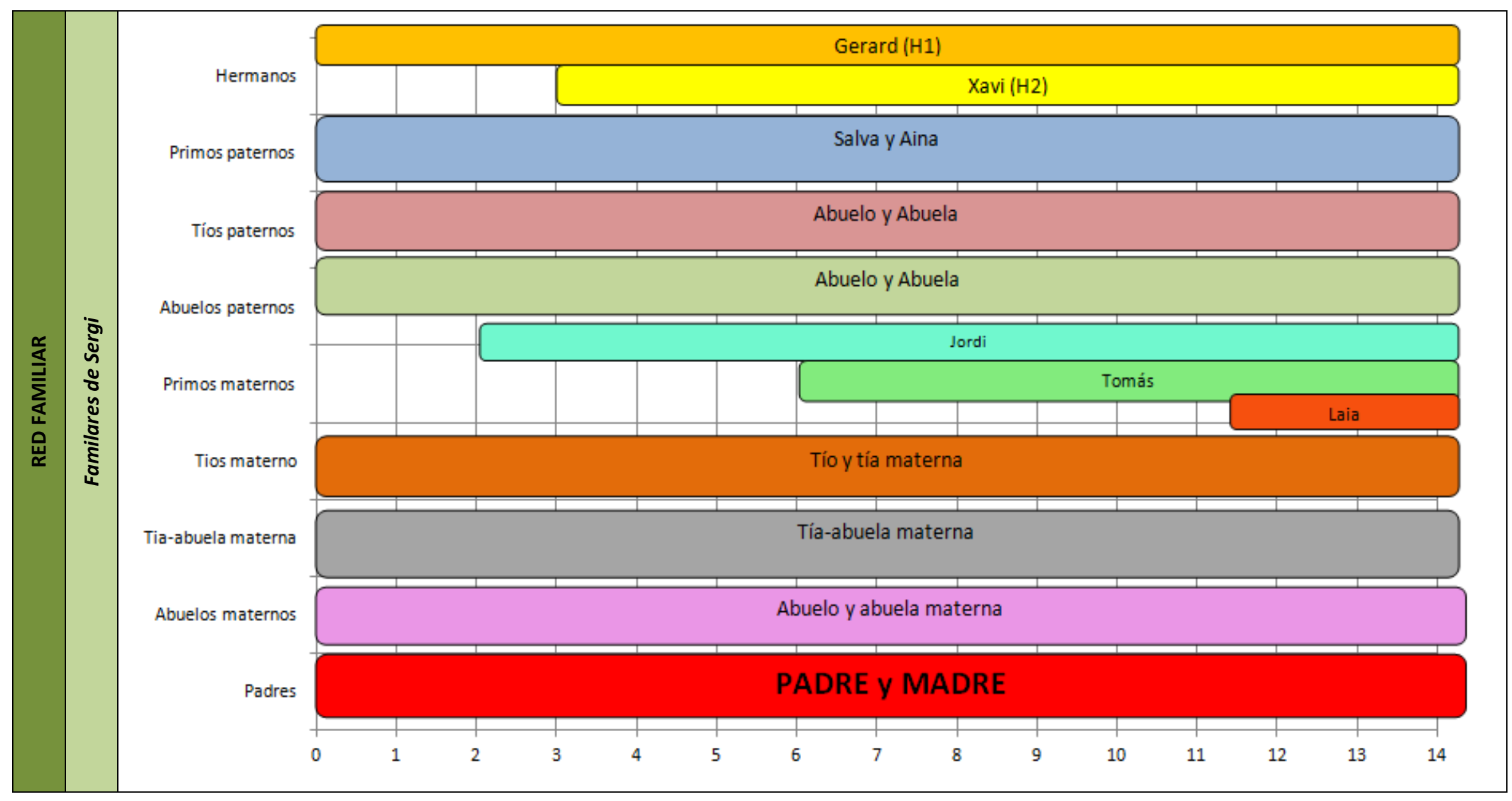

Gráfico 3. Diagrama de personas en la trayectoria de vida de Sergi 


\subsection{Resultados Fase II: La historia de vida de Sergi}

En esta segunda fase de los resultados se recoge la historia de vida de Sergi como el último de los resultados, no sin antes hacer un breve repaso sobre el proceso de construcción de la misma.

\subsubsection{Proceso de construcción de la historia de vida}

En el momento en que se inició el proceso de construcción de la historia de vida de Sergi, arrancó un momento profundo y solitario de elaboración y confección hasta lograr que las piezas de este complejo 'puzle' empezaran a encajar. La historia de vida de Sergi se construyó en base a la cronología vital de nuestro protagonista (desde que nació hasta los 15 años), a la vez que se iban describiendo los diferentes contextos y ámbitos de su vida en los que los participantes iban apareciendo en escena.

Tal y como ya se abordó en el capítulo 3 de este trabajo, según Pujadas (1992) existen múltiples formas de presentación de una historia de vida. En nuestro caso, hemos elegido el relato biográfico de tipo cruzado para construir la historia de vida de Sergi.

Como sabemos, una de las premisas del método biográfico-narrativo es el respeto a la voz de cada participante a través de su reconocimiento preservando su esencia. Esta tarea, resulta fundamental pero, a su vez, se torna compleja cuando nos aventuramos en un relato de tipo cruzado. Por esta razón, ha sido necesario realizar ciertas modificaciones en las aportaciones de los participantes para garantizar la legibilidad de la propia historia pero sin alterar la intencionalidad de cada participante. Para ello, se han realizado tan solo cambios considerados necesarios pero siempre revisando el contexto de las aportaciones y señalando cada modificación mediante el subrayado. Así mismo, para asegurar la fidelidad y neutralidad de estos cambios, la coinvestigadora de este trabajo (y madre de Sergi) revisó personalmente todas las modificaciones realizadas.

Al iniciar la lectura de la historia de vida de Sergi encontraremos, en primer lugar, una narración escrita por Gerard (H1), el hermano de Sergi. Este texto procede de manera casi íntegra de una redacción que Gerard elaboró para un concurso literario nacional. En dicho concurso, reunieron a alumnos seleccionados de diferentes centros y les pidieron que elaboraran, a partir de una imagen concreta, una redacción. La imagen y el texto elaborado por Gerard (H1) son utilizados en este capítulo como antesala a la propia historia de Sergi. Como se podrá comprobar, en dicho texto Gerard (que entonces tenía 13 años) consigue captar y sintetizar en escasas líneas la esencia de la historia de vida de su hermano. Este texto precede a la historia de vida de Sergi redactada y trabajada en forma de relatos cruzados por la investigadora principal.

Seguidamente encontraremos el texto de la historia narrado por la investigadora en $1^{\text {a }}$ persona. En él, podremos identificar mediante la cursiva las aportaciones de los participantes de la investigación. Asimismo, con la finalidad de que el lector pueda rastrear la procedencia de estas aportaciones, se indicará entre paréntesis las siglas del instrumento del que procede cada cita junto con el número de párrafo de donde se ha extraído la información (Todos estos instrumentos se podrán encontrar ordenados en el anexo IX). Veamos un ejemplo de ello: 
El profesor de pedagogía terapéutica, explica su postura sobre este asunto de la siguiente manera: el tema ha sido que no es solo Sergi, es Sergi, es el aula y es un poco el instituto entero. Entonces Sergi es una lección de vida. Es así de claro. (ET PT IES, 19)

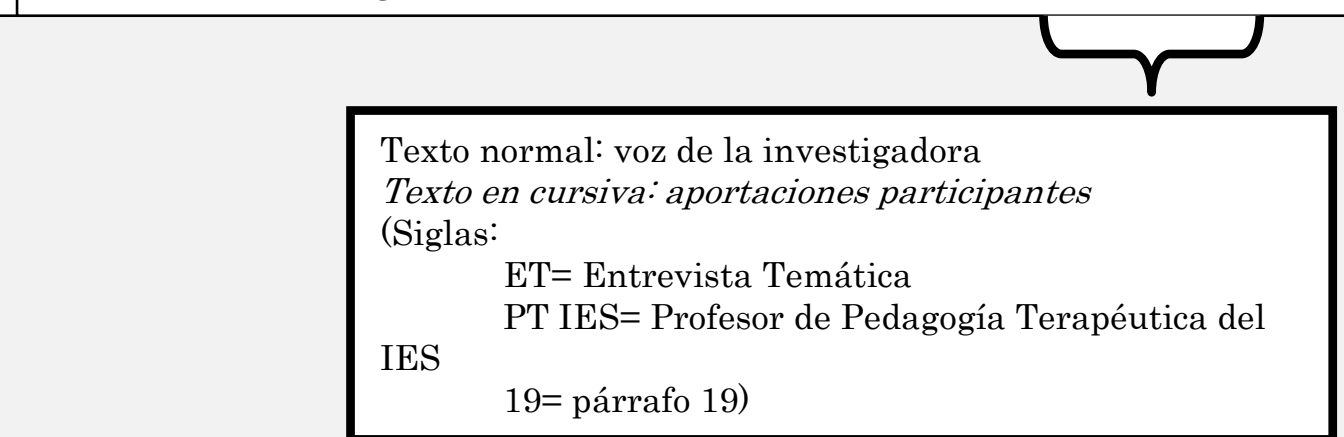

Figura 24. Ejemplo de texto de la historia de vida

Así mismo, se podrán encontrar ciertas imágenes intercaladas en el texto. Éstas provienen de la recogida de datos y fueron aportadas por los participantes. En cada imagen se podrá reconocer la procedencia de la misma y dónde localizarla en el anexo IX (técnica fotográfica (TF), técnica documento escrito (TDE) o técnica gráfica (TG)). Una última consideración sobre esta narración son las pequeñas imágenes que se encuentran en el margen del texto. Estas fueron elaboradas por Sergi y simbolizan a cada uno de los participantes de la investigación. Estas pequeñas ilustraciones pretender ser una rápida identificación de quiénes y con qué frecuencia hacen sus aportaciones a lo largo de la historia de vida además de visibilizar cómo son estas personas a través de los ojos de Sergi. 

estructura:

La narración de la historia de vida de Sergi presenta la siguiente

\section{PRIMERA PARTE}

1. Una pequeña aproximación a quién es Sergi:

1.1. La distancia impide abrazos, no sentimientos...

1.2. El secreto del éxito es la constancia en el propósito (Benjamin Disraeli)

SEGUNDA PARTE

2. La historia de vida de Sergi: empezar desde cero...

2.1. El diagnóstico, la enfermedad que más prolifera (Karl Kraus)

2.2. Yo puedo perder el tiempo, pero Sergi no (Àngels (M))

3. Nuevos retos...

3.1. Una imagen vale más que mil palabras

3.2. Si quieres llegar rápido camina solo, si quieres llegar lejos camina en grupo (proverbio africano)

3.3. Si el plan no funciona cambia el plan, pero no cambies la meta

3.4. El $90 \%$ del éxito se basa simplemente en insistir (Woody Allen)

3.5. No hay mejor educador que el que cree en sus alumnos (Joel Artigas)

4. Un día en la vida de...

4.1. En la natación, como en la vida no puedes ponerte límites, cuando más sueñes, más lejos llegarás (Michael Phelps)

4.2. La creatividad es la inteligencia divirtiéndose

5. No cambié, solo aprendí, y aprender no es cambiar, ES CRECER.

5.1. El salto al vacío... transición a la educación secundaria

5.2. El abandono escolar de los docentes... ¿̇es posible?

5.3. Arrinconamiento + abandono $=$ exclusión

5.4. Tensiones... el corporativismo como ideología

5.5. Entonces, estamos hablando de injusticia educativa, ¿no?

6. Quedarse en lo conocido por miedo a lo desconocido, equivale a mantenerse con vida pero no vivir (Anónimo)

6.1. No llores Lidia, estaré bien (Sergi (S))

6.2. El sabor agridulce del paso por la escuela

7. Reempezar... una excelente manera de crecer.

7.1. Instituto- Familia... simbiosis correspondida

7.2. Planificación y planteamiento pedagógico... ejes fundamentales para la inclusión

7.3. Tejiendo redes para la participación: un medio para la inclusión

7.4. Sergi a día de hoy...

7.5. La única discapacidad en la vida es una mala actitud (Scott Hamilton)

TERCERA PARTE

8. Te estoy tejiendo un par de alas, sé que te irás cuando termine, pero no soporto verte sin volar (Andrés Casturera-Micher)

8.1. El hándicap del lenguaje

8.2. De mayor quiero ser artista, cuidador de zoo y deportista. Voy a ser todo... (Sergi (S))

Tabla 21. Estructura de la historia de vida de Sergi 


\subsubsection{Historia de vida de Sergi}

Texto introductorio:

Cuando era pequeño deseaba continuamente poder tener un hermano al que pudiera contar mis secretos, jugar con él, protegerle... Pasado un tiempo mi madre dio a luz a un precioso bebé que llamamos Sergi. Me alegré muchísimo, ya que él era para mí toda la felicidad que necesitaba encarnada en un niño.

Con el tiempo fue creciendo y nos dimos cuenta que no era un niño normal. Sergi no pronunciaba bien las pocas palabras que conocía, tenía la mirada pérdida, como si estuviera en otro mundo. Al principio fue duro, mis padres fueron de médico en médico hasta que nos pudieron afirmar que Sergi era autista. Para mí fue muy delicado ver como mi hermano intentaba explicarnos lo que le rondaba por su mente y que solo pudiéramos escuchar palabras sin sentido saliendo de sus labios mientras mis padres lloraban a su lado abrazándolo con firmeza.

Con los años, Sergi mejoraba poco a poco mientras nosotros lo queríamos y seguíamos intentándolo. Al cabo de un tiempo tuvimos un nuevo hermano al que Ilamamos Xavi. Cuando creció un poco se pasaban el día juntos y siempre pasaban el rato con juegos muy creativos que, sin saberlo, estimularon mucho a Sergi y pudimos observar una gran mejoría. Mi madre dejó de trabajar para dedicarse en cuerpo y alma a Sergi que al fin hablaba bastante bien. Le faltaba vocabulario pero solo era cuestión de tiempo.

La cara de mi familia cambió por completo, fue desapareciendo la impotencia de no poder entenderlo y empezó a conocer de nuevo lo que significaba sonreír. Sabíamos que Sergi nunca sería normal pero estábamos orgullosos de que pudiera contarnos lo que le pasaba en el colegio, lo que le dolía cuando estaba enfermo,... Pero no todo eran risas, aunque los niños de su clase lo apoyaban y lo querían mucho, siempre había algunos que se reían o simplemente se aprovechaban de su discapacidad. Nosotros les explicábamos su problema y se arrepentían al acto.

Ahora Sergi vive conmigo. Es muy inteligente y tiene mucha memoria fotográfica. Aún se acuerda de la habitación 316 del hotel de Port Aventura donde pasó su primera noche fuera de casa. Para mi ha sido muy

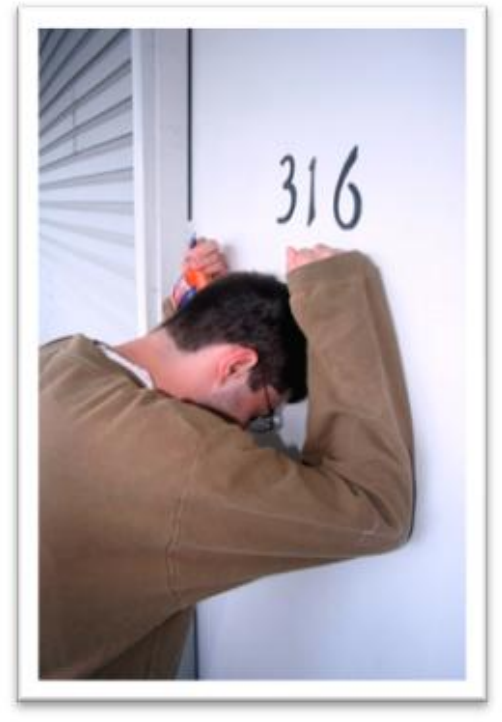

Enfermés dehors (Pfefferle, 2006) importante tener a Sergi en mi vida porque me ha enseñado el significado de la empatía y me encantaría que la gente conociera lo que es el autismo y convivir con ellos por lo especiales que son, te abre el corazón.

Gerard Castell (13 años). Junio de 2011. 
Así es como Gerard, hermano, protector y amigo de Sergi contaba la historia de lucha, resistencia y perseverancia de Sergi y su familia en un concurso literario. Para ello, Gerard se inspiró en una fotografía de Miles Pfefferle en la que aparecía un joven apoyado contra una puerta cerrada blanca con el número 316. El relato de Gerard, su inocencia, potencial y sencillez, tocaron el corazón de profesores y compañeros. Esta es solo una pequeña muestra para ir 'abriendo boca' sobre la historia de vida de Sergi. Y es que con esto pretendo trasmitir aquello que como investigadora y persona he sentido desde el primer día que inicié este trabajo: cuando uno se acerca a Sergi, a su familia y su historia, no queda impasible. Su forma de ser, su voluntad y su fortaleza hacen que uno se posicione firmemente y sienta el orgullo y la rabia de todo aquello vivido y logrado por Sergi.

\section{PRIMERA PARTE}

\section{1.- Una pequeña aproximación a quién es Sergi}

Sergi, un joven de 15 años diagnosticado con TEL y autismo, es una persona bien distinta a la que uno puede imaginar. Parece que la tendencia general es asociar autismo con palabras como 'rincón', 'silencio', 'falta de expresión' y, lo que es más triste para nuestra sociedad, 'falta de capacidad'. Pues bien, estamos ante una historia de esas que rompen estereotipos y lo hacen con mucha fuerza. Una de esas personas que cuando pasan por la vida de uno dejan un buen rastro de excepcionalidad, admiración y excelencia.

Aquellos que conocen bien a Sergi, aquellos que lo han visto crecer y evolucionar, destacan en él singularidades propias como la simpatía, la bondad y la felicidad que desprende. Su madre recuerda que desde bien pequeñito cuando alguien se acercaba a la cuna ya se reía, era muy bueno. Si lo dejabas ahí en la 'cunita' se quedaba quietecito, jugando con sus manitas, y en cuanto te acercabas enseguida se ponía contento (EPM1, 20). Era un amor de niño, se quería ir con todos, no tenía problemas, siempre riendo... (EPM1, 24)

De bien pequeñito, su madre rememora con cariño la felicidad que desprendía. Para ella era tranquilizador verle siempre tan feliz. Iba siempre contento al colegio, pues allí se sentía muy querido. Según ella, al llegar a casa tras trabajar un poco en sus quehaceres automáticamente se iba a mirar la tele y se ponía a reír, o se ponía a dibujar, a jugar, a montar lo que le gustaba. Siempre lo veía tan ocupado y tan feliz... Eso me daba satisfacción porque pensaba, sé que es un niño que siempre tendrá alguna ocupación en la vida, me tranquilizaba; porque si lo hubiera visto como otros casos que he conocido, que están allí en un rinconcito... piensas "jolín, iqué pena!" pero él no, era todo felicidad. Verlo jugar, verlo... ies que era tan feliz! (ETM1, 70).

Si te digo la verdad, no recuerdo haberme enfadado con él. Era un amor, de verdad. No puedo decir nada más que cosas bonitas, y es así. Era un niño muy agradecido, muy obediente,... cuando le decíamos que no tocara algo, sorprendentemente no lo tocaba. Ahora que lo pienso en la distancia, creo que a lo mejor es que ya era 'cuadriculado', porque le decías "no toques eso" y no lo tocaba (EPM1, 27). Con el paso del tiempo, y a pesar de sus dificultades, no limitó a la familia para nada. Yo creo que siempre encontramos gente buena, y como él era un niño que no era pegón, no tenía rabietas, se dejaba llevar... Al principio iba un poco a la suya, pero con mucho trabajo fue aprendiendo a saber estar. (EPM1, 58) 
A partir de una cierta edad, cuando empezaron los primero indicios del autismo, Sergi empezó a cerrarse en sí mismo. No miraba a la cara, le costaba mucho la interacción con otros, aunque esta fuera simplemente visual. Hubo que trabajar muy duro para que mirara, para que buscara la mirada del otro y, sobretodo, para que entendiera la interacción resultaría provechosa para él. Cuando esto fue superado con mucho esfuerzo y tesón, entró en juego un nivel de interacción superior: el contacto físico.

El abrazo hubo que trabajarlo con Sergi. Su madre, recuerda cómo en casa siempre fue muy cariñoso con su padre, con su madre y con sus hermanos, pero fuera de casa no. EI abrazo él lo daba con los brazos estirados y con el culo hacia atrás, evitando el contacto físico. Entonces cuando hacía algo bien le decíamos "un abrazo como los Teletubbies". Utilizábamos cosas así para que tolerara el contacto con otras personas. Le costaba consentir el contacto y los abrazos a las personas que no eran muy cercanas a él y les decía "¿por qué me tocas?", no lo entendía... (ETM3, 243). En ciertos momentos, incluso si tenía que abrazar o cogerse con su hermano lo hacía con el brazo estirado y sin tocar el cuerpo (TF H2, 28).

Con el tiempo y la constancia de los suyos, Sergi empezó a tolerar los abrazos y, para quienes le conocen, sus abrazos eran especiales como pocos. Su logopeda y amiga, observó cierta transformación en él en este sentido. Una reacción como pueda ser un abrazo de él significa muchísimo, a él le costaba mucho más que a cualquier otra persona. Creo que una de las cosas que más recuerdo con cariño es notar que él venía y me contaba cosas como amiga, cositas que me quería contar. Ahí sí hubo un cambio. Él empezó a contarme cosas, estaba cariñoso, empecé a notar que yo ya estaba formando parte de su vida, y él me lo estaba demostrando contándome cosas o abrazándome. Yo noté que él me había metido en su vida. (ET Log, 43)

Sin darnos cuenta, Sergi fue creciendo de una manera que, tal vez, nadie sabe muy bien cómo fue. El Sergi del principio era un Sergi distante, que prácticamente nunca miraba a los ojos, que tenías tú que dirigirle la mirada y el contacto ocular. Era difícil acercarse a él desde fuera su familia y era complicado cogerlo, abrazarlo,... Mi tendencia natural como educador era siempre abrazarlo y hacerle algún cariño o algún beso, y él siempre se limpiaba la mejilla tras el beso, le molestaba el contacto de mis labios con su piel. Hoy en día, el hecho de dejarse abrazar, aunque a veces él mismo con el gesto te dice que no, es increíble. Hoy en día se ha convertido en una persona muy, muy cercana no solo físicamente sino afectivamente, expresando sentimientos, emociones,... (ET Edu, 36-38).

Sergi, siempre ha sido una persona muy alegre y feliz, y esto lo ha trasladado a los distintos contextos y ámbitos de su vida. Su maestra, lo recuerda como un niño feliz que, aunque en cierta manera estaba en su mundo, dentro de su mundo era feliz. Un niño muy educado, siempre ha sido muy educado. Tenía sus prontos y sus arrebatos, pero cuando lo frenabas él sabía que había hecho las cosas mal. Siempre ha demostrado muchas ganas de aprender y, sobretodo, muy buen compañero, lo querían muchísimo en clase. (ET Maes, 33).

A pesar de sus dificultades de expresión y comprensión del mundo, era un niño muy espabilado, tal y como es ahora, espabilado. Era comunicativo, con su mirada y su expresión comunicaba mucho, no era un niño de estos que están encerrados en su mundo. Yo creo que sensible también... Era un niño muy espabilado, era un niño muy vivo (ET Log, 36)
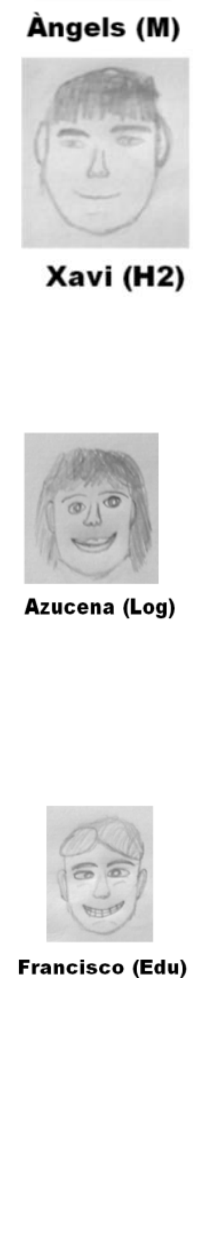

Xavi (H2)

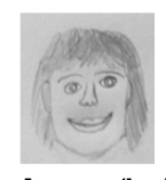

Azucena (Log)

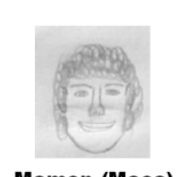

Mamen (Maes)

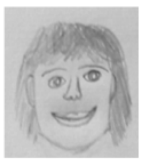

Azucena (Log) 
Entre sus virtudes, sus maestros destacan su bondad, las ganas de compartir, y la cosa que más sorprende de Sergi evidentemente es su pulcritud extrema. Todo en orden, lo tiene todo controlado (ET PT IES, 30). El profesor de pedagogía terapéutica recuerda con cariño la rotundidad y sinceridad en sus respuestas y explica que al poco de conocerlo le cogió sin preguntar un bolígrafo de su estuche. Sin pensarlo Sergi le interpeló: "¿Qué estás haciendo?" y yo le decía "Sergi, no te enfades", "qué yo no me enfado" (con voz seria). Tenías que habituarte a aquel tono de voz, a aquellas expresiones,... y bueno, al final te das cuenta que es una persona muy, muy entrañable, mucho. Muy bonita. (ET PT IES, 30).

Sus compañeros, lo consideran un estudiante perfecto, mucho mejor que cualquier otro (ET C IES, 64). Es más, la originalidad y naturalidad en todo lo que hace es un motivo de admiración por parte de sus amig@s y compañer@s de clase. Es una persona muy natural, con él nunca tienes la sensación de estar teniendo una conversación forzada. Cuando le interesa algo, le interesa de verdad (ETG CE, 280, Vero). Se refieren a él como un 'crack' en todo lo que hace. Su amigo Rodrigo, recuerda que una vez le regaló una figura de arcilla que era 'flipante', yo no sabría hacerlo. Creo que se expresa con sus manos mejor que hablando incluso. Esa capacidad de expresarse pintando y haciendo cosas con sus manos más que hablando es sorprendente (ETG CE, 709, Rodrigo) Su profesora de la escuela de arte, también aprecia estas características en Sergi y apunta que probablemente toda esa creatividad y la capacidad de tener puntos de vista totalmente originales procede precisamente de la poca influencia que recibe de los demás. Esto puede ser una ventaja en casi cualquier campo profesional o de estudio.(ET PEA, 67)

En general, Sergi se define a sí mismo como una persona bien educada, tranquila y 'poco enfadosa', solo si me molestan o si se portan mal, pero no me suelo enfadar. Me gusta ayudar a las personas y estar tranquilo (ET S, 24-30)

\section{1.- El secreto del éxito es la constancia en el propósito (Benjamin Disraeli)}

Sergi, siempre ha sido una persona constante, trabajadora, con muchas ganas de aprender y con un nivel de exigencia y autoexigencia bastante elevado. El profesor de Pedagogía Terapéutica destaca sobre todas sus características su constancia y plasticidad. Es un niño muy trabajado y, por lo tanto, es un 'caramelo en dulce' para una persona que trabaja en el ámbito de lo que son las necesidades educativas especiales. Él es una persona que por sU TEL sí que representa una serie limitaciones, pero se merece que haya caminos abiertos por los que poder transitar, y la sorpresa es que realmente transita, y tiene muchísimas ganas, es una personas con muchísimas ganas, con muchísima constancia, con muchísima voluntad y una persona que siempre está dispuesta a trabajar. Por lo tanto, si a eso le añadimos el que es una persona que está muy apoyada por el entorno llegamos a una situación que es idónea totalmente. (ET PT IES, 19). Sergi siempre intenta superarse a sí mismo y mejorar, pues como comentan sus compañeros cuando no llega al límite que él quiere se enfada porque él quería más, él quería tenerlo... Él quiere sacar todo lo bueno que él tiene dentro. Siempre se intenta superar a sí mismo (ETG CE, 28 - Jordi).

A todos estos atributos Sergi, hay que añadir algunos indispensables en sus quehaceres diarios como la autonomía y la independencia. Cuando es el momento de trabajar o hacer cualquier cosa él no espera órdenes, no necesita que se le repita qué hay que hacer. Su madre, cuenta cómo desde casa, siempre han propiciado que sea una 
persona autónoma y autosuficiente: le hemos enseñado a hacerse la cama, a recogerse la ropa, a dejarse la ropa bien doblada por la noche para que al día siguiente estuviera bien... Le enseñamos a recoger, que cada uno se tiene que recoger el plato, el vaso, y el cubierto de la mesa, y hay que decir que es el primero que lo hace... La cama se la hace todas las mañanas, sobre todo en verano, yo no le hago la cama para nada, ni le tengo que decir que lo tiene que hacer (ETM3, 276).

Esta misma autogestión en sus ocupaciones, la observa su profesora de la Escuela de Arte en el día a día: él es capaz de llegar a clase y ponerse a trabajar inmediatamente, sin que se le diga nada. Si un alumno es creativo e independiente, es capaz de motivarse a sí mismo y no necesita que se lo digan todo. Siempre se adaptará mejor a un ambiente flexible que le permita expresarse. En cambio otros alumnos necesitan ir mucho más dirigidos, se agobian y se atascan cuando tienen que tomar decisiones solos. Si se pretende dar pautas de trabajo muy cerradas a Sergi, probablemente pierda pronto el interés en la actividad. (ET PEA, 34)

Él necesita sentir esa libertad y potestad sobre todo lo que hace y demostrar a los suyos y al mundo que es capaz de hacerlo solo. En este sentido su familia, y especialmente sus padres, siempre han luchado y luchan por lo mismo, para que el nivel de autonomía de Sergi sea el más alto posible. Pero ¿hasta dónde? ¿hasta cuándo? ¿de qué manera?... solamente Sergi puede responder a estas cuestiones. Pero cada día es mejor, es más adaptativo, es más funcional. (ET Edu, 38) Desde casa la educación que ha recibido ha sido siempre muy, muy disciplinada y eso le ha hecho un niño muy disciplinado. Esto le ha llevado a intentar adaptarse lo mejor que ha podido a cada una de las situaciones o experiencias en las que sus padres le han ido 'bautizando'. Siempre intentando que la experiencia anterior fuera menos autónoma que la siguiente, y siempre y cuando Sergi diera garantías de que pudiera alcanzar. De hecho, a día de hoy, prácticamente, es autónomo. Hay pocas cosas que a día de hoy Sergi no pueda desarrollar de una forma autónoma como cualquier persona. $Y$ eso es fruto del trabajo de los padres dándole siempre posibilidades de ir creciendo a esos niveles, de experiencias y de prácticas. (ET Edu, 45)

La voluntad por aprender y la curiosidad siempre han estado presentes en Sergi. Ya desde niño, era un niño muy social, con una buena intención, con una dificultad grande en el lenguaje pero que era fácil de 'enganchar' porque el punto social era un punto fuerte para él. Tenía un pensamiento muy literal, pero con una buena capacidad de superación, de querer aprender, de querer hacer las cosas. (ET Mir, 55). De hecho, su padre remarca: él es un niño que viene y te dice un domingo "¿me preguntas la lección papá?" y vas a preguntarle y si no se acuerda sin decir nada te coge el folio y se va a repasarlo. Con una gran voluntad... Al que pone todo lo que puede no le puedes exigir más (ET P, 320). Los hermanos, también le han ayudado siempre ha estudiar y recuerdan verlo siempre en sus ratos libres repasando, con mucho interés. Sin embargo, el hermano mayor, Gerard, resalta que incluso nos han llegado a decir que le forzábamos, y era él el que quería aprender, nos pedía él. Yo creo que él necesitaba saber más (EG H1 y H2, 189)

Sin embargo, el día a día trae consigo momentos duros, momentos de inseguridad en los que Sergi se percata de sus dificultades y de su carencia de herramientas para superarlas. Ante esto, Sergi con sinceridad y honestidad pide ayuda a sus padres y hermanos si, por ejemplo, va a la biblioteca, o a hacer la compra y tiene algún problema. Es fácil escucharlo decir "la chica no me entiende, ven a ayudarme", pues a veces no se expresa bien o le han cambiado algo y no sabe cómo hacerlo ( EPM2, 435)

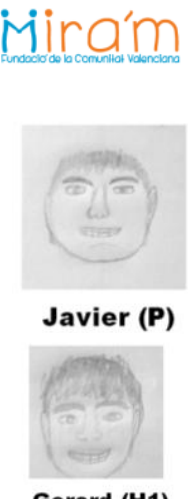

Gerard (H1) 
Él es totalmente sincero y transparente en esto. Se da cuenta de sus debilidades y pide aprender más para poder hacerlo por sí mismo. Habitualmente le dice a su logopeda Azucena: “Azu, esto no sé, por favor ¿̇me puedes enseñar?"(ET Log, 43). Ella misma cuenta: hubo un antes y un después en el que él me empezó a introducir en su vida y empezó a darse cuenta de que yo estaba para ayudarlo y lo aceptó. (ET Log, 43). Es capaz de darse cuenta, de preguntarte y de demandarte que es lo que no está aprendiendo o lo que necesita. Hay que encontrar su vía de aprendizaje, hay que adaptarse a él, a cómo aprende, a cómo te va exigiendo. (ET Log, 46)

Esta consciencia sobre las dificultades y debilidades de uno mismo, ese darse cuenta de que no es comprendido por la gran mayoría, generaba de alguna manera ciertas mellas en la propia autoestima de Sergi. Al principio no tenía prácticamente autoestima porque comparado con los demás siempre salía perdiendo (ET Edu, 61). Sin embargo, su afán de superación y su perseverancia han logrado que a día de hoy incluso se pueda comparar, y ver que en muchos aspectos es incluso superior a los otros. Eso le produce muchísima autoestima y seguridad en él mismo. (ET Edu, 61).

Un ejemplo de ello es la natación. En este deporte, se inició como algo complementario, para desestresarlo de toda la carga formativa e instruccional que llevaba, y a día de hoy, se ha convertido en una de las fortalezas más importantes de Sergi porque destaca sobre los demás. Él es consciente de eso, él sabe que lo que hace está bien hecho, tiene medallas. Por lo tanto, no solamente le ayudan a considerarse igual o competitivamente mejor que los demás, sino que además le da fuerzas para continuar mejorando en aquello que él sabe que es peor, que sería en todo el tema instruccional. Porque claro, él se compara con los demás, y aunque esté en una aula muy bien dotada, adecuada, también está en el aula ordinaria y ve la rapidez en la que los alumnos trabajan. Él es consciente de que hasta ese nivel de rapidez no puede llegar de momento, pero sí que la tendencia es que no se puede dormir porque tiene que continuar siendo competitivo en estos aspectos. Es algo que le ayuda a estar más equilibrado, a tener más armonía, que en él no sea todo negativo ni todo positivo, sino que tenga pues, como todas las personas, aspectos positivos y aspectos negativos. Hay cosas en las que destacamos, somos más ingeniosos o menos ingeniosos... y hay aspectos que por mucho que lo intentemos no lo podemos resolver. Por ello, yo creo que siempre desde este punto de vista, la natación lo que hace es equilibrarlo, darle un equilibrio sobretodo emocional y de vida. No se sabe hasta dónde llegará en el tema de la natación pero evidentemente todo lo que hasta ahora lleva hecho, eso es algo que siempre podrá utilizar en su vida. (ET Edu, 61)

Además de la natación, Sergi disfruta aprendiendo en su día a día, sobretodo en relación a todo lo que tenga que ver con animales, naturaleza, aventuras,... Su maestra de primaria recuerda cómo, en ocasiones, en clase estaba Sergi trabajando con su educador Francisco y ella explicando alguna cosa al resto de compañeros: él parecía que no estuviera escuchando, pero a lo mejor podías decir "dinosaurio", y entonces veías que ya levantaba la cabeza. Y dices "¿cómo es posible? Parece que no esté escuchando pero cuando algo realmente le interesa y le gusta, icómo conecta!" (ET Maes, 87).Esta pasión por los animales y la naturaleza, se traducen incluso en intereses restringidos, pues son temáticas que le hacen conectar muchísimo con la gente, pero de no ser así parece que la conexión se rompa. Él tiene intereses restringidos. Él no se relacionará con nadie que no lo escuche. Le interesan mucho los animales o ahora los Pokemon... Si encuentra un niño que le gusta eso sí, pero sino no, no le interesa y se va, intereses restringidos a tope. (ETM3, 318) 
Entre sus virtudes, Sergi destaca por ser una persona muy disciplinada, sobretodo consigo mismo. Como virtud la autodisciplina (ET Edu, 47), remarca su educador. Cuando era pequeño, con sus carencias, ya era disciplinado. Siempre ha sido muy perfeccionista y las cosas le gusta hacerlas de una manera muy, muy, muy, muy perfecta y por lo tanto a día de hoy, es muy exigente. $Y$ yo creo que lo primero que destacaría de sus potencialidades y sus fortalezas fundamentales sería su disciplina, su orgullo, las ganas de aprender y su competitividad. (ET Edu, 47)

De manera colateral a esta disciplina, y por lo tanto, autodisciplina, su educador hace referencia a las dificultades que tuvo Sergi para lograr interiorizar la autoridad. Él mismo explica que si se hubiera pensado que Sergi por ser peculiar o ser diferente en aquellos momentos, hubiera podido hacer siempre lo que quisiera, evidentemente hoy en día sería mucho más difícil para él entender las normas de la sociedad. Y además curiosamente, estas normas, las que él no entendía, se volvían en su propia contra. Esta era la gran dificultad: Una norma puede ser interiorizada por un niño o por una niña y a Sergi le costaba mucho interiorizarla, pero una vez interiorizada él no la transgredía, los otros sí. Un ejemplo muy claro, "no hay que hacer ruido, no hay que tirar papeles, no hay que...", con la presencia del profesor o la maestra no pasa, se va y pasa, Sergi no. Denuncia. "Señorita han tirado papeles, Señorita han escrito en la pizarra, Señorita han chillado" ¿por qué? Porque él entiende que no es necesario que haya una persona delante de ti para que tú cumplas esta norma, si está, está. Él siempre ha partido de la base de la generalidad de las situaciones y después no podía entender cómo él lo hacía y los demás no, y contra eso se rebotaba. Eso es lo que yo entiendo que como norma social a él le costaba más entender "¿por qué yo lo hago y los demás no? Es decir, ¿de qué sirve que mi padre y mi madre me digan en historias sociales no tienes que levantarte del sitio, no tienes que chillar, tienes que pedir permiso... cuando los demás después no lo hacen?" Es la misma norma la que cuando no es compartida por todos le crea problemas a Sergi, no es Sergi que no pueda entenderla. La diferencia fundamental entre Sergi y los demás alumnos era que él tenía muy claro desde el principio qué era una norma y cómo tenía que trabajarla, y los otros alumnos pues depende un poco del talante de cada uno, si estaba el profesor lo respeto y si no, no, es decir, en este sentido siempre ha sido muy leal, muy leal. Siempre ha respetado muchísimo la norma y cuando realmente la ha podido interiorizar siempre la ha cumplido. (ET Edu, 49)

Con toda esta riqueza de peculiaridades y singularidades de Sergi, con toda la problemática de lenguaje y de interacción social y con las dificultades que se le plantean a la hora de entender el mundo, Sergi jamás olvida que los suyos están ahí para apoyarle y se siente inmensamente agradecido por ello. Cada día, en cada pequeña acción de ayuda que recibe Sergi nunca olvida dar las gracias, e incluso, cuando el día ha terminado, desde la cama se lo hace saber a sus padres: "Mamá, buenas noches, muchas gracias" "Papá, te quiero mucho".(ETM3, 247)

\section{SEGUNDA PARTE}

\section{2.- La historia de vida de Sergi: Empezar desde cero...}

Volvamos atrás, volvamos al inicio de toda la historia. Sergi llegó al mundo un 11 de abril del año 2000, su madre recuerda que fue el segundo de los tres hermanos (...) Sergi era querido y deseado, además tan solo se llevaba 2 años y medio con el hermano mayor (...) Cuando me enteré de que era un niño me alegré mucho porque pensé que eran dos hermanitos, que se llevarían bien (...)ya que además Gerard quería y pedía un 
hermanito, y claro, yo pues encantada porque yo lo que quería en un compañero para él, más que para mí. Me daba igual lo que viniera, porque él estaba contento y yo también lo estaba, y yo siempre pensaba en la poca edad que se llevaban y lo mucho que eso les favorecería. (EPM1, 16).

Con el paso del tiempo, Sergi fue creciendo, adaptándose al entorno y el entorno adaptándose a él. Sus familiares la recuerdan como una etapa muy alegre y agradable, pues veían a los niños bien, crecer y evolucionar poco a poco. Sergi empezó a andar, a decir cómo se llamaba, a cantar...tuvo una evolución completamente normal, pero de repente sobre los 19 o 20 meses, sin saber cómo, se dio un cambio radical. Àngels explica cómo sucedió: De un día para otro, Sergi dejó de cantar, empecé a notar que no me escuchaba. Fue como una marcha atrás y eso fue entre los 18 meses y los dos años (EPM1, 31). Fue una etapa caótica porque nos angustiábamos todos, él no hablaba y empezó a tener algunas rabietas, sobretodo de impotencia por no poder decir algo, pedir algo. (EPM1, 29). A partir de ahí fue cuando empezamos a ir a la doctora preguntando, que si podía ser esto, que si podía ser aquello... que le podía estar pasando, que no sabíamos bien... (EPM1, 31).

En un principio, parecía que el problema podía tener relación con vegetaciones en el oído que no le permitían escuchar bien y por eso Sergi estaba como un poco abstraído de la realidad. Sobre los 2 años, lo operaron de vegetaciones esperando una evidente mejoría que lamentablemente no llegó. Sergi no solo no mejoró tras la operación, sino que siguió sin hablar y continuaba cerrándose en sí mismo.

Este momento de 'retroceso evolutivo' o 'parón' es una vivencia bastante compartida en las familias con niños autistas. De una manera muy sencilla, Javier, el padre de Sergi, recuerda el antes y el después de ese aparente momento crítico en la evolución de Sergi: Hubo una cosa que me marcó mucho de su infancia (...)antes de los 2 años cuando le poníamos la película de Marco el niño siempre cantaba... "en un pueto... itanano...", el niño cantaba la cancióny Àngels siempre me decía "parece mentira, cómo se nota que es el segundo que no lo has grabado nunca". Un día de tantos le dije "vuélvelo a poner, que lo acaba de cantar, y voy a grabarlo". De repente, ya no conseguimos que cantara, pero es que ya no volvió a hablar. Fue muy fuerte porque fue como si hubiera sido el momento determinante en el que el niño dejó de decir lo poco que decía (ETP, 25).

Vista esta misma situación desde una perspectiva técnica, Marisa, de la fundación Mira'm, explica este proceso y lo describe como algo común en niños con Trastorno del Espectro Autista: En Sergi, antes de los tres años, ya había alguna parte de imitación, había algunos gestos de saludo, señalaba para pedir y para compartir, y luego, algo habitual en los niños con TEA, intentaba conseguir las cosas por él mismo antes que acudir a un adulto o a un igual. Esto es muy común porque entra dentro del proceso de la comunicación. Es decir, tengo una barrera en comunicación, no soy capaz de interpretar que el otro me pueda ayudar. Entonces siempre intentaría sacar las cosas por él mismo. Las primeras palabras fueron a los quince meses, y entre los quince y los dieciocho meses, también muy común, a nivel neurológico se produce una explosión, tiene un parón. En el caso de Sergi (...) el lenguaje se estancó y lo que había llegado a conseguir ya no lo tenía. Intentaba realizar frases pero eran muy inconexas, no tenían una estructura morfosintáctica adecuada y algunas palabras eran muy idiosincrásicas. (ET Mir ,21 - 22) 


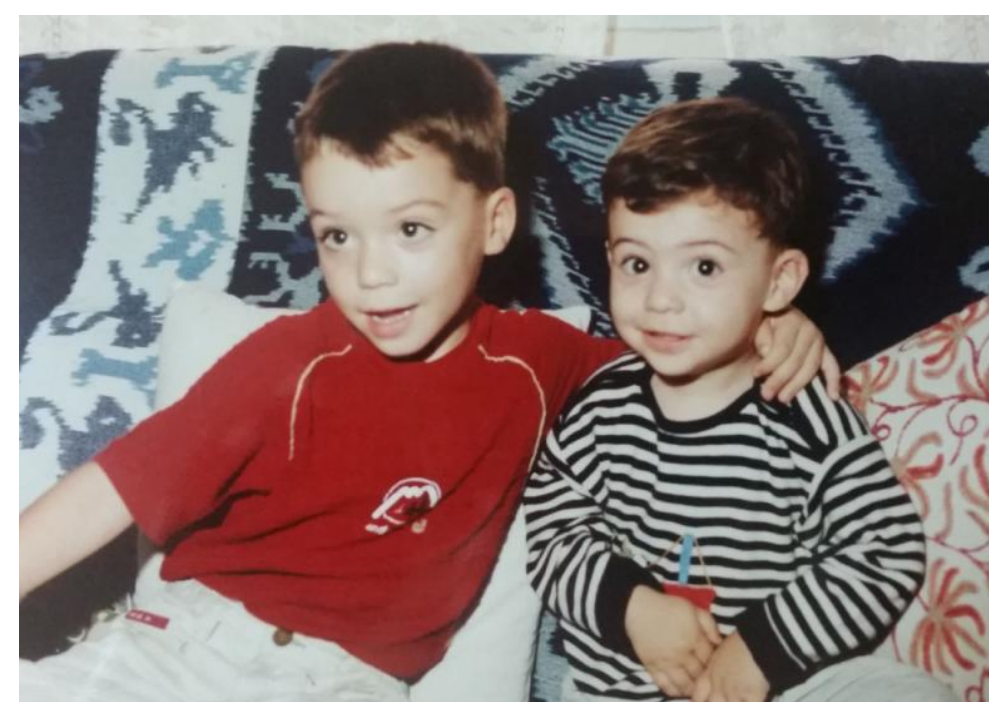

Imagen 1. Fines de semana en el pueblo (fotografía $n \cong 1$, TF M)

La madre recuerda con nostalgia como Sergi hasta ese momento era un niño alegre, un niño que se relacionaba con normalidad con su entorno. El niño prestaba atención, recuerdo aquellas tardes de sábado en el sofá de la abuela después de comer. Un día les hice una foto a los dos hermanos, estaba tan mono, tan contento con el hermano, recuerdo perfectamente ese día. Poco tiempo después hacerle una foto se convirtió en algo imposible. Ya no había manera de hacerle una foto, tenías que hacer de todo para conseguir que mirara. (...) Esa foto es para mí un recuerdo especial porque creo que es la última en la que él miraba a la cámara. Después de esto el niño empezó a esconderse, a huir, a girarse, se enfadaba,... no le podíamos hacer una foto, no quería. (...) Hasta ese momento todo fue normal, después de ahí ya empezamos con las alteraciones, el no relacionarse con el entorno... todo, a huir del hermano, no quería que lo tocáramos (...) Después ya no hubo forma de que hablara, se desconectó. (EPM1, 11-22)

\section{1.- El diagnóstico... la enfermedad que más prolifera (Karl Kraus)}

Llegado este punto, como es de esperar, las visitas a unos médicos y otros buscando una explicación, buscando un poco de luz sobre la situación se volvió cotidiano. Uno de los primero sitios a los que fueron es el Hospital Sant Joan de Déu (Barcelona) y según la madre: enseguida nos dijeron que era un trastorno del desarrollo. Nosotros empezamos a buscar en internet y nos volvíamos locos... Nos dijeron que mejor fuéramos a una psicóloga (EPM1, 33).

De repente, de la noche a la mañana, se encontraron ante un diagnóstico de "saco roto", donde todo tiene cabida. La madre no dejaba de preguntarse ¿Donde voy? ¿Qué hago? ¿Lo que me dicen es verdad? (EPM1, 35). Fueron muchos los profesionales a los que la familia visitó en esta época para determinar qué le pasaba exactamente a Sergi y cómo abordar el problema. En principio, parecía que la cosa indicaba autista de alto rendimiento, pero claro, su trastorno del lenguaje era tan, tan profundo que no se sabía dónde empezaba una cosa y donde acababa la otra (ET Log, 21).

La ambigüedad diagnóstica, el desconocimiento de qué significa cada una de las etiquetas que le ponían a Sergi y la necesidad de entender qué le estaba pasando a su hijo siempre, hasta día de hoy, ha inquietado a su madre Àngels: Sergi es un niño que dicen que está en frontera, es un niño fronterizo, porque siempre ha estado que si es

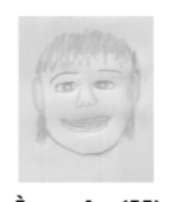

Àngels (M)

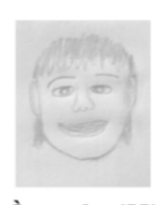

Àngels (M)

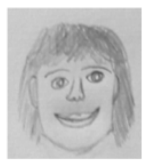

Azucena (Log)

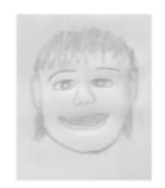

Àngels (M) 
$T G D$, que si es TEL, que si es... Nosotros siempre hemos dejado de lado el diagnóstico, no nos importa, pero ¿qué manda ahí?, porque él la intención comunicativa siempre la ha tenido, desde bien pequeño, ¿es ese trastorno del lenguaje tan grave que tiene que no le deja comunicarse? (...) Todavía a día de hoy, te pones a hablar y él te explica cosas, pero llega un momento que se va y dices "¿por qué se va?" ¿Porque ya no quiere seguir la conversación? ¿Porque ya no tiene más necesidad de interactuar contigo? ¿O porque no puede seguir la conversación? (EPM2, 169 - 171) A él lo diagnosticaron con Trastorno Generalizado del Desarrollo no especificado (...), pero a medida que el niño iba avanzando, "iuy! Pues tiene un TEL!" (Trastorno Específico del Lenguaje), porque es evidente que tiene un TEL. $Y$ entonces se ha quedado en la frontera entre el TEL y el autismo, y ahí está (...) Se inclina hacia un lado, pero de repente se inclina hacia el otro, ¿Qué predomina? ¿EI TEL sobre el autismo? ¿o el autismo sobre el TEL? (ETM1, 45 - 49)

A pesar de esta indeterminación diagnóstica, la familia tenía claro que había que empezar a trabajar, pero no sabía cómo. Acudían a todos los profesionales del campo que tenían a su alcance $y$, sin esperarlo, empezaron a encontrarse con personas poco sensibles y muy poco profesionales. Desde el propio SPE (Servicio Psicopedagógico Escolar), el psicopedagogo asignado al centro donde Sergi estaba escolarizado, les advirtió que Sergi no lograría grandes cosas en su vida. La madre, recuerda que les remarcaron desde un principio que su hijo no podría aprender: nos dijeron que nos mentalizáramos que este niño no haría nada, que no sabía si hablaría que no sé cuantos... Que no llegaría a restar llevando, que no entendería los conceptos, que era demasiado abstracto para él... (ETM3, 347). Ante esta desfachatez antipedagógica e inhumana, los padres 'tragaron saliva' y siguieron su camino. Continuaron yendo a buscar nuevas opiniones, nuevas ideas sobre cómo trabajar con Sergi, pero la respuesta parecía ser más 'pasota' que otra cosa. A Javier, le impactó cómo ante esta situación ciertos profesionales les instaban a seguir observando y esperar, sin que ellos pudieran dar crédito de ello: "hombre, pero si ahora tiene casi 3 años, ¿Cómo vamos a esperar? Tenemos que empezar a actuar ya" (ETP, 34).

Esta situación generaba en los padres de Sergi impotencia, rabia y desorientación y acabaron aferrándose a una profesional que parecía poder ayudarles a empezar a trabajar. Empezamos a hacer viajes semanales a Barcelona para acudir a la psicóloga de una conocida clínica, pero acabamos dejando de ir a su consulta porque estresaba mucho al niño (...) Nos quiso hacer creer que Sergi se autolesionaba y no era verdad. Nunca en la vida se ha autolesionado, nunca, nunca, nunca, nunca. Ni morderse en una rabieta... Nos dijo "tendréis que venir todas las semanas porque es que a estos niños hay que enseñarles la funcionalidad de las cosas, tiene que aprender para qué sirven las cosas" Fuimos la primera semana y le da un collar y él se lo cuelga, le dio algo de montar y lo montó rápidamente; le dio unas cazuelitas se pone a jugar con la cucharita,... Entonces nos dijo "uy, este niño es muy funcional, entonces no hay que enseñarle para qué sirven las cosas", pero seguía insistiendo en que se autolesionaba, y entonces dijimos que no, que no íbamos a Barcelona y pagábamos 250 euros para que nos dijera que el niño se autolesionaba... Aquello fue un sacadinero (EPM1, 39).

\section{2.- "Yo puedo perder tiempo, pero Sergi no" (Àngels Ferreres, madre de Sergi (M))}

Ante este aparente desamparo por parte de los profesionales de la educación, la familia optó por las tomar las riendas de la educación de Sergi. Sentían que no eran bien atendidos, que unos y otros se 'pasaban la pelota' para finalmente dejar pasar el tiempo. Ese paso del tiempo, no ayudaba en nada a Sergi, más bien todo lo contrario. No avanzaba, seguía encerrado en sí mismo y no lograba conectar con el entorno. Por 
ello, los padres decidieron 'buscarse la vida' y Àngels empezó a formarse: Me dijo otra chica que venían unas chicas al CEFIRE (Centros de Formación, Innovación y Recursos Educativos) a hacer una ponencia sobre Sistemas de Comunicación Alternativos y Aumentativos. Entonces era cuando empezábamos a trabajar con el niño, lo preguntamos y nos dijeron que podíamos ir. (ETM1, 103). Esta ponencia, la hacían dos personas de Valencia especialistas en autismo y sistemas de comunicación (Cristina y Marisa) quienes al cabo del tiempo se constituyeron como Fundación Mira'm (en castellano 'mírame'). Marisa (de Mira'm) también recuerda con mucha exactitud el día que se cruzó en su camino Sergi y familia: A Sergi y su familia los conocimos en un curso que hicimos para el CEFIRE, que fuimos a Calders Cristina y yo, y Àngels acudió a ese curso. Le acababan prácticamente de decir que su hijo tenía unas necesidades y ya en ese momento veías que se podían hacer muchas más cosas de las que en ese momento se estaban haciendo. Después de ese curso quedamos un día e hicimos el diagnóstico de Sergi (...) Esa fue la primera toma de contacto y Àngels ya se veía una persona súper avanzada, buscando millones de materiales, viendo cómo podía organizar las cosas, pues en ese omento Sergi tenía muy poquito lenguaje (ETMir, 18).

Àngels, recuerda la desesperación que sentía al no saber cómo atender a su hijo: Yo necesitaba ayuda porque yo no sabía cómo hacerlo. Yo me encontraba con un niño que todos los días se levantaba enfadado porque no entendía al mundo, ni el mundo lo entendía a él. Necesitábamos ayuda todos. (ETM1, 105 - 107) De esta manera, se inició el trabajo entre la familia de Sergi y la Fundación Mira'm, concretamente con Marisa y Cristina.

Desde la Fundación Mira'm acudían dos veces al año al domicilio de la familia, y a partir de un programa individualizado basado en las necesidades de Sergi, se orientaba a la familia y a la escuela sobre cómo debían ir trabajando con Sergi: En el programa se establecía qué actividades tenían que trabajar, y dentro de este se incluían unos registros para controlar el trabajo (...) Lo que hacíamos era definir qué pretendíamos, nuestro objetivo general, y a través de ahí le dábamos ideas de actividades que podían realizar. (ET Mir, 28). En este momento, lo más importante era la constancia. Es decir, el que todo el mundo estuviera haciendo las actividades que le correspondian. Entonces los registros, en lugar de para Sergi eran para los adultos, para que los adultos tuvieran algo visual y detectar se estaba haciendo o no (...) Además, en cada actividad o en las libretas se iba anotando lo más significativo de cada actividad, de modo que esta información nos sirviera a la hora de decidir sobre una actividad "Pues mira sí, hemos trabajado la fluidez verbal, estamos en 5 palabras pero todavía se 'engancha' un poco", pues la mantenemos... Claro, toda esa información la tenían que ir dando ellos para luego ver qué otras cosas proponer (...) La cuestión es que muchas veces dices "esta actividad no funciona", pero realmente luego te paras a pensar y dices " $y a$, pero es que lo has hecho dos veces a la semana. Se ha quedado corto"... (ET Mir, 47)

A partir la das indicaciones de Mira'm, la familia, y en especial la madre de Sergi, empezaron a trabajar. Estas orientaciones se traducían en largas y densas horas que Àngels se pasaba en el despacho de su casa: pegando palabras, haciendo dibujos, creando materiales, buscando imágenes, confeccionando actividades, creando paneles de comunicación... A Sergi había que enseñárselo todo y ayudarle a comprender cómo funcionaba el mundo. Pero no solo aquello que ocurría dentro de las paredes de casa, sino que también había que crear y buscar materiales para la escuela, había que organizar su tiempo, lograr que entendiera las normas sociales,... Àngels recuerda que Sergi no quería ir a ningún sitio en un principio, pero sin embargo era necesario que fuera con logopedas, con pedagogos, a la escuela de arte,... Había que organizarle el
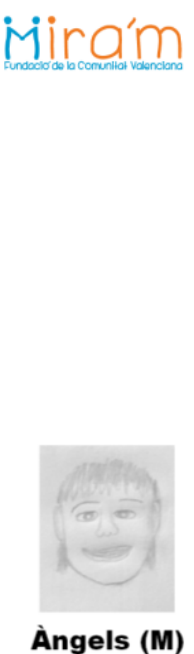

Àngels (M)
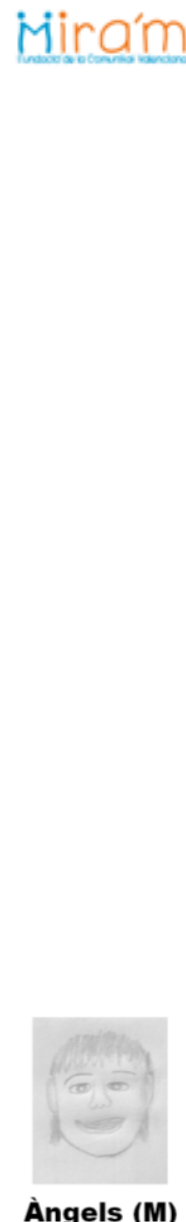
trabajo, había que organizarle las cosas, y desde Mira'm me decían que debía ser en función de él: "¿Dónde va? ¿a multideportes? ¿qué quieres...? ¿a qué juegan? ¿a escalar...?" Y me decían "pues hazle un panel, para que las chicas de allí se lo enseñen cuando llegue, y así ya sabe cuando llega lo que tiene que hacer". Ellas eran las que me decian y me ayudaban a organizar los paneles pero siempre en función de las demandas del niño... (TDE M, 50).

Sin embargo, el papel de Àngels en la educación de su hijo no acababa ahí. Cada vez que hacían alguna cosa en la universidad o en cualquier evento de AVATEL (Asociación Valenciana de padres de niños con Trastorno Específico del Lenguaje) se iba sin pensarlo: iba a todo y cuando salía de allí había un montón de expositores de sistemas de comunicación, libros,... y entonces yo allí iba loca apuntando, apuntando, apuntando, apuntando, apuntando,... (ETM1, 111)Todo esto se convertía de nuevo en la base de trabajo para nuevos materiales y nuevos paneles de comunicación que ayudaran a Sergi a seguir aprendiendo cómo funcionaba el mundo.

Al trabajo diario e incesante con Sergi, había que añadirle que la familia en su conjunto tenía que seguir adelante, tenía que seguir haciendo sus quehaceres, realizando actividades en familia, reunirse con amigos,... De nuevo, se abría otro frente para Sergi. Debía aprender la cotidianeidad de salir a la calle, de encontrarse y relacionarse con gente distinta a su familia, de asumir y respetar normas y pautas sociales tanto explícitas como implícitas. En ese momento, aún eran 4 en casa, Xavi todavía no había nacido y Àngels explica: Intentábamos ir los 4 a los sitios, adaptarnos. Desde Mira'm nos dijeron "tenéis que salir de casa, tenéis que ir a los sitios y Sergi tiene que saber qué hay en un restaurante, que se tiene que esperar para que le traigan la comida, si queréis ir a un parque temático tiene que saber que tiene que esperar un turno...". Así lo hicimos. Le decíamos "Ahora iremos aquí, ahora iremos allá" y hacíamos nuestras historietas sociales para que él lo comprendiera. (EPM1, 58) En Mira'm siempre nos dijeron "vosotros tenéis que ser una familia normal, tenéis que saltar barreras y saltar barreras significa ir a los sitios". Si nosotros la primera vez que fuimos a Port Aventura (parque temático) y la segunda y la tercera que él no quería hacer colas y nos montaba un 'pollo' nos hubiéramos ido para casa, eso se hubiera acabado así. Pero dijimos "no, porque nosotros tenemos dos hijos más" y nosotros íbamos a Port Aventura e íbamos allí, y allá, y claro, a los sitios donde a él más le gustaba subir era donde más cola había, pero había que esperar (...) Yo en la cola cogida de su mano y con el pictograma en la otra mano. Y cuando se me rebotaba "iSergi!" (señalaba el pictograma) y entonces ahí se paraba. (ETM3, 227 - 229)

Todas estas cosas requieren de mucha paciencia y nos hemos tenido que ir turnando Javier y yo. Ir a una pizzería, ir a un restaurante,... a él le costaba mucho estar allí sentado sin moverse y no hablar con voz alta. Todo eso hemos tenido que ir salteando. Nosotros hemos salido siempre de casa con todo bien estudiado. Ahora ya te digo, hemos ido a todos los sitios (...) Una amiga muchas veces me dice "jolín, Àngels, icómo te lo has currado! porque yo ya lo hubiese...", pero aquello era cuestión de paciencia. Alguna vez le iba alguna colleja, porque hay veces que la paciencia se agota, pero en Valencia siempre nos decían "paciencia, vuestra palabra es paciencia, paciencia y paciencia. Haced un cartel bien grande en la pared, paciencia, paciencia y paciencia, y paciencia, paciencia y paciencia..." Y siempre así, paciencia. Es que no hay otra cosa más que paciencia. (ETM3, 233 - 235).

Es precisamente esta constancia y perseverancia en el trabajo, la que poco a poco iba encaminando a Sergi hacia nuevos aprendizajes a través de un camino lento y muy 
complejo. De hecho, aunque desde otra perspectiva pueda sonar extraño, uno de los trabajos más costosos para Sergi fue el tiempo y su organización. Este trabajo Àngels lo recuerda como un momento clave y delicado: La organización temporal fue muy importante en su vida. Él no era capaz de entenderlo, no sabía nada, lo teníamos que relacionar todo haciendo dibujos "esto es navidad, esto es enero, en marzo vamos a esquiar, carnaval, tu cumpleaños...". Entonces el calendario ha sido una parte indispensable en su vida, porque había que organizarnos en el tiempo. De muy pequeño le tuve que enseñar la diferencia entre el día y la noche, porque para él no había distinción. Él de noche quería jugar, y entonces claro, hubo un momento que le hice el sol y la luna, y la luna con el pijama y dormimos, y de día el papá y la mama trabajando, cocinando,... todo esto utilizando fotos reales de nuestra familia. Y así fue cuando logró distinguir la noche del día. Cuando teníamos clara esta diferencia, llegó el momento de trabajar los días de la semana: lunes, martes, miércoles, jueves,... "El papá está en casa los domingos, está también por la tarde etc". Después íbamos orientándonos mes a mes (...) "ahora estamos en este mes, y cuando vi que le llamaba atención la navidad (...) íbamos contando "ahora falta tanto para la navidad" y cuando llegábamos a navidad le decía "iremos a esquiar en marzo". Lo importante es que él siempre tuviera un aliciente. Yo pensaba "no sé hasta qué punto lo entiende, pero sí sé que se queda con la 'copla', porque él está contento y busca el calendario". De repente empezaba "el esquí, el esquí..." y tu decías "ostras, estamos llegando a finales de febrero" (TDE M, 33 - 35)

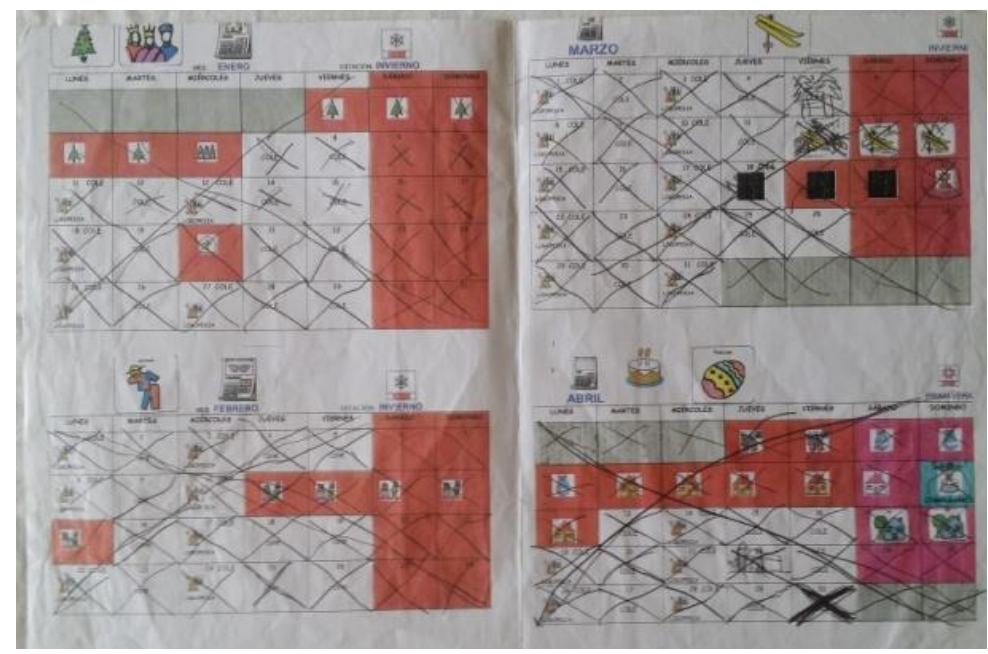

Imagen 2. Calendario de Sergi (documento 28, TDE M)

Todo este esfuerzo de la familia, es el que le ha permitido a Sergi recorrer mundo, conocer lugares cerca y lejos de casa, aprender idiomas, cultura e historias. Como dicen sus abuelos: "está muy guerreado" (...) es un niño que no parado, no lo han escondido nunca, todo lo contrario. (ETA, 97 - 101). De hecho, él detalla gozoso y satisfecho todos los lugares que ha podido conocer junto a su familia: Fuimos a París, a DisneyLand Paris, fuimos a Londres a ver el museo y a Legoland que es un parque de atracciones todo de 'lego'. Hemos ido a Madrid, a Barcelona a patinar con Gerard con los patines de hielo (...) A Sevilla, fuimos a Isla Mágica, disfrutamos mucho... En París vimos también la Torre Eiffel, Notre Dame, vimos la historia de cómos se construyó Notre Dame, vimos el museo del hombre neandertal, fuimos con el coche de mi madre a una reserva africana, vimos osos negros, leones, rinocerontes y un avestruz (...) Y luego iremos a Roma en verano, quiero ver estatuas, museos y muchos lugares más... (ETS, 368 - 395)

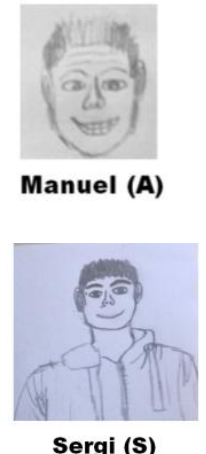

Sergi (S) 


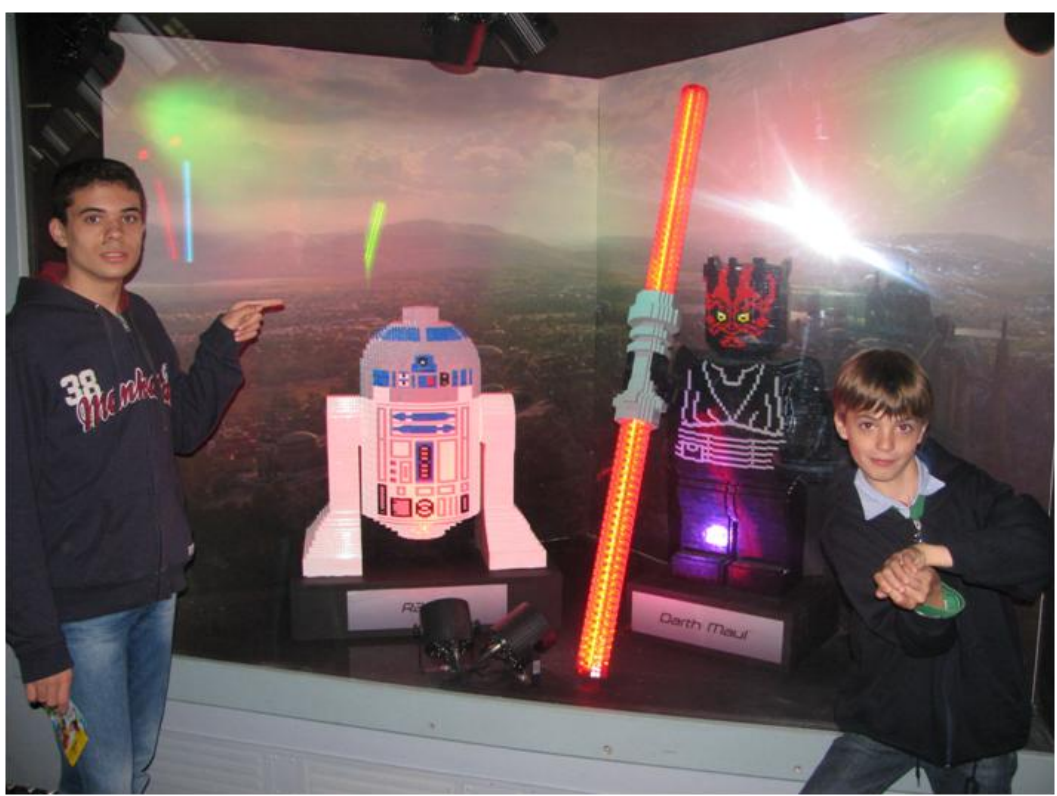

Imagen 3. En Legoland (Fotografía no2, TF S)

\section{3.- Nuevos retos}

Sergi entró en la escuela (Virgen del Carmen) con 3 años, tras haber pasado cierto tiempo en una ludoteca. Su hermano mayor, Gerard, ya estaba escolarizado en ese centro y cuando llegó el momento de escolarizar a Sergi, las modalidades de la administración pública no resultaban del todo satisfactorias para la familia: nosotros intentamos que hiciera una combinada con el aula CyL (aula de Comunicación y Lenguaje), porque como le costaba tanto aprender a leer y hablar... pero no nos dejaron. Nos dijeron que una combinada solo podría ser con un centro de educación especial pero con Virgen del Carmen (un centro concertado) no lo permitían. (ETM2, 328) Si algo tenían claro los padres es que Sergi no era un niño adecuado para acudir a un centro de educación especial. Sin embargo, parecía que era complicado asegurarse de que podría tener apoyo en el aula en cualquier otro centro ordinario. Por ello, ante la pregunta de por qué eligieron este centro para Sergi y no otro, la respuesta es sencilla: en este centro concertado podíamos llevar nosotros un educador externo, y en la pública no nos dejaban. Además, cuando Sergi entró en la escuela el aula TEL no existía todavía, porque cuando se creó Sergi ya llevaba unos años escolarizado. Claro, todo eso fue en contra de Sergi. Nosotros siempre, más o menos, tuvimos claro que si se hubiera podido hacer una mixta entre el aula TEL y el colegio donde estaba integrado hubiera sido perfecto no queríamos otro, queríamos en el mismo centro y no cambiar de amigos, ya que en aquella edad era muy peligroso porque él no hablaba casi nada (ET P,141 - 145).

Los padres, tenían las ideas muy claras sobre lo qué necesitaba Sergi y estaban dispuestos a hacer lo que fuera necesario para que lo tuviera. Según explica el educador de Sergi: ellos necesitaban una escuela que pudiera permitir plantear con Sergi una escolaridad diferente de la que la Administración les ofrecía, pues esta escolaridad cubría algunos aspectos pero otros no. Encontraron el centro Virgen del Carmen y este fue receptivo con su propuesta de incorporar a un educador/a externo/a. A partir de ahí la función de los padres de Sergi fue buscar recursos especializados para ir complementando a la escuela. En este sentido hubo, por parte de los padres (...), una voluntad de que, para llegar a eso, ellos tenían que poner todo su esfuerzo en que eso fuese así. Si en un momento determinado ellos hubieran bajado su autoexigencia, (...)

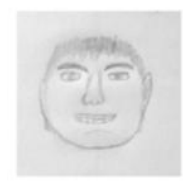

Javier (P)

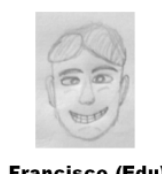

Francisco (Edu) 
no se hubiera dado lo que estamos hablando a día de hoy. En todas las subidas y bajadas que ha podido haber, ellos han estado siempre muy, muy alerta de cuál era el objetivo, y el objetivo no era otro que la autonomía de Sergi. Y para eso necesitaban, de alguna manera, tener criterio a la hora de poder valorar lo que la escuela les ofrecía y cualquier profesional que quisiera trabajar con Sergi. Por lo tanto, sobretodo, fundamentalmente Àngels tuvo que formarse o autoformarse para poder ella tener criterio a la hora de poder tratar este tema (...) Cuando yo les conocí, ellos tenían una idea muy clara, y ellos ya sabían que querían una educación inclusiva para su hijo pero no sabían lo que era. Lo que ellos sí querían es que Sergi fuera uno más, y no fuera diferente del resto. Esta era su idea fundamental, es decir, "tenemos que hacer lo posible para que Sergi sea uno más, y que los niños no lo vean como algo diferente", y fue es su lucha. A día de hoy continúa siéndolo. (ET Edu,116)

Cuando, finalmente, tras las pertinentes negociaciones con el centro, Sergi fue escolarizado, se encontraron con un centro receptivo y que además quería ayudar a Sergi y a su familia. En aquel momento, Sergi ya había sido diagnosticado y habían empezado a trabajar con diferentes profesionales (entre ellos la fundación Mira'm de Valencia). Con la corta edad de 3 años, Sergi ya tenía las tardes organizadas con sesiones de trabajo en casa.

Por esta razón, desde el principio, los padres pidieron a la administración educativa y al centro flexibilizar el horario de Sergi. La madre de Sergi, cuenta que esta medida fue aceptada sin problemas: Pedimos a inspección que Sergi solo entrara por la mañana y nos dijeron que sí, porque por las tardes venía una chica a casa a trabajar con él. Sergi se sentaba en una mesita (...) y trabajaba ella un rato y un rato yo, y le enseñábamos sobretodo con imágenes. Él sabía lo que eran las cosas, pero no sabía decirlo y teníamos que enseñarle. Le decíamos "muñeca", "toca muñeca, toca coche, toca pelota, dame pelota, dame muñeca..." y así. Después empezamos a intentar enseñarle a dibujar y más tarde en el ordenador: relacionar, asociar,... Todo eso lo hemos ido trabajando todo en casa por la tarde (EPM1, 41)

En principio, parecía que su llegada al centro no había acarreado grandes problemas, la administración pública y el centro les estaban ofreciendo ciertas facilidades en cuanto a la escolarización y parecía que no había oposición o desacuerdo por ninguna de las partes. No obstante, al llegar al aula el talante de la primera maestra de educación infantil fue bien distinta a la esperada. Àngels recalca la falta de profesionalidad y sensibilidad con la primera maestra que se encontró: Recuerdo que un día la maestra me dijo "tu hijo me alborota la clase, se pone a reír sin venir a cuento..." Seguramente Sergi pensaba en sus películas y sus cosas porque no podía seguir la clase. Entonces su nivel comprensivo era caótico y ella no lo entendía. Ese día me fui a casa llorando (...) porque yo pensaba "a ver, lo hemos traído a la escuela ordinaria porque en una escuela especial no tenía sentido". Además que el niño estaba sentadito y no daba ningún problema, cuando le decían de ir al aseo él se levantaba, cuando le decían de ir al patio, iba al patio,... pero no seguía la clase. Él necesitaba a alguien que le ayudara. (EPM1, 41)

Los padres, son conscientes de que este primer año fue duro para Sergi, pero no solo por su incorporación a la escuela, sino también por no ser comprendido por parte de su maestra y tener que luchar contra él mismo. Javier, el padre, explica que Sergi era y es una persona muy sensible de oída, vista y tacto, de tal forma que los sonidos fuertes o el ruido le resultan estremecedores: se ve que cuando cantaban todos en clase al niño le retumbaba la cabeza y se tapaba los oídos y chillaba. Ante esto, la maestra lo 
castigaba en el pasillo en lugar de llamarnos y decirnos lo que pasaba (...) Incluso lo metió en el coro de la clase y, claro, el niño lloraba y chillaba (ETM2, 232-237). Pero aun así, la implicación y voluntad de esta maestra era más bien escasa, pues a los padres les hizo comentarios que no dejaban lugar a dudas de cual iba a ser su aportación en el caso de Sergi: Le dijimos Esther, toma este móvil y el número de la psicóloga de la clínica de Barcelona, por favor cuando tengas un problema la llamas, nos ha dicho que a la hora que sea", y decía "a mí no me hace falta hablar con nadie que yo también hice psicología" (ETM2, 232).

Llegado este punto, la negociación y la inminente incorporación de un apoyo en el aula para Sergi fue inmediata. La situación se desbloqueó de la siguiente manera: el colegio les facilitaría la entrada de personal externo vinculado a un supuesto Programa de Fomento de la Lectura que sería costeado por los padres y, de esta manera, el educador externo podría estar en el aula con Sergi. No era el primer caso en el centro de personal externo facilitado por parte de la familia y según la logopeda externa de Sergi, Azucena, el centro les dio facilidades para ello: En ese sentido les dieron facilidades, aunque desde mi punto de vista no son facilidades extraordinarias. Creo que también es un derecho que tiene Sergi, que como niño con una discapacidad debe tener sus apoyos en el 'cole'. Entonces claro, llegó un momento que los padres dijeron "pues si tú no me lo das y te propongo pagarlo yo y si me dices que sí, pues adelante". (ET Log, 110).

\section{1.- Una imagen vale más que mil palabras...}

Poco a poco, y con la ayuda de Mira'm, Àngels aprendió a organizar y estructurar las imágenes para que fueran de fácil acceso para Sergi. De hecho, estas imágenes, dibujos e iconografía fueron un elemento inicial de trabajo con Sergi y previo a la incorporación de los pictogramas como elemento funcional de la comunicación. La madre, ya había observado que desde que era muy pequeñito que era capaz de abstraer mucha información a partir de una simple imagen: le ponía una imagen delante y él enseguida lo captaba, sin embargo era totalmente diferente cuando le empezaba a explicar un cuento, por ejemplo. El cuento se me iba de las manos cuando era pequeño, a mí me encantaba contarle cuentos y el niño no miraba. Yo le hablaba y él diría "esta ¿qué me está contando?" Entonces él te cogía el cuento, se tragaba las imágenes y pasaba de página, y yo "iespera!" y yo leyendo... y él 'pam', otra vez pasaba la página. No quería. Él se quedaba con la imagen, y ya está. Él lo miraba todo y (...) se quedaba tranquilo y contento. Cuando le decía "ahora nos iremos a Cervera", le ponía la foto de Cervera y él cuando entraba en el coche ya sabía que nos íbamos a Cervera. Él siempre observaba mucho las imágenes y yo creo que le ayudaron mucho. Desde luego él cambió cuando empezamos a darle imágenes porque al fin y al cabo le estábamos dando información. (ETM1, 145).

Cuando yo tenía pocos años no podía hablar. Me sentía muy agobiado. Le pedía a mi madre que me ayudara para que pueda hablar. Entonces yo aprendí a decir palabras que ponían en el panel gracias a mi madre (Técnica proyectiva Sergi, 'Las palabras de Sergi')

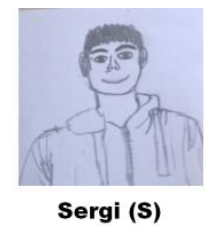




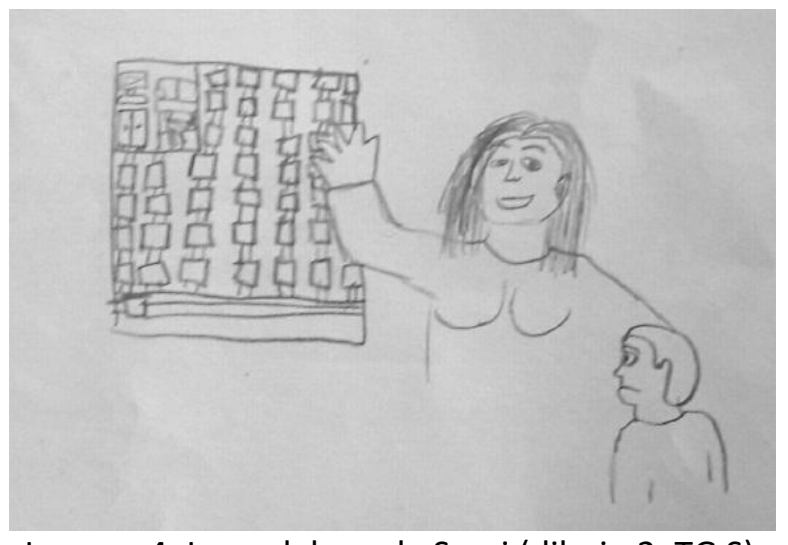

Imagen 4. Las palabras de Sergi (dibujo 2, TG S)

La cantidad de información que Sergi era capaz de obtener a partir de una imagen era tal que el uso de la imagen se trasladó a la escuela. Ángels, preparaba cientos de imágenes y pictogramas sencillos para que él pudiera aprender poco a poco el funcionamiento del centro e ir interiorizando las dinámicas que seguía la clase: Tenía que aprender. Sentado ya sabía estar, pero había que seguir enseñándole con las imágenes (...) los diferentes momentos de la clase "pues ahora vamos a contar un cuento, ahora vamos a ver una película...". Él tenía un librito con lo que tenía que hacer "cuando entramos nos ponemos la bata", "rezamos" porque al entrar rezaban. Después le ponían otra imagen "ahora sacamos la ficha" "ahora el bocadillo" Entonces esto era siempre, aunque ya tenía a una persona con él, lo más importante en aquel momento era que él aprendiera el funcionamiento de la clase. (EPM1, 45)

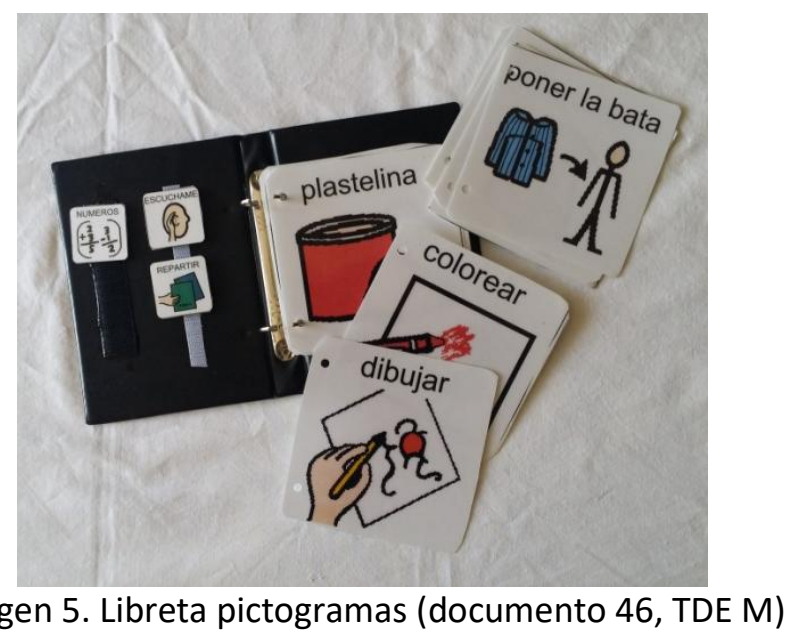

En esos momentos, la comprensión del lenguaje de Sergi era muy limitada a escasos enunciados y era capaz de seguir instrucciones siempre y cuando fueran muy sencillas y directas. Marisa (de Mira'm), nos ofrece una visión general de cuáles eran sus principales dificultades con el lenguaje: En aquel entonces, Sergi cambiaba el orden de las sílabas y la alteración del lenguaje era lo más notorio (...). Se veía que había una capacidad social, que le gustaba toda la parte de jugar, de acercarse al otro, de hacer cosas, pero el lenguaje era una de las partes más frustrantes para él, sobre todo el lenguaje pragmático, el uso social del lenguaje. (ET Mir, 24) La morfosintaxis estaba muy alterada, si conseguía hacer frases, las hacía cortitas o desordenadas. (...) y la necesidad más imperante era poder estructurar todo ese lenguaje que tenía (...) para más tarde pasar a las categorías pragmáticas, que es una de las partes más complejas (ET Mir, 28). 
En un intento de aprender a superar las dificultades del lenguaje, su uso y estructuración, se empezó a trabajar con pictogramas. Àngels, siguiendo las indicaciones de Mira'm y buscando ejemplos en internet y libros, empezó a confeccionar pictogramas y paneles de organización para Sergi. Ella misma explica el proceso que siguió para ello: El primer sistema de comunicación que tuve fue el BoardMaker, que me lo pasaron desde Mira'm. Estaba traducido al hispano, con lo cual tenía que retocar todo. La piscina era alberca, el coche era carro, y claro, lo tenía que retocar todo y empecé a hacerlo con velcro, cartulinas y todo el material necesario. (ETM1, 120) Yo imprimía e iba buscando imágenes sobre las cosas cotidianas que él necesitaba, y si alguna no existía la dibujaba yo. Aprendí a dibujar gracias a él. (ETM1, 130).

El abuelo de Sergi y padre de Àngels, recuerda que sufría al ver a su hija horas y horas preparando estos materiales: Àngels acostándose a las 2 y las 3 de la mañana para hacer aquellos dibujos, haciendo todos aquellos cuadritos,... Ella trabajó mucho, pero mucho, hizo mucho. A mí me decía "padre, ayer me acosté a las 3 de la mañana haciendo cosas para el niño", y de hecho todas las profesoras y todos lo que han tratado al niño, todos le han dicho que ha tenido una madre de las que ya no se encuentran. (ET A, 179). Desde luego, que la parte visual y pictográfica fue mérito de Àngels nadie lo duda. Era tal la dedicación, la voluntad, y como no, la esperanza que tenía depositada en los pictogramas que lograba hacer cosas realmente sorprendentes incluso para los profesionales de la fundación Mira'm: Àngels ahí era la estrella, porque además tiene muchísima creatividad y se le ocurrían cosas que eran una maravilla. En algunos casos le llevábamos alguna idea, pero la gran carga era para ella. Y logró descubrir el poder de los sistemas visuales bueno, eso ya fue la bomba. (ET Mir, 49).

Con el tiempo y la experiencia, Àngels aprendió a organizar y gestionar los paneles de y los pictogramas en función de las necesidades de Sergi: los paneles eran súperimportantes, llegó un momento que tuve que hacerlos por toda la casa y pudimos empezar a comunicarnos: "Yo, me pongo jabón en la bañera..., y la ropa, a la cesta de la ropa sucia". De esta manera, poco a poco le enseñé hábitos y rutinas diarias, todo. Fue muy importante. Sin embargo esto no me lo dijo nadie, eso me lo inventé yo. Es decir, me dieron el programa para poder obtener las imágenes, pero cómo usar estos pictogramas en concreto me lo inventé yo. Cuando Marisa vieron a casa yo todo esto ya lo tenía hecho. (TDE M, 63) 


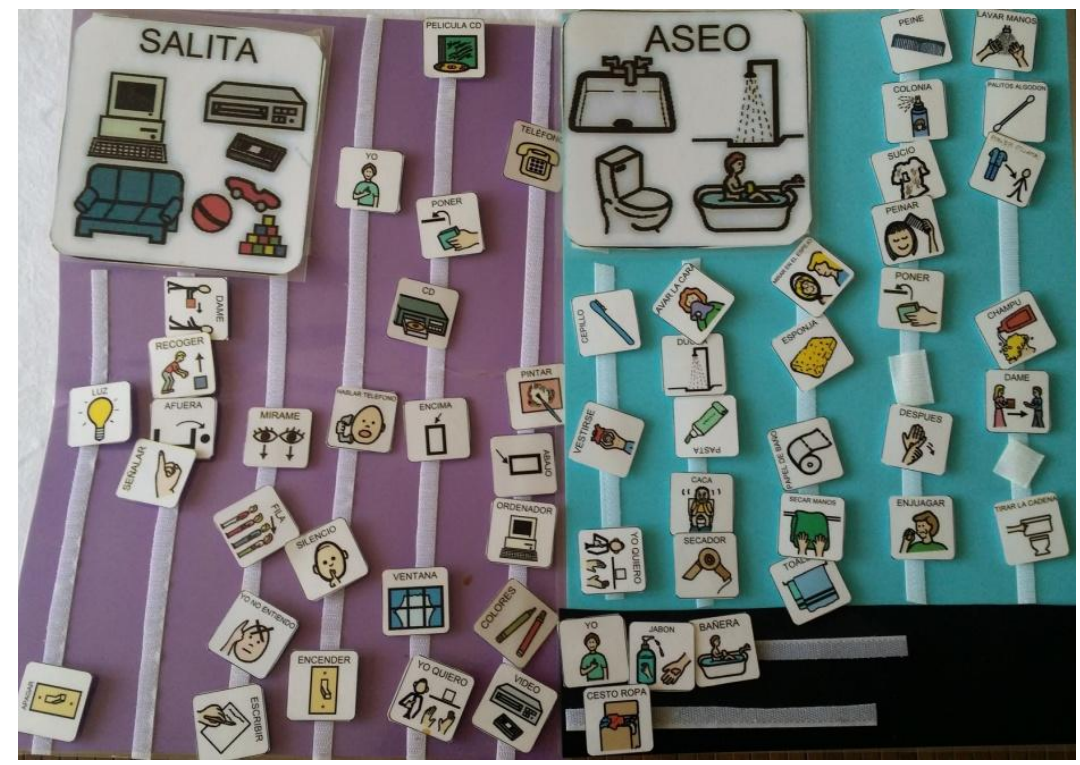

Imagen 6. Paneles de comunicación (documento 50, TDE M)

En un primer momento, cuando empezaron a ponerle los paneles parecía que Sergi no le veía una gran utilidad. Al principio, se trataba de una herramienta de comunicación que solo utilizaba la madre: Al principio lo cogía de la manita y lo llevaba ahí pero nada... era tan buen niño que se dejaba llevar y ya está. Sin embargo, llegó un momento en que se dio cuenta de que eso funcionaba, que lo entendía... y entonces empezó a darle uso. (TDE M, 70). Con el tiempo Sergi entendió el funcionamiento de aquellos paneles y empezó a comunicarse: Cuando yo era pequeñito lo hacíamos con dibujitos que yo tenía que ordenar (...) teníamos paneles por toda la casa, en el comedor, en la cocina,... Yo lo ponía en la cartulina, como si fuera un puzle, una pieza al lado de la otra... (ET S, 105-108)

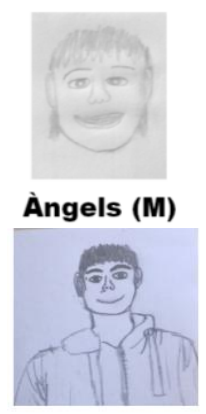

Sergi (S)

\section{2.- Si quieres llegar rápido camina solo, si quieres llegar lejos camina en grupo (proverbio africano)}

En aquel entonces, eran muchas las personas que estaban al lado de Sergi trabajando en forma de equipo multidisciplinar, dentro y fuera de la escuela. Este gran equipo estaba compuesto tanto por agentes pertenecientes al centro como externos a este (costeados por la familia de Sergi). Desde el centro contaban con el trabajo de la maestra asignada, la PT y la logopeda. Externos al centro estaba el educador/a que acompañaba a Sergi en el aula, la logopeda de fuera del centro, los profesionales de Mira'm y la madre que trabajaba con él en casa.

De todos los profesionales del centro, la madre de Sergi destaca por encima de otros el papel que tuvo la primera PT en la etapa de educación infantil. Àngels recuerda de ella su profesionalidad, su implicación y dedicación verdaderamente vocacional: Silvia era muy buena. Gracias a ella Sergi en P3 aprendió a escribir su nombre, aprendió los colores, los números hasta el 10. Ella consiguió mucho. Y al año siguiente, en P4, ella se lo llevaba y le empezó a enseñar a leer basándose en un método más constructivista. (...)Ella era muy buena, lo tenía todo. Ella decía "¿qué le hace falta al niño? ¿esto? Pues voy a enseñarle... ¿Qué tiene que aprender? ¿a escribir el nombre y le cuesta estar sentado en el aula? Me lo llevo, le 'planto' una pizarra en el suelo, si hace falta me lo llevo a la placita de delante del colegio con una tiza y lo pintamos en el suelo. Él tiene que saber que ése es su nombre y que se llama Sergi" Ella era así. (...) Con Silvia siempre saltaba la chispa, "pues ya sé cómo voy a hacer eso, pues ya sé cómo le voy a hacer lo

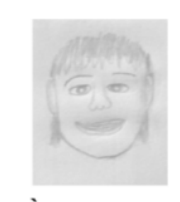

Àngels (M) 
otro" $Y$ siempre se apuntaba a cualquier cosa que hicieran de la que pudiera aprender (...) Ella se apuntaba a todo, en todos los 'bombardeos' estaba ella (ETM2, 226 -230)

Àngels recuerda con lástima como sintió que Silvia, esa profesional de la pedagogía terapéutica, se presentara a las oposiciones porque eso suponía su marcha del centro: yo le dije a Javier "Ias aprobará seguro, seguro, porque es muy profesional y está muy 'puesta"” (...) (ETM2, 220) Silvia le decía: "si no apruebo las oposiciones yo sé cómo enseñar a Sergi a leer. Sergi leerá, tardará un año, tardará dos,... pero Sergi leerá. Tardará tres..., pero yo sé cómo va a aprender a leer, y a hablar y a todo" (ETM2, 226). Finalmente, a pesar de la esperanza que los padres depositaron en ella, Silvia aprobó las oposiciones y se fue del centro cuando Sergi estaba terminando su etapa de educación infantil.

Coincidiendo en el tiempo y el espacio con Silvia, dentro del aula Sergi disponía también de otras dos profesionales del campo: como maestra de educación infantil tenía a Carmen (durante P4 y P5) y como educadora externa aportada por la familia tenía a Rocío (de P4 a 10 de educación primaria). Ambas, fueron las primeras en trabajar con Sergi a nivel más conductual, de comportamiento, normas sociales,... Veamos cada una de ellas por separado:

Carmen era la maestra de infantil de Sergi, y es recordada por los padres como una persona entrañable, cariñosa y muy amorosa con Sergi, la recuerdan con mucho cariño: Carmen fue muy buena, se portó muy bien la verdad (...) Carmen tenía mucho interés, no hacía grandes cosas en clase pero siempre tenía en cuenta avisar para que pudiéramos trabajar: "Àngels pues el niño ha hecho esto, pues el niño ha hecho esto..." Ella me lo comunicaba todo y yo ya me ponía en contacto con Mira'm para ver cómo hacerlo. (...) Tenía mucha paciencia, pero a la vez era de las que se le 'plantaba' delante y "ivenga Sergi! Esto no podemos hacerlo..." (...) Tenía carácter, porque con él en aquel entonces, necesitabas un 'par de huevos' para dominarlo, no se dejaba, no era tan fácil. (ETM2, 148 - 152).

Sin embargo, la madre siente que algo más faltó por parte de las maestras en esos años, Àngels cree que hubieran podido hacer algo más por Sergi: Volviendo la vista atrás, creo sinceramente que Sergi hubiera sido más feliz en una escuela pública trabajando por rincones y basándose en el juego simbólico. En esta escuela eran tan solo fichas y fichas y fichas... y trabajar y fichas y fichas y fichas (...). Obsesionadas con la Cartilla Palau (método fotosilábico), y dale con la Cartilla Palau y empeñándose en que tenía que leer con la Cartilla Palau. Eso fue un poco duro porque luchamos mucho y no había manera. Yo llegué a la conclusión que el tema 'constructivista' no lo conocían, no lo querían utilizar y no lo utilizaban para nada. Ellas seguían el método tradicional (...), se ciñeron a la cartilla y fue una lucha bestial (...). Tengo un mal recuerdo de eso porque no nos echaron cuenta y Sergi tuvo que aprender a leer fuera de la escuela. (ETM 3, 469)

Rocío, la educadora costeada por la familia, siempre estaba en el aula al lado de Sergi y trabajaba codo con codo con Carmen. Àngels explica porqué con esta profesional, tuvieron que dejar de trabajar al cabo de un tiempo: Rocío era buena chica, era delicada con Sergi pero tuvimos que dejar de trabajar con ella (...) En aquella época, Sergi había empezado a hablar algo, muy poco, y la comprensión la tenía muy tocada, entonces nosotros le hacíamos los calendarios, le hacíamos las programaciones. Por ejemplo "hoy tocaba gimnasia", pero llovía, a Sergi le encantaba hacer gimnasia, ¿Qué pasaba? Que no había patio y se hacía en la clase. Sergi enfadaba mucho y un día le 
clavó el lápiz en la pierna a Rocío. Ella no me lo contó, me lo contó la maestra, ella mientras tanto me decía que todo estaba bien (...) Si ella le hubiera dicho "Sergi llueve y hoy estaremos en la clase y dibujarás" no hubiera pasado nada. Tenía que anticiparle las cosas al niño, pero ella no creía en los pictogramas (EPM1, 90). Yo le decía, tienes que improvisar un dibujo "llueve, gimnasia NO" Yo me improvisaba dibujos sin saber cómo pero es que ella era pedagoga... pero ella me decía "no, es que él me entiende, las imágenes no las necesita" (ETM2, 160).

\section{3.- Si el plan no funciona cambia el plan, pero no cambies la meta}

Pasaban los meses, y a pesar de la insistencia de Àngels en que la educadora aplicara los pictogramas y trabajara basándose en imágenes, ésta seguía sin hacerlo. Llegado este punto, desde Mira'm se 'plantaron' y hablaron con la familia: me dijeron "si no te deshaces de esta chica no seguimos trabajando con Sergi, porque Sergi necesita las imágenes por encima de todo. Sin imágenes está perdido y una persona que no confía en este sistema o no tiene ganas de trabajar con este sistema fuera. No nos interesa" (ETM2, 160). Ante esta situación y la oposición de Rocío en utilizar las imágenes, la familia decidió dar un nuevo giro y prescindir de ella. Àngels y Javier priorizaron las necesidades de su hijo y decidieron buscar a una persona que pudiera hacer esta función en el aula y que, a su vez, trabajara en consonancia con el resto de profesionales de este gran equipo.

Esta nueva educadora fue Luz, una joven de 22 años con mucha implicación, con ganas de trabajar y mucha fuerza. Para la familia fue un gran apoyo, pues Luz no solo ejercía como educadora dentro del aula, sino que cuando Sergi terminaba de la escuela, se lo llevaba a su casa y trabajaba logopedia con él. Luz, estuvo trabajando con ellos un par años (hasta que se fue fuera de la localidad): con Luz ya cambiamos el chip, porque Luz se lo dibujaba todo, continuaba trabajando los pictogramas... y entonces ahí la empezó a sumar, restar llevando... empezó a leer un poquito, pero no acababa de leer del todo (EPM 1, 90) Con ella íbamos a Valencia a la Fundación Mira'm, ella venía siempre con nosotros (...) y se vio que el niño empezaba a evolucionar, lo que pasa es que no leía. (LV M,17)

Durante estos años, de los 3 a los 6 años de edad más o menos, se empezó a trabajar la integración de Sergi en el aula, sobre todo durante el periodo de tiempo que Carmen fue su maestra. La madre recuerda que: El niño relaciones sociales como tal no tenía, pero en aquella época le tenía mucho cariño a un niño que era como un Osito Yogui (su amigo Rodrigo) y a veces se acercaba a él. Pero principalmente se dedicaba a dar vueltas por el patio solo. Tenía su mundo y no necesitaba interacciones. (EPM 1, 54). No obstante, bueno es el dicho de 'el roce hace el cariño' y tanto fue así que a pesar de las dificultades comunicativas de Sergi, sus compañeros/as empezaron a interactuar más con él, a intentar entenderlo un poco más. La familia se percató de este cambio: Llegábamos a la puerta del colegio y venían a buscarlo sus amigos, y lo abrazaban y él estaba muy contento. Entonces yo ya me quedaba con una tranquilidad... Es que eso no se paga con dinero (...), una sensación muy bonita. (EPM 1, 70)

Los amigos y compañeros de Sergi son conscientes de sus dificultades de comunicación y recuerdan que Sergi estaba siempre un poco más aislado. Aun así, Sergi era aceptado y querido como uno más. Su compañero Rodrigo recuerda sentarse en clase con él y Rocío (la educadora): En infantil Sergi todavía no había empezado a comunicarse, le costaba pero (...) igual estábamos con él y jugábamos con él aunque no acabara de comunicarse. (TF CE4, 16- Eva)

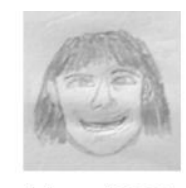

Eva (C3) 


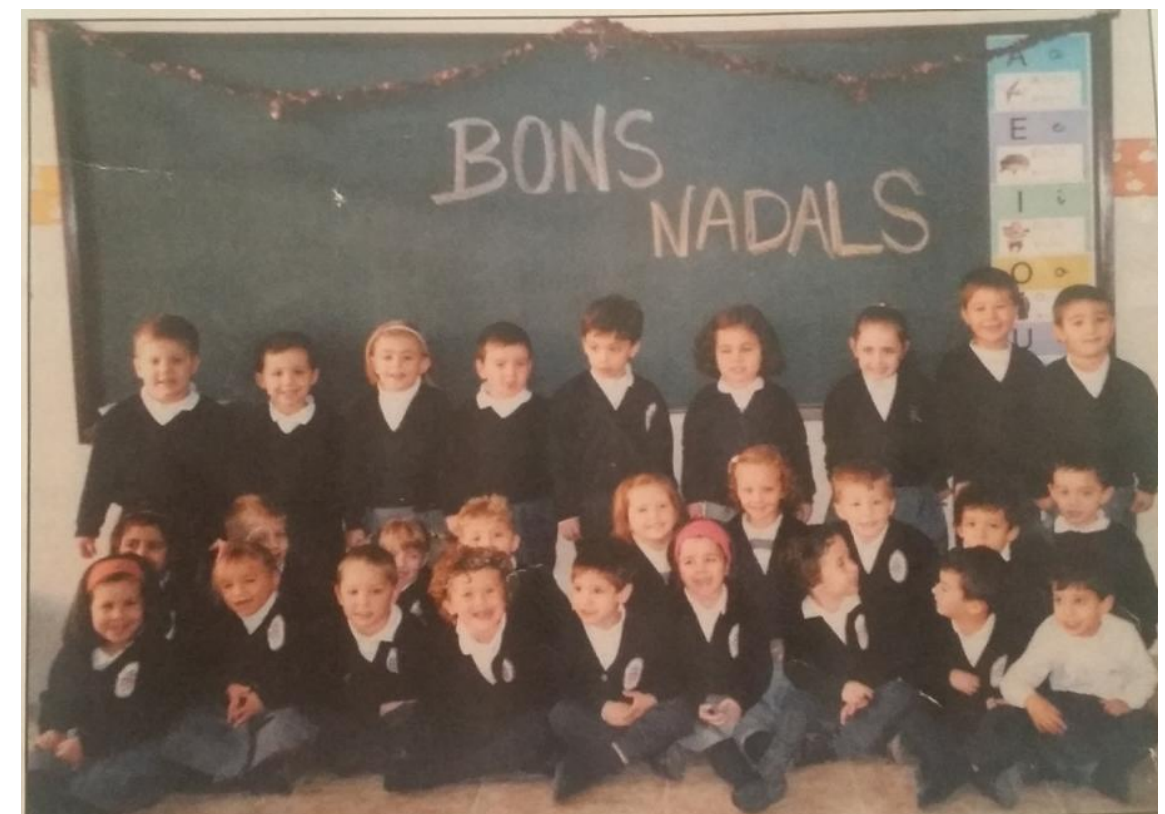

Imagen 7. Feliz Navidad. (fotografía no1, TF CE4 (R))

Gracias al trabajo desde fuera del centro, a las directrices de Mira'm y a la implicación de profesionales como Carmen e Luz, Sergi empezó a cambiar. Empezó a ser algo más receptivo con su alrededor, a interiorizar las primeras normas sociales y a formar los primeros cimientos de su aprendizaje. En ese momento, el aspecto comunicativo seguía siendo un gran hándicap para Sergi y su familia. Si bien es cierto que los padres veían a Sergi un niño feliz, era imposible saber qué pasaba por su mente. Su madre recuerda con frustración momentos como la salida del colegio: Es algo que recuerdo mucho y siempre lo cuento. Sus dos hermanos, cuando salían del colegio me decían "mamá hoy hemos hecho esto, ha venido un niño nuevo, y nos ha dicho esto o aquello..." y él pobrecito nunca me contaba nada. Salía y no sabía nunca lo que había pasado lo sabía por lo que ponían en la libreta o lo que me contaban, pero nunca porque me lo contara Serqi. Él salía bien, no salía nunca enfadado, pero siempre me quedaba con ganas de que me contara algo, eso era... un gusanito que se quedaba dentro. (EPM1, 70).

Hay que tener en cuenta, que si bien esta etapa es una de las más bonitas en cualquier niño, para Sergi y su familia fue más bien la etapa de la confusión y de la angustia. El desconcierto que provocó en la familia los primeros años hasta saber qué le pasaba y Sergi y cómo encontrar el camino de la comunicación con él fue muy duro. La madre se refiere a esta etapa con términos como frustración y confusión: La recuerdo una etapa con mucha confusión (...) y mucha frustración de no saber cómo actuar. Yo sabía que tenía un niño que era un ángel, porque lo es, y que sabía reaccionar, pero también tenía ese miedo a que depende de donde fuera, el cómo reaccionaría. Muchas veces me levantaba por la mañana y sabía que se tenía que ir de excursión y sabía que le hacía ilusión pero no sabía cómo explicarle que no vendría hasta la tarde. Era un poco de confusión, frustración, al mismo tiempo. Nerviosismo, sufrimiento siempre sufrimiento. Me planteaba ¿cómo le explico eso? Y no podía dormir, me despertaba. Y al día siquiente ¿cómo se levantará? Porque había días que decías "hoy se ha levantado más claro" pero había días que decía "hoy se ha levantado muy espeso". Siempre con ese miedo sobre el cómo. Aun así pobrecito siempre reaccionaba bien, siempre tuve la 
suerte de que reaccionaba bien. Pero recuerdo mucho esa frustración, esa confusión, ese no saber cómo. En un momento de "no quiero ir al 'cole" o cuando iba a vestirlo y no quería ponerse la ropa, recuerdo que entonces hacía venir corriendo a Gerard y le decía "mira el tete, hoy toca 'cole" y entonces me iba corriendo y le traía los pictogramas, los clics, el bocadillo de Nocilla, y ahí ya. Se motivaba y ya. (EPM1, 62)

Mi mayor preocupación no era pensar en el hoy, yo lo podía dominar, sabía cómo llevarlo, el problema era pensar en el más adelante, en lo que venía después. Todo eran dudas, dudas, dudas, ¿qué pasará? ¿Cuándo? Había que enseñárselo todo en la vida y me superaba (...). Estaba siempre en el teléfono, siempre estaba en internet, con Mira'm: "y si me hace eso, ¿qué hago?" y todo el día así, todo el día así, todo el día así, y siempre así... La verdad que fueron dos o tres años muy estresantes porque me obsesioné un poco con que yo puedo perder el tiempo, pero él no. Entonces eso se me puso mucho en la cabeza y cada segundo, cada minuto lo aprovechaba (...). Cuando vi que el reaccionaba, que él iba aprendiendo, que me iba señalando las imágenes que yo llevaba en el bolso, entonces yo pensaba "tengo que hacer más, tengo que hacer más, tengo que hacer más. No puedo perder el tiempo, no puedo perder ni un segundo". Era angustiante. (EPM1, 62).

De esta manera, el tiempo se convirtió en un detractor para Sergi. El tiempo pasaba y lo hacía rápido y mientras tanto había que conseguir que Sergi aprendiera tantas cosas como fuera posible. En el momento que Sergi salía por la puerta del colegio, empezaba otra jornada de trabajo para él, ahora con su logopeda y con su madre en casa: En aquellos momentos me faltaban 48 horas al día. Por eso me hubiera gustado que en la escuela hubieran tenido más recursos, hubiera sido de gran ayuda para mí, y el niño no hubiera tenido que trabajar tanto fuera de la escuela. A Sergi había que enseñarle conceptos, había que enseñarle tantísimas cosas fuera de ahí, que no se podía ... Me hubiera gustado (...) que escuela hubiera tenido más recursos, me hubiera quitado angustia a mí y le hubieran quitado angustia a él (EPM1, 68). Sin embargo, a pesar de esta falta de recursos en el centro y la gran carga de trabajo que esto supuso para Àngels, ella concibe que la escuela, en esta etapa, actuó como un gran facilitador para el aprendizaje de Sergi: En esta etapa la escuela fue un facilitador y a por la inclusión total. En infantil lo integraron muchísimo, ellos nos facilitaban nuestra entrada en la escuela, a Mira'm, teníamos una libreta que nos la íbamos pasando, ellos escribían y yo escribía en la libreta. Yo sabía en todo momento todo lo que hacía Sergi, "hoy hemos trabajado esto, hemos trabajado aquello" para que cuando llegara a casa yo lo pudiera saber y trabajar a partir de ahí (...) En aquella época era inclusión, completamente, porque nos facilitaban la entrada a nosotros, nos dejaron entrar materiales, que vinieran las de Mira'm las veces que hiciera falta, reuniones continuamente, no tenía que preocuparme de nada. Una maravilla. Entonces sí, en esta etapa sí. Siempre pienso que ellas, por lo que respecta a materiales, si nosotros no hubiéramos aportado no hubieran hecho nada, porque tenían 32 alumnos, una maestra sola y no tenían refuerzo (...) pero se dejaba ayudar, y entonces ahí estaba lo bueno del tema. (EPM1, 52).

\section{4.- El $90 \%$ del éxito se basa simplemente en insistir (Woody Allen)}

Con mucho esfuerzo y perseverancia, la familia de Sergi había logrado lo que deseaba para su hijo: un centro donde Sergi fuera no solo integrado, sino incluido, donde sus compañeros/as lo quisieran y trataran bien, con profesionales a su disposición, donde ellos pudieran participar como un elemento educativo más y contando siempre con el respaldo y apoyo de Mira'm. En aquellos momentos entre todos conformaban un equipo coordinado y bien articulado, la familia era el pilar, el eje central y Mira'm era 
el satélite que giraba en torno a todo el equipo desde diferentes ópticas (...) y con una visión externa del proceso. (ET Edu, 99). El tiempo pasaba rápido, Sergi cumplió 6 años y empezó las clases en educación primaria. El entorno era el mismo, el grupo de alumnos se mantenía intacto, los profesionales referentes eran los mismos, y únicamente cambiaba el docente. No se vislumbraba ninguna problemática.

Durante los 2 primeros años de educación primaria ( 1 - y 20 curso) se encontraron con una maestra permisiva, dispuesta pero sincera con los padres de Sergi. Debido a su edad, a la carga de trabajo que supone el primer curso y el agotamiento laboral, no aseguraba poder hacer por Sergi todo lo que los padres quisieran, era la señorita Júlia. Júlia, que llevaba muchos años trabajando en educación, al conocer a Sergi y el sistema de trabajo que había que seguir con él se sinceró con la familia: $\underline{O s}$ voy a ser sincera, a mi esto me pilla un poco mayor. Tengo 32 alumnos que llegan a primaria, algunos no saben leer, algunos saben leer, algunos no sé cuánto, aunque tenga ayuda con Luz, a mi esto me pilla mayor. (EPM1, 90). Además, a pesar de que la maestra aseguraba no poder implicarse con Sergi tanto como quisiera, la familia fue adoptando nuevas posturas respecto a Sergi. Decidieron que debía empezar a estar unas horas solo en el aula, fomentando de esta manera su autonomía y ofreciéndole la oportunidad de aprender del conjunto de la clase.

De vez en cuando, muy de vez en cuando, podían darse situaciones con Sergi un tanto inesperadas y relacionadas con conductas inadecuadas que había que atajar. En estas ocasiones la maestra establecía rápidamente contacto con la madre para que ésta lo corrigiera trabajando desde casa: Recuerdo que cuando se quedó solo no le hacía caso a la maestra y cuando le decía "Sergi, ven que te corrijo la actividad", iba saltando y haciendo la rana por la clase. La maestra me lo dijo "Àngels esta conducta no me gusta, mira a ver si puedes hacer algo" (EPM1, 90). Esta clase de actitudes no solían ser habituales en Sergi y, desde luego, no significaban un acto retador o desobediente a la autoridad, simplemente, como indica su madre: seguramente habría visto Barrio Sésamo y a él le encantaba la Rana Gustavo. La rana hacia 'croac, croac' y él también (ETM1, 220), pero estas acciones no se podían consentir en el aula y Àngels debía hacer lo que estuviera en sus manos por corregirlo.

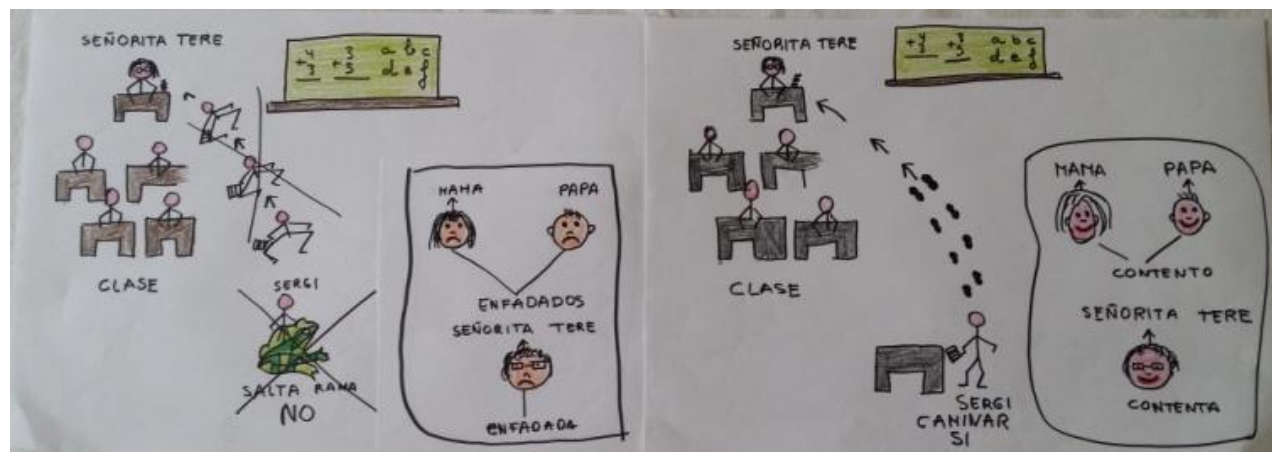

Imagen 8. Historia social (Documento 42, TDE M)

Yo hice esta historia social, basándome en la cara de enfado y contento porque la parte de la inteligencia emocional Sergi la tenía más o menos desarrollada. Las emociones más fuertes las entendía desde muy pequeño y no soportaba ver a nadie enfadado, a ninguna de las personas que le rodeaban. Entonces utilizaba esta táctica para quitarle malos hábitos que él iba adquiriendo. (TDE M, 58)

Fueron muchas las historias sociales y explicaciones visuales que Àngels tuvo que ir 
inventando e ideando para que Sergi entendiera qué cosas se podían hacer y qué cosas no. El padre, recuerda también un conflicto en clase que se resolvió con un simple folio y un bolígrafo: Se ve que se peleaba casi todos los días porque quería estar el primero en la fila para entrar a clase (...) Entonces Àngels dibujó cuatro niños y le puso "primero, segundo, tercero y cuarto. Sergi cuarto, papá contento, mamá contenta y señorita contenta". Volvió a poner lo mismo y puso primero a Sergi y puso "señorita enfadada, papá enfadado y mamá enfadada" y le dio el papel y el niño fue y se puso el cuarto y se acabó el problema. (EPM 2, 82). El problema vino cuando a los días de tener esto muy claro faltó a clase el segundo de la fila. Esta situación se convirtió en un tanto caótica para él, pues su gran memoria y aquello que había aprendido días antes le indicaban que él debía ir el cuarto en la fila. Le costó muchísimo comprender que esto se daba siempre y cuando no faltara ninguno de sus compañeros, porque entonces debería ocupar el tercer lugar.

Àngels, siempre ha estado muy pendiente de los materiales y recursos que se utilizaban en el aula con Sergi. Ya en los primeros años de Sergi en la escuela, la madre llegaba al centro cargada con cientos de materiales para todo el curso escolar: cuando empezaba el curso yo llegaba allí con dos maletas llenas de materiales idos maletas! $Y$ cuando acababa el curso me decían "Ángels, trae las maletas". Iba y lo recogía todo. (EPM1, 76). El requerimiento de construir o elaborar un nuevo material siempre iba vinculado a una necesidad de Sergi (manifiesta o no), la madre lo explica del siguiente modo: Por ejemplo, las de valenciano me decían "vamos a trabajar conceptos", pues yo buscaba libros, buscaba conceptos, si me decían "vamos a trabajar verbos", pues buscaba imágenes de verbos. Y lo tenía todo clasificado por carpetas, una carpeta de una cosa, otra carpeta de otra,... Entonces yo iba haciendo material y lo iba llevando. Si por ejemplo me decían "Ahora trabajaremos este libro para trabajar la grafía", pues yo lo compraba y lo llevaba todo allí. Todo esto lo hacía por la noche, tenía que acoplar imágenes, después llevarlas, plastificarlas, ponerlas en un fondo... todo eso lo hacía yo por la noche. (ETM1, 161-163).

Este duro y laborioso trabajo, a la vez que estar al mando de una gran familia, no pasaba desapercibido para cualquiera que conociera a Àngels. Mamen, maestra de Sergi en 3 y 40 de primaria, recuerda con gran admiración la dedicación y creatividad de Àngels elaborando materiales: Es Impresionante (...), yo le decía "es que yo no sé cómo puedes hacerlo", lo de los materiales a mí me dejo alucinada. Yo no lo he visto nunca, nunca. (ET Maes, 81-83). Y es que Àngels no solo se volcaba en elaborar materiales comunicativos y organizativos para Sergi, sino que además preparaba y elaboraba los materiales didácticos que él necesitaba para trabajar en clase. Àngels lo hacía de la siguiente manera: Yo le pedía el libro al niño de mis vecinos de abajo, que es como Sergi, "Marina, déjame el libro por favor". Yo miraba los contenidos y se los adaptaba a Sergi. Así cuando la maestra explicara esa parte en clase Sergi también tendría su material y yo pensaba "algo le quedará" y así era, lo hacía yo todo (EPM 1, 117). Por ejemplo, ¿qué estaban dando? ¿el ciclo del agua? Pues yo le imprimía todo lo del ciclo del agua, en ejercicios y todo. Pero si yo no lo llevaba, el niño no tenía nada. (ETM 1, 181).

La familia era consciente que si ellos no aportaban y elaboraban el material para Sergi, éste estaría mucho tiempo de brazos cruzados. Saben de primera mano del caso de una alumna con Síndrome de Down que estudiaba en el mismo centro que pasaba horas y horas haciendo caligrafías y sumas porque no le preparaban nada. Àngels explica hasta que punto han sido imprescindibles en la elaboración de los recursos materiales : los materiales allí siempre los hemos traído nosotros. Nunca le han dado 
nada, nada, nada, nada. Ni una simple fotocopia, ni una ficha inada! Pero contenta estoy que hayan trabajado todo lo que yo he traído y que el niño haya ido avanzando, porque si no hubiera sido por nosotros no hubiera hecho nada. (EPM 1, 111) Bueno, $\underline{a}$ veces pienso que a lo mejor hubieran hecho algo, digo yo. A lo mejor es culpa nuestra por haber traído el material porque dirían "como lo traen ellos nosotros no hacemos nada", ya no sé qué pensar. Lo que sí sé es yo veía que cuando se acababa algo, si no llevaba nada no hacía nada... (EPM 1, 113)

La escuela nos ha permitido que nosotros lleváramos el material, dejaban entrar a las personas que han trabajado con él, y tanto en infantil como en primaria han ayudado al niño a interactuar al niño con actividades, lo han hecho participar y han trabajado de acuerdo con el papel del educador, que ha sido siempre muy importante. (...) Ahora, lo que es desde dentro, ellos preocuparse por buscar material no. Lo que nosotros hemos hecho desde fuera, eso no lo hemos tenido nunca desde dentro. Hemos sido nosotros los que hemos aportado todo siempre a la escuela. Incluso no se ha dado el caso de llegar un nuevo curso y que nos digan "pues este año hemos hecho el ACls", tampoco. Las adaptaciones las hacían siempre basándose en el material que nosotros habíamos llevado. (EPM 2, 35). Creo eso no era normal, lo normal hubiera sido que nosotros fuéramos colaboradores del proceso, eso hubiera sido normal. (EPM 2, 253)

De esta manera, la familia se convirtió en la guía del proceso educativo de Sergi, tanto dentro como fuera del colegio y a pesar de no ser éste un ideal educativo, la familia se siente satisfecha y orgullosa de haberlo podido hacer, otra opción hubiera sido simplemente peor: En el fondo hemos sido afortunados, afortunados en el sentido de que nosotros nos hemos sabido mover mucho por fuera, hemos sabido buscar buenos profesionales: Mira'm, la logopeda, educadores,... Ellos están muy preparados y nos han ayudado mucho a nosotros, nosotros hemos llevado todo esto a la escuela y la escuela lo ha llevado adelante con nuestra ayuda, con los educadores externos, con las maestras. (...) A pesar de todos los pesares pienso que hemos sido afortunados porque hemos podido dirigir nosotros el trabajo, es como si nos hubiéramos quedado nosotros con el niño. (...) No ha sido la escuela en casa, pero sí que se ha hecho lo que nosotros hemos dicho (EPM 2, 249)

Como es de esperar, en estos años, las directrices de la familia traspasaban a los distintos ámbitos y sus aportaciones servían de guía para cualquier persona que trabajara con Sergi. Para ello, Àngels no solo se valía de buscar horas y horas en internet o en la librería, sino contaba con pequeños 'consejeros' que le ayudaban en esta difícil labor. Contaban con personas como Juanjo, logopeda durante unos años en el centro, las personas de Mira'm que orientaban desde la distancia o incluso la figura del educador de Sergi que daba ideas sobre posibles materiales o temáticas.

Cuando Àngels tenía la información que necesitaba, la organizaba y sintetizaba en forma de materiales y actividades para Sergi que después se aplicaban en el aula. Una de sus maestras reconoce la gran labor de la madre en este sentido: Lo fuerte es que estábamos en conocimiento del medio dando las plantas y ya veías que te aparecía en un dosier todas las 'fichas' de las plantas, con todas las partes de las plantas, todo adaptado a él. Pero es que dabas el tema de la historia y ya tenía su dosier con el tema de la historia, estaba todo. Todo, todo, todo (ET Maes, 83) Tenía además su calendario (...) al final de la clase, en un rincón (...) y allí estaba todo su día a día. Estaba hasta lo que hacía cuando salía a las 5 de la tarde, las fotos de los maestros, cada uno con la asignatura que daba, si había una excursión lo poníamos alli, todo, todo, todo. (...)Por supuesto era también material hecho por ella, no es que fuera y comprara el material, o 
sea, hecho por ella. Todo plastificado, todo, todo. (ET Maes, 83).

\section{5.- No hay mejor educador que el que cree en sus alumnos (Joel Artigas)}

La humildad, la proximidad y la dulzura son algunas de las características de las maestras de Sergi en la escuela. Carmen y Júlia, maestras de infantil y del primer ciclo de primaria respectivamente destacaron por su cariño hacia Sergi y saber tratar con él; como dice Àngels, 'sabían llevarlo'. Más adelante, aparecieron en escena maestras como Mamen ( 2 o ciclo de primaria) y Ma Jesús (3r ciclo de primaria). Ambas, destacan por su bondad con Sergi, trasmitir ternura y aprecio no solo hacía él sino también hacia sus padres y hermanos. $M$ a Jesús, había sido monja durante unos años y transmitía amabilidad, benevolencia y serenidad en a su práctica diaria.

Mamen, había sido su maestra de educación física durante el primer ciclo de primaria y ya lo conocía. Sin embargo, reconoce que el día que se asignaron la tutoría de este grupo sintió miedo de no saber hacerlo bien: Yo ya lo conocía porque había sido su maestra de educación física y nunca había tenido ningún problema con él, pero debo reconocer que me hizo respeto cuando lo tenía que tener de tutora. Era mi primer año de tutora y pensé "ostras, ¿lo sabré hacer? ¿sabré llevarlo?" Entonces fue cuando, en septiembre, los primeros días que aún no hay alumnos, vino Àngels a hablar conmigo. Ella me explicó un poco lo de Sergi, me explicó cómo trabajaba, que estaba la logopeda, todo lo que le hacía Àngels, que le llevaba todo, todo el material que le aportaba, y entonces ya fue cuando empecé a conocer a Àngels más en profundidad (...) Ella me informó un poco de cómo estaban trabajando con Sergi, de todos los especialistas que tenían, y entonces, me dijo que en clase también estaría Francisco, que empezaba ese año como educador sustituyendo a Luz. (ET Maes, 23). Francisco y yo empezamos a la vez, y a mí la verdad es que me daba mucho respeto porque además de lo que suponía para mi esta tutoría tenía a una persona adulta dentro de clase que no conocía. Lo conocía de vista del pueblo, pero pensaba "pues no sé yo cómo irá la cosa..." Y la verdad es que al principio me dio mucho, mucho respeto (ET Maes, 25).

La familia, estableció de una manera muy clara cuál sería el papel de Francisco y qué esperaban de él: Desde un principio, acordamos muy claramente que la relación de la familia y la escuela tenía que ser muy directa, y mi figura consistía fundamentalmente no solo en apoyar a Sergi como educador o profesor de apoyo dentro del aula, sino también de intentar mantener con la familia toda la información diaria y que ellos pudieran utilizarla después cuando Sergi saliera de la escuela para continuar trabajándolo. Ellos pensaban que toda actuación de la escuela no servía de nada si después en casa no continuaban estimulándolo. Era una estimulación continua, continua. (ET Edu, 23)

Maestra y educador, eran personas muy distintas entre ellas pero que aprendieron a combinarse generando un tándem muy interesante. Mamen: maestra con buena predisposición, colaboradora, empática, coordinadora, disponible pero sin dejar de ser directiva respeto a su función docente, con un fuerte carácter y mucho respeto (ET Edu, 26). Francisco: una persona que lo vivía mucho y estaba muy encima de Sergi (...), se volcó mucho en él. Cualquier cosa que hacía lo celebraba por lo alto estaba muy coordinado con Àngels (...) y tuvo un papel fundamental. Sergi lo quería como un amigo, conectaban muchísimo. (ET Maes, 96)

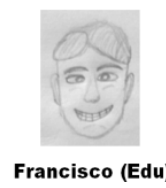

En esta etapa, la familia seguía estando en la base de este gran equipo trabajando, dando directrices, aportando materiales, ayudando a preparar exámenes,... pero la 
diferencia es que esta vez, desde dentro del aula, la inclusión y exigencia académica con Sergi alcanzó límites inimaginables años atrás. El educador, observó como el trabajo de la maestra, junto con el de la familia, produjeron en Sergi una explosión académica y personal: Mamen siempre tuvo muy claro lo que tenía que hacer, y simplemente era tratarlo como un más. Exigirle lo mismo que a los demás, siempre respetar su nivel, pero respecto a su nivel, el nivel de exigencia era absoluto. Es decir, si íbamos a sacar resultados tenían que ser óptimos, no podían ser mínimos y a partir de ahí hubo un crecimiento madurativo y evolutivo de Sergi que a la vez facilitaba más todo el proceso. Por lo tanto, todo el material que se iba incorporando, con más dificultades o menos dificultades, Sergi lo iba interiorizando e iba, evidentemente, creciendo poco a poco intelectualmente con este material. Es muy importante también manifestar que uno de los aspectos fundamentales era que pudiera estar el máximo número de horas dentro del aula, incluso en las horas en las que yo no estaba. Esta fue mi lucha siempre, y la familia lo tenía igual de claro que yo (...) Las personas que entendieron esto no tuvieron ningún problema en hacerlo y Sergi se benefició muchísimo. Esta maestra logró romper dinámicas de aula importantes, hizo muchos trabajos en grupo y reorganizó el aula de forma que todos los alumnos pudieran participar. Rompimos la estructura típica de las mesas, las puso en ' $U$ ', las íbamos cambiando y donde iba Sergi, iba yo. El resto de alumnos me concebían como uno más. Sergi y Francisco eran un pack (ET Edu, 28)

En el aula, Mamen hacía que Sergi participara activamente y que sintiera su pertenencia a ella: Sergi tenía contenidos totalmente diferentes a lo que nosotros hacíamos. Él estaba con Francisco y el que realmente hacía el trabajo con él era Francisco, lo que pasa es que yo aprovechaba cualquier cosa para que Sergi también pudiera participar en la clase. Por ejemplo, si estábamos dando las sumas y él también estaba haciendo las sumas con Francisco (...), pues lo hacía salir a la pizarra para que hiciera una suma igual que los otros compañeros. En conocimiento del medio, por ejemplo, que le encantaba porque eran cosas que él entendía, cuando hablábamos de animales o temas que a él le gustaban lo hacía participar, hablar de algún animal o que nos contara alguna anécdota (...). Si recogía deberes, recogíamos también los deberes de Sergi, como uno más (ET Maes, 69). El cometido de Mamen era lograr la inclusión, y esto era apreciado y valorado por el resto de alumnos de la clase: Mamen se implicaba mucho en Sergi (...), estaba mucho con él pero estaba también con todos, no solo se centraba en Sergi (...). Estaba con él, le explicaba o le ayudaba, venía con nosotros otra vez a explicarnos... ¿Eso qué dices que uno no se pueden partir en dos? Pues ella se partía en dos. (ETG CE, 180-186- Jordi).

Este trabajo de incluir a Sergi en el aula a través de una participación activa, venía acompañado del duro trabajo que Francisco y Àngels realizaban desde sus diferentes posiciones. Mamen considera que el trabajo de estos fue la clave para el progreso de Sergi: Yo pienso que el gran mérito lo han tenido sus padres, sobretodo Àngels. Yo he alucinado. Àngels es una madre 10, por no ponerle un 11. Àngels es una persona encantadora y los que realmente hicieron el trabajo yo pienso que fueron ellos, y Francisco. Yo me limité a lo que era integrarlo dentro de clase, a que fuera uno más, que ya era fácil porque los niños lo querían muchísimo, pero aquí quien hizo el trabajo fueron Francisco y sus padres. Es decir, sus padres han sido su pilar y los que le han guiado tanto a nivel académico como a nivel de conducta. Yo, como maestra, lo tenía muy fácil, no he hecho tanto trabajo como parece que haya hecho (ET Maes, 37).

A este gran equipo conformado por la maestra de Sergi, el educador y la familia falta añadirle un cuarto elemento: Azucena. Azucena, fue la logopeda apareció en la vida de 
Sergi tras la marcha de Luz, recordemos que Luz fue su educadora en el centro educativo y su logopeda fuera de este. En aquel entonces, Sergi llevaba un par de años trabajando a nivel logopédico fuera del centro con Luz y ya estaba acostumbrado a trabajar con dibujos y pictogramas. Sergi había empezado a sumar, a restar llevando y parecía que empezaba a leer. Sin embargo, no se sabía por qué no acababa de lanzarse a la lectura, algo fallaba. Ante aquel aparente bloqueo lector de Sergi, Àngels decidió ir al centro 'Entender y Hablar' de Marc Monfort : yo me iba a ir Madrid, a lo de Marc Montfort, al centro de Entender y Hablar, ya me había puesto en contacto con ellos y me iba a ir 5 o 6 meses a Madrid a ver si me decían, "no se puede" o "sí que se puede", porque aquí no había Cristo que le hiciera leer (EPM 1,90). Estando a punto de ir, apareció en la librería familiar una chica que venía a fotocopiar un sistema de pictogramas visuales, el SPC. Àngels se sorprendió de que alguien llevara ese material y se pusieron a conversar: Yo le dije, 'este material lo conozco, yo lo tengo, el BoardMaker" y entablamos un poco de conversación. Al cabo de unos días volvió y le comenté que me iba a Madrid, (...) y ella me dijo "espérate, no te vayas a Madrid, dame dos o tres meses con Sergi". Y efectivamente en dos o tres meses Sergi leyó y ya no fui a Madrid. Ella le enseñó a leer. (ETM 1, 166 - 169). Así fue como Azu se incorporó a este equipo de trabajo con Sergi.

Más o menos, en la época en la que conocieron a Azu Sergi había empezado a hablar. Hasta el momento, la comunicación con él estaba basada en pictogramas y palabras sueltas que ayudaban a entender sus necesidades. Àngels recuerda los problemas de expresión y comunicación que tenía Sergi en esos momentos: Él estaba que no acababa de arrancar, estaba enganchado con las trabadas, las inversas... ahí 'enganchado'. En cambio, cuando Azucena llegó empezó "bueno, ya verás, no sé cuanto... 'patapim, patapam'". Unos machaques de 'no te menees' y el niño ahí empezó a hablar y más tarde a leer. (ETM 2,178).

Hasta entonces, debido a las dificultades comunicativas y la gran retentiva que posee, Sergi optó por las ecolalias basadas en extractos de películas. Empezó a utilizar este tipo de estrategia como medio de comunicación. Su padre rememora situaciones en las que Sergi le puso en un cierto compromiso: él se aprendió frases enteras y empezó a hablar así. Él se aprendía frases enteras de las películas y las ponía donde las tenía que poner, y normalmente quedaban bien. Lo que pasaba es que a veces eran de una pedantería total. Una vez subíamos en el ascensor y dijo "mi padre dice "la regla de las reglas es que no hay ninguna regla", y la gente se me quedaba mirando como diciendo "ipues que imbécil este!". Después descubrimos que era de una película. (EPM 2, 192). Él hacía como propias frases y expresiones y sentimientos que veía en las películas, estaba actuando. Como si de una frase hecha se tratara, "aquí va esta frase" y 'patapam', daba un 'martillazo' y la soltaba. (ET P, 67). Cuando Azu empezó a trabajar con él, enseguida se percató de este tipo de ecolalias en Sergi y empezó a trabajarlas. Àngels explica: Azu fue quitando toda esa imitación, empezó a trabajar con historias sociales, empezó a trabajar la Teoría de la Mente "¿qué piensas? ¿qué piensa? ¿qué ves?", para conseguir que el niño empatizara con su entorno. La verdad es que Azucena lo ha conseguido todo. (ETM 2, 178)

Hasta que conoció a Azu, el mundo de la lectura había sido un mundo enigmático para Sergi. Los libros, más allá de las imágenes, se convertían en rompecabezas para él, Sergi sabía que ahí estaba la información, pero no sabía cómo sacarla. Cuando Azu conoció a Sergi, éste estaba deseoso de aprender y descifrar aquello que ponía en los libros. Ella misma recuerda verlo sentado entre libros en la librería de sus abuelos: Cuando lo conocí en la librería, recuerdo que me dijo Àngels "mira Sergi está ahí en el fondo".

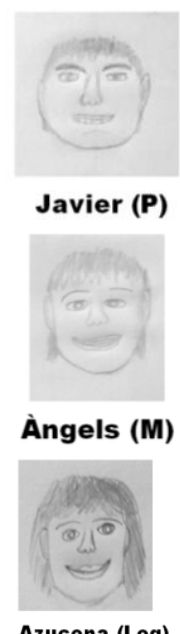

Azucena (Log) 
Estaba entre libros, mirando libros, porque a él le encantaban. Su madre y yo comentábamos "es que él quiere, y se le nota", y entonces es ¿cómo? ¿por qué no podemos encontrar la vía de ayudarle? La verdad es que a medida que fuimos trabajando conciencia fonológica, él fue enlazando las letras porque las conocía, sabía construir sílabas, incluso palabras sencillas. $Y$ yo vi aquello y pensé "iostras! si ha aprendido esto, es capaz de aprender, eso es evidente". Y poco a poco encontramos el camino (ET Log, 17).

El contacto con la lectoescritura le permitió a Sergi aprender a generar, aprender a decir, a construir frases, a ¿esto qué significa?, el concepto del tiempo, del pasado, del futuro, ¿cómo utilizar esta partícula?, ¿qué significa esta pregunta? Todo eso le abrió tanto la mente para comprender, para hacerse entender,... En ese momento acababa de acceder al lenguaje oral, y estaba empezando a ampliar sus conocimientos. Esto, unido a que aprendió a leer y a escribir le hizo crecer muchísimo (ET Log, 139). De hecho, el propio Sergi reconoce este trabajo en Azucena y la concibe una profesional pero también una amiga: Azu es mi logopeda y me ayuda a aprender de todo: sobre el dinero, a hablar bien, matemáticas. También hablamos sobre el futuro, presente y el pasado. Se preocupa mucho por mí (...) Yo la quiero mucho (...), pero a veces me enfado con ella porque es muy dura aunque sé que lo hace para que pueda aprender más. (ET S, 246-252).

Esta etapa de la vida de Sergi, entre los 8 y los 12 años, fueron años fáciles y cómodos para Sergi y su familia. La familia seguía siendo el eje vertebrador del equipo de profesionales que trabajaban con Sergi. Para lograr que aprendiera, la primera premisa era que el foco de atención había que ponerlo en Sergi, es decir, sus necesidades y motivaciones personales eran la base de cualquier planteamiento pedagógico. Dicho de otra manera, Sergi era el guía de su propio aprendizaje: él es el que guía el trabajo, en el sentido de que él siempre va expresando sus necesidades contantemente. Es el primero que nos marca los objetivos, porque igual algo nos puede parecer importante pero luego nos damos cuenta de que para él no. (ET Log, 17). Una vez, esta premisa era asumida, había que tener en cuenta diversos aspectos:

1. El aprendizaje debía estar basado en imágenes y elementos visuales

2. Había que anticiparle los hechos a Sergi para evitar situaciones de estrés y desconcierto

3. Los aprendizajes debían estar lo más vinculados a la realidad posible.

Precisamente, el último de estos 3 elementos es destacado por su logopeda Azucena. En la medida en que los aprendizajes estén vinculados a la realidad, más fácil será para Sergi relacionarlos con ejemplos reales y aplicarlo en su día a día: La forma de hacer que él asocie e interiorice los conceptos con más rapidez es haciéndolo todo muy unido al dibujo y muy unido a la 'teatralización'. Cuando Sergi vive algo, cuando le estás enseñando una cosa que está viendo, que es física o de su día a día, es más fácil que lo aprenda. (ET Log, 17).

El sistema de trabajo con Sergi era aceptado y aplicado por todas las partes de este gran equipo y fruto de eso Sergi empezó a dar grandes avances a nivel madurativo y académico. Uno de los campos en los que más evolución se pudo apreciar fue en cuanto a su lenguaje. A los 8 años, más o menos, Sergi empezó a hablar y con 10 ya podía explicar cosas perfectamente. Su maestra Mamen recalca que pudo observar este cambio en primera persona: Noté el cambio sobretodo en el habla y a la hora de hacer frases, ya construía frases enteras... Él te podía explicar cualquier cosa, dentro de

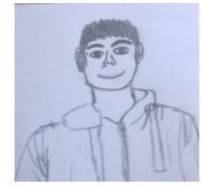

Sergi (S)

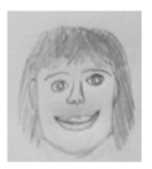

Azucena (Log) 
sus limitaciones. A lo mejor se dejaba preposiciones o se podía dejar algo, pero a su manera hacía frases que podías entender perfectamente. Ahí fue donde noté mucho cambio, en el habla. (ET Maes, 91). En relación a esto, su logopeda Azucena recalca cómo una vez que se abrió el camino del lenguaje y la comunicación, el resto de aprendizajes se volvieron más sencillos para Sergi: En todo el proceso de adquisición del lenquaje y de la lectoescritura, Sergi aprendió tantas cosas, y había estado tanto tiempo 'en blanco' (...) que tenía cosas abiertas, sin terminar de aprender. Por ejemplo, conocía las letras del abecedario pero no había nada más, se había quedado ahi; había empezado a hablar pero el tema de construir frases no lo tenía demasiado claro o no sabía la diferencia entre una palabra y una frase. Tenía muchas cosas abiertas pero necesitaba encaminarlas, de manera que cuando encontró el camino empezó a crecer. (ET Log, 123)

Otro de los grandes avances que se pudieron observar en Sergi fue en relación a la apertura hacia su entorno. Con el paso del tiempo, y a medida que él podía entender y relacionarse mejor con su entorno empezó a ser más partícipe de este, a abrirse más a las diferentes oportunidades que se le brindaban. Su educador explica el cambio que vivió con respecto a formar parte de representaciones teatrales en el centro: El centro Virgen del Carmen, ha sido una escuela que siempre ha fomentado la participación de los alumnos en representaciones teatrales, en fiestas de final de curso,... y Sergi antes no quería salir nunca. Sin embargo, cerca de los 11 o 12 años, no solo salía en estas actuaciones sino que además tenía un papel representativo, decía frases, participaba en las obras,... (...) Recuerdo la primera obra de teatro en la que él participó. Àngels estaba asustada porque no sabía lo que haría y yo estaba de acuerdo con ella. Sergi salió, se aprendió el papel que tenía que decir, unas frases o una canción, y participó como uno más. Hasta entonces no había querido salir nunca, no iba a ninguna representación y al final, como producto de esa naturalidad en su crecimiento lo hizo todo. (ET Edu, 47).

Toda esta evolución, estos avances a nivel cognitivo y social acabaron por dar lugar a algo mucho más completo. Sergi estaba creciendo a nivel académico pero también a nivel personal. La madre reconoce este crecimiento en Sergi y desea que siga esta progresión en el futuro: Yo he visto un cambio muy grande en Sergi. Yo siempre pensaba que lo tendría que llevar con la maleta a todos los sitios, pero de repente he visto que todo lo que le hemos ido enseñando, él se ha interiorizado. (...) Lo único que me da miedo es que aún queda mucho trabajo hasta que se pueda expresar bien del todo. A mí me gustaría que trabajara 10 años más con logopedia a ver si puede expresarse mejor, que la gente le entendiera a él y él entendiera a los demás. Hemos visto un cambio muy grande en Sergi y a veces lo comentamos "si nos lo hubieran dicho no nos lo hubiéramos creído" (EPM 2, 453).

\section{4.- Un día en la vida de....}

En aquellos momentos, un día en la vida de Sergi era sinónimo de múltiples momentos, personas y espacios diferentes. Cuando empezaba el día, Sergi salía de su casa con sus hermanos (Gerard y Xavi) camino del colegio. A su llegada lo esperaban sus compañer@s y amig@s y empezaba el trabajo en el aula. Allí contaba con el apoyo y ayuda de la maestra y, en las asignaturas instrumentales, con Francisco, su educador. Ciertas horas, Sergi las pasaba fuera del aula acompañado de la profesional de Pedagogía Terapéutica o el logopeda del centro. Cuando terminaban las clases, a eso de las 5 de la tarde, Sergi se dirigía a su casa de nuevo con los hermanos para merendar y empezar la jornada de la tarde. En función del día de la semana en el que estuviera, 
sus tardes se repartían entre Azu, la logopeda, la Escuela de Arte o practicando natación en la piscina. El día terminaba en casa, trabajando otro tanto con la madre (repasando, realizando ejercicios o aprendiendo nuevos conceptos) para finalmente jugar un poco con los hermanos, cenar en familia y acostarse.

Desde bien entrada la mañana, Sergi empezaba sus quehaceres con júbilo y entusiasmo. Su educador, recuerda la alegría con la que él acudía siempre al centro: Él siempre ha querido ir a la escuela, siempre, porque yo entiendo que para él la normalidad de ir a la escuela lo hacía sentir uno más. No podía entender el no ir a la escuela, y la escuela aunque a veces no le gustaba, había propuestas preparadas para él y siempre ha ido muy cómodo (...). Cuando él llegaba lo veías llegar como si fuera un militar en un desfile. Yo creo que la escuela era un hábito más, era un hábito que a él, aunque no todo, una parte muy importante del mismo le gustaba, Él entendía que a la escuela iba a pasárselo bien, no tenía ningún conflicto, y dentro de la escuela tenía actividades que le gustaban más y otras que le gustaban menos, pero yo creo que se sentía bien, se sentía feliz, le gustaba, lo tenía como un hábito, un hábito cotidiano (ET Edu,76-78).

A su llegada al centro, le esperaban los compañeros y compañeras con los que compartía espacios y amistad desde los 3 años. Esta amistad se vio maximizada a partir del trabajo y dedicación de Mamen por su integración y ella misma pudo observar la relación de respeto y cariño entre Sergi y sus amigos del colegio: la relación con los compañeros era buenísima, era buenísima. Además a mí me llamaba la atención porque si alguna vez tenía algún favoritismo con Sergi nadie se quejaba nunca. Las típicas tonterías de "Sergi va, pues sal tú el primero", que eso se lo haces a otro y se quejan "'Hala! iQue 'morro' señorita!" Si era Sergi no pasaba nada. Es decir, todos lo respetaban y Sergi era Sergi. Era intocable. A la hora de relacionarse si a él le apetecía jugar a lo que fuera, en ningún momento se le decía que no. Él podía jugar a lo que quisiera (...) Sin embargo, sí que es verdad que a veces notaba que él necesitaba su espacio. Se iba por el patio, se iba solo y estaba en su mundo. Alguna vez sí que lo hacía, había días que sí. (ET Maes, 118). Esta relación tan particular entre Sergi y sus amigos no solo era percibida desde fuera, sino que amigos como Vero y Jordi también hacen referencia a ella: Cuando hacíamos partidos entre cursos él siempre se acercaba y participaba, siempre súper entusiasmado (ETG CE, 126- Vero), incluso recuerdo un día que aunque jugáramos con dos equipos diferentes estábamos todos con Sergi. Sergi estaba en los dos equipos. Nos reímos un montón aquel día (ETG CE, 85- Jordi). Sin embargo, había días que podía no interesarle algo, y se iba. Simplemente no le interesaba y decía "me voy" y se iba. (ETG CE, 124- Eva). Era como si necesitara tomarse su tiempo, todo el mundo necesita su tiempo. Lo que pasa es que nosotros no podemos estar en una conversación que no nos importa, pues no podemos desconectar. Nos enseñan a decir "sí, sí,..." a pesar de que no nos interese. Pero él, si no le interesa, no está. (ETG CE, 279- Eva)

Como bien indica su hermano, el caso de Sergi hay dos formas de tomárselo: o piensas que "no vale la pena" o lo admiras mucho, y esta última fue la opción que tomaron sus compañeros. Todos lo han admirado mucho y le han tenido mucho cariño (EG H1 y H2, 152- Gerard). Tanto es así, que Sergi tiene muy claro que las personas de su grupoclase, no solo son sus compañeros y compañeras, sino que son sus amigos: $A$ Rodrigo, a Eva, a Vero, a Jordi, a Santi, Carla, Mar,... los conocí cuando estaba en la guardería y hemos crecido juntos. Han sido mis amigos desde entonces (ET S, 130). Yo siempre les he ayudado mucho y ellos me ayudaron también a mí a aprender (...) Les solía ayudar en cosas de tecnología y en informática, y también les explicaba que no tiene que
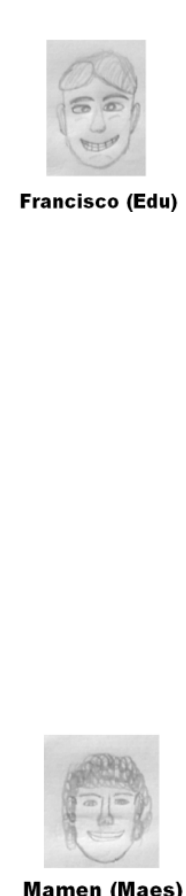

Mamen (Maes)

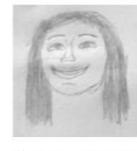

Vero (C4)

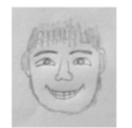

Jordi (C2)

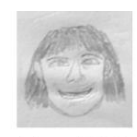

Eva (C3)

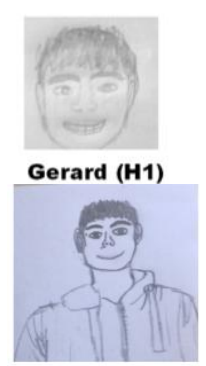

Sergi (S) 


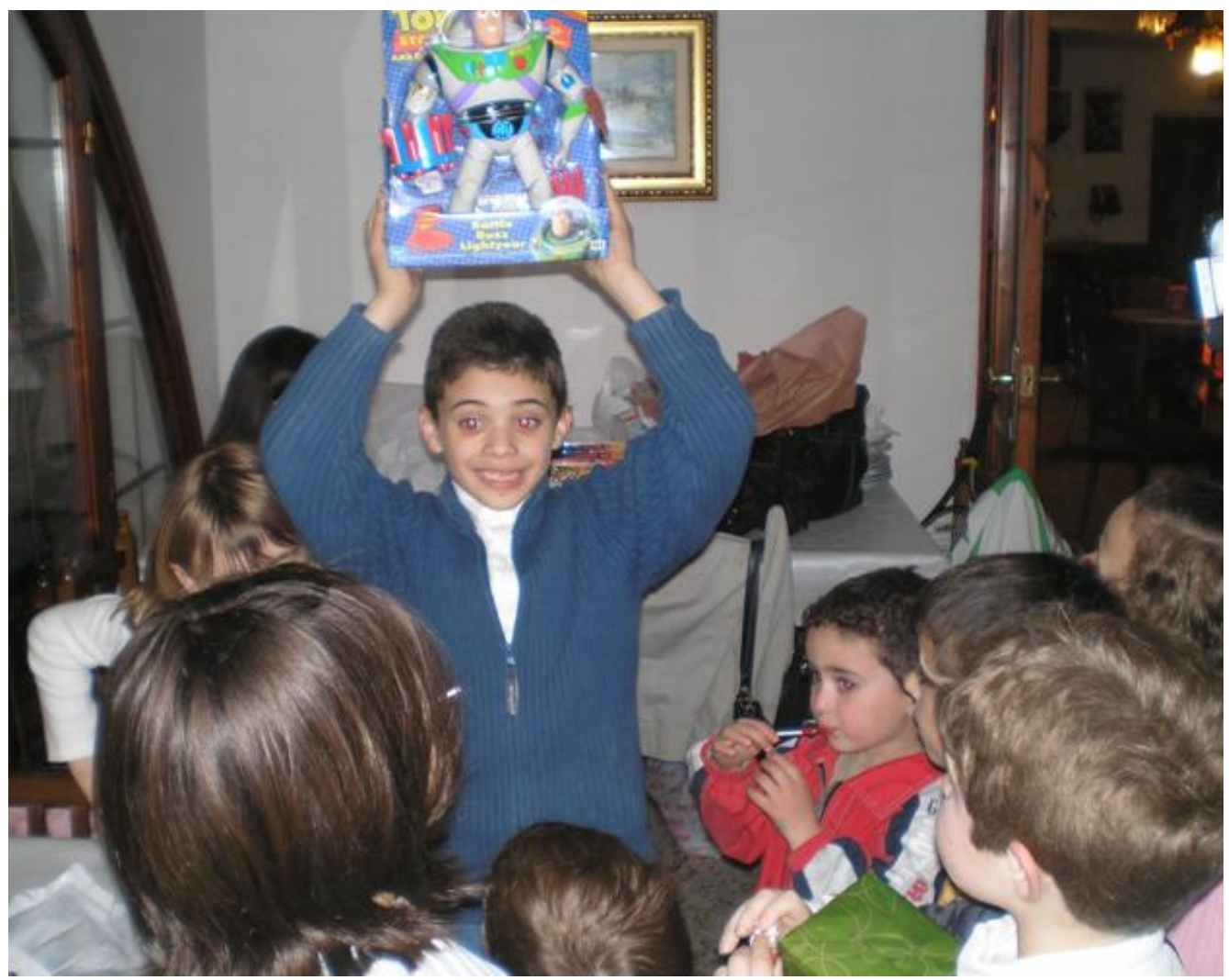

Imagen 9. Sergi y Buzz LightYear (fotografía no1, TF S)

Sergi y los suyos han estado siempre muy unidos, de hecho, desde bien pequeños ya se preocupaban por él. Àngels explica cómo sus compañer@s de aula, se interesaban por él y sus problemas de comunicación: han crecido juntos y cuando ya se daban cuenta de que Sergi era diferente llegaban a casa y preguntaban a sus padres sobre lo que le pasaba a Sergi para poder ayudarlo. De hecho, incluso las maestras a veces se tenían que enfadar porque si Sergi quería ir al aseo iban todos detrás a acompañarlo. (TDE M 131).

Este fue el bonito resultado de un largo proceso de construcción de la amistad entre Sergi y sus amigos, que si bien se debe a ellos mismos y su forma de ser, también tiene que ver con otras cuestiones añadidas. Por un lado, la labor que la maestra Mamen, pues como indica Francisco, ella fue una de las que hizo posible esta admirable relación: Hay que destacar en este sentido la figura de una persona que fue muy importante: su tutora Mamen. "La señorita Mamen" como Sergi la llamaba cariñosamente, fue la primera persona que sí creyó la historia de Sergi desde el principio. Se la creyó y como se la creyó ella, los compañeros y compañeras de Sergi se habituaron perfectamente a su presencia, aunque fuera un poco extraña en algunas circunstancias. No por eso dejaban de tener a Sergi como uno más, nunca lo han rechazado, nunca le han segregado y nunca le han hecho que Sergi se sintiera diferente a ellos. Eso ha ayudado muchísimo pues el papel de Sergi dentro del aula era muy diferente al del resto de alumnos, todos lo sabíamos y éramos conscientes de ello. (ET Edu, 24).

Por otro lado, cabe considerar también el trabajo con Sergi, pues para él el concepto de 
amistad y lo que implica, resultaba algo muy complejo de entender: Partiendo de una historia social, al igual que se trabajaron las normas, se trabajaron los sentimientos y las emociones. La historia social es un registro que permitía a Sergi ir identificando las experiencias buenas y malas, de forma que cuando estas experiencias buenas eran positivas para él las iba integrando. Poco a poco, a partir de las emociones de "es tu amigo, no es tu amigo. A un amigo no se le puede insultar. A un amigo no se le puede pegar. Un amigo te ayuda..." mediante las historias sociales, permitió que Sergi entendiera lo que era la amistad. El concepto abstracto de amistad él no lo entiende, pero sí entiende las experiencias. En la medida que él las entiende, las va interiorizando, las va replicando, las va reproduciendo y finalmente le resultan adaptativas. A partir de ahí él ya las anticipa, ya es posible no ser tan ritualizando en estos aspectos y, poco a poco, todo se produce de manera evolutiva y natural. Él acaba rompiendo esa barrera de la distancia afectiva y, poco a poco, va incorporándolo. (...) Hay que tener en cuenta que el distanciamiento afectivo de Sergi con respecto al resto de los alumnos al principio era muy grande, pero poco a poco, con mucho trabajo, se fomentó el acercamiento. Hoy en día, Sergi entiende perfectamente lo que es un amigo: amigo es aquel que te ayuda, que te quiere, que te hace algún favor y el 'no-amigo' es aquella persona que 'pasa de ti', o que incluso es malo contigo. Desconozco cuantos amigos tiene ahora mismo, pero sí tengo claro que él va con aquellas personas que le aportan cosas positivas y no va con aquellas que le dan cosas negativas. Eso lo diferencia muy bien, lo positivo de lo negativo de las personas, más que el concepto de la amistad o la no amistad. (ET Edu, 59).

La relación entre Sergi y el resto del grupo era admirable. Entre ellos se entendían bien y se respetaban. Como bien indica la madre, esta fue la gran aportación de la escuela para Sergi: Lo más positivo de su paso por la escuela es que 'encontró' una clase en la que tanto las familias como los niños han sido muy buenos con él. Muy cariñosos, muy educados, muy mentalizados de que Sergi era diferente pero que tenía unas cualidades muy buenas. Lo veían como un héroe porque hacía cosas que ellos no sabían hacer y siempre lo quisieron mucho y lo demostraron hasta el último día. Lo más positivo de todo ha sido el grupo. (ETM 3, 471)

Estas relaciones y las vivencias con el grupo, le permitieron a Sergi experimentar lo que es la amistad y valorarla como tal, pues la vertiente social de una persona es tan importante como la académica e intelectual. Sin embargo, cabe destacar que sus relaciones sociales se proyectaban también hacia otros contextos distintos al educativo. Sergi acudía a espacios de ocio que, si bien no fueron socialmente tan estimulantes para él, sí lo fueron para desarrollar sus habilidades y capacidades más internas e inesperadas. Desde bien pequeñito, la familia alentó que Sergi desarrollara capacidades como la artística y la deportiva, de forma que el arte y la natación, han acabado siendo partes tan complementarias como necesarias para Sergi.

4.1.- En natación, como en la vida... No puedes ponerte límites, cuanto más sueñes, más lejos llegarás (Michael Phelps)

La natación, fue de las primeras actividades en las que Sergi se inició. Tenía aproximadamente 3 años y tras pasar por varias piscinas y monitores dieron con la definitiva. Los padres de Sergi se enteraron de la existencia de este club de deporte adaptado y lo consideraron la mejor opción. Laura fue su primera entrenadora y la que lo inició en este deporte. Desde un primer momento, Sergi no quería entrar en el agua, lloraba y se resistía agarrándose a su madre: Empezamos a llevarlo a natación porque 
nos dijeron que el contacto con el agua era bueno y es que él tampoco tenía otra opción a nada más. En aquellos momentos se agarraba a mis piernas y no había manera de que entrara al aqua. Le costó mucho al principio, pero después (...) Laura se lo fue 'camelando' y bien. (ET P, 232 - 238). La solución a estos problemas iniciales con la natación requirieron, como en otros ámbitos, la intervención con pictogramas. La madre debía tenerlos siempre a mano: Yo llegaba y sacaba los pictogramas y le decía "nadar", la "mamá contenta" y el "papá contento" y le hacía caritas. Entonces él se quería quedar allí (EPM 1,56). Cuando volvía a buscarlo me recibía con una gran alegría y se tiraba encima de mí en plan "ya está, ahora ya hay alguien que me entiende". Evidentemente el hecho de no saberse explicar, lo frustraba, le causaba angustia, frustración... (EPM 1,56), pues hay que recordar que en esa época Sergi no tenía lenguaje oral y aun no utilizaba los pictogramas para comunicarse.

Gracias a la natación, Sergi ha podido conectar con otros chichos y jóvenes en situaciones similares a la suya generando amistad incluso fuera de la piscina. Es el caso de su relación con Cristian, pues empezó siendo un compañero en la piscina y acabó siendo un amigo fuera de ella: Cristian es su amigo, es muy inocente como él y se llevan bien. Cristian habla mucho y Sergi más bien poco (ETM 3, 129). Además de esta aportación a nivel social, la natación contribuye a que a Sergi obtenga otros beneficios a nivel físico y somático. Le relaja mucho la piscina, además de que le beneficia porque él tiene un poco de escoliosis en la parte alta de la columna y le beneficia físicamente, le beneficia en todos los aspectos, lo relaja y le ayuda a dormir. Los días que va a la piscina duerme mucho, mucho más pronto y mejor. A él le va muy bien. (ETM 3, 204).

Sin embargo, la natación también puede convertirse en un arma de doble filo contraproducente para Sergi. Su logopeda trabaja con él aspectos como el 'ganar y pender' y las necesidades de relativizar la competitividad: La natación sin duda le aporta diversión de alguna manera, y le aporta desconexión y le disciplina, pero por otro lado también hay que tener en cuenta que no le frustre el decir "no gano", que no le estrese demasiado. (...) Entonces en ese sentido hay que tener cuidado, que no sea contraproducente, hay que tener cuidado en el punto ese. Esta es una de esas cosas que le aportan una disciplina, un aprendizaje, otra faceta que llena parte de su vida, pero hay que tener cuidado. (ET Log, 67).

\section{2.- La creatividad es la inteligencia divirtiéndose}

Otra de las grandes pasiones de Sergi en su día a día, tiene que ver con sus aptitudes, con su talento innato, tiene que ver con el arte. Algunos días alternos a la semana, Sergi acude con su hermano pequeño Xavi a la Escuela de Arte. Según su madre, sus inicios como alumno de este centro se remontan a una vía de explotar algo que parecía motivarle: Yo quería que se relacionara con gente, (...) además ya me había dado cuenta en casa que era muy creativo y hacía cosas muy bonitas, entonces pensé "bueno, voy a darle la oportunidad de la Escuela de Arte, que pruebe con el barro y todo eso". Empezó a los 10 años con Josefina (ET P, 274). Al cabo de un tiempo, Josefina dejó de ser su profesora y empezó a serlo Lara, quien a día de hoy sigue enseñándole y ayudándole a crecer desde su vertiente artística.

Lara, recuerda cómo y cuando conoció a Sergi: Yo lo conocí como alumno de la escuela, no lo conocía de antes porque no soy de aquí (...). Recuerdo que el primer día que vino o de los primeros, fue corriendo hacia el laboratorio de cerámica e intentó beberse un vaso de óxido de manganeso, que confundió con chocolate. Dijo "ichocolate!" y salió corriendo desde la puerta hacia allá y lo paramos ahí en el acto. No se lo bebió

Javier (P)

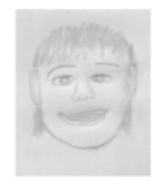

Àngels (M)

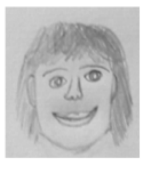

Azucena (Log)

Javier (P)

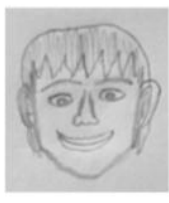

Lara (PEA) 
evidentemente, se hubiera envenenado o vete a saber lo que hubiera pasado ahí. Nosotros seguimos una normativa que no cogemos a gente menor de diez años por cosas como ésta y, en teoría, pues una persona con discapacidad solo si es capaz de acoplarse a las normas. La cosa empezó así, pero sin embargo no pasó nada y de hecho Sergi luego no ha tenido ningún problema. Sergi es un chaval muy obediente en general, lo que pasa es que le costaba mucho prestar atención a los demás. Si conseguías llegar a él te escuchaba y atendía, pero tenías que llegar a él porque de entrada no te miraba a los ojos. Conseguir que mirara fue la primera parte del trabajo con él (ET PEA, 19).

En este entorno, Sergi encontraba un espacio para sí mismo, como un refugio y le costaba entrar en contacto con el resto de personas: Un hándicap grande con Sergi, sobre todo al principio, era que él no buscaba integrarse en su grupo de iguales, a pesar de que la mayoría de niños aprenden mucho entre ellos. Entonces, la manera de empezar a entrarle fue justamente dándole libertad. Dejándole trabajar libre conseguíamos que le interesara, pues a continuación había que solucionar los problemas que le surgían con el barro. El barro es muy técnico, el barro por desgracia no es como la plastilina y si no lo trabajas bien no hace lo que tú quieres. Esto era complicado con él porque no atendía mucho a razones, él ya ha había hecho su muñeco y no se daba cuenta de que de esa manera no iba a sobrevivir al paso por el horno. Solo cuando le hacíamos entender que necesitaba trabajar de cierta manera empezaba a tenernos en cuenta porque le habíamos solucionado el problema (...) Era cuestión de poner un poco de interés y de ser prácticos, lógicamente, si tú estás haciendo algo y se te cae, se te raja, y se te agrieta y te dicen cómo arreglarlo una y otra vez lo más probable es que empieces a hacer caso a esos consejos. (ET PEA, 38).

Entonces la manera de llegar a él fue esa, fue empezar a solucionarle los problemas que él tenía, y que él se diera cuenta de que me tenía si me necesitaba. A pesar de que le gustara estar en su planeta, había cosas que sin mí no iban a funcionar igual de bien. De la misma manera, en el grupo, cuando damos unas instrucciones, ellos (...)se observan entre ellos y se hablan, y eso también les da una capacidad de aprendizaje muy amplificada. En cambio una persona autista eso no lo tiene, si eres muy listo podrás contar con tus propios recursos pero resulta que no cuentas con los de los demás, ni siquiera con los del profesor. Si eres muy listo te puede ir bien, si eres suficientemente listo como para vivir tú solo, pero si no lo eres tanto o si tienes alguna dificultad con algo muy técnico pues no vas a salir de ahí tu solo. En este sentido, los hándicaps son los propios del autismo: falta de empatía y comunicación. Su potencialidad era evidentemente, que es una persona muy capaz y dentro de lo que es el autismo él es adaptable, porque una vez descubre que algo le sirve rápidamente lo adopta, pero hay que conseguir que se abra. (ET PEA, 40 - 41)

En este contexto artístico, Sergi parece que encontró como un espacio de distanciamiento social, como una forma de aislamiento y refugio personal. Una forma de desconectar un poco del entramado de las relaciones sociales y lo que conllevan. Su profesora Lara, así lo ha identificado desde que lo conoció: Después de años compartiendo espacio con sus compañeros, estos le respetan, quien lo conoce, quien lo llega a conocer, lo entiende o por lo menos se da cuenta de que es especial y no solamente porque tenga autismo sino porque él como persona tiene cosas valiosas. Pero no han sido sus amigos en el sentido de ser amigos, no por culpa de ellos, por supuesto, porque los niños son niños y también están aprendiendo a desenvolverse, pero es que él tampoco se muestra y las relaciones sociales son un 'toma y daca', das y recibes. Una persona con autismo nunca podrá corresponder de la misma manera. Lo 
intentará, hará lo que pueda pero no llega a ser una amistad. (ET PEA, 49). Sin embargo, esta forma de aislamiento de Sergi en la Escuela de Arte no es percibido como algo necesariamente negativo, sino que simplemente por esta condición no puede beneficiarse de otras personas con facilidad: Él llega con sus cascos y se pone a pintar y no pasa nada. Al fin y al cabo viene a relajarse y a hacer un poco la suya (...). El aislamiento le permite trabajar con una gran intensidad y concentración y le permite conseguir buenos muy resultados, sin embargo ese aislamiento le impide incorporar las ideas y la ayuda de los otros. Este es su mayor hándicap y en cierto modo una gran virtud. (ET PEA, 43)

Que el arte es una vía de escape y de expresión para Sergi es reconocido por aquellos que le conocen. Azucena, así lo explica: Me impacta mucho la sensibilidad que tiene con las manos, es muy artista, haciendo barro o pintando, en sus dibujos es muy detallista. Es como si cuando no puedes expresar de una manera pues la expresas de otra, y él a través del dibujo, la pintura (...) expresa mucho, puede incluso más de lo que puede expresar con palabras. (ET Log, 46). Además, el tema del arte le aporta mucha tranquilidad, es como algo que controla, le gusta, algo en lo que se desarrolla, le encanta, disfruta, pinta, aprende... Él llegaba y me contaba cosas que había hecho en la Escuela de Arte: "mi señorita me ha enseñado esto, lo he hecho con barro,..." (...) Todo ese tipo de cosas te hacen ver que es que le encanta, lo que te está contando, lo que ha aprendido, lo que ha pintado (...) Yo creo que a él la Escuela de Arte le ayuda desarrollarse a nivel artístico, yo creo que tiene una vena muy artística y la desarrolla. Ve que lo hace bien y es que además se siente a gusto. Ahí le aporta disfrute, aprendizaje, se realiza, le gusta mucho. Entonces claro le da también calidad de vida porque en el fondo es también un poco de desconexión del día a día. (ET Log, 67)

En un ambiente pacífico y tranquilo como la Escuela de Arte, Sergi busca dar rienda suelta a lo que se le pasa por la cabeza, a desarrollar su creatividad. Según Lara: Es como si al llegar a la Escuela de Arte dijera "aquí llego y me suelto". Y desde la visión de profesora no está mal que haga esto, para eso se hace en realidad. La creatividad, al menos en mi experiencia es un rasgo habitual en los autistas, y se le debe dar rienda suelta. Lo que pasa es que su creatividad a veces no es de este mundo y a lo mejor no es interpretada como tal, pero no es malo. No está mal ser excesivamente creativo, siempre puedes contenerte un poco y ya está, lo malo es no tenerlo. En ese sentido, el arte no es tan rígido como otras cosas. Es un terreno ganado para una persona creativa y capaz de ver cosas radicalmente distintas. En otros campos, tienes que hacer una serie de demostraciones, y si vas contra la creencia general te van a marginar, pero en el arte justamente lo que se precia es romper esquemas constantemente. Una persona con un punto de vista rompedor y con una creatividad muy desbordada, no tiene porqué no encontrar su lugar en el mundo del arte. Además la técnica en el arte tampoco lo es todo, (...) hay una parte del arte que es completamente conceptual, tu no creas una obra, incluso la obra es lo de menos. Es el resultado de una serie de lucubraciones tuyas lo que importa. Evidentemente, en este sentido una persona que no acepte las convenciones o que no las entienda porque tiene las suyas propias tiene campo ganado. (ET PEA, 56)

Gracias al arte, Sergi ha podido no solo crecer como artista sino desarrollar también la parte técnica del arte tan importante para lograr creaciones nuevas y diferentes. Sergi ha demostrado que es capaz de asimilar y de aplicar las soluciones que va aprendiendo. Él tiene la capacidad de ser metódico que es una cosa que la gente no asocia al arte y es vital. La gente cree que el arte es una cosa gratuita que te la da Dios y que no hay que trabajar ni esforzarse y por eso también a veces no se valora. Entonces la capacidad de 
ser organizado y metódico en tu trabajo es un valor grandísimo cuando te dedicas al arte (...) La mayoría de alumnos te dice "dime lo que tengo que hacer y punto", él no, eso es un valor añadido, además de la capacidad de abstraer. Esa capacidad de entender que la representación de las formas en la plástica no es solamente lo literal y lo que uno ve, sino que uno tiene que ir más allá y desintegrar las formas para reconstruirlas y reinterpretarlas y eso él lo hace. (ET PEA, 54)

Un ejemplo de cómo Sergi ha ido adquiriendo y asumiendo las técnicas propias del arte es la siguiente pieza:
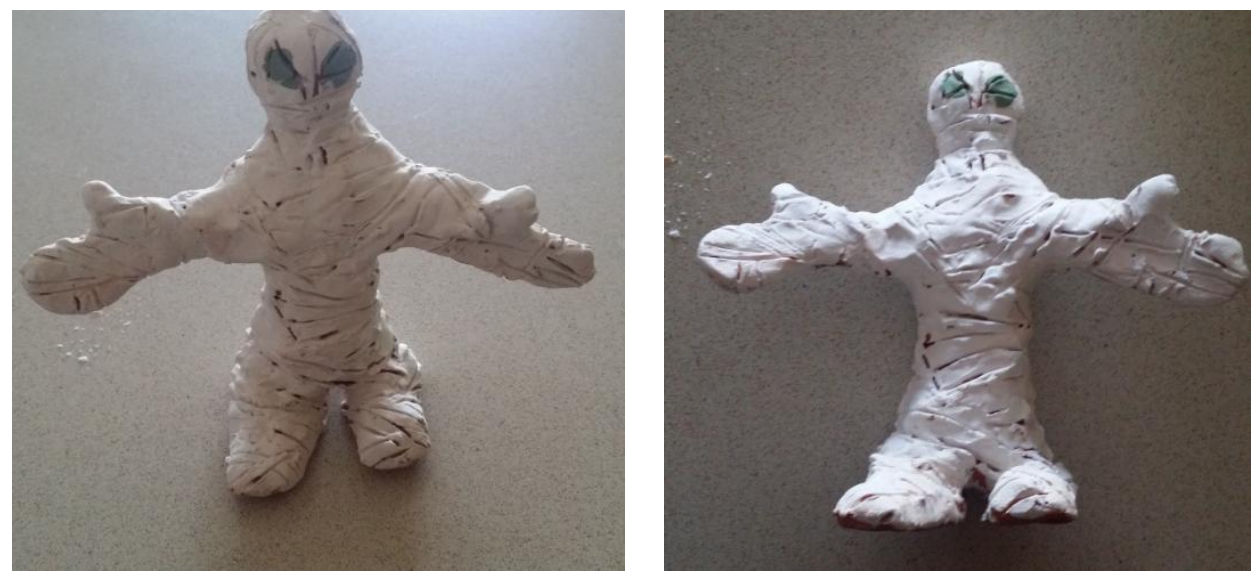

Imagen 10. La momia (Escultura 1, TPE PEA)

Esta pieza la hizo cuando llevaba poco tiempo en la Escuela de Arte, y aunque no la trabajó directamente con Lara, ella recuerda cómo fue este proceso: El problema que tenía Sergi al principio en las figuras es que el barro es muy técnico, no se puede modelar como plastilina y él lo trataba como plastilina (como todos los niños). Aquí se ve que desproporciona, tiene zonas de mucho peso y por cómo está hecho, seguramente se debió caer para atrás 50 veces y se le rompió otras 50. Pero a él hacerle trabajar de una forma técnica y siguiendo unas fases es bastante complicado. Él tiene su propia idea de cómo se deben trabajar las cosas y es complicado decirle lo contrario. Cuando la pieza se le rompió 51 veces dijo "vale, a lo mejor esto que me están diciendo no me lo dicen para fastidiar". Es una forma de aprender. De todas maneras se aprecia cómo se fija en los detalles, él a lo mejor no entiende cómo es un cuerpo humano, ni entiende que hay piernas, pero entiende perfectamente cómo conseguir el efecto de las vendas enrolladas. Entiende cómo simular las vendas y eso está bien trabajado. Otro niño seguramente hubiera intentado ordenar las vendas. Un niño cualquiera no se hubiera dado cuenta de cómo las capas de vendas se giran y se superponen desordenadamente en una momia. Probablemente hubiera intentado hacer una verdadera espiral que rodee el cuerpo, porque todos tendemos a ordenar y a simplificar. Es más fácil pensar en las vendas de esa manera que pensar en un caos que se entrecruza y una está por encima de la otra. Esos detalles son los que capta Sergi (TPE PEA, 15)

Ese gran detalle en sus trabajos se observa en todos su trabajos artísticos. Su peculiar forma de ver las cosas sorprende cuando uno se pone delante de un trabajo suyo y, sobretodo, teniendo en cuenta la edad con la que lo ha elaborado. Lara, recuerda con detalle la minuciosidad en algunos trabajos de Sergi: Él empezó en la cerámica, no empezó con el dibujo, y en cerámica era curioso porque sus temáticas de trabajo eran muy distintas a las de los demás niños. A mí me llamó mucho la atención aquella vez 
que estábamos hablando de modelar cosas del campo, de hacer plantas, y él hizo un mapa. Hizo una superficie plana y empezó a situar un montón de elementos muy pequeñitos: árboles, montañas, etc., en lugar de hacer elementos referidos a la naturaleza. Él hizo "un campo" literalmente. A mí ese trabajo me llamó mucho la atención también por la capacidad que tenía en un momento dado de abstraer, de simplificar, de coger un montón de elementos diferentes y ponerlos juntos, de dar un enfoque original y personal a un tema corriente. A la mayoría de los niños este tipo de cosas les cuesta, pero Sergi siempre ha sido creativo, a lo mejor a nivel de modelado no era un virtuoso, pero tiene esa capacidad y este fue un trabajo muy interesante. (ET PEA, 29 - 30) En las cuestiones artísticas hay que dejar que la mente de Sergi fluya, que encuentre vías de expresión y que plasme aquello que imagine. Él es muy imaginativo, pero si es una cosa impuesta probablemente se coarte. Hay niños que pueden ser muy imaginativos con un tema dado, y que si no les dices nada se quedan muy bloqueados, y Sergi funciona totalmente al revés. Si tu le dejas solo él sacará muchas cosas, pero si le pones una pauta, como le cuesta tanto seguirlas, se bloquea con mayor facilidad. (TPE PEA, 22)

Pero la virtuosidad de Sergi con sus manos no solo tiene su esplendor dentro de la Escuela de Arte. En el día a día, la familia ha ido descubriendo en él habilidades y destrezas artísticas tan espontáneas como inesperadas. Sergi es capaz de crear desde figuras de arena en la playa como si de un artista callejero se tratara a reproducir sombras chinas con las manos dignas de un gran especialista. La habilidad de Sergi con las sombras chinas, la descubrieron sus padres de manera fortuita, pues cuando Àngels se paraba a hablar con alguien en la calle, el niño se entretenía jugando con sus manos y con la sombra proyectada por el sol: Yo es que soy de esas que siempre me paro a hablar con todo el mundo en la calle, y como él era tan buen niño se plantaba al ladito. Si veía un poco de sol empezaba a hacer movimientos con sus manitas y aprendió a hacer el conejo, aprendió a hacer el pato... cuatro o cinco cosas. Entonces un día su padre le buscó un vídeo de sombras chinas por internet y a partir de ahí empezó a hacer todo lo que veía en el vídeo. Lo verdaderamente sorprendente es que lo hacía sin ver la postura que tenía que poner con las manos, solo veía las sombras. Ahí nos dimos cuenta que era un virtuoso en esto. (ETM 3, 387).

Esta habilidad poco a poco empezó a ser conocida por toda su familia, amigos y compañeros de clase: En el momento en que Serqi representó las sombras chinas frente a sus compañeros de clase, éstos entendieron que en algunos aspectos Sergi está por encima de ellos y el respeto hacia él se dimensionó. Lo intentaron hacer y es imposible (...) Son aspectos que él ha ido trabajando de una manera muy interna y que aparecen de una forma muy natural (...) La cosa es que Sergi tiene una memoria visual fantástica y esto le ayuda muchísimo a trabajar (ET Edu, 57).

Poco a poco, el tema de las sombras chinas en Sergi se fue dando a conocer, se fue extendiendo en el entorno de su localidad hasta que un día en su pueblo natal se le ofreció un espacio en la programación de fiestas para que deleitara a todos los vecinos con esta gran habilidad. Le prepararon una gran pantalla, un buen foco y música. Había mucha gente observándolo, disfrutando del espectáculo en silencio y él supo estar perfectamente a la altura y disfrutar del momento. Como bien dice Sergi: Ese día me sentí muy bien (...) me aplaudió mucha gente y yo estaba muy contento (ETM 3, 399404). Su padre, reconoce los beneficios que este tipo de apariciones y reconocimientos públicos le puede aportar a Sergi: Este tipo de apariciones públicas le pueden venir bien y ayudar en su autoestima. Él tiene la dificultad de darse cuenta que no es como los demás y que tiene un problema. Entonces, el hecho de que le puedas decir "sí, mira,

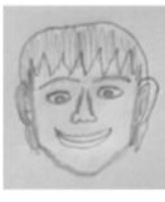

Lara (PEA)
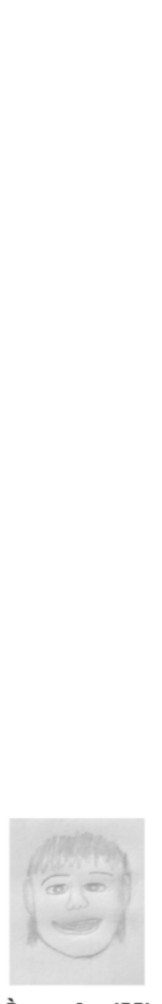

Àngels (M)

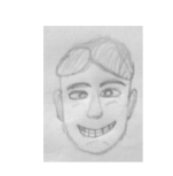

Francisco (Edu)

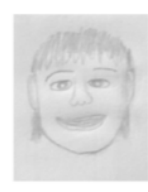

Àngels (M)

Javier (P) 
pero tú sabes hacer esto y los otros no. Tú eres especial" Le puede ayudar un poco a superar el hándicap que le representa el ver que los otros aprueban, aprenden más rápido y él no. Es una manera de superar un poco la frustración que le puede producir. (ET P, 302)

\section{5.- No cambié, solo aprendí, y aprender no es cambiar, ES CRECER.}

El tiempo fue pasando, y Sergi fue creciendo acompañado por su familia, aprendiendo dentro y fuera de la escuela, y disfrutando de sus espacios de ocio como la natación y el arte. Un niño muy completo, sano y que con mucho esfuerzo continuaba en su dura tarea de conocer y formar parte el mundo que le rodea.

La escuela, supuso una etapa fundamental para él. Desde su incorporación como alumno se sintió arropado e integrado en el día a día del aula y, con el tiempo, empezó a participar en las diferentes actividades del centro. Para ello, contaba con un equipo multidisciplinar constituido entre los profesionales de dentro y de fuera de la escuela, contaba con compañeros y amigos que lo valoraban y querían tal como era, contaba con un educador que lo acompañaba, lo ayudaba y además era su amigo, contaba con un centro que permitía aportaciones de la familia y además, contaba con dos hermanos en el mismo centro que lo protegían y supervisaban contantemente. Un ambiente exquisito para el aprendizaje.

Aunque los hermanos no formaban parte directa del contexto de aprendizaje de Sergi, si eran un gran apoyo para él dentro del centro. Su educador Francisco, recuerda cómo especialmente el hermano mayor de Sergi, Gerard, estaba siempre muy pendiente de él para 'echarle un cable' si fuera necesario: Gerard ha sido una prolongación de la familia en la escuela: supervisión, control, observación, el espía; responsabilizándose muchísimo de Sergi. Su relación ha sido siempre muy natural, no solo como protector, en la cual el hermano mayor protege al pequeño sino también como a ayudante de Sergi o como compañero de Sergi. No acabo de ver muy claro si era más un amigo o un hermano. Siempre ha querido estar ahí muy, muy presente para ayudarlo en todos los aspectos, entonces como hermano ha sido hermano, pero también el mejor amigo, como aquella persona que sabes que siempre que puedes contar con ella "¿qué te ha pasado? ¿quién te ha insultado? ¿quién te ha dicho...?" Siempre que podía pasaba por el aula de Sergi a mirarlo o cuando se cruzaban en las escaleras hacían su particular juego de manos. Xavi, el hermano pequeño, también pero lo he visto participar más en casa, compartiendo juegos y colaborando muchísimo. Cada uno desde su ámbito, resultan totalmente complementarios para Sergi. (ET Edu, 55)

En definitiva, en su paso por la escuela y a pesar de ciertos matices, Sergi pudo participar en el aula y en el centro, tuvo oportunidades de aprendizaje, materiales adaptados a su alcance y sintió que formaba parte de la realidad del aula como uno más. Sin embargo, parece que no se acabó de alcanzar el ideario de escuela inclusiva. El educador de Sergi lo explica de la siguiente forma: Partiendo de la base de que la inclusión debería de ser el aprovechamiento de la igualdad de oportunidades dentro del aula, no podemos decir que esta fuera una escuela realmente inclusiva. Es decir, yo no he visto nunca la posibilidad de que él pudiera tener un aprovechamiento en igualdad de oportunidades al resto de alumnos. $Y$ de hecho toda la inquietud de los padres iba en relación a que él pudiera aprovechar al máximo estas oportunidades que el centro le daba. Tampoco tengo claro a día de hoy si es posible hacer realmente aulas inclusivas en un centro de modalidad de escolaridad ordinaria, pero creo que atendiendo a la parte de cualidad y singularidad de los alumnos afectados, en el caso de Sergi, hubiera 
sido posible creando el recurso de maestra de apoyo dentro del aula (...)Creo en la educación inclusiva, creo en la normalización, pero es importante que todos los alumnos se sientan igual de representados y por lo tanto las figuras que representan al centro, tienen que representar al aula y a los alumnos. Entonces sí es posible pero con esta simultaneidad de decir: hay dos profesores o dos figuras en el aula, da igual que sea una maestra de apoyo o lo que sea, pero tiene que estar dentro del aula y tiene que participar con Sergi, y después con el otro que le cuesta dividir, y con el otro que le cuesta leer, y con el otro que le cuesta otra cosa. La profesora debería dejar su mesa e ir hasta la mesa de Sergi. Es decir, estas relaciones de simultaneidad, en un aula si es inclusiva tiene que ser interactiva (ET Edu, 90)

\section{1.- El salto al vacío... transición a la educación secundaria}

A lo largo de toda la trayectoria vital de Sergi, la familia y los profesionales de la educación fueron tejiendo una estructura en la que Sergi pudiera ir aprendiendo y mejorando día a día. A pesar de ciertas carencias, parece que el sistema iba rodando y funcionando y que Sergi crecía y aprendía junto a sus compañeros sin graves problemas. Sin embargo, en contra de los pronósticos, las dificultades empezaron a plantearse a la hora de pasar de la educación primaria a la secundaria.

Cuando llegó el momento de transición a secundaria, el equipo de orientación y la directiva del centro, con el apoyo de la inspección educativa, plantearon a la familia la posibilidad de que Sergi repitiera curso. El centro iba a ser el mismo, pero los profesores, contenidos y horarios en secundaria se tornarían mucho más duros. Pensaban que si Sergi repetía podría afianzar conocimientos que le permitirían adaptarse mejor a la siguiente etapa educativa. Los padres barajaron las distintas posibilidades: Tuvimos que decidir en un par de días si lo dejábamos repitiendo o pasaba de curso. Dijimos, "mira, decidamos lo que decidamos si nos equivocamos nos equivocamos, ¿nosotros qué pensamos? ¿Nosotros qué creemos que es mejor para el niño?" (...) Hablamos también con Francisco y nos dijo lo mismo, pensábamos que iría un poco perdido, que secundaria es otra historia y tendría varios profesores en lugar de uno pero en cambio estaba muy integrado con los niños (...). Yo les he visto jugar a fútbol y les he visto cuidar de él, y pensaba "¿cómo les tenemos que separar?". Nosotros pensamos en eso, y tampoco lo vimos capaz de, aunque nos decían que sí, que se pudiera 'enganchar' totalmente. Yo pensaba el niño sufriría mucho, no se 'engancharía' y me daba miedo que se cerrara de nuevo (EPM 2, 408). Finalmente, optaron por negarse a que repitiera y apostaron porque siguiera con sus compañeros: Se luchó porque pasara. Consideramos que era más importante que él fuera feliz y estuviera con los compañeros a que lo podía dejar de aprender, siempre pensado que iría Francisco a su lado. (...) Pero sin embargo, ese mismo verano, Francisco nos llamó diciendo que la directora del centro le había dicho que no podría continuar dando las complementarias porque hacía tres años que estaba contratado y lo tenían hacer fijo. Eso ya no nos gustó, yo pensé "pero si lo pagamos nosotros como animador a la lectura ¿qué problema hay?" (EPM 2, 293-299)

Así fue el comienzo de 10 de ESO de Sergi. Hasta el último momento no se supo si repetiría o no, y de repente, el tema del educador parecía ser un problema para el centro. Aunque un poco a trompicones, el curso empezó, las clases arrancaron y Sergi estaba acompañado de Francisco unas pocas horas al día. Los primeros días de curso, como siempre, Àngels llevó al centro libros y materiales para trabajar con Sergi. Al tiempo recibió una llamada: Pasó el mes de octubre, pasó el mes de noviembre y un día me llama el psicopedagogo y me dice "iuff! Estoy desbordado con tu hijo. Los maestros 
no saben cómo enseñarle". Y yo pensé, bueno, en junio ya sabía que entraba un niño con autismo y con tales características, ¿y no se prepara? ¿no se documenta? ¿tú eres un especialista en trastornos de aprendizaje? (ETM 2, 278).

\section{2.- El abandono escolar por parte de los docentes... ¿es posible?}

El descontento de la familia con el psicopedagogo era un tema generalizado, pues con respecto a su hijo consideran que no solo no hacía su trabajo, sino que lo desatendió y menospreció. La madre explica cómo se generó este malestar: En la primera reunión que tuvimos empezó la reunión diciéndonos: "os voy a decir una cosa pero os lo diré en voz baja para que no me peguéis. Es que vuestro hijo es retrasado mental". A nosotros esto nos enfureció. Nuestro hijo es autista, tiene un trastorno del lenguaje, pero no es retrasado mental. Es que es palabra ya está fuera del diccionario, es que no hay nadie que sea retrasado mental, tiene un coeficiente más bajo, tiene una discapacidad, lo que tú quieras decir pero retrasado mental no, retrasado mental eres tú. Es que es muy fuerte. Javier ya no ha pisado más la escuela. No ha vuelto a ir, dice que no está preparado y que no va a soportar verle la cara. Desde entonces cada vez que llamaban por algo, para firmar un papel o algo iba yo. (ETM 2, 313).

A pesar de esta falta de sensibilidad del psicopedagogo, y la nefasta opinión de la familia sobre lo que éste podría hacer por Sergi, se mantuvo el contacto en él para intentar facilitarle el aprendizaje a Sergi. En sucesivas reuniones, la madre le explicó al psicopedagogo cómo se había estado trabajando con Sergi todos estos años con la finalidad de que éste orientara a los profesores en su labor docente: Yo le dije "mi hijo es muy visual, necesita esquemas, dibujos,... y así va aprendiendo", y él diría "iuy! iMucho trabajo! ¿Yo tengo que hacer todo eso? Ni hablar" $Y$ a partir de ahí ya vino el 'desborde'. (ETM 2, 280). Pasaba el tiempo y Sergi no trabajaba prácticamente nada en el centro Virgen del Carmen, nadie le prestaba atención cuando Francisco no estaba.

Ante esta situación, Àngels tomó de nuevo 'cartas en el asunto': Fui al colegio y dije a la directora "mira, yo quiero hablar con Inspección. Para esto tiene que haber una solución, quiero el teléfono de la inspectora". Pasó una semana, pasaron dos semanas, pasaron tres semanas, y no había manera de que me dieran el teléfono. Yo iba allí y me decían "la directora no está, no te puede atender". Cansados de esta situación, al cabo de un tiempo Javier y yo decidimos ir por nuestra cuenta "no pasa nada, en internet está el teléfono. Entramos en la página Conselleria cogemos el teléfono y pedimos una reunión con ella si puede ser". La inspectora nos atendió enseguida y le explicamos el problema que teníamos. Ella nos dijo: "hay una persona en Conselleria que es especialista en Trastornos de lenguaje que va a los colegios a dar orientaciones ¿queréis que hable con ella?". Nosotros le dijimos: "Sí, pero habla con el colegio primero, y coméntalo. Y que vaya esta persona y que les oriente". Esta persona era Ana. Ana fue a la escuela y les explicó que es importante que Sergi esté en primera fila, las posiciones del niño, les llevó un montón de material para trabajar con el niño, 'patatim y patatam', yo encantada. Ése día, me llamaron a mí para que me reuniera también con ellas y hablar. Estábamos la inspectora, la especialista en Trastornos de Lenguaje, el equipo directivo, el departamento de orientación y yo. La inspectora me decía: "ya he hablado con todos, tienen ganas de trabajar, trabajaran así, trabajaran asá" y yo encantada de la vida y contentísima. Sin embargo, cuando ya nos íbamos me cogió del brazo la directora en la puerta y me dijo "¿qué? ¿ya estás contenta, no?"(con sonrisa falsa en la boca) como diciéndome "la que has liado aqui". Yo le dije: "pues sí, por mi hijo lo que haga falta". Eso fue justo antes de Navidad, y en Navidad, el día del festival, me encontré a la tutora y ya no me quiso saludar, me miró pero hizo como si no me 
conociera de nada. (ETM 2, 280).

Para la familia el problema de partida fue que no solo parecía que la presencia de la familia molestaba al centro, sino que además no creían en Sergi y sus posibilidades: En ese momento no confiaron en él, no creyeron en él. Yo les planteaba que le apretaran un poco, que Sergi podía hacer más, que estaba estudiando mucho... Pero nada. (ETM 3 , 347). De la misma manera, Francisco observó esta transición a la secundaria desde dentro del centro y explica como la falta de preparación e implicación era muy Ilamativa: La transición entre primaria y secundaria fue dura. Es muy diferente la forma de trabajar del profesorado, hay muchos profesores, uno por materia o área, y cada uno tiene su metodología, su estilo. Sin embargo, al tratarse el mismo centro no tendría que haber cambiado demasiado (...) Entre el profesorado, había algunos que estaban muy dispuestos a colaborar, me acuerdo de la profesora de tecnología y plástica, me acuerdo del profesor de educación física, me acuerdo de la profesora de castellano y valenciano. Profesoras que sí que han entendido que Sergi tenía que tener un protagonismo y que este protagonismo no podía ser el mismo que el de otros, sino que tenía que estar mediatizado, tenía que estar trabajado para poder sacar de él lo mejor. Esto tenía que ser consensuado, coordinado, no podían llegar allí y "Sergi sal a la pizarra". No. Una semana antes se trabajaba una redacción "describes cualquier cosa, Francisco te ayuda, te ayudan tus padres, tú la redactas y al cabo de tres días, cuatro días, una semana, que te la has estudiado sales y la lees", pero no le puedes decir "para mañana la redacción". En Sergi hay que anticipar, hay que prevenir situaciones que después en la práctica se dan de una forma muy natural en los alumnos y que los profesores creen que también es muy natural en Sergi, pero con él no podía ser así. Yo vi mucha precipitación porque no había una preparación previa de las actividades dirigidas a Sergi y por lo tanto, mientras estaba yo teníamos el material, y lo trabajábamos, pero cuando yo no estaba esto no era así. (ET Edu, 70)

Los días pasaban y la situación en el centro iba de mal en peor. Las relaciones entre los docentes y Francisco se rompieron y éste se planteaba abandonar por la falta de comunicación y consideración. Àngels explica cómo fue este proceso: A la vuelta de Navidad Francisco no podía más y me dijo "yo me lo dejaré Àngels, a mí me están haciendo bulling, no me cuentan nada. Así no puedo trabajar". Él siempre había tenido mucho feeling con la maestra, era como el enlace entre nosotros y la escuela. Me decía "no me comentan nada. Esto no me lo han hecho nunca, me siento fatal". Yo lo entendí. Al ver que todo seguía igual volvimos a ir a Conselleria a hablar con la persona que orientó al centro. Le dijimos "mira Ana, esto no puede ser, al niño no le dan material, no le explican nada". En ese momento nos dijo que nos esperáramos, que solo habían pasado 3 semanas desde que habían estado en el colegio, había que darles un margen de confianza. Yo le dije: "Vale, les damos un margen, pero que sepas que nosotros volveremos" (...) En ese momento, nos dijeron que Francisco no podía estar ahí, que en el centro había personal preparado, que tenían material suficiente y que Francisco debía dejar de ir. (ETM 2, 280-282). Los padres no tienen muy claro porqué de la noche a la mañana Francisco tenía que dejar el centro, cuando estaba pagado por ellos y no había habido ningún problema hasta ese momento: No sabemos bien si eso de que Francisco no podía ir era cosa del centro o de Inspección. La Inspectora nos dijo que no era legal, que Francisco no podía estar ahí, pero llevaba muchos años con Sergi. Además en el mismo centro hay un niño que tiene un $10 \%$ de visibilidad y tiene a una persona de la ONCE con él (...) No lo tenemos claro.( EPM 2, 320 - 324)

De un día para el otro Francisco desapareció y Sergi tuvo que aprender a estar solo y trabajar de manera totalmente autónoma. Àngels, explica como Sergi no entendía 
porque Francisco ya no estaba ni porque sus cosas estaban en el pasillo: El pobre lo llevó muy mal al principio. Se volvía loco. Además es que lo hicieron muy mal, porque le sacaron la mesa al pasillo con la carpeta, el estuche... Sergi llegaba a casa y me decía. "Mamá, esta todo en el pasillo, se lo robarán" y yo le dije "tráelo a casa"(ETM 2, 207). También tuve que buscar una razón y explicarle que en el colegio habían pensado que era muy mayor, " ¿y verdad que ninguno de tus amigos tiene un compañero que le explique las cosas?, pues tú tampoco, tú tienes que esforzarte más, intentar entender más las cosas, intentar trabajar tú solo y ya está, porque Francisco ya se tiene que ir" y el niño lo admitió (EPM 2, 439).

Sobre la marcha de Francisco, en el centro no se dijo nada, no se comentó ni se dio ninguna explicación en clase. Los compañer@s de Sergi recuerdan este momento y la manera en que le afectó a Sergi: Desde el colegio no se nos dijo porqué Francisco no venía ni nada, no nos informaron. Simplemente dejó de venir (ETG CE, 371-Vero) Había rumores de si había sido culpa del psicopedagogo, porque decía que le negaba la personalidad a Sergi o algo así, eso lo escuché (ETG CE, 354- Rodrigo). Lo peor de todo es que a Sergi se le notó la marcha de Francisco, no era el mismo, había cambiado (ETG CE, 377-Jordi), incluso se iba solo más frecuencia (ETG CE, 378-Rodrigo).

\section{3.- Arrinconamiento + abandono= exclusión}

Tras la marcha de Francisco, Sergi se quedó solo y a pesar de que parecía que ya no había más cambios, nuevas modificaciones estaban por llegar. Ahora el centro decidió reubicar a Sergi dentro del aula. Para ello optaron por poner su mesa en una esquina de la clase, delante de todo. Sergi se sentaba pegado a la pared, al lado del radiador y dejando a su espalda la mesa del profesor y los alumnos. Sergi tenía la clase a sus espaldas.

Sus compañeros no podían creer lo que estaban viviendo: La tutora de ese momento, cogió a Sergi y lo movió al frente de la clase, al lado del radiador solo, totalmente solo (...) El decía que no quería estar ahí, que tenía mucho calor, pero no le escuchaban. (ETG CE, 381 - 394- Rodrigo). Él le decía a la tutora "tengo calor, tengo calor, tengo calor... ¿me puedes cambiar?" y le contestaban "Sí, ya miraremos, ya..." (ETG CE, 402Rodrigo) Nosotros pensábamos "¿Qué forma es esta de marginar a un niño?"(ETG CE, 327 - 332-Vero). A Sergi no le gustaba estar en ese rincón y así lo manifestaba: Yo quería estar con mis amigos (...) Tenía ganas de trabajar con ellos, ver cómo estudiaban, leían... pero la tutora me puso ahí (ET S, 183 - 192). Su madre explica que al final, tras tanta negativa por parte de los docentes Sergi aceptó el rincón como su espacio: Él quería salir de ese rincón porque sus amigos estaban detrás de él, y quería ser como los otros. Sergi se sentía diferente, pero cuando ya se le dijo tantas veces "no, ahi estás bien" pues él lo aceptó y ya está (EPM 2,66).
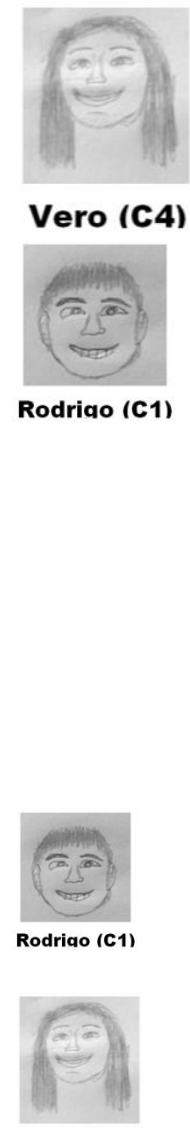

Vero (C4)

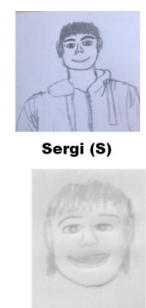

Àngels (M) 


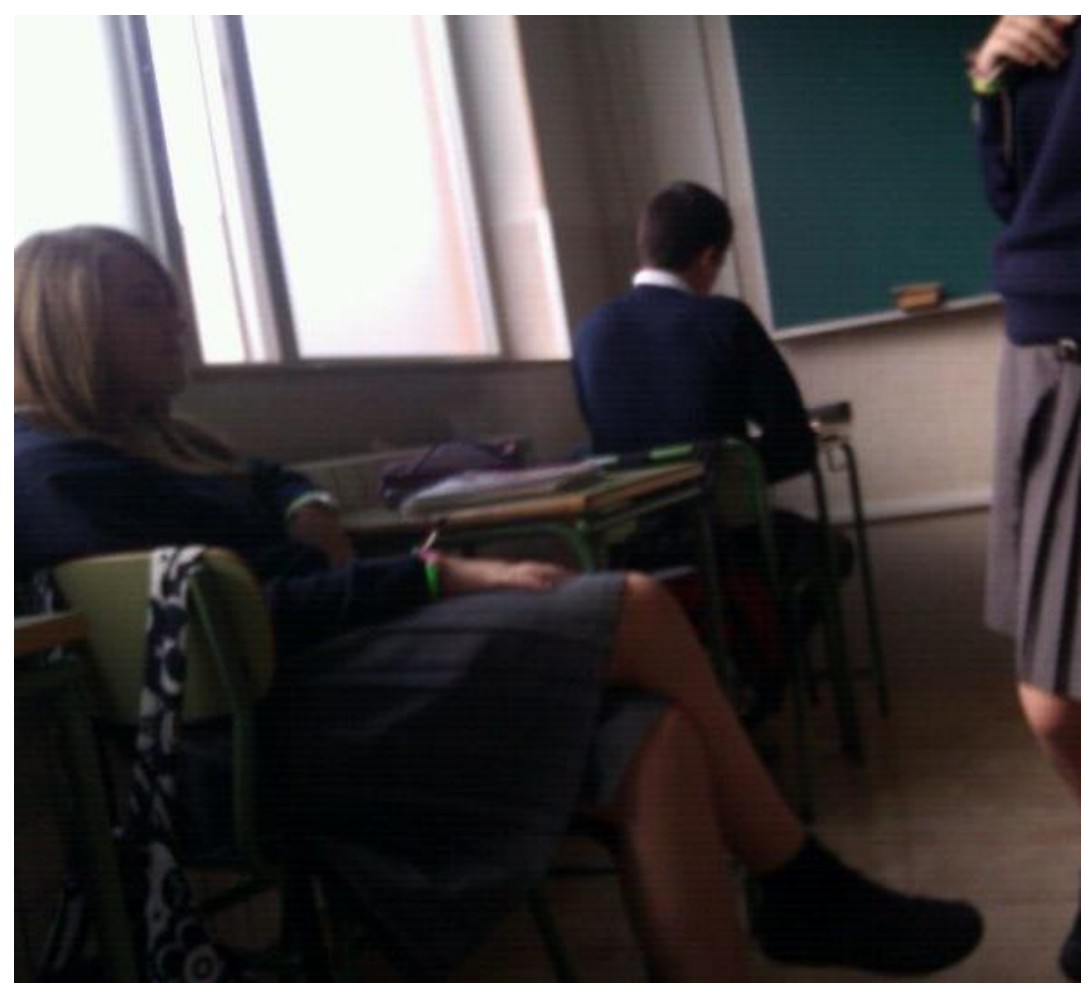

Imagen 11. Exclusión de Sergi (fotografía noㄴ, TF M)

A la familia, le llegó la foto de Sergi ubicado en la esquina de la clase mediante un compañero del aula que les pedía que hicieran algo por él. Àngels recuerda cuanto les decepcionó y enfureció esta situación: Cuando esta foto llegó a nuestras manos pensé "no es posible, eso es un montaje. No puede estar pasando que haya a un niño con autismo en una clase, y un psicólogo y una profesional de la Pedagogía Terapéutica, consideren que esto es lo mejor, que esté solo contra una pared, y sobre todo cuando el niño pedía ir detrás con los compañeros". No tengo palabras. Cuando llegó la foto a mis manos lloraba, la miraba y lloraba de rabia y pataleaba. Me fui enseguida al colegio a hablar con ellos y me dijeron, repitieron e insistiendo que no podía ser, que el niño tenía que estar ahí. En casa, a las 4 de la mañana mi marido y yo les escribimos un correo diciendo "por favor, esto no puede ser seguir así, el niño no puede estar solo..." y nos contestaron que no lo podían sacar, que era el mejor sitio para él. Otras familias se enteraron y se pusieron de nuestro lado, pero nada (...). No fueron capaces de hacer nada por Sergi. Esta foto realmente demuestra la incompetencia y la poca empatía por una persona así. Todas las barbaridades que me puedan pasar por la cabeza en este momento las añadiría. Nunca hubiera pensado que dos profesionales de la enseñanza de necesidades educativas especiales fueran capaces de hacer eso a un niño, y que consideraran después de hablar con ellos y hacerlos reflexionar sobre el tema, tanto nosotros como personas de Conselleria, que tenían la razón y que ese era el lugar adecuado para ese niño. Esta foto fue el principio de mi enfermedad. Yo a partir de este día tuve que medicarme para dormir porque yo no podía soportar pensar que cada día mandaba a mi hijo a este rincón, cada día, cada día... (TF M, 48)

Sergi trabajaba solo en el aula, y ciertas horas salía del aula con la PT o con el psicopedagogo. Especialmente en relación a esto Sergi estaba muy disgustado y así se lo comentaba a sus compañeros: Nos decía que estaba enfadado porque cuando trabajaban con él le hacían dibujar gotitas de lluvia y cosas totalmente estúpidas para su capacidad (ETG CE, 379 - Vero). Nos contaba que se lo llevaban arriba y le enseñaban el sol y las nubes, y ahí ya es cuando nosotros nos empezamos a indignar

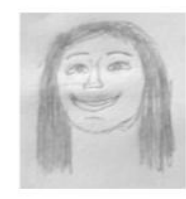

Vero (C4) 
un poco porque estaban tratando muy mal a Sergi (ETG CE, 349 - 358- Vero). Esta situación resultaba irritante para Sergi quien, sin dudarlo, trasladaba su descontento a los profesores. La madre cuenta como el psicopedagogo se sorprendió por ello: el psicopedagogo me dijo "He estado dos noches sin dormir porque tu hijo me ha faltado al respeto. Me ha dicho que le hago perder el tiempo" Pero es que el psicopedagogo lo que no veía era que estaba haciendo actividades de Winnie de Poh con un niño de 1 o de la ESO. Lo que pasa es que el niño estaba indignado y dijo lo que pensaba. (ETM 2, 276).

Desde ese momento, cualquier persona que conocía a Sergi y sus capacidades sabía que estaba perdiendo el tiempo. Sus compañeros creen firmemente que en ese año académico Sergi no aprendió nada: Víctor le enseñaba cosas que él ya sabía, no le hacía esforzarse para aprender más. Así Sergi no avanzaba, se quedaba donde estaba, y estaba muy enfadado (ETG CE, 422 - Eva). Siempre nos decía es que Víctor "se cree que soy un niño de primaria o de parvulitos", siempre se quejaba de él. Es como si ahora nos enseñaran a sumar otra vez, no tiene sentido... (ETG CE, 423 - Jordi). Además el tiene mucha iniciativa, y cuando le van a enseñar algo él quiere aprenderlo todo y hacerlo bien. Que le enseñaran estas cosas para él era como una ofensa (ETG CE, 424 - Eva).

Los padres de Sergi eran conscientes de esta situación, pero el miedo a que hubiera represalias contra sus otros dos hijos les frenaba a la hora de tomar ciertas decisiones: Yo sé que las horas que él pasaba solo, que no fueran de educación física o dibujo eran horas perdidas. Además cuando se lo llevaba la PT lo metía delante del ordenador con el 'Libro Gordo de Petete' que te digo yo, cosas absurdas, y no hacía nada. Javier estaba muy enfadado con ella y muchas veces estuvimos a punto de firmar para que no pudieran sacar a Sergi del aula, pero siempre pensábamos "Va no, que están los otros dos dentro y se nos enfadaran...". Siempre así. (ETM 3, 385)

No solo ubicaron a Sergi en una esquina y trabajaban con él conceptos más que superados, sino que había profesores que ignoraban su existencia y desatendían por completo sus necesidades. Es el caso, por ejemplo del profesor de matemáticas, o incluso su tutora. Sus compañer@s vivieron esto en primera persona y no podían creerlo:

Muchos profesores, como por ejemplo el de matemáticas, mientras explicaban dejaban a Sergi haciendo lo que fuese... Le mandaba ejercicios "haz este, este, este y este"... (ETG CE, 383- 384, Rodrigo). Le mandaba cualquier tontería, ejercicios largos y lo dejaba ahí y en toda la clase no le hacía nada de caso. (ETG CE, 386- Jordi). No sabemos por qué, pero hubo un cambio brusco, brutal... Yo creo que no entendían su forma de verlo todo, de entender. No entendían cómo pensaba Sergi, no sé. Había profesores que sí, que se implicaban un montón por él, pero había otros que nada (ETG CE, 305- 310- Eva) Yo me sentaba cerca de Sergi, y cuando estaba la PT en clase, se ponía a hablar con la profesora o con quien fuera y no le hacía caso a Sergi, pasaba de él (...) Sergi preguntaba "¿qué hago?" y le decía "Espera, espera Sergi"(...). Y él volvía a preguntar "¿qué tengo que hacer? ¿tengo que leer algo?", "sí, sí espera, ahora te lo digo" y se pasaba la clase hablando. (ETG CE, 314 - 325- Jordi). Sin embargo, había profesores que no consentían tener a Sergi en aquel rincón, y durante su clase optaban por cambiarlo. Algunos profesores como Pilar, Sónia, Jaume,... cuando llegaban a clase lo cambiaban, siempre lo cambiaban. Por lo menos en valenciano, castellano, sociales, música, tecnología... lo cambiaban y estaba con nosotros. Los demás profesores ni caso. (ETG CE, 395 - 397- Rodrigo).

La rabia e impotencia era vivida no solo por la familia, sino también por sus

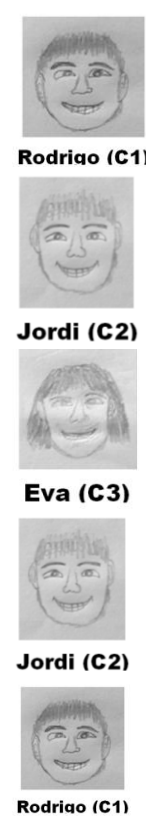


compañeros, quienes, además de pedir al profesorado que cambiaran a Sergi de sitio y que le tuvieran en cuenta, iniciaron acciones de protesta adaptadas a sus posibilidades: Estando en clase con la tutora, empezamos a escribirnos todos en la frente, en la cara, en las manos, en los brazos,... "Todos con Sergi". Era una forma de protesta porque no podíamos hacer mucho más. Teníamos miedo de que nos expulsaran y de esta manera quedaba constancia de nuestra indignación (ETG CE, 506- Vero)

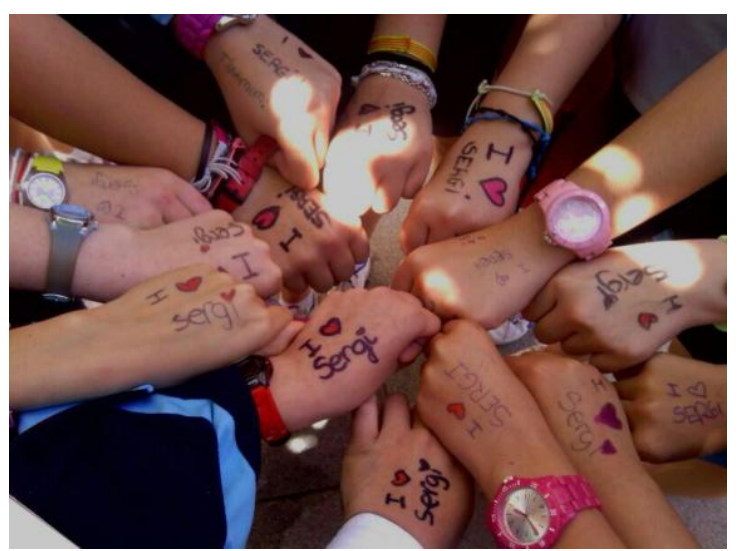

Imagen 12. Manos de los compañeros de Sergi (fotografía cedida por la madre (M))

Francisco, desmenuza con esmero, cómo este centro paso de ser un centro integrador y responsable con Sergi, a ser un centro totalmente hostil para él:

El problema surgió cuando el profesorado no estuvo a la altura de las circunstancias, el departamento de orientación no supo o no pudo (...) entender que su adaptación curricular a veces era significativa y a veces era no significativa, pero aun así la significativa no tenía un distanciamiento curricular tan grande como ellos pensaban. Podían ser dos años, podían ser tres años pero no de dos ciclos. Es decir, si está en primero de la ESO tiene que tener unos exámenes de 5o o 6o, o incluso algunos adaptados de primero de la ESO pero no podía hacer exámenes de 4 o de primaria. Esta concepción de que Sergi es menos capaz que otros, a él lo penalizó muchísimo porque las expectativas del profesorado sobre él no eran buenas. Yo como educador tenía expectativas, sus padres tenían expectativas, el profesorado no tenía ninguna expectativa. La mayoría (...) no creían en él, no tenían esta creencia de que él pudiera hacerlo.

Lo minusvaloraban mucho, y esta minusvaloración de sus capacidades iba siempre en detrimento hacia él y eso se notaba en el día a día. Eso no lo podía consentir y mi obligación era denunciarlo a los padres y decirles "oye, esto no va bien, el profesorado cada vez cree menos en sus posibilidades, no le dan el protagonismo que merece..." $y$ bueno, las reuniones no eran positivas ni daban lugar a concreciones. Lo entendieron mal. Por parte de los padres, no era una forma de inmiscuirse en su tarea, ni ningún afán de fiscalizar su tarea docente, ellos tienen libertad de cátedra, todos lo sabemos. Sabemos que un profesor es responsable de un área o una materia y que él es el primero interesado en que las cosas vayan bien y, por lo tanto, es muy autónomo en sus decisiones. Sin embargo el tema de Sergi requería más coordinación, más voluntariedad, más disponibilidad. La cosa acabó mal porque al final la Inspección pues evidentemente defendió sus intereses, que no estaban tan alejados de los de la escuela, aunque no fueran los de la familia. Una familia evidentemente no era representativa con respecto a 35 familias. Por lo tanto, conjugando los intereses de la escuela y los de la administración, se adoptó por la decisión 'salomónica' de "aquí el 
que sobra es Francisco y si se va Francisco esto volverá a la normalidad porque no tendrán ninguna dependencia técnica de Francisco y el profesorado y los recursos de la administración serán suficientes como para eso". De alguna manera, mi presencia era una alerta y mi presencia les obligaba a tener una actuación determinada. El contacto con la familia era directo, era diario. Yo hablaba todos los días con Àngels, todos los días. Por lo tanto lo que pasaba a las 14h cuando salía Sergi, a las 14:30h Àngels ya lo sabía. Las medidas se tomaban de manera inmediata telefoneando, contactando, porque es que Sergi no puede perder tiempo. El tiempo va en contra de sus intereses. Eso la escuela se lo tomó como algo personal, como algo peyorativo. No entendió nada... (ET Edu, 64 - 68)

Además, al margen del caso particular de Sergi, uno de los grandes problemas de la escuela actual reside en la carente colaboración y comunicación entre escuela y familia. Así lo considera y explica Àngels:

Uno de los grandes problemas de la escuela es que tendrían que dejar a los padres formar parte de ella constantemente. No solo con él por sus características, sino también con su hermano que tiene altas capacidades. A veces un padre o una madre ve cosas que los docentes no ven, y al revés. Creo que hoy por hoy el tema "yo soy el maestro y tú ¿qué vienes a contarme?" es un error, ahí se equivocan. Una cosa es la madre pesada que siempre está allí y que "mi hijo esto, que mi hijo lo otro...", en ese sentido entiendo que hay que decir "basta". Pero en casos así, y teniendo en cuenta que cada niño es un mundo, debería ser diferente. En los países nórdicos en Finlandia, Suecia,... los padres forman parte de la escuela, y asi tendría que ser. De esta manera se cambiarían mentalidades de los padres de "en la escuela lo harán todo", lo verían desde otra perspectiva... Bueno, lo que sería una educación inclusiva... (ETM 3, 460)

\section{4.- Tensiones... el corporativismo como ideología}

De puertas del centro hacia afuera, parecía que todo el centro estaba de acuerdo en estas medidas cuestionables que se adoptaron con respecto a Sergi. Dada la actitud del centro, parecía que la familia estaba exigiendo cosas totalmente desorbitadas y fuera de lugar, pero con el tiempo se dieron cuenta de que no todo el mundo en el centro estaba en contra de la familia. Desde el centro empezaban a tomarse represalias con aquellos que lo cambiaban de ubicación en su clase o que lo integraban en el grupo Una de las profesoras que solía cambiar de sitio a Sergi habló con la familia y les pidió expresamente que no le saludaran cuando la vieran: Pilar me llamó casi llorando. Ella nos aprecia mucho a nosotros y al niño lo quiere mucho. Me dijo "por favor, cuando nos veamos por ahí no me saludéis. Me despedirán y mi marido no tiene trabajo, tengo dos niños, por favor". Nos dijo que el psicopedagogo y la PT ya ni siquiera le hablaban (EPM $2,380-381$ )

Años atrás, la familia había elegido este centro para Sergi pensando que era un modelo de escuela que no solo permitiría a Sergi estar con sus hermanos, sino que permitirían todo tipo de medidas familiares para fomentar el aprendizaje de Sergi. Hoy en día, su opinión es totalmente distinta y consideran que el corporativismo es la lacra de los centros concertados, especialmente del Virgen del Carmen: Este colegio es una secta, yo lo puedo decir. Mi hijo puede tener problemas con un profesor o con dos pero no con todos. Aquello es una secta. Alli se les dice desde arriba "eh señores, este niño... sus padres son un poco pesados ifuera! iA por él!" y todos a obedecer (ETM 2, 309). Esta idea del corporativismo, y la lucha por la imagen externa es compartida por Francisco, quien vivió en primera persona todo el proceso de repulsión a Sergi: 
Partiendo de la idea que todas las escuelas son corporativas, todas, ¿qué diferencia puede haber entre el corporativismo de un centro público y un centro privado concertado? Una muy clara, en los centros públicos, al fin y al cabo, el profesorado es responsable de su trabajo y desde esta responsabilidad y, a no ser que transgreda de manera muy flagrante actuaciones de competencia profesional, no creo que nadie le llame la atención porque un padre esté en desacuerdo en su forma de trabajar (...) En cambio, en los centros concertados lo que quieren es que no haya problemas, porque los problemas normalmente se cuentan, y la forma de contar los problemas a lo mejor es subjetiva y no refleja la realidad. Cuando apareció la problemática de Sergi, la escuela lo que sí hizo fue protegerse contra opiniones de personas que, de alguna manera, (...) pudieran ir en contra de los intereses de la escuela. Lo que hicieron fue protegerse primero ellos a través de un pensamiento único. Es decir, todos pensamos de esta manera "no hay entre nosotros diferencias a la hora de interpretar la situación de Sergi". Si uno piensa blanco, todos pensamos blanco, si uno piensa negro, todos pensamos negro. Y frente a esta postura, fue muy difícil para los padres de Sergi demostrar la situación de desigualdad en la que se encontraba Sergi porque todos los profesores tenían un pensamiento único, y la gente que divergía de este pensamiento eran recriminados de manera interna por pensar de forma diferente.

¿Eso quiere decir dogmatismo? ¿Eso quiere decir sectarismo? ¿Eso quiere decir corporativismo? Deberíamos buscar la definición para saberlo, pero creo que irá en esta línea: un pensamiento único, una forma de pensar general respecto a lo particular. El tema de Sergi siempre es particular y la opinión de las personas tiene que ser particular, porque todas las personas no pensamos lo mismo, y querer convertirlo en un pensamiento único genera problemas. Si cada uno hubiera sido responsable de su actuación con Sergi, podría haber matices o diferentes formas de entenderlo, pero no hubiera pasado esto. El problema es que hubo una directiva de la escuela que dijo "no, esto es así y aquí no se mete nadie". Y esto no es solo para esta familia sino para todas (...) "si no están contentos no pasa nada, se van a otro centro y en el sitio de Sergi entrará un alumno o una alumna y ya está, y no pasa nada". (ET Edu, 107)

\section{5.- Entonces, estamos hablando de injusticia educativa, ¿no?}

La falta de recursos educativos, la desatención y abandono a Sergi, las carencias del sistema y el conflicto entre la familia y la escuela, llevaron a la familia a sentir que estaban ante una situación de injusticia educativa. Los padres estuvieron pensando incluso de querellarse contra el centro, pero decidieron abandonar y tomar otro tipo de decisiones: Esto fue una injusticia, estuvimos hablando incluso con un par de especialistas en el tema porque íbamos a poner una querella contra el centro, $y$ en especial contra el orientador como principal culpable, junto con la tutora y la directora. Lo estuvieron examinando pero visto las consecuencias que podía haber respecto a los compañeros y que teníamos dos hijos más alli, sopesamos pros y contras y consideramos que era mejor no hacer nada. (ET P, 314).

Esta sensación era compartida por los compañer@s de Sergi, quienes consideraban esta situación como abusiva: Sorprendentemente Sergi pasó de estar en primaria genial, estar bien, estar cómodo (...), a estar como oprimido, marginado, fuera de la clase, sin que le hicieran caso... (ETG CE, 662-664- Jordi). Si normalmente son los alumnos los que les hacen 'bulling' a niños con problemas, aquí fue totalmente al revés, aquí fueron los profesores, y es que pasaron de él totalmente. La cosa cambió de primaria, de verlo como un alumno más de la clase, como parte de la 'piña' que somos,

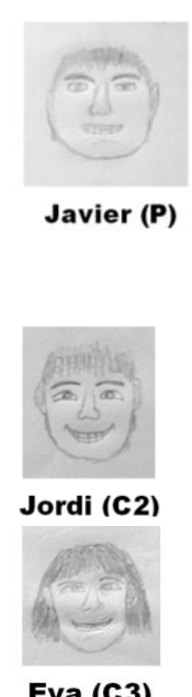

Eva (C3) 
a verlo como un marginado, un niño con problemas, que hay que tratarlo diferente,... ahí fue cuando se lió... (ETG CE, 666- Eva).

Incluso su hermano mayor Gerard, intentó actuar desde dentro del centro: Todos necesitamos que nos hagan caso, incluso Sergi un poco más (...) y ha tenido mucho menos del que se merecía. Este último año no sabría cómo explicarlo porque es algo que piensas que no pasa, "eso es de cuento, eso no pasa en la vida real", pero sí pasa. Yo he tenido los mismo profesores que él y me quedaba muy impresionado de cómo nos trataban a nosotros y después lo que veía que hacían con él. (...) Sus compañeros venían y me decían "Gerard, haz algo" Eran cosas inexplicables. Por ejemplo, en una ocasión repartieron autorizaciones para ir a un parque de atracciones y se lo dieron a todos menos a Sergi. Pero es que él levantaba la mano para que se lo dieran pero pasaban de él. Después otro tema fue el ubicarlo en el rincón. Yo pasaba por delante de su clase y lo veía mal. Una vez incluso hablé de esto con Sónia, una profesora con la que tengo mucha confianza, y le pedí que hiciera algo para que lo cambiaran de sitio en el aula. Ella me dijo que no le dejaban, que ella lo intentaba y que en su clase siempre lo cambiaba de sitio, pero solo en su clase, después tenía que volver a su sitio (...) Son cosas que no sé si son por ignorancia o por impotencia, yo supongo que es ignorancia porque es que tanta maldad no sé si existe...Yo creo que Sergi se les quedó grande y no sabían cómo tratarlo, ni la logopeda, ni el psicólogo del cole, nadie (EG H1 y H2, 160165- Gerard).

Según el abuelo de Sergi, esta situación podría haberse evitado si la escuela hubiera sido sincera y franca con la familia: En el único sitio donde no comprendieron a Sergi fue en este centro, allí no lo comprendieron. Lo que le hicieron... que el niño estaba al lado del radiador, quemándose, se lo dijo a la maestra, y le dijo que se aguantara ceso se lo dice a un niño así? No se le tiene que decir a nadie, pero a un niño así menos. Y créetelo que me caían bien pero ahora las odio mucho, porque es que el niño no se merecía eso, porque nunca se ha enfrentado a nadie, nunca se ha pegado con nadie, "hombre, pues no le hagáis eso al niño" (...) Si no iban a atenderlo bien tendrían que haberlo dicho. Eso se dice "mira, nosotros no lo podemos tener, buscad otro sitio" y ya está, y se queda bien y no hace falta hacer estas 'marranadas'. Un día le preguntó un profesor "¿en verano qué ropa llevas?" y él le dijo "no me tome el pelo". El niño se daba cuenta de cómo lo trataban (ET A, 87- 89).

\section{6.- Quedarse en lo conocido por miedo a lo desconocido, equivale a mantenerse con vida pero no vivir (Anónimo)}

Ante esta situación, los padres optaron por hablar con la inspección de nuevo y buscar una salida a esta problemática. Desde Consellería al principio no se creían lo que les contábamos y nos pedían paciencia y confianza, pero después, cuando conocieron al psicopedagogo, se dieron cuenta de que era verdad, y acabaron comprobando que era mentira todo lo que él les contaba. Más que intervenir y solucionar el tema 'poniéndoles en su lugar', lo que hicieron fue intentar buscar una salida y la solución rápida fue sacar al niño. Eso es lo más cómodo, sale el niño y se ha acabado el problema. (ET P, 310) Para irnos a otro centro, nos dieron todas las facilidades del mundo, nos dijeron que allí en nuestro centro no tenían medios (...) y que en la escuela pública están mucho mejor preparados, que es verdad. (...) De todas formas, lo que no puede ser es que de ahi salga 'escaldado' el niño y punto, y se acabe el problema. Ahí se hubiera tenido que expedientar a alguien (ET P, 312)

La solución que adoptaron y creyeron más adecuada, fue cambiar de centro a Sergi y 
escolarizarlo en el centro IES Ciutat del Mar, un centro de Educación Secundaria Público de la misma localidad. La idoneidad de este centro tenía que ver con la cantidad y variedad de recursos específicos con los que podría contar, pues se trataba de un centro de escolarización preferente de personas con sordera, y con una alta dotación de recursos. Sin embargo, la decisión tomada por la familia no solo afectaba a Sergi, sino que la familia optó por reubicar también en al hermano pequeño, Xavi, en un centro cercano al domicilio familiar y Gerard, debido a su edad, se mudó a Barcelona a estudiar un Bachillerato específico. Este último, relata la necesidad de este cambio en su familia: Yo creo que no podíamos seguir en esas condiciones. Sergi, lo pasó muy mal. Nos dolió que dejara a sus amistades porque era un punto muy, muy importante para él (...) Pero las condiciones en las que estaba Sergi no se podían mantener. Ellas no hacían nada, mi madre se 'curraba' lo que fuera, un libro, una noche hasta las tantas trabajando para que Sergi pudiera hacer un buen examen, y cuando llegaba al colegio le habían cambiado las preguntas. Era para decirles "pero si es que te lo estamos dando todo, si es que no hacéis nada". Lo que 'jode' es que fuera su trabajo y no cumplieran. Y no podíamos seguir. Nos hablaron del otro centro, yo me iba fuera a estudia,... Era un cambio muy necesario, no había otra opción, quedarse no era una opción (EG H1 y H2, 1 205-Gerard)

A pesar de haber tomado esta decisión, la familia prefirió que Sergi acabara el curso en el centro en el que estaba. No tenía sentido escolarizarlo en el nuevo instituto a dos meses de finalizar las clases. Mientras tanto, Àngels y Azucena seguían trabajando con Sergi por las tardes, a sabiendas que en el centro no haría gran cosa. La decisión fue trasladada al centro y esta entristeció solo a una parte del profesorado. En lo que concierne al psicopedagogo, Àngels explica como éste siguió mostrando una gran falta de sensibilidad: Cuando se enteró de la decisión que tomamos, me dijo me dijo "como solo le queda un mes y medio en la escuela lo pondré en la primera hilera para que se lleve un buen recuerdo" (ETM 2, 313).

Muy distinta, fue la reacción de los amigos y compañeros de Sergi, quienes se sintieron verdaderamente conmocionados y apenados por esta decisión. No podían creer lo que estaba pasando pero entendían que este cambio era necesario. Sabían que el centro se había portado muy mal con él, pero querían que se llevara un bonito recuerdo de ellos, por lo que decidieron homenajearle como amigo y despedirlo como el gran compañero que es.

\section{1.- "No llores Lidia, estaré bien" (Sergi)}

Faltaban un par de semanas para terminar el curso y se comentó la posibilidad de organizar una cena de final de curso. A esta acudirían tanto los alumnos como sus padres, pues era habitual realizar este tipo de cenas antes del verano. En realidad, lo que estaban preparado no era una cena al uso, sino una fiesta de despedida para Sergi. Ese día, el día de la cena, cuando Sergi y su familia llegaron al restaurante estaban todos los compañeros de Sergi esperándoles con una enorme pancarta en la que ponía "Sergi, eres un gran amigo". Sus amigos no pudieron contener la emoción: El día de la cena de despedida, fue verlo venir y empezar todos a llorar y a aplaudir. Fue algo súper bonito (ETG CE, 440-441, Vero). La idea de hacer una fiesta de despedida salió de nosotros, fue idea de todos (ETG CE, 468-469-Vero), había que hacer algo para demostrar que no lo íbamos a olvidar, para demostrarle que estábamos con él (ETG CE, 471- 472 - Jordi)

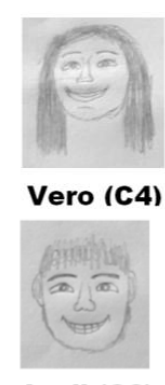

Jordi (C2) 
Sergi, a nosotros nos ha cambiado muchísimo. Eso que dicen todos los profesores de que somos un curso muy bueno, creo que en realidad es gracias a Sergi porque estar siempre con él, todas las clases, aprender a no marginar a compañeros,... Eso nos lo ha enseñado él. Nunca ha habido serios problemas así como hay en casi todas las clases, con nosotros nunca lo ha habido (ETG CE, 497- Vero). Yo creo que Sergi ha sido la persona que ha hecho que seamos todos una familia. Pocas clases pueden decir que 'forman una familia', y creo que Sergi ha hecho eso. (ETG CE, 498 - Eva). Siempre nos ha dado las gracias, ¿gracias? Gracias a ti por habernos enseñado cómo es el mundo desde tu perspectiva, tu forma de pensar debe de ser una manera alucinante de ver las cosas... (ETG CE, 567- Eva)

Esta demostración de cariño y aprecio hacia Sergi no pasó desapercibido para su familia, quienes se sintieron muy bien por este gran detalle: Yo creo que este detalle demuestra que Sergi marcó una etapa muy importante en la vida de sus compañeros. Nos gustó mucho ver que no solo para nosotros Sergi es una persona importante, sino que por él mismo ha podido influir tanto en la vida de sus amigos y que realmente lo hicieron porque les importaba Sergi (...) A pesar de que le cuesta expresar los sentimientos, yo creo que Sergi también se ha dado cuenta de que fue un año complicado y ver que sus amigos le demostraban lo mucho que le querían en una fiesta le gustó mucho. Yo creo que le subió la autoestima, es una cosa importante. (EG H1 y H2, 19- Gerard)

Ese día, su cara irradiaba felicidad y orgullo de ver a sus compañeros, sus amigos, dándole tanto apoyo y cariño. Fue una cena muy especial para todos. Sin embargo, sus padres y hermanos echaron en falta que Sergi mostrara y expresara un poco sus sentimientos: El niño no lloró. Fue muy emotivo y lloramos todos pero él no. Cuando le daban los regalos sin un ápice de tristeza le dijo a su amiga "no llores Lidia, estaré bien" mientras el resto de personas estábamos todos con lágrimas en los ojos. Xavi venía y me decía "mamá, no entiendo como Sergi no ha llorado, yo me he tenido que ir fuera a la calle a llorar porque no podía más. (EPM 2, 172 -175). Era como si Sergi no entendiera el significado real de aquella reunión. Sin embargo, cuando se le preguntaba si sabía por qué le hicieron aquella fiesta, él lo tenía muy claro: Le dijimos "Sergi, ¿tú sabes por qué te hacen esta fiesta tus amigos?" y dijo "sí, porque me voy del Virgen del Carmen". (ET P, 61)

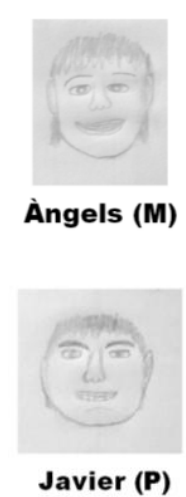

Al parecer, la noticia de que se había realizado esta fiesta llegó a oídos de la directiva y profesores del centro y no les sentó bien. No les gustó la idea de esta fiesta en la que no se contó con ellos y decidieron hacer su propia versión. Así lo cuentan los compañeros de Sergi:

Desde el centro, quisieron hacer una fiesta de despedida exactamente igual a la que hicimos nosotros (ETG CE, 507- Rodrigo) Dos días después de hacer la cena para Sergi, en el patio, vino la tutora y me preguntó "¿le habéis hecho una cena para Sergi? Ya me he enterado". Me empezó a interrogar y me dijo que ellos también iban a hacerle una fiesta para Sergi. A mí en ese momento me pareció raro ¿Qué necesidad tenían si no le habían ayudado en todo este tiempo? ¿Qué necesidad...? ¿por qué ahora? ¿Por qué en el último momento cuando Sergi ya se iba a ir? (ETG CE, 513- Eva) Sinceramente, creemos que les molestó que nosotros le hiciéramos la fiesta e intentaban causar buena impresión... (ETG CE, 526- Jordi). Recalcamos, intentaron dar buena impresión, pero en realidad lo que hicieron fue todo lo contrario para nosotros. (ETG CE, 529-Rodrigo).

El centro se organizó la fiesta de Sergi la última semana del curso, pero estos días Sergi

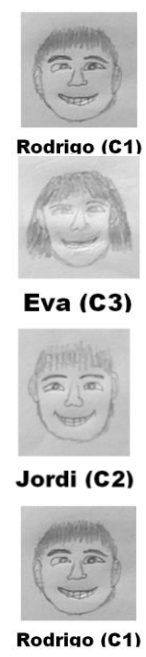


no fue a clase. La familia se había enterado de que le estaban organizando la fiesta y se sentían tan indignados y defraudados que decidieron que Sergi no acudiría al centro esos días. No quisieron darle el gusto a la escuela de sentir que con Sergi se habían portado bien.

\section{2.- El sabor agridulce del paso por la escuela}

La decisión de cambio de centro de Sergi y de sus hermanos, fue una apuesta familiar muy fuerte. A pesar del miedo y la inseguridad que esto generaba, familia y profesionales estaban de acuerdo en la necesidad de sacar a Sergi de este centro y buscar una solución mejor. Su educador Francisco, considera este momento como un punto de inflexión del que Sergi logró salir fortalecido:

El último año de Sergi en este centro fue un caos totalmente. No es posible que durante 5 o 4 años largos se trabaje en una línea en la que se le da mucha seguridad y de repente se rompe. No sabría dar un ejemplo en concreto pero es como si tú estuvieras acostumbrada a vivir de una manera determinada y de repente cambian las condiciones de vida. Un día está Francisco, al día siguiente no está Francisco. La mesa de Francisco está fuera del aula en el pasillo y nadie le dice qué pasa. Él pregunta donde está Francisco y nadie se le contestaba. Y todo aquello que hasta el momento ha estado haciéndose cambia por completo. La familia intentó adaptarse a la nueva situación, pero fue muy precipitado y los cambios de Sergi tienen que ser paulatinos, no puede ser algo inmediato. Por lo tanto, este proceso de adaptación al nuevo escenario, le genera inseguridad, y eso los padres lo notan. Creo que no 'fue de recibo' que la escuela hiciera eso, sin tener la seguridad de que si yo no estaba, o al menos la figura que yo representaba, Sergi podía seguir. No sé decir si esto fue traumático o no para Sergi, pero que hubo un sufrimiento del niño sí, y eso no se puede concebir. Sergi no puede sufrir en un proceso de escolaridad que hasta ahora había sido bueno para él y del que disfrutaba. Disfrutaba aprendiendo, disfrutaba sacando buenas notas, disfrutaba teniendo buena relación con los compañeros, y eso la escuela no tuvo la suficiente dignidad para entenderlo. Como no era más que un alumno más en un conjunto de treinta y pico alumnos, no les importó, $O$ puede que realmente buscaran al final que Sergi se fuera de la escuela, no lo sé. Sin saber cómo llegó un momento en que Sergi incomodaba al profesorado y, por lo tanto, si ya se había hecho todo lo que se podía, no quedaba nada por hacer. (...)

No obstante, había una gran duda sobre cómo Sergi iba a resolver una situación novedosa para él como era un nuevo centro, nuevas relaciones, nuevo profesorado y nuevas amistades. Esta fue una apuesta por parte de los padres que, igual que salió bien, seguramente, hubiera podido salir mal, y por lo tanto, era muy arriesgado, era un riesgo muy grande, y de mucha responsabilidad directa de la escuela. Ahí la escuela se la jugó, porque (...) nadie sabía lo que iba a pasar. Los padres tuvieron mucho miedo y estuvieron durante mucho tiempo angustiados. Es decir, la angustia de años atrás que había desaparecido se instauró de nuevo ¿por qué se instauró? Porque no sabíamos qué podría pasar. Confiábamos mucho en Sergi pero cabía la duda de decir "bueno, ¿cómo se adaptará?" cuando en la escuela este aspecto estaba totalmente cubierto. Finalmente salió bien. Pero la pregunta es ¿y su hubiera salido mal? (...) Esto no es como en la natación. La natación si un día se acaba él siempre sabrá nadar, pero educativamente él estaba arraigado a unas relaciones personales y sociales de un grupo muy concreto. Iba y venía a casa, podía participar más o menos en las actividades fuera de la escuela, etc., etc., etc. Se fomentaba esta relación y a partir de ahí todo era una gran duda, y de hecho el verano en el que ellos tomaron la 
determinación de cambiarlo de centro, hasta que no empezó en septiembre, yo creo que fue el año, el verano más duro y más angustioso de los padres (...) Este fue un punto de inflexión muy, muy, delicado. (ET Edu, 94)

De esta manera, la relación entre Sergi y el que había sido su colegio desde los 3 años terminó. Angustia, espanto, desasosiego, inseguridad... todo estaba en el aire y solo se cabía la posibilidad de esperar. Tras el verano, un nuevo ventanal de oportunidades para Sergi se abría en un nuevo instituto.

\section{7.- Reempezar... una excelente manera de crecer.}

El nuevo curso llegó y Sergi acudió por primera vez a su nuevo instituto, el Ciutat del Mar. Allí, le esperaban para trabajar su tutora, compañeros/as y los profesionales específicos. En este nuevo centro contaría con el apoyo de dos profesionales de pedagogía terapéutica que trabajaban con él en el aula (Paco y Pedro), la logopeda del centro y los profesores de las diferentes asignaturas.

Paco, uno de los profesores de PT, cuenta como desde el centro sintieron que tenían una gran responsabilidad para con Sergi y esperaban poder estar a la altura de las circunstancias: Cuando Sergi llegó a nuestro centro tuvimos muchas conversaciones (...) y pensaba "madre, pues no sé en ese instituto, es muy grande y también es muy diverso". Yo soy consciente de que trabajo en la pública, y en la pública tenemos algo muy positivo que en estos momentos la concertada no tiene: Tenemos más recursos. Eso es un hecho objetivo que no es necesario entrar a valorar pedagogías ni mitologías. Tenemos más recursos. Esto, podría ser un punto positivo, pero también es verdad que una de las cosas que se habían preservado hasta el momento con Sergi era la continuidad en el grupo de compañeros, y ahora esto se convertía en un reto. Hubo muchas conversaciones y muchas dudas con los padres antes de empezar el curso y finalmente, en septiembre de hace unos pocos años Sergi y yo nos encontramos.

(ET PT IES, 22)

El reto, cuando hablábamos con los padres, era "no queremos que nuestro hijo esté en un centro de educación especial, sino probar la posibilidad de que pueda participar en una escuela inclusiva". La escuela inclusiva es una idea muy bonita pero que no cuenta ni con recursos, ni cuenta con las condiciones que tendría que contar, por lo tanto, se hace lo que se puede. Y sí que es verdad que Sergi en estos momentos está en una realidad de escuela inclusiva que no es la ideal, pero que sin embargo tiene muchos anexos en común con lo que debería ser una escuela inclusiva. Al fin y al cabo se trata de un espacio donde, con los demás, puedes participar con tu personalidad, aportando tu forma de ser, donde además aprendemos que no somos todos iguales. (ET PT IES, 22)

Como era de esperar, la llegada a este nuevo centro se preparó con tiempo. Durante ese verano, Azucena y Àngels trabajaron con Sergi los cambios que iban a acontecer para que estuviera preparado: le enseñaron cómo coger el autobús, a desplazarse por la localidad haciendo un recorrido diferente, le anticiparon cómo estaba organizado su nuevo instituto... Sergi, no tardó en aprender todas estas novedades y muy pronto se sintió parte del centro. Se le veía cómodo y se desenvolvía con mucha naturalidad. Esta facilidad de adaptación al cambio sorprendió a familia, amigos y profesionales por igual. 
Para la madre, esta condición, supuso un gran descanso: El niño se adaptó enseguida, eso fue mi tranquilidad porque yo estaba con una angustia tremenda, y en pleno auge de mi enfermedad. Desde el primer día fue como si toda la vida hubiera estado allí. (...) Fue sorprendente. (ETM 1, 267). La asimilación del funcionamiento del centro no fue un problema para él. Paco, su profesor de pedagogía terapéutica explica cómo Sergi interiorizó las rutinas y normas rápidamente: Desde su llegada, Sergi asumió todas las normas del centro de una manera muy rápida. El primer día se le dijo "tienes que subir la silla cuando te vas", y él es el primero en subir la silla cuando se va. Es una persona muy disciplinada y muy rigurosa. Hasta el punto de que si toca el timbre eso es señal de que tienes que acabar lo que haces, y si no es así se enfada. (...) Es una persona que le gusta mucho interiorizar normas porque le hacen sentirse más seguro y es el primero que las cumple. (ET PT IES, 76)

Las primeras semanas que Sergi estaba en el centro, el departamento de orientación organizó una charla para que los compañeros de Sergi le conocieran y entendieran qué significa el autismo. Óscar, compañero del instituto de Sergi cuenta qué les explicaron exactamente: Al poco de haber empezado las clases, nos dieron la charla del instituto sobre el autismo, nos dijeron que teníamos que tratar a Sergi con cuidado, en qué cosas era diferente, cómo relacionarnos con él (ET C IES, 26-27). Sergi, también participó en esta charla aportando su granito de arena. Sus padres le ayudaron a preparar lo que tenía que decir: Le ayudamos prepararse, y con sus palabras explicó lo que es el autismo " $a$ veces necesito estar solo, sobretodo me cuesta el lenguaje, entender y hablar, pero si me ayudáis yo puedo..." Lo explicó todo. (ETM 3, 353).

Sergi no tardó en integrarse en el centro y relacionarse con sus nuevos compañeros. Su profesor de pedagogía terapéutica, Paco, se sorprendió de la rapidez con la que estableció las primeras relaciones: Cuando no llevaba más que tres días ya empezaba a enseñar a los demás sus habilidades y quería compartir con ellos su gesticulación de sombras, una de sus especialidades. Sergi es una persona que cuando está en el patio está solo la mayor parte del tiempo, pero se para con cualquier persona también. Sus tics pueden ser ir de una punta a la otra del patio no sé cuantas veces, pero en un momento determinado cortaba, y empezaba a hablar con cualquiera. Otra de las cosas sorprendentes de Sergi es que él considera a la clase sus amigos, y con total normalidad puede quedar en un momento determinado con ellos y puede acudir a cualquier cita de la clase. (...) A mí esto me sorprendió mucho, porque de verdad que tengo una imagen del autismo por mis conocimientos teóricos que me hacían pensar que todo esto era poco probable, y será poco probable pero es real. (ET PT IES, 30).

Su compañero de clase, Oscar, reconoce que Sergi es una persona que se lleva bien con todo el mundo. Sergi conoce mucha gente, los de clase más los que le van saludando por el patio (...) En general todo el mundo lo respeta. Cuando les habla Sergi le dejan que hable y le dan conversación, y si alguna vez he visto que no se portaban bien con él yo les he llamado la atención. (...) Normalmente yo me voy a la pista, y él se queda con un grupo de amigos suyos jugando al 'pilla pilla', o a veces él se queda solo... con un palo y persiguiendo cosas... (ET C IES, 97 - 103).

\section{1.- Instituto- familia... simbiosis correspondida}

La relación familia- escuela, ese tira y afloja que tantos quebraderos de cabeza había dado a los padres de Sergi hasta el momento, de repente, se convirtió en algo muy sencillo: Hubo un cambio radical. Pasé de ir detrás de los docentes todo el tiempo a despreocuparme, ahora me llaman ellos. Me llaman y me comentan: "a ver cómo 
organizamos los exámenes, ¿te va bien que pongamos dos una semana y el otro a la siguiente porque si consideras que le costará estudiar?" $Y$ así lo hacemos. En el centro anterior no querían ni hacerle exámenes porque lo estresaban, y yo les decía "oye, yo también me estresaba en los exámenes..." iPor el amor de dios! iHay que exprimirlo! (ETM 1, 265)

Ahora por fin, nuestro papel en el centro es el de colaborador. Lo que tendría que haber sido siempre. Nosotros estamos de apoyo y no como antes que hacíamos intervención directa. Nosotros le hacemos esquemas en casa, le ayudamos a repasar, le ayudamos si no entiende algo,... pero no elaboramos nosotros los temas como teníamos que hacer antes. Es que nosotros no somos docentes. (ET P, 173 - 175)

Javier (P)

\section{2.- Planificación y planteamiento pedagógico... ejes fundamentales para la inclusión}

Uno de los éxitos educativos de este centro, reside no solo en la implicación y sensibilidad de sus profesionales, sino también en una buena planificación y organización pedagógica. El trabajo previo a la llegada de Sergi y la distribución de responsabilidades han conseguido una coordinación exitosa desde el departamento de orientación implicando a todos los agentes correspondientes. Según Paco, esta idea no está totalmente instaurada en el centro, pero gracias a la responsabilidad docente ha sido posible:

Una persona con necesidades educativas especiales no puede ser un planteamiento $o$ un compromiso de un PT, de un departamento de orientación. Ha de ser un compromiso del instituto, y eso hoy en día es muy complicado debido a los horarios, a los recortes, a la falta de tiempo para la coordinación,... Por lo tanto, ¿qué hicimos en el caso de Sergi? Hicimos varias reuniones iniciales donde estaba el equipo de curso, de aula, estaban todos los profesores más el departamento de orientación y representantes del equipo directivo (...) y una persona de la Conselleria (Ana, especialista en trastornos de lenguaje). En esa reunión, decidimos cual sería la 'hora de ruta' con Sergi analizando sus limitaciones.

Descartamos en un principio determinadas asignaturas como el inglés y el valenciano y nos centramos en castellano porque Sergi había tenido siempre el aprendizaje en castellano. Sobre el resto de asignaturas hemos tenido el mismo horario que los demás, y hemos intentado en la medida de lo posible que Sergi tuviera la atención específica dentro del aula. Eso tendría que pasar con cualquier alumno con necesidades educativas pero cuesta mucho. Cuesta mucho porque cada uno, evidentemente, representa una personalidad diferenciada y porque también el profesorado está muy habituado a que el alumno con necesidades educativas salga de clase (...) En cuanto a los materiales, Sergi ha funcionado en asignaturas como sociales y naturales a base de un material adaptado, que no está editado en ningún sitio, que se está haciendo día a día en base a los materiales que tienen el resto de alumnos. (...) Todo eso ¿por qué? Porque queríamos que si estábamos hablando en clase de la prehistoria, Sergi tenía que hablar de la prehistoria en su trabajo. No queríamos otra cosa y eso ha sido muy positivo.

Pondré un par de ejemplos: si un día en sociales tocaba hacer un examen, un ejercicio del mapa de Europa, Sergi tenía que hacer aquello. Y ¿por qué? Porque averiguaron que Sergi por ese camino transitaba, y transitaba muy bien, a un rendimiento además espectacular. Porque si en Sergi se ha desarrollado algún aspecto, uno de ellos ha sido la memoria. La memoria la ha desarrollado 'a tope', y la ha desarrollado porque le han 
dado ejercicios, le han dado ocasiones para poder demostrar una memoria increíble, increíble. Sus resultados a nivel de lo que era el aprendizaje memorístico fue espectacular, pero es que si después tocaba el tema de la prehistoria había que adaptar el tema, había que adaptar los 'controles', y el resultado de Sergi continuaba siendo espectacular. (...) Ese resultado espectacular genera a nivel humano una cuestión inherente al aprendizaje, y es que el alumno tenga la sensación de que tiene la posibilidad de éxito. El alumno con necesidades educativas especiales, si alguna cosa tiene interiorizada es que yendo con ese profesor o profesora de PT, es ir a la 'jaula de los tontos'y además "¿para qué? Si no me van a aprobar". Con Sergi, desde el principio, apostamos por una dinámica diferente. Todo ello reforzado en casa y un ámbito familiar que ha sido un complemento absolutamente indispensable. Todo lo que estamos hablando es imposible sin tener el refuerzo de casa, imposible. El trabajo coordinado, el material que se ha generado, más lo que se trabajaba en casa, más la atención a nivel logopédico fuera el ámbito escolar, han sido cruciales. El instituto tomó conciencia de que es un alumno en el que había que apostar de manera inclusiva. (ET PT IES, 26)

Para la familia, la esencia del éxito educativo de Sergi en este centro reside en el departamento de orientación: En este centro el departamento de orientación funciona, y como funciona, funciona todo lo demás también. Ese es el pilar. (ETM 3, 294). Si algún profesor no sabe cómo hacer algo, si hay algún problema, ellos le informan enseguida "pues mira, eso se lo tienes que hacer así, y así,..." Es que los profesores necesitan de la colaboración de los PTs. No puede ser de otra manera... (ETM 3, 291).

La implicación y sensibilización del profesorado en cuestiones de inclusión se convierten en necesarios para que todo este engranaje funcione: Dentro del ámbito educativo hace falta que el profesorado entienda que tú cuando estás en una aula no estás para dar solo física, química o valenciano. Estás para atender a personas, y esas personas serán diversas, y serán diferentes, y tendrás personas con necesidades educativas, y forman parte de tu grupo. Sí que es verdad que habrá una cuestión reivindicativa y dirás "es que no puedo llegar". Pide más apoyo, pide que haya más recursos, más profesionales, pero no pidas que ese alumno salga de esa aula, porque estarás haciendo una aula que será 'mutilada' de lo que realmente es la sociedad. Eso cuesta mucho de entender porque el instituto es una realidad sumamente compleja. Te la habían contando pero cuando llegas ahí ves realmente el valor de las personas que están trabajando y lo entiendes de verdad. (ET PT IES, 37)

Nosotros pretendemos que Sergi tenga la ocasión de hablar de palabras y conceptos que están hablando los demás, es un intento de que él esté conectado. Todo esto es un propósito muy loable pero es muy difícil, no hay que mentir. De esta manera hemos conseguido que él haga lo mismo que los demás, lo que hemos conseguido es que él no esté en un rincón pintando y se acabó, lo que hemos conseguido es que el 'profe' entienda que esa persona está allí también y que puede hacer cosas. Hemos demostrado que puede hacer cosas y que tiene un rendimiento muy positivo, pero aún así tenemos visiones por parte del profesorado del tipo y "esto ¿para qué? Esto no puede ser. A un niño de estos ¿cómo van a aprobarlo?" Estamos hablando de la parte fantástica, pero también existe esta parte real y áspera. (TDE PT IES, 25)

\section{3.- Tejiendo redes de participación: un medio para la inclusión}

En su día a día en el centro, Sergi combina la estancia en su aula de referencia (prioritaria) con la estancia en el aula de PT para trabajar ejercicios específicos y más 
individualizados (sobre todo en el área de matemáticas y lenguaje) .Como venía siendo habitual, su actitud siempre ha sido de plena colaboración y el trabajo en grupo pequeño facilita totalmente la atención especializada en sus dificultades de expresión y comprensión. (TF PT IES, 11)

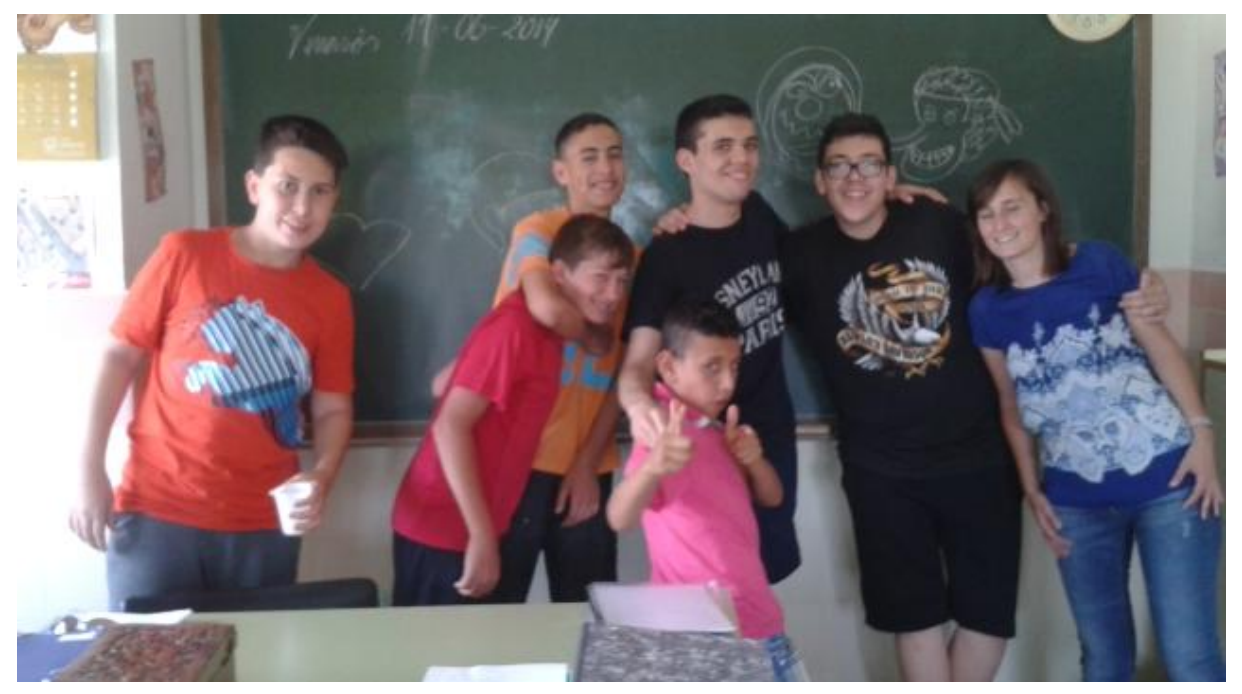

Imagen 13. Sergi en el aula de PT (fotografía n1, TF PT IES)

Tanto en su aula de referencia como en el aula de PT, Sergi es uno más en el grupo y como tal, y participa tanto en actividades de aula (trabajos en grupo, exposiciones, debates,...) como en actividades extracurriculares. Si hay una cosa que le gusta a Sergi es ir de excursión con sus compañeros: Hemos ido de campamento al pantano, a Fredes y dormíamos en una caseta en la montaña, hemos ido a Tarragona, a las ruinas romanas, a la fábrica de sardinas, a Port Aventura, a las minas de hierro para ver cómo se descubrió el metal y hemos usado un imán de verdad. También hemos ido a Peñíscola al castillo del Papa Luna. Vimos su habitación, había pergaminos y una mesa de escritorio. (ET S, 310 - 337)

Sus horarios en el centro son los mismos que los de sus compañeros, con la diferencia que él está atendido en un 30 o $40 \%$ por profesorado especifico. A veces dentro del aula, a veces fuera, pero no cambia nada. La única cosa especial que hay dentro de su horario, es que hay determinadas asignaturas que se aprovechan para trabajar el lenguaje o para trabajar aspectos más concretos, pero en el resto de cosas va al mismo ritmo que los demás. Además, cuando se trata de hacer actividades extra se intenta que Sergi participe y hasta ahora todo ha ido bien. (ET PT IES, 78)

Durante todo el tiempo que lleva en el centro, ha participado en actividades que, si te digo de verdad, pensábamos en principio que serían muy difíciles o que tendrían que estar más tuteladas. Sin embargo, en estos momentos, Sergi se va a excursiones y no se va con un profesor específico para él, va con el grupo. Se ha ido hace 4 días a Fredes a andar por allí con los demás, y se ha quedado a dormir fuera de casa y ahora se irá a Santes Creus (...) Pero es que él sabe dónde irá, y que verá la Tarragona Romana porque en casa y en clase le explicaremos cosas, y él tendrá claro dónde va. Eso es muy importante para Sergi. Cuando te paras a observar a Sergi en una excursión (...) dirías "es que es como si Sergi no se enterara" pero no es verdad. Él está absorbiendo un montón de cosas y hablará de ello después. Esto es muy apasionante en él. Esa necesidad que tiene de continuar aprendiendo cosas, la bondad, la sensibilidad, la 
creatividad,... la capacidad que tiene memorística, es alucinante lo bien que la utiliza.

La dificultad en el lenguaje es su 'pega' (...) Ahí tiene su dificultad máxima, y ahí es donde se tiene que trabajar más, en el lenguaje. Es fundamental porque a medida que él vaya teniendo más instrumentos de lenguaje, podrá hacer más y más cosas. Sus virtudes son tantas... la creatividad, la expresión artística y la sensibilidad, tiene muchísima sensibilidad. Yo estoy seguro que es una persona muy sensible, muy afectiva. Es una persona sorprendente con sus especialidades $y$, aunque no puedo afirmarlo, creo que empatiza con todo el mundo. Él puede ponerse perfectamente junto a alguien y desea que los demás también lo tengan en cuenta. (ET PT IES, 33)

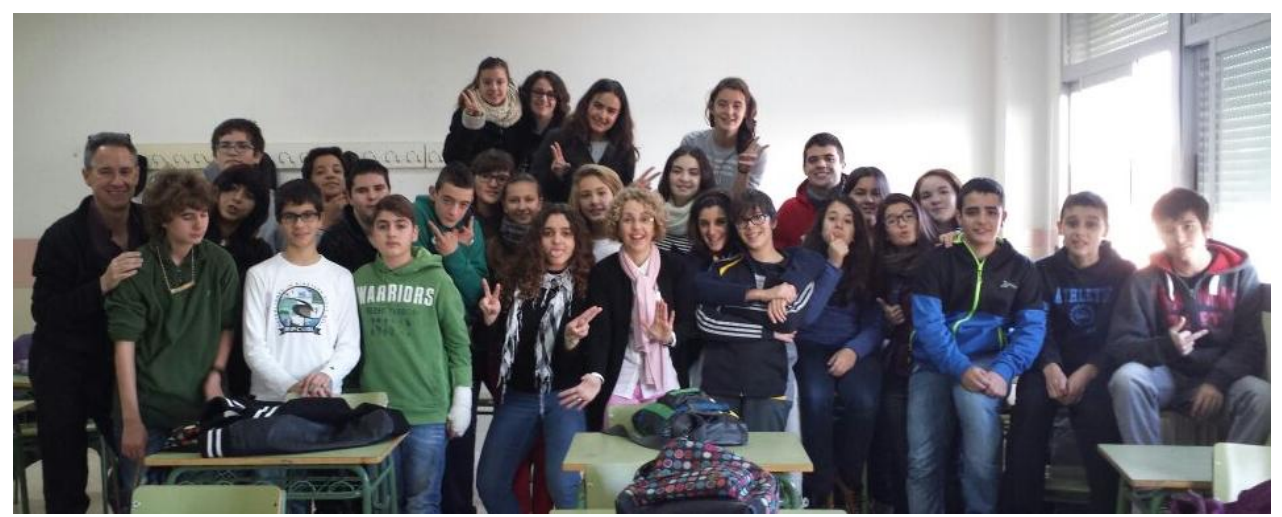

Imagen 14. La clase. (Fotografía no1, TF C IES)

De toda esta situación, si algo ha sacado en claro Sergi es que su instituto es el Ciutat del Mar, y que no quiere volver al centro Virgen del Carmen. Según su madre, este sentimiento lo exteriorizó expresamente: Dicen que estos niños no se enteran de nada, pero el otro día pasando por la puerta del Virgen del Carmen me dijo "solo me dan pena mis amigos" como diciendo 'no vale la pena estar ahí dentro'. Él no quiere saber nada de ese centro, claramente dice "mi instituto es el Ciutat del Mar" (ETM 2, 145). Sergi considera que a ese centro ya no tiene que volver: Ahora estoy ya en el instituto porque ya soy mayor, tengo 15 años (...) Yo no quiero volver, no puedo volver (...) Me gustan más los profesores del instituto, me tratan mejor y tengo a Paco, que es muy listo y me ayuda, como Francisco (ET S, 212-224).

\section{4.- Sergi a día de hoy...}

Hoy en día, Sergi se define como un joven abierto, maduro, amigo de sus amigos, cariñoso, respetuoso y exigente. Hay que tener en cuenta que estamos hablando de una persona con muchos problemas de comunicación, pero cuidado, de comunicación formal, porque Sergi es muy fácil entender cuando está bien, no siendo así cuando está mal. Una cosa que es sorprendente en Sergi es su capacidad de trabajo, es alucinante. Sergi en estos momentos está atendiendo a las tareas del instituto, y no de manera pasiva (...), y prácticamente todos los días tiene trabajo para casa. Pero es que además va a la logopeda, pero es que además va a la escuela de arte, pero es que además está en el club de natación. Todas estas cosas han sido muy importantes para él y le han establecido una sensación de éxito tremenda, de capacidad para decir "mi vida tiene sentido y mi vida es gratificante por muchas razones" (ET PT IES, 78)

Tal y como explica Paco (PT IES), en el equilibrio entre la educación formal y no formal, las artes y los deportes, reside el sentido y esencia del éxito de Sergi. En la Escuela de 
Arte es feliz, se siente libre, se expresa y crece como persona. En la natación ha encontrado una de sus mayores grandezas, y a través de ella, ha sido capaz de demostrar que aquello que se propone lo consigue.

Una de las bases de los logros de Sergi en el mundo del deporte tiene que ver con el papel que ha ejercido su abuelo materno. No solo la iniciación de Sergi en el mundo deportivo, sino la constancia y perseverancia en el camino pasan indiscutiblemente por ese abuelo entregado. La madre de Sergi, explica cómo si no fuera por él, Sergi no hubiera podido llegar donde ha llegado: Mi padre, antes, sino estaba trabajando estaba dedicado al campo, pero llegó un momento en su vida que dijo "no, yo no voy a ir 'aparcando' cosas y dedicándome a quien me necesita, tengo que ayudar a mi hija". Sergi ya estaba apuntado a natación, pero había nacido Xavi y yo no podía llevarlo. Nos habían dicho que era muy importante el tema del agua, el contacto y que debía ir al menos 3 días a la semana, pero yo no podía. En principio me llevaba al bebé a la piscina, aquel calor, se resfriaba,... al final Sergi no iba a la piscina. Entonces mi padre empezó a venir dos o tres tardes a casa, le lo llevaba y después lo traía de vuelta. De hecho, todo lo que ha conseguido en natación se lo debe a mi padre. Él ha hecho mucho tanto en natación como en la escuela de arte, él se encargaba de llevarlo. Él iba allí y se quedaba todo el tiempo viendo al niño nadar. (ETM 2, 232)

Fueron varios los entrenadores de natación que trabajaron con Sergi desde su inicio en este deporte. Tras su incorporación al club de natación adaptada de su localidad, su entrenadora Laura trabajó duro con él. Según Javier, ella sentó las bases de este deporte en Sergi: Laura Palacios le enseñó a nadar, al cabo de un mes de trabajar con ella ya hacía de todo, buceaba, nadaba,... Fue una persona fundamental (ET P, 223). Más tarde aparecieron otros entrenadores en el club, hasta que Enrique, el segundo de los entrenadores, vio posibilidades y apostó por él: Enrique López fue el que le enseñó a competir. Enrique es el que dijo por primera vez "este niño tiene cualidades" y empezó a trabajar con él para que rebajara el tiempo. Tanto él como Laura fueron dos personas importantísimas en el tema de la natación (ET P, 223). Del trabajo de Enrique, derivaron posibilidades de ir accediendo a distintos tipos de campeonatos, a conocer otros contextos, a mejorar,...

Gracias a la constancia, al tesón, al esfuerzo y perseverancia, Sergi fue poco a poco mejorando sus cualidades deportivas decidieron ir probando suerte en distintos campeonatos. El primero de los campeonatos a los que asistió fue en Valencia, en Nazaret, donde tenía que hacer unas marcas mínimas para poder ir después al campeonato de absolutos, pero no hubo suerte. Sergi siguió trabajando y entrenando y el siguiente paso fue el campeonato Autonómico en Torrevieja donde ganó una medalla de plata en braza. Esto fue todo un logro para Sergi y para los suyos, pero lo que nadie se esperaba es que esto fuera solo el principio. Tras muchas horas de entrenamiento y dedicación, poco a poco, Sergi se fue haciendo un hueco en el mundo de la natación adaptada. Fueron muchos los campeonatos de la geografía española en los que ha participado: Badajoz, Benidorm, Valladolid, Cádiz, Sevilla,... Hasta llegar a formar parte de la selección valenciana de natación adaptada y ser subcampeón y campeón de España en su categoría.

Sin duda alguna, uno de los momentos deportivos y personales más intensos y representativos de Sergi fue el Campeonato de Natación Adaptada y en Edad Escolar de Badajoz, en 2014. Para su familia, hermanos y padres, significó mucho. Fue uno de los momento más álgidos en la vida de Sergi. Según su hermano, esto supuso para él una buena dosis de autoestima: Que Sergi llegara a este campeonato y que Sergi 
ganara no nos lo esperábamos y para él significó mucho a nivel de autoestima. Toda la familia estábamos con él, volcados con él y estaba muy feliz. (...) A él le importó mucho vernos a todos apoyándole, tras él en la carrera y que lo llamáramos estando lejos... La verdad es que Sergi en natación, hasta ese momento, no había destacado mucho, pero esto marcó un antes y un después. (TF H1, 60 - 62). Su hermano pequeño Xavi (H2) admira mucho a Sergi por ello: estoy muy orgulloso de él y me pregunto si algún día llegaré a ser como él, no en natación pero en algo. Ese momento me emocionó mucho. (TF H2, 69)

Especialmente su madre concibe este momento como uno de los más importantes en la vida de Sergi y una recompensa tras el trabajo de toda una vida:

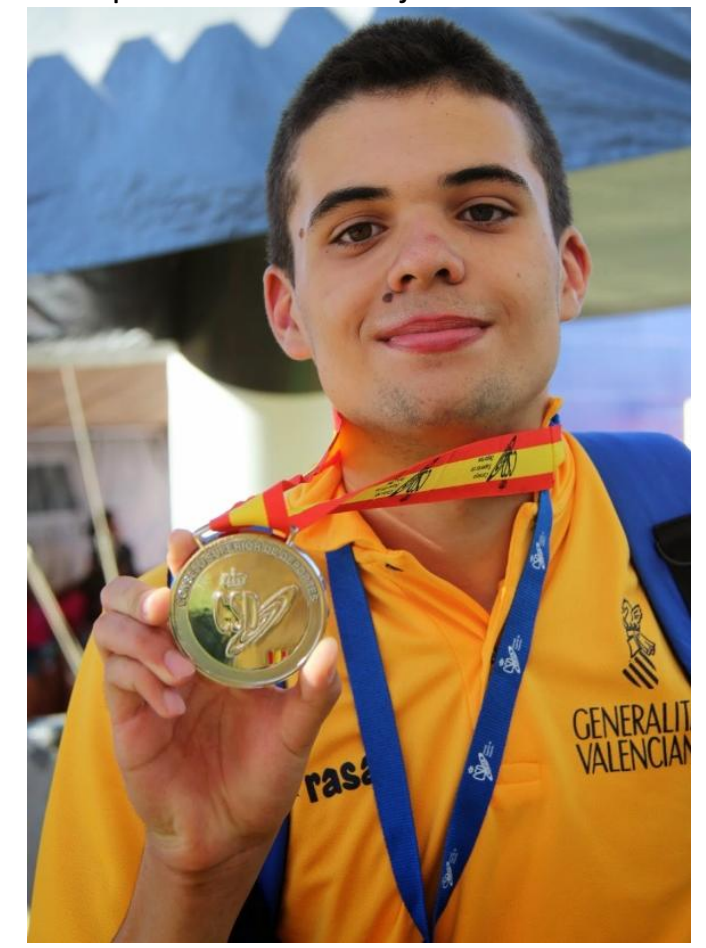

Imagen 15. Consiguiendo lo inimaginable (fotografía nำ, TF M)

La imagen de Sergi en el Campeonato de España de natación adaptada con una medalla en el pódium se consideró un logro de toda la familia. Concretamente yo acababa de salir de una enfermedad muy grave, aquel invierno Sergi luchó todo el invierno para conseguir ir a campeonatos y lograr llegar al campeonato de España. Yo, que había sido siempre la que había estado a su lado, llevándolo de pequeño aquí a allá, no pude llevarlo en todo el invierno, fue su padre. Su padre me decía "en verano si conseguimos ir a Badajoz iremos los dos a verle" y yo pensaba: "No sé si podré...", pero pude y para mí fue precioso poder ver a mi hijo allí. Toda la vida esforzándonos, llevándolo por aquí y por allá... y finalmente poder ver este momento. Si te digo la verdad, en ciertos momentos pensaba que a lo mejor no lo vería...

Cuando él ya estaba en Badajoz me llamaba por teléfono y me decía "mamá, ¿tu vas a venir?" y yo "sí cariño, sí que iré", "¿por qué no vienes?" y yo le decía "porque no puedo, porque estoy enferma". Cuando me vio allí estaba supercontento y me decía "mamá, voy a ganar por ti, ya lo verás". (...) Aunque no lo parezca en esta foto hay muchos años de sacrificio. Todo empezó a los 2 años, cuando ni siquiera se quería bañar, era una pelea continua y nunca me hubiera imaginado poder llegar a esto. Gracias a dios es un niño muy disciplinado y la disciplina le ha llevado a poder llegar a estos sitios, porque realmente aunque sean personas con discapacidad, los jueces los 
eliminan, no hay piedad. Si tú haces una cosa mal vas fuera. (...) Jamás me hubiera imaginado que hubiera podido llegar a una disciplina tan dura como es la natación o ir a un campeonato de España. Me emociona, después de un año tan malo en el instituto, que lo tuvieran en el rincón, salir del instituto... cuando vi eso creía que me moría. Consiguió lo inimaginable. (TF M, 38 - 42)

A raíz de este gran logro, todo el mundo supo que Sergi había sido subcampeón de España de natación. Familiares y amigos llamaban para felicitarle, la gente por la calle lo paraba para darle la enhorabuena e incluso el ayuntamiento de su localidad le hizo un homenaje por ser un deportista reconocido.

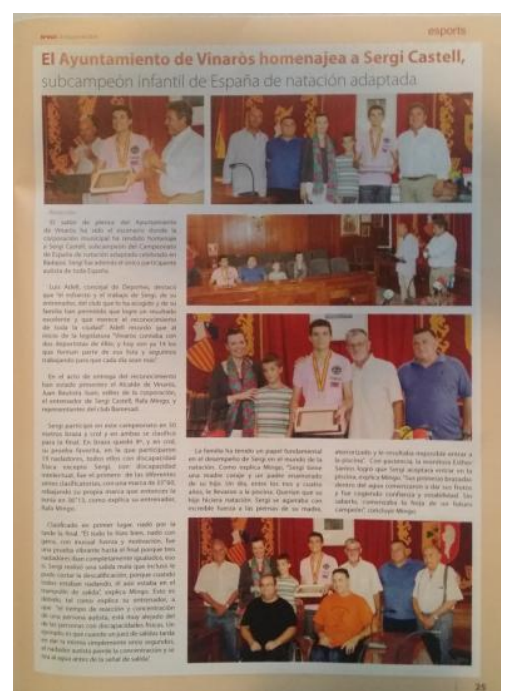

Imagen 16. Notícia en la revista local (Documento 68, TDE M)

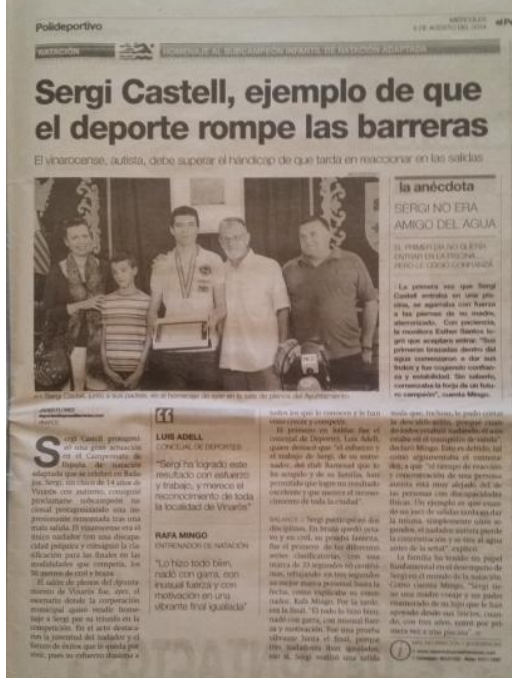

Imagen 17. Notícia en El Periodico

(Documento 69, TDE M)

Todos me conocen porque soy nadador, y gracias a mi entrenador aprendí a nadar rápido, y también en estilo de crol. En Badajoz quedé el segundo (...) y me hicieron un homenaje en el ayuntamiento. Fuimos papá, mamá, Xavi, el abuelo... y me dieron una placa. Me hicieron el homenaje porque soy un deportista de élite, (...) soy muy bueno en natación. (ET S, 485 - 498)

Este reconocimiento de la localidad a Sergi y a su carrera deportiva emocionó muchísimo a su familia. Este momento supuso para la madre un gran orgullo además de una grata sorpresa por el comportamiento de Sergi: Ese homenaje fue muy bonito. Además su comportamiento, cómo reaccionó delante de una situación así, que le hicieron el homenaje... muy emocionante. Él fue muy consciente de todo en todo momento, dando las gracias a todos, estaba muy contento. (...) Todo el mundo lo felicitaba y nos felicitaban... La gente que realmente lo quería y nos quería a nosotros nos ha felicitado por hasta donde ha llegado Sergi. (TDE M, 116 - 120)

\section{5.- La única discapacidad en la vida es una mala actitud (Scott Hamilton)}

Como es bien sabido, el ámbito de mayor dificultad para una persona con autismo es todo aquello que tiene que ver con lo social: comunicación, relaciones, bromas, amistades, normas,... por lo que las relaciones sociales de Sergi están muy vinculadas a contextos específicos (colegio o natación). Su familia, describe su red de relaciones como escasa y superficial pero lo suficientemente satisfactoria para él. Su madre

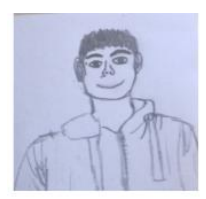

Sergi (S)

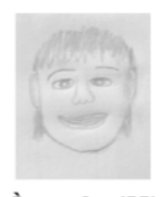

Àngels (M) 
recalca como, a pesar de que sus amigos del colegio lo llaman para hacer alguna actividad, esto es un hecho aislado y del que él, realmente, no sabe disfrutar en plenitud:

Algunas veces han venido a buscarlo a casa sus amigos del colegio y él se pone muy contento "han venido a buscarme mis amigos" y se va a pasear con ellos(...) Yo me lo imagino dos metros delante del resto, hablando solo, gesticulando y pasando películas mentalmente. Él no participa en la conversación y de repente dirá "oh, oh, es muy tarde, yo tengo que ir a casa" y se irá. (EPM 2, 134 - 138). Él tiene un gran hándicap con la comunicación, a veces nos dice "yo quiero ser un niño normal, ¿qué le pasa a mi cerebro? ¿Por qué?” (...) Él se da cuenta que algo no va, que es diferente, pero aun así no se plantea si sus relaciones sociales son lo normales o no. (EPM 2, 123-126). Alguna madre de vez en cuando me dice "pues llama a mi hijo", pero va, se está una "horita' y vuelve. Yo a veces le pregunto "¿qué haces con tus amigos?", y me dice "es que ellos hablan de sus cosas y yo esto allí y escucho". Dependiendo de las conversaciones que lleven, él se irá a su mundo y por eso no intenta ir. (ETM 3, 94 - 96)

A Àngels le gustaría que Sergi se relacionara más, pero reconoce que él no lo necesita: Bajo su punto de vista, el tipo de interacción social que tiene es lo normal. Él tiene sus necesidades cubiertas, y no tiene esa necesidad de contarse las cosas, la vida, los problemas... él no (EPM 2, 162). Incluso hay veces en que le obligo un poco a relacionarse y le digo "llama a tu amigo Cristian, llama a no sé cuanto" y Javier me dice "Àngels es que le estás obligando a hacer una cosa con la que él no es feliz, ¿no acordamos que lo primordial sería su felicidad? Pues él es feliz en casa ¿para qué tienes que vaya, esté una hora y venga enseguida a casa? iSi no es feliz! Es más importante su felicidad, él se aburre. Siempre ha habido gente que le gusta más estar solo y no pasa nada". Además cuando él quiere algo se lo pide a un hermano, o se busca la vida. Si le apeteciera ir a la piscina iría y allí se encontraría con alguien seguramente. Pero en general, él vive muy asolas. (ETM 3, 100)

Sergi siempre ha trabajado muy duro para entender la sociedad y formar parte de ella de manera plena. De hecho, sus logros académicos, deportivos y artísticos son fruto de este gran esfuerzo y dedicación. En general, la sociedad acepta la diversidad, acepta la diferencia como parte de ella, pero parece no estar totalmente informada y sensibilizada para ello. Marisa, profesional de Mira'm que lleva muchos años trabajando con personas autistas, afirma que la sociedad no está preparada para personas como Sergi, cuyo problema reside en no entender la sencillez de la interacción social:

La sociedad no está preparada para personas como Sergi, y no lo está por no ver lo simples que son estas personas. Es decir, simples en el sentido de que realmente somos una sociedad muy compleja, nos pasamos el día atribuyendo, interpretando,... y no somos capaces de entender que para ellos existe lo que se ve. Si no se ve no existe. Eso es muy difícil de entender para las personas neurotípicas. Por ejemplo, con un chaval ya mayor, de 18 años, nos pasó un anécdota. Él se enfadó con su maestra porque su maestra había entrado en el vestuario de chicos. Claro, la maestra no podía entender porqué se había enfadado. Y yo le decía "¿cómo que no lo logras entender, si es la cosa más sencilla del mundo?", ojalá que todos los análisis de conducta fueran igual, "porque le has invadido, porque le has dicho que ahí solo pueden entrar chicos, y tú no eres un chico y le estás provocando un lío cognitivo". Es algo muy sencillo pero muy complejo para entender para la sociedad. (ET Mir, 66). 
Esta visión de falta de información y sensibilidad, es compartida por la familia de Sergi, pero también es cierto que consideran que en la medida que una persona conoce 0 tiene cerca a una persona con autismo o con diversidad funcional se vuelve más sensible: por desgracia creo que todavía nos falta mucha evolución y madurez en este tema. Está claro que todos los que tenemos un niño con un problema o un familiar, tenemos más sensibilidad, (...) eres más comprensivo. Cuando viene alguno a la librería o al ayuntamiento lo trato muy diferente ahora que antes de tocar este tema porque me doy cuenta de la dificultad que les representa a ellos. (ET P, 305). De la misma manera, cuando los hermanos se llevan a Sergi con ellos, consideran que ofrecen a sus amigos la oportunidad de conocerlo y estos no solo aprenden valorar la diversidad, sino también de apreciar y reconocer las capacidades de Sergi. Gerard explica cómo sus amigos han aprendido a valorar a Sergi por sus capacidades en lugar de por sus dificultades: Mis amigos lo ven como una cuestión de autosuperación, de lucha constante. Tienen a Sergi en un pedestal. Cuando Sergi viene con nosotros les impone su figura y cuando les hace lo de las sombras chinas o cualquier otra cosa dicen "es que este chico es algo que nunca sabemos lo que pasa por su cabeza". Yo creo que les impone y les gusta mucho su presencia. Desde que está en el instituto se ha hecho un chico muy cariñoso y tranquilo, y estar a su lado no es molestia ninguna. Es un chico muy amable, que dice cosas muy graciosas, una compañía agradable, y eso tiene mucho que ver (EG H1 y $\mathrm{H} 2$ 1, 108-Gerard) 


\section{8.- Te estoy tejiendo un par de alas, sé que te irás cuando termine, pero no soporto verte sin volar (Andrés Casturera-Micher)}

El futuro, incierto y desconocido, genera grandes expectativas a la vez que miedos en el entorno de Sergi. Es cierto, que vista la evolución de Sergi, lo que ha sido capaz de lograr en todos los ámbitos de su vida, y la voluntad y tenacidad con la que hace aquello que le gusta, hace predecir un exitoso futuro. No obstante, y dadas las circunstancias, desde el principio la familia se planteó vivir el día a día y no pensar en el día de mañana: No nos planteamos nada, si hay algo que tengo muy claro es vivir el día a día. Llegó un momento en que nos agobiábamos mucho y entonces dijimos "viviremos el día a día, y cada día será algo muy bonito, muy especial, si encontramos una barrera la saltaremos y a la mañana siguiente será un día nuevo". No nos planteamos nada, vivir el día a día. Yo no me quiero plantear nada, porque no sé cómo evolucionará. Sergi nos ha sorprendido tanto... Ha llegado al Campeonato de España un niño que no quería ni entrar en el agua. ¿Qué se puede esperar? Pues no lo sé, seguramente nos siga sorprendiendo, entonces ¿para qué nos vamos a calentar la cabeza y sufrir? (ETM $3,340)$

El que conoce a Sergi, sabe que aunque se prevé un porvenir pleno, sus hándicaps o dificultades van a seguir estando ahí y habrá seguir trabajando. Su logopeda asume que habrá que ir transformando el trabajo con Sergi a medida que emerjan nuevas necesidades: Sergi se va haciendo mayor y en cada etapa encontrará unas dificultades. Llegará el momento en que empezará a tener sentimientos por alguna niña y no sepa como asimilar esto. Ahí siempre va a haber un punto en el que hay que estar trabajando para que él comprenda, para que comprenda emociones, para que comprenda intenciones, para que comprenda todo eso. (ET Log, 46). De hecho, su padre es consciente de que es muy difícil que supere todas sus dificultades sociales, aunque no descarta que no sea capaz de hacerlo: Sergi está evolucionando de una manera que nadie nos esperábamos. Entonces no sé hasta dónde llegará el niño, no sé qué clase de amistades o vida normal podrá llegar a tener, porque cada día me sorprende con algo nuevo. Yo creo que si continúa evolucionando puede no tener ningún problema, tal vez pueda conservar amigos... no lo sé, aunque soy consciente que todo esto para una persona con autismo es muy difícil (ET P,101).

Dentro de las relaciones sociales, el tema de las relaciones interpersonales e intimas preocupa un poco a su logopeda, pues no sabe cómo se va a abordar este tema con Sergi: No tengo claro si el día de mañana va a tener pareja o no, pero estoy segura que capacidad para ello tiene. Cuando tú conoces a una persona hay un proceso de enamoramiento, de quedar, del tonteo,... Tendremos que ver cómo canalizar, cómo expresar esto, cómo actuar,... (...) No es que no sea capaz de querer a alguien o enamorarse de alguien, pero habrá dificultades en cómo se lo comunica a esa persona, cómo lo entiende esa persona, cómo elaboro un inicio de pareja..., es complicado. "¿qué hago, siempre llevo una carpeta de historias sociales para saber cómo tengo que actuar con esta chica? ¿Me lo tienen que explicar mis padres o las personas que estén conmigo cuando yo me encuentre en la vida con estas situaciones? ¿Sabré actuar?" Esto es lo que no sé cómo será dentro de unos años (ET Log, 163)

Sin embargo, sus amigos, tienen claro que, pase lo que pase, Sergi no tendrá ningún problema en encontrar una persona que le quiera y con la que compartir su vida. Sergi 
es una persona muy inteligente, con la que te lo pasas bien, te demuestra el cariño que siente por ti. Creo que no va a ser difícil que Sergi tenga novia o lo que sea el día de mañana. Es una persona que se hace querer. (ETG CE, 690 - Eva)

\section{1.- El hándicap del lenguaje...}

Sus dificultades son las que son y, como dice Paco, asumir que la clave del éxito de Sergi reside en el lenguaje: Vamos a necesitar más profesionales y más tiempo para favorecer en Sergi lo que es la explosión, el ejercicio, del lenguaje. El lenguaje mientras no se demuestre lo contrario es la base de todo. Hasta ahora, él lo ha suplido con el esfuerzo de su madre, con el esfuerzo que hacemos nosotros, pero es el lenguaje donde está la llave de todo. Él ha progresado muchísimo, hasta puntos que prácticamente muchos de los profesionales que lo reconocieron cuando era pequeñito decían que era imposible. No es verdad. Nunca tenemos que decir que es imposible una cosa. Hay que ofrecerles caminos y que puedan transitar (ET PT IES, 95)

Esta visión, coincide con la que posee Francisco, quien focaliza no tanto en los logros conseguidos sino más bien en todo lo que está por llegar: De entrada Sergi es una persona que tiene unas competencias, que deben mejorar para que sea una persona con criterio, autónoma. Su mundo es un mundo, de momento, es indefinido (...) y su mayor logro es que cada vez las diferencias entre su entorno y él son más pequeñas. (...) Creo que lo mejor es no ponerle hitos, no ponerle metas, que vaya creciendo, que vaya haciendo cosas. Él es feliz, yo creo que es un niño feliz, porque tiene una familia que lo quiere muchísimo, porque le dan muchísimas oportunidades, porque hace actividades que a él le dan mucho placer, y dentro de esta felicidad tiene que seguir viviendo. Todas las presiones que tú quieras y todas las obligaciones que tú quieras, pero desde el punto de vista en el Sergi sea feliz, que crezca, que se marque sus propios hitos, los hitos que sus padres consideren. Si tiene que ser campeón de España, pues que sea campeón de España, si tiene que sacarse el graduado, que se lo saque, si tiene que hacer una formación profesional, que la haga. Creo que debe normalizarse su salida a un mundo laboral o productivo, con las mejores circunstancias posibles y que después, como toda persona, tenga aspectos de su vida, deportivos, de ocio o artísticos, que le ayuden a ser cada vez más brillante. (ET Edu, 124)

Es muy difícil hablar de lo que Sergi podrá hacer o no en un futuro, pero si algo comparten las personas que lo conocen es que cada vez seguirá demostrando más y más su capacidad de ser autónomo: Sergi, en la adolescencia nos está demostrando que tiene habilidades y que tiene cosas para ir encaminándose hacia ciertos temas con una mayor autonomía que a lo mejor chavales con una mayor necesidad de apoyo. Está consiguiendo ser una persona válida por sí sola e independiente en algunos contextos, y hay que continuar fomentándolo. El tiempo nos lo irá diciendo. Sobre todo hay que avivar aquello dónde Sergi sienta que todas sus habilidades emergentes pueden brillar. No sé si Sergi puede ser independiente al 100\%, pero si con ciertos modelos de apoyo o en un empleo con apoyo supervisado, o en su propia casa supervisado con gente ¿por qué no? Hay que continuar trabajando. (ET Mir, 70). Sea como fuere, ahora mismo su futuro es un interrogante, (...) y si continua creciendo de esta manera no hay límites, tiene los límites que cualquier persona podemos tener, y él irá descubriéndolos como todos. (...) Lo que sí es seguro es que será una persona feliz, será una persona que, de alguna manera, tendrá que realizarse y tiene muchos talentos para poder hacerlo. Estos talentos que tiene naturales, que son innatos, hay que ponerlos a trabajar, simplemente eso. Ojalá pueda ser una persona autónoma totalmente insertada en la sociedad y que tenga las mismas obligaciones, derechos y deberes que cualquiera de nosotros. Ojalá. (ET Edu, 131) 
La idea de que Sergi puede explotar su autonomía en casas o pisos tutelados, es un planteamiento que los padres siempre han considerado para Sergi: Yo siempre he pensando que si siguen funcionando los pisos tutelados para él sería lo mejor. Él tendría su habitación, su ordenador, su tele,... su autonomía. Se iría a trabajar, sus hermanos también harían su vida pero de vez en cuando se podrían reunir. No podemos pretender que los otros carguen con él siempre, es que no sé tampoco si él lo permitiría, porque él necesita tener su vida y su espacio. Él podría vivir en un piso con más gente, cocinando,... Es un niño súper dispuesto, le encanta, él siempre me ayuda a hacer pizzas, a hacer tortillas,... Es muy autónomo y por eso creo que sería feliz viviendo así con gente como él. Imagínate que su hermano se va a vivir al otro lado del mundo ¿qué pinta él allí? No puede ser. Él tiene que ser él, él tiene que tener su vida, tiene que tener unos tutores que controlen, su trabajito y un piso tutelado sería lo mejor. (EPM 2, 451).

Sin embargo, a pesar de que los pisos tutelados son una posibilidad futura para Sergi, sus hermanos nos descartan que viva y comparta casa con ellos: Creo como más feliz sería Sergi es compartiendo una vida con nosotros, con sus hermanos, y a lo mejor los domingos ir todos juntos y comer con la familia, no sé, una vida un poco lejana a la que tiene ahora, demostrando que ha crecido, que él también puede valerse por sí mismo y puede seguir madurando y haciendo muchas cosas. (EG H1 y H2 2, 52-Gerard) Yo siempre he pensado que no será ningún problema que viviera conmigo porque no es un obstáculo, para mí no es una preocupación, me gusta mucho vivir con Sergi. Pienso que él no querrá estar aquí, querrá hacer su vida y querrá, tal vez, tener más independencia, ser cada vez más independiente. (EG H1 y H2, 2, 44-Gerard).

\section{2.- De mayor quiero ser artista, cuidador de zoo y deportista. Voy a ser todo... (ET S,} 578)

Otra de las vertientes que el entorno de Sergi considera, son los caminos y posibilidades académicas con los que se encontrará en un futuro no muy lejano. El profesor de Pedagogía Terapéutica analiza las opciones formativas que hoy por hoy ofrece el sistema para personas como Sergi: El mayor problema de Sergi es que el sistema educativo está planificado para las personas entre comillas que funcionen. Para este tipo de personas el sistema tiene contemplados aspectos como antes eran los PQPI o ahora los cursos de formación profesional básica, pero es que hay alumnos que están siempre en territorio de nadie. (...) Los programas de formación básica y otras posibilidades no están pensadas para personas que tengan muchas carencias cognitivas, y visto lo visto parece que la única cosa que queda es educación especial, pero evidentemente no es lo más adecuado para Sergi. A Sergi le haría falta otro ámbito más intermedio donde poder desarrollar todas las aptitudes que tiene a nivel manual, con el apoyo en las cuestiones de lenguaje y razonamiento matemático. Necesitaría esa posibilidad, y esa posibilidad hoy por hoy no está. Hay que esperar y ver en qué situación se encuentra Sergi dentro de unos años. Llegado ese momento, tendremos que analizar las opciones que hay e intentar buscar la que más se adapte. La principal dificultad es el propio sistema. Las personas con carencias cognitivas están demasiado arrinconadas, y ese es el problema. Hay una segregación importante (...) Es en la propia organización del sistema donde se encuentran las dificultades más grandes (ET PT IES, 68).

La línea de trabajo con Sergi, debe ir encaminada a favorecer tanto el lenguaje como potenciar las competencias que ya posee y que su inserción en el mundo laboral sea lo más fácil posible. 
Es importante trabajar con él desde un balance de competencias ¿qué competencias profesionales podría ir desarrollando Sergi? Él tiene unos talentos naturales, y esos talentos, en el fondo, no son más que destrezas que con entrenamiento y perfeccionamiento se pueden mejorar muchísimo y convertir en técnicas que puedan tener una aplicación práctica dentro del mundo laboral. El reto ahora mismo es acompasar sus competencias intelectuales, (...) con unas competencias profesionales que le puedan ayudar después de dos, tres, cuatro, cinco años, seis años. (...) Habrá que ver de estos talentos naturales que Sergi tiene, cuáles son de aplicación práctica a una posible profesión. Este sería el nuevo reto que ahora tendría que nacer en Sergi a partir de ahora. (ET Edu, 127)

Su profesora de la Escuela de Arte tiene claro que Sergi, si quiere, podría desarrollarse y crecer dentro del mundo del arte, siempre y cuando se enfoque correctamente su formación: Yo creo que si Sergi se propusiera desarrollar más el aspecto artístico tal vez podría tener un futuro en el mundo del arte ¿por qué no?, pero habría que hacer otro planteamiento. Es decir, hasta ahora él lo que ha recibido en la Escuela de Arte es lo que reciben los niños, es decir dos o tres horas por semana, eso es muy poco. Si se quiere ver realmente de qué es capaz Sergi, habría que meterle otro tipo de estímulo (ET PEA, 72)

Lo que sí es innegable, es que, al margen de la arte y la natación, Sergi será una gran persona y un gran profesional en un futuro. Así lo explica Paco, su profesor de pedagogía terapéutica: Pienso que Sergi el día que tenga que desarrollar una actividad, y el día que la tenga absolutamente interiorizada, será un profesional fantástico en esa actividad. Será escrupuloso, una persona detallista que hará las cosas como nadie porque ahí sí sabe mantener la atención. (...) De todas formas, estoy tranquilo, sé que Sergi cuenta con unos abales tremendos que es su propia familia. Sergi a mi no me da ningún miedo, porque sé que tiene una familia que le apoyará, que le buscará su espacio, que no se conformará con que esté en casa haciendo no sé qué, sino que intentaran que pueda participar en actividades. (ET PT IES, 91)

Sergi tiene muy claro, que su futuro debe estar unido a la naturaleza y al mundo animal: Me gustaría vivir con mi hermano Gerard en Barcelona. Estudiaré para aprender a ser cuidador del zoo. Tengo que aprender los tipos de animales que hay, cómo se alimentan y aprender sus cuidados. Durante el fin de semana no trabajaré y los días de diario trabajaré. Me gustaría tener una habitación para dormir y la 'Play', y el fin de semana hacer experimentos tecnológicos (TGS, dibujo 4)

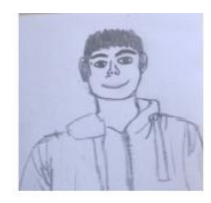

Sergi (S)

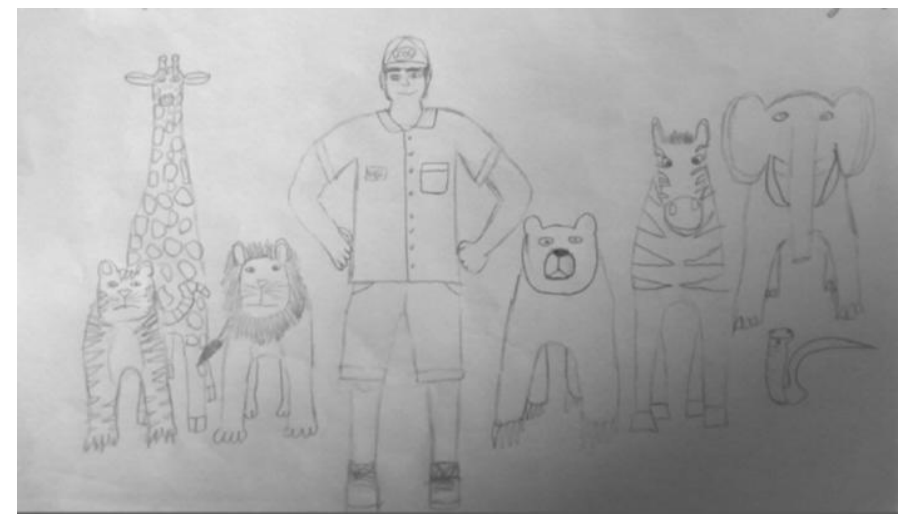

Imagen 18. El trabajo de cuidador de zoo (dibujo 4, TG S) 
El gusto por los animales y el cariño que siente por ellos, siempre había estado presente en Sergi, pero según su madre, este se vio altamente incrementado a partir de una visita a un centro de delfines en los que pasaron unos días. Este fue un momento muy especial tanto para Sergi como para los suyos:

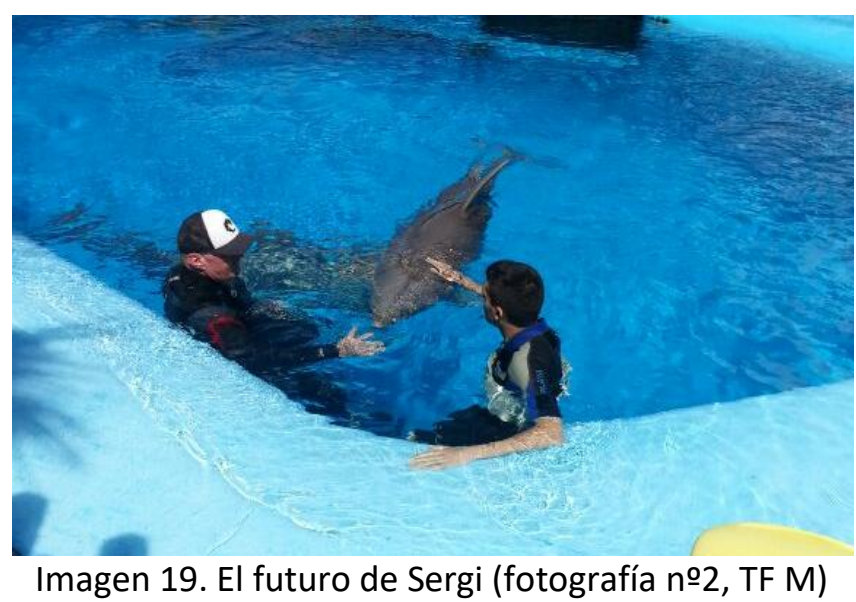

Realmente, cuando estuvimos con los delfines, me di cuenta que su vida debe estar dedicada a los animales porque realmente lo vivía, y nos lo hacía vivir a nosotros (...) Cuando estábamos allí tenía obsesión por estar con ellos desde que se levantaba por la mañana. Incluso el día que nos fuimos se despidió de ellos hablándoles como si fueran sus dos mejores amigos. La imagen de Sergi con los delfines me trasmite un poco de visión de futuro. Creo que él nunca me ha dicho directamente "yo quiero hacer eso", ni yo se lo había preguntado, ni nunca se lo había cuestionado. En esta ocasión fue él el que dijo "yo quiero hacer esto de mayor" sin que nadie se lo preguntara. (...) Esto me despeja un poco las dudas de qué pasará el día de mañana. Yo estoy segura de que trabajará con los animales, tiene mucho cariño por los animales y siempre quiere saber más. Creo que ese es el futuro de Sergi. (TF M, 28).

Otro de los aspectos futuros que no se puede obviar en Sergi son sus altísimas probabilidades de llegar lejos como nadador. Entre las últimas novedades deportivas de Sergi, debe añadir que Sergi se ha incorporado recientemente a un club de natación más grande y con más posibilidades de promoción que el que estaba hasta el momento. Su abuelo explica que ahora se encuentra compitiendo a un nivel muy alto y sintiéndose muy reconfortado: Con el nuevo entrenador disfruta mucho porque le corrige mucho. Éste entrenador nada a su lado (...) y eso es muy importante porque él ve lo que tiene que hacer y cómo lo tiene que hacer. De momento, este entrenador ya ha conseguido que logre tiempo de nadadores profesionales teniendo 15 años. Si no dice "basta" llegará muy lejos. (ET A, 239). Hoy por hoy, además de estar dentro de la selección valenciana de natación adaptada, sabemos que el seleccionador nacional de paralímpicos se ha fijado en él. Ahora tiene 15 años, es muy jovencito ojalá que fuera un gran campeón y nadador paraolímpico. Es una gran forma de relacionarse y sequir creciendo como persona. (ET P, 251).

Sin duda alguna, Sergi es una persona que nunca nos va a dejar de sorprender. (ET Log, 167). Es una caja de sorpresas que acabará haciendo algo importante, llegará lejos. Esa cabecita nos seguirá sorprendiendo (ET Maes, 216). Lo mejor que podemos hacer por él es darle camino para recorrer y que su futuro sea una incógnita abierta. Si a Sergi se le dan las herramientas y continúa teniendo el apoyo, familiar y del entorno, continuará
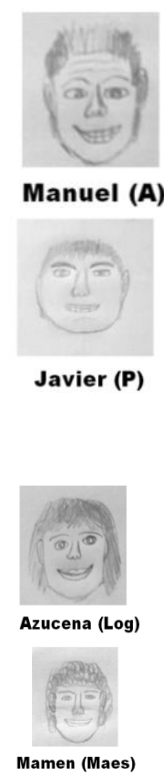
dando sorpresas. Es un chicho asombroso. Los demás somos un poco estúpidos, somos tan presuntuosos que pensamos que nosotros sí seremos capaces de algo pero ellos no, 'pobrecitos'. De eso nada, pueden. (ET PT IES, 97) 


\subsection{La vida de Sergi a día de hoy}

Tal y como se habrá podido comprobar en el cronograma de esta investigación (capítulo 5), desde que finalizó la recogida de datos hasta el cierre del informe de la tesis pasaron aproximadamente entre un año y medio y dos años. Como es de esperar, muchas cosas han acontecido desde entonces, cosas interesantes, logros, decepciones, nuevas barreras, nuevas estrategias.

Los padres de Sergi y la investigadora principal, consideramos necesario elaborar un último apartado en este capítulo sobre cómo es la vida de Sergi a día de hoy (marzo de 2017). La información que aportaremos en este apartado no ha sido registrada con la rigurosidad que hemos realizado la recogida de datos, ni ha sido analizada. Únicamente se trata de un apartado que pretende resituar al lector en el Sergi del presente:

A día de hoy Sergi sigue escolarizado en el IES Ciutat del Mar. Los grandes avances que ha ido adquiriendo en cuanto a su aprendizaje y al lenguaje no solo le han permitido progresar académicamente, sino también mejorar en cuanto a sus habilidades sociales. Conversa con amigos y vecinos de una manera más natural y espontánea y esto es percibido por su entorno familiar y social.

En cuanto al ocio, sigue progresando tanto en el arte como en el deporte. A nivel artístico ha adquirido más técnicas y sigue explotando día a día su creatividad. Diversos profesionales del campo han reconocido recientemente esta evolución artística y tiene pendiente ciertas exposiciones de sus trabajos. A nivel deportivo, ha seguido trabajando mucho, ha adquirido mucha técnica y rebajado tiempos. En el último año ha sido incluido en la Selección Paralímpica Junior y realiza competiciones por toda España. Uno de los encuentros destacados por su familia fue la concentración a la que acudió en el Centro de Alto Rendimiento (CAR) de Sierra Nevada (Granada). Uno de los grandes logros de este encuentro fue que él, junto a una compañera de la selección, viajaron sin familia ni acompañantes hasta Granada y allí estuvieron varios días compartiendo entrenamientos y conviviendo con otros compañeros y compañeras. Recientemente, en marzo de 2017, ha conseguido 1 oro, 3 platas y un bronce en la categoría junior del Camponato de España de natación de la Federación Española de Deportes para personas con Discapacidad Intelectual (FEDDI).

A nivel educativo podemos destacar dos variantes: la social y la académica. En cuanto a la vertiente social de la educación Sergi se encuentra altamente realizado. No solo posee cada vez más amigos en el IES Ciutat del Mar, sino que muchos de sus compañeros y compañeras del centro anterior (Virgen del Carmen) han sido escolarizados en este IES para cursar el bachillerato. Sergi se siente muy feliz y está muy contento de ver en los descansos a sus antiguos amigos y amigas. Siempre le dieron mucha seguridad y confianza $y$, de nuevo, vuelven a estar juntos. En palabras de Sergi "es como volver a los viejos tiempos".

La vertiente académica es, ahora mismo, un poco más desalentadora. Sergi se encuentra inscrito en el PMAR (Programa de Mejora del Aprendizaje y el Rendimiento) cuya duración máxima es de 2 años (equivalente a $2^{\circ}$ y $3^{\circ}$ de la ESO). El problema con el que se encuentran Sergi y su familia es que al finalizar la escolarización obligatoria Sergi no podrá obtener el título de secundaria por no alcanzar los objetivos mínimos de etapa (lleva ACIS en diversas materias). Terminará la escolarización obligatoria y no hay ni título ni opciones formativas de continuidad que se adapten a sus características y posibilidades. Entonces, ¿ahora qué? Esta es la pregunta que se formulan constantemente la familia de Sergi y los profesionales del centro. Parece que la lucha ahora es reivindicar un camino para Sergi, adaptado a sus necesidades pero también a sus capacidades y deseos. Un camino real que le permita seguir caminando y creciendo como persona. 
Paralelamente, aunque no concierne a Sergi directamente, su hermano pequeño ha sido diagnosticado como 'altas capacidades'. Parece que, aunque en menor medida, la historia se repite de nuevo. Un sistema público deficiente en atención a este tipo de diversidad, leve o ninguna formación de los profesionales y escasos materiales adaptados. La familia se encuentra en estos momentos buscando profesionales que puedan formar e informar a los docentes del centro y revisando materiales y adaptaciones que puedan ser útiles para su hijo Xavi (H2), evitando así su frustración y abandono.

La familia siente que ambos (Sergi y Xavi) son dos casos de diversidad invisible a los ojos de la sociedad y de las administraciones educativas. Motivo por el cual han luchado y seguirán luchando por su inclusión. Como bien dice la madre de ambos en una de las últimas conversaciones "Tenemos que luchar por nuestros hijos. Seguimos ahí porque sin inclusión estamos perdidos". 
CAPÍTULO 7:

Discusión de resultados y conclusiones 

Finalmente llegamos a la discusión de los resultados y elaboración de las conclusiones. En este punto es donde todo este trabajo de años de lecturas y relecturas, reuniones, charlas, negociaciones, grabaciones y diálogos intra e interpersonales, empiezan a tomar sentido. El capítulo de las conclusiones es el que redondea el trabajo, el que fusiona la teoría con la práctica, la revisión con la elaboración: es la contribución académica y científica a nuestro campo de estudio.

En este último capítulo responderemos a nuestras preguntas de investigación y discutiremos nuestros resultados con los trabajos y aportaciones de otros autores. En la última parte de este capítulo expondremos cuáles son las limitaciones que hemos detectado en nuestro estudio así como las propuestas de mejora para el mismo. En este capítulo tomaremos en cuenta la siguiente estructura:

7.1. Una vida de diversidad: principales elementos

7.1.1.¿Cuáles son los principales hechos y acontecimientos que describen y explican la trayectoria de vida de Sergi?

7.1.2. ¿Qué personas han acompañado a Sergi a lo largo de su vida desde contextos como el familiar, social y educativo?

7.1.3. ¿Cuáles son los elementos, personas y hechos clave de la historia de vida de Sergi?

7.2. Barreras, limitaciones y estrategias de superación hacia una inclusión social y educativa

7.2.1. ¿Cuáles son las principales barreras y limitaciones educativas y sociales con las que Sergi se han encontrado a lo largo de su vida?

7.2.1.1. Barreras y limitaciones sociales

7.2.1.2. Barreras y limitaciones educativas

a) Barreras administrativas

b) Barreras institucionales

c) Barreras profesionales

7.2.2.¿Cuáles han sido los principales apoyos, ayudas y estrategias de superación que ha tenido Sergi (familiares, educativas y sociales?

7.2.2.1. Apoyos y ayudas sociales

7.2.2.2. Apoyos y ayudas educativas

7.2.2.3. Apoyos y ayudas para la comprensión e interacción con el entorno

7.2.2.4. Apoyo y ayudas familiares

7.2.3. ¿Qué decisiones o determinaciones se han tomado desde el ámbito familiar para superar estas barreras?

7.3. Perspectiva de futuro desde la diversidad

7.3.1. ¿Cuáles son expectativas de futuro de Sergi y las personas de su entorno en cuanto a su desarrollo académico, profesional y social?

7.3.2. ¿Qué herramientas o estrategias se prevén necesarias desde el ámbito familiar y educativo para garantizar la calidad de vida de Sergi?

7.4. A modo de conclusión...

7.5. Limitaciones del estudio

7.6. Propuestas post-investigación y futuras líneas de investigación 
Tal y como ya hemos ido introduciendo en capítulos anteriores, en investigación cualitativa las conclusiones son un elemento que se van construyendo poco a poco, a lo largo de todo el proceso de recogida y análisis de datos. Generalmente, se suele pensar que el momento de concluir es cuando un investigador arranca el capítulo de las conclusiones tras terminar todo el proceso analítico y de elaboración de resultados, pero no es así. Al investigar mediante métodos cualitativos, mientras revisamos datos, desmenuzamos aportaciones y preparamos los resultados, de alguna manera, ya vemos venir nuestras propias conclusiones, ya nos 'olemos' por dónde abordar este último capítulo. De hecho, Strauss y Corbin (1990) ya lo adelantaban cuando indicaban que el mismo proceso de codificación implica interpretación.

En este capítulo, pretendemos no solo extraer conclusiones y discutir con otros autores, sino que procuraremos transformar los relatos individuales de todos los participantes en un relato propio de la investigadora principal (Tójar, 2006), es el momento en que los datos, las interpretaciones y las deducciones deben pasar por cada recodo de mi ser.

Para la presentación y exposición de las conclusiones tomaremos como referencia las preguntas de nuestra investigación. Después de diversas 'idas y venidas' sobre cómo elaborar este capítulo, hemos considerado que ésta es la manera más clásica, pero más lógica, pues es una forma muy estructurada de resolver les cuestiones sobre las que hemos estado indagando.

En este sentido, y con la intención de resituar al lector, expondremos de nuevo la tabla de nuestras preguntas y objetivos de investigación del capítulo $4 \mathrm{y}$, seguidamente, responderemos a cada una de las preguntas a la vez que discutimos con otros autores y estudios de referencia. 


\section{Preguntas de investigación}

g. ¿Cuáles son los principales hechos y acontecimientos que describen y explican la trayectoria de vida de Sergi?

h. ¿Qué personas han acompañado a Sergi a lo largo de su vida desde contextos como el familiar, social y educativo?

i. ¿Cuáles son los elementos, personas y hechos clave de la historia de vida de Sergi?

j. ¿Cuáles son las principales barreras $y$ limitaciones educativas y sociales con las que Sergi se han encontrado a lo largo de su vida?

k. ¿Cuáles han sido los principales apoyos, ayudas y estrategias de superación que ha tenido Sergi (familiares, educativas y sociales)?

1. ¿Qué decisiones o determinaciones se han tomado desde el ámbito familiar para superar estas barreras?

i. ¿Cuáles son expectativas de futuro de Sergi y las personas de su entorno en cuanto a su desarrollo académico, profesional y social?

j. ¿Qué estrategias se consideran necesarias para garantizar la calidad de vida en el futuro de Sergi?

\section{Objetivos generales de investigación}

\section{Objetivos específicos}

2. Describir y explicar los principales acontecimientos, hechos y personas de la trayectoria vital de Sergi, así como los elementos clave de su historia en cuanto a los ámbitos educativo, familiar y social.

3. Profundizar y analizar cuáles han sido las barreras y limitaciones con las que se ha encontrado Sergi así como las estrategias de superación con las que ha contado para superarlas.

3. Determinar cuáles son las expectativas y los posibles itinerarios o recorridos educativos y profesionales de Sergi a medio y largo plazo.
2.2. Conocer las vivencias y experiencias de Sergi en relación a sus contextos familiar, educativo y social como visibilización de aquello con lo que convive una persona con diversidad funcional.

2.3. Exponer y evidenciar las personas han acompañado a Sergi en su trayectoria vital desde los diferentes contextos y cuál ha sido su papel.

2.4. Determinar los elementos se clave en la trayectoria vita de nuestro protagonista.

2.1. Describir cuales han sido las barreras y limitaciones sociales y educativas con las que Sergi se ha encontrado a lo largo de su vida.

2.2. Identificar el tipo y procedencia de apoyos, ayudas y estrategias de superación de barreras con las que Serg ha contado y que han contribuido su éxito personal, académico y social

3.1. Conocer cuáles son las expectativas de futuro (social, educativo y laboral) de Sergi y así como de su entorno inmediato.

3.2. Explorar los procesos de formación (formal y no formal) de los que dispone Sergi para garantizar su calidad de vida y un pleno desarrollo personal y profesional a medio y largo plazo.

Tabla 22. Preguntas de investigación, objetivos generales y objetivos específicos (II) 


\subsection{Una vida de diversidad: principales elementos}

Entendemos la historia de vida de Sergi por lo que es, como algo peculiar, algo singular que le ocurre a nuestro protagonista en un contexto y una temporalidad concreta y que, en cierta manera, puede ser extrapolable y coincidente con otras historias de diversidad funcional. Su vida es suya, es única e irrepetible y poder reconocerla y visibilizarla es una herramienta poderosísima de sensibilización y empoderamiento.

Como hemos podido observar en los resultados, a lo largo de la vida de Sergi han sido muchos los acontecimientos, los hechos coyunturales y circunstanciales, los momentos de 'subidas' y de 'bajadas', de alegrías y de penas y, cómo no, de llegadas y de partidas. Sin embargo, los datos nos indican que no todo es igual de importante, y que para una persona con diversidad funcional como Sergi, no todo tiene la misma repercusión. Existen personas especiales, momentos especiales, decisiones especiales que generan cambios de rumbo, obtienen giros inesperados y, finalmente, obtienen resultados insospechados.

Justamente con esta idea de elementos, momentos y personas especiales y destacables se constituye el primer bloque de preguntas de nuestra investigación:

a. ¿Cuáles son los principales hechos y acontecimientos que describen y explican la trayectoria de vida de Sergi?

b. ¿Qué personas han acompañado a Sergi a lo largo de su vida desde contextos como el familiar, social y educativo?

c. ¿Cuáles son los elementos, personas y hechos clave de la historia de vida de Sergi?

Como podemos observar, este primer apartado de conclusiones tiene que ver con elementos totalmente descriptivos y particulares de la historia de vida de Sergi. Desde la posición de investigadora, resulta sumamente complicado extraer conclusiones (y discutir) sobre algo tan particular de una persona y sus circunstancias de vida. La respuesta a estas preguntas tiene que ver con quién ha estado o no al lado de Sergi, y qué acontecimientos se pueden considerar clave o destacables en esta historia.

Además, estamos ante preguntas de investigación con respuestas muy similares, pues ciertos elementos abordados en la primera pregunta, por ejemplo, tendrán cabida en la tercera. Por lo tanto, para evitar la redundancia en las respuestas y la repetición de aquello ya expuesto en el capítulo de resultados, hemos optado por realizar una breve verificación de aquellas personas clave en la vida de Sergi así como de aquellos hechos y acontecimientos destacables:

\section{Personas clave en la vida de Sergi:}

Por muy obvio que parezca, la primera persona clave en la vida de Sergi es el propio Sergi y su particular forma de ser. Sergi es una persona agradecida, solidaria, cariñosa, con mucha bondad, simpática, feliz y entrañable. Una persona con una gran capacidad de superación, de trabajo, y memoria, que sorprende con la 
voluntad y empeño en que supera sus propias barreras y se adapta a los cambios que acontecen. Una persona que a pesar de sus dificultades para comprender el mundo y de la frustración que esto le provoca, siempre manifiesta un gran entusiasmo y tenacidad para seguir aprendiendo y creciendo.

Pero a lo largo de su trayectoria vital, Sergi no ha transitado solo, ha contado con ciertas personas en su vida para llegar donde ha llegado. Como personas clave en su vida destacaremos a sus padres, personas críticas, defensores de sus derechos y luchadores incansables, y en especial a su madre, gran referente educativo y social tanto para Sergi como para los profesionales que trabajan con él. También tendremos en cuenta a sus hermanos, Gerard por su carácter protector y defensor, y Xavi por ser un gran estímulo de comunicación e interacción para Sergi. Sin olvidar a su abuelo materno, uno de sus 'mejores amigos y compañeros' de Sergi y con una dedicación absoluta en la vertiente más social de la vida de Sergi.

En el ámbito educativo destacaremos a la fundación Mira'm, por ayudar a la familia a delimitar los primeros pasos en el camino, a Azu (logopeda) por su dedicación y profesionalidad arrolladora, a Francisco (educador) por su paciencia incansable y perseverancia en el trabajo en el aula con Sergi y a Paco (PT IES), por su creencia ciega en Sergi y sus posibilidades. En último lugar, y no por ello menos importante, destacaremos a los amigos y amigas del centro Virgen del Carmen, grandes referentes sociales y educativos para Sergi, los que como él dice son sus 'amigos para siempre'.

Sin ellos esta historia no sería la que es, y lo más importante, Sergi no hubiera llegado a poder realizarse como lo está haciendo. Estos son algunos de los apoyos naturales (Riera, 2003; Echeita y Simón, 2007; Pallisera, Fullana, Martín y Vilà, 2013) con los que ha contado a lo largo de su vida y gracias a los cuales hoy en día pertenece a un centro donde se le quiere, con amigos dentro y fuera del instituto, con aficiones deportivas y artísticas, con una familia que le apoya y con grandes aspiraciones para un futuro no muy lejano.

\section{Algunos acontecimientos destacables en la vida de Sergi:}

Las circunstancias, acontecimientos y hechos también han tenido su parte de protagonismo en la historia de vida de Sergi. Consideramos que en este punto no corresponde realizar una descripción profunda de los principales hechos y acontecimientos, pues esto será abordado en los apartados venideros. Pensamos que es más idóneo hacer una selección de aquellos acontecimientos o hechos más destacados a lo largo de la historia de vida de Sergi.

Uno de los primero hechos destacables tiene que ver con la lucha de la familia, en especial de los padres, por lograr no solo un entorno educativo inclusivo sino también un contexto social en el que Sergi pueda sentirse parte del mismo y miembro activo. Otro de los hechos destacables es la búsqueda de profesionales adecuados que garanticen un óptimo aprendizaje y crecimiento personal de Sergi. En este sentido la familia optó por no conformarse con los 'concedido' por la administración pública y buscó y seleccionó a los mejores profesionales para trabajar con Sergi dentro y fuera del contexto educativo.

El más reciente, arriesgado y fructífero hecho en la trayectoria vital de Sergi fue la decisión de cambio de centro cuando se encontraba en $1^{\circ}$ de la ESO. 
Esta determinación, motivada por continuas e inquietantes discriminaciones a Sergi por parte de ciertos profesionales del centro, preocupaba profundamente a la familia y entorno de Sergi. Finalmente, resultó ser una de las decisiones más acertadas en los últimos años.

Estos y otros hechos y acontecimientos colaterales serán abordados a lo largo de este capítulo de manera más detallada.

\subsection{Barreras, limitaciones y estrategias de superación hacia la inclusión social y educativa}

\subsection{1. ¿Cuáles son las principales barreras y limitaciones educativas y sociales con las que Sergi se han encontrado a lo largo de su vida?}

El protagonista de nuestra historia de vida se ha encontrado con múltiples barreras y limitaciones a lo largo de su trayectoria. Desde una visión analítica de las mismas, podemos discriminar aquellas que pertenecen al ámbito más social (contexto social más o menos inmediato de nuestro protagonista) y aquellas que pertenecen al ámbito educativo (vinculadas a los centros educativos en los que ha estado escolarizado). Somos conscientes de que ambos tipos de barreras se encuentran íntimamente relacionados entre sí, pues las actitudes, valores y creencias sociales sobre la diversidad se reflejan en acciones, hechos y sensibilidades dentro de las paredes del centro educativo y viceversa. De hecho, tal y como indica Moriña (2014) las barreras, sean del tipo que sean, se son respaldadas por una sociedad que, aunque se haya dotado de una legislación antidiscriminatoria no lo es.

Con la intención de desmenuzar las barreras halladas en esta investigación e ir discutiéndolas con otros autores, elaboraremos dos bloques claramente diferenciados: Barreras y limitaciones sociales, y barreras y limitaciones educativas.

\subsubsection{Barreras y limitaciones sociales}

Las barreras y limitaciones sociales son una herramienta muy sutil, pero muy efectiva, de exclusión social pues, en ocasiones, pueden ser invisibles y difíciles de delimitar, pero igualmente generan daños a la participación e inclusión con una fuerza abrumadora.

En el caso de Sergi, las limitaciones sociales con las ha tenido que lidiar están vinculadas principalmente a actitudes y atribuciones sociales negativas debido a la falta de información y falta de sensibilidad respecto a la diversidad funcional. Estas necesidades de formación y sensibilización social ya fueron detectadas recientemente en estudios como los de Mella et al. (2014). Burlas, incomprensión, impaciencia y dificultades en la interacción son solo algunos de las respuestas generadas por este vacío informativo y de valores en nuestra sociedad. De hecho, tal y como se reconoce en los resultados de nuestra investigación, en la medida en que las personas conocemos e interactuamos con la diversidad, somos 
más capaces de aceptarla y apreciarla y, por lo tanto, de ser sensibles y defensores respecto a ella y sus derechos.

Esta idea nos lleva a pensar de nuevo en la concepción social de la diversidad. A través de las vivencias de Sergi, podemos reconocer cómo las barreras a la inclusión no recaen solo y exclusivamente sobre programas de información y formación, y sobre las acciones políticas, sino que poseen una índole mucho más de esencia y trasfondo. Más allá de las políticas, el problema radica en la mirada social que ejercemos sobre la diversidad: en ver el autismo o el TEL pero no la persona que hay detrás, en ver las dificultades y necesidades pero no las capacidades y virtudes, en estancarnos en modelos de la diversidad médicos, rehabilitadores $\mathrm{o}$, incluso, sociales que otorgar el protagonismo y el control a quienes no se debería. En cierta manera estamos hablando de aquellas barreras a la inclusión social que autores como Reynolds (2002) y Verdonschot, De Witte, Reichrath, Buntix y Curfs (2009) identificaron como vacíos de aceptación social y actitudes discriminatorias.

No podemos, o no nos atrevimos, a concluir si fue antes 'el huevo o la gallina'. Si para que haya una concepción social de la diversidad justa, se necesitan políticas y acciones sociales que la fomenten, o si tales acciones no están debidamente implantadas por falta de una concepción social de la diversidad. Entendemos que unos y otros van de la mano, y que sea como fuere, se debe fomentar el desarrollo de políticas que permitan verdaderamente eliminar las barreras sociales que impiden la inclusión y que, por supuesto, no generen la aparición de nuevas barreras (Martínez Ríos, 2011).

Lamentablemente, un claro ejemplo de nuevas políticas del gobierno que genera nuevas barreras a las personas con diversidad, es la propuesta de modificación del artículo 56 del Código Civil del Estado Español. A partir de una modificación legislativa se aprobó que las personas con diversidad funcional debían aportar un certificado médico sobre la aptitud para prestar el consentimiento a la hora de contraer matrimonio. Esto medida supuso un gran revuelo e indignación por parte de un gran sector de nuestra sociedad, pues era una evidente vulneración del artículo 23 de la Convención sobre los Derechos de las Personas con Discapacidad (art. 23: Los Estados Partes tomarán medidas efectivas y pertinentes para poner fin a la discriminación contra las personas con discapacidad en todas las cuestiones relacionadas con el matrimonio, la familia, la paternidad y las relaciones personales, y lograr que las personas con discapacidad estén en igualdad de condiciones con las demás).

Finalmente, a fecha de 23 de diciembre de 2016 se aprobó en el Congreso de los Diputados que esta medida solo sería aplicable cuando la 'discapacidad afecte sustancialmente a la prestación de consentimiento por parte del contrayente'. A pesar de la rectificación política final, queremos poner de manifesto esta situación como muestra de todas esas políticas sobre diversidad que se hacen al margen de las personas afectadas.

Como vemos, se generan políticas y acciones, presuntamente bajo un marco o paraguas de los derechos humanos y de autodeterminación, que realmente enmascaran nuevas barreras y limitaciones sociales a la participación de todos y todas. Este tipo de propuestas políticas no contribuyen en absoluto a la calidad de vida de las personas con diversidad funcional, además de ignorar por completo aquello que es colectivo reclama. El movimiento de las personas con diversidad 
funcional exige al gobierno que las respuestas y políticas sociales aseguren la implicación de las personas afectadas en la planificación, implementación y monitorización de todo el trabajo de desarrollo, así como en la toma de medidas para eliminar barreras a la participación, y combatir las prácticas, políticas, actitudes y ambientes discriminatorios (Martínez Ríos, 2013).

\subsubsection{Barreras y limitaciones educativas:}

En cuanto a las barreras y limitaciones propiamente del ámbito educativo, en nuestro estudio hemos detectado y diferenciado diversos tipos: barreras administrativas (relativas a la administración educativa), barreras institucionales o de centro y barreras docentes o profesionales (no necesariemtne de aula ni didácticas).

\section{a) Barreras administrativas}

En el caso de la historia de vida de Sergi, las barreras administrativas son aquellas que se asocian más bien al papel que la administración educativa ejerce en cuanto al proceso de escolarización del alumnado con diversidad funcional. Observamos en los resultados un claro desajuste entre las posibilidades de escolarización y los derechos de las personas con diversidad funcional, generando un gran descontento en cuanto a las trayectorias o caminos de escolarización posibles.

Las circunstancias sociales, políticas y económicas del momento parecen justificar y argumentar que la educación ordinaria está incapacitada o mermada para poder ofrecer una atención a la diversidad basada en la igualdad de oportunidades de todo el alumnado. De hecho, durante los primeros años de escolarización y, vistas las carencias formativas del centro ordinario, los padres de Sergi se plantearon la posibilidad de escolarización combinada entre el centro de Sergi (donde estaba totalmente integrado) y aulas específicas de apoyo para la comunicación y el lenguaje (como las aulas TEL o las aulas CyL). Ante esta propuesta, la administración no solo se negó a esta posibilidad, sino que de aceptarla, la restringía a determinados centros públicos de la localidad o a centros de educación especial. De esta manera, para acceder a una escolarización combinada, Sergi se veía obligado a inscribirse en otro centro, vulnerando así el artículo 74 de la LOE 2/2006 vigente en aquel momento (la escolarización del alumnado que presenta necesidades educativas especiales se regirá por los principios de normalización e inclusión y asegurará su no discriminación y la igualdad afectiva en el acceso y la permanencia en el sistema educativo, pudiendo introducirse medidas de flexibilización de las distintas etapas educativas, cuando se considere necesario).

Estamos por lo tanto ante una escolarización no solo muy pautada y estandarizada, sino que además es discriminatoria para las personas con diversidad funcional. Las familias deben luchar insistentemente contra las barreras construidas por la tradición escolar, y reforzadas por determinadas culturas escolares, que tienden a limitar la presencia y las posibilidades de aprendizaje y participación de los alumnos con necesidades educativas en condiciones de igualdad (Echeita, 2011). Diversos estudios evidencian grandes deficiencias de escolarización de alumnado con dificultades en nuestro contexto (Marchesi, Martín, Echeita, Babío, Galán, Aguilera y Pérez, 2003; Echeita y 
Verdugo, 2004; Echeita, Simón, Verdugo, Sandoval, López, Calvo y González, 2009; Verdugo, Rodríguez, Sarto, Calvo y Santamaría, 2009), mostrando así un panorama ambivalente, de avances notables pero de estancamientos preocupantes (Echeita, 2011) en el que todavía nos queda mucho camino por recorrer y muchas políticas que repensar.

\section{b) Barreras institucionales (de centro)}

En nuestra investigación, observamos que las barreras de tipo institucional o de centro tienen que ver con cuestiones relativas a la promoción, la organización de recursos y las relaciones entre el centro y la familia. Estos resultados, discrepan de aquello identificado en el trabajo Fernández de la Iglesia et al (2013), quien apunta más bien a cuestiones organizativas de centro y la posibilidad que esta genera a la colaboración docente.

En este apartado, expondremos las barreras institucionales de este estudio en base a si son elementos relativos a la promoción, a la organización de recursos o a las relaciones centro-familia:

\section{b.1. Barreras institucionales de promoción}

Las barreras institucionales de promoción son aquellas que se generan a partir de las decisiones de centro en cuanto a lo que se considera aceptable o no para la promoción y progresión del alumnado. Trabajos como los de Toboso, Ferreira, Díaz, Fernández-Cid, y Gómez de Esteban (2012) ya recogían este tipo de barreras a la inclusión generada por la 'des-integración' del alumnado con necesidades educativas entre la etapa de educación primaria y la de educación secundaria. Según estos autores, solo el $65 \%$ del alumnado con necesidades educativas que empieza su escolarización en la enseñanza ordinaria continúa hasta la ESO (siendo un 35\% de alumnado el que no llega a esta transición), y un escaso $3 \%$ llega a estudios de bachillerato. Cabe tener en cuenta que estos datos tienen que ver con el alumnado con necesidades educativas escolarizado en un centro ordinario (el cual supone un $78,4 \%$ del total de alumnos con necesidades educativas de cualquier tipo).

En el caso de Sergi, el tema de la promoción y progresión académica siempre había estado vinculado a la priorización de las relaciones sociales. Debido a la excelente relación entre Sergi y sus compañeros y la plena inclusión en su grupo de referencia, se había decidido priorizar desde el inicio de la escolarización los aspectos sociales frente a los curriculares. Sin embargo, contra todo pronóstico, esta tónica se rompió en la transición entre educación primaria y secundaria, y desde el centro se propuso la repetición del último curso para el afianzamiento de conocimientos (propuesta que coincidió con la constitución de un nuevo equipo directivo). Tras diversas reuniones y debates, los padres se opusieron a la repetición y finalmente el centro aceptó que Sergi continuara con su grupo de referencia en $1^{\circ}$ de la ESO. Esta resistencia del centro a la promoción y progresión de Sergi es identificada en nuestra investigación como una gran barrera institucional, pues consistió en una acción discriminatoria y segregadora de Sergi respecto su grupo y entorno de referencia (tan beneficioso a nivel académico y social para él). 
Revisando nuestros datos, podemos deducir que las barreras institucionales de promoción vienen motivadas por dos elementos o componentes. El primero de ellos es la concepción de la diversidad del equipo directivo. En función de cómo se conciba la diversidad desde la dirección de la escuela ésta se proyectará sobre el resto del centro propiciando un tipo de atención educativa $u$ otra. El segundo elemento es la transición entre primaria y secundaria. Diversos estudiosos han indagado sobre este tema y coinciden en que las mayores dificultades de permanencia en el sistema educativo para los alumnos con diversidad se encuentran en la etapa de educación secundaria (Echeita et al., 2009; CERMI, 2010). Tanto es así que el paso por la ESO se está configurando como un período de gran impacto emocional y social negativo para este tipo de alumnado, provocando que muchos de ellos ni siguiera inicien esta etapa, o no lleguen a terminarla, con las consiguientes rupturas y frustraciones en su trayectoria escolar (Echeita, 2011)

\section{b.2. Barreras institucionales de organización de recursos}

En la historia de vida de nuestro protagonista la falta de recursos materiales está presente en toda la trayectoria educativa. Desde el inicio de la escolarización de Sergi su familia ha sido la que ha aportado al centro los recursos materiales necesarios de todo tipo (comunicativo, organizativo y didáctico). La familia, especialmente la madre, era la que se preocupaba de elaborar y adaptar a las necesidades de Sergi los pictogramas comunicativos, los paneles semanales de organización, los materiales didácticos, los esquemas, los libros e incluso de preparar ciertos exámenes. Por ello, la carencia de recursos materiales del centro, así como la ausencia de voluntad profesional para elaborarlos, se convierten en un nuevo y claro ejemplo de barreras al aprendizaje y a la participación de Sergi. Pues, como sabemos, los recursos adaptados a las circunstancias personales de cada alumno son los que posibilitan (entre otros) la atención a la diversidad y un entorno de aprendizaje en igualdad de oportunidades.

En relación a este tema, investigaciones recientes señalan los recursos materiales y humanos como los facilitadores de un óptimo desarrollo de la inclusión educativa y apuntan a la falta de apoyos como un obstáculo para la implementación de ésta en los centros escolares (Benítez, 2014). Tanto es así que ya no se trata solo de una cuestión de inexistencia de recursos que faciliten la inclusión educativa, sino la aplicación poco eficaz a la práctica (CERMI, 2010).

Otra de las barreras institucionales de organización de recursos tiene que ver con los recursos personales y la gestión de los mismos. Los recursos humanos, su gestión y organización, son los que posibilitan la plena participación y acceso al aprendizaje de todos los alumnos. Sin embargo, en el centro que nos acontece no solo era limitada la dotación de recursos humanos de los que se disponía en el centro, sino que sus acciones pedagógicas con Sergi se restringían principalmente a actividades fuera del aula en contra de la voluntad expresa de Sergi y de su familia. Esta negativa a los recursos fuera del aula viene siendo rechazada desde hace tiempo por padres y asociaciones de personas con diversidad funcional. Postura reiterada recientemente en el estudio realizado por Villegas, Simón y Echeita (2014), quienes destacaron que las madres de alumnos con diversidad funcional en centros ordinarios expresan su total descontento con este tipo de actuaciones educativas y reclaman que estos apoyos se lleven a cabo dentro del aula, a fin de ajustar los contenidos y la enseñanza a la realidad del grupo, pues 
dentro del aula es la forma en que se entienden los apoyos desde el paradigma inclusivo (Gallego, 2011; Sandoval, Simón y Echeita, 2012).

Esta cuestión de extraer o 'segregar' a un alumno de su aula ordinaria para tratar sus necesidades de manera individual viene respaldada, en parte, por la legislación educativa actual desde la cual se concibe este tipo de actuaciones como 'posibles' en el caso de que se considere 'necesario'. Si bien es cierto que en algunos casos concretos puede considerarse la posibilidad de trabajar fuera del aula, el problema se genera cuando la 'necesidad puntual' se convierte en la 'norma', de forma que lo que supuestamente es un apoyo a la participación e inclusión se convierte en una trampa perspicaz más propia de la exclusión.

En este sentido, y ante la insuficiente y deficiente gestión de los recursos humanos del centro de Sergi, la familia decidió, previa negociación con el centro, disponer de un profesor de apoyo dentro del aula. Este recurso altamente valioso para Sergi y su aprendizaje, fue seleccionado y costeado por la familia. El centro solo debía aceptar su presencia y compaginarla con las actividades grupales. Este educador 'privado' actuaba como profesorado de apoyo dentro del aula y era el elemento clave para que Sergi pudiera seguir el ritmo de las clases y trabajar los contenidos adaptados mediante los materiales que preparaba su familia.

Sin duda alguna estamos ante una cuestión de falta concienciación profesional, pues según como entendamos el perfil profesional del apoyo educativo propiciaremos acciones para la atención a la diversidad dentro o fuera del aula, o lo que es lo mismo, acciones con un carácter más inclusivo o más segregador. Sin embargo, y al margen de esta vertiente profesional, no podemos olvidar la parte política de esta cuestión. En la medida en que la administración educativa genere legislaciones nacionales y autonómicas coherentes con los tratados internacionales que ha ratificado, estará facilitando el trabajo para la construcción de una escuela verdaderamente inclusiva (Cabero y Córdoba, 2009), y por lo tanto con una gestión de recursos (materiales, humanos y organizativos) acorde con este modelo de escuela.

\section{b.3. Barreras institucionales de relación familia-escuela}

El último tipo de barrera institucional detectado en la historia de vida de Sergi tiene que ver con la relación entre el centro y la familia de nuestro protagonista. Como sabemos, la relación entre la escuela y la familia, son un elemento necesario para el éxito educativo (Kñallinsky, 2003; Garreta, 2003, 2007, 2015; Redding, 2005, 2006; Simon \& Epstein, 2001; Turnbull, Turnbull \& Kyzar, 2009; Martínez González, Rodríguez Ruíz y Gimeno Esteo, 2010; Valdes, Urías, Wendlandt, \& Torres, 2014; Gestwicki, 2016). De esta manera, si dicha relación se torna inexistente o conflictiva deja de ser una herramienta para la inclusión y empieza a convertirse en una barrera al aprendizaje, especialmente para aquellos alumnos con diversidad funcional.

En lo que a nuestra investigación se refiere, la relación entre la familia y la escuela se inició sobre cimientos de colaboración y respeto entre unos y otros. En diversos trabajos ya se indicaba estas las relaciones positivas y colaborativas entre familias y profesionales de la educación como uno de los elementos indispensables para una respuesta educativa coherente con el modelo educativo inclusivo (Moliner, 2008; Turnbull et al., 2009; Villegas et al., 2014). 
Esta inercia inicial y colaborativa entre familia y escuela se mantuvo durante unos años hasta que, coincidiendo de nuevo con el cambio de dirección y transición a la secundaria, empezaron a emergen los primeros conflictos entre ambos. Ausencia de respuesta ante las propuestas o peticiones de la familia, opacidad en documentación educativa sobre Sergi e impedimentos para la comunicación familia-escuela son algunos de los principales problemas surgidos entra ambos agentes.

La carente o inexistente relación y colaboración entre familia y profesorado se considera una gran barrera a la escuela, pues esta necesita de diálogo, comprensión y participación institucional (López Melero, 2008) para que pueda forjarse una educación para todos. De hecho, en estudios recientes sobre la visión de las familias en relación a la educación inclusiva, se destaca que, entre otros, factores como la relación entre familia y profesionales, y la participación de la familia en el proceso educativo son factores críticos para una verdadera inclusión educativa (Villegas et al., 2014).

En el caso de Sergi, esta mala relación con la comunidad educativa no solo tenía que ver con la familia, sino que tras años de trabajo colaborativo, la relación también se quebró con el educador externo que la familia facilitaba al centro. Coincidiendo de nuevo con ese cambio de dirección y de etapa educativa, el centro (y algunos docentes) empezaron a prescindir e ignorar el trabajo de este educador. De esta manera, progresivamente, una de las piezas angulares de la inclusión de Sergi y nexo entre escuela y familia, empezó a ser desplazada. La comunicación fluida se rompió, el trabajo 'codo con codo' con otros docentes del centro se fue extinguiendo, y de repente, el educador empezó a sentir el vacío institucional.

De una manera imprevista y casi sin hacer ruido, el centro se fue cerrando poco a poco en sí mismo. Aquello que venía de fuera empezaba a no ser bien recibido e incluso parecía molestar. Familia y profesionales externos empezaron a sentir una respuesta negativa unánime por parte del centro y el corporativismo más puro empezó a emerger. El mensaje de respuesta era siempre el mismo: "Estamos haciendo lo que consideramos más oportuno para Sergi y su aprendizaje", sin acciones o cambios acorde con ello.

Este corporativismo también fue detectado como una barrera educativa en otros estudios (Aróstegui y Gaintza, 2014) en los que además se remarcaba la cantidad y calidad de la comunicación entre profesionales, la coordinación entre los servicios, y la adecuación de respuesta a las necesidades del alumnado como fundamentales para la etapa escolar. Irremediablemente este tipo de barreras institucionales de relación solo pueden acabar generando nuevas problemáticas cada vez más insostenibles, y en el caso de Sergi, un aislamiento y exclusión total. Como última medida de atención a la diversidad, el centro decidió ubicar a Sergi en la parte frontal de la clase, pegado a la pizarra y el radiador y de espaldas a sus compañeros e incluso al profesor. Esta fue una medida motivada por las orientaciones sobre la atención a un alumno con TEA que les hicieron llegar desde Conselleria. Concretamente, una de ellas recomendaba ubicar a Sergi en la primera fila de mesas para una mayor atención en la dinámica del aula y participación en las tareas y actividades. Ante esta propuesta, el centro decidió 'traspasar' esta línea y llevarlo al frente de la clase. De esta manera, en lugar de adoptar una medida inclusiva y facilitadora del aprendizaje se generó un aislamiento social y académico de Sergi y, por lo tanto, su exclusión del espacio educativo. 
De nuevo, ante las peticiones de cambio de ubicación de la familia, de los compañeros y del propio Sergi, la respuesta del centro seguía siendo unánime y negativa. Un corporativismo llevado al extremo que solo se rompía cuando algún docente contrario a esta medida, resituaba a Sergi entre sus compañeros alegando cuestiones didácticas propias de la asignatura.

Estamos pues, ante una situación de exclusión e injusticia educativa provocada por una decisión institucional, a raíz de un conflicto de relación con la familia y respaldada por gran parte de los docentes del centro. Al margen de los motivos personales y profesionales de esta decisión, sin duda alguna, lo más preocupante es la impasividad y aceptación de aquellos docentes que, sin ser partidarios de la medida apoyaban, o al menos respetaban, la decisión adoptada con Sergi. Él reclamaba el cambio de ubicación, se quejaba de calor y picores provocados por la calefacción, no participaba en el aula, no seguía las indicaciones de la clase,... ante lo que solo recibía ignorancia, desatención y abandono por la mayor parte los docentes. Un claro ejemplo de segregación, aislamiento y exclusión que transgrede los derechos humanos básicos y, por supuesto, atenta contra los principios de presencia, aprendizaje y participación necesarios para crear un entorno educativo inclusivo. Se trata de una barrera institucional de relación que, al degradarse y llevarse al extremo acaba convirtiendo el conflicto entre familia y escuela en un ataque al alumnado, provocando graves daños en el desarrollo de los más vulnerables.

\section{c) Barreras profesionales (docentes y profesionales de la educación)}

En cuanto a las barreras docentes o profesionales, en nuestros resultados detectamos diversos tipos según la naturaleza o procedencia de la barrera. Por esta razón, distinguiremos entre barreras actitudinales y barreras formativas:

\section{c.1. Barreras actitudinales del docente}

En diversos momentos de la historia de vida de Sergi hemos podido observar que, según el talante y la actitud de cada docente, puede aparecer o bien implicación y dedicación pedagógica admirable, o bien una lamentable despreocupación sobre los avances y aprendizajes de nuestro protagonista. Sin duda, uno de los efectos más dañinos de este tipo de actitudes por parte del docente, radica en poner límites al aprendizaje del alumnado, pues si se desatienden los procesos de aprendizaje, si se subestiman los efectos de las adaptaciones curriculares y metodologías diversificadas, y se menosprecian los apoyos educativos dentro del aula, se acaban generando grandes impedimentos al aprendizaje y se construyen 'techos' al crecimiento académico y personal del alumnado. En otros estudios en nuestro contexto se evidencia que la actitud docente abierta y la creencia en las posibilidades de todos los alumnos, son algunos de los factores que favorecen la inclusión educativa (Poveda, 2014), mientras que una actitud docente inadecuada hacia la atención a la diversidad se convierte en un gran obstáculo y barrera para ello (Hernández de la Torre y Medina, 2014).

En nuestra investigación, se ha puesto de manifiesto que la actitud negativa hacia la diversidad no se da de manera aislada, sino que además viene acompañada de otras sinergias y actuaciones docentes acordes con la misma. Hemos podido observar cómo este tipo de actitud se encuentra altamente vinculada a una falta de sensibilidad hacia la diversidad del alumnado y, en consecuencia, a 
una gran falta de implicación docente en este sentido. Son nuevas formas o materializaciones de las barreras actitudinales que mellan más, si cabe, el desarrollo académico del alumnado.

En este punto, consideramos necesario destacar también el papel de los servicios psicopedagógicos en la historia de vida de Sergi. Si bien es cierto que a lo largo de su escolarización el papel de este servicio fue, mayoritariamente, colaborador, al llegar a la educación secundaria la actitud e implicación el departamento de orientación no continuó con esta dinámica. En los resultados de nuestra investigación, detectamos una gran falta de formación, información y sensibilidad para tratar cuestiones del autismo con la familia y con el propio Sergi, así como acciones y actuaciones que poco o nada tienen que ver con la inclusión educativa del alumnado. De hecho, Calderon (2014a) ya apuntaba en su trabajo que una manera de legitimar desigualdades es a través de informes psicopedagógicos, que junto a otras derivaciones y propuestas diferenciadas consiguen concienciar a lo largo de los años sobre la incapacidad del alumnado, convenciendo finalmente de la imposibilidad de que concluya con éxito su escolarización (Echeita y Calderon, 2014)

Llegado este punto, y antes de pasar al siguiente apartado, consideramos necesario remarcar la siguiente consideración: En este apartado hemos diferenciado claramente entre barreras actitudinales y barreras formativas del docente por cuestiones de estructuración del texto. Sin embargo, nuestra experiencia, nuestra investigación y los trabajos de otros autores (Molina y Marqués, 2009), evidencian la estrecha e irremediable interrelación que existe entre la formación del profesorado y su actitud hacia la diversidad, pues son dos tipos de barreras que se retroalimentan mutuamente.

\section{c.2. Barreras formativas del docente}

En nuestra historia de vida hemos podido observar una gran falta de formación docente en cuanto a metodologías inclusivas que permitieran el aprendizaje de Sergi. El desconocimiento pedagógico y didáctico, y la falta de voluntad autoformativa acabaron por relegar y delegar la educación de Sergi a la iniciativa de su propia familia. En este sentido la falta de información, de formación, de sensibilidades y de actitudes pro-inclusivas provocó en Sergi un estancamiento tanto a nivel personal como académico que solo pudo romperse con la marcha a otro centro educativo.

Una de las barreras más autodestructivas del sistema educativo es una formación docente insuficiente y desvinculada del modelo educativo inclusivo. En este sentido, a partir de nuestro estudio podemos deducir que varios son las consecuencias o efectos de un mal planteamiento en la formación de nuestros docentes y profesionales de la educación. La primera consecuencia tiene que ver con un sistema de formación inicial deficitario que imposibilita el desarrollo de los conocimientos prácticos necesarios en el futuro docente. La desvinculación entre las instituciones universitarias y la realidad en los centros educativos provoca brechas que revierten de nuevo sobre nuestro sistema creando un bucle que se retroalimenta a sí mismo. La segunda de las consecuencias la atribuimos a la formación continua del docente y al reciclaje formativo. En nuestro contexto, existen escasos canales de formación y autoformación y se pone de manifiesto la falta de concienciación profesional al respecto. Pues al igual que ocurre con un 
médico, los problemas y acontecimientos sociales revierten directamente sobre nuestro de trabajo, y aplicar conceptos o teorías desfasadas destruye por completo las posibilidades de éxito.

Somos conscientes de los grandes beneficios educativos y sociales que conlleva un modelo educativo inclusivo. Sin embargo, para que éste se consolide, los centros necesitan de manera inmediata de una renovación pedagógica fuerte, necesitan nutrirse de docentes formados, y de un reciclaje formativo constante que posibilite acciones y métodos educativos amplios y diversos (González, Medina y Domínguez, 2016). No obstante, la realidad es un tanto más desalentadora, pues existe un evidente desequilibro entre la formación docente inicial y la práctica real (Fernández de la Iglesia et al., 2013) que genera en nuestros centros, y por lo tanto en nuestros docentes, una escasa información y formación sobre necesidades educativas (Echeita, 2011), vital para que el profesorado pueda dar una respuesta efectiva a la diversidad existente en el aula (Sánchez Palomino, 2011).

De esta manera, se convierte en necesaria una reestructuración del sistema de formación docente (inicial y continua) que no solo transmita conocimientos teóricos que aplicar en un futuro, sino que genere experiencias en los docentes, reflexiones críticas, vivencias prácticas y transformaciones profundas hacia una concepción de una educación inclusiva y de calidad para todos. Es una cuestión a abordar principalmente desde la administración educativa, que debería revisar a fondo su modelo de formación del profesorado, incentivando una mayor implicación de los docentes de enseñanzas no universitarias en proyectos de investigación e innovación y optimizando así sus prácticas y acciones educativas. (Santos-Rego, Cernadas-Ríos y Loranzo, Molelo, 2014)

A modo de conclusión, añadiremos que solo podremos acabar con las barreras educativas descritas anteriormente (actitudinales y formativas) mediante la implementación de la inclusión en las aulas a través de los recursos materiales y personales, metodología y organización y planificación adecuados (Valenzuela, Gillén y Campa, 2014). Tarea en la que tanto la administración, como los propios docentes poseen un papel fundamental en términos de políticas, formación y actitud hacia la inclusión.

\subsection{2. ¿Cuáles han sido los principales apoyos, ayudas y estrategias de superación que ha tenido Sergi (familiares, educativas y sociales?}

En contraposición a todas las barreras y limitaciones expuestas anteriormente, Sergi ha contado desde su nacimiento con ciertos apoyos, ayudas y estrategias de superación que no solo le han servido para ir sorteando las dificultades, sino que además le han ayudado a fortalecerse y crecer como persona.

En nuestra investigación, podemos diferenciar claramente cuatro tipos de apoyos o ayudas con los que ha contado Sergi a lo largo de su trayectoria. Estos son: las ayudas y apoyos sociales, provenientes del contexto social inmediato o espacios de ocio; las ayudas y apoyos educativos aportados por los dos centros educativos en los que trascurre su trayectoria educativa; las ayudas y apoyos a la comunicación, provenientes de diversos profesionales externos al centro; y las ayuda y apoyos familiares durante toda la trayectoria vital. 


\subsubsection{Apoyos y ayudas sociales}

En esta historia de vida, existe una interesante relación entre los apoyos naturales en el ámbito social y los contextos de ocio en los que Sergi se desarrolla. Estos contextos son la natación y el arte; contexto que actúan como un instrumento que favorece las relaciones sociales, las habilidades sociales, la autonomía personal y la toma de decisiones, a la vez que al compartir estos espacios sociales con grupos de iguales, se favorece la creación de 'pandillas naturales' (Huete y Pallero, 2016).

\section{a) Natación}

En el caso de Sergi, la natación ha sido un medio para poder obtener un genuino y espontáneo círculo de amistades. Este contexto deportivo le ha permitido conocer lugares y gente nueva, desarrollar habilidades sociales y cognitivas, fomentar capacidades como la perseverancia y el perfeccionismo, mejorar sus condiciones físicas y de salud, y, entre otros, aumentar su autoestima.

El trabajo técnico constante y perseverante de Sergi en natación junto con el esfuerzo de la familia por apoyarle y facilitarle la oportunidad de crecer en el deporte, han tenido un efecto mediático y social tan inesperado como sorprendente. En los últimos años, Sergi ha tenido una progresión deportiva impresionante y la mejora de la técnica, resistencia y velocidad le han llevado a conseguir medallas en casi todas las competiciones autonómicas y nacionales en las que ha participado. Estos logros han dado la oportunidad a Sergi de desarrollar habilidades sociales y comunicativas que de otra forma no serían posibles. Sergi se ha visto en la tesitura de tener que hablar con desconocidos, responder a felicitaciones andando por la calle, hablar en público en el homenaje que se le hicieron en su localidad, trasladarse solo a nuevos lugares y concentraciones técnicas, y convivir con otros nadadores. Más allá de las destrezas comunicativas, estos éxitos han generado en nuestro protagonista el florecimiento de una mayor seguridad y confianza en sí mismo en la interacción social, una gran mejora en el autoconcepto y, por supuesto, en su autoestima.

El deporte le proporciona a Sergi una gran ayuda en cuanto se convierte un medio para el aumento de las oportunidades de relaciones interpersonales y experiencias de inclusión social (García-Gómez et al., 2014), además de otros muchos beneficios físicos. Sin duda alguna, la familia de Sergi (y en especial sus padres) siente que ha encontrado un posible camino de futuro para Sergi y que sus esfuerzos económicos y físicos han sido y son totalmente reconfortados y reflejados en sus éxitos deportivos.

La relación entre natación y autismo es un campo de estudio reciente (Yilmaz, Yanarda, Birkan \& Bumin, 2004; Vonder Hulls, Walker \& Powell, 2006; Lang, Koegel, Ashbaugh, Regester, Ence \& Smith, 2010; Sowa \& Meulenbroek, 2012; Pimienta, Zuchetto, Bastos y Corredeira, 2016) que debido a los grandes beneficios físicos y sociales que genera en la persona con diversidad funcional se encuentra en auge.

Hoy en día, existen múltiples programas, clubes y asociaciones de personas con diversidad funcional dedicadas al deporte. En general, estas organizaciones fomentan en los niños y jóvenes diversos tipos de deportes, individuales y de grupo, 
además de organizar actividades y competiciones intra e interclubes. En el campo concreto de la natación, estas actividades suelen darse en ciertos clubes locales de natación y, sobre todo, en federaciones autonómicas que dependen directamente de la comunidad autónoma a la que pertenecen. En estos contextos, existe una clara diferenciación entre las personas que realizan natación adaptada (por cualquier motivo de diversidad funcional) y el resto, quedando totalmente extinguida la posibilidad de interacción acuática y social entre unos y otros. Los motivos deportivos y competitivos de esta diferenciación son más que obvios, pero sin embargo, consideramos necesarias interacciones sociales, deportivas y técnicas alejadas de la competición que fomenten un verdadero sentimiento de unión deportiva, de pertenencia a un grupo y de representación social.

\section{b) Arte}

A través de llamativas y originales creaciones artísticas (sombras chinas, figuras de arena, montajes audiovisuales, pinturas, esculturas,...) Sergi obtiene un gran apoyo para expresarse y realizarse a nivel personal. Es decir, no es que Sergi encuentre en el contexto artístico un lugar de apoyos naturales y amistades, sino más bien un apoyo para desarrollar su expresión y comunicación a través del arte. Tal y como se recoge en los resultados, en sus producciones artísticas se observa, por lo general, una perspectiva diferente a lo convencional, con grandes detalles y tecnicidad que, normalmente, emergen de forma espontánea y sin instrucción alguna. En ciertos momentos, Sergi recibe por parte de su profesora de arte directrices sobre nuevas técnicas y métodos artísticos que, cuando son adquiridos, generan de nuevo un resultado sorprendente en su distribución espacial, perspectiva, uso de tonalidades y/o forma del producto.

Tal y como Fernández (2003) apuntaba en su trabajo, las palabras imponen límites difíciles de sobrepasar, mientras que las imágenes poseen un poder de penetración mental que sobrepasa el pensamiento discursivo. Por ello, el arte es un elemento muy valioso en personas con dificultades sociales y comunicativas, ya que permite sobrepasar esa 'palabra' y lograr la expresión e interpretación de sentimientos y emociones a través del lenguaje visual y manipulativo.

Como sabemos, el arte en todas sus versiones (pintura, música, escultura,...) son un medio para las emociones, la imaginación, la creatividad, la comunicación, la expresión, el diálogo,... El arte es beneficioso para el desarrollo personal, social e intelectual de cualquier ser humano. Concretamente en las personas con autismo, las actividades artísticas aportan grandes beneficios en materia de promoción del juego simbólico, facilitar la comunicación, potenciar la imaginación, la creatividad,... (Orellana, 2016).

Por lo general, son pocos los trabajos y escritos que focalizan en el autismo y la creatividad, bien sea por la creencia de que no es posible que las personas con TEA la posean, o porque se considere un campo complejo de explorar, no siendo así en cuanto a los trabajos sobre la creatividad en niños con Síndrome de Asperger o autistas de alto rendimiento (Fernández, 2003). Curiosamente, en el caso de Sergi, la creatividad y originalidad son rasgos destacados no solo en sus trabajos artísticos sino también en los académicos y en su día a día. 


\subsubsection{Apoyos y ayudas educativas}

En cuanto a los apoyos y ayudas educativas a la inclusión, hemos detectado en nuestra investigación tres tipos de apoyo o ayudas provenientes de: (a) la administración educativa, (b) la institución educativa (c) los docentes y profesionales, y (d) los iguales. Estos resultados son muy semejantes a los expuestos por Fernández de la Iglesia et al., (2013), quien diferenciaba entre ayudas en torno a: la administración, el centro escolar y el aula.

\section{a) Apoyos y ayudas de la Administración Educativa.}

En la historia de vida que nos acontece, los apoyos y ayudas provenientes de administración educativa ejecutan un papel un tanto 'intermitente'. Si bien es cierto que la administración actuó como un apoyo en ciertos aspectos durante los primeros años de escolarización de Sergi, estos desaparecieron hasta que, pasados unos 8 años brindó de nuevo ayudas. En este caso, las ayudas y apoyos de la administración tienen que ver, en primer lugar, con la flexibilización de horarios durante los primeros años de escolarización. En estos primeros años que Sergi asistió a Educación infantil, Conselleria permitió su ausencia en el centro por las tardes para poder recibir atención logopédica fuera del centro. Una segunda ayuda vino de la mano de ciertos profesionales de apoyo públicos que, aunque insuficientes, fueron facilitados por la administración.

La última y más reciente ayuda de la administración en el caso de Sergi, tiene que ver un el seguimiento de su caso y preocupación por su inclusión educativa y aprendizaje fructífero. Este apoyo apareció tras una de las mayores barreras de Sergi, la exclusión propiciada desde el centro donde estaba escolarizado. Cuando la familia empezó a denunciar esta situación, demandar más recursos y exigir cambios, la administración facilitó información y ayudas al centro para que fueran utilizadas con Sergi, y con otro alumnado si fuese necesario. En el momento de la ruptura de la relación entre la familia y la institución, la Conselleria apoyó y facilitó a la familia el traslado al nuevo centro y se encargó del seguimiento de Sergi y su evolución en este nuevo contexto.

En este sentido, consideramos necesario el seguimiento y rastreo por parte de la administración en cuanto al alumnado con diversidad funcional, pues esto facilitaría nuevas mejoras e intervenciones educativas más adaptadas a la realidad de nuestras aulas y contrarrestaría la sensación de 'abandono administrativo' de muchas familias. Se trata de crear un sistema que permita establecer prioridades, formular políticas, asignar los recursos necesarios y hacer un seguimiento de los avances y dificultades del alumnado (Blanco, 2013) en aras de contribuir a un modelo educativo inclusivo.

De hecho, la base para una real estructura de apoyos y ayudas educativas generada desde la propia administración podríamos localizarla en lo que Gerschel (2003) denomina como la 'política de apoyo'. Este autor define este término como una política de igualdad de oportunidades que proporciona los fundamentos sobre los que la práctica del centro se construye y orienta a los miembros de la comunidad escolar. Es decir, una política que permita generar una igualdad de oportunidades real para todo el alumnado, proporcionando a los docentes las herramientas y estrategias necesarias para ello (p.e. elementos organizativos, materiales adaptados, flexibilidad organizativa, innovación educativa,...). 


\section{b) Ayudas y apoyos institucionales}

En cuanto a las ayudas y apoyos recibidas por Sergi desde la institución, podemos diferenciar varios subtipos. En primer lugar destacamos las ayudas de consentimiento o aprobación. Este tipo de ayudas son aquella que simplemente conllevan la aceptación por parte de la institución de una propuesta o sugerencia de la familia de Sergi. Algunos ejemplos de ello son la aceptación de pictogramas y paneles comunicativos, la admisión de materiales didácticos provenientes de la familia, la aceptación reuniones informativas con profesionales externos al centro, y la tolerancia e integración del educador externo dentro del aula.

Un segundo tipo de ayuda es la que tiene que ver con la coordinación y la comunicación entre el centro y familia. Este tipo de ayuda se dio tanto por parte del centro de referencia de Sergi, como por parte del instituto en el que fue escolarizado más tarde. La coordinación y comunicación entre el centro y la familia es un elemento indispensable en educación y, sobre todo, si estamos ante un caso en el que la familia es la que lleva la 'voz cantante' del proceso educativo. Tal y como ya hemos adelantado en apartados anteriores, la relaciones positivas y colaborativas entre familias y profesionales son indispensables para la inclusión (Moliner, 2008; Turnbull et al., 2009; Villegas et al., 2014), pues el centro necesita del apoyo e información de la familia para adaptar las estrategias de aprendizaje y metodológicas a las casuísticas y singularidades de cada estudiante.

El último tipo de ayuda institucional tiene que ver con las ayudas y apoyos de acción que implican cambios, reestructuraciones o actuaciones concretas por parte del centro. Este tipo de apoyos se dieron principalmente en el instituto de secundaria al que fue trasladado Sergi y se materializaron en un plan de acción coordinado desde el departamento de orientación. Estas acciones de apoyo a la inclusión educativa de Sergi, requería de tiempo, de organización, de gestión de recursos, de seguimiento de la evolución y, por supuesto, de sensibilización de toda la comunidad educativa con el autismo. Desde el departamento de orientación se coordinaron y gestionaron todas estas acciones mediante la colaboración de los agentes implicados (profesionales específicos, docentes del centro y compañeros/as del aula), la coordinación con la familia y otros profesionales externos y la supervisión de la administración educativa.

Sin duda alguna, la escuela debe ser un espacio tranquilizador, un espacio donde se garanticen los apoyos y medidas necesarias para favorecer oportunidades educativas de éxito, y cuyo esfuerzo continuo y sistemático abarque desde las políticas públicas más generales a las acciones de directivos, docentes, familias y comunidad educativa (Andújar y Rosoli, 2014)

\section{c) Ayudas y apoyos de docentes y otros profesionales}

A partir de los resultados de nuestro estudio, podemos deducir que, al margen de las barreras y limitaciones interpuestos por los centros, tanto uno como otro ofrecen las mismas ayudas y apoyos (aunque en momentos y medidas bien distintas). Entre las ayudas y facilidades generadas por los docentes y profesionales específicos podemos distinguir:

- Implicación docente. Se entiende por implicación docente todas aquellas acciones realizadas desde la postura del docente y que demuestran una 
actitud inclusiva con los alumnos y una predisposición y voluntad didáctica para que cualquier alumno pueda crecer académica y personalmente. Se trata de algo intrínseco al docente y se manifiesta de múltiples formas: atención educativa, facilidades y herramientas para el aprendizaje, comunicación con la familia,... y permite tanto la socialización y pertenencia en el aula, como un aprendizaje efectivo y acorde con las capacidades de los alumnos. Un elemento muy importante en la implicación docente tiene que ver con la relación con la familia, pues la información y colaboración con ésta es esencial para que los procesos educativos inclusivos sean efectivos (Salend \& Garrick, 2002; Verdugo y Rodríguez, 2012).

- Oportunidades de aprendizaje. En la medida que un docente facilite oportunidades y ocasiones de aprendizaje estará facilitando y propiciando un entorno más inclusivo, no solo para el alumnado con diversidad funcional, sino para cualquier alumno/a. Se trata de generar sinergias y dinámicas en el aula que fomenten el aprendizaje de todos, pues para que se dé una verdadera inclusión educativa no solo basta con estar presente, sino que se necesita también de participación y aprendizaje.

- Participación activa. La participación del alumnado y las estrategias docentes empleadas para ello, son la tercera de las ayudas y apoyos docentes a la inclusión educativa. En el caso de Sergi, diversos docentes y en diversos momentos de su historia, emplearon estrategias de participación activa en el aula a través las cuales no solo hacían sentir a Sergi que era uno más, sino que realmente lo era: exámenes, trabajos en grupos heterogéneos, exposiciones, actividades individuales, actividades extracurriculares,... Toda una serie de estrategias docentes que acababan generando dinámicas grupales inclusivas y socializadoras, así como una motivación y predisposición de aprendizaje en Sergi que difícilmente se podía conseguir por otros medios.

Llegado este punto, cabe tener en cuenta que estas ayudas y apoyos de los docentes, tienen mucho que ver con las barreras actitudinales apuntadas en apartados anteriores. Es decir, en función de cuál sea la concepción docente sobre la diversidad funcional y sobre la inclusión, este poseerá unas creencias sobre lo que Sergi (y cualquier otro alumno/a) es o no capaz de hacer. Creencias que derivan, irremediablemente, en expectativas de logro y, por lo tanto, en acciones docentes favorecedora o limitadoras de la inclusión.

No obstante, consideramos que aunque las creencias y expectativas son un elemento necesario para proporcionar ayudas y apoyos adecuados, el docente necesita también de espacio y tiempo para ello. Planificar, coordinar y actuar en pro de la educación inclusiva necesita de otros elementos, pues los mismos docentes identifican los recursos materiales y el tiempo como dificultades para el desarrollo de prácticas inclusivas en sus aulas (Sanhueza, Granada y Bravo, 2012)

Otra tipo de ayuda detectado en esta investigación, son los recursos humanos de apoyo en el aula. En este caso, no referimos principalmente al papel ejercido por el educador externo en educación primaria, y del Profesorado de Pedagogía Terapéutica en el IES. En esta investigación, el cometido de estos profesionales se encuentra, obviamente, vinculada a acciones de apoyo y atención individualizada, adaptación de materiales y recursos y, por supuesto, adaptaciones 
de tipo curricular. Sin embargo, uno de los grandes logros educativos de estos profesionales radica en que su presencia en el aula supera, con creces, estas funciones específicas, convirtiéndose en agentes educativos y socializadores propios del aula, y no de alumnos concretos. Esta idea, coincide con la propuesta de Blanco (2013), quien apuntaba que los profesionales de apoyo deben ser colaboradores de los docentes, no sus sustitutos, en el análisis de los procesos educativos, identificando y promoviendo los cambios necesarios para remover las barreras que enfrenta el alumnado a la hora de participar y aprender, generando beneficios al conjunto de estudiantes y docentes del centro. Sin duda, es una cuestión de responsabilidad de apoyos compartida por todos los docentes y profesionales respecto a todo su alumnado (Echeita, Simón, López y Urbina, 2013).

\section{d) Ayudas y apoyos de los iguales (compañeros/as)}

Los resultados de esta investigación, apuntan al papel de los iguales de Sergi como uno de sus grandes apoyos educativos. Esta misma idea, fue manifestada por diversos autores (Johnson, Johnson \& Holubec, 1999; Slavin, 1991; Stevens \& Slavin, 1995; Carter, Asmus \& Moss, 2014) quienes apuntan a la ayuda entre iguales como un elemento indispensable para la inclusión educativa, la cual aporta diversos beneficios académicos y sociales tanto a las personas con diversidad funcional como al resto de alumnado.

Al desmenuzar los resultados relativos a este tipo apoyo, detectamos dos condiciones generadoras de la inclusión en el entorno escolar. La primera de las condiciones tiene que ver con la valoración de la diversidad. En la medida en que el alumnado valore de manera positiva la diversidad, fomentará interacciones de apoyo y ayudará al alumnado con diversidad funcional contribuyendo a la construcción de un espacio más inclusivo. En este sentido, la valoración de la diversidad tiene mucho que ver con la sensibilización y empatía del resto del alumnado y el papel que ejerce el docente. Por lo tanto, en la medida que fomentemos la interacción entre el alumnado, propiciaremos el respeto $\mathrm{y}$ otorgaremos oportunidades de sensibilización, nuestros alumnos serán personas con actitudes más positivas hacia la diversidad.

En el caso de Sergi, los vínculos de amistad fueron un instrumento de garantía de inclusión, pues sus compañeros/as no solo lo apoyaban incondicionalmente dentro y fuera del centro, sino que además eran absolutos defensores de sus derechos cuando consideraban que se estaban vulnerando, y actuaban en consecuencia (protestas a docentes, acciones reivindicativas, notificación a la familia de vulneración de derechos,...). De esta manera, aparece una segunda condición a la inclusión basada en el apoyo entre iguales: la amistad. Cuando existe una valoración positiva de la diversidad aparecen dinámicas de interacción y socialización que derivan en relaciones sociales y, por lo tanto, en la posibilidad de nuevos vínculos de amistad, fomentando la inclusión social.

En palabras de Stainback y Stainback (1999) "la variedad de apoyo social que los amigos pueden proporcionar a otros alumnos es ilimitada" (p.152), es más según estos autores, el punto de partida debe ser la implantación de estrategias de colaboración y apoyo entre el alumnado para que los alumnos tengan la oportunidad de decidir activamente, participar en la educación, actuar como miembros de la sociedad a través de experiencias de la vida real, experimentar y afrontar la diversidad. De esta manera, el propio alumnado se convierte en un 
recurso muy valioso de interacción de aprendizaje con alumnado diverso (Molina, 2015) y en una de las principales fuentes de apoyo para su inclusión (Jenkins, Antil, Wayne \& Vadasy, 2003).

\subsubsection{Ayudas y apoyos para la comprensión e interacción con entorno}

En el caso de Sergi, el trabajo sobre el entorno (cómo se estructura, las normas y conductas socialmente aceptadas, las no aceptadas, etc.) ha sido imprescindible para su crecimiento personal y académico. De hecho, ésta es una de las áreas más delicadas y confusas para las personas con TEA por lo que ciertas ayudas y apoyos para ello se convierten en fundamentales.

La familia de Sergi, ante la falta de recursos, información y formación por parte de los profesionales de la escuela, decidió 'tomar las riendas'. Buscaron profesionales, la madre se informó y formó en autismo, en TEL y en sistemas de comunicación aumentativa, y poco a poco fueron ampliando la red de profesionales de referencia. Con el tiempo, consiguieron establecer un equipo multidisciplinar (y extraescolar) de trabajo que permitía a Sergi evolucionar en aspectos relativos a esta área. Este equipo estaba compuesto por los padres de Sergi (principalmente la madre) como coordinadores y punto central del equipo, la asociación Mira'm (asociación de atención a niños autistas y sus familias), una logopeda (que trabajaba varias tardes a la semana con él) y el educador que trabajaba como profesorado de apoyo educativo (en horario lectivo) en su aula de referencia.

Este equipo, compuesto por profesionales con enfoques pedagógicos diferentes, ha trabajado durante años para contrarrestar las carencias de atención a la diversidad de la escuela de Sergi. De esta manera, en el contexto extraescolar, se constituyeron y organizaron diferentes tipos de apoyos para el aprendizaje de Sergi. En base a los resultados de nuestra investigación, estos apoyos se pueden clasificar en:

Apoyos comunicativos: los apoyos comunicativos son elementos pictográficos (pictogramas y paneles de comunicación) propios de los Sistemas Pictográficos de Comunicación (SPC), que fueron utilizados para introducir la comunicación aumentativa con Sergi, y más tarde acompañar y apoyar su lenguaje oral. Estos sistemas pictográficos representan todo tipo de conceptos, acciones (individuales o grupales) u objetos en forma de dibujos. En ellos se utiliza un lenguaje visual a través de imágenes muy simples para un mejor entendimiento de lo que se expone, ayudando a comprender mejor las "leyes" que rigen la sociedad y el comportamiento del ser humano (Regis y Callejón, 2015)

A día de hoy Sergi ya no necesita este tipo de apoyos en sus interacciones sociales pero supusieron un elemento indispensable para la comunicación con su entorno familiar, educativo y social. Este sistema de ayuda fue elaborado por la madre en la colaboración del resto de equipo de profesionales externos al centro. Este tipo de apoyo es muy utilizado en el trabajo de niños con TEA puesto que estos asimilan y retienen mejor la información si les llega por la vía visual. Estrategias didácticas y materiales con esta fuente de entrada de datos, fueron confeccionadas por la madre de Sergi para garantizar una mejor comprensión de su entorno y lograr así la 
consecución de objetivos educativos propuestos (Lledó, Lledó y Palomares, 2011).

- Apoyos de acceso a la información: este tipo de ayudas son aquellas adaptaciones que cualquier miembro de este equipo multidisciplinar elaboraba para garantizar que Sergi pudiera acceder a la información. Estos apoyos podían ser (a) imágenes y elementos visuales de los que Sergi podía extraer información, (b) historias sociales (explicaciones gráficas con apoyos visuales sobre algo a argumentar) que permitieran a Sergi comprender instrucciones y conductas prosociales y (c) cualquier tipo de adaptación de materiales y recursos educativos para trabajar tanto dentro como fuera del centro educativo. En este sentido, en la confección de materiales y realización de actividades, los apoyos visuales son un recurso imprescindible a tener en cuenta (Castillo y Grau, 2016).

- Apoyos organizativos: Este tipo de apoyos son sistemas anticipatorios como horarios semanales o agendas, mediante los que propiciaba que Sergi asociara una imagen a la acción que iba a suceder en un momento determinado. Se trata de una estrategia que permite anticipar la acción mediante la clave visual (Tamarit, De Dios, Domínguez y Escribano, 1990, citado en López y Abad, 2000). Este tipo apoyos organizativos permitían a Sergi comprender la organización temporal como elemento social (estaciones, meses, semanas, días...), constructo que resultaba altamente complicado para él y generaba grandes dificultades. Con la pretensión de superar estas dificultades, la madre elaboró calendarios, horarios y agendas visuales que permitieran a Sergi no solo ubicarse en aquello que pasaba en cada momento del día, sino también prever lo que iba a ocurrir en un futuro a corto y medio plazo. A día de hoy este tipo de apoyos ya no son necesarios para Sergi, sino que con un calendario o agenda común, es capaz de ubicarse y organizarse en el tiempo.

- Apoyo logopédico: Desde los primeros años de vida Sergi ha recibido apoyo logopédico mediante una profesional contratada para ello. La logopedia potencia en los niños con TEA el desarrollo de los distintos ámbitos del lenguaje, y especialmente, de la comunicación (Frontera, 2010). Gracias a éste apoyo, Sergi accedió al mundo de la lectoescritura, y progresó notablemente en el área expresión y comprensión oral. A día de hoy, Sergi sigue precisando este tipo de apoyo extraacadémico mediante el cual se van adaptando los objetivos en función de las necesidades o dificultades con las que Sergi se encuentra en su día a día.

\subsubsection{Ayudas y apoyos familiares}

En el caso de Sergi, los apoyos generados a partir de la familia (especialmente sus padres) se pueden denominar como elementos de reivindicación y posicionamiento. Estos apoyos tienen que ver, por un lado, con la 'toma de riendas' en lo que a la educación de Sergi se refiere. Tal y como hemos introducido en apartado de "barreras educativas", ante la falta de formación, recursos y actitudes en materia de inclusión de la escuela, los padres (en especial la madre) optan por empoderarse y empezar a coordinar y 'dirigir' en la medida de lo posible todo su proceso educativo. De la misma manera, en múltiples momentos de la historia hemos podido apreciar cómo la familia se enfrenta a adversidades y 
vulneración de derechos educativos y sociales de Sergi, ante los cuales, impone resistencia y lucha por mantenerlos. Esto tiene ver con aquello que Calderón (2014b) identifica como el 'discurso de la resistencia', mediante el cual se rechazan las explicaciones tradicionales del fracaso escolar y las conductas de oposición y reconduce su análisis: del terreno de la desviación al de la indignación política y moral, de la psicología a la política y la sociología. Esta se convierte en la lucha incansable y de carácter resiliente de Sergi y su familia. Se convierte en un elemento esencial sin el cual se habría mermado la evolución educativa y social de Sergi, quien muy probablemente hubiera sido ubicado en entornos formales de educación especial.

Como ya apuntábamos en los capítulos teóricos, estamos por lo tanto ante un caso que refleja el sentido de la denominada teoría de la resistencia, por la cual se explica cómo las personas con diversidad funcional (y sus familias en este caso) resisten a los discursos dominantes del estigma, a la exclusión política y social y al poder de los expertos en la vida de las personas con discapacidad (Gabel \& Peters, 2004).

En la historia de vida de Sergi, detectamos el apoyo y ayuda de los hermanos de Sergi (hermano mayor y hermano pequeño) con un carácter especial. Debido a la condición de igualdad dentro del sistema familiar, la cercanía y la complicidad que se genera entre hermanos, éstos otorgan un tipo de ayuda y apoyo a Sergi con una esencia diferente a la de los padres. En función de los resultados podemos concluir que existen tres tipos de ayudas provenientes de los hermanos:

- Protección y supervisión: Este tipo de ayuda tiene que ver con la supervisión constante que los hermanos ejercen en el contexto educativo y social, y con el desarrollo del instinto de protección a Sergi en momentos complicados o difíciles. Los hermanos, principalmente el mayor, se preocupan porque Sergi se encuentre bien allá donde esté, preguntando a maestras, compañeros de clase, amigos,... sobre cómo se desenvuelve en las distintas situaciones. En caso de detectar una situación complicada para él acuden en su ayuda (pero no a resolver su situación), a actuar como agentes de socialización y resolución de conflictos.

- Estímulo de interacción: Este tipo de ayuda hace referencia al apoyo comunicativo y social de los hermanos. Nos referimos principalmente a las situaciones cotidianas en las que mediante el juego, bromas o actividades extraescolares los hermanos han ejercido como verdaderos estímulos de interacción, pues la motivación de Sergi para comunicarse e interactuar con ellos era altamente significativa.

- Patrón social. Este último tipo de ayuda tiene que ver con el patrón social que los hermanos suponen para Sergi. Debido a la estima y admiración que Sergi tiene hacia sus hermanos estos se convierten para él en modelos tanto en términos de hábitos y conducta, como de relación e interacción social, propiciando de una manera natural el crecimiento y desarrollo social y personal de Sergi.

Por lo tanto podemos añadir que la familia ejerce un papel primordial en el desarrollo de Sergi en concreto y las personas con diversidad funcional en general. Es más, tal y como apunta Pallisera et al. (2013), concretamente los hermanos, se 
convierten en fundamentales en la etapa de transición a la vida adulta, pues en la constitución de redes de apoyos familiares reside la clave para favorecer la inclusión (Huete y Pallero, 2016).

\subsection{3. ¿Qué decisiones o determinaciones que se han tomado desde el ámbito familiar para superar estas barreras?}

En esta historia de vida sobre diversidad funcional donde las irresponsabilidades, la incompetencia profesional, la falta de sensibilidad y las injusticias poseen un papel protagonista, se requiere de determinación, decisión y perseverancia para luchar contra ellas y salir adelante. Tal y como hemos podido observar en el apartado anterior, la familia ha ejercido un papel fundamental mediante la toma de decisiones y determinaciones sin las cuales los logros y éxitos educativos y sociales de Sergi no hubieran sido posibles.

Evidentemente, estas decisiones o determinaciones para garantizar los derechos de Sergi, poseen una relación directa con los apoyos y ayudas brindados desde el ámbito familiar, de manera que repasarlos de nuevo ahora en forma de 'decisiones familiares' resultaría redundante e inapropiado. Sin embargo, con miras a responder a esta pregunta de investigación, consideramos necesario citar cuáles han sido las principales decisiones familiares que han contribuido a superar las barreras (de todo tipo) con las que se ha encontrado Sergi:

- Toma de riendas: La primera y principal decisión que tomó la familia con respecto a Sergi fue responsabilizarse de cualquier acto sobre de su vida. Esto es algo más que la responsabilidad, crianza y supervisión a nivel familiar. En este caso significa que, ante la falta de recursos, formación, sensibilización, y carencia de estructuras educativas y sociales para las personas con diversidad funcional, la familia optó por supervisar, coordinar y dirigir cualquier acción, de cualquier tipo, que tuviera que ver con Sergi. A partir de esta primera decisión, derivaron una serie de determinaciones que han garantizado una evolución positiva de Sergi y han contribuido a que éste alcance éxitos educativos, deportivos y artísticos impredecibles en los primeros años de su vida.

- Elaboración y provisión de recursos materiales y personales: Otra de las determinaciones por parte de la familia de Sergi tiene que ver con el compromiso y responsabilidad (y financiación) de los recursos materiales y personales necesarios. En este sentido, la familia elaboró y facilitó al centro los recursos materiales para el aprendizaje de Sergi y se aseguró de que éste tuviera los recursos humanos necesarios para garantizar una verdadera inclusión educativa y un desarrollo académico y social al máximo de sus posibilidades.

- Trabajo extraescolar: la familia también se encargó de crear un equipo multidisciplinar de trabajo compuesto por los padres y ciertos profesionales de la educación que garantizaran a Sergi el pleno desarrollo académico y social, y contribuyeran además a un tratamiento inclusivo de ello. La familia era indiscutiblemente el punto central y motor de este equipo de profesionales sin el cual la coordinación y adaptación a las necesidades de Sergi no hubiera sido posible. 
- Constitución de estructuras sociales y de ocio: otra de las decisiones familiares consistió en la creación de estructuras de ocio mediante actividades como la natación y el arte. Estas estructuras no solo permitieron a Sergi encontrar un espacio de ocio en el que disfrutar, sino también conocer gente nueva y abrir posibles caminos futuros para su desarrollo profesional y social.

- Cambio de centro educativo: esta fue una de las determinaciones más recientes tomada por la familia en cuanto a Sergi. Ante la exclusión y discriminación sufrida en el centro educativo y las injusticias a consecuencia de ello, la familia tomó la determinación de cambiar a Sergi a un IES público de la misma localidad. Sin duda alguna ésta fue una decisión muy acertada que brindó a Sergi la oportunidad de desarrollarse en un nuevo entorno, interactuar con gente nueva, construir nuevas amistades y adquirir nuevos hábitos de trabajo en el aula. En otras palabras, nuevas estrategias que de no haber optado por este cambio no se hubieran podido producir.

Como vemos, estas determinaciones y decisiones adoptadas desde el ámbito familiar no solo fueron previstas de los apoyos necesarios para ello, sino que además suponen el inicio de nuevos caminos para Sergi que contribuyen a la construcción de un entorno educativo y social más inclusivo.

\subsection{Perspectiva de futuro desde la diversidad}

El presente apartado tiene que ver con idea de futuro que tanto Sergi como su familia y entorno poseen respecto a los años venideros. Por lo general, para las familias de personas con diversidad funcional este suele ser un tema inquietante y preocupante (APPS, 2007; Verdugo, Rodríguez y Sanchez, 2007; Rodríguez, Verdugo y Sánchez, 2008). Pensar en qué va a pasar, cómo se las va arreglar cuando sea mayor, si sus hermanos podrán apoyarle y responsabilizarse de él, de qué vivirá, dónde vivirá,... son solo algunas dudas que las familias se planetan. No obstante, en un caso como el de Sergi, la confianza en el trabajo hecho y la voluntad y motivación de seguir trabajando son elementos que alientan tanto a Sergi como a su familia.

\subsection{1. ¿Cuáles son expectativas de futuro de Sergi y las personas de su entorno en cuanto a su desarrollo académico, profesional y social?}

Las expectativas de futuro son aquellas ideas preconcebidas que las personas nos formulamos sobre lo que va a pasar en un futuro más o menos lejano. Según Bajoit (2000) es una mirada temporal referida al futuro que implica aquello que se espera como posible o aquello que puede ser proyectable, sin que necesariamente se tenga certeza de alcanzarlo totalmente. Se trata de una mirada en la que, por supuesto, influyen las condiciones sociales, económicas y educativas tanto actuales como futuras. 
En esta investigación, los resultados apuntan a expectativas en relación a diferentes ámbitos (personal, social, educativo y profesional). Veamos con detalle cada uno de ellos:

- Expectativas personales: Los resultados de esta investigación vinculan necesariamente las expectativas personales de Sergi a su ámbito familiar. En mayor o menor medida se prevé que su familia seguirá formando parte de su vida (padres, hermanos, primos,...), bien sea manteniendo una relación frecuente o bien conviviendo con ellos, pero resulta difícil imaginarse el futuro de Sergi sin su familia. De hecho, situándonos en un modelo de diversidad que responsabiliza a la sociedad de la inclusión de todos y todas, la familia sigue siendo un pilar indiscutible en ámbitos como la formación, información y capacitación de las personas con diversidad funcional hacia su futuro (Madrigal-Lizano, 2015).

Otro de los elementos emergentes en cuanto a las expectativas personales de esta investigación son las relaciones interpersonales. En el caso de Sergi, los resultados evidencian la necesidad de seguir trabajando en las relaciones interpersonales, la empatía y la correspondencia, para ofrecer a Sergi estrategias comunicativas necesarias en futuras relaciones de pareja. De hecho, este tipo de relaciones es uno de los elementos recogidos en el modelo de calidad de vida de las personas con diversidad funcional (Verdugo, 2000).

En este sentido, por desgracia, sigue existiendo cierta tendencia social de infantilizar a las personas con diversidad funcional negando su capacidad de sentimiento o expresión sexual. De hecho, se les atribuyen ciertas características como la dependencia, necesidad de ayuda, mal carácter e infidelidad que acaban resultando poco atrayentes para las personas desconocidas (López González, 2010). En esta misma línea, trabajos como el de Blum, Resnick, Nelson y Germaine (1991, citado en López González, 2010) aseguran que las personas con diversidad funcional, hombres y mujeres, tienen dificultades para establecer relaciones de pareja, iniciándolas más tarde y con menor frecuencia que sus coetáneos

- Expectativas sociales: Las expectativas y posibilidades sociales de Sergi se materializan en contextos como el artístico y el deportivo. Los resultados de nuestra investigación apuntan a que ambos contextos son, y continuarán siendo, un elemento fundamental de socialización y realización personal para Sergi.

El mundo artístico ha servido a Sergi para desarrollar su creatividad y originalidad y se ha convertido en un aliciente para él. Hasta día de hoy, la intervención artística con él se ha realizado con una finalidad de ocio, pero en el caso de que lo desee, cabe la posibilidad de seguir explorando este campo, pues tiene a su disposición herramientas (humanas y materiales) dispuestas a facilitarle el camino. En lo que a lo deportivo se refiere, Sergi ha demostrado y sigue demostrando unas aptitudes sorprendentes. El trabajo y evolución técnico han generado grandes expectativas tanto en su familia como en miembros de otros clubes y federaciones, considerando la natación como una posible vía profesional de futuro. 
- Expectativas educativas: Las expectativas formativas y académicas sobre Sergi son altas en cuanto a sus capacidades pero de dudosa resolución en cuanto a las opciones reales. Por un lado encontramos las pretensiones y propósitos de la familia y profesionales que trabajan con él. Estos apuestan ciegamente en que Sergi puede encontrar un camino formativo fructífero siempre y cuando se tengan en cuenta sus competencias y capacidades, y se continúe trabajando paralelamente sobre el lenguaje y la comunicación.

No obstante, a pesar de esta apuesta firme por continuar en el sistema educativo ordinario, parece que al acabar la educación secundaria los caminos formativos para las personas con diversidad funcional se difuminan y desaparecen. A pesar de haber luchado y guerreado por permanecer escolarizado en la vía ordinaria, las posibilidades de futuro de Sergi se diluyen al agotar la escolarización obligatoria y parece que la única salida es la educación especial (escuelas taller o talleres ocupacionales).

Por razones como ésta, las expectativas de éxito de los alumnos con diversidad funcional fortalecidas durante las etapas de educación infantil y primaria, se tornan en frustración al llegar a la educación secundaria. No hay duda de que el sistema educativo presenta carencias en este sentido, y genera grandes desilusiones a familias y jóvenes que han dedicado grandes esfuerzos y sacrificios por mantenerse en entornos ordinarios.

Tal y como ya hemos adelantado en apartados anteriores, Toboso et al. (2012) exponían en su trabajo que solo el 65\% del alumnado con necesidades escolarizado en el sistema ordinario continúa hasta la ESO, un escaso 3\% llega al Bachillerato y prácticamente es imperceptible la cantidad de alumnado que accede a programas de cualificación profesional o ciclos formativos. Sin duda, un derecho a la educación mermado por la carencia de vías formativas para todos que ponen en entredicho la dedicación de recursos y medidas de atención a la diversidad que, sin más opción, confluyen de nuevo en un sistema de educación especial.

- Expectativas laborales: A partir de los resultados podemos deducir que las expectativas laborales de Sergi están totalmente ligadas a sus deseos, intereses y motivaciones personales: en este caso el arte, el deporte y el mundo animal. Justamente este último, es uno de los campos en los que él entiende que tiene posibilidades de futuro, y su familia manifiesta estar dispuesta a apoyarlo en ofrecerle herramientas y vías de crecimiento y aprendizaje en este sentido. Precisamente la familia y su apoyo son uno de los factores críticos que determinan las posibilidades laborales futuras de las personas con diversidad funcional (OMS, 2011), pues sus expectativas influyen directamente en la creencia que la persona con diversidad funcional construye sobre sí misma y sus posibilidades de futuro (Lent \& Hackett, 1994, citado en Gómez Puerta, 2013). Pero al igual que con las expectativas académicas, laboralmente existe un gran vacío político y legal. A las carentes vías formativas para todos y todas le siguen inexistentes camino profesionales alejados del contexto especial (p.e. talleres ocupacionales). Las administraciones deberían realizar orientación profesional tanto a la persona con diversidad funcional como su familia, incidir en el autoconocimiento de la persona y sus posibilidades reales, e involucrar a la persona como eje central de la toma de decisiones respecto a 
su vida (Gómez Puerta, 2013), propiciando vías laborales accesibles para todas las personas.

Estas expectativas de Sergi y su entorno, tienen que ver con lo que Sergi es, con lo que expresa, con lo que demuestra y, por lo tanto, pretenden explotar al máximo sus capacidades y aptitudes. En este sentido, al apostar por un modelo de la diversidad propiciamos que cada persona controle, gestione y asuma las riendas de su propia vida, y junto a los apoyos y ayudas de su entorno, pueda no solo pertenecer sino también participar en una sociedad de todos y todas.

\subsection{2. ¿Qué estrategias se consideran necesarias para garantizar la calidad de vida en el futuro de Sergi?}

El futuro de Sergi tiene mucho que ver con expectativas que él mismo y su entorno poseen a nivel académico, personal y laboral. Sin embargo, estas expectativas difícilmente se podrán alcanzar si Sergi no posee las herramientas o estrategias necesarias para ello. Desde este punto de vista, los participantes de esta investigación apuntan hacia ciertas herramientas que se prevén necesarias para el existo académico, social, laboral y personal de Sergi, las cuales se pueden clasificar en:

\section{Vías de formación alternativas:}

Previamente hemos expuesto como en el contexto educativo se detecta una gran falta de opciones formativas y académicas tras finalizar la educación obligatoria. Los resultados de esta investigación, indican la necesidad de crear nuevas vías de formación alternativas a las existentes, pues concretamente la familia de Sergi, posee la sensación que tras años de lucha las opciones formativas parecen desvanecerse. De esta manera, las medidas de atención a la diversidad por las que se ha apostado a lo largo de todos estos años se 'esfuman' al terminar la escolarización obligatoria, afectando muy negativamente a sus posibilidades de incorporación al mundo laboral.

Actualmente, una de las pocas, por no decir la única, vía formativa ofrecida por el entorno educativo en el que se encuentra Sergi es el PMAR: Programa de Mejora y del Aprendizaje y el Rendimiento (DECRET 87/2015, de 5 de juny, del Consell, pel qual establix el currículum i desplega l'ordenació general de l'Educació Secundària Obligatòria i del Batxillerat a la Comunitat Valenciana), programa que sustituye al antiguo programa de diversificación curricular (ORDEN de 16 de junio de 2008, de la Conselleria de Educación, por la que se regula el programa de diversificación curricular en la educación secundaria obligatoria). El PMAR es una medida específica de atención a la diversidad que se desarrolla desde $2^{\circ}$ de la ESO (y prorrogable a $3^{\circ}$ ), destinada al alumnado que posee dificultades relevantes de aprendizaje no imputables a la falta de estudio o esfuerzo y que hayan repetido, al menos, un curso en cualquier etapa educativa. Se trata de un programa cuya finalidad última es que, mediante una metodología globalizada y específica, el alumnado pueda acceder al Programa de Refuerzo para $4^{\circ}$ de la ESO (PR4, programa que da continuidad al PMAR y que utiliza la misma metodología) o incorporarse a $4^{\circ}$ de la ESO en la vía ordinaria. En ambos casos, cualquier alumno/a podrá obtener el título de graduado en ESO siempre y cuando alcance las 
competencias clave y los objetivos de la etapa de Educación Secundaria Obligatoria; título incompatible con ACI y/o ACIS (como es el caso de Sergi).

Éste es el principal problema de las medidas de atención a la diversidad actuales. Cuando el alumnado con adaptaciones curriculares derivadas de diversidad funcional alcanza el final de la vía formativa no es posible ni la obtención del certificado académico de secundaria, ni existe camino alguno para continuar formándose, por lo que parece que todo acabe derivando en talleres ocupacionales y formación postobligatoria en un contexto de educación especial. De esta manera, podemos decir que estamos ante un nuevo 'parche' educativo que adopta una terminología diferente pero que sigue generando el mismo problema.

En este sentido Tabarini y Montes (2015) identifican en su trabajo ciertas vías educativas diferenciadoras y vías muertas de formación que ponen en riesgo la igualdad de oportunidades y la equidad educativa. Ante esto, la propia OCDE (2012) alerta el peligro de estas vías, sobre todo cuando se articulan como callejones sin salida. Dicha organización recomienda que se mejore la calidad de la formación profesional, haciendo que todas las vías educativas (académica y profesional) tengan el mismo valor, prestigio y reconocimiento.

\section{Viviendas o pisos tutelados:}

A partir de los resultados de esta investigación, se concluye que las viviendas o pisos tutelados conforman una de las herramientas y estrategias que pueden contribuir a un futuro exitoso de Sergi. Según la familia, se trata de un planteamiento todavía lejano para él, pero sus padres ya conciben esta herramienta como necesaria para dentro de unos años. En otros trabajos, ya se apunta a las viviendas tuteladas como la opción de vivienda más positiva para las personas adultas con TEA (Vidriales, Hernández y Plaza, 2016). Sin duda, disponer de un hogar incluido en la comunidad, sin desarraigo de su ambiente social y familiar y contando con los apoyos adecuados para favorecer, en la medida de lo posible, una vida independiente y participativa, es esencial para la calidad de vida de cualquier persona (Happé \& Charlton, 2011).

En definitiva, en aras de garantizar el derecho de las personas con diversidad funcional, debemos escuchar su voz y la de sus familiar y así contribuir a que ellas mismas guíen su propia toma de decisiones (Vidriales, Cuesta, Plaza y Hernández, 2015), pues esto es clave para promover la participación de las personas como agentes activos de sus vidas y disfrutar de manera plena y satisfactoria de una calidad de vida óptima (OMS, 2011).

\section{Planificación centrada en la persona:}

Otra de las necesidades detectadas en esta investigación tiene que ver con la planificación y elaboración de planes de trabajos adaptados no solo a las necesidades de las personas, sino vinculados también a sus posibilidades y deseos vitales. Se trata de lograr un modelo de calidad de vida para las personas con diversidad funcional, pues solo desde este enfoque lograremos entornos sociales y educativos realmente inclusivos. 
En ese camino hacia la calidad de vida de las personas con diversidad funcional, la Planificación Centrada en la Persona (PCP) se convierte en una de las estrategias o métodos por excelencia para ello. La PCP es un enfoque surgido del movimiento de inclusión social de las personas con discapacidad intelectual (Holburn, 2003) basado en la autodeterminación de la persona y que resalta la capacidad del individuo para convertirse en el agente causal de su propia vida (Wehmeyer, 2006). Tuvo su origen sobre los años 80 en Estados Unidos de la mano de J. O'Brien, C.L. O’Brien, B. Mount, J.Pearpoint, M.Forest, M. Smull. (O'Brien \& O’Brien, 2000) aunque se extendió rápidamente a otros países anglosajones (Canadá, Australia, Reino Unido, Irlanda,...), su extensión en España es relativamente reciente. Los contextos y ámbitos de aplicación de este método de apoyo no son exclusivamente el de personas con diversidad funcional, pues también se aplica con éxito en otros colectivos en riesgo de exclusión (Herrera y Abellán, 2008).

Como bien indica Pallisera (2011), se trata de buscar soluciones creativas a las demandas generadas por los proyectos de las personas en lugar de "encajonarlas" en alguno de los servicios que se ofrece desde una organización o institución determinada. Se trata de explorar abiertamente la comunidad y construir los apoyos partiendo de la red natural y desde la propia comunidad. La PCP requiere de unos ejes básicos para su efectividad (Bradley, 2004):

- La persona es el centro del proceso: sus derechos, sus sueños y deseos son el foco desde el que construir los apoyos.

- La familia y amigos se convierten en plenos participantes: El poder reside en la persona interesada pero lo comparte con los miembros de su familia, amigos y otras personas significativas, los cuales constituyen su grupo de apoyo.

- Se centra en las capacidades de la persona, las cosas que ella considera importantes y el apoyo que necesita. Se debe repensar y reformular el papel de los "expertos" que se convierten en participantes del proceso de PCP.

- Existe la responsabilidad compartida en la consecución de los derechos: La PCP versa sobre acciones compartidas que llevan a cambios para la persona y promueve su inclusión en las propias comunidades donde viven. Implica un proceso de cambio continuo que necesita construir sistemas creativos para ayudar a las personas a realizar sus aspiraciones, ofreciendo los apoyos que necesitan para conseguir los estilos de vida que ellos desean.

- Se basa en la escucha continua, aprendizaje y acción continuada: a medida que la persona evoluciona y cambia, lo hacen también sus circunstancias y aspiraciones, por lo que la PCP se convierte en un proceso continuo.

En las últimas décadas se ha desarrollado y perfeccionado algunas estrategias y herramientas en la PCP como: MAPS (Making Action Plans), Método de Círculos de apoyo, Paths (Planning an Alternative Tomorrow with Hope) y ELP (Essential Lifestyle Plan). Cualquiera de estas herramientas podría colaborar a la elaboración de planes de futuro de Sergi (académicos, personales y/o laborales), pues con la implicación de todos los agentes y personas involucradas en esta historia se obtendrían planes de futuro y círculos de apoyo acorde con los deseos y voluntades de Sergi y con las posibilidades reales de consecución. 


\subsection{A modo de conclusión...}

Tras la discusión de resultados con otros autores y la exposición de conclusiones de este trabajo, consideramos oportuno incorporar unas líneas finales de conclusión de un modo más general. A lo largo de este capítulo hemos desgranado tanto como hemos podido las personas, acontecimientos, barreras, ayudas, etc. que han ido sucediendo a lo largo de la vida de Sergi. Sin embargo, llegado este punto ¿qué balance podemos hacer? ¿qué podemos sacar en claro de esta investigación? Veamos algunas ideas en claro:

La primera idea que extraemos es que las barreras de están en todos lados pero dependen de las personas. Con esto queremos resaltar que si bien es cierto que Sergi y su familia siempre se han encontrado con barreras de todo tipo, estas se han convertido en barreras más o menos 'duras' en función de las personas que las sustentan. Es decir, cuando ha habido barreras de tipo administrativo o institucional, la superación de estas siempre ha dependido de la postura que adoptan las personas que están detrás (Conselleria, equipo directivo, docente,...), pues en base a su voluntad, actitud, sensibilidad hacia la diversidad, formación e información, facilitan o dificultan la superación de la barrera. Esto nos ayuda a entender porqué en ciertos momentos de la historia de vida de Sergi, por ejemplo, los docentes han actuado como una gran ayuda, y en otras como una barrera difícil de franquear.

La segunda idea tiene que ver con las ayudas: ha habido muchas barreras pero las ayudas y apoyos han sido más 'altos y fuertes'. Con esta idea queremos transmitir que Sergi está donde está por la lucha, por la incansable voluntad suya y de su entorno por lograr no solo por una educación y/o pedagogía inclusiva, sino por una sociedad inclusiva y justa. Sin esas ayudas y apoyos Sergi difícilmente podría haber crecido y realizarse y disponer de un futuro tan prometedor.

De esta manera llegamos a la tercera idea: la familia es fundamental. De todas esas ayudas mencionadas si algo resalta por encima de todo es el papel de la familia. La lucha, el apoyo, el amor incondicional, la exigencia educativa y social, la crítica y sobre todo la resistencia de la familia han sido elementos necesarios para la inclusión de Sergi en cualquiera de los ámbitos o contextos en los que se ha desarrollado. La familia nunca ha desistido, la familia siempre ha creído en él, en sus posibilidades y le ha ayudado a demostrarlo allá donde vaya, otorgándole y facilitándole el camino con los apoyos que fueran necesarios. Sin duda alguna esa es la clave del éxito del protagonista de esta historia.

En último lugar, añadiremos una cuarta idea: las etiquetas son vistas por quien quiere verlas. Ya en los capítulos teóricos de esta investigación introducimos el peligro de las etiquetas y lo dañinas que pueden llegar a ser, pero la propia investigación nos ha llevado a descubrir una nueva percepción sobre ellas, que no todos las ven. En los diversos encuentros, a no ser que se hablara específicamente de la fase de diagnóstico, el autismo no aparecía en la conversación, no se mencionaba, no era relevante. Por lo tanto, cuando se cree realmente en una persona, cuando se valora la diversidad y uno vive y se enriquece gracias a ella, las etiquetas no tienen razón de ser, solo existen en los ojos de aquellos que las quieren ver. 


\subsection{Limitaciones del estudio}

Tras haber finalizado toda la exposición de conclusiones y discusión con otros autores, llega el momento de hacer un breve pero profundo repaso sobre aquello acontecido y reflexionar sobre lo ocurrido. Al echar la vista atrás, podemos determinar ciertas limitaciones del estudio que podrían haberse mejorado. Algunas de ellas fueron externas al estudio e irremediables, otras se hubieran podido evitar o mejorar de haberlas tenido en cuenta.

La primera de las limitaciones detectadas en este estudio tiene que ver con la clarificación conceptual sobre lo que es y lo que no es una historia de vida, lo que son o no son relatos, lo que se enmarca dentro del método biográfico-narrativo y lo que no. Tal y como se ha podido apreciar en capítulo 3 (creado expresamente para ello) existe una inquietante confusión o 'cóctel' terminológico que, a quienes nos lanzamos por primera vez a estos lares, nos abruman y agobian de una manera un tanto perturbadora. En nuestro caso, la delimitación metodológica supuso una demora temporal imprevista. Cuando llegó el momento de diseñar el plan de investigación y 'encajarlo' en el método, descubrimos una gran variedad conceptual y teórica, y las correspondientes contradicciones. Por ello, tuvimos que estudiar en profundidad (más de lo esperado), consultar a compañeros expertos en el tema e incluso debatir internamente para esclarecer el proceso que íbamos a seguir.

Otra de las limitaciones tiene que ver con el tiempo de recogida de información. Tal y como se ha podido observar en el capítulo 4 y 5, la recogida de datos de esta investigación ha seguido una especie de 'cadena'. Es decir, nos dirigíamos a contactar con un nuevo participante siempre y cuando (a) fuera nombrado de manera significativa en alguna entrevista previa y (b) la madre y coinvestigadora lo considerara oportuno. Esto, por un lado, ha supuesto una selección de los participantes totalmente adaptada a los objetivos de esta investigación, pero que, en contrapartida, ha demorado mucho el tiempo transcurrido entre una entrevista y otra. Pues hasta que no se terminaba y transcribía una entrevista, se negociaba con la coinvestigadora la incorporación de un nuevo participante, se establecía el contacto, se construían los instrumentos de recogida y se acordaba el encuentro pasaban una media de 2 o 3 meses. Ante esto, tal vez una previsión y negociación inicial con la coinvestigadora sobre los participantes de la investigación hubiera reducido considerablemente el tiempo empleado en esta fase.

La siguiente limitación tiene que ver con la reducción de la muestra. Una vez la recogida de datos estaba cerrada y la investigación se encontraba en la fase de análisis, ciertos desajustes y conflictos entre la familia de Sergi y el entrenador de natación (Enrique, entrenador 2), provocaron la rotura de su relación. Por cuestiones personales ajenas a la investigación, los padres de Sergi, y Ángels como coinvestigadora, decidieron excluir del análisis los datos provenientes de este participante. Decidieron que no fuera negada u obviada su existencia en la historia de vida, pero que no fuera considerado un participante de la investigación como tal. Ante esta propuesta, los datos recabados de este participante fueron desestimados.

Otra de las limitaciones tiene que ver con el análisis de datos. Tal y como se ha expuesto en el capítulo 5, el análisis de datos ha contado con dos fases distintas (el análisis deductivo y el análisis narrativo y estructural). Sin embargo, 
la idea original contenía una tercera fase, el análisis centrado en la voz (Voice Centred Relacional Model basado en el trabajo de Mauthner y Doucet, 1998, citado en Moriña, 2016), en la que las personas expertas (participantes de la investigación) realizan una lectura crítica sobre la historia de vida resultante. Esta última fase se desestimó por falta de tiempo en los plazos de entrega de la tesis doctoral y de disponibilidad tanto de la investigadora como de los participantes clave (los padres y el propio Sergi), inmersos en la fase final de la escolarización obligatoria.

Por último, las circunstancias personales de tanto de la investigadora principal como de la coinvestigadora han retrasado considerablemente el proceso de investigación: enfermedades, fallecimientos, nacimientos, procesos emancipatorios, cambios de residencia,... Un conjunto de coyunturas imposibles de prever y contrarrestar pero que influyen directamente en el tiempo, implicación y dedicación a esta tesis doctoral.

\subsection{Propuestas post-investigación y futuras líneas de investigación}

A lo largo de la investigación, diversas propuestas e ideas sobre la investigación han brotado en diferentes momentos del proceso. Algunas de ellas, las que ha sido posible, se han incorporado sobre la marcha pero otras han quedado en el tintero como futuras líneas de trabajo e investigación.

Una de las futuras líneas de trabajo tiene que ver con el análisis centrado en la voz, esa fase de análisis que no se pudo realizar por los motivos expuestos a pesar de considerarla idónea para este tipo de investigación. En investigación con historias de vida trabajamos por y con las personas, procurando involucrarlas e incluirlas en todas las fases del proceso investigador como elemento de empoderamiento. Sin embargo, por cuestiones de tiempo y la aplicación de métodos más tradicionales, el análisis de los datos suele ser uno de los momentos más complicado para ello. Por ello, consideramos que en futuros trabajos debemos incorporar el análisis centrado en la voz para facilitar la participación de las personas protagonistas en todo el proceso de investigación y 'entrehilar' así su voz con la del investigador/a principal.

Una segunda línea de investigación tiene que ver con la formación del profesorado. En esta investigación se ha detectado un sistema de formación inicial y continua carente con la realidad en las aulas. Consideramos necesario indagar en cómo reconvertir nuestro sistema de formación actual en tipo de formación que genere experiencias, reflexiones críticas, vivencias prácticas y transformaciones profundas hacia una concepción de una educación justa, equitativa y de calidad para todos.

Por último, consideramos necesario añadir una tercera línea de investigación: la Planificación Centrada en la Persona (PCP). En este mismo capítulo la PCP ha sido expuesta como herramienta potente que contribuye a garantizar la calidad de vida de las personas con diversidad funcional. Por este motivo, consideramos necesario que en casos como el de Sergi se plantee la PCP como una herramienta de toma de decisiones y de reconfiguración del camino. Bajo 
nuestro punto de vista, esta tesis doctoral se complementaria con la aplicación de ciertas estrategias de PCP en la que Sergi y sus apoyos naturales contribuyan a confeccionar nuevos planes de acción acorde con los deseos y posibilidades de éxito de Sergi. 


A

Abberley, P. (2008). El concepto de opresión y desarrollo de una teoría social de discapacidad. En L. Barton (comp.), Superar las barreras de la discapacidad (pp.34-50). Madrid: Morata

Abbott, S., \& McConkey, R. (2006). The barriers to social inclusion as perceived by people with intelectual disabilities. Journal of Intellectual Disabilities, 10, 275-287.

Abrisketa, J. (2014). El derecho a la educación y los derechos en la educación en España: Análisis crítico de la LOMCE. International Multilingual Journal of Contemporany Research, 2(4), 1-18. doi: 10.15640/imjcr.v2n4a2

Agarwal, N., Moya, E.M., Yasui, N.Y \& Seymour, C. (2015). Participatory Action Research with College Students with Disabilities: Photovoice for an Inclusive Campus. Journal of Postsecondary Education and Disability, 28 (2), 243-250. Recuperado de: https://eric.ed.gov/?id=EJ1074679

Agosta, E., Graetz, J.E., Mastropieri, M.A. \& Scruggs, T.E. (2004). Teacherresearcher partnerships to improve social behaviour through socialstories. Intevention in School and Clinic, 5 (39), 276-287.

Ainscow, M. (2008a), Desarrollo de escuelas inclusivas: ideas, propuestas y experiencias para mejorar las instituciones escolares. Madrid: Narcea.

Ainscow, M. (2008b). Developing inclusive education systems: what are the levers for change? En La educación inclusiva, un camino hacia el futuro. Conferencia Internacional de Educación $48^{a}$ reunión. Ginebra, Suiza.

Ainscow, M. (2012). Haciendo que las escuelas sean más inclusivas: lecciones a partir del análisis de la investigación internacional. Revista de Educación inclusiva, 5 (1), 39-49. Recuperado de: https://dialnet.unirioja.es/servlet/articulo?codigo $=4105297$

Ainscow, M., Booth, T. \& Dyson, A. (2006). Improving Schools, Developing Inclusión. Nueva York: Routledge.

Ainscow, M., Dyson, A., Goldrick, S. \& West, M. (2013). Promoviendo la equidad en educación. Revista de Investigación en Educación, 3, 44-56. Recuperado de: http://reined.webs.uvigo.es/ojs/index.php/reined/article/view/732

Alaminos, A. y Castejón, J.L. (2006). Elaboración, análisis e interpretación de encuestas cuestionarios y escalas de opinión. Alcoy: Marfil.

Albert Gómez, M.J. (2006). Investigación educativa: claves teóricas. Madrid: McGraw Hill.

Albores, L., Hernández, L., Díaz, J. A. y Cortés, B. (2008). Dificultades en la evaluación y diagnóstico del autismo. Una discusión. Salud Mental, 31, 37-44. Recuperado de: http://www.scielo.org.mx/scielo.php?pid=S0185$33252008000100006 \&$ script=sci_arttext 
Aldridge, J. (2012). The participation of vulnerable children in photographic research. Visual Studies, 27(1), 48-58. doi: 10.1080/1472586X.2012.642957

Allen, Q. (2012). Photographs and stories: ethics, benefits and dilemmas of using participant photography with Black middle-class male youth. Qualitative Research, 12 (4), 443-458. doi: 10.1177/1468794111433088

Almeida, M.E., Angelino, M.A., Kipen, E., Lipschitz, A., Marmet, M., Rosato, A. y Zuttión, B. (2010). Nuevas retóricas para viejas prácticas. Repensando la idea de la diversidad y su uso en la comprensión y abordaje de la diversidad. Política y Sociedad, 47 (1), 27-44. Recuperado de: http://revistas.ucm.es/index.php/POSO/article/view/POSO1010130027A

Alonso, L. R. (1994). Sujeto y discurso: el lugar de la entrevista abierta en las prácticas de la sociología cualitativa. En J. M. Delgado y J. Gutiérrez (coords.), Métodos y técnicas cualitativas de investigación en ciencias sociales (pp. 225-240). Madrid: Síntesis.

Álvarez-Gayou, J.L. (2003). Cómo hacer investigación cualitativa. Fundamentos y metodología. Barcelona: Paidós.

Amar, H., Tello, C., Bianchi, G. y Asprella, G. (2015). Las relaciones entre "Educación e Inclusión Social" en Argentina y Brasil: las aportaciones específicas de algunos debates e ideas educativos de la trama discursiva internacional circulante. Revista Educação Especial, 28 (53), 557-568. doi:10.5902/1984686X

Amezcua, M. y Gálvez, A. (2002). Los modos de análisis en investigación cualitativa en salud: perspectiva crítica y reflexiones en voz alta. Revista Española de Salud Pública, 76 (5). Recuperado de: http://scielo.isciii.es/scielo.php?script=sci_arttext\&pid=S113557272002000500005

Andújar, C. y Rosoli, A. (2014). Enseñar y aprender en la diversidad: el desarrollo de centros y aulas inclusivas. En A. Marchesi, R. Blanco y L. Hernández (coords.), Avances y desafíos de la educación inclusiva en Iberoamérica (pp.47-60). Madrid: OEI. Recuperado de:

http://www.oei.es/historico/noticias/spip.php?article13613\&debut_5ultimasOE $\mathrm{I}=35$

Anspal, T., Eisenshmidt, E. \& Löfström, E. (2012). Finding myself as a teacher: exploring the shaping of teacher identities through students teachers' narratives. Teachers and Teaching: Theory and practice, 18 (2), 197-216. doi: 10.1080/13540602.2012.632268

Apalategui, J. (1987). Introducción a la historia oral: a través de los Kontuzaharrak (cuentos viejos) de la comunidad guipuzcoana de Ataun. Barcelona: Anthropos.

Appaurai, A. (ed.) (1986). The Social Life of Things: Commodities in Cultural Perspective. Cambridge: Cambridge University Press.

Aquino, S. P., García, V. e Izquierdo, J. (2012). La inclusión educativa de ciegos y baja visión en el nivel superior: Un estudio de caso. Sinéctica, 39, 01-21. 
Recuperado

de:

http://www.scielo.org.mx/scielo.php?script=sci_arttext\&pid=S1665-

109X2012000200007\&lng=es\&tlng=en.

Araque, N. y Barrio, J.L. (2010). Atención a la diversidad y desarrollo de procesos educativos inclusivos. Prisma Social. Revista de Ciencias Sociales, 4, 1-37.

Recuperado de: https://dialnet.unirioja.es/servlet/articulo?codigo $=3632700$

Arias, M.M. y Giraldo, C. (2011). El rigor científico en la investigación cualitativa. Investigación y Educación en Enfermería, 29 (3), 500-514. Recuperado de: http://www.redalyc.org/articulo.oa?id=105222406020

Armstrong, A.C., Armstrong, D. Lynch, C. \& Severin, S. (2005). Special and inclusive education in the Eastern Caribbean: Policy practice and provision. International Journal of Inclusive Education, 9(1), 71-87. doi: 10.1080/1360311042000302905

Aróstegui, I. y Gaintza, Z. (2014). La voz de un grupo de familiares de personas con enfermedades minoritarias de Bizkaia: análisis de su experiencia en el proceso de escolarización, de la evolución y necesidad de mejora. Revista nacional e internacional de educación inclusiva. 7 (3): 50-67. Recuperado de: http://www.revistaeducacioninclusiva.es/index.php/REI/article/view/131/0

Artigas, J. (2001). Las fronteras del autismo. Revista de Neurología Clínica, 2(1), 211-224.

Asis, R. y Barranco, M.C. (2010). El impacto de la Convención Internacional sobre los derechos de las Personas con Discapacidad en la Ley 39/2006, de 14 de diciembre. Madrid: Ediciones Cinca.

Asociación Americana de Psiquiatría. (2013). Manual Diagnóstico y Estadístico de los Trastornos Mentales (5 ed.). Arlington, VA:. American Psychiatric Publishing

Asociación Americana de Psiquiatría. (2002). Manual Diagnóstico y Estadístico de los Trastornos Mentales (4 ${ }^{\mathrm{a} e d}$.). Washington: American Psychiatric Publishing

Asociación Nacional de Lesionado Medulares y Grandes Discapacitados. (2007). Experiencia hacia la Vida Independiente. Madrid: Aspaym Recuperado de: http://www.diba.cat/c/document_library/get_file?uuid=90507a0c-82f5-45e7b3ec-436f6b52b6b8\&groupId=527890

Aspaym. (2007). Experiencia hacia la Vida Independiente. Madrid: Aspaym. Recuperado http://www.diba.cat/c/document_library/get_file?uuid=90507a0c-82f5-45e7b3ec-436f6b52b6b8\&groupId=527890

Aziz Ghoneim, S. E. A. (2014). Requirements for Inclusion of Children with Disabilities in Public Education in Egypt. Journal of Educational and Social Research, 4 (4), $192 . \quad$ Recuperado de: http://www.mcser.org/journal/index.php/jesr/article/view/3490

Atkinson, P. (1998). The life story interview. Thousand Oak CA: Sage. 
Atkinson, D. (2005). Research as Social Work: Participatory Researchin Learning Disability. British Journal of Social Work,35 (4), 425-234. doi: 10.1093/bjsw/bch189

Atkinson, P., Delamont, S. \& Hammersley, M. (1988). Qualitative research tradicions: a British response to Jacob. Review of Educational Research, 58 (2), 231-250. doi: 10.3102/00346543058002231

B

Badilla, L. (2006). Fundamentos del paradigma cualitativo en la investigación educativa. Revista de Ciencias del Ejercicio y la Salud. 4 (1). doi: 10.15517/pensarmov.v4i1.411

Baez, J. (2009). Investigación cualitativa. Madrid: Esic

Báez, I. y Cabeza, C. (2006). Sordera, Lenguas de signos y patologías del lenguaje. En B. Gallardo, C. Hernández y V. Moreno (Eds.), Lingüística clínica y neuropsicología cognitiva. Actas del Primer Congreso Nacional de Lingüística Clínica. Investigación e intervención en patologías del lenguaje (pp.207-224). Valencia: Universitat de Valencia

Bajoit, G. (2000). Qu'est-ce que la socialisation. En G. Bajoit, F. Digneffe, Q. N. De Brauwere et J.M. Jaspartd. Jeunesse et société: La socialisation des jeunes dans un monde en mutation (pp.19-43). Bruxelles: Boeck Université.

Bagnoli, A. (2009). Beyond the standard interview: The use of graphic elicitation and arts-based methods. Qualitative Research, 9(5), 547-570. doi: $10.1177 / 1468794109343625$

Baltar, M.J. (2003). El sentido del diagnóstico psicológico escolar. Un análisis crítico y una propuesta en construcción. Psicoperspectivas. Revista de la escuela de psicología, 2, 7 -34. Recuperado de: http://www.psicoperspectivas.cl/index.php/psicoperspectivas/article/view/1

Banks, M. (2001). Visual methods in social research, London, SAGE Publications.

Banks, M. (2010). Los datos visuales en investigación cualitativa. Madrid: Morata.

Baña Castro, M. (2015). El rol de la familia en la calidad de vida y la autodeterminación de las personas con trastorno del espectro del autismo. Ciencias Psicológicas, 9 (2), 323-336. Recuperado de: https://dialnet.unirioja.es/servlet/articulo?codigo $=5297074$

Barrios, S. (2013). Ayúdame a comprender el mundo. Apoyos visuales para la promoción de la autonomía en personas con trastorno del espectro del autismo y trastornos específicos del lenguaje. Revista Electrónica de Terapia Ocupacional, 10(8), 92-104. Recuperado de: http://www.revistatog.com/suple/num8/autismo.pdf

Bartolomé, M. (1992). Investigación cualitativa en educación: ¿comprender o transformar? Revista de Investigación Educativa, 20 (2), 7-36. 
Barton, L (1998). Sociología y discapacidad: algunos temas nuevos. En Barton, L. (comp.), Discapacidad y sociedad (pp.19 33).Madrid: Morata

Barton, L. (2009). Estudios sobre discapacidad y la búsqueda de la inclusividad. Observaciones. Revista de Educación, 349, 137-152. Recuperado de: www.revistaeducacion.mec.es/re349/re349.pdf

Bellver, M C., Díez, M., López, M.J. y Navarro, A. (2009). La programación didáctica en un aula CyL: La experiencia del CEIP "El Parque" de la Cañada (Paterna). En FEPAL (ed), Actas del XIX Congreso Nacional de la Federación Española de Asociaciones de Profesores de Audición y Lenguaje, Valencia. Recuperado http://www.jmunozy.org/files/9/Logopedia/aula_al/documentos/C03aulascyl.pdf

Benington, J. \& Hartley, J. (2004). Co-research: insider/outsider teams for organizational research. In C. Cassell, \& G. Symon, (eds.) Essential Guide to Qualitative Methods in Organizational Research. (pp. 361-371). London: Sage Publications Ltd.

Benítez, L. (2010). Autismo, familia y calidad de vida. Cultura: Revista de la Asociación de Docentes de la USMP, 24, 1-20. Recuperado de: https://dialnet.unirioja.es/servlet/articulo?codigo=3701024

Benítez, A.M. (2014). La inclusión educativa desde la voz de los padres. Revista nacional e internacional de educación inclusiva. 7 (1), 110-120. Recuperado de: http://www.revistaeducacioninclusiva.es/index.php/REI/article/view/166

Bermúdez, N. y Rodríguez, M. (2009). La fuente oral en la reconstrucción de la memoria histórica: su aporte al documental "Memorias del Zulia Petrolero". Revista de Ciencias Sociales, 15 (2), 317-328. Recuperado de: http://www.produccioncientifica.luz.edu.ve/index.php/rcs/article/view/13631/1 3614

Bertaux, D. (2005). Los relatos de vida. Perspectiva etnosociológica. Barcelona: Edicions Bellaterra.

Biklen, D. (2000). Constructing inclusion: lessons from critical, disability narratives. International Journal of Inclusive Education, 4(4), 337- 353. doi: 10.1080/13603110050168032

Bisquerra, R. (Coord.) (2004). Metodología de la Investigación Cualitativa. Madrid: La Muralla.

Black-Hawkins, K. (2017). Understanding inclusive pedagogy. Learning with and from teachers. En V. Plows \& B. Whitburn (eds.) (2017) Inclusive education. Making sense of everyday practice. Rotterdam: SensePublishers. doi: 10.1007/978-94-6300-866-2_15

Blaikie, N. (2000). Desinging social research: The logic of anticipation. Cambridge, UK: Polity.

Blanco, R. (2005). Protagonismo docente en el cambio educativo. En UNESCO, Proyecto Regional para América Latina y el Caribe. Chile. 
Blanco, R. (2013). Inclusión educativa en América Latina: caminos recorridos y por recorrer. En A. Marchesi, R. Blanco y Hernández, L. (coords). Avances y desafios de la educación inclusiva en Iberoamérica. Madrid: FUNDACIÓNMAFRE.

Blasco, M., Martínez, M. y Santamaría, M. (2006). La creación y funcionamiento de Aulas Especializadas en Lenguaje y Comunicación. Actas de III Jornada sobre Trastorno Específico del Lenguaje, Valencia. Recuperado de: http://www.dcam.upv.es/avatel/Textos/Textos\%20AVATEL/AVATEL\%20Cong reso\%20Logopedas.pdf

Blume, K.K. (2015). Narrative learning through life: Kenyan teachers' life-stories and narrative learning, and what this means for their relation to the teaching profession. International Journal of Educational Development, 40, 145-155. doi: 10.1016/j.ijedudev.2014.10.006

BOE (1970). Ley 14/1970, de 4 de agosto, General de Educación y Financiamiento de la Reforma Educativa. Recuperado de:

https://www.boe.es/diario_boe/txt.php?id=BOE-A-1970-852

BOE (1978). Constitución Española. Recuperado de:

https://www.boe.es/buscar/act.php?id=BOE-A-1978-31229

BOE (1982). Ley 13/1982, de 7 de abril, de Integración Social de los Minusválidos (LISMI). Disponible en web: https://www.boe.es/diario_boe/txt.php?id=BOEA-1982-

BOE (1985). Real Decreto 334/1985, de 6 de marzo, de ordenación de la Educación Especial. Recuperado de: https://www.boe.es/diario_boe/txt.php?id=BOE-A1985-4305

BOE (1985). Orden de 20 de marzo de 1985 sobre planificación de la Educación Especial y experimentación de la integración en el curso 1985/86. Recuperado de: https://www.boe.es/diario_boe/txt.php?id=BOE-A-1985-4763

BOE (1990). Ley Orgánica 1/1990, de 3 de octubre, de Ordenación General del Sistema Educativo. Recuperado de:

https://www.boe.es/diario_boe/txt.php?id=BOE-A-1990-24172

BOE (2003). Ley 51/2003, de 2 de diciembre, de igualdad de oportunidades, no discriminación y accesibilidad universal de las personas con discapacidad. Disponible en: https://www.boe.es/buscar/act.php?id=BOE-A-2003-22066

BOE (2006). Ley Orgánica 2/2006, de 3 de mayo, de Educación. Recuperado de: https://www.boe.es/buscar/act.php?id=BOE-A-2006-7899

BOE (2006). Ley 39/2006, de 14 de diciembre, de Promoción de la Autonomía Personal y Atención a las personas en situación de dependencia. Recuperado de: https://www.boe.es/buscar/act.php?id=BOE-A-2006-21990

BOE (2013). Ley Orgánica 8/2013, de 9 de diciembre, para la mejora de la calidad educativa. Recuperado de: https://www.boe.es/diario_boe/txt.php?id=BOE-A2013-12886 
Boggino, N. y Boggino, P. (2014). Pensar la escuela desde la accesibilidad universal y la complejidad. Abolir las fronteras, los eufemismos y los estigmas. Paulo Freire. Revista de Pedagogía Crítica, 13 (15), 31- 51. Recuperado de: http://bibliotecadigital.academia.cl/handle/123456789/3123

Bolivar, A., Domingo, J. y Fernández, M. (2001). La investigación biográficonarrativa en educación. Enfoque y metodología. Madrid: La Muralla.

Bolívar, A., Domingo, A. y Fernández, M. (2011). La investigación biográficonarrativa en educación. Enfoque y metodología. Madrid: La Muralla

Booth, T. \& Ainscow, M. (2011). Index for Inclusion Developing learning and participation in schools. Bristol: Centre for Studies on Inclusive Education (CSIE).

Booth, T., Ainscow, M., Black-Hawkins, K., Vaughan, M. \& Shaw, L. (2002). Index for Inclusion. Bristol: Centre for Studies in Inclusive Education.

Boyatzis, R.E. (1998). Transforming Qualitative Information. Thematic Analysis and code development. Thousand Oaks, CA: Sage Publications.

Bowman-Perrott, L., Davis, H., Vannest, K., Williams, L., Greenwood, C., \& Parker, R. (2013). Academic benefits of peer tutoring: A meta-analytic review of single-case research, School Psychology Review, 42(1), 39-55. Recuperado de: https://eric.ed.gov/?id=EJ1007216

Brazelton T. y Greenspan S. (2005). Las necesidades básicas de la infancia. Barcelona: Graó.

Bradley, A. (2004). Positive Approaches to Person Centred Planning. Glasgow: BILD.

Brookes, I., Archibald, S., McInnes, K., Cross, B., Daniel, B. \& Johnson, F. (2012). Finding the words to work together: developping a research design to explore risk and adult protection in co-produced research. British Journal of Learning Disabilities, 40, 143-151. doi: 10.1111/j.1468-3156.2012.00740.x

Buendía, L., Colás, M.P., y Hernández, F. (1997). Métodos de investigación en psicopedagogía. Madrid: McGraw-Hill.

Bullough, R.V. (2016). Early Childhood Education Teachers: Life History, Life Course and the Problem of Family - Work Balance. Journal of Research in Childhood Education, 30 (4), 441-445. doi: 10.1080/02568543.2016.1214936

Bunch, G. (1991). Don't Pass Me By. Writings from the Street. Toronto: Inclusion Press.

Bunch, G. \& Finnegan, K. (1996). Kids, Disabilities and regular classromms. An annotated bibliography os selected children's literatura on disability. Toronto: Inclusion Press.

Buysse, V., Wesley, P. \& Keyes, L.(1998). Implementing early childhood inclusion: Barrier and support factors. Early Childhood Research Quarterly, 13 (1), 169-84. doi: 10.1016/S0885-2006(99)80031-3 
Cabero, J. y Córdoba, M. (2009). Inclusión educativa: inclusión digital. Revista de Educación inclusiva. 2 (1), 61-77. Recuperado de: http://hdl.handle.net/10272/11296

Cajide, J. (1992). La investigación cualitativa: Tradiciones y perspectivas contemporáneas. Bordón, 44 (4), 357-373.

Calderon, I. (2014a). Educación y esperanza en las fronteras de la discapacidad. Madrid: CERMI.

Calderon, I. (2014b). Sin suerte pero guerrero hasta la muerte: pobreza y fracaso escolar en una historia de vida. Revista de Educación. 363, 184-209. Recuperado de: http://online.ucv.es/resolucion/files/re36308.pdf

Calderón I. (2015a). Liberarse de la escuela. Historia de vida de Elena. RIUMA, Málaga.

Calderón, I. (2015b). Sin suerte, pero guerrero hasta la muerte. Educación, pobreza y exclusión en la vida de José Medina. Granada, Octaedro Andalucía.

Calderón, I. (2016). Fracaso escolar y desventaja sociocultural. Una aproximación biográfica. Barcelona, Editorial UOC.

Calderón, I. y Habegger, S. (2012). Educación, hándicap e inclusión. Una lucha familiar contra una escuela excluyente. Granda: Mágina.

Calvo, A. y Manteca, F. (2016). Barreras y ayudas percibidas por los estudiantes en la transición entre la educación primaria y secundaria. Revista Iberoamericana sobre Calidad, Eficacia y Cambio en Educación, 14 (1), 49-64. doi: 10.15366/reice2016.14.1.003

Calvo, A. y Susinos, T. (2006). Ausencias y presencias femeninas. Estudio de la exclusión social y la construcción de la subjetividad femenina en mujeres jóvenes a través de metodología biográfico-narrativa. En M. García Lastra (eds.) Convergencia con Europa y cambio en la universidad (pp.123-124) Alzira: Germania.

Canales, M. (coord.) (2006). Metodologías de investigación social. Santiago de Chile: LOM Ediciones.

Canales, M. y A. Peinado (1995). Grupos de discusión. En J.M. Delgado y J. Gutiérrez (coords.) Métodos y técnicas cualitativas de investigación en ciencias sociales (pp. 288-316). Madrid: Editorial Síntesis.

Carrington, S. (1999). Inclusion needs a different school culture. International Journal of Inclusive Education, 3 (3), 257-268. Recuperado de: http://www.tandfonline.com/doi/abs/10.1080/136031199285039

Carrignton, S. (2017). Inclusive Education: Two Steps Forward and One Step Back In V. Plows \& B. Whitburn (eds.), Inclusive education. Making sense of everyday practice. Rotterdam: SensePublishers. doi: 10.1007/978-94-6300866-2_15 
Carter, E.W., Asmus, J.M. \& Moss, C.K. (2014). Peer Support interventions to support inclusive schools. En J. Mcleskey, N.L. Waldron, F. Spooner, \& B. Algozzine (coords). Handbook of effective inclusive schools. Research and practice (pp. 377-394) New York: Routledge.

Casado, D. (1991). Panorámica de la discapacidad. Barcelona: INTRESS.

Casanova, M. A. (2011). De la educación especial a la inclusión educativa. Estado de la cuestión y retos pendientes. Participación Educativa, 18, 8-24.

Recuperado de: http://www.educacion.gob.es/revista-cee/pdf/n18-casanovarodriguez.pdf

Casanova, M.A. y Rodríguez, H.J. (coords.)(2014). La inclusión educativa, un horizonte de posibilidades. Madrid: La Muralla.

CAST (2011). Universal Design for Learning guidelines version 2.0. Wakefield, MA: Author. Recuerado de: http://www.udlcenter.org/aboutudl/udlguidelines

Castejón J.L. y Navas, L. (eds.) (2013). Dificultades y trastornos de aprendizaje y del desarrollo en infantil y primaria. Alicante: Editorial Club Universitario.

Castel, R. (2014). Los riesgos de exclusión social en un contexto de incertidumbre. Revista Internacional de Sociología, 72(1), 15-24. doi: 10.3989/ris.2013.03.18

Castells, M. (1997). Flujos, redes e identidades: una teoría crítica de la sociedad informacional. En M. Castells, R. Flecha, P.Freire, H. Giroux, D. Macedo y P. Wills (Eds.). Nuevas perspectivas críticas en educación (pp. 15-34). Barcelona: Paidós.

Castillo, A. y Grau, C. (2016). Conductas disruptivas en el alumnado con TEA: estudio de un caso. ENSAYOS, Revista de la Facultad de Educación de Albacete, 31(2). Recuperado de: http://www.revista.uclm.es/index.php/ensayos

Cea D'Ancona, M. A. (1996). Metodología cuantitativa: estrategias y técnicas de investigación social. Madrid: Síntesis.

Centeno, A., Lobato, M. y Romanach, J. (2008). Indicadores de Vida Independiente (IVI) para la evaluación de políticas y acciones desarrolladas bajo la filosofía de Vida Independiente. Foro de Vida Independiente. Recuperado de: http://www.minusval2000.com/pdf/Indicadores_de_Vida_Independiente.pdf

CERMI (2010). Los jóvenes con discapacidad en España. Informe de situación 2010. Madrid. Cinca. Recuperado de: http://www.intersocial.es/images/stories/pdf/jovenes_con_discapacidad.pdf

Chacón- Ortiz, M. (2015). El proceso de evaluación en educación no formal: un camino para su construcción. Revista electrónica Educare, 19 (2), 21-35. doi: 10.15359/ree.19-2.2

Chappell, A. (2000). The emergence of participatory methodology in learning disability research: Understanding the context. British Journal of Learning Disabilities, 28 (1), 38-43. doi: 10.1046/j.1468-3156.2000.00004.x

Chawarska, K., Paul, R., Klin, A., Hannigen, S., Dichtel, L. E., \& Volkmar, F. (2007). Parental recognition of developmental problems in toddlers with 
autism spectrum disorders. Journal of autism and developmental disorders, 37(1), 62-72. doi: 10.1007/s10803-006-0330-8

Clandinin, J. \& Connelly, M. (1994). Personal experience method. En N. K. Denzin \& Y.S. Lincoln (Eds.). Handbook of qualitative research (pp. 413-427). Londres: Sage.

Cihak, D.F., Kildare, L.K., Smith, C.C., McMahon, D.D. \& Quinn-Brown, L. (2012). Using video socialstories [TM] to increase task engagement for middle school students with autism spectrum disorders. Behavior Modification, 3 (36), 399425. Recuperado de: https://www.ncbi.nlm.nih.gov/pubmed/22609764

Cisterna, F. (2005). Categorización y triangulación como procesos de validación del conocimiento en investigación cualitativa. Theoria, 14 (1), 61-70. Recuperado de: http://www.redalyc.org/articulo.oa?id=29900107

Coffey, A. \& Atkinson, P. (2003). Encontrar el sentido a los datos cualitativos: estrategias complementarias de investigación. Alicante: Universidad de Alicante.

Colás, P. y Buendía, L. (1992). Investigación educativa. Sevilla: Alfar.

Compton, D. (2003). La Disyuntiva de la inclusión: crear una inclusión plena con ayuda de actividades recreativas y de estructuras sociales ostensibles para personas con discapacidad, Boletín ADOZ. Revista de Estudios de Ocio, 26, 920. Recuperado de: https://dialnet.unirioja.es/servlet/articulo?codigo=2083329

Connick F. \& Godard, F. (1998). El enfoque biográfico a prueba de interpretaciones. Formas temporales de causalidad. En T. Lulle, P. Vargas y L. Zamudio (coord.) Los usos de la historia de vida en ciencias sociales II. (pp. 250-292). Barcelona: Anthropos.

Cortés, P., Leite, A. y Rivas, J.I. (2014). Un enfoque narrativo de la identidad profesional en profesorado novel. Tendencias pedagógicas, 24, 199-214. Recuperado de: https://revistas.uam.es/tendenciaspedagogicas/article/view/2101

Cortés, $M^{a}$ D., y Moriña, A. (2014). Luces y sombras en la Enseñanza Superior desde la perspectiva del alumnado con discapacidad en el área de Ciencias de la Salud. Revista de Investigación en Educación, 12 (2), 145-163. Recuperado de: https://dialnet.unirioja.es/descarga/articulo/4888830.pdf.

Cotán, A. (2015). Enseñanza Superior y educación inclusiva: múltiples miradas desde las historias de vida de estudiantes con discapacidad. (Tesis Doctoral, Universidad de Sevilla, España). Recuperado de: https://idus.us.es/xmlui/handle/11441/32051

Creswell, J.W. (1998). Qualitative inquiry and research design: Choosing among five traditions. London: Sage.

Creswell, J. (2005). Educational research: Planning, conducting, and evaluating quantitative and qualitative research. Upper Saddle River: Pearson Education.

Crotty, M. (1998). The foundations of social research. Meaning and perspective in the research process. Londres: Sage. 
Cuenca, M. (2000). Ocio humanista. Documentos de Estudios de Ocio, 16. Bilbao. Universidad de Deusto.

Cuenca, P. (2012). Sobre la inclusión de la discapacidad en la teoría de los derechos humanos. Revista de Estudios Políticos, 158, 103-137. Recuperado de: http://www.repositoriocdpd.net:8080/handle/123456789/1575?show=full

D

Da Rosa, F. M, \& Baraldi, I. M. (2015). O uso de narrativas (auto)biográficas como uma possibilidade de pesquisa da prática de professores acerca da educação (matemática) Inclusiva . Bolema, 29 (53), 936-954. doi:10.1590/19804415v29n53a08

Davies, D. K., Stock, S. E., Holloway, S., \& Wehmeyer, M. L. (2010). Evaluating a GPS-based transportation device to support independent bus travel by people with intellectual disability. Intellectual and Developmental Disabilities, 48, 454-463.

De Asis, R. (2007). Reflexiones en torno a la Ley de protección de la autonomía personal y atención a las personas en situación de Dependencia. Universitas. Revista de Filosofía, Derecho y Política, 5. Recuperado de: http://universitas.idhbc.es/n05/05-02.pdf

De Asis, R. y Barranco, M. C. (2010). El impacto de la convención internacional sobre los derechos de las personas con discapacidad en la ley 39/1006, de 14 de diciembre. Madrid: CERMI.

De Garay, G. (2001) (comp.) Cuéntame tu vida. Historia oral: historias de vida. México: Instituto Mora.

De la Cruz, J. (2012). Desigualdad educativa, jerarquías de poder y violencia simbólica en la formación de investigadores de la educación. Revista Iberoamericana de Educación Superior, 3 (8). Recuperado de: https://ries.universia.net/article/view/93/279

De la Fuente, Y.M. y Hernández, J. (2013). Rehabilitación de viviendas con criterios de accesibilidad en España. Respuestas inclusivas ante la diversidad humana y social. Revista de Urbanismo, 28, 61-78. doi: 10.5354/0717-5051.2013.25961

De La Rosa, L. (2008). Historia de Vida de Ángel. Parálisis cerebral, normalidad y comunicación. Madrid: La Muralla. Colección Aula Abierta.

De La Rosa, L. (2010). ¿Investigamos juntos? Personas con discapacidad, historias de vida y emancipación. Revista de Educación Inclusiva, 3 (3), 11-22. Recuperado de: https://dialnet.unirioja.es/servlet/articulo?codigo $=3607983$

De la Rosa, L. (2013). Detalles de la historia de vida de José Ángel Lobato Carvajal "buscando la normalidad en un mundo anormal". Revista de Educación Inclusiva, 6(1), 107-128, Recuperado de: https://dialnet.unirioja.es/servlet/articulo?codigo $=4335116$

De Laine, M. (2000). Fieldwork, participation and practice: ethics and dilemas in qualitative research. Thousand Oaks: Sage. 
De Miguel, M. (1998). Paradigmas de la investigación educativa Española. En I. Dendaluce (Ed.) Aspectos metodológicos de la investigación educativa (pp. 6077). Madrid: Narcea.

Declaración de Salamanca (2004). Conferencia Mundial sobre Necesidades Educativas Especiales: Acceso y Calidad. Recuperado de: http://mda.una.edu.ve/UserFiles/Declaracion_de_Salamanca_1994.pdf

Deguara, M., Jelassi, O., Micallef, B. \& Callus, A. (2012). How we like to live when we have the chance. British Journal of Learning Disabilities, 40 (2), 123-127. doi: 10.1111/j.1468-3156.2012.00743.x

DeJean, W. (2008). Picture This: Using Photography to Conceptualize Social Justice. Multicultural Perspectives, 10(2), 105-109. doi:

10.1080/15210960801998021

Del Rincón, D., Arnal, J., Latorre, A., y Sans, A. (1995). Técnicas de investigación en ciencias sociales. Madrid: Dykinson.

Del Río, N. (2016). El penoso camino a la inclusión social de los niños con diversidad funcional. En A. Picornell y E. Pastor (coords.) Políticas de inclusión social de la infancia y la adolescencia. Una perspectiva internacional. Madrid: Ciclo Grupo 5.

Delgado, M. (2015). Historias de vida profesional docente y tutoría en la universidad (Tesis doctoral, Universidad de Huelva, España). Recuperado de: https://openlibra.com/es/book/historias-de-vida-profesional-docente-y-tutoriaen-la-universidad

DeMarassé, R.L. (2006). Still Determinated After all these Tears. A Story of Tumors, Trajedies and Triumphs. Toronto: Inclusion Press

Demazière, D. \& Dubar, C. (1997). Analyser les entretiens biographiques.

L'exemple de récits d'insertion. Paris : Nathan.

Denzin, N.K. (1989). Interpretative biography. Londres: Sage.

Denzin, N.K. \& Lincoln, Y.S. (1994) The sage handbook of qualitative research. Thousand Oaks, California : Sage Publications.

Denzin, N.K. \& Lincoln, Y. S. (1998). Entering the field of qualitative research. En N. K. Denzin e Y. S. Lincoln (Eds.), Collecting and interpreting qualitative materials (pp. 1-34). Londres: Sage.

Denzin, N.K. \& Lincoln, Y.S. (2005). Handbook of qualitative research. (3rd ed.) Thousand Oaks, CA : Sage Publications.

Denzin, N.K. \& Lincoln, Y.S. (2012). Manual de investigación cualitativa Vol. II. Paradigmas y perspectivas en disputa. Barcelona: Gedisa.

Dey I. (1993). Qualitative Data Analysis. A User-Friendly Guide for Social Scientists. London: Routledge.

Díaz Velázquez, E. (2010). Ciudadanía, identidad y exclusión social de las personas con discapacidad. Política y Sociedad, 47 (1), 115-135. Recuperado de: http://revistas.ucm.es/index.php/POSO/article/view/POSO1010130115A 
DOGV (2001). ORDEN de 16 de julio de 2001 por la que se regula la atención educativa al alumnado con necesidades educativas especiales escolarizado en centros de Educación Infantil ( $2^{\circ}$ ciclo) y Educación Primaria. Recuperado de: http://www.dogv.gva.es/portal/ficha_disposicion_pc.jsp?sig=3840/2001\&L=1

DOGV (2008). Orden, de 16 de junio de 2008, de la Conselleria de Educación, por la que se regula el programa de diversificación curricular en la educación secundaria obligatoria. Recuperado de:

http://www.dogv.gva.es/datos/2008/06/20/pdf/2008_7629.pdf

DOGV (2015). Decret 87/2015, de 5 de juny, del Consell, pel qual establix el currículum i desplega l'ordenació general de l'Educació Secundària Obligatòria i del Batxillerat a la Comunitat Valenciana. Recuperado de: http://www.dogv.gva.es/datos/2015/09/09/pdf/2015_7393.pdfDOGV (2016). Resolución de 27 de julio de 2016 por la que se dictan instrucciones para la organización y el funcionamiento de las unidades específicas de comunicación y lenguaje ubicadas en centros públicos. Recuperado de: http://www.dogv.gva.es/datos/2016/08/01/pdf/2016_6151.pdf

Domingo, B. y Palomares, A. (2013) La necesidad de nuevas estrategias metodológicas en la educación inclusiva del alumnado autista. ENSAYOS. Revista de la Facultad de Educación de Albacete, 28. Recuperado de: http://www.revista.uclm.es/index.php/ensayos

Dos Santos, M. (2003). Pedagogía de la diversidad: Desafío del mundo contemporáneo. Santiago de Chile: Lom Ediciones.

Doval, M. I., Martinez- Figueira, M. E. y Raposo, M. (2013). La voz de sus ojos: la participación de los escolares mediante Fotovoz. Revista de Investigación en Educación, 11 (3), 150-171. Recuperado de: http://reined.webs.uvigo.es/ojs/index.php/reined/article/view/741

Durán, D. (2009). El aprendizaje entre alumnos como apoyo a la inclusión. En C. Giné (Coord.), La educación inclusiva (pp. 95-111). Barcelona: Horsori.

$\mathbf{E}$

Echavarría, A.L. y Hernández, C. M. (2013). Uso de plataformas social media en la práctica docente universitaria: Investigación biográfico-narrativa en un estudio de caso. Signo y Pensamiento, 32 (63), 154-168. Recuperado de: https://search.proquest.com/docview/1470088967?accountid=15297

Edwards, M., Perry, B., Janzen, K. y Menzies, C. (2012). Using the artistic pedagogical technology of photovoice to promote interaction in the online post-secondary classroom: The students' perspective. Electronic Journal of $e^{-}$ Learning, 10 (1), 32-43. Recuperado de: https://www.learntechlib.org/p/55169

Echeita, G. (2011). El proceso de inclusión educativa en España. ¡Quien bien te quiere te hará llorar! CEE Participación Educativa, 18. 117-128. Recuperado de: http://www.educacion.gob.es/revistacee/pdf/n18-echeita-sarrionandia.pdf

Echeita, G. (2013). Inclusión y Exclusión Educativa. De Nuevo, "Voz y Quebranto". REICE. Revista Iberoamericana sobre Calidad, Eficacia y 
Cambio en Educación, 11(2), 99-118. Recuperado de:

http://www.rinace.net/reice/numeros/arts/vol11num2/art5.pdf

Echeita, G. y Calderon, I. (2014). Obstáculos a la inclusión: cuestionando concepciones y prácticas sobre la evaluación psicopedagógica. Ámbits de psicopedagogia $i$ orientación, 41 (2). Recuperado de: http://ambitsdepsicopedagogiaiorientacio.cat/es/obstaculos-a-la-inclusioncuestionando-concepciones-y-practicas-sobre-la-evaluacion-psicopedagogica/

Echeita, G. y Simón, C. (2007). La contribución de la educación escolar a la calidad de vida de las personas con discapacidad. Ante el desafío de su inclusión social. En R. de Lorenzo y L. C. Pérez Bueno, Tratado sobre Discapacidad (pp.1103-1134). Madrid: Thomson \& Aranzadi

Echeita, G., Simón, C., López, M., y Urbina, C. (2013). Educación inclusiva. Sistemas de referencia, coordenadas y vórtices de un proceso dilemático. Discapacidad e inclusión. Manual para la docencia, 329-357.

Echeita, G., Simón, C., Verdugo, M. A., Sandoval, M., López, M., Calvo, I. y González, F. (2009). Paradojas y dilemas en el proceso de inclusión educativa en España. Revista de Educación, 349: 153-178. Recuperado en: http://www.revistaeducacion.mec.es/re349/re349_08.pdf

Echeita, G. y Verdugo, M.A. (coord.) (2004). La "Declaración de Salamanca" sobre Necesidades Educativas Especiales diez años después: valoración y prospectiva. Salamanca. INICO. Recuperado en: http://sid.usal.es/idocs/F8/FDO9045/declaracion_salamanca_completo.pdf

EDAD (2008). Encuesta sobre Discapacidades, Autonomía personal y situaciones de Dependencia. Madrid. Instituto Nacional de Estadística. Recuperado de: $\mathrm{http} / / / \mathrm{www}$. ine.es/jaxi/menu.do?L=0\&type=pcaxis\&path=/t15/p418\&file=ineb ase

Elliot, J. (1999). La investigación-acción en educación. Madrid: Morata.

Emmel, N. \& Clark, A. (2011). Learning to Use Visual Methodologies in Our Research: A Dialogue between Two Researchers. Forum Qualitative Social Research, 72(1), Art. 36. Recuperado de: http://nbnresolvirm.de/urn:nbn:dc:0114-fqsl 101360

Eisner, E.W. (1990). The enlightened eye. Qualitative inquiry and the enhancement of educational practice. Prentice Hall, Inc.

Eraso Insuasty, A. D., Muñoz, C. A., y Salcedo Rodríguez, J. (2016). La educación inclusiva para la transformación de barreras a oportunidades desde los patrones culturales y las prácticas sociales en la IE José Antonio Galán del municipio de Iles-Nariño. Centro de Recursos de Información Digital: Universidad de Manizales.

Erlandson, D. A., Harris, E. L., Skipper, B.L. y Allen, S. D. (1993). Doing naturalistic inquiry. London: Sage.

Escudero, J.M. (2016). Inclusión y exclusión educativa: Realidades, miradas y propuestas. Valencia: Nau Llibres.

Essomba, M. (2009). Liderar escuelas interculturales e inclusivas. Barcelona: Graó. 
Esteban-Guitart, M. y Llopart, M. (2016). La inclusión educativa a través de la aproximación de los fondos de conocimiento e identidad. Revista Nacional e Internacional de Educación Inclusiva. 9 (3), 145-157.

Esteban-Guirart, M., Pallisera, M., Fullana, J., y Gifre, M. (2017). Más allá de la palabra escrita. La utilización de recursos visuales como estrategia metodológica en ciencias sociales y de la educación. REMA Revista electrónica de metodología aplicada, 22 (1), 1-22. doi: 10.17811/rema.22.1.2017.1-22

Estevez, B. (2015). La inclusión educativa del alumnado con TDA/TDAH. Rompiendo con las barreras curriculares y organizativas en los centros escolares de Educación Primaria. (Tesis doctoral, Universidad de Granada, España). Recuperado de: http://digibug.ugr.es/handle/10481/41749\#.WGOwq_nhDIU

Etxeberria, X. (2011). La Convención de la ONU sobre los derechos de las personas con discapacidad: la perspectiva ética. Revista Española sobre Discapacidad Intelectual, $\quad 42 \quad$ (1), 33-46. Recuperado de: https://dialnet.unirioja.es/servlet/articulo?codigo $=3618012$

$\mathbf{F}$

Fantova, F. (2000). Significado y aplicación de los apoyos en el nuevo enfoque sobre la discapacidad intelectual. X Congreso Internacional CONFE 2000. México.

Fantova, F. (2007). Ocio, discapacidad e inclusión. Un esquema de referencia. En E.D. Eusse (2007). Educación física y discapacidad. Prácticas corporales inclusivas. Medellín: Funámbulos Editores.

Farough, S. (2006). Believing is seeing: The matrix of vision and white masculinities. Journal of Contemporary Ethnography, 35 (1), 51- 83. doi: $10.1177 / 0891241605280494$

Federació Catalana Pro Persones amb Retard Mental (APPS). (2007). Estudio sobre las necesidades de las familias de personas con discapacidad Intelectual en Cataluña. Barcelona: Universidad Ramón Llull

Fernández, I. (2003). Creatividad, arte terapia y autismo. Un acercamiento a la actividad plástica como proceso creativo en niños autistas. Arte, individuo y sociedad, 15, 135-152. Recuperado de: http://revistas.ucm.es/index.php/ARIS/article/view/ARIS0303110135A/5837

Fernández Batanero, J. M. (2009). Un currículo para la diversidad. Madrid: Editorial Síntesis.

Fernández Batanero, J.M. (2015). Atención a la Diversidad en el Aula de Educación Infantil. Madrid: Paraninfo.

Fernández de la Iglesia, C.J., Fiua, M.J. y Zabalza, M.A. (2013). A propósito de cómo analizar las barreras a la inclusión desde la comunidad educativa. Revista de Investigación en Educación, 11 (3), 172-191. Recuperado de: http://reined.webs.uvigo.es/ojs/index.php/reined/article/viewFile/742/309

Fernández Enguita, M. (2001). Educar en tiempos inciertos. Madrid: Morata. 
Fernández Santamaría, R. (2011). El camino hacia la integración. Participación Educativa, 18, 79-90. Recuperado de: http://www.educacion.gob.es/revistacee/pdf/n18-fernandez-santamaria.pdf

Fernández, J. y Santos, M. (1992). Evaluación cualitativa de programas de educación para la salud. Málaga: Ediciones Aljibe

FESPAU Confederación Española de Autismo (2012). Autismo. Recuperado de: http://www.fespau.es/autismo-tea.html

Fisher, D., Roach, V. \& Frey, N. (2002). Examining the general programmatic benefits of inclusive schools. International Journal of Inclusive Education, 6 (1), 63-78.doi: 10.1080/13603110010035843

Fisk, M., Kendall, P. L., \& Merton, R. K. (1998). Propósitos y criterios de la entrevista focalizada (traducción de Consuelo del Val y Javier Callejo).Empiria. Revista de metodología de ciencias sociales, 1, 215-227. Recuperado de: http://revistas.uned.es/index.php/empiria/article/view/740

Flores Díaz, R. (2007). Las emociones en el niño autista a través del cómic: estudio de caso. (Tesis Doctoral, Universidad de Sevilla, España). Recuperado de: http://fondosdigitales.us.es/tesis/tesis/482/las-emociones-en-el-nino-autista-atrl

Flick, U. (2004). Introducción a la investigación cualitativa. Madrid: Morata.

Flick, U. (2006). An Introduction to Qualitative Research (3rd Ed). Londres: Sage.

Flick, U. (2007). Introducción a la investigación cualitativa. Madrid: Morata.

Flick, U. (2014). La gestión de la calidad en Investigación Cualitativa. Madrid: Morata.

Flick, U. (2015). El diseño de Investigación Cualitativa. Madrid: Morata.

Flores Díaz, R. (2013). Desarrollo de la creatividad en alumnos con talento especial. Aula de Encuentro, 15, 43-65. Recuperado de: http://revistaselectronicas.ujaen.es/index.php/ADE/article/view/1006

Florian, L. \& Black-Hawkins, K. (2011). Exploring Inclusive Pedagogy. British Educational Research Journal, 37(5), 813-828. doi: 10.1080/01411926.2010.501096

Frontera, M. (2010). Cuarta propuesta: El desafío del desarrollo. Alumnos con síndrome de Aspeger. Necesidades y respuesta educativa. En E. Arrimadas, S. Ramos y A. DíazGüemes (Coords.), Desafíos de la diferencia en la escuela (pp. 179-252). Madrid: Edelvives.

Forner, A., y Latorre, A. (1996). Diccionario terminológico de investigación educativa y psicopedagógica. Barcelona: EUB.

Foro de Vida Independiente y Divertad (2016). Foro de vida independiente y Divertad. Recuperado de: http://forovidaindependiente.org/el_modelo_de_la_diversidad/ 
FVID (2016). Foro de vida independiente $y$ Divertad. Recuperado de: http://forovidaindependiente.org/el_modelo_de_la_diversidad/

\section{G}

Gabel, S. \& Peters, S. (2004). Presage of a new paradigm: Beyond the social model of disability toward resistance theories of disability. Disabiliy and Society, 19, 571-596. doi: 10.1080/0968759042000252515

Galeano, M.E. (2004). Diseño de proyectos de investigación cualitativa. Medellín: Fondo Editorial Universidad EAFIT.

Gallego, C. (2011). El apoyo inclusivo desde la perspectiva comunitaria. Revista Interuniversitaria de Formación del Profesorado, 25(1), 93-109. Recuperado de: http://www.redalyc.org/pdf/274/27419147006.pdf

Gallego, C. (2015). Conceptualización y evolución de la atención a la diversidad. En Fernández Batanero, J.M. (ed.). Atención a la diversidad en el aula de educación infantil (pp.3-32). Madrid: Ediciones Paraninfo.

Garbutt, R., Tattersall, J., Dunn, J. \& Boycott-Garnett, R. (2009). Accessible article: involving people with learning disabilities in research. British Journal of Learning Disabilities, 38, 21-34. doi: 10.1111/j.1468-3156.2009.00556.x

García, J.V. (coord.) (2003). El movimiento de vida independiente. Experiencias Internacionales. Madrid: Fundación Luís Vives. Recuperado de: http://www.independentliving.org/docs6/alonso2003.pdf

García, C. (2003). Segregación, integración y exclusión. Bordón, 55 (1), 9-26.

García, A. J. (2008). El movimiento de vida independiente: experiencias internacionales. Madrid: Fundación Luís Vives.

García, I. (2008). Educación inclusiva en Latinoamérica y el Caribe. El caso mexicano. Banco Mundial-UASLP. En prensa.

García, M.,A. y Doñate, A. M. (2008). La utilización de las narraciones e historias en la práctica docente. Cuadernos De Trabajo Social, 21, 247-261. Recuperado de: https://search.proquest.com/docview/213904152?accountid=15297

García-Gómez, A., Risco, M. L., Rubio, J. C., Guerrero, E., y García-Peña, I. M. (2014). Efectos de un programa de equitación Adaptada y terapéutica en un grupo de niños con trastornos del espectro autista. Electronic Journal of Research in Educational Psychology, 12 (32), 107-128. Recuperado de: http://www.redalyc.org/articulo.oa?id=293130506005

García Jorba, J.M. (2000). Diarios de campo. Colección Cuadernos metodológicos, 31. CIS: Madrid.

García Luque, A. (2016). La LOMCE bajo una mirada de género/s: ¿Avances o retrocesos en el s. XXI? Revista Educación, Política y Sociedad, 1 (2), 100-124. Recuperado de: http://hdl.handle.net/10486/674642

Garreta, J. (2003). El espejismo intercultural. La escuela de Cataluña ante la diversidad cultural. Madrid: CIDE. 
Garreta, J. (2007). La participación de los progenitores en las instituciones escolares: realidades e imágenes. Lleida: Universitat de Lleida.

Garreta, J. (2015). La comunicación familia- escuela en Educación Infantil y Primaria. Revista de Asociación de Sociología de la Educación, 8, 1, 71-85. Recuperado de: https://ojs.uv.es/index.php/RASE/article/view/8762

Gauntlett, D. (2007). Creative explorations: New approaches to identities and audiences. London: Routledge.

Gebretsadik Y. (2015). Towards more inclusive university curricula: the learning experiences of visually impaired students in higher education institutions of Ethiopia, (Tesis doctoral. University of South Africa, Pretoria). Recuperado de: http://hdl.handle.net/10500/19196

Gerschel, L. (2003). Igualdad de oportunidades y necesidades educativas especiales: equidad e inclusión. En C. Tistone, L. Florian \& R. Rose (Coord.). Promoción y desarrollo de prácticas educativas inclusivas (pp. 101-119). Madrid: EOS

Geschwind, D. H. (2009). Advances in autism. Annual review of medicine, 60, 367380. doi: 10.1146/annurev.med.60.053107.121225

Gestwicki, C. (2016). Home, school \& Community Relations (9th edition). Boston: Cengage Learning.

Gibbs, G. (2012). El análisis de datos cualitativos en investigación cualitativa. Madrid: Morata.

Gimeno Sacristán, J. (2001). Educar y convivir en la cultura global. Madrid: Morata.

Gimeno Sacristán, J. (2014). La LOMCE ¿una ley más de educación? Revista interuniversitaria de formación del profesorado, 81 (28.3), 31-44. Recuperado de: https://dialnet.unirioja.es/descarga/articulo/5007012.pdf

Gimero Soria, X. (2005). El diari d'aula com a eina per a la formació i l'avaluació en l'educació superior dels professionals de l'educació. En IDES: Innovació Docent en Educació Superior. Universitat Autónoma de Barcelona. Disponible en: http://www.uab.cat/iDocument/diariaula.pdf

Giroux, H.A. (1993). La escuela y la lucha por la ciudadanía: pedagogía crítica de la época moderna. Madrid, Siglo XXI.

Giroux, H. (1992). Teoría y Resistencia en Educación. Ciudad de México: Siglo XXI Editores

Gitlow, L. (2001). Occupational therapy faculty attitudes toward the inclusion of students with disabilities in their educational programs. The Occupational Therapy Journal of Research, 21(2), 115-131. Recuperado de: http://journals.sagepub.com/doi/abs/10.1177/153944920102100206

Glaser B.G. (1978). Theoretical Sensitivity: Advances in the Methodology of Grounded Theory. Sociology Press, Mill Valley, CA. 
Glazzard, J. (2011). Perceptions of the barriers to effective inclusion in one primary school: voices of teachers and teaching assistants. Support for Learning, 26, 56-63. doi:10.1111/j.1467-9604.2011.01478.x

Glover-Graf, N. (2000). Student-produced photography: A constructivist approach to teaching psychosocial aspects of disability. Rehabilitation Education 14(3), 285-296.

Gómez, G.E. y Molina, M.E. (2006). Evaluación ética de proyectos de investigación: una experiencia pedagógica. Universidad de Antioquia, Colombia. Investigación y Educación en Enfermería, 24 (1), 68.77. Recuperado de: http://www.redalyc.org/articulo.oa?id=105215400006

Gómez Puerta J.M. (2013). Expectativas laborales de las personas con discapacidad intelectual. En Investigación e Innovación Educativa al Servicio de Instituciones y Comunidades Globales, Plurales y Diversas: Actas del XVI Congreso Nacional/II Internacional Modelos de Investigación Educativa de la Asociación Interuniversitaria de Investigación Pedagógica (pp. 921-927). Alicante. Recuperado de: https://www.uv.es/aidipe/congresos/Actas_XVI_Congreso.pdf

González, A. (2003). Los paradigmas de investigación en ciencias sociales. ISLAS, 45 (138), 125-135.

González, M. (2003). Aspectos éticos de la investigación cualitativa. Revista Iberoamericana de Educación, 29, 85-103. Recuperado de: http://www.redalyc.org/pdf/800/80002905.pdf

González, R., Medina, M.C. y Domínguez, M.C. (2016). Ventajas del tratamiento inclusivo de la diversidad: perspectivas de los principales agentes encargados de su desarrollo. Enseñanza \& Teaching, 34, 2: 131-148. Recuperado de: http://revistas.usal.es/index.php/0212-5374/article/view/et2016342131148

González, M.F. y Padilla-Carmona, M.T. (2014). Investigación narrativa: las historias de vida. En Ballesteros, B. (coord.), Taller de investigación Cualitativa. Madrid: UNED.

González Rodríguez, B. (2000). Nuevas perspectivas en la explotacion y aprovechamiento de los datos secundarios En M. García Ferrando, J. Ibáñez y F. Alvira Martín (comps.). El análisis de la realidad social: Métodos y técnicas de investigación ( $3^{\mathrm{a}} \mathrm{ed}$ ) (pp. 245-273). Madrid: Alianza.

Goodson, I.F. (1996). Representing teachers. Essays in teacher'lives, stories and histories. Nueva York: Teachers Colleges Press.

Goopy, S., \& Lloyd, D. (2005). Documenting the human condition in everyday culture: Finding a partnership between ethnography and photo-documentary. International Journal of the Humanities, 3 (5), 33-38. Recuerado de: https://experts.griffith.edu.au/publication/ndf76291f1ca217d27586b7af26cdc3 48

Gorbeña, S. (1999). Prácticas de ocio de las personas con discapacidad: resultados preliminares ¿hasta dónde llega la equiparación de oportunidades? En: M. Cuenca. Ocio y equiparación de oportunidades (pp. 35-52). Bilbao: Universidad de Deusto 
Granada, M., Pomés, M.P. y Sanhuerza, S. (2013). Actitud de los profesores hacia la inclusión educativa. Papeles de Trabajo, 25, 51-59. Recuperado de: http://www.scielo.org.ar/scielo.php?script=sci_arttext\&pid=S185245082013000100003

Graziano, K. (2004). The power of teaching and learning with documentary photography and storytelling: a photovoice case study. En L. Cantoni y C. McLoughlin (eds.), Proceedings of World Conference on Educational Multimedia, Hypermedia and Telecommunications (pp. 3881-3886). Chesapeake, VA: AACE.

Greertz, K.J. (1989). El antropólogo como autor. Barcelona: Paidós.

Guba, E.G. \& Lincoln, Y.S. (1989). Fourth Generation Evaluation. Newbury Park, Sage.

Guba, E., y Lincoln, Y. (2002). Paradigmas en competencia en la investigación cualitativa. En C. Denman, y J.A. Haro (comp.) Por los rincones. Antología de métodos cualitativos en la investigación social (pp. 113-145). Sonora: Colegio de Sonora.

Guerrero, A. \& Tinkler, T. (2010). Refugee and Displaced Youth Negotiating Imagined and Lived Identities in a Photography- Based Educational Project in the United States and Colombia. Anthropology \& Education Quarterly, 41(1), 55-74. doi: 10.1111/j.1548-1492.2010.01067.x

Gutiérrez, I. (2006). Prólogo. En R.E. Aranda (coord.), Educación especial: áreas curriculares para alumnos con necesidades educativas especiales, Madrid: Pearson-Prentice Hall.

Guzmán-Valenzuela, C. M. (2014). Polos epistemológicos, uso y construcción de teoría en investigación cualitativa en educación. Magis, Revista Internacional de Investigación en Educación, 7(14), 15-28.

\section{$\mathbf{H}$}

Habermas, J. (1986). Conocimiento e interés. Madrid: Taurus.

Hahn, H. (1986). Public support of rehebilitations programs: the analysis of US Disabily Policy. Disability, Handicap, \& Society, 1 (2), 121-138. Recuperado de: http://www.tandfonline.com/doi/abs/10.1080/02674648666780131?journalCode $=$ cdso19

Hamilton, L.C. (2010). Teachers, narrative identity and ability constructs: exploring dissonance and consensus in contrasting shcools system. Research Papers in Education, 25 (4), 409-431. doi: http://dx.doi.org/10.1080/02671520903045574

Hammersley, M. y Atkinson, P. (1983). Etnografía. Barcelona: Paidós.

Happé, F. \& Charlton, R. (2011). Aging in Autism Spectrum Disorders: A MiniReview. Gerontology, 58(1), 70-78. doi: 10.1159/000329720 
Harper, D. (2002). Talking about pictures: A case for photo elicitation. Visual Studies, 17 (1), 13-26. doi: 10.1080/14725860220137345

Hartley, J. \& Benington, J. (2000). Co-research: A new methodology for new times. European Journal of Work and Oganizational Psychology, 9 (4). 463-476. doi: $10.1080 / 13594320050203085$

Harwood, V., \& Allan, J. (2014). Psychopathology at school: Theorizing mental disorders in education. Abingdon: Routledge

Hasler, F., Barnes, C. y Zarb, G. (2003). El concepto de la vida independiente a través de tres visiones: filosófica, socio-política y económica. En J.V. García, (coord.), El movimiento de vida independiente. Experiencias Internacionales (pp.55-68) Madrid: Fundación Luís Vives. Recuperado de: http://www.independentliving.org/docs6/alonso2003.pdf

Hernández, R., Fernández, C. y Baptista, P. (2006). Metodología de la Investigación. México: Mc Graw Hill

Hernández de la Torre, E. y Medina Herasme, R. (2014). Análisis de los obstáculos y barreras para el cambio y la innovación en colaboración en los centros de secundaria: un estudio de caso. Revista de Investigación Educativa, 32 (2), 499-512. doi: 10.6018/rie.32.2.172041

Herrera, C. (2015). La historia de vida de Shila Delargo. Análisis sociopedagógico de un proceso de reforma juvenil. (Tesis doctoral. Universidad de Málaga, España). Recuperado de: http://riuma.uma.es/xmlui/handle/10630/9043

Herrera, G. y Abellán, R. (2008). Nuevas tecnologías para favorecer la inclusión: soluciones concretas. En: M.D. Hurtado y F.J. Soto (coords.), La igualdad de oportunidades en el mundo digital. Murcia: Universidad Politécnica de Cartagena.

Heward, W.L. (2000). Niños excepcionales. Una introducción a la educación especial. Madrid: Prentice Hall.

Heyd-Metzuyanim, E. (2013). The co-construction of learning difficulties in mathematics -teacher- student interactions and their role iin the development of disabled mathematical identity. Educational Studies in Mathematics, 83 (3), 341-368. doi: 10.1007/s10649-012-9457-Z

Hodder, I. (1994). The interpretation of documents and material culture. En N. Denzin \& Lincoln (eds.), Handbook of qualitative research (pp. 393-402). Thousand Oaks CA: Sage.

Holburn, S. (2003). Cómo puede la ciencia evaluar y mejorar la planificación centrada en la persona. Siglo Cero, 34 (4) 208, 48-64. Recuperado de: http://riberdis.cedd.net/handle/11181/3077

Holt, L. (2003). Disabling children in primary schoool microspaces: geographies of inclusion and exclusión. Health and Place, 9, 119-128. doi: 10.1016/S13538292(02)00066-7 
Hopkins, L. (2011). The path of least resistance: a voice-relational analysis of disabled students' experiences of discrimination in English universities. International Journal of Inclusive Education, 15 (7), 711-727. doi: 10.1080/13603110903317684

Horne, P. E. \& Timmons, V. (2009). Making it work: Teachers' perspectives on inclusion. International Journal of Inclusive Education, 13, 273-286. doi: 10.1080/13603110701433964

Huamán, H.G. (2005). Manual de técnicas de investigación. Conceptos y aplicaciones. Lima: Ipladees.

Huete, A. y Pallero, M. (2016). La situación de las personas con capacidad intelectual límite en España, Revista Española de Discapacidad, 4 (I), 7-26. doi: http://dx.doi.org/10.5569/2340-5104.04.01.01

Husen, T. (1988). Paradigmas de la investigación en educación. Un informe del estado de la cuestión. En I. Dendaluce (Ed.), Aspectos metodológicos de la investigación educativa (pp. 46-59). Madrid: Narcea.

Illán, N. (2013). Discapacidad y vida independiente. Revista Latinoamericana de Educación Inclusiva, 7 (1), 17-19. Recuperado de: http://www.rinace.net/rlei/numeros/vol7-num1.html

Illán, N. y Molina, J. (2013). La filosofía de Escuelas de Vida. Sus aportes para la promoción de la vida independiente en el colectivo de personas con discapacidad intelectual. Revista latinoamericana de Educación Inclusiva, 7 (1), 23-38. Recuperado de: http://www.rinace.net/rlei/numeros/vol7num1.html

Intenational Institue for Higher Education in Latin America and the Caribbean (2006). Informe sobre la Educación Superior en América Latina y el Caribe 2000-2005: la metamorfosis de la educación superior (IESALC) Recuperado de: http://www.mineducacion.gov.co/cvn/1665/article-100800.html

Jacob, E. (1988). Clarifying qualitative research: A focus on traditions. Educational Researcher, 17(1), 16-24. Recuperado de:

http://www.indiana.edu/ educy520/readings/jacob88.pdf

Janesick, V.J. (1998). The dance of qualitative research design: methaphor, methodolatry, and meaning. In N.K. Denzin \& Y.S. Lincoln (Eds). Strategies of qualitative inquiry. (pp. 35-85). Thousand Oaks, Sage

Jenkins, J.R., Antil, L.R., Wayne, S.K. \& Vadasy, P.F. (2003). How cooperative learning works for special education and remedial students. Exceptional children, 69 (3), 279-292.doi: 10.1177/001440290306900302 
Jiménez-Domínguez, B. (2000).Investigación cualitativa y psicología social crítica. Contra la lógica binaria y la ilusión de la pureza. Dossier Investigación cualitativa en Salud. Centro de Estudios Urbanos. Universidad de Guadalajara. Recuperado de:

https://es.scribd.com/document/234711447/Investigacion-cualitativa-ypsicologia-social-critica-docx

Jiménez Lara, A. (2007). Conceptos y tipologías de la discapacidad. Documentos y normativas de clasificación más relevantes. En R. Lorenzo y L. Cayo Pérez (eds.), Tratado sobre discapacidad. Cizur Menor (Navarra): Aranzadi.

Jiménez-Rodrigo, M.L. y Guzmán-Ordaz, R. (2016). Defendiendo a los otros: relatos académicos sobre la diversidad en la escuela. Convergencia Revista de Ciencias Sociales, 71, 13-39. Recuperado de: http://convergencia.uaemex.mx/article/download/3987/2654

Jiménez, F. y Vilà, M. (1999). La investigación en educación especial y en integración escolar. Revista de Educación Especial, 26, 127-148.

Jobling, A., Moni, K.B. \& Nolan, A. (2000). Understanding friendship: Young adults with Down Sindrome exploring relationships. Jounal of Intellectual \& Developmental Disability, 25 (3), 235-245. Recuperado de: http://www.tandfonline.com/doi/abs/10.1080/13269780050144299

Johnson, D. W., Johnson, R. T. y Holubec, E. J. (1999). El aprendizaje cooperativo en el aula. Barcelona: Paidós

Johnston, K. (2009). No longer researching about us without us: a researcher's reflection on rights and inclusive research in Ireland. British Journal of Learning Disabilities, 37, 250-256. doi: 10.1111/j.1468-3156.2009.00579.x

Joubert, I. (2012). Children as photographers: Life experiences and the right to be listened to. South African Journal of Education, 32 (4), 449-464. Recuperado de: http://www.scielo.org.za/scielo.php?script=sci_arttext\&pid=S025601002012000400011

Jurado, M.D. (2011). El diario como un instrumento de autoformación e investigación. Revista Qurriculum, 24, 173-200.

$\mathbf{K}$

Kam Pum, D. (2008). Do contacts make a difference?: The effects of mainstreaming on student attitudes toward people with disabilities. Research in Developmental Disabilities, 29 (1), 70-82. doi: 10.1016/j.ridd.2006.11.002

Kaplan, I. \& Howes, A. (2004). 'Seeing Through Different Eyes': exploring the value of participative research using images in schools. Cambridge Journal of Education, 34 (2), 143- 155. Recuperado de: http://www.tandfonline.com/doi/abs/10.1080/03057640410001700534

Karanth, P. \& Chandhok, T. (2013). Impact early intervention on children with autism spectrum disorders as measured by inclusion and retention in mainstream schools. Indian Journal of Pediatry, 80 (11), 911-919. doi:10.1007/s12098-013-1014-y 
Keats, P. (2009). Multiple text analysis in narrative research: visual, written, and spoken stories of experience. Qualitative Research, 9, 181-195. Recuperado de: http://journals.sagepub.com/doi/abs/10.1177/1468794108099320.

Kemmis, S. y Mctaggart, R. (1988). Cómo planificar la investigación-acción. Barcelona: Laertes.

Klin, A., Klaiman, C. y Jones, W. (2015). Rebajar la edad de diagnóstico del autismo: la neurociencia del desarrollo social afronta un importante problema de salud pública. Revista Neurología; 60 (1), 3-11. Recuperado de: http://www.neurologia.com/articulo/2015019

Killion, C. (2001). Understanding cultural aspects of health through photography. Nursing Outlook 49, 50-54. doi: 10.1067/mno.2001.110011

King, N. (1998). Template analysis. In G. Symon \& C. Cassell (Eds.), Qualitative methods and analysis in organizational research: A practical guide (pp. 118134). London: Sage.

Kñallinsky, E. (2003). Familia-Escuela: una relación conflictiva. El Guiniguada, 12, 71- 93. Recuperado de:

http://ojsspdc.ulpgc.es/ojs/index.php/ElGuiniguada/article/view/615

Kirk, J. \& Wall, C. (2010). Resilience and loss in work identities: a narrative analysis of some retired teachers' work-life histories. British Educational Research Journal, $36 \quad$ (4), 627-641. doi: http://dx.doi.org/10.1080/01411920903018216

Kiuppis, F. (2014). Why (not) associate the principle of inclusion with disability? Tracing connections from the start of the 'Salamanca Process'. International Journal of Inclusive Education, 18 (7), 746-761. Recuperado de: http://www.tandfonline.com/doi/abs/10.1080/13603116.2013.826289

Kroeger, S., Embury, D., Cooper, A., Brydon-Miller, M., Laine, C. \& Johnson, H. (2012). Stone soup: Using co-teaching and photovoice to support inclusive education. Educational Action Research, 20 (2), 183-200. doi: 10.1080/09650792.2012.676285

Kvale, S. (2007). Doing interviews. Thousand Oaks, CA: Sage Publications

Kvale, S. (2011). Las entrevista en Investigación Cualitativa. Madrid: Morata.

\section{$\mathbf{L}$}

Lang, R., Koegel, L.K., Ashbaugh, K., Regester, A., Ence, W. \& Smith, W. (2010). Physical exercise and individuals with autism spectrum disorders: A systematic review. Research in Autism Spectrum Disorders. 4 (4), 565-76. doi: 10.1016/j.rasd.2010.01.006

Laparra, M., Obradors, A., Pérez, B., Pérez Yruela, V.R., Renes, V., Sarasa, S., Subirats, J. y Trujillo, M. (2007). Una propuesta de consenso sobre el concepto de exclusión. Implicaciones metodológicas. Revista Española el Tercer Sector, $5,15-57$. 
Latorre, A., Del Rincón, D., y Arnal, J. (1996). Bases metodológicas de la investigación educativa. Barcelona: GR92.

Latz, A. O. (2012). Understanding the educational lives of community college students: A photovoice project, a bourdieusian interpretation, and habitus dissonance spark theory. Current Issues in Education, 15 (2). 1- 21. Recuperado de http://cie.asu.edu/ojs/index.php/cieatasu/article/v iew/836

Law, M., Petrenchik, T., King, G., \& Hurley, P. (2007). Perceived environmental barriers to recreational, community, and school participation for children and youth with physical disabilities. Archives of physical medicine and rehabilitation, 88 (12), 1636-1642. doi: 10.1016/j.apmr.2007.07.035

Lázaro, Y. (1999). La formación de los profesionales que trabajan en las asociaciones. En M. Cuenca. Ocio y equiparación de oportunidades. (53-60). Bilbao: Universidad de Deusto

Lázaro, Y. (2008) El derecho al ocio de las personas con discapacidad en la normativa autonómica española. Educación y diversidad. Revista interuniversitaria de investigación sobre discapacidad e interculturalidad, 2, 167212.

Leandro, A. L. A. L., Costa, M. A. C., \& Aquino, S. S. (2012). Narrativas de formação, (auto) biografia e incluso: experiências de profesores e alunos no ensino médio. Holos, 28 (2), 225-233. Recuperado de: https://search.proquest.com/docview/1115550620?accountid=15297

Leipert, B. y Anderson, E. (2012). Rural nursing education: a photo voice perspective. Rural \& Remote Health, 12 (2), 1-11. Recuperado de: https://www.ncbi.nlm.nih.gov/pubmed/22668083

Leite, A. (2011). Historias de vida de maestros y maestras. La interminable construcción de las identidades: vida personal, trabajo y desarrollo profesional. (Tesis doctoral, Universidad de Málaga, España). Recuperado de: http://riuma.uma.es/xmlui/handle/10630/4678

Leite, A., Cortés, P. y Rivas, J.I. (2016) Narrativa y creatividad en la universidad: ¿Es posible transitar otros caminos en la enseñanza y el aprendizaje? En P. Cortés, M.J. Márquez (eds.) Creatividad, comunicación y educación. Más allá de las fronteras del saber establecido. (pp.151-164). Málaga: Universidad de Málaga.

Lewis-Beck, M.S., Bryman, A. \& Liao, F.T. (2004). The SAGE Encyclopedia of social science research methods. ( $3^{\text {rd }}$ ed). CA: Sage Publication.

Lincoln, Y.S. (1991). The Detached Observer and the Passionate Participant: Discourses in Inquiry and Science. Chicago: American Educational Research Association.

Limbach-Reich, A. (2015). Reviewing the Evidence on educational inclusion of students with disabilities: Differentiating ideology from evidence. International Journal of Youth and Family Studies, 6 (3), 358-378. Recuperado de: https://journals.uvic.ca/index.php/ijcyfs/article/view/13560 
Lledó, A., Lledó, G. y Pomares, J. (2011). Las necesidades del alumnado con síndrome de Asperger: orientaciones y propuestas desde una innovación inclusiva. En R. Roig Vila y C. Lavene (Eds.), La práctica educativa en la sociedad de la información. Innovación a través de la investigación (pp. 243254). Alcoy: Marfil.

Llopis, R. (2004). Grupos de discusión. Madrid: ESIC Editorial.

López, R., y Moriña, A. (2015). Hidden voices in Higher Education: inclusive policies and practices in Social Science and Law Classrooms. International Journal of Inclusive Education. 19 (4), 365-378. doi: $10.1080 / 13603116.2014 .935812$

López, G. y Abad, J. (2000). El trabajo en el aula con niños pequeño con autismo. En A. Riviere y J. Martos (Eds.), El niño pequeño con autismo (pp. 107-126). Madrid: APNA.

López González, M. (2010). Mujeres con discapacidad. Mitos y realidades en las relaciones de pareja y en la maternidad. Madrid: Narcea ediciones.

López Górriz,I. (1997). Experiencias de innovación pedagógica. Hacia la formación del profesorado que pide la LOGSE. Ed. CCS: Madrid.

López Górriz, I., Gabari Gambarte, I., Vega, A. y Jurado, M.D. (2007). El diario como instrumento transversal de investigación, evaluación y formación en los procesos educativas de innovación universitaria. En F. Etxeberria, L. Sarasola, J.F. Lukas, J. Etxeberria y A. Martxueta. Actas del XII Congreso Nacional de Modelos de Investigación Educativa: Convivencia, Equidad, Calidad (pp. 79-91). Recuperado de: http://www.uv.es/aidipe/congresos/XIII_Congreso.pdf

López Melero, M. (1997). Un proyecto educativo en/para la diversidad (la escuela un lugar para enseñar a pensar y a descubrir la cultura). En N. Illán Romeu y A. García Martínez (coords.), La diversidad y la diferencia en la educación secundaria obligatoria: Retos para el siglo XXI. (pp.227 -267) Málaga: Aljibe.

López Melero, M. (2008). Ética y escuela pública: ¿Es posible una escuela sin exclusiones? En J. Ipland (eds.), La atención a la diversidad: diferentes miradas. (pp. 13-53). Huelva: Hergué.

López, S., y Rivas, R. (2014). El trastorno del espectro del autismo: Retos, oportunidades y necesidades. Informes Psicológicos, 14(2), 13-31. Recuperado de:

https://revistas.upb.edu.co/index.php/informespsicologicos/article/view/5485

Lozano, J. y Alcaraz, S. (2010). La enseñanza de emociones y creencias a alumnos con trastornos del espectro autista: una investigación colaborativa. Profesorado. Revista de currículum y formación del profesorado, 14 (1), 367382.

Luque Parra, D.J. y Luque Rojas, M.J. (2015). Relaciones de amistad y solidaridad en el aula. Un acercamiento psicoeducativo a la discapacidad en un marco inclusivo. Revista Mexicana de Investigación Educativa. 20 (65), 369-392. Recuperado de: http://www.scielo.org.mx/pdf/rmie/v20n65/v20n65a3.pdf

Luttrell, W., \& Chalfen, R. (2010). Lifting up voices of participatory visual 
research. Visual Studies, 25 (3), 197-200. doi: 10.1080/1472586X.2010.523270

M

MacDonald, K. \& Tipton, C. (1993). Using documents. In N. Gilbert, (comp.): Researching social life (pp. 187-200). London: Sage.

Madariaga, A. (2000). Protocolo de evaluación del grado de inclusión de las personas con discapacidad en las zonas de uso público de los espacios naturales protegidos: Descripción de la herramienta y metodología para su administración. En: M. L. Setien (coord.), Ocio, calidad de vida y discapacidad (143-152). Instituto de Estudios de Ocio. Bilbao: Universidad de Deusto.

Madariaga, A. (2009). Ocio y Discapacidad el reto de la inclusión. En DINAMIA 2009 e-dinamia: ocio y tecnología. Elche, España. Recuperado de: http://www.joveselx.com/dinamia/archivos/documentosdinamia09/texto

Madrigal-Lizano, A.M. (2015). El papel de la familia de la persona adulta con discapacidad en los procesos de inclusión laboral: Un reto para la educación especial en Costa Rica. Revista Electrónica Educare. 19(2), 197-211. doi: 10.15359/ree.19-2.12

Manson, J. \& Danby, S. (2011). Children as Experts in Their Lives: Chils Inclusive Research. Child Indication Research, 4 (2), 185-189. doi: 10.1007/s12187011-9108-4

Mantxoukas, S. (2004). Issues of respresentatioin within qualitative inquiry. Qualitative Health Research. 14 (7), 994-1007. Recuperado de: https://www.ncbi.nlm.nih.gov/pubmed/15296668

March, J., Steingold, B., Justice, S. \& Mitchell P. (1997). Follow the Yellow Brick Road. People with learning difficulties as researchers. British Journal of Learning Disabilities, 23 (3), 94-7. doi: 10.1111/j.1468-3156.1997.tb00015.x

Marchesi, A., Martín, E., Echeita, G., Babío, M., Galán, M., Aguilera, M. J. y Pérez, E. (2003). Situación del alumnado con necesidades educativas especiales asociadas a discapacidad en la Comunidad de Madrid. Madrid. Informe de Investigación presentado al Defensor del Menor de la Comunidad de Madrid. Recuperado https://www.uam.es/personal_pdi/stmaria/sarrio/DOCUMENTOS,\%20ARTIC ULOS,\%20PONENECIAS,/Estudio\%20defensor\%20menor.pdf

Mareño Sempertegui, M. y Masuero, F. (2010). La discapacitación social del "diferente". Intersticios: Revista Sociológica de Pensamiento Crítico, 4 (1), 95-105. Recuperado de: http://www.intersticios.es/article/view/4564/3700

Maritza, G. (2005). La nueva cultura de la discapacidad y los modelos de rehabilitación. Aquichán, 5 (1), 108-113. Recuperado de: http://www.scielo.org.co/scielo.php?script=sci_arttext\&pid=S1657$59972005000100011 \& \operatorname{lng}=$ en\&tlng=pt.

Maroto, G.E. (2016). Análisis de la acción tutorial de las unidades de aldeas infantiles SOS en Andalucía (Tesis doctoral. Universidad de Granada, España). Recuperado de: http://hdl.handle.net/10481/43573 
Marshall, M. (1996). Sampling for qualitative research. Family Practice, 13(6): 522525. Recuperado de: https://www.ncbi.nlm.nih.gov/pubmed/9023528

Martínez, B. (2011). Luces y sombras de las medidas de atención a la diversidad en el camino de la inclusión educativa. Revista Interuniversitaria de Formación del Profesorado, 25 (1), 165-183. Recuperado de: http://www.redalyc.org/pdf/274/27419147010.pdf

Martínez-Salgado, C (2012). El muestreo en investigación cualitativa. Principios básicos y algunas controversias. Ciência \& Saúde Colectiva, 17 (3), 613-619. Recuperado de: http://www.scielo.br/pdf/csc/v17n3/v17n3a06.pdf

Martínez González, R. A., Rodríguez Ruiz, B., y Gimeno Esteo, J.L. (2010). Áreas de cooperación entre los centros docentes y las familias. Estudio de caso. Educación siglo XXI: Revista de la Facultad de Educación, 28 (1), 127-156. Recuperado de: http://revistas.um.es/educatio/article/view/109761

Martínez Ríos, B. (2013). Pobreza, discapacidad y derechos humanos. Revista Española de Discapacidad, 1 (1), 9-32. Recuperado de: http://www.cedd.net/redis/index.php/redis/article/view/33/22

Mascarell, A. y Grau, C. (2014). Aula de Comunicación y Lenguaje en los centros de educación infantil y primaria: estudio de un caso. Actas del XI Congreso Internacional y XXXI Jornadas de Universidades y Educación Inclusiva, Castellón de la Plana, Quaderns digitals. Recuperado de: file://C:/Users/Propietario/Documents/Downloads/archivoPDF.pdf

Mayan, M. (2009). Essentials of qualitative inquiry. Walnut Creek: Left Coast Press.

McDonald, K. \& Tipton, C. (1993). Using documents. In N. Gilbert (comp.). Researching social life (pp. 187-200). London: Sage.

McGregor, G. \& Vogelsberg, R.T. (1998). Inclusive schooling practices: pedagogical and research foundations. A synthesis of the literature that informs best practices about inclusive schooling. Los Angeles, CA: Allegheny University of Health Sciences.

McKernan, J. (1999). Investigación-acción y currículum: Métodos y recursos para profesionales reflexivos. Madrid: Morata.

McMillan, J.H. y Schumacher, S. (2005). Investigación educativa. Una introducción conceptual. Madrid: Pearson Educación.

McMillan, J.H. y Schumacher, S. (2012). Investigación cualitativa: una introducción conceptual. Madrid: Pearson-Addison Wesley

Mella, S., Díaz, N., Muñoz, S., Orrego, M., y Rivera, C. (2014). Percepción de facilitadores, barreras y necesidades de apoyo de estudiantes con discapacidad en la Universidad de Chile. Revista latinoamericana de educación inclusiva, 8 (1), 63-80. Recuperado de: http://www.rinace.net/rlei/numeros/vol8-num1/art4.pdf

Mertens, D. (1998). Research methods in education and psychology. Integrating diversity with quantitative and qualitative approaches. Londres: Sage. 
Mertens, D. (2005). Research and evaluation in Education and Psychology: Integrating diversity with quantitative, qualitative, and mixed methods. Thousand Oaks: Sage.

Messiou, K. (2006). Conversations with children: making sense of marginazation in primary school setting. European Journal of Special Need Education, 21 (1), 39-54.doi: 10.1080/08856250500491807

Messiou, K. (2012) Confronting marginalisation in education: a framework for promoting inclusion. Abingdon, GB: Routledge.

Miles, M. \& Huberman, A.M. (1984). Qualitative data analysis. A source book of new methods. Beverly Hills: Sage.

Miles, M. \& Huberman, A.M. (1994). Qualitative data analysis: an expanded sourcebook. Newbury Park, CA: Sage.

Miller, D., Topping, K., \& Thurston, A. (2010). Peer tutoring in reading: The effects of role and organization on two dimensions of self-esteem. British Journal of Educational Psychology, 80(3), 417-433. doi:10.1348/000709909X481652

Ministerio de Salud y Política Social (2009). Guía de práctica clínica para el manejo de pacientes con TEA en atención primaria. Madrid: Ministerio de Ciencia e Innovación. Recuperado de: http://www.guiasalud.es/egpc//autismo/completa/index.html

Minton, C. A., \& Dodder, R. A. (2003). Participation in religious services by people with developmental disabilities. Mental Retardation, 41, 430-439. Recuperado de: http://www.aaiddjournals.org/doi/abs/10.1352/00476765\%282003\%2941\%3C430\%3APIRSBP\%3E2.0.CO\%3B2?code=aamr-site

Mitchell, C. (2011) Doing Visual Research. London/California: Sage

Mizen, P., \& Ofosu-Kusi, Y. (2010). Unofficial truths and everyday insights: understanding voice in visual research with the children ofAccra's urban poor. Visual Studies, 25 (3), 255-267. doi: 10.1080/1472586X.2010.523278

Molina, S. (2015). La inclusión del alumnado con necesidades educativas especiales en Comunidades de Aprendizaje. Intagible Capital, 11, 3, 372-392. doi: $10.3926 /$ ic. 642

Molina, J., y Marques, C. (2009). Experiencia docente en Educación Física y alumnos con necesidades educativas específicas: estudio de correlación. Retos. Nuevas tendencias en Educación Física, Deporte y Recreación, 16, 16-21. Recuperado de: http://www.redalyc.org/html/3457/345732281003/

Molina, V., Perera, V. H., Melero, N., Cotán, A. \& Moriña, A. (2016). The role of lecturers and inclusive education. Journal of Research in Special Educational Needs, 16 (1), 1046-1049. doi: 10.1111/1471-3802.12361

Moliner, O. (2008). Condiciones, procesos y circunstancias que permiten avanzar hacia la inclusión educativa: retomando las aportaciones de la experiencia canadiense. Revista Electrónica Iberoamericana sobre Calidad, Eficacia y Cambio en Educación, 6 (2), 27-44. Recuperado de: http://www.rinace.net/arts/vol6num2/art3.htm 
Moreno- Pérez, F.J. (2013). La inclusión escolar de los alumnos con trastornos del espectro de autismo. Análisis de la respuesta educativa al alumno con TEA. ACLPPinforma, 30, 15-16. Recuperado de: https://dialnet.unirioja.es/servlet/articulo?codigo $=4351717$

Moriña, A. (2004). Teoría y práctica de la Educación inclusiva. Archidona, Málaga: Aljibe.

Moriña, A. (2008). La escuela de la diversidad. Editorial Síntesis, Madrid.

Moriña, A. (Ed.) (2014). Análisis de las barreras y ayudas que los estudiantes con discapacidad identifican en la universidad. Alicante: 3ciencia.

Moriña, A. (2015). Inclusive university settings? An analysis from the perspective of students with disabilities. Cultura \& Educación. 27 (3), 669-694, doi: 10.1080/11356405.2015.1072361

Moriña, A. (2016). Investigar con historias de vida. Metodología biográficonarrativa. Madrid: Narcea.

Moriña, A. (2017). "We aren't Heroes, we're Survivors:" Higher Education as an Opportunity for Students with Disabilities to Reinvent an Identity. Journal of Futher and Higher Education, 41 (2), 215-226. doi: 10.1080/0309877X.2015.1070402

Moriña, A., Cortés, M.D. \& Melero, N. (2014). Inclusive curricula in Spanish higher education? Students with disabilities speak out. Journal Disability \& Society, 29 (1), 44-57. doi: 10.1080/09687599.2013.769862

Moriña, A., Cortés, M ${ }^{a}$ D. \& Molina, V. (2015). What if we could imagine the ideal professor? Proposals for improvement by university students with disabilities. Teaching and Teacher Education. 52, 91-98. doi: 10.1016/j.tate.2015.09.008

Moriña, A., López, R., \& Molina, V. (2015). Do lecturers aid or hinder students with disabilities: a biographical-narrative study. Higher Education Research \& Development, 34 (1), 147-159. doi: 10.1080/07294360.2014.934329

Moriña, A. Molina, V.M., Melero, N. y Carballo, R. (2015). La necesidad de formación del profesorado universitario en tecnología para favorecer la inclusión del alumnado con discapacidad. V Congreso Internacional sobre Buenas Prácticas con TIC. Universidad de Málaga.

Moriña, A. y Perera, V.H. (2015). ¿Educación inclusiva en la Enseñanza Superior? El caso del alumnado con discapacidad. Revista Ibero-Americana de Estudos em Educação, 10, 599- 614. Recuperado de:

http://piwik.seer.fclar.unesp.br/iberoamericana/article/view/7914/5422

Morse, J.M. (1994). Designing funded qualitative research. In N.K. Denzin \& Y.S. Lincoln (Eds.), Handbook of qualitative research (pp. 220-235). Londres: Sage.

Moss, J. (2008). Researching education: Digitally־visually־spatially. Rotterdam: Sense Publishers.

Moura, M.A.V., Araújo, C.L.F., Flores, P.V.P., Muniz, P. y Braga, M.F. (2002). Necessidades e expectativas da parturiente no parto humanizado: a qualidade 
da assistência. Revista de Enfermagem UERJ, 10 (3), 187-193. Revisado en: http://bases.bireme.br/cgi-

bin/wxislind.exe/iah/online/?IsisScript=iah/iah.xis\&src=google\&base=LILACS \&lang=p\&nextAction=lnk\&exprSearch=411777\&indexSearch=ID

Muntaner, J.J., Forteza, M.D. y Roselló, M.R. (1996). Nuevo paradigma de la educación Especial. En P. Jurado (comp.), Actas de las XIII Jornadas de Universidad y Educación Especial: Las necesidades educativas: presente y futuro (pp.340-346). Barcelona: Universidad Autónoma de Barcelona.

Muthukrishna, N. (2002). Inclusive Education in a rural context in South Africa: Emerging polity and practices. International Journal of Special Education, 17 (1), 1-10.

Myers, F., Ager, A., Kerr, P., \& Myles, S. (1998). Outside looking in? Studies of the community integration of people with learning disabilities. Disability \& Society, 13, 389-413.

$\mathbf{N}$

Naciones Unidas (2006). Convención sobre los Derechos de las Personas con Discapacidad y su protocolo Facultativo. New York. Recuperado en: http://www.un.org/disabilities/documents/convention/convoptprot-s.pdf

Narayan, D. (2000). La voz de los pobres: ¿Hay alguien que nos escuche? Madrid:

Banco Mundial Ediciones Mundi-Prensa. Recuperado de:

http://siteresources.worldbank.org/INTPOVERTY/ Resources/3356421124115102975/1555199-1124115187705/vol1_sp.pdf

Norwich, B. \& Kelly, N. (2004). Pupils' views on inclusion: moderate learning difficulties and bullying in mainstream and special schools. British Educational Research Journal, 30 (1), 43-65. doi: 10.1080/01411920310001629965

Nussbaum, M. (2007). Las fronteras de la justicia. Consideraciones sobre la exclusión. Barcelona: Paidós.

\section{$\mathbf{0}$}

O’Brien C.L \& O'Brien J. (2000) The origins of person-centered planning: a community of practice perspective. In S. Holburn \& P. Vietze, Personcentered planning: research, practice, and future directions. Baltimore: Paul H. Brookes.

OCDE, (2012). Equity and Quality in Education: Supporting Disadvantaged Students and Schools. París: OCDE.

Okilwa, N. S. A., \& Shelby, L. (2010). The effects of peer tutoring on academic performance of students with disabilities in grades 6 through 12: A synthesis of the literature. Remedial and Special Education, 31(6), 450-463. doi: 10.1177/0741932509355991. 
Olcott, D. (2013). Nuevas líneas de aprendizaje: potenciar el uso de recursos educativos abiertos para reforzar la educación no formal. Revista de Universidad y Sociedad del Conocimiento, 10 (1), 151-169. doi: 10.7238/rusc.v10i1.1562

Oliver, M. (1998). ¿Una sociología de la discapacidad o una sociología discapacitada? En L. Barton, (coord.), Sociología y discapacidad. (pp.3458).Madrid: Morata.

Oliver, M. (2008). Políticas sociales y discapacidad. Algunas consideraciones teóricas. En L. Barton (comp.). Superar las barreras de la discapacidad (pp.19-33). Madrid: Morata.

ONU (2006). Convención sobre los Derechos de las Personas con Discapacidad. Recuperado de: http://www.un.org/spanish/disabilities/default.asp?id=497

Orellana, L. (2016). Actividades en las aulas de Comunicación y Lenguaje con niños/as con Trastorno del Espectro del Autismo. Una investigación narrativa. Experiencias Educativas, 13, 82-99. Recuperado de: http://repositori.uji.es/xmlui/handle/10234/159144

Organización Mundial de la Salud (2001). Clasificación Internacional de Funcionamientos, la Discapacidad y la Salud (CIF). Madrid: Ministerio de Trabajo y Asuntos Sociales.

Organización Mundial de la Salud (2011). Informe mundial sobre la discapacidad. Malta. Recuperado de: http://www.who.int/disabilities/world_report/2011/es/

Ortiz, M.A. (coord.) (2010). Arte y Ciencia. Creación y Responsabilidad. Coimbra: Fernando Ramos.

Ostovar-Namaghi, S., Norouzi, S., \& Hosseini, S. M. (2015). Exploring the professional beliefs of an EFL teacher: A narrative inquiry. The Qualitative Report, 20(12), 1995-2009. Recuperado de:

https://search.proquest.com/docview/1753369867? accountid=15297

Packard, J. (2008). 'I'm gonna show you what it's really like out here': the power and limitation of participatory visual methods. Visual Studies, 23(1), 63-77. doi: 10.1080/14725860801908544

Padilla, A. (2011). Inclusión educativa de personas con discapacidad. Revista Colombiana de Psiquiatría, 4, 670-699. Recuperado de: http://repositoriocdpd.net:8080/bitstream/handle/123456789/1282/Art_Padilla MunozA_Inclusioneducativa_2011.pdf?sequence=1

Palacios, A. (2006). ¿Modelo rehabilitador o modelo social? La persona con discapacidad en el derecho español. En E. Jiménez, (Ed.) Igualdad, No Discriminación y Discapacidad (pp.243-305). Ediar-Dykinson: Buenos Aires, Argentina. 
Palacios, A. y Romañach, J. (2006). El modelo de la diversidad: La Bioética y los derechos humanos como herramientas para alcanzar la plena dignidad en la diversidad funcional. Santiago de Compostela: Diversitas Ediciones.

Pallisera, M. (2011). La planificación centrada en la persona (PCP): una vía para la construcción de proyectos personalizados con personas con discapacidad intelectual. Revista Iberoamericana de Educación, 56 (3), 1-12. Recuperado de: http://www.oei.es/historico/noticias/spip.php?article9576

Pallisera, M., Fullana, J., Martín, R. y Vilà, M. (2013). Transición a la vida adulta de jóvenes con discapacidad intelectual, la opinión de los profesionales de servicios escolares y postescolares. Revista Española de Orientación y Psicopedagogía, 24 (2), 100-115. Recuperado de: http://revistas.uned.es/index.php/reop/article/view/11261

Pallisera, M. y Puyalto, C. (2014). La voz de las personas con discapacidad intellectual en la investigación: hacia el desarrollo de investigaciones inclusivas. Revista nacional e internacional de educación inclusiva, 7 (2), 8497. Recuperado de: http://riberdis.cedd.net/xmlui/handle/11181/4280

Palomares, A. (2004). Profesorado y educación para la diversidad en el siglo XXI. Cuenca: Universidad de Castilla-La Mancha

Paniagua, G. (1999). Familias con niños con necesidades educativas especiales. En A. Marchesi, C. Coll y J. Palacios, Desarrolo psicológico y educación 3. Trastornos del desarrollo y necesidades educativas especiales (pp. 469-493). Madrid: Alianza

Pari, A. (2011). Historia de vida y metodología de enseñanza de la matemática de Jaime Alfonso Escalante Gutiérrez. (Tesis doctoral, Universidad de Salamanca, España).

Parra, C. (2010). Educación inclusiva: Un modelo de educación para todos. Revista ISEES, 8, 73-84. Recuperado de:

https://dialnet.unirioja.es/servlet/articulo?codigo $=3777544$

Parker, I. (2005). Qualitative Psychology - Introducing Radical Research. Buckingham, R.U.: Open University Press.

Parrilla, A. (2001). El largo camino hacia la inclusión. Revista Galega de ensino, $32,35-54$.

Parrilla, A. (2002). Acerca del origen y sentido de la educación inclusiva. Revista de Educación, 327, 11-29. Recuperado de: http://www.mecd.gob.es/dctm/revistade-educacion/articulos327/re3270210520.pdf?documentId=0901e72b81259a76

Parrilla, A . (2009). ¿Y si la investigación sobre inclusión no fuera inclusiva?Reflexiones desde una investigación biográfico-narrativa. Revista de Educación, 349, 101-117

Parrilla, A. (2010) Educación y escuela inclusiva: del pensamiento global al desarrollo local. VV.AA. (Eds.) La Educación Inclusiva en la Escuela del Siglo XXI. Universidade da Coruña pp. 17-23 
Parrilla, A. y Susinos, T. (2004). La construcción del proceso de exclusión social en las mujeres: origen, formas, consecuencias e implicaciones formativas. Instituto de la Mujer. Ministerio de Trabajo y Asuntos Sociales. Recuperado de:

http://www.uam.es/personal_pdi/stmaria/sarrio/DOCUMENTOS,\%20ARTICU LOS,\%20PONENECIAS,/informe\%20exclusion\%20y\%20genero\%20parrilla\%2 0susinos.pdf

Parrilla, Á y Susinos, T. (2008). Dar la voz en la investigación inclusiva. Debates sobre inclusión y exclusión desde un enfoque biográfico-narrativo. REICE. Revista Iberoamericana sobre Calidad, Eficacia y Cambio en Educación, 6 (2), 157-171. Recuperado de: http://www.redalyc.org/articulo.oa?id=55160212

Pascualetto, G. (2015). Sujetos, trabajo grupal y convivencia escolar: Una mirada desde la formación docente. Anuario, 12, 1-16. doi:10.19137/an1209.

Patton, M. Q. (1990). Qualitative evaluation and research methods. Londres: Sage.

Pegalajar, M. del C. y Colmenero, M. de J. (2017). Actitudes y formación docente hacia la inclusión en Educación Secundaria Obligatoria. Revista Electrónica de Investigación Educativa, 19 (1), 84-97. Recuperado de http://redie.uabc.mx/redie/article/view/765

Peirats, J. (2012). Atención a la diversidad: medidas organizativas y curriculares. En C. Grau y M. D. Gil (coords.), Intervención Psicoeducativa en Necesidades Específicas de Apoyo Educativo (pp.3-28). Madrid: Pearson Educación.

Pennef, J. (1990). La méthode biographique: De l'École deChicago a l'histoire orale. París: Armand Colin.

Pérez, F. (2005). La entrevista como técnica de investigación social. Fundamentos teóricos, técnicos y metodológicos. Extramuros, 8 (22), 187-210. Recuperado de: http://www2.scielo.org.ve/scielo.php?script=sci_arttext\&pid=S131674802005000100010

Peterson, P. (2006). Inclusão nos Estados Unidos: filosofia, implementação e capacitação de professores. Revista Brasileira de Educação Especial, 12 (1), 310. doi: 10.1590/S1413-65382006000100002

Pfefferle, M. (2006) Enfermés dehors [fotografía]. Recuperado de http://es.freeimages.com/photo/locked-out-1435488

Pié, A. (coord.), Duch, R., Martínez, M., Miró, R.M. y Rodríguez, I. (2014). Diversidad(es). Discapacidad, altas capacidades intelectuales y trastornos del espectro autista. Barcelona: Editorial UOC.

Pimenta, R.A., Zuchetto, A.T., Bastos, T. y Corredeira, R. (2016). Efectos de la natación para jóvenes con trastorno del espectro autista. Revista Internacional de Medicina y Ciencias de la Actividad Física y el Deporte, 16 (64), 789-806. doi: 10.15366/rimcafd2016.64.011

Pineda, J. (2014). Barreiras para a construção da educação inicial como um espaço educativo em municípios rurais. Polis (Santiago), 13 (37), 145-165. doi: 10.4067/S0718-65682014000100009 
Pink, S. (2006). Doing visual ethnography: images, media and representation in research. London: Sage Publications.

Plavnick, J.B. \& Ferreri, S.J. (2011). Establishing verbal repertoires in children with autism using function-based video modeling. Journal of Applied Behavior Analysis, 4 (44), 747-766.

Popkewitz, T. (1988). Paradigma e ideología en investigación educativa. Las funciones sociales del intelectual. Madrid: Mondadori.

Poveda, P. (2014). La inclusión es posible. Integración. Revista sobre discapacidad visual, 64 (edición digital). Recuperado de: http://www.once.es/new/serviciosespecializados-en-discapacidad-visual/publicaciones-sobre-discapacidadvisual/nueva-estructura-revista-integracion/copy_of_numerospublicados/numero-64/la-inclusion-es-posible

Powell, J.J.W. (2016). Barriers to inclusión. Special Education in the United States and Germany. New York: Routledge.

Prat, J. (1997). El estigma del extraño: Un ensayo antropológico sobre sectas religiosas. Barcelona: Ariel.

Priestley, M. (ed.) (2001). Disability and the Life Course: Global Perspectives. Cambridge: Cambridge University Press.

Procacci, G. (1999). Ciudadanos pobres, la ciudadanía social y la crisis del Estado del Bienestar. En S. García y S. Lukes (eds.)Ciudadanía, justicia social, identidad y participación. Madrid: S XXI.

Prosser, J. \& Loxley, A. (2008). Introducing Visual Methods. ESRC National Centre for Research Methods. Recuperado de: http://eprints.ncrm.ac.uk/420/1/MethodsReviewPaperNCRM-010.pdf

Puig de Bellacasa, R. (1990). Concepciones, paradigmas y evolución de las mentalidades sobre la discapacidad. En SID, Discapacidad e información (pp.63-96). Madrid: Real Patronato de Prevención y Atención a Personas con Minusvalías.

Pujadas, J. (1992). El método biográfico: El uso de las historias de vida en ciencias sociales. Madrid: Centro de Investigaciones Sociológicas.

Pyett, P.M. (2003). Validation of qualitative researcn in the "real world". Qualitative Health Research; 13 (8), 1170-1179. Recuperado de: https://www.ncbi.nlm.nih.gov/pubmed/14556426

$\mathbf{R}$

Radley, A., Hodgetts, D., \& Cullen, A. (2005). Visualizing homelessness: A study on photography and estrangement. Journal of Community and Applied Psychology, 15 (4), 273-295. doi: 10.1002/casp.825

Real Academia Española. (2014). Diccionario de la lengua española (23 ${ }^{\mathrm{a}}$ ed.). Recuperado de: http://dle.rae.es/?id=E0b0PXH 
Redding, S. (2005). Improving student learning outcomes through school initiatives to engage parents. En R.A. Martínez González, H. Pérez Herrero y B.

Rodríguez Ruiz (Eds.). Family-School-Community Partnerships merging into Social Development. Oviedo, Grupo SM.

Redding, S. (2006). Qué piensan los padres y profesores de la escuela y unos de otros. Cultura y Educación, 18 (3-4), 267-281.

Regis, J. (2014). La fototerapia y videoterapia en un proyecto de intervención socioeducativa para adolescentes con síndrome de Asperger. Arte y Movimiento, 10. Recuperado de:

http://revistaselectronicas.ujaen.es/index.php/artymov/article/view/2597/2158

Regis, P. J. y Callejón, M.D. (2015). Del pictograma a la imagen: herramientas de comunicación y lenguaje en personas con síndrome de Asperger a través de recursos visuales para la inclusión. Arteterapia- Papeles de arteterapia y educación artística para la inclusión social, 10, 329-241. doi:10.5209/rev_ARTE.2015.v10.51700

Rescorla, L. (2003). Outcome for toddlers with specific expressive language delay (SELD) at ages 3, 4, 5, 6, 7 \& 8. Society for Research in Child Development Abstracts. 9 (566).

Reyes, J. L. y Méndez, R. (2016). La función educativa de las ciencias sociales en la LOMCE: El ejemplo de la educación patrimonial en la enseñanza primaria. Revista Educación, Política y Sociedad. 1 (2), 125-144. Recuperado de: http://hdl.handle.net/10486/674643

Reynolds, F. (2002). An exploratory survey of opportunities and barriers to creative leisure activity for people with learning disabilities. British Journal of Learning Disabilities, 30, 63-67. doi: 10.1046/j.1468-3156.2002.00151.x

Riera, C. D. (2003). Personas con discapacidad intelectual y necesidad de apoyos intermitentes: situación, necesidades y demandas. Madrid: IMSERSO.

Ritchie, J., Spencer, L. \& O'Connor, W. (2003). Carrying out qualitative analysis. In J. Ritchie \& J. Lewis (eds.). Qualitative research Practice: A guide for social science students and researchers (pp. 219-262). Londres: Sage.

Rivas, J.I. (2007). Vida, experiencias y educación: la biografía como estrategia de conocimiento. En I. Sverdlick (coord.), La investigación educativa. Buenos Aires: Novedades Educativas.

Rivas, J.I. (2014). Nuevas indentidades en la formación del profesorado: la voz del alumnado. International Journal of Developmental and Educational Psychology, 7(1), 487-494. doi: 10.17060/ijodaep.2014.n1.v7.819

Riviére, A. (1999). Símbolos, arte y autismo. En Autismo Burgos (Ed): Desde el silencio (pp. 69-71). Burgos: Junta de Castilla y León.

Riviére, A. (2001). Autismo: Orientaciones para la intervención educativa. Madrid: Editorial Trotta. 
Romero Sánchez, G., García Luque, A. y Cambil Hernández, M. E. (2016). Valores sociales en la nueva realidad curricular: LOE versus LOMCE. Opción, 32 (2): 689-712. Recuperado de: http://www.redalyc.org/articulo.oa?id=31048481040

Rodríguez, G.; Gil, J., y García, E. (1996). Metodología de la investigación cualitativa. Málaga: Aljibe.

Rodríguez, A., Verdugo, M.A. y Sánchez, M.C. (2008). Calidad de vida familiar y apoyos para los progenitores de personas con discapacidad intelectual en proceso de envejecimiento. Siglo Cero. Revista Española de Discapacidad Intelectual, 39 (3), 227, 19-34.

Rodríguez, S. y Ferreira, M.A. (2010). Diversidad funcional: sobre lo normal y lo patológico en torno a la condición social de la dis-capacidad. Cuadernos de Relaciones Laborales, 28 (1), 151- 172.

Rodríguez-Picavea, A. (2013). Divertad: libertad y dignidad en la diversidad. Revista Latinoamericana de la Educación Inclusiva. 7(1), 39 - 58. Recuperado de: http://www.rinace.net/rlei/numeros/vol7-num1/art2.pdf

Rojas, G., Gómez, M.G. y García Vázquez, N.J. (2013). El uso de un software educativa para promover el aprecio por la diversidad en alumnos de primaria. $\begin{array}{llll}\text { Apertura, } & 5 & \text { (2). Recuperado de: }\end{array}$ http://www.udgvirtual.udg.mx/apertura/index.php/apertura/article/view/406/3 31

Romañach, J. (2009): Bioética al otro lado del espejo. Diversitas Ediciones. Disponible en: http://www.asoc-ies.org/diversitas/bioeticatras.html

Rubin, H.J. \& Rubin, I.S. (1995) Qualitative interviewing. The art of hearing data. Thousand Oaks, CA: Sage.

Ruiz, E. T. L. (2013). La atención a la diversidad en la futura LOMCE. En Investigación e Innovación Educativa al Servicio de Instituciones y Comunidades Globales, Plurales y Diversas: Actas del XVI Congreso Nacional/II Internacional Modelos de Investigación Educativa de la Asociación Interuniversitaria de Investigación Pedagógica. Alicante, España: Universidad de Alicante. Recuperado de: https://www.uv.es/aidipe/congresos/Actas_XVI_Congreso.pdf

Ruiz Olabuénaga, J. I. (1996). Metodología de la investigación cualitativa. Bilbao: Universidad de Deusto.

Ruiz Olabuénaga, J. I. e Ispizua, M. A. (1989). La descodificación de la vida cotidiana. Métodos de investigación cualitativa. Bilbao: Universidad de Deusto.

$\mathbf{S}$

Salend, S. \& Garrick, L. (2002). What do families have to say about inclusion?, Teaching Exceptional Children, 35 (1), 62-66. Recuperado de: http://www.casenex.com/casenex/cecReadings/whatDoFamilies.pdf 
Salem, L.C. (2006). Children's literatura studies: cases and discussions. London: Libraries Unlimited.

Salgado, A.C. (2007). Investigación cualitativa: diseños, evaluación del rigor metodológico y retos. Liberabit, 13, 71-78. Recuperado de: http://www.scielo.org.pe/scielo.php?script=sci_arttext\&pid=S172948272007000100009

Samuels, J. (2004). Breaking the ethnographer's frames: Reflections on the use of photoelicitation in understanding Sri Lankan monastic culture. American Behavioral Scientist, 47 (12), 1 528-1 550. doi: 10.1177/0002764204266238

Samuel, P. S., Lacey, K. K., Giertz, C., Hobden, K. L., \& LeRoy, B. W. (2013). Benefits and quality of life outcomes from transportation voucher use by adults with disabilities. Journal of Policy and Practice in Intellectual Disabilities, 10, 277-288.

Sánchez Palomino, A. (2011). La Universidad de Almería ante la integración educativa y social de los estudiantes con discapacidad: ideas y actitudes del personal docente e investigador. Revista de Educación, 354, 575-603. Recuperado de: http://www.revistaeducacion.mec.es/re354_23.html

Sandín, M. P. (2003). Investigación Cualitativa en Educación. Fundamentos y Tradiciones. McGraw-Hill / Interamericana de España.

Sandín, M. P. (2010). Investigación cualitativa en educación. Fundamentos y tradiciones. Madrid: McGraw-Hill.

Sandoval, C. A. (1996). Investigación cualitativa. Bogotá: ICFES.

Sandoval, C.A. (2002). Investigación cualitativa. Bogotá: ICFES

Sandoval, M., Simón, C. y Echeita, G. (2012). Análisis y valoración crítica de las funciones del profesorado de apoyo desde la educación inclusiva. Revista de Educación, núm. extr., 117-137. Recuperado de: http://recyt.fecyt.es/index.php/Redu/article/view/16410

Sanhueza, S., Granada, M. y Bravo, L (2012) Actitudes del profesorado de Chile y Costa Rica hacia la inclusión educativa. Revista Cadernos de Pesquisa. 42 (147). doi: 10.1590/S0100-15742012000300013

Sanjek, R. (Ed.) (1990). Fieldnotes: The Making of Anthropology.Ithaca: CornellUniversityPress.

Sanmartín, R. (2003). Observar, escuchar, comparar, escribir: La práctica de la investigación cualitativa. Barcelona: Ariel.

Sansosti, F.J., Powell-Smith, K.A. \& Kincard, D. (2004). A research synthesis of social story interventions for children with autism spectrum disorders. Focus on Autism and Other Developmental Disabilities, 4 (19), 194-204.

Santos-Rego, M.A., Cernadas-Ríos, F.X. y Lorenzo-Moledo, M.M. (2014). La inclusión educativa de la inmigración y la formación intercultural del profesorado. Revista Electrónica Interuniversitaria de Formación del Profesorado, 17(2), 123-137. doi: http://dx.doi.org/10.6018/reifop.17.2.196931 
Sanz, A. (2005). El método biográfico en investigación social. Asclepio, 57 (1), 99115.

Sanz del Río, S. (1996). Integración de alumnos con necesidades educativas especiales: panorama internacional. Madrid: Real Patronato de Prevención y Atención a Personas con Minusvalías.

Sarmento, M. J. (2014). Metodologias visuais em ciências sociais" En L. Lima y J.A. Palhares (eds.), Metodologia de investigação em Ciências Sociais da Educação. V. N. Famalição: Edições Húmus.

Sarto, P. y Venegas, M.E. (coords.) (2009). Aspectos clave de la Educación Inclusiva. Salamanca: Instituto Universitario de Integración en la Comunidad

Savvidou, C. (2011). Exploring teachers' narratives of inclusive practices in higher education. Teacher Development: An International Journal of teachers' profesional development, 15 (1), 53-67. doi: 10.1080/13664530.2011.555224

Scattone, D., Tingstrom, D.H. \& Wilczynski, S.M. (2006). Increasing appropriate social interactions of children with autism spectrum disorders using socialstories [TM]. Focus on Autism and Other Developmental Disabilities. 4 (21), 211-222.

Schaefer, N. (1997). Yes, She Knows She’s Here. Toronto: Inclusion Press.

Schalock, R. L., Gardner, J.F. \& Bradley, V. J. (2007). Quality of life for persons with intelectual and other developmental disabilities: Applications across individuals, organizations, communities, and systems. Washington, DC: American Association on Intellectual and Developmental Disabilities.

Schalock, R. y Verdugo, MA. (2007). El concepto de calidad de vida en los servicios y apoyos para personas con discapacidad intelectual. Siglo Cero, 38(4), 21-36.

Schütz, A. (1995). El problema de la realidad social. Buenos Aires: Amorrortu.

Sennett, R. (2009). El artesano. Barcelona: Anagrama.

Sharma, U., Loreman, T. \& Simi, J. (2017). Stakeholder perspectives on barriers and facilitators of inclusive education in the Solomon Islands. Journal of Research in Special Educational Needs, 1-9. doi:10.1111/1471-3802.12375

Sherman, J. \& Sherman, S. (2013). Preventing Mobility Barriers to Inclusion for People With Intellectual Disabilities. Journal of Policy and Practice in Intellectual Disabilities, 10 (4), 271-276. doi:10.1111/jppi.12052

Simarro, L. (2013). Calidad de vida y educación en personas con autismo. Madrid: Editorial Síntesis.

Simon B.S. \& Epstein, J.L. (2001). School, family and community partnerships: Linking theory to practices. En D.B. Hiatt-Michael (Ed.). Promising practices for family involvement in schools (pp.1-24). Greenwich, CT: Information Age Publishing.

Sklilar, C. (2002). ¿Y si el otro no estuviera ahí? Notas para una pedagogía (improbable) de la diferencia. Madrid: Miño y Davila Editores. 
Skliar, C. (2015). Preguntar la diferencia: cuestiones sobre la inclusión. Sophia, 11 (1), 33-43. Recuperado de: http://www.scielo.org.co/scielo.php?script=sci_arttext\&pid=S1794$89322015000100004 \& \operatorname{lng}=$ en\&tlng=es.

Slavin, R. (1991). Synthesis of research of cooperative learning. Educational Leadership, 48 (5), 71-82.

Slavin, R. (2002). Aprendizaje cooperativo: teoría, investigación y práctica. Buenos Aires: Aique.

Slee, R. (2005). Education and the politics of recognition. Inclusive education - an Australian snapshot. In D. Mitchell (Ed.), Contextualizing inclusive education. Evaluating old and new international perspectives (pp. 139-165). London: Routledge.

Slee, R. (2012). La escuela extraordinaria. Exclusión, escolarización y educación inclusiva. Madrid: Morata.

Smith, I. H. (1994). Biographical method. En N.K. Denzin \& Y.S. Lincoln (Eds.). Handbook of qualitative research (pp. 286-305). Londres: Sage.

Smith, J. A. (1995). Semi-structured interviewing and qualitative analysis. In J A. Smith, R. Harre, \& L. Van Langenhove (Eds.). Rethinking methods in psychology (pp. 9-26). London: Sage.

Snow, J. (2011). Who's Drawing the Lines? Toronto: Inclusion Press.

Sotos, M., López, C. y Sánchez, A.B. (2016). La perspectiva biográfica. El proceso de construcción del saber pedagógico. Teoría de la Educación. Revista interuniversitaria. 28 (2), 249-265. doi: 10.14201/teoredu2016282249265

Sowa, M. \& Meulenbroek, R. (2012). Effects of physical exercise on Autism Spectrum Disorders: A meta-analysis. Research in Autism Spectrum Disorders, 6, 46-57. doi: 10.1016/j.rasd.2011.09.001

Stainback, S. y Stainback, W. (1999). Aulas inclusivas. Un nuevo modo de enfocar y vivir el currículum. Madrid: Narcea.

Stefanini, J. R., Scherer, Z. A. P., Scherer, E. A., Cavalin, L. A., \& Guazzelli, M. S. (2015). Adolescents with attention deficit hyperactivity disorder and exposure to violence: parents' opinion. Revista latino-americana de enfermagem, 23(6), 1090-1096. Recuperado de: http://www.scielo.br/scielo.php?pid=S0104$11692015000601090 \&$ script $=$ sci_arttext\&tlng=es

Stevens, R. \& Slavin, R. (1995). The cooperative elementary school: Effects on students' achievement, attitudes, and social relations. American Educational Research Journal, 32: 321-351. doi: 10.3102/00028312032002321

Strauss, A. (1987). Qualitative analysis for social scientists. MA, Cambridge: University Press.

Strauss, A., \& Corbin, J. (1990). Basics of qualitative research. Grounded theory procedurs and techniques. Callifornia: Sage. 
Stubbs, S. (2008). Inclusive Education. Where there are few resources. Oslo: The Atlas Alliance

Subirats, J. (Dir.)(2005). Análisis de los factores de exclusión social. Bilbao: Fundacion BBVA.

Subirats, M. (2014). La LOMCE: Hacia una educación antidemocrática. Revista interuniversitaria de formación del profesorado, 28 (3), 45-57. Recuperado de: http://www.redalyc.org/pdf/274/27433841004.pdf

Susinos, T. y Parrilla, M.A. (2008). Dar la voz en la investigación inclusiva. Debates sobre inclusión y exclusión desde un enfoque biográfico-narrativo. Revista Electrónica Iberoamericana sobre Calidad, Eficacia y Cambio en Educación. $\quad 6 \quad(2), \quad 157-\quad 171 . \quad$ Recuperado de: http://www.redalyc.org/pdf/551/55160212.pdf

Susinos, T. y Parrilla, A. (2013). Investigación inclusiva en tiempos difíciles. Certezas provisionales y debates pertinentes. Revista Iberoamericana sobre Calidad, Eficacia y Cambio en Educación, 11, 2, 88-98. Recuperado de: http://www.rinace.net/reice/numeros/arts/vol11num2/art4.pdf

Suter, W. N. (2011). Introduction to educational research: A critical thinking approach. SAGE: publications.

Swain, J., French, S., Barnes, C. \& Thomas, C. (2004). Disabling Barriers, enabling environments. Thousand Oaks: Sage Publications.

$\mathbf{T}$

Tarabini, A. y Montes, A. (2015). La agenda política contra el abandono escolar prematuro en España: La LOMCE contra las evidencias internacionales. Revista Avances en supervisión educativa. 23, 1 - 20. Recuperado de: https://avances.adide.org/index.php/ase/article/view/20/21

Taylor, C. (2004). Modern social imaginaries. Durham: University Press.

Taylor, S. y Bogdan, R. (1992). Introducción a los métodos cualitativos de investigación. Barcelona: Paidós Básica.

Taylor S. y Bodgan, R. (1994). Introducción a los métodos cualitativos de investigación: La búsqueda de significados. Barcelona: Paidós.

Taylor, S. y Bogdan, R. (2009). Introducción a los métodos cualitativos de investigación. Barcelona: Paidós Básica.

Teddlie, Ch. \& Yu, F. (2007). Methods sampling. Typology with examples. Journal of Mixed Methods Research. 1 (1), 77-100. doi: 10.1177/2345678906292430

Tellechea, N. (2013). Trastorno del Espectro Autista y Trastorno Específico del Lenguaje ¿Dos entidades diferentes o un continuo de manifestaciones neurpsicológicas? Medicina, 73 (1), 10-15. Recuperado de: http://www.scielo.org.ar/scielo.php?script=sci_arttext\&pid=S0025-

76802013000500003 
Terrén, E. (2001). La conciencia de la diferencia étnica: identidad y distancia cultural en el discurso del profesorado. Papers, 63/64, 83-101.

Tesch, R. (1990). Qualitative research. Analysis types and software tools. Nueva York: The Falmer Press.

Tezanos, J.F. (ed.)(1999). Tendencias de desigualdad y exclusión social. Tercer foro sobre tendencias sociales. Madrid. Ed. Sistema.

Tezanos, J.F.(2001). La sociedad dividida: estructuras de clases y desigualdades en las sociedades. Madrid: Biblioteca Nueva.

Toboso, M., Ferreira, M.A., Díaz, E., Fernández-Cid, M., Villa, N. y Gómez de Esteban, C. (2012). Sobre la educación inclusiva en España: Políticas y Prácticas. Revista Sociológica de Pensamiento Crítico. 6 (1), 279- 295. Recuperado de: http://www.intersticios.es/article/view/10048

Tójar, J.C. (2006). Investigación cualitativa: Comprender y actuar. Madrid: La Muralla.

Tomás, R. y Grau, C. (2016). Modalidades de escolarización para el alumnado con trastornos del espectro autista. Revista nacional e internacional de educación inclusiva, $9(2), 35-53$.

Topping, K. J. (2001). Peer assisted learning: A practical guide for teachers. Cambridge, MA: Brookline Books.

Tosi, I., Peláez, L., D’Orazio, L., Larrañaga, M., Saavedra, E. y Baeza, E. (2016). Educación inclusiva y vida independiente. Universitas, 24, 134-164. doi: 10.20318/universitas.2016.3178

Turnbull, A.P., Turnbull, H.R. y Kyzar, K. (2009). Cooperación entre familias y profesionales como fuerza catalizadora para una óptima inclusión: enfoque de los Estados Unidos de América. Revista de Educación, 349: 69-99. Recuperado de: http://www.revistaeducacion.mec.es/re349/re349_04.pdf

UNESCO (1994). Declaración de Salamanca. Conferencia Mundial sobre Necesidades Educativas Especiales: acceso y calidad. Salamanca: UNESCO.

UNESCO (2007). Educación para Todos en 2015 ¿Alcanzaremos la meta? Informe de Seguimiento de la EPT en el Mundo. París: UNESCO.

UNESCO (2009). Towards Inclusive Education for Children with Disabilities: A Guideline. Bangkok: UNESCO.

Valdes, A. A., Urías, M., Wendlandt, T.R. \& Torres, G.M. (2014). Relation between Family Dynamics and Teachers' Practices with the Participation of Mothers in the Education of the Children. Journal of Education and Human 
Development, 3 (3), 309-315. Recuperado de:

http://jehdnet.com/journals/jehd/Vol_3_No_3_September_2014/25.pdf

Valenzuela, C.E. (2008). Coinvestigación: organización populares y nuevas prácticas de saber. Nómadas (Col), 29, 112-127.

Valenzuela, B. A., Guillén, M. y Campa, R. (2014). Recursos para la inclusión educativa en el contexto de educación primaria. Infancias Imágenes, 13(2), 64-75. Recuperado de: http://revistas.udistrital.edu.co/ojs/index.php/infancias/article/view/7436

Vallejo, R., y Finol de Franco, M. (2010). La triangulación como procedimiento de análisis para investigaciones educativas. REDHECS, 7 (4), 117-133. Recuperado

de: http://publicaciones.urbe.edu/index.php/REDHECS/article/viewArticle/620/15 78

Vallés, M. S. (1997). Técnicas cualitativas de investigación social. Reflexión metodológica y práctica profesional. Madrid: Síntesis.

Valles, M.S. (1999). Técnicas cualitativas de investigación social. Reflexión metodológica y práctica profesional. Madrid: Síntesis.

Valles, S. (2014). Entrevistas cualitativas. Madrid: Centro de Investigaciones Sociológicas.

Vega Fuente, A. (2004). El movimiento de la discapacidad: Nuevo reto educativo. En M. Cuevas López, F. Díaz Rosas, A.M. Fuentes Viñas y J.A. Pareja Fernández de la Reguera (coord.) Atención a la diversidad y Calidad Educativa (pp. 97-109). Granada: Grupo Editorial Universitarios.

Velasco, H. y Díaz de Rada, A. (1997). La lógica de la Investigación Etnográfica. Madrid: Trotta.

Verdonschot, M. M. L., De Witte, L. P., Reichrath, E., Buntinx, W. H. E., \& Curfs, L. M. G. (2009). Impact of environmental factors on community participation of persons with an intellectual disability: A systematic review. Journal of Intellectual Disability Research, 53, 54-64. doi: 10.1111/j.13652788.2008.01128.x

Verdugo, M. A. (2000). Educación y calidad de vida: La autodeterminación de alumnos con necesidades educativas especiales. En III Congreso "La atención a la diversidad en el sistema educativo" Universidad de Salamanca. Recuperado

de https://campus.usal.es/ inico/actividades/actasuruguay2001/14.pdf

Verdugo, M.A., Gómez, L., Arias, B. y Schalock, R. (2009). Escala Integral. Evaluación Objetiva y Subjetiva de la Calidad de Vida de Persona con Discapacidad Intelectual. INICO Salamanca. Editorial CEPE.

Verdugo, M.A. y Parrilla, A. (2009). Presentación. Aportaciones actuales a la inclusión educativa. Revista de Educación. 349, 15-22. Recuperado de: http://www.revistaeducacion.educacion.es/re349/re349_01.pdf

Verdugo, M.A. y Rodríguez, A. (2012). La inclusión educativa en España desde la perspectiva de alumnos con discapacidad intelectual, de familias y de 
profesionales, Revista de Educación, 358, 450-470. Recuperado de: http://www.revistaeducacion.mec.es/doi/358_086.pdf

Verdugo, M.A., Rodríguez, A. y Sánchez, M. (2007). Necesidades percibidas por la familia de adultos con discapacidad intelectual en fase de envejecimiento. Informe de investigación, IMSERSO e Instituto de Integración en la Comunidad (INICO). Universidad de Salamanca.

Verdugo, M. A., Rodríguez, A., Sarto, P., Calvo I. y Santamaría, M, (2009). Situación de la inclusión educativa en España. Salamanca. INICO.

Vidriales, R., Cuesta, J.L., Plaza, M. y Hernández, C. (2015). Personas con Trastorno del Espectro del Autismo con necesidades intensas y generalizadas de apoyo: estrategias para mejorar su calidad de vida, Revista Española de Discapacidad, 3(2), 101-115. doi: 10.5569/2340-5104.03.02.06

Vidriales, R., Hernández, C. y Plaza, M. (2016). Envejecimiento y Trastorno del Espectro del Austimo. Una etapa vital invisible. Autismo España.

Vieytes, R. (2004). Metodología de investigación en organizaciones, mercado y sociedad. Epistemología y técnicas. Buenos Aires: Editorial de las Ciencias.

Viloria, M.E. (2016). El derecho social fundamental de la educación para escolares con discapacidad en Venezuela. Universidad, Ciencia y Tecnología, 80, 94105. Recuperado de: http://www.uct.unexpo.edu.ve/index.php/uct/article/view/763

Villegas, M., Simón, C. y Echeita, G. (2014). La inclusión educativa desde la voz de las madres de estudiantes con trastornos del espectro autista en una muestra chilena. Revista Española de Discapacidad, 2 (2), 63-68. doi: 10.5569/23405104

Vlachou, A.D. (1999). Caminos hacia una educación inclusiva. Madrid: La Muralla.

Vonder Hulls, D.S., Walker, L.K. \& Powell, J.M. (2006). Clinicians' perceptions of the benefits of aquatic therapy for young children with autism: a preliminary study. Physical \& occupational therapy in pediatrics 26 (1-2), 13-22. doi: 10.1080/J006v26n01_03

\section{W}

Wagner, D. A. (2017). Learning, Literacy and Sustainable Development: Inclusion, Vulnerability and the SDGs. In A.M. Battro, P. Léna, M. Sánchez \& J. Von Braun, Children and Sustainable Development. Ecological Education in a Globlalized World (pp.45-65). Cham, Switzerland: Springer International Publishing. doi: 10.1007/978-3-319-47130-3_5.

Walmsley, J. (2004). Involving users with learning difficulties in Health improvement: lessons from inclusive learning disability research. Nursing Inquiry. 11, 54-64.

Wamsley, J. (2008). Normalización, investigación emancipadora e investigación inclusiva en el ámbito de la discapacidad intelectual. En L. Barton (2008) Superar las barreras de la discapacidad. Madrid: Morata. 
Walmsley, J. (2001). Normalisation, emancipatory research and inclusive research in learning disability. Disability \& Society, 16, 187-205. doi: http://dx.doi.org/10.1080/09687590120035807

Walmsley, J. \& Johnson, K. (2003). Inclusive Research with People with Learning Disabilities: Past, Present and Future.London: Jessica Kingsley Publishers.

Wehmeyer, M. L. (2000). Riding the third wave: Self-determination and selfadvocacy in the 21st century. Focus on Autism and Other Developmental Disabilities. 15 (2), 106-116.

Wang, C., Cash, J., \& Powers, L. (2000). Who knows the streets as well as the homeless? Promoting personal and community action through Photovoice. Health Promotion Practice, 7 (1 ), 81 -89. doi: 10.1177/152483990000100113

Wehmeyer, M. (2006). Autodeterminación y discapacidades severas. En M. A. Verdugo y F. B. Jordán (coords.) Rompiendo inercias. Claves para Avanzar. VI Jornadas Científicas de Investigación sobre personas con discapacidad (pp.89-100). Salamanca: Amarú.

Wetherby A.M., Brosnan-Maddox S., Peace. V, \& Newton L. (2008). Validation of the Infant-Toddler Checklist as a broadband screener for autism spectrum disorders from 9 to 24 meses of age. Autism, 12, 487-511. doi: $10.1177 / 1362361308094501$

Whitburn, B. \& Plows, V. (2017). Making sense of everyday practice: By Whom, for Whom, for What?. In V. Plows \& B. Whitburn (eds.), Inclusive education. Making sense of everyday practice. Rotterdam: SensePublishers. doi: 10.1007/978-94-6300-866-2_15

Wiggins, L. D., Baio, J. O. N., \& Rice, C. (2006). Examination of the time between first evaluation and first autism spectrum diagnosis in a population-based sample. Journal of Developmental \& Behavioral Pediatrics, 27(2), 79-87.

World Heath Organization (2002). International Classification of Functioning, disability and Health. Geneva.

Xu, Y., Gelfer, J. I., Sileo, N., Filler, J., \& Perkins, P. G. (2008). Effects of peer tutoring on young children's social interactions. Early Child Development and Care, 178, 617- 635. doi:10.1080/03004430600857485

Yilmaz I, Yanarda M, Birkan B, Bumin G. (2004). Effects of swimming training on physical fitness and water orientation in autism. Pediatrics International. 46 (5), 624-626. doi: 10.1111/j.1442-200x.2004.01938.x 
Zabert, M.A. (2013). Políticas de formación docente e investigación educativa. El docente, su rol como transformador de estructuras desde el aula. Horizonte de la ciencia, 3 (4), 13-19. Recuperado de: http://www.uncp.edu.pe/revistas/index.php/horizontedelaciencia/article/view/5 4

Zarb, G. (1997). Researching disabling barriers. En C.Barnes y G. Mercer, Doing disabilityresearch (pp. 49-66). Leeds: The DisabilityPress.

Ziller, R. (1990). Photographing the self. Newbury Park, CA: Sage. 